UNIVERSIDADE DE SÃO PAULO

ESCOLA POLITÉCNICA

BERNARDO LUIZ HARRY DINIZ LEMOS

Investigação do Escoamento no Dispositivo de Assistência Ventricular

Pediátrico do InCor por Velocimetria de Imagem de Partículas Resolvida no Tempo

SÃO PAULO

2020 



\title{
Investigação do Escoamento no Dispositivo de Assistência Ventricular Pediátrico do InCor por Velocimetria de Imagem de Partículas Resolvida no Tempo
}

\author{
Versão Corrigida \\ (Versão original encontra-se na Biblioteca Central da EPUSP)
}

Dissertação apresentada à Escola Politécnica da Universidade de São Paulo para obtenção do título de Mestre em Ciências.

Área de Concentração: Engenharia Mecânica de Energia e Fluidos

Orientador: Prof. Dr. Julio Romano Meneghini

Coorientador: Dr. Rodrigo de Lima Amaral

São Paulo 
Autorizo a reprodução e divulgação total ou parcial deste trabalho, por qualquer meio convencional ou eletrônico, para fins de estudo e pesquisa, desde que citada a fonte.

Este exemplar foi revisado e corrigido em relação à versão original, sob responsabilidade única do autor e com a anuência de seu orientador.

São Paulo, de de

Assinatura do autor:

Assinatura do orientador:

Catalogação-na-publicação

Lemos, Bernardo Luiz Harry Diniz

Investigação do Escoamento no Dispositivo de Assistência Ventricular Pediátrico do InCor por Velocimetria de Imagem de Partículas Resolvida no Tempo / B. L. H. D. Lemos -- versão corr. -- São Paulo, 2020. $225 \mathrm{p}$.

Dissertação (Mestrado) - Escola Politécnica da Universidade de São Paulo. Departamento de Engenharia Mecânica.

1.Dispositivo de Assistência Ventricular 2.Fluidodinâmica 3.PIV I.Universidade de São Paulo. Escola Politécnica. Departamento de Engenharia Mecânica II.t. 
Nome: LEMOS, Bernardo Luiz Harry Diniz

Título: Investigação do Escoamento no Dispositivo de Assistência Ventricular Pediátrico do InCor por Velocimetria de Imagem de Partículas Resolvida no Tempo

Dissertação apresentada à Escola Politécnica da Universidade de São Paulo para obtenção do título de Mestre em Engenharia Mecânica.

Aprovado em:

Banca Examinadora

Prof. Dr. Julio Romano Meneghini

Instituição: Universidade de São Paulo (USP) / Escola Politécnica Julgamento:

Assinatura:

Prof. Prof. ‥ Dra . Idágene Aparecida Cestari Instituição: Universidade de São Paulo (USP) / Instituto do Coração Julgamento:

Assinatura:

Prof. Dr. César Monzu Freire

Instituição: Universidade Federal do ABC (UFABC) Julgamento:

Assinatura: 

A todos os pesquisadores de bioengenharia. 



\section{AGRADECIMENTOS}

Agradeço a meus pais pelo apoio, suporte e incentivo para realizar o mestrado, bem como aos demais membros de minha família que também favoreceram a realização deste trabalho.

A lldeanara Ítala Rezende pela compreensão das inúmeras horas que dediquei a este trabalho.

A Universidade de São Paulo (USP), em especial ao Departamento de Engenharia Mecânica (PME) e ao Instituto do Coração (InCor) por oferecer o curso de mestrado nesta área tão especial.

Ao Prof. Dr. Julio Romano Meneghini pela oportunidade de pesquisar sobre a mecânica dos fluidos em bioengenharia, e por todo o suporte fornecido pelo Núcleo de Dinâmica e Fluidos (NDF) e pelo Research Centre for Gas Innovation (RCGI).

A Prof. a. Dra . Idágene Aparecida Cestari pela oportunidade de pesquisa e por permitir o acesso aos dispositivos da Divisão de Bioengenharia do InCor do Hospital das Clínicas (HC) da Faculdade de Medicina da Universidade de São Paulo (FM USP).

Ao Dr. Rodrigo de Lima Amaral pelos sábios conselhos que ajudaram nesta imensa pesquisa e discussão sobre os dispositivos de assistência ventricular (DAV).

Ao Vítor Augusto Andreghetto Bortolin por me ajudar diversas vezes durante a preparação deste trabalho e pelas discussões que muito enriqueceram o desenvolvimento do mesmo.

Ao Marcelo Mazzeto do InCor pelas informações fornecidas e pela atenção dedicada no momento dos experimentos.

Aos técnicos da Mecânica Douglas Silva, Eric Piaga Pessoa Lima da Silva e Laércio Carlos Damacena, e aos técnicos da Mecatrônica Carlos Alberto de Souza Lima e Cicero Cirlanio Cruz pelos serviços prestados na confecção de peças essenciais para o desenvolvimento deste trabalho.

Aos profissionais do RCGI (Research Centre for Gas Innovation): Romi Albuquerque e Claudenor Rocha Lima.

Aos amigos João Henrique Antoniazzi de Gouveia, Filipi Martins Fernandes Silva, Julian Camilo Restrepo Lozano e Beethoven Narváez-Romo que estiveram presentes neste mestrado.

А Александра Асановна Элбакян, Dušan Barok, Josephine Berry, Bodó Balázs, Sean Dockray, Kenneth Goldsmith, Anthony Iles, Lawrence Liang, Sebastian Lütgert, 
Pauline van Mourik Broekman, Marcell Mars, spideralex, Tomislav Medak, Dubravka Sekulić, Femke Snelting por tornar livre materiais essenciais para esta pesquisa.

A Marirosa Correia pelo suporte necessário.

O presente trabalho foi realizado com apoio da Coordenação de Aperfeiçoamento de Pessoal de Nível Superior - Brasil (CAPES) - Código de Financiamento 001.

O presente trabalho foi realizado com apoio do Conselho Nacional de Desenvolvimento Científico e Tecnológico (CNPq), processo 311191/2017-7.

Agradeço aos processos n 2012/50283-6 e no 2014/50279-4, Fundação de Amparo à Pesquisa do Estado de São Paulo (FAPESP).

Agradeço a Financiadora de Estudos e Projetos (Finep) pelo apoio. 
"Writing is excessive drudgery. It crooks your back, dims your sight, twists your stomach and your sides. Three fingers write, but the whole-body labors." Anotação de um monge copista (sec. VIII) (SKORUPSKA, 2017) 



\section{RESUMO}

LEMOS, Bernardo Luiz Harry Diniz. Investigação do Escoamento no Dispositivo de Assistência Ventricular Pediátrico do InCor por Velocimetria de Imagem de Partículas Resolvida no Tempo. 2020. 225p. Dissertação (Mestrado em Engenharia Mecânica de Energia e Fluidos) - Escola Politécnica, Universidade de São Paulo, São Paulo, 2020.

Todos os anos milhões de pessoas morrem devido às doenças cardiovasculares em todo o mundo. Uma delas é a insuficiência cardíaca, que consiste na incapacidade do coração em bombear o sangue para o corpo. Para uma parte dos acometidos por esta patologia, a solução consiste no transplante de coração. Entretanto, poucos órgãos estão disponíveis para transplante, o que produz uma lista de espera extensa e demorada. A fim de evitar a morte de pacientes durante a espera, os dispositivos de assistência ventricular (DAV) são implantados para suplementar a função do coração. Os DAVs não são biológicos e, portanto, precisam de constantes aprimoramentos para evitar danos ao sangue como, por exemplo, a formação de trombos e a hemólise. Os aprimoramentos são especialmente interessantes para o DAV pediátrico pois as crianças e adolescente que os utilizam estão em uma ampla faixa de idades, tamanhos e demandas corporais. Uma maneira de aperfeiçoar o DAVP está na investigação da fluidodinâmica do dispositivo. A aplicação da velocimetria de imagem de partículas (PIV), técnica óptica não invasiva, permite mensurar grandezas físicas do escoamento no interior do dispositivo, como campos de velocidade e tensões de cisalhamento instantâneos. Todavia, o PIV apresenta desvantagens causadas por fontes ruidosas, por exemplo: distorções, reflexões do laser e sombras causadas pela geometria complexa e pelo diafragma do DAVP pulsátil. Além de desenvolver uma metodologia para garantir a qualidade das medidas PIV, o objetivo deste trabalho é avaliar o funcionamento do DAVP do Instituto do Coração (InCor) em 70 batidas por minuto com dois ângulos de válvula de entrada, $0^{\circ}$ e $30^{\circ}$, para avaliar a fluidodinâmica do DAVP e consequentemente a formação de trombos e a hemólise com o PIV resolvida no tempo. Os resultados apontaram para maior penetração do jato diastólico e lavagem do dispositivo quando a válvula de entrada esteve a 0 o e menor regurgitação para a válvula a $30^{\circ}$.

Palavras Chave: Dispositivo de Assistência Ventricular. Fluidodinâmica. Particle image velocimetry. 



\begin{abstract}
LEMOS, Bernardo Luiz Harry Diniz. Investigation of the Flow in the InCor Pediatric Ventricular Assist Device by Time Resolved Particle Image Velocimetry. 2019. 225p. Dissertação (Mestrado em Engenharia Mecânica de Energia e Fluidos) - Escola Politécnica, Universidade de São Paulo, São Paulo, 2020.

Every year millions of people die from cardiovascular disease worldwide. One of these diseases is heart failure (HF), which is the inability of the heart to pump blood to the body. For a part of those affected by this pathology, the solution consists of heart transplantation. However, few organs are available for transplantation, which produces an extensive and lengthy waiting list. In order to prevent patient death while waiting, ventricular assist devices (VADs) are implanted to supplement heart function. VADs are not biological and therefore need constant improvement to prevent damage to the blood such as thrombus formation and hemolysis. The enhancements are especially interesting for pediatric VAD (PVAD) because the children and adolescents who use them are in a wide range of ages, sizes and body demands. One way to improve PVAD is by investigating the device's fluid dynamics. The application of particle image velocimetry (PIV), a non-invasive optical technique, allows the measurement of physical quantities of the flow within the device, such as instantaneous velocity fields and shear stresses. However, PIV has disadvantages caused by noisy sources, for example: distortions, laser reflections, and shadows caused by the complex geometry of pulsed DAVP diaphragm. In addition to developing a methodology to guarantee the quality of PIV measures, the objective of this work is to evaluate the functioning of the DAVP from Instituto do Coração (InCor) at 70 beats per minute with two inlet valve angles, $0^{\circ}$ and $30^{\circ}$, to evaluate the fluid dynamics of PVAD and consequently thrombus formation and hemolysis with time-resolved PIV. The results shown better penetration of the diastolic jet and device washing when the inlet valve was at $0^{\circ}$ and less regurgitation for the valve at $30^{\circ}$.
\end{abstract}

Keywords: Ventricular Assist Device. Fluid dynamics. Particle image velocimetry 



\section{LISTA DE FIGURAS}

Figura 1 - Mortes de crianças no mundo por DCV no período de 16 anos 39

Figura 2 - Número de mortes de crianças no Brasil por DCV em 2016. 40

Figura 3 - Necessidade de Transplante de Coração (Ped.) no Brasil em 2018 ........40

Figura 4 - Problemas relacionados às estimativas PIV 41

Figura 5 - Circulação sanguínea no coração .43

Figura 6 - Anatomia interna do coração (corte frontal) .44

Figura 7 - Diagrama de Wiggers .46

Figura 8 - Diagrama pressão-volume do ventrículo esquerdo 46

Figura 9 - Relação da duração da sístole pela frequência cardíaca em adultos .......48

Figura 10 - Relação da duração da sístole pela frequência cardíaca pediátrica ......48

Figura 11 - Causas da insuficiência cardíaca geral ............................................50

Figura 12 - Fisiologia e patofisiologia de um coração............................................50

Figura 13 - Causas da insuficiência cardíaca pediátrica ......................................51

Figura 14 - Número de transplantes de coração e fila de espera .............................52

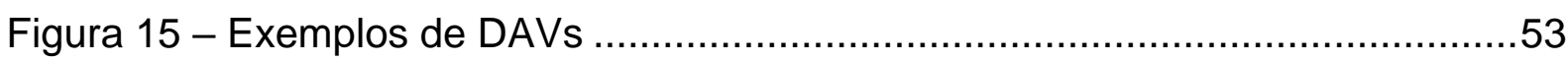

Figura 16 - Mecanismo de funcionamento do DAV pneumático................................53

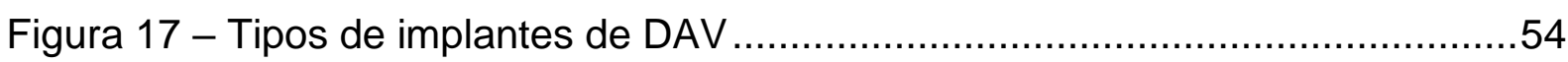

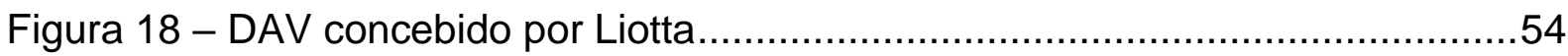

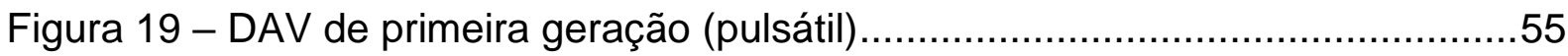

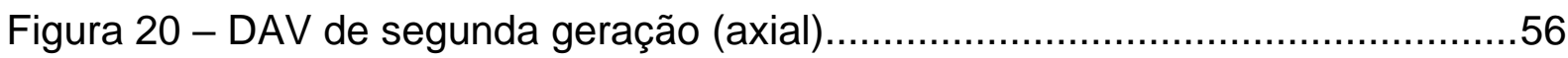

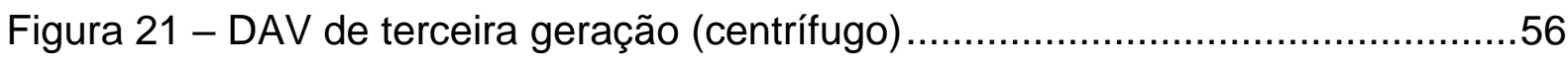

Figura 22 - Disposição de um DAV em um bebê....................................................58

Figura 23 - Gama de DAVs da Berlin Heart EXACOR .......................................59

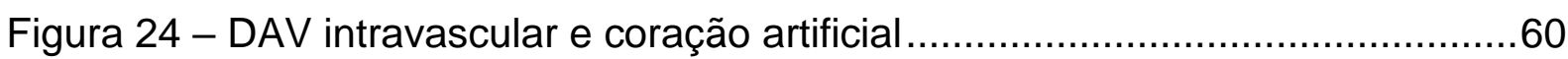

Figura 25 - Fatores que podem causar trombose e hemólise no DAV .....................62

Figura 26 - Taxa de cisalhamento na parede do DAV de $50 \mathrm{~mL}$ da Penn State ......62

Figura 27 - Plano de medição PIV e taxas de tensão de cisalhamento.....................63

Figura 28 - Modelos de DAVs e taxas de cisalhamento ........................................64

Figura 29 - Representação física das forças que atuam no fluido............................65

Figura 30 - Representação física da tensão de cisalhamento viscosa .....................66

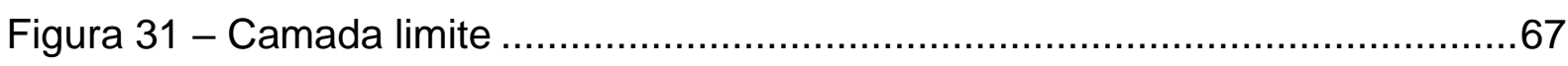

Figura 32 - Representação física da vorticidade ................................................67 
Figura 33 - Limites de VSS pelos tempos de exposição para hemácias 69

Figura 34 - Limites de VSS pelos tempos de exposição para plaquetas 69

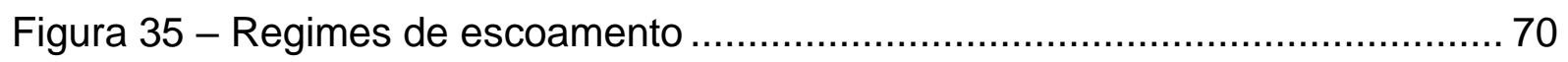

Figura 36 - Limites de RSS e tempos de exposição .............................................. 72

Figura 37 - Cascata de energia da turbulência ................................................ 74

Figura 38 - Taxa de cisalhamento normalizada na parede de dois DAVs .............. 77

Figura 39 - Esquema da técnica PIV .............................................................. 78

Figura 40 - Princípio de funcionamento PIV 2D ………................................. 79

Figura 41 - Espalhamento de partículas e sincronização PIV ................................ 80

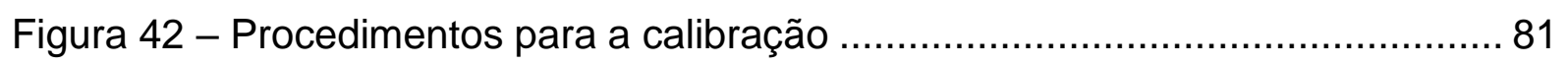

Figura 43 - Modo de gravação double frame/single exposure ................................ 81

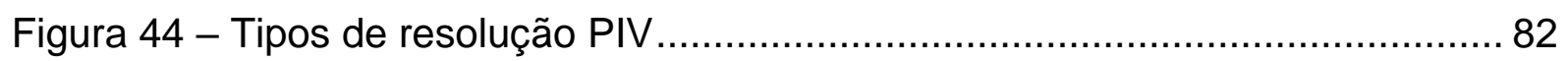

Figura 45 - Intensidade de uma partícula com e sem pré-processamento ............... 83

Figura 46 - Exemplo de pré-processamento ....................................................... 84

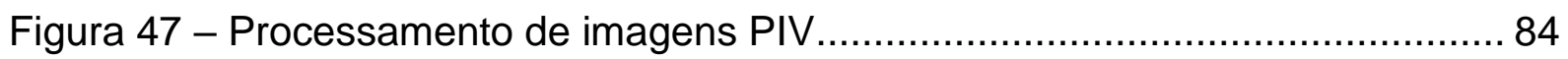

Figura 48 - Processo para aplicação da correlação cruzada em PIV ...................... 85

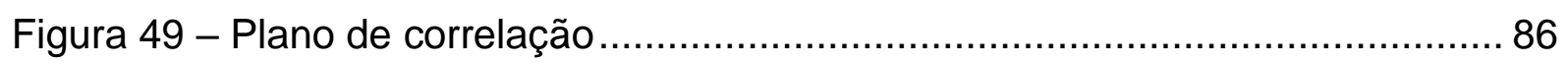

Figura 50 - Plano de correlação de imagens com e sem pré-processamento .......... 86

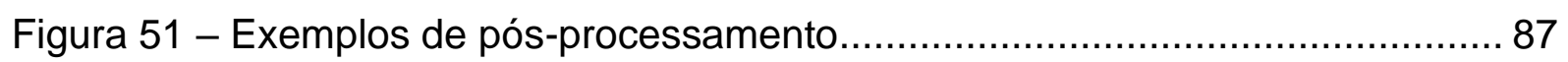

Figura 52 - Evolução temporal das velocidades de uma bolha de cavitação............ 88

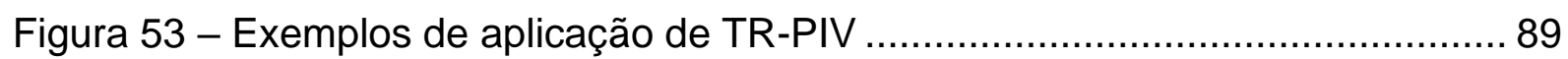

Figura 54 - Tipos de gravação single frame …………..................................... 90

Figura 55 - CVM e WSR no DAV de $50 \mathrm{ml}$ da Penn State ....................................... 91

Figura 56 - TKE no DAV de $50 \mathrm{ml}$ da Penn State ................................................... 92

Figura 57 - Planos PIV do DAVP de $12 \mathrm{ml}$ da Penn State ....................................... 92

Figura 58 - Velocidades próximas à parede no DAVP da Penn State ..................... 93

Figura 59 - Taxa de cisalhamento na parede do DAV de $50 \mathrm{ml}$ da Penn State ....... 93

Figura 60 - Percentual de estagnação e tensão de cisalhamento turbulenta............ 94

Figura 61 - Ruídos nas imagens PIV no DAVP de 12 ml da Penn State ................. 96

Figura 62 - Visão geral das fontes de erros em PIV .......................................... 97

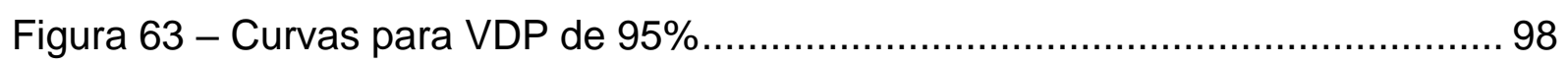

Figura 64 - Relação do diâmetro da partícula na imagem com o erro aleatório....... 99

Figura 65 - Diâmetro da partícula, erro e tipo de correlação................................... 100

Figura 66 - Diâmetro da partícula e erro aleatório e sistemático............................ 100 
Figura 67 - Representação gráfica do SNR no plano de correlação .....................101

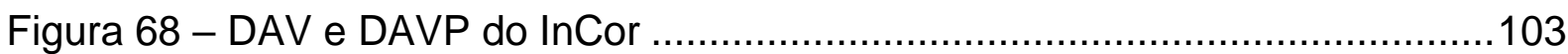

Figura 69 - Detalhes da válvula 21 AJ-501 ............................................... 104

Figura 70 - Cunha do DAVP .............................................................. 106

Figura 71 - Diagrama do sistema de controle eletropneumático do DAVP ............108

Figura 72 - Esquema do MCL utilizado nos experimentos do DAVP....................109

Figura 73 - Diagrama de Wiggers do DAVP do InCor ....................................110

Figura 74 - Exemplo de curva de vazão ao longo do fechamento da válvula.........111

Figura 75 - Energia do laser e transmitância do filtro óptico ..............................114

Figura 76 - Sincronização do experimento .................................................115

Figura 77 - Visão geral da estratégia de pré-processamento PIV .......................116

Figura 78 - Visão geral do processamento e pós-processamento PIV ..................117

Figura 79 - Representação da média temporal e da média de conjunto ................119

Figura 80 - Esquema de medição dos planos ...............................................119

Figura 81 - Posição da válvula de entrada do DAV ...........................................120

Figura 82 - Divisão temporal do ciclo do DAV ..............................................121

Figura 83 - DAVP com locais das sondas demarcados....................................122

Figura 84 - Campos de velocidades $\left(0^{\circ}\right.$ e $\left.30^{\circ}\right)$ no plano frontal no intervalo t 1 .......124

Figura 85 - Campos de velocidades $\left(0^{\circ}\right.$ e $\left.30^{\circ}\right)$ no plano médio no intervalo t 1 .......125

Figura 86 - Campos de velocidades $\left(0^{\circ}\right.$ e $\left.30^{\circ}\right)$ no plano traseiro no intervalo t $1 \ldots . .126$

Figura 87 - Evolução temporal de v na saída do DAVP no plano médio em $t_{1} \ldots \ldots . .127$

Figura 88 - Curvas de pressão e vazão para o intervalo t 1 .................................127

Figura 89 - Campos de tensões $\left(0^{\circ}\right.$ e $\left.30^{\circ}\right)$ no plano frontal no intervalo $t_{1} \ldots \ldots . . . . . .128$

Figura 90 - Campos de tensões para a válvula em $0^{\circ}$ e $30^{\circ}$ no intervalo $t_{1} \ldots \ldots \ldots . .129$

Figura 91 - Campos de tensões $\left(0^{\circ}\right.$ e $\left.30^{\circ}\right)$ no plano traseiro no intervalo $\mathrm{t}_{1} \ldots \ldots \ldots . . . .130$

Figura 92 - Evolução temporal de VSS próximo à parede no plano médio em $\mathrm{t}_{1} \ldots 131$

Figura 93 - Campos de TKE $\left(0^{\circ}\right.$ e $\left.30^{\circ}\right)$ no plano médio no intervalo $t_{1} \ldots \ldots \ldots \ldots \ldots . . . . . . .132$

Figura 94 - Campos de velocidades $\left(0^{\circ}\right.$ e $\left.30^{\circ}\right)$ no plano frontal no intervalo t2.......133

Figura 95 - Campos de velocidades $\left(0^{\circ}\right.$ e $\left.30^{\circ}\right)$ no plano médio no intervalo t2 .......134

Figura 96 - Campos de velocidades $\left(0^{\circ}\right.$ e $\left.30^{\circ}\right)$ no plano traseiro no intervalo t2.....135

Figura 97 - Evolução temporal de u e v na saída do DAVP no plano médio em t2.136

Figura 98 - Campos de tensões $\left(0^{\circ}\right.$ e $\left.30^{\circ}\right)$ no plano frontal no intervalo t2 ............137

Figura 99 - Campos de tensões $\left(0^{\circ}\right.$ e $\left.30^{\circ}\right)$ no plano médio no intervalo t2 ............138

Figura 100 - Campos de tensões $\left(0^{\circ}\right.$ e $\left.30^{\circ}\right)$ no plano traseiro no intervalo t2 .........139 
Figura 101 - Evolução temporal de VSS próximo à parede no plano médio em t2 140 Figura 102 - Campos de TKE ( $0^{\circ}$ e $\left.30^{\circ}\right)$ no plano médio no intervalo t2 140

Figura 103 - Campos de velocidades $\left(0^{\circ}\right.$ e $\left.30^{\circ}\right)$ no plano frontal no intervalo t3 .... 141

Figura 104 - Campos de velocidades ( $0^{\circ}$ e $\left.30^{\circ}\right)$ no plano médio no intervalo t3 .... 142

Figura 105 - Campos de velocidades $\left(0^{\circ}\right.$ e $\left.30^{\circ}\right)$ no plano traseiro no intervalo t3 .. 142

Figura 106 - Evolução temporal de u e $|\mathrm{U}|$ entre as válvulas do DAVP em t3........ 143

Figura 107 - Campos de tensões $\left(0^{\circ}\right.$ e $\left.30^{\circ}\right)$ no plano frontal no intervalo t3........... 144

Figura 108 - Campos de tensões $\left(0^{\circ}\right.$ e $\left.30^{\circ}\right)$ no plano médio no intervalo t3........... 145

Figura 109 - Campos de tensões $\left(0^{\circ}\right.$ e $\left.30^{\circ}\right)$ no plano traseiro no intervalo t3......... 146

Figura 110 - Evolução temporal de VSS próximo à parede em t3........................ 147

Figura 111 - Campos de TKE ( $0^{\circ}$ e $\left.30^{\circ}\right)$ no plano médio no intervalo t3 ............... 147

Figura 112 - Campos de velocidades ( $0^{\circ}$ e $\left.30^{\circ}\right)$ no plano frontal no intervalo t $4 . . .148$

Figura 113 - Campos de velocidades $\left(0^{\circ}\right.$ e $\left.30^{\circ}\right)$ no plano médio no intervalo t4 .... 149

Figura 114 - Campos de velocidades $\left(0^{\circ}\right.$ e $\left.30^{\circ}\right)$ no plano traseiro no intervalo $t_{4} . .149$

Figura 115 - Evolução temporal de v no plano médio em t4............................... 150

Figura 116 - Campos de tensões $\left(0^{\circ}\right.$ e $\left.30^{\circ}\right)$ no plano frontal no intervalo t 4 ............ 151

Figura 117 - Campos de tensões ( $0^{\circ}$ e $\left.30^{\circ}\right)$ no plano médio no intervalo t4........... 152

Figura 118 - Campos de tensões $\left(0^{\circ}\right.$ e $\left.30^{\circ}\right)$ no plano traseiro no intervalo t $4 . . . . . . .153$

Figura 119 - Campos de TKE ( $0^{\circ}$ e $\left.30^{\circ}\right)$ no plano médio no intervalo t4 ............... 154

Figura 120 - Campos de velocidades $\left(0^{\circ}\right.$ e $\left.30^{\circ}\right)$ no plano frontal no intervalo t5 .... 155

Figura 121 - Campos de velocidades $\left(0^{\circ}\right.$ e $\left.30^{\circ}\right)$ no plano médio no intervalo t 5 .... 156

Figura 122 - Campos de velocidades $\left(0^{\circ}\right.$ e $\left.30^{\circ}\right)$ no plano traseiro no intervalo $t_{5}$.. 156

Figura 123 - Evolução temporal de v na entrada do DAVP no plano médio em t5. 157

Figura 124 - Evolução temporal de v na entrada do DAVP no plano médio em t5. 157

Figura 125 - Campos de tensões $\left(0^{\circ}\right.$ e $\left.30^{\circ}\right)$ no plano frontal no intervalo t5........... 158

Figura 126 - Campos de tensões $\left(0^{\circ}\right.$ e $\left.30^{\circ}\right)$ no plano médio no intervalo t5........... 159

Figura 127 - Campos de tensões $\left(0^{\circ}\right.$ e $\left.30^{\circ}\right)$ no plano traseiro no intervalo t5......... 160

Figura 128 - Campos de TKE ( $0^{\circ}$ e $\left.30^{\circ}\right)$ no plano médio no intervalo t5 ............... 160

Figura 129 - Campos de velocidades $\left(0^{\circ}\right.$ e $\left.30^{\circ}\right)$ no plano frontal no intervalo t6 .... 161

Figura 130 - Campos de velocidades $\left(0^{\circ}\right.$ e $\left.30^{\circ}\right)$ no plano médio no intervalo t6 .... 162

Figura 131 - Campos de velocidades ( $0^{\circ}$ e $\left.30^{\circ}\right)$ no plano traseiro no intervalo t6 .. 162

Figura 132 - Evolução temporal de $|\mathrm{U}|$ e v na saída do DAVP no plano médio (t6) 163

Figura 133 - Campos de tensões $\left(0^{\circ}\right.$ e $\left.30^{\circ}\right)$ no plano frontal no intervalo t6........... 164

Figura 134 - Campos de tensões $\left(0^{\circ}\right.$ e $\left.30^{\circ}\right)$ no plano médio no intervalo t6........... 165 
Figura 135 - Campos de tensões $\left(0^{\circ}\right.$ e $\left.30^{\circ}\right)$ no plano traseiro no intervalo t6 ..........166

Figura 136 - Campos de TKE $\left(0^{\circ}\right.$ e $\left.30^{\circ}\right)$ no plano médio no intervalo t6.................166

Figura 137 - Evolução temporal do ponto A ………......................................170

Figura 138 - Evolução temporal do ponto B …............................................171

Figura 139 - Evolução temporal do Ponto C .................................................171

Figura 140 - Evolução temporal do Ponto D...................................................172

Figura 141 - Evolução temporal do Ponto E................................................173

Figura 142 - Evolução temporal do Ponto F ..............................................174

Figura 143 - Evolução temporal do Ponto G .................................................174

Figura 144 - Evolução temporal do Ponto H.................................................175

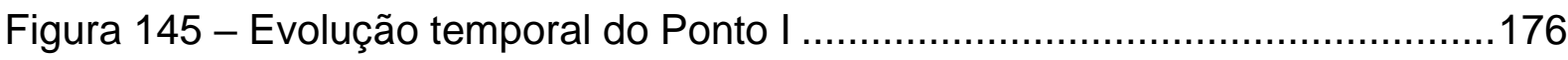

Figura 146 - Evolução temporal do Ponto J ..................................................176

Figura 147 - Perfis de velocidade na válvula 21AJ-501 ..................................178

Figura 148 - Pontos da evolução temporal nos limites de VSS para hemácias .....181

Figura 149 - Pontos da evolução temporal nos limites de VSS para plaquetas .....182

Figura 150 - Pontos da evolução temporal nos limites de RSS ..............................182

Figura 151 - Magnitude de velocidade no plano $7 \mathrm{~mm}$......................................185

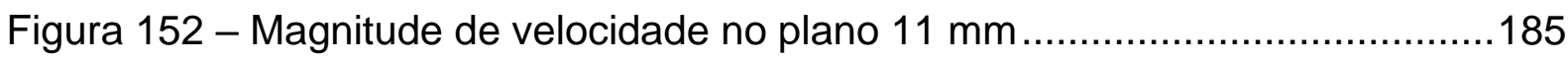

Figura 153 - Evolução temporal das velocidades em tı na válvula de saída ..........219

Figura 154 - Evolução temporal das velocidades em t $\mathrm{t}_{1}$ entre as válvulas ..............219

Figura 155 - Evolução temporal das velocidades em t 1 na válvula de entrada.......220

Figura 156 - Evolução temporal das velocidades em t2 na válvula de saída ..........220

Figura 157 - Evolução temporal das velocidades em t2 entre as válvulas ...............220

Figura 158 - Evolução temporal das velocidades em t2 na válvula de entrada.......221

Figura 159 - Evolução temporal das velocidades em t3 na válvula de saída ..........221

Figura 160 - Evolução temporal das velocidades em t3 entre as válvulas ...............221

Figura 161 - Evolução temporal das velocidades em t3 na válvula de entrada.......222

Figura 162 - Evolução temporal das velocidades em t4 na válvula de saída ...........222

Figura 163 - Evolução temporal das velocidades em t $t_{4}$ entre as válvulas ...............222

Figura 164 - Evolução temporal das velocidades em t4 na válvula de entrada.......223

Figura 165 - Evolução temporal das velocidades em t5 na válvula de saída...........223

Figura 166 - Evolução temporal das velocidades em t5 entre as válvulas ..............223

Figura 167 - Evolução temporal das velocidades em t5 na válvula de entrada.......224

Figura 168 - Evolução temporal das velocidades em to na válvula de saída..........224 
Figura 169 - Evolução temporal das velocidades em to entre as válvulas ............. 224

Figura 170 - Evolução temporal das velocidades em to na válvula de entrada ...... 225 


\section{LISTA DE TABELAS}

Tabela 1 - Durações das fases do ciclo cardíaco para 75 bpm ..............................47

Tabela 2 - Comparação de DAVs de diferentes gerações ...................................57

Tabela 3 - Comparação de DAVs de diferentes gerações .......................................58

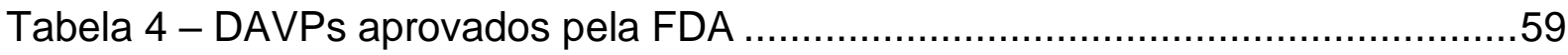

Tabela 5 - Dispositivos na diretriz de circulação mecânica da SBC .........................60

Tabela 6 - Histórico das medições PIV em DAVs pneumáticos ……......................95

Tabela 7 - Materiais empregados no DAVP do InCor e no DAVP utilizado no PIV 105

Tabela 8 - Vantagens e desvantagens dos testes de DAVs...............................107

Tabela 9 - Valores de Re e St para os dispositivos incluindo o DAVP InCor .........113

Tabela 10 - Resumo comparando as estruturas, velocidades e regurgitação ........167

Tabela 11 - Resumo comparando as tensões e energia cinética turbulenta ..........167

Tabela 12 - Dados iniciais dos pontos da evolução temporal das tensões ............169 



\section{LISTA DE SIGLAS}

2C

duas componentes

2D

duas dimensões

3D

três dimensões

AD

Átrio Direito

AE

Átrio Esquerdo

ANS

Agência Nacional de Saúde

bit

binary digit (dígito binário)

bpm

batidas por minuto

CCD

Charge-Coupled Device (dispositivo de carga acoplada)

CFD

Computational Fluid Dynamics (dinâmica dos fluidos computacional)

CMOS Complementary Metal-Oxide-Semiconductor (semicondutor de metal-óxido complementar)

$\mathrm{CO}_{2}$ dióxido de carbono

CVM Campos de Velocidade Média

D

Diástole

DAV

Dispositivo de Assistência Ventricular

DAVP Dispositivos de Assistência Ventricular Pediátricos

DCV doenças cardiovasculares

DPSS Diode-Pumped Solid-State (estado sólido bombeado por diodo)

EUA Estados Unidos da América

FDA Food and Drug Administration

FFT Fast Fourier Transform (transformada rápida de Fourier)

FM USP Faculdade de Medicina da Universidade de São Paulo

FWHM Full Width at Half Maximum (largura à meia altura)

HC Hospital das Clínicas

HIV Human Immunodeficiency Virus (vírus da imunodeficiência humana)

$\mathrm{Hz} \quad$ Hertz

IC Insuficiência Cardíaca

IFT Inverse Fourier Transform (transformada inversa de Fourier)

InCor Instituto do Coração

Info. informado 


\begin{tabular}{|c|c|}
\hline kg & quilograma \\
\hline kHz & quilo-Hertz \\
\hline $\mathrm{L} / \mathrm{min}$ & litros por minuto \\
\hline LDA & Laser Doppler Anemometry (anemometria laser Doppler) \\
\hline LES & Large Eddy Simulation \\
\hline LoS & Line of Sight (linha de visão ou linha de visada) \\
\hline $\mathbf{m} / \mathbf{s}$ & metro por segundo \\
\hline $\mathbf{m}^{2}$ & metro quadrado \\
\hline $\mathbf{m}^{3}$ & metro cúbico \\
\hline MCL & Mock Circulation Loops (circuitos de circulação simulada) \\
\hline $\mathrm{mJ} /$ pulso & mili-Joule por pulso \\
\hline mJ & mili-Joule \\
\hline $\mathbf{m L}$ & mililitros \\
\hline $\mathrm{mm} / \mathrm{px}$ & milímetro por pixel \\
\hline mm & milímetro \\
\hline $\mathrm{mmHg}$ & milímetros de mercúrio \\
\hline Mpx & megapixel \\
\hline mrad & mili-radiano ou mil angular \\
\hline ms & milissegundo \\
\hline Nd:YAG & $\begin{array}{l}\text { Neodymium-Doped Yttrium Aluminum Garnet (granada de alumínio } \\
\text { com ítrio dopada com neodímio) }\end{array}$ \\
\hline Nd:YLF & $\begin{array}{l}\text { Neodymium-Doped Yttrium Lithium Fluoride (fluoreto de lítio ítrio } \\
\text { dopado com neodímio) }\end{array}$ \\
\hline NHLBI & $\begin{array}{l}\text { National Heart, Lung, and Blood Institute (Instituto Nacional de } \\
\text { Coração Pulmões e Sangue dos Estados Unidos) }\end{array}$ \\
\hline nm & nanômetro \\
\hline NWV & Near Wall velocity (velocidades próximas à parede) \\
\hline $\mathrm{O}_{2}$ & gás oxigênio \\
\hline OD & Optical Density (absorbância) \\
\hline OMS & Organização Mundial de Saúde \\
\hline p. ex. & por exemplo \\
\hline Pa.s & Pascal vezes segundo \\
\hline $\mathrm{Pa}$ & Pascal \\
\hline
\end{tabular}




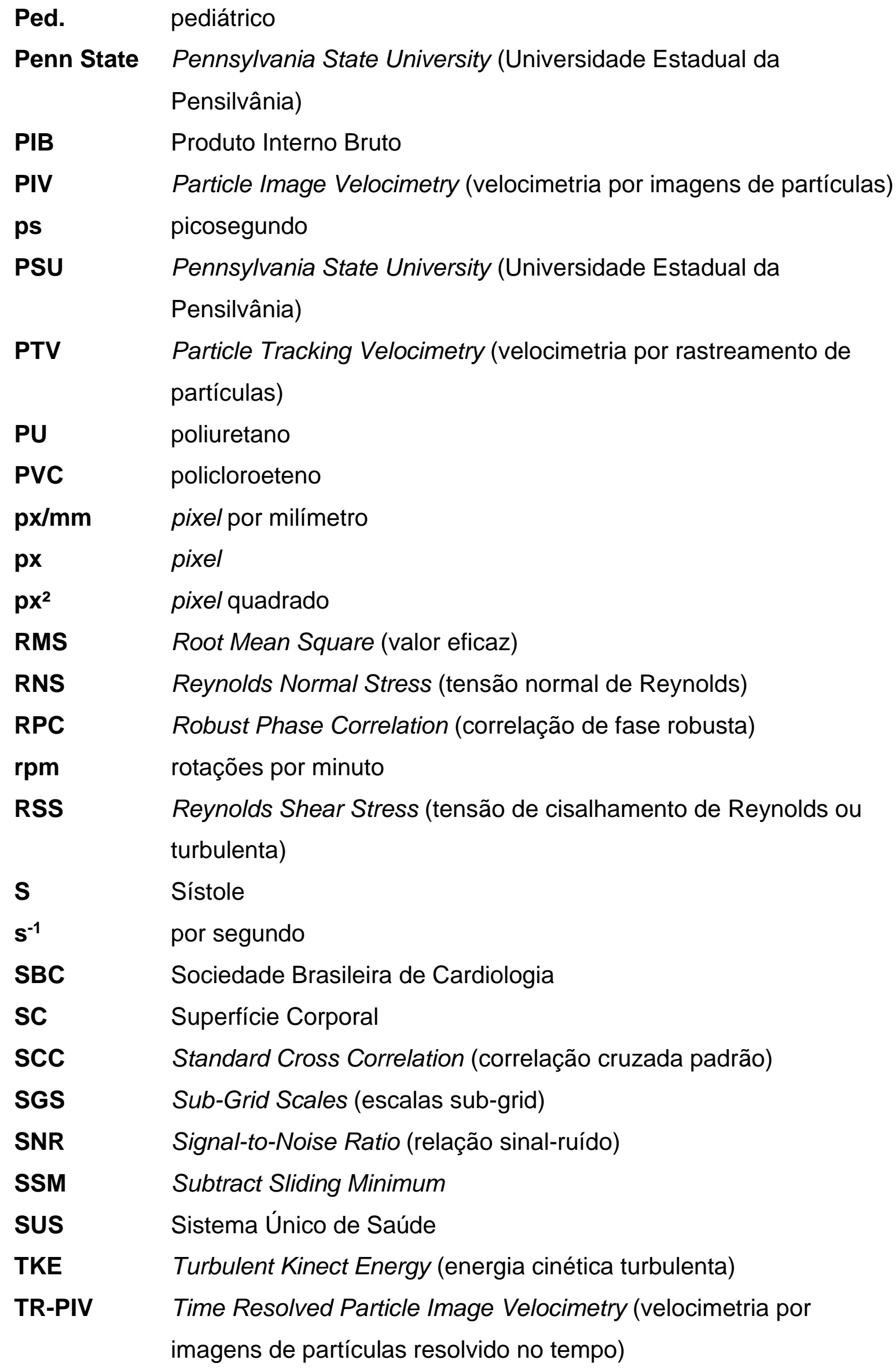


TSP Thrombus Susceptibility Potential (potencial de susceptibilidade de formação de trombos)

TVSS Turbulent Viscous Shear Stress (tensão de cisalhamento viscosa turbulenta)

U\$ dólares americanos

UTŁ Politechnika Łódzka (Universidade Tecnológica de Łódź)

VD Ventrículo Direito

VDP Valid Detection Probability (probabilidade de detecção válida)

VE Ventrículo Esquerdo

VS Volume Sistólico

VSS Viscous Shear Stress (tensão de cisalhamento viscosa)

VSZ Volume of Stagnation Zone (volume da zona de estagnação)

WSR Wall Sher Rate (taxas de cisalhamento próximas à parede)

ZE Zonas de Estagnação

$\mu \mathrm{m} / \mathrm{px} \quad$ micrometro por pixel

$\mu \mathrm{m} \quad$ micrometro

Hs microssegundo 


\section{LISTA DE SÍMBOLOS}

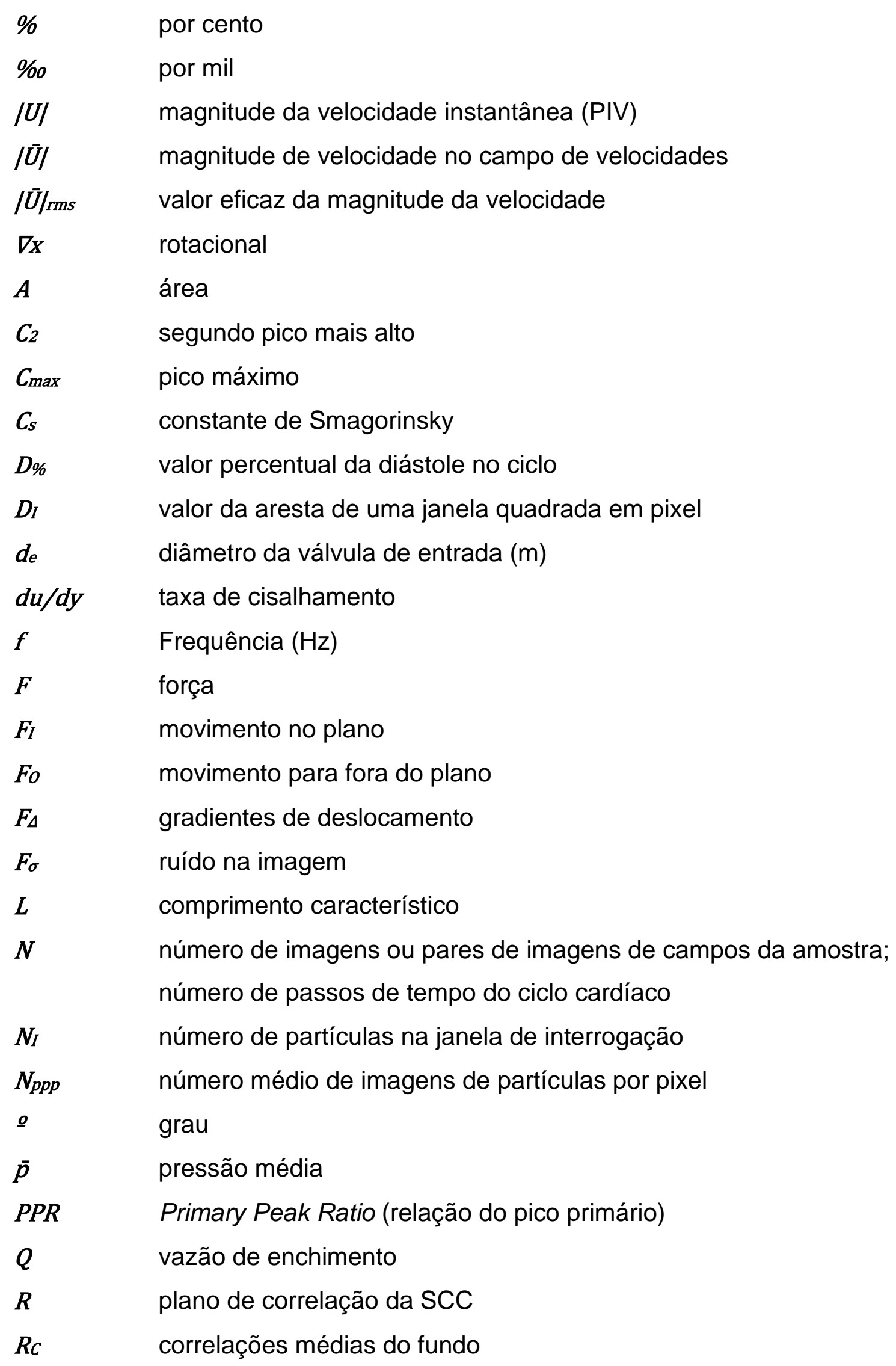




\begin{tabular}{|c|c|}
\hline$R_{D}$ & maior probabilidade de deslocamento de partículas \\
\hline $\operatorname{Re}$ & número de Reynolds \\
\hline$R_{F}$ & correlação correspondente à flutuação aleatória \\
\hline$R N S$ & Reynolds Normal Stress (tensão normal de Reynolds) \\
\hline$R N S_{\max }$ & máxima tensão de cisalhamento de Reynolds \\
\hline$\overline{R S S}$ & tensão de cisalhamento de Reynolds média no campo de tensões \\
\hline RSS & Reynolds Shear Stress (tensão de cisalhamento de Reynolds) \\
\hline$\overline{R S S}_{\text {max }}$ & $\begin{array}{l}\text { máxima tensão de cisalhamento de Reynolds média no campo de } \\
\text { tensões }\end{array}$ \\
\hline$R S S_{\max }$ & Máxima tensão normal de Reynolds \\
\hline St & número de Strouhal \\
\hline$T$ & período característico (s) \\
\hline$t_{1}$ & intervalo correspondente ao início da ejeção \\
\hline$t_{2}$ & intervalo correspondente ao pico da ejeção \\
\hline$t_{3}$ & intervalo correspondente ao final da ejeção \\
\hline$t_{4}$ & intervalo correspondente ao início do enchimento \\
\hline$t_{5}$ & intervalo correspondente ao pico de enchimento \\
\hline$t_{6}$ & intervalo correspondente ao fim do enchimento \\
\hline$t_{\text {crit }}$ & o dobro de $\Delta \mathrm{t}$ \\
\hline$\overline{T V S S}$ & $\begin{array}{l}\text { tensão de cisalhamento viscosa turbulenta média no campo de } \\
\text { tensões }\end{array}$ \\
\hline TVSS & $\begin{array}{l}\text { Turbulent Viscous Shear Stress (tensão de cisalhamento viscosa } \\
\text { turbulenta) }\end{array}$ \\
\hline$\overline{\boldsymbol{u}}$ & velocidade média em x no campo de velocidades \\
\hline$u$ & $\begin{array}{l}\text { velocidade no sentido de x (tangencial); velocidade instantânea } \\
\text { medida na direção x; velocidade instantânea em x (PIV) }\end{array}$ \\
\hline$u^{\prime}$ & flutuação da velocidade na direção $x$ \\
\hline$u_{c}$ & velocidade média característica do escoamento $(\mathrm{m} / \mathrm{s})$ \\
\hline$u_{t}$ & componente de velocidade tangencial próxima a parede \\
\hline$u_{w}$ & velocidade na parede \\
\hline$\vec{v}$ & campo de velocidades \\
\hline$\overline{\boldsymbol{V}}$ & velocidade média em y no campo de velocidades \\
\hline V & velocidade no sentido de y; velocidade instantânea medida na \\
\hline
\end{tabular}




\begin{tabular}{|c|c|}
\hline$V^{\prime}$ & flutuação da velocidade na direção y \\
\hline$\overline{\mathrm{VSS}}$ & tensão de cisalhamento viscosa média no campo de tensões \\
\hline VSS & Viscous Shear Stress (tensão de cisalhamento viscosa) \\
\hline$y$ & $\begin{array}{l}\text { distância entre a região de velocidade zero e a região onde ocorre o } \\
\text { cisalhamento }\end{array}$ \\
\hline$y t$ & distância entre ut e a parede \\
\hline$y_{w}$ & localização da parede \\
\hline$\dot{\gamma}$ & taxa de cisalhamento \\
\hline$\gamma_{\text {cutoff }}$ & valor de corte definido experimentalmente \\
\hline$\gamma_{p i c o}$ & valor limite para deposição de trombos \\
\hline$\gamma_{w}$ & taxa de cisalhamento na parede \\
\hline$\partial u / \partial x$ & gradiente de velocidade \\
\hline$\Delta$ & distância entre dois pontos medidos \\
\hline$\Delta t$ & tempo entre os quadros de imagens gravados \\
\hline$\varepsilon$ & dissipação turbulenta \\
\hline$\kappa I$ & escala integral \\
\hline$\kappa_{\eta}$ & escala de Kolmogorov \\
\hline$\mu$ & viscosidade dinâmica do fluido \\
\hline $\boldsymbol{\nu}$ & viscosidade cinemática (m²/s) \\
\hline$\rho$ & densidade do fluido \\
\hline$\sigma$ & tensão normal \\
\hline$\tau$ & tensão de cisalhamento viscosa no plano \\
\hline$\tau_{i j}\left(\overline{S_{\imath \jmath}}\right)$ & dissipação no turbilhão \\
\hline$\tau_{i j}$ & tensor das tensões SGS \\
\hline$\tau_{w}$ & tensão de cisalhamento na parede \\
\hline$\omega$ & vorticidade \\
\hline
\end{tabular}





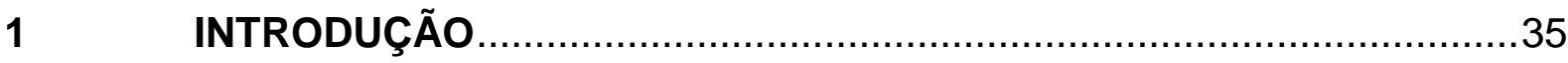

1.1 Objetivos

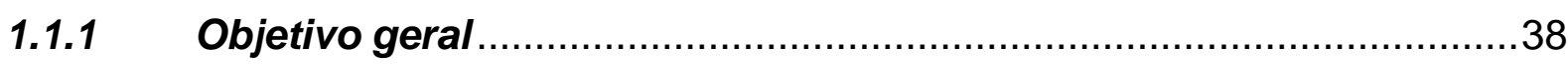

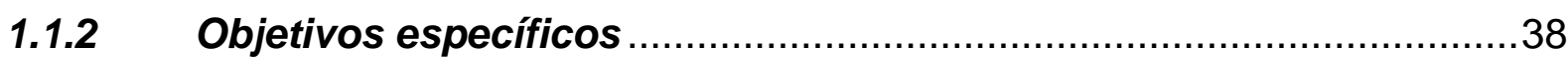

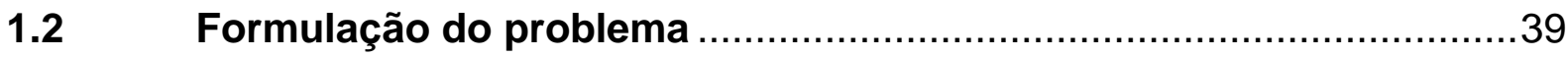

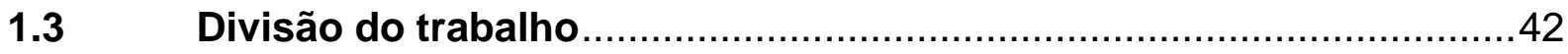

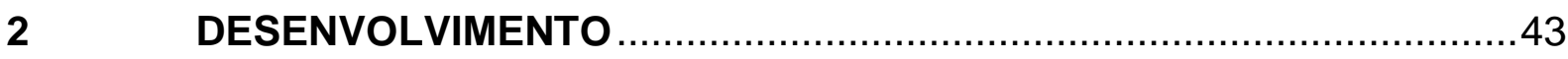

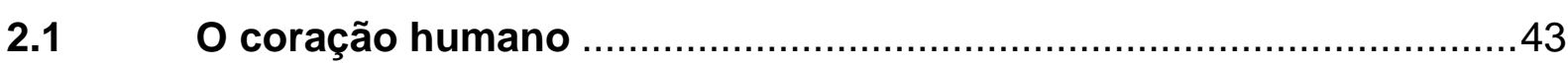

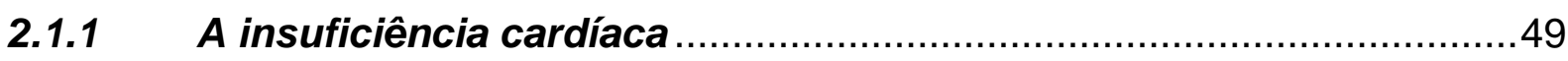

2.2 Os dispositivos de assistência ventricular....................................

2.3 Desafios tecnológicos nos DAVs: análise do escoamento interno ...61

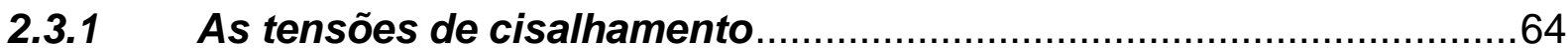

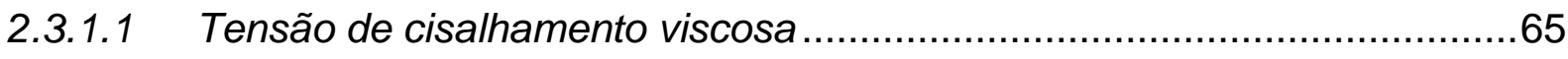

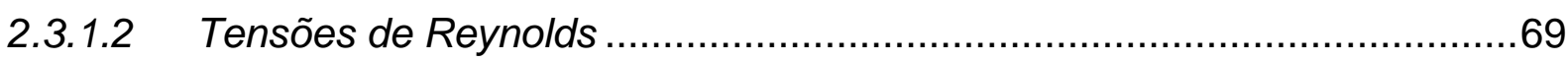

2.3.1.3 Tensão de cisalhamento viscosa turbulenta ........................................72

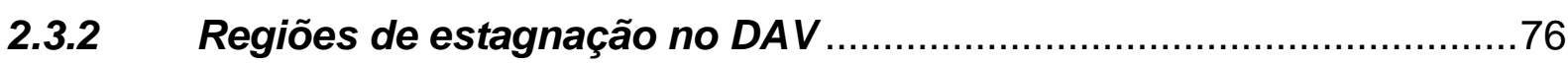

$2.4 \quad$ Velocimetria por imagens de partículas (PIV) …............................ 77

2.4.1 Princípio de funcionamento PIV .........................................................

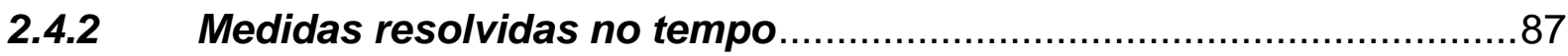

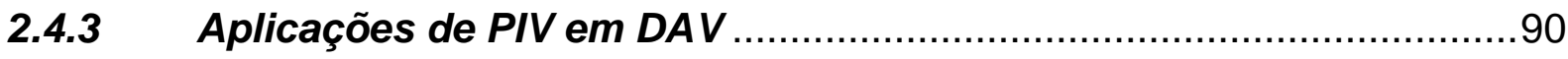

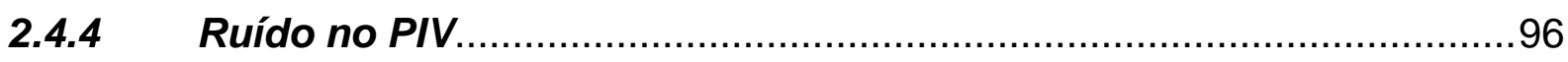

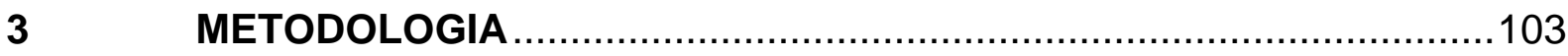

3.1 O dispositivo de assistência ventricular pediátrico (DAVP) do Instituto

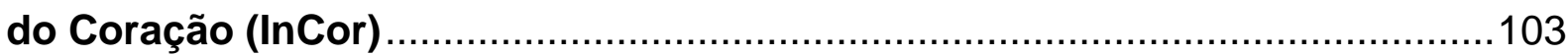

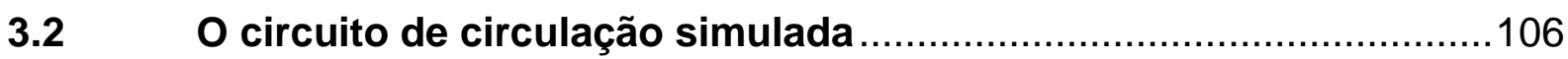

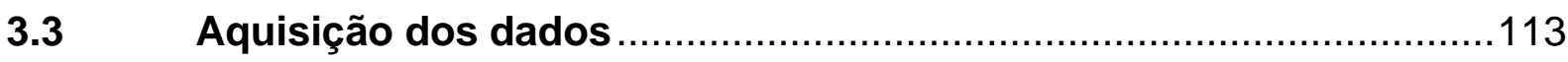

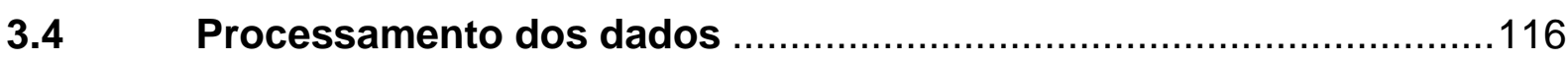

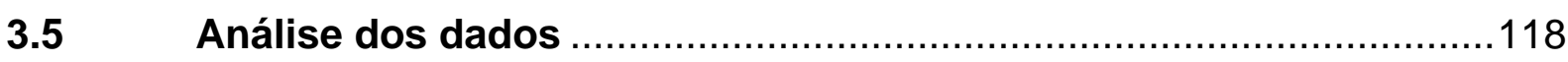




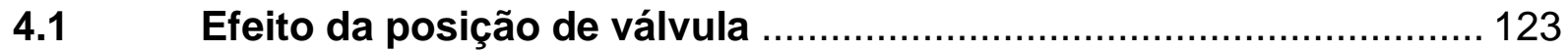

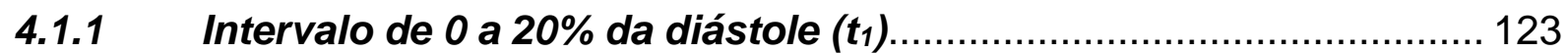

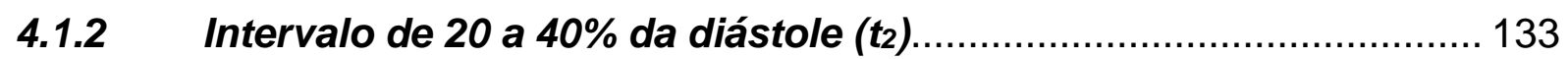

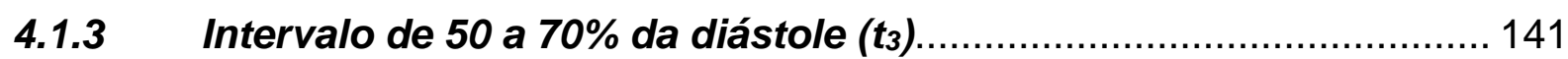

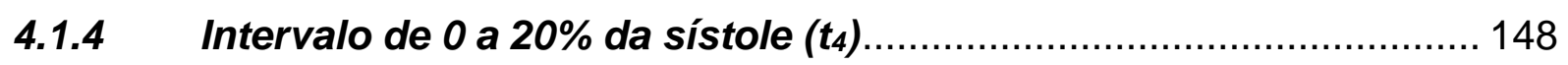

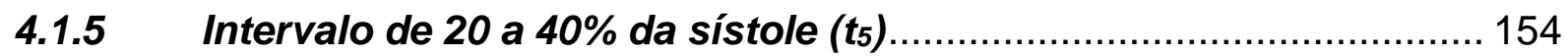

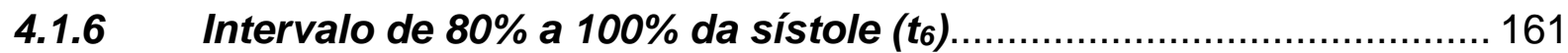

4.2 Evolução temporal das tensões viscosa e de Reynolds .................. 168

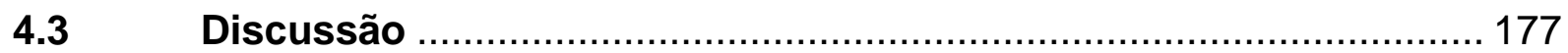

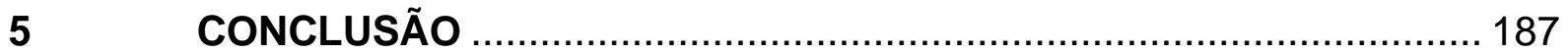

REFERÊNCIAS

APÊNDICE A - EVOLUÇÃO TEMPORAL DA SONDAS P1 A P9 NOS SEIS

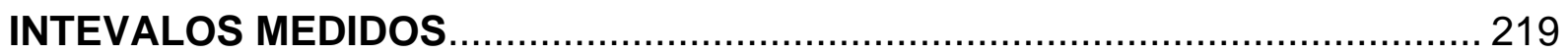




\section{INTRODUÇÃO}

A função primária do sistema cardiovascular é bombear sangue para os órgãos e tecidos. Este sistema é constituído pelo coração e pelos vasos sanguíneos, a saber, artérias e veias. O coração é constituído por duas bombas pulsáteis separadas, ambas de deslocamento positivo. O lado direito do coração, também conhecido como coração direito, é responsável por bombear o sangue para os pulmões onde a troca gasosa é realizada. Por outro lado, o coração esquerdo bombeia o sangue para o resto do corpo (HALL, 2016).

O coração é uma máquina de mecânica perfeita, mas apesar disto, como muitos outros órgãos, está sujeito a doenças. As assim chamadas doenças cardiovasculares (DCV) representam um dos maiores problemas relacionados à saúde mundial. Por mais de 15 anos, as DCV lideram a classificação das causas de morte. Em 2016, das quase 57 milhões de pessoas que vieram a óbito no mundo, aproximadamente 18 milhões faleceram decorrentes de DCV, o que corresponde a $31,4 \%$. No Brasil, o número de mortes associadas à DCV foram 369 mil no ano de 2016, o que corresponde a $27,9 \%$ do total (WORLD HEALTH ORGANIZATION, 2018). Os custos estimados do Sistema Único de Saúde (SUS) - reembolso da Agência Nacional de Saúde (ANS), com morbidade, mortalidade, previdência social e medicamentos - por DCV no ano de 2015 foi de 37,1 bilhões de reais, o que correspondia a $0,6 \%$ do produto interno bruto (PIB) do Brasil (SIQUEIRA, SIQUEIRAFILHO e LAND, 2017).

Parte dos portadores de doenças cardíacas evolui para a insuficiência cardíaca (IC), que consiste na incapacidade do coração em bombear o sangue para o corpo, resultante " $[\ldots]$ de qualquer disfunção cardíaca estrutural ou funcional que dificulta a ação do ventrículo em se preencher ou ejetar sangue" (AMERICAN HEART ASSOCIATION apud SANTOS e BITTENCOURT, 2008). A grande maioria dos casos de IC se resolvem através de tratamento clínico seja com dieta ou com fármacos. Para casos mais graves, a solução seria o transplante de coração, todavia, o número de pacientes que necessitam de um coração é maior do que os órgãos disponíveis, inviabilizando a maioria dos transplantes demandados. Em 2018 estimava-se que 1661 corações fossem transplantados, entretanto apenas 353 cirurgias foram realizadas, o que corresponde a $21 \%$ da necessidade (ASSOCIAÇÃO BRASILEIRA DE TRANSPLANTE DE ÓRGÃOS, 2018). Além da quantidade insuficiente de órgãos, 
o tempo na fila de espera é outro problema para os pacientes, que no Sistema Único de Saúde (SUS) pode levar até dez meses para receber um coração compatível (MARINHO, CARDOSO e ALMEIDA, 2010). Ademais, cerca de $25 \%$ dos pacientes falecem durante o período de espera do órgão (LIMA et al., 2010).

Mesmo com tantas dificuldades, para muitos pacientes, a única solução é aguardar na fila do transplante. Porém, tendo em vista a gravidade do quadro faz-se necessário a assistência de um dispositivo de circulação mecânica para auxiliar ou substituir o bombeamento em um dos lados do coração. Dentre estes dispositivos destaca-se o dispositivo de assistência ventricular (DAV) que consiste em uma bomba de um deste três tipos: pulsátil, centrífuga ou axial. Geralmente, o DAV é aplicado no lado esquerdo, devido a maior força empregada neste lado, contudo, também pode ser instalado no lado direito ou em ambos os lados (TANG, OYER e MALLIDI, 2009). O DAV garante uma maior sobrevida ao paciente além de ser uma ponte para 0 transplante (bridge to transplant). Em alguns casos é uma ponte para a recuperação (bridge to recovery) ou terapia de destino.

Os DAVs são opções viáveis para tratamento a curto e médio prazo nos pacientes adultos que sofrem com IC. No entanto, quando o foco muda para pacientes pediátricos, o desenvolvimento de DAVs é lento e apresenta problemas. Os dispositivos existentes apresentam formação de trombos, ou seja, coágulos entre $38 \%$ a $63 \%$ dos casos em pacientes infantis, enquanto a taxa em adultos é de $18 \%$ (WEISS et al., 2012).

Ainda, quanto aos dispositivos de assistência ventricular pediátricos (DAVP) é importante destacar que existem menos opções e estas são menos eficazes em relação aos dispositivos para adultos. Isto se deve aos diferentes tamanhos corporais e devido a tal fato, existem poucos DAVs disponíveis no mercado, o que acarreta em incompatibilidades e taxas de bombeamento muito abaixo do necessário causando trombose, mesmo com DAVPs pequenos (BURKI e ADACHI, 2017). Aliado a este fator, existe a dificuldade em encontrar um órgão com dimensões compatíveis para a criança, exigindo uma maior confiabilidade do DAV.

Nos Estados Unidos da América (EUA) um DAV só será utilizado em pacientes após a aprovação da Food and Drug Administration (FDA) que é o órgão verificador dos vários fatores de segurança e eficácia dos dispositivos. Um destes fatores é a taxa de destruição das hemácias, ou hemólise o que agrava o estado do paciente (GIARRA, 2009). Os grandes responsáveis pela hemólise são as tensões turbulenta 
e de cisalhamento no sangue durante o funcionamento das bombas (JONES, 1995). Outro fator é a formação de trombos devido às alterações das condições reológicas e o contato com superfícies não biológicas. Isto resulta na ativação das plaquetas e consequentemente na ativação da cascata de coagulação. Neste caso, a tensão de cisalhamento desempenha um papel importante pois a hemólise ativa as plaquetas que causarão a trombose (KOLIOPOULOU et al., 2016). A hemólise e a trombose diminuem a expectativa de vida, portanto, qualquer DAV será testado a fim de determinar os valores das tensões produzidas no fluido e consequentemente a taxa de hemólise.

As análises experimentais (in vitro ou in vivo em animais) e computacionais (in silico) são importantes pois apresentam os efeitos colaterais dos DAVs sem a necessidade de causar risco a um paciente. Após a análise destas adversidades pode-se desenvolver outro dispositivo ou aprimorá-lo. Por exemplo, Topper et al. (2014) estudou regiões de formação de trombos microscópicos por meio de experimentos com velocimetria por imagem de partículas (Particle Image Velocimetry - PIV). Por sua vez, Benk et al. (2011) realizou experimentos com imagens por ressonância magnética (Magnetic Resonance Imaging, MRI) para investigar diferentes condições de operação do DAV. Pode-se ainda avaliar as tensões e a turbulência em válvulas no DAV (LI et al., 2011). É importante ressaltar os trabalhos de Caimi et al. (2017) e Torner et al. (2018) que utilizaram a dinâmica dos fluidos computacional (Computational Fluid Dynamics, CFD) para comparar os dados simulados com os dados experimentais do PIV e para analisar zonas com tensões de cisalhamento elevadas, respectivamente.

Uma das formas de análise experimental do escoamento mais utilizada nos dispositivos é o PIV. A técnica PIV consiste na adição de partículas traçadoras, que devem acompanhar o escoamento do fluido. O fluido será iluminado por uma fonte laser que produz uma folha de luz, e uma câmera de alta velocidade gravará a luz refletida por estas partículas. Posteriormente, as imagens gravadas serão comparadas por um algoritmo que determinará os vetores e o campo de velocidade entre as imagens. O PIV possibilita a determinação de campos de velocidades em duas dimensões ou três dimensões. Algumas das técnicas de PIV podem ser resolvidas no tempo (time resolved ou TR-PIV), ou seja, as medições são realizadas com uma taxa de aquisição alta o suficiente para demonstrar a evolução dinâmica do fluxo (RAFFEL et al., 2018). 
Os sistemas PIV utilizam os princípios ópticos, portanto, requerem um fluido e um objeto transparente. Os primeiros registros da aplicação PIV para obtenção de campos de velocidade no DAV, com acesso óptico, são do início dos anos 2000. Nesta mesma época, os estudos de cisalhamento na parede do dispositivo já demonstravam a capacidade do PIV de estimar estes valores (HOCHAREON et al., 2004). Todavia, a técnica PIV possui aspectos que podem aprimorar os resultados obtidos. No caso do DAV, as adversidades como distorções, espalhamento de luz, ausência de préprocessamento dos dados, movimento do fluido tridimensional, movimento das partículas para fora do plano de interesse e a sombra do diafragma são ignorados por vários autores. Todas estas mazelas são importantes pois representam a realidade no espaço da imagem e geram problemas no momento da determinação correta do campo de velocidades.

\subsection{Objetivos}

A seguir serão apresentados os propósitos do presente trabalho, divididos em objetivo geral e objetivos específicos.

\subsubsection{Objetivo geral}

O propósito do presente trabalho é analisar as características do escoamento no dispositivo de assistência ventricular pediátrico (DAVP) desenvolvido pelo Instituto do Coração (InCor) do Hospital das Clínicas (HC) da Faculdade de Medicina da Universidade de São Paulo (FM USP) por meio das velocidades e tensões e com isto avaliar a probabilidade de formação de trombos e da lise celular utilizando a velocimetria por imagem de partículas resolvida no tempo (TR-PIV).

\subsubsection{Objetivos específicos}

A fim de atingir o objetivo principal, os seguintes objetivos específicos serão realizados:

a) Adaptar e desenvolver tecnologia de medição e análise de imagem que forneça resultados confiáveis; 
b) Medição dos campos instantâneos de velocidade em três planos dentro do DAVP utilizando a técnica PIV, com as devidas correções;

c) Cálculo dos campos de velocidade média;

d) Cálculo dos campos médios de tensões a partir das velocidades medidas;

e) Cálculo do tempo de permanência de uma partícula virtual no escoamento e das tensões a que ela esteve sujeita no percurso;

f) Análise dos valores encontrados para as tensões de cisalhamento viscosas e turbulentas e suas relações com a formação de trombos e hemólise.

\subsection{Formulação do problema}

O número de crianças ( 0 a 14 anos) que faleceram no mundo em consequência de doenças cardiovasculares (DCV), muitas das quais decorrentes de insuficiência cardíaca (IC) vêm diminuindo ao longo dos dezesseis anos pesquisados (Figura 1) pela Organização Mundial de Saúde (OMS). Porém, o número ainda é alarmante pois em 2016 quase 57 mil crianças faleceram de DCV, sendo aproximadamente $68 \%$ delas devido à IC.

Figura 1 - Mortes de crianças no mundo por DCV no período de 16 anos

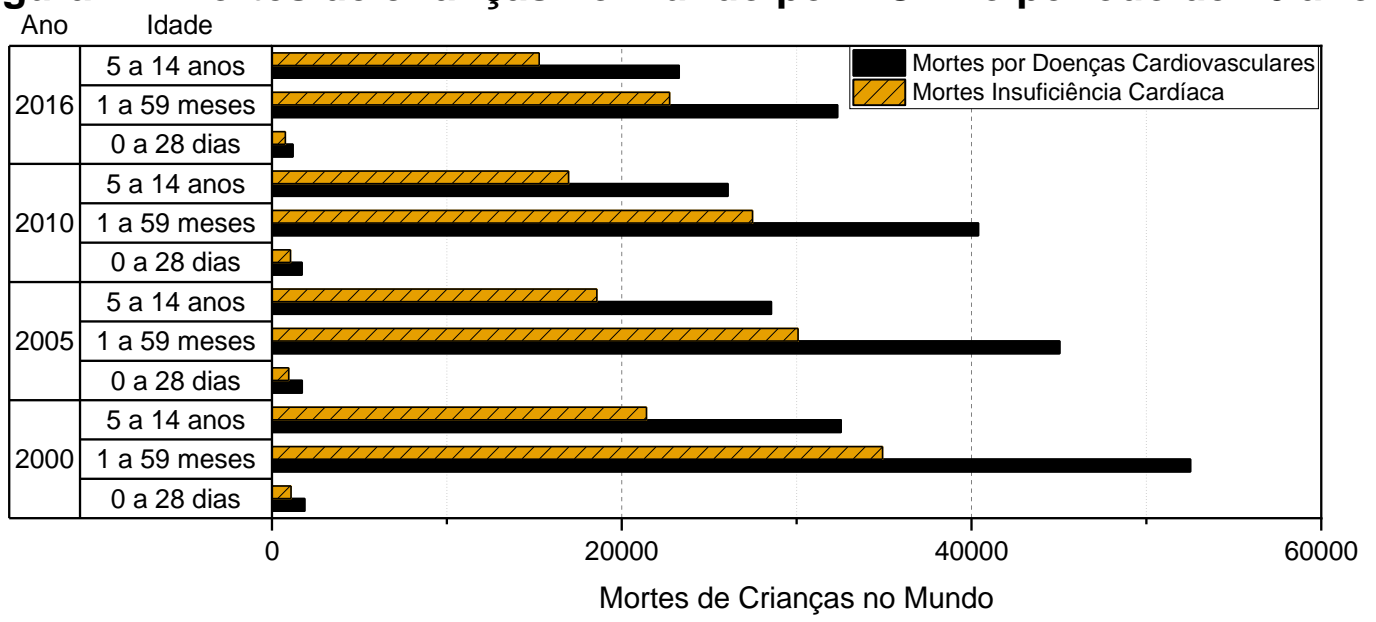

Fonte: World Health Organization (2018).

No Brasil, as estatísticas não são confiáveis, mas ainda assim os números também são alarmantes. No ano de 2016 o total de óbitos infantis devido a DCV foi de 1453 e dentro deste valor, 73,5\% estão relacionados a IC (Figura 2). Estes dados refletem principalmente o baixo índice de transplantes cardíacos pediátricos (Figura 3), que ainda é a melhor solução para a IC infantil. 
Figura 2 - Número de mortes de crianças no Brasil por DCV em 2016

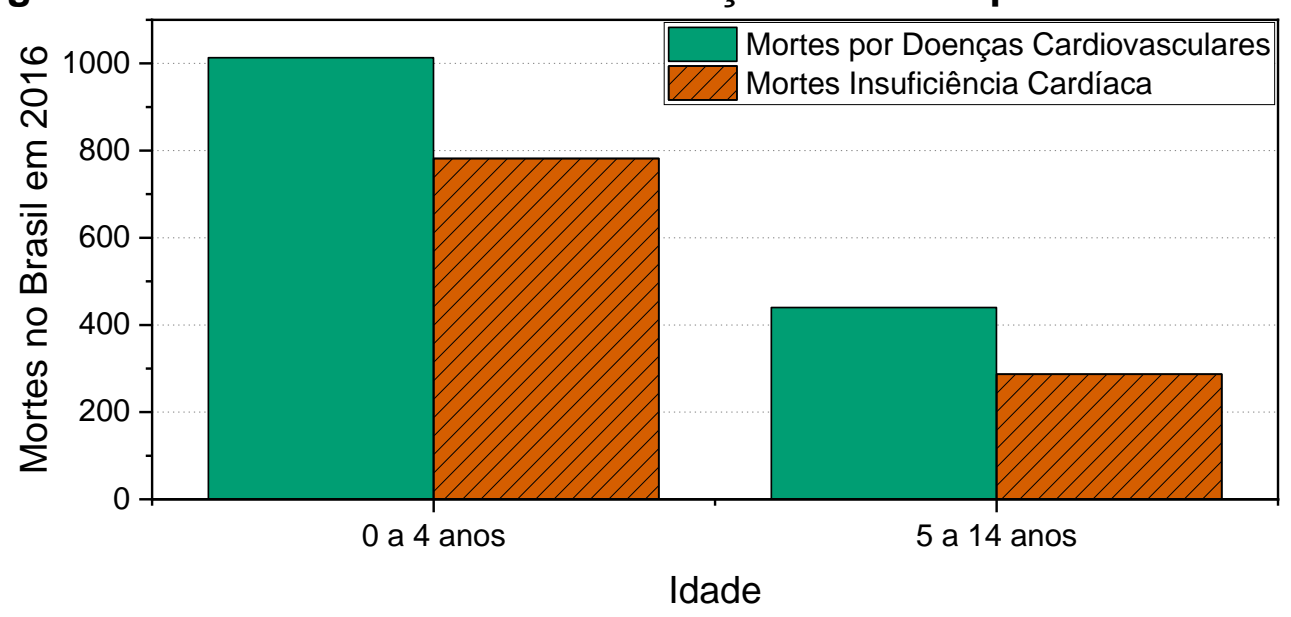

Fonte: World Health Organization (2018).

Figura 3 - Necessidade de Transplante de Coração (Ped.) no Brasil em 2018

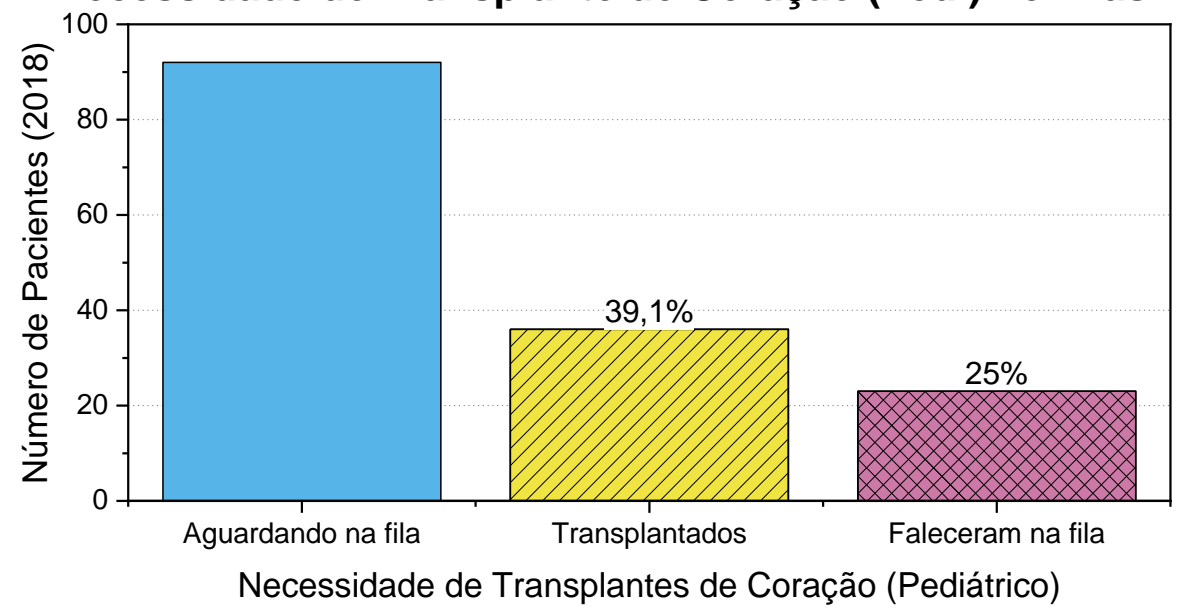

Fonte: Associação Brasileira de Transplante de Órgãos (2018).

Para aumentar o tempo de vida dos pacientes que aguardam na fila de transplante, os médicos utilizam dispositivos de circulação mecânica. De acordo com Almond et al. nos Estados Unidos da América crianças com IC ficaram em média 40 dias com um dispositivo de assistência ventricular pediátrico (DAVP), e a taxa de sobrevivência em um ano foi de $75 \%$, sendo $64 \%$ transplantados posteriormente, $6 \%$ se recuperaram e não necessitaram de transplante e $5 \%$ aguardavam na fila para receber um órgão (ALMOND et al., 2013).

Apesar dos avanços já alcançados, os DAVPs disponíveis ainda não são perfeitos por apresentarem problemas físicos, pois ainda provocam hemólise e/ou formação de trombos. Além disso há uma discrepância entre as opções existentes de DAVPs quando comparados aos DAVs para adultos. Como o DAVP deve funcionar numa ampla faixa etária, ou seja, de recém-nascido ao início da adolescência, o 
dispositivo deve acompanhar as diferentes demandas de cada corpo, já que os adultos possuem um regime bem definido de demanda fisiológica. Estima-se que seis em cada um milhão de crianças que possuem uma cardiopatia necessitarão de um DAVP. Devido aos fatos citados e à demanda crescente, as universidades, instituições governamentais e setores da indústria estão pesquisando e desenvolvendo DAVPs para esta ampla faixa etária. (VANDERPLUYM, FYNN-THOMPSON e BLUME, 2014).

Além dos problemas físicos propriamente ditos, há também os problemas relacionados à identificação destes, ou seja, a representação do escoamento investigado. Todas as técnicas empregadas nos estudos de fluidos apresentam certos inconvenientes. A velocimetria por imagem de partículas (Particle Image Velocimetry, PIV) é uma técnica óptica que permite a visualização de partículas em fluidos. Nesta técnica amplamente utilizada em DAVs, os inconvenientes podem ocorrer devido a limitações de planos passíveis de medição, às regiões sombreadas, aos altos deslocamentos e/ou baixa concentração de partículas e às interferências ópticas, como por exemplo, refração, reflexão, intensidade do laser e distorção causada pelo meio (CAIMI et al., 2017). Estes problemas geralmente produzem erros como valores aberrantes, também chamados de outliers, bem como regiões sem valores. No PIV isto se reflete nos vetores do campo de velocidades (ADRIAN e WESTERWEEL, 2011). A Figura 4a apresenta os vetores espúrios observados por Ferrara (2005) em seu DAVP, já a Figura 4b as regiões sem vetores observados por Manning et al. (2008) em outra versão de DAV.

\section{Figura 4 - Problemas relacionados às estimativas PIV}

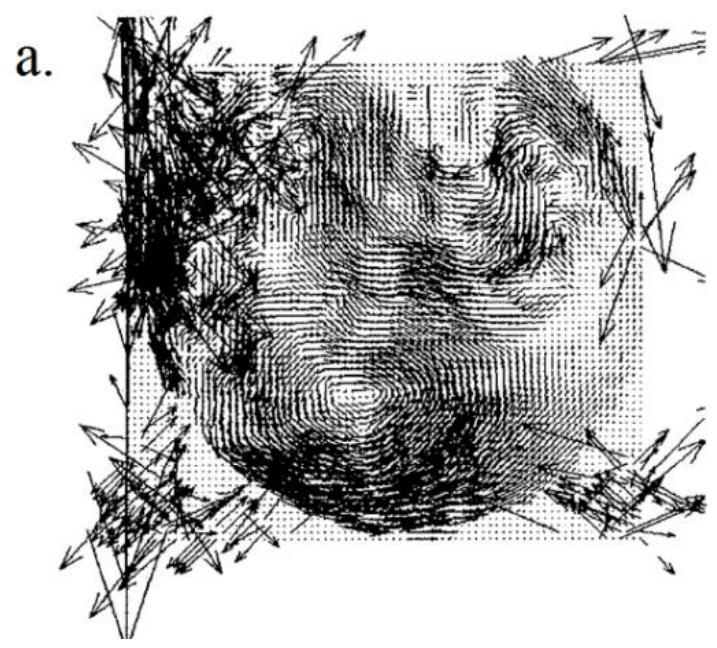

b.

(a) Campo com falsos vetores e (b) regiões sem vetores. Fonte: Adaptado de Ferrara (2005) e Manning et al. (2008). 
Pesquisas realizadas por Shinneeb, Bugg e Balachandar (2004), Masullo e Theunissen (2015), Lee, Yang e Yin (2017) propõem diferentes meios para remover os outliers, entretanto a detecção destes vetores com precisão é complexa. Esta dificuldade está relacionada aos tipos de vetores espúrios, sejam dispersos, sejam agrupados, além da intensidade da turbulência. Devido a este fato, deve-se testar qual a melhor maneira para remover os falsos vetores sem prejudicar o resultado do experimento.

\subsection{Divisão do trabalho}

Esta dissertação de mestrado foi organizada em cinco capítulos, de acordo com os assuntos, a saber:

a) Capítulo 1: Introdução do tema;

b) Capítulo 2: Desenvolvimento, o qual apresenta o estado da arte e as técnicas que serão utilizadas neste trabalho;

c) Capítulo 3: Metodologia, explicações e justificativas adotadas neste trabalho acadêmico;

d) Capítulo 4: Resultados e Discussão, explicados através do método utilizado;

e) Capítulo 5: Conclusão, relatando toda a análise feita e uma crítica sobre todo o projeto. 


\section{DESENVOLVIMENTO}

Neste capítulo é apresentada a fisiologia do coração humano, as características do Dispositivo de Assistência Ventricular (DAV), as tensões envolvidas no escoamento do DAV e os princípios da técnica de Velocimetria de Imagem de Partículas (PIV).

\subsection{O coração humano}

O coração é o órgão responsável pelo bombeamento de sangue para o corpo através dos vasos sanguíneos, compondo o sistema circulatório. O coração humano situa-se na cavidade torácica entre os pulmões. Possui dois lados cada qual com duas câmaras chamadas de átrios (superiores) e ventrículos (inferiores). As funções (Figura 5) do átrio e do ventrículo são, respectivamente, levar sangue ao ventrículo através de um bombeamento fraco e impulsionar o sangue para o seu destino por um bombeamento forte (MOORE, DALLEY e AGUR, 2018).

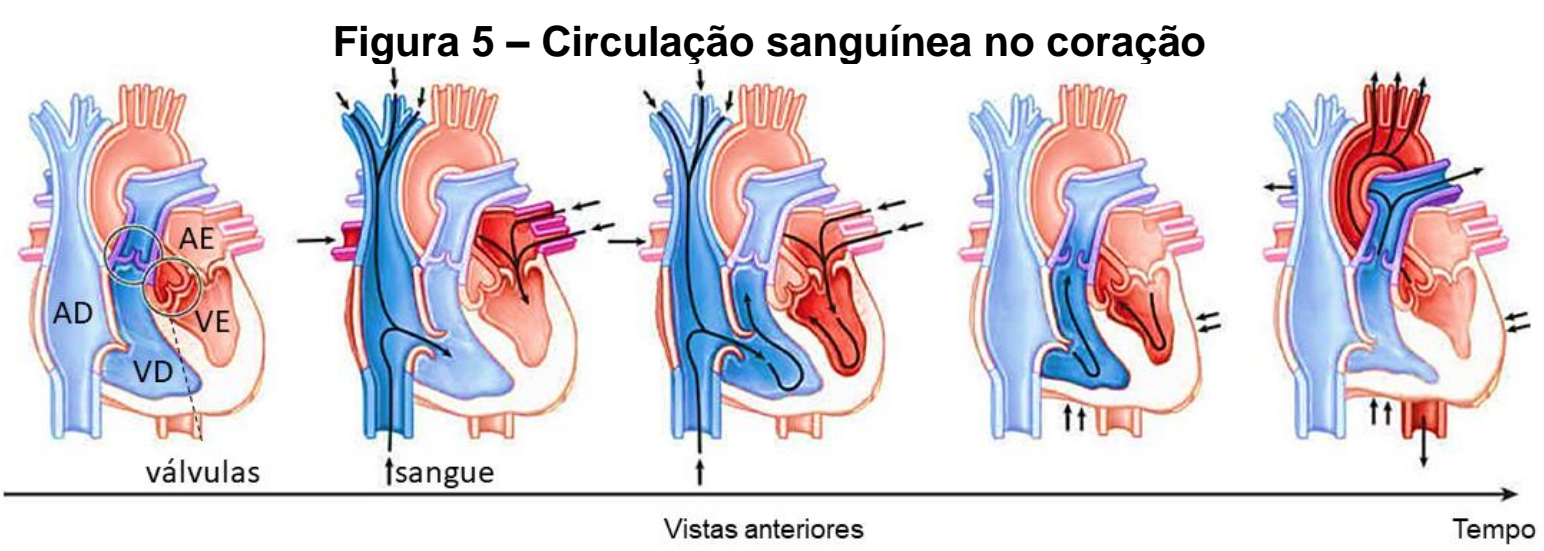

AD: átrio direito; $A E$ : átrio esquerdo; VD: ventrículo direito; VE: ventrículo esquerdo Fonte: Adaptado de Moore, Dalley e Agur (2017).

Um ciclo cardíaco é definido pelos eventos necessários para um batimento do coração. Cada ciclo se inicia pela geração de um potencial elétrico que viaja dos átrios para os ventrículos. Desta forma, os átrios atuam como bombas primárias para os ventrículos que são a principal fonte de energia do sistema (HALL, 2016).

Considerando o início do ciclo de bombeamento a partir das veias cava superior (Figura 6c) e inferior (Figura 6n), o sangue venoso, rico em dióxido de carbono $\left(\mathrm{CO}_{2}\right)$ adentra $\mathrm{o}$ átrio direito (Figura $6 \mathrm{f}$ ). $\mathrm{O}$ átrio direito então bombeia $\mathrm{o}$ sangue para $\mathrm{o}$ 
ventrículo direito (Figura 6l). Entre as duas câmaras há uma válvula unidirecional chamada de válvula tricúspide (Figura 6j) cujo sentido de fluxo é do átrio para o ventrículo. Posteriormente, o ventrículo direito ejeta o sangue para os pulmões por meio das artérias pulmonares (Figura 6r). Novamente, há uma válvula para evitar 0 refluxo, chamada de válvula pulmonar (Figura 6t). Nos pulmões ocorre a troca gasosa e o sangue retorna ao coração através das veias pulmonares (Figura 6s). Neste retorno, o sangue adentra o átrio esquerdo (Figura 6u) que bombeia o sangue para o ventrículo esquerdo (Figura 6x). No meio das câmaras esquerdas há outra válvula unidirecional conhecida como válvula mitral ou bicúspide (Figura 6v). Finalmente o sangue é ejetado para o corpo após passar pela válvula unidirecional (Figura 6w) da artéria aorta (LABROSSE, 2019). Todas as partes constituintes do coração são apresentadas na Figura 6.

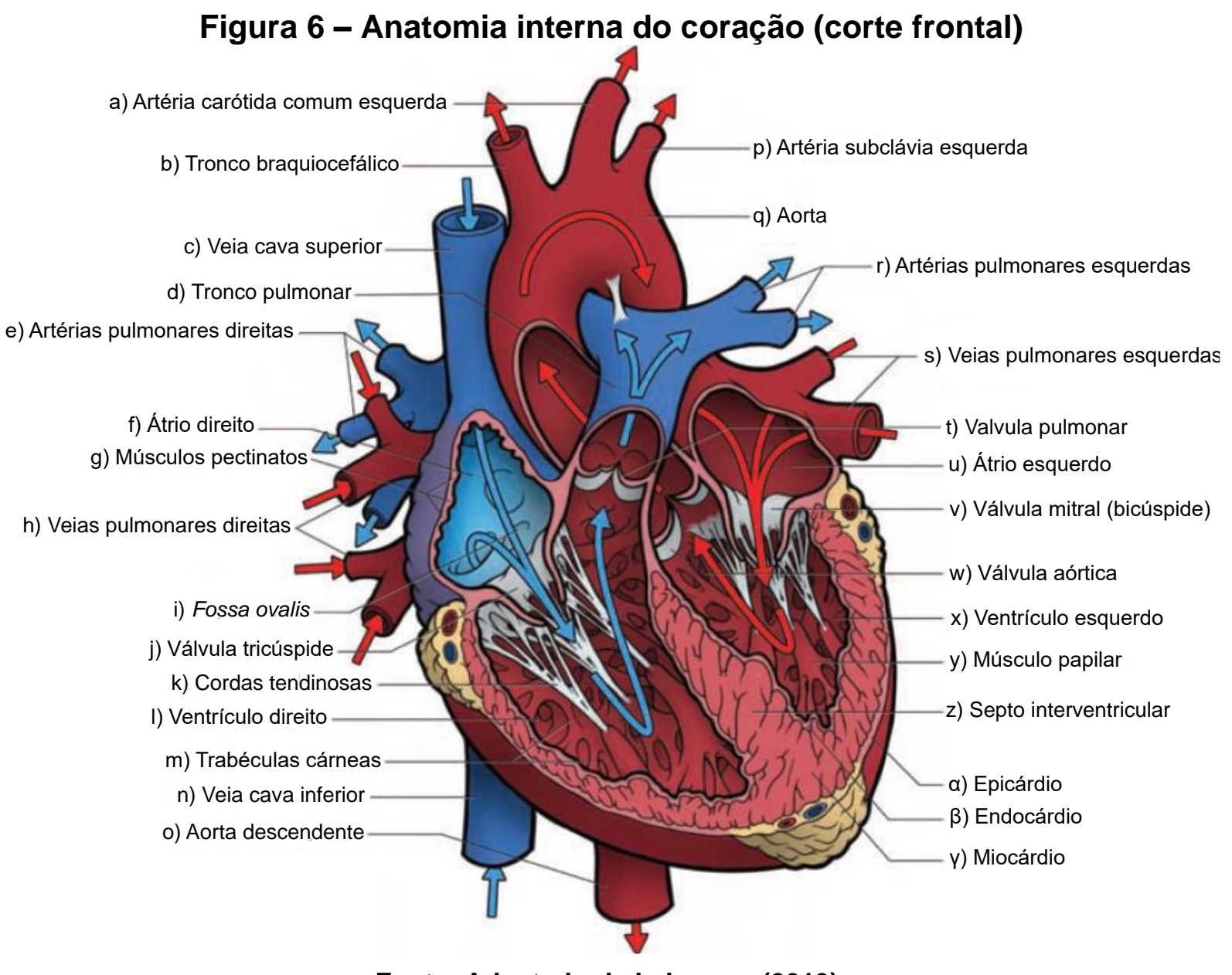

Fonte: Adaptado de Labrosse (2019).

Pelas veias, com exceção das veias pulmonares, circula o sangue venoso proveniente das outras partes do corpo. O sangue venoso é rico em gás dióxido de 
carbono $\left(\mathrm{CO}_{2}\right)$ e é representado na Figura 6 pelas setas de cor azul. Nas artérias, excetuando-se as artérias pulmonares, corre o sangue arterial, rico em gás oxigênio $\left(\mathrm{O}_{2}\right)$ e representado na Figura 6 pelas setas de cor vermelha. Nas veias pulmonares (Figura 6s) o sangue que circula é arterial e nas artérias pulmonares (Figura 6r) corre sangue venoso. A explicação para a utilização deste padrão de cores para os tipos de sangue está relacionada ao coeficiente de absorção na região espectral do vermelho de cada gás presente nas hemácias. Visto que o $\mathrm{CO}_{2}$ absorve mais a luz vermelha do que $\mathrm{O}_{2} \mathrm{O}$ sangue venoso apresenta uma coloração azulada ou arroxeada (KIENLE et al., 1996). O percurso do sangue partindo do ventrículo esquerdo, passando pelo corpo e retornando ao átrio direito é denominado circulação sistêmica. Por sua vez, o percurso do sangue que deixa o ventrículo direito, passa pelos pulmões e retorna ao átrio esquerdo é denominado circulação pulmonar.

Os átrios possuem paredes finas e volume aproximado de $35 \mathrm{~mL}$, com pouca variação durante o bombeamento. A máxima pressão atingida pelos átrios é $10 \mathrm{mmHg}$ (AUNE et al. 2009). A pressão de ejeção é baixa pois a maior parte do sangue que adentra os átrios flui diretamente para os ventrículos. Por sua vez, os ventrículos possuem um volume diastólico final de aproximadamente $120 \mathrm{~mL}$, ou seja, quando o músculo está relaxado. Após a contração este volume reduz para aproximadamente $50 \mathrm{~mL}$, que é nomeado volume sistólico (VS) final. As pressões de pico que os ventrículos direito e esquerdo atingem são $30 \mathrm{mmHg}$ e $120 \mathrm{mmHg}$, respectivamente. A pressão é maior no lado esquerdo pois a perda de carga no percurso do sangue pelo corpo é maior (LABROSSE, 2019).

No ciclo cardíaco, há dois períodos bem característicos, a sístole e a diástole. A primeira é o período de contração e a segunda é o período de relaxamento do musculo cardíaco. O diagrama de Wiggers (Figura 7), apresenta as curvas dos eventos que ocorrem durante um ciclo para o lado esquerdo do coração ao longo do tempo. A curva azul representa a mudanças de pressão no ventrículo esquerdo. Já as curvas vermelha e amarela apresentam, respectivamente, as variações de pressão na aorta e no átrio esquerdo. Por fim, a curva rosa mostra a variação volumétrica no ventrículo. A onda " $a$ " corresponde à contração atrial, a onda " $c$ " corresponde a um aumento na pressão da valva mitral para o átrio após o fechamento, e a onda " $V$ " corresponde ao preenchimento atrial passivo. As linhas verticais pontilhadas representam as fases do ciclo. 


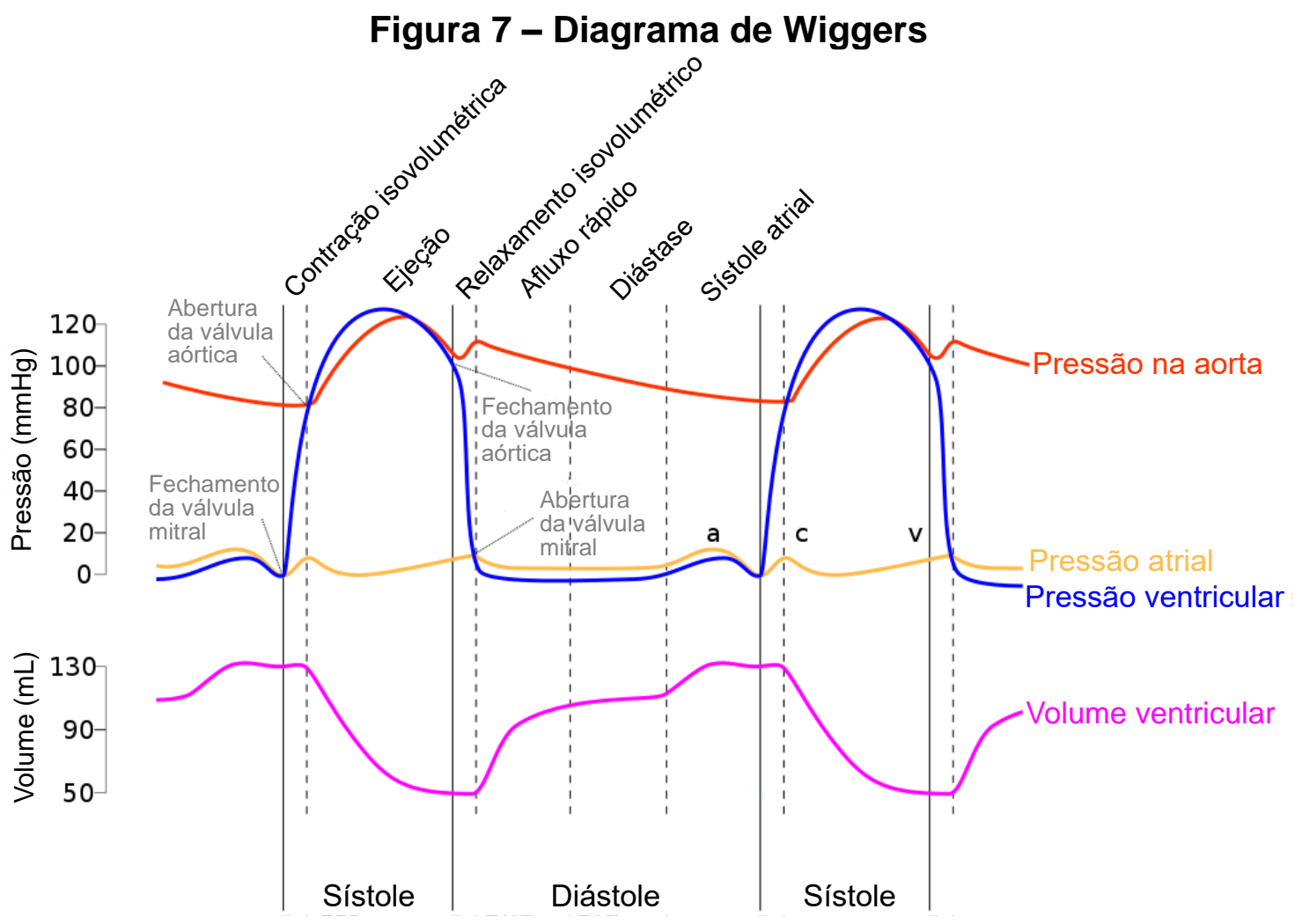

Fonte: Adaptado de Hall (2016).

No diagrama de pressão-volume do ventrículo esquerdo (Figura 8) a sístole inicia com o fechamento da válvula mitral e encerra com o fechamento da válvula aórtica.

Figura 8 - Diagrama pressão-volume do ventrículo esquerdo

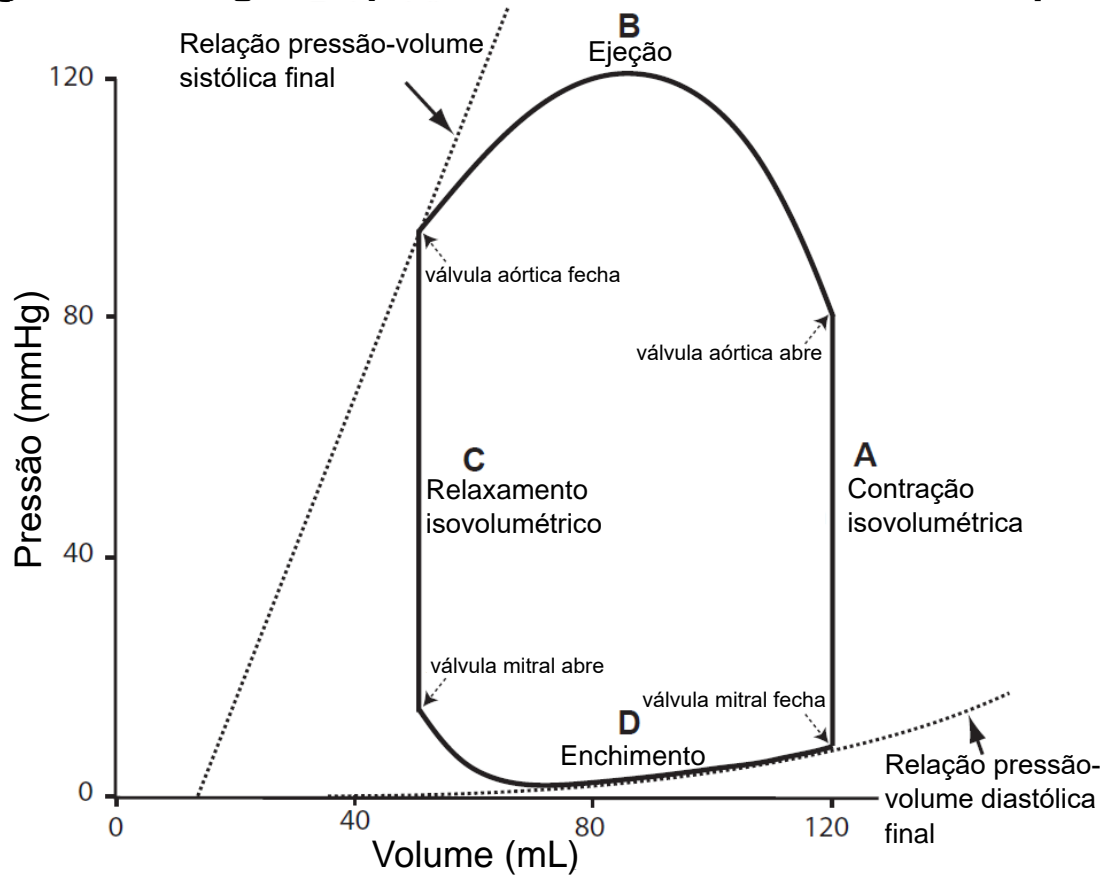

Fonte: Adaptado de Fung (1984). 
Após o fechamento da válvula mitral o volume do ventrículo não se altera, pois, a válvula aórtica também está fechada, portanto a pressão sobe num processo isovolumétrico (Figura $8 \mathrm{~A}$ ). Ao final do processo isovolumétrico a válvula aórtica se abre e ocorre a ejeção (Figura 8B). Terminada a ejeção, o volume e a pressão reduzem até atingir a curva de relação pressão-volume sistólica final e válvula aórtica fecha-se. Inicia-se a diástole e o ventrículo passa por um relaxamento isocórico (Figura $8 \mathrm{C}$ ) até a pressão atingir um nível inferior à pressão do átrio. Neste instante a válvula mitral abre-se e ocorre o enchimento (Figura $8 \mathrm{D}$ ) do ventrículo esquerdo que finaliza quando a pressão e o volume encontram com a curva de relação pressãovolume diastólica final.

Destas curvas pode-se extrair também a porcentagem de tempo gasto com a sístole e a diástole. No caso de uma frequência cardíaca de 75 batidas por minuto (bpm) a sístole corresponde a aproximadamente $40 \%$ do ciclo. A duração das demais fases do ciclo para $75 \mathrm{bpm}$ é apresentada na Tabela 1. Na frequência de $130 \mathrm{bpm}$ a sístole corresponde a $61 \%$ do ciclo (OCCHETTA et al. 2010).

\begin{tabular}{lrr}
\hline \multicolumn{3}{c}{ Tabela 1 - Durações das fases do ciclo cardíaco para 75 bpm } \\
\hline \multicolumn{1}{c}{ Fase } & Duração (s) & Duração (\%) \\
\hline Contração isovolumétrica & 0,05 & $6 \%$ \\
Ejeção máxima & 0,09 & $11 \%$ \\
Ejeção reduzida & 0,17 & $21 \%$ \\
Total da sístole & $\mathbf{0 , 3 1}$ & $\mathbf{3 9 \%}$ \\
Relaxamento isovolumétrico & 0,08 & $10 \%$ \\
Enchimento rápido & 0,11 & $14 \%$ \\
Diástase & 0,19 & $24 \%$ \\
Sístole atrial & 0,11 & $14 \%$ \\
Total da diástole & $\mathbf{0 , 4 9}$ & $\mathbf{6 1 \%}$ \\
Total do ciclo & $\mathbf{0 , 8}$ & $\mathbf{1 0 0 \%}$ \\
\hline
\end{tabular}

Fonte: Adaptado de Wiggers (1915) e Katz (2011).

As curvas que relacionam a duração da sístole e a frequência cardíaca em adultos são apresentadas na Figura 9. Akhras e Rickards (1981), Rickards e Norman (1981), e Boudoulas et al. (1981) já afirmavam que a relação entre a duração da sístole (em milissegundos) e a frequência cardíaca era linear. 
Figura 9 - Relação da duração da sístole pela frequência cardíaca em adultos

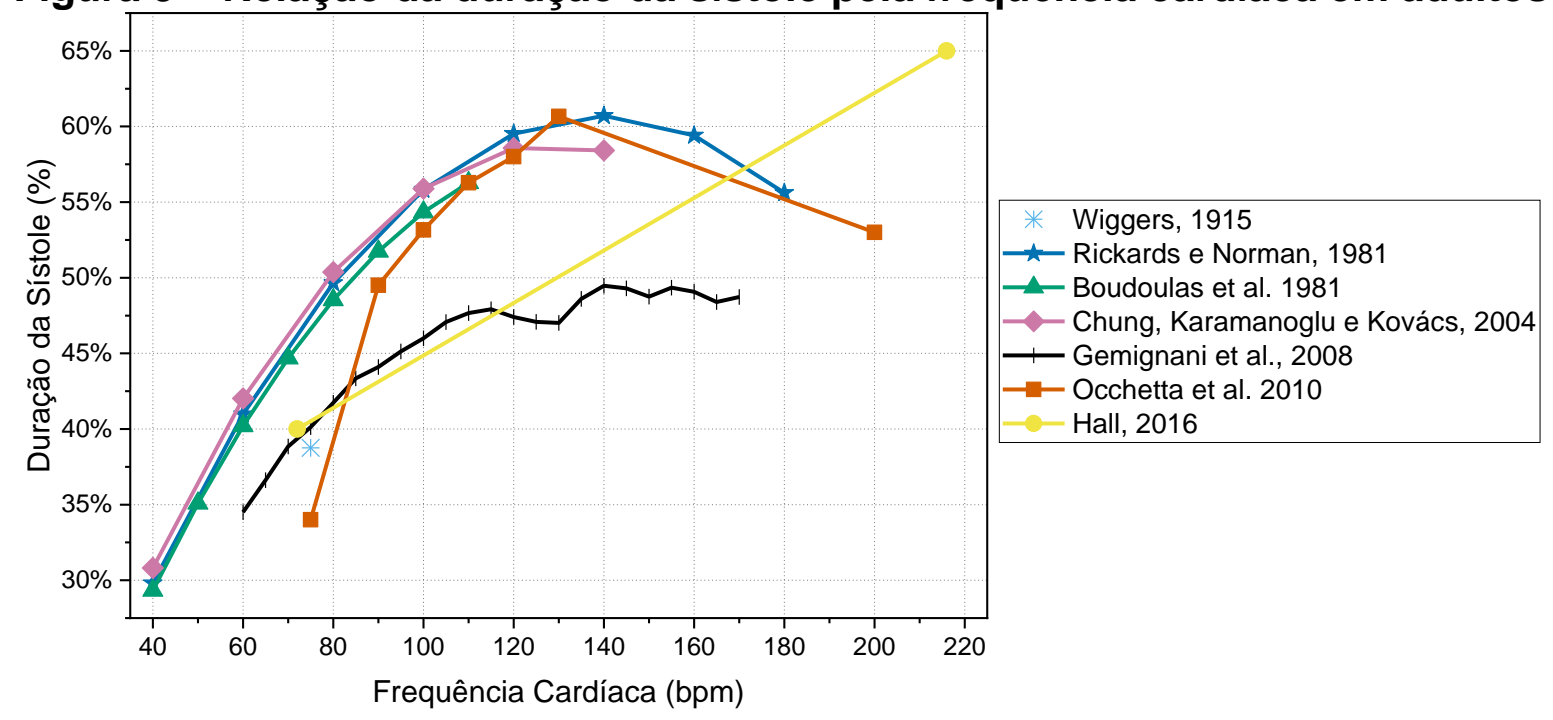

A Figura 10 exibe as curvas da relação entre a duração da sístole, em porcentagem, e a frequência cardíaca para prematuros, recém-nascidos e crianças. Neste caso, as curvas não possuem valores tão próximos, pois a idade e 0 crescimento são fatores importantes. Harris et al. (1964) mediu os batimentos e a duração da sístole em bebês prematuros com menos de $2 \mathrm{~kg}$, bebês com idade média de 2 dias e crianças com idade média de 8 anos. Spitaels et al. (1974) mediu em crianças com média de idade de 7 anos e área da superfície corporal (SC) média de $0,87 \mathrm{~m}^{2}$, Sarnari et al. (2009) mediu em crianças com médias de 6 anos, 0,85 $\mathrm{m}^{2}$ e 26 $\mathrm{kg}$.

Figura 10 - Relação da duração da sístole pela frequência cardíaca pediátrica

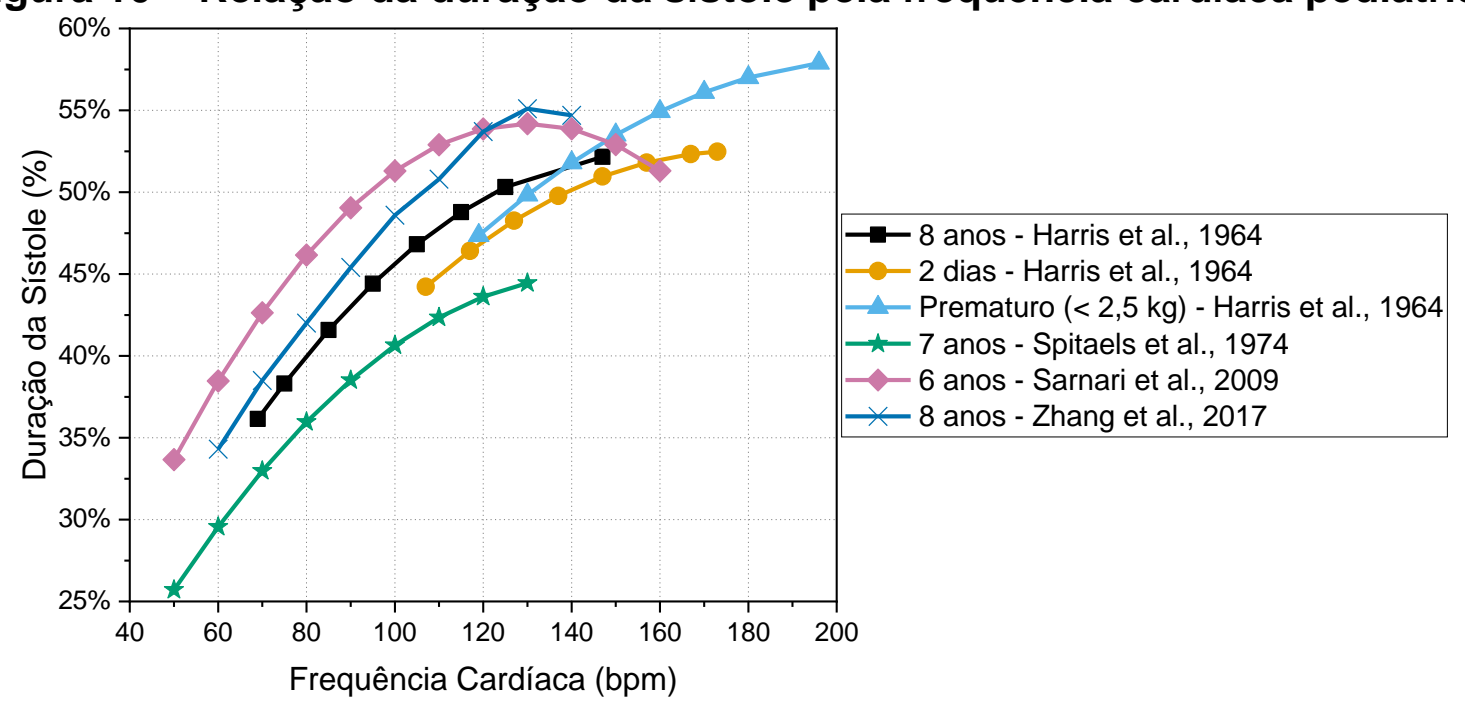


Em relação às características da bomba cardíaca, com o foco no ventrículo esquerdo, apresentam-se três parâmetros importantes: o volume sistólico, o débito cardíaco e a fração de ejeção. O volume sistólico, que representa a quantidade de volume deslocado, é encontrado pela diferença entre o volume diastólico e o volume sistólico. Portanto, o valor médio do volume sistólico em adultos é $70 \mathrm{~mL}$ (KATZ, 2011). A vazão volumétrica, ou débito cardíaco é o produto do volume sistólico pela frequência cardíaca. Considerando-se uma frequência cardíaca normal de 72 batidas por minuto (bpm) o débito cardíaco resultante é $5 \mathrm{~L} / \mathrm{min}$. A fração de ejeção consiste na razão entre o volume sistólico e o volume diastólico final. Os valores usais de fração de ejeção são próximos a 66\% (MACEIRA et al., 2006).

\subsubsection{A insuficiência cardíaca}

A insuficiência cardíaca (IC) é reconhecida desde a antiguidade. Por volta de 1500 a.C. no Egito, há um relato registrado no papiro de Ebers sobre a IC. Da mesma forma, Hipócrates relatou na Grécia a IC por volta de 400 a.C. Desta forma, sabe-se que a IC é um problema que persiste por milênios na humanidade (MCDONAGH et al., 2011).

Em 2017, estimou-se que 26 milhões de adultos ao redor do mundo sofriam com IC, números que poderiam considerá-la como uma pandemia. Nos Estados Unidos da América, a população com IC corresponde a 5,7 milhões de pessoas que produziram um custo total com a saúde de U\$33 bilhões (SAVARESE e LUND, 2017).

A IC, segundo Ponikowski et al. (2014) é definida como "[...] uma condição na qual o coração de uma pessoa não consegue bombear sangue suficiente para o corpo [...]". As possíveis causas etiológicas da IC são agrupadas em: hipertensão, problemas cardíacos e pulmonares, infecções, estilo de vida e outras condições médicas. As causas e os fatores relacionados são apresentados na Figura 11.

O coração possui uma capacidade extraordinária de adaptação e remodelagem às demandas do corpo. Por exemplo, um atleta de alto rendimento possui um coração maior e bradicárdico, ou seja, o músculo cardíaco adaptou-se para bombear mais sangue aumentando o débito cardíaco em uma frequência menor de batimentos, que consequentemente melhora a fração de ejeção (PRIOR e GERCHE, 2012). No entanto, se o músculo cardíaco perder esta capacidade ou a remodelagem persistir a longo prazo, ocorrerá a IC. 


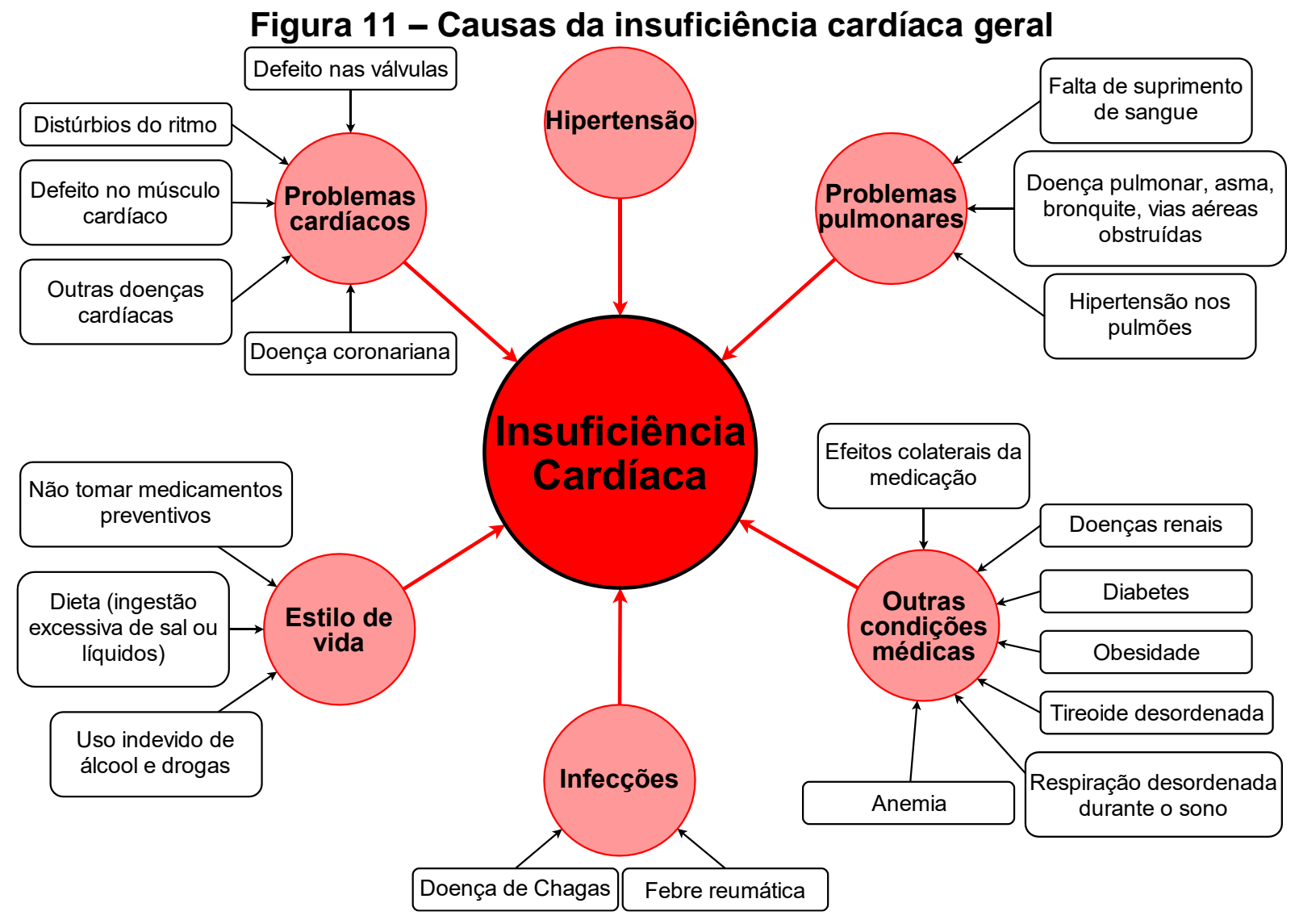

Fonte: Adaptado de Ponikowski et al. (2014).

A patofisiologia do coração afetado pela IC consiste na redução da força dos músculos na região dos ventrículos, e por consequência a cardiomegalia (Figura 12).

a)

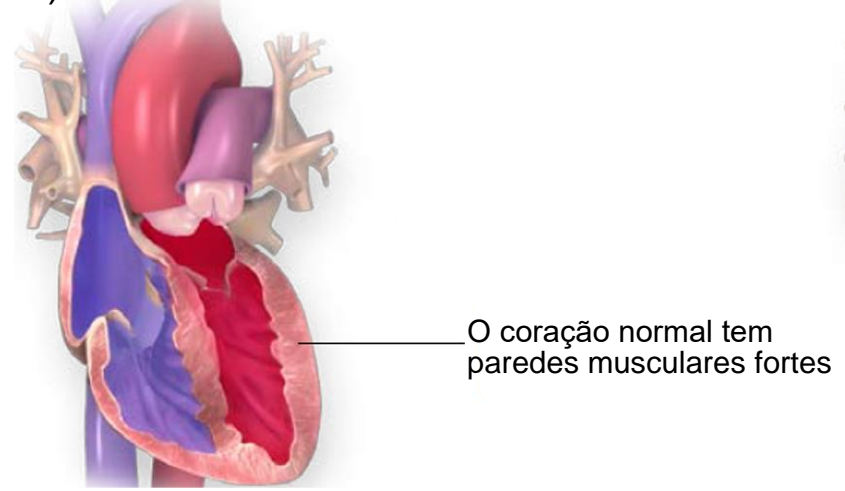

b) insuficiência cardíaca apresenta músculos fracos e flácidos (cardiomegalia)

(a) coração normal e (b) coração com IC Fonte: American Heart Association (2015).

Por outro lado, a IC infantil difere da IC em adultos em muitos aspectos. Devido ao pequeno número de pesquisas, bem como o menor desenvolvimento de terapias para IC infantil, o tratamento das crianças é focado na experiência clínica e na 
extrapolação de dados dos pacientes adultos para os infantis (JAYAPRASAD, 2016). As principais causas da IC pediátrica são: cardiopatias congênitas, débito cardíaco elevado, cardiomiopatias, arritmias e infecções (Figura 13).

\section{Figura 13 - Causas da insuficiência cardíaca pediátrica}

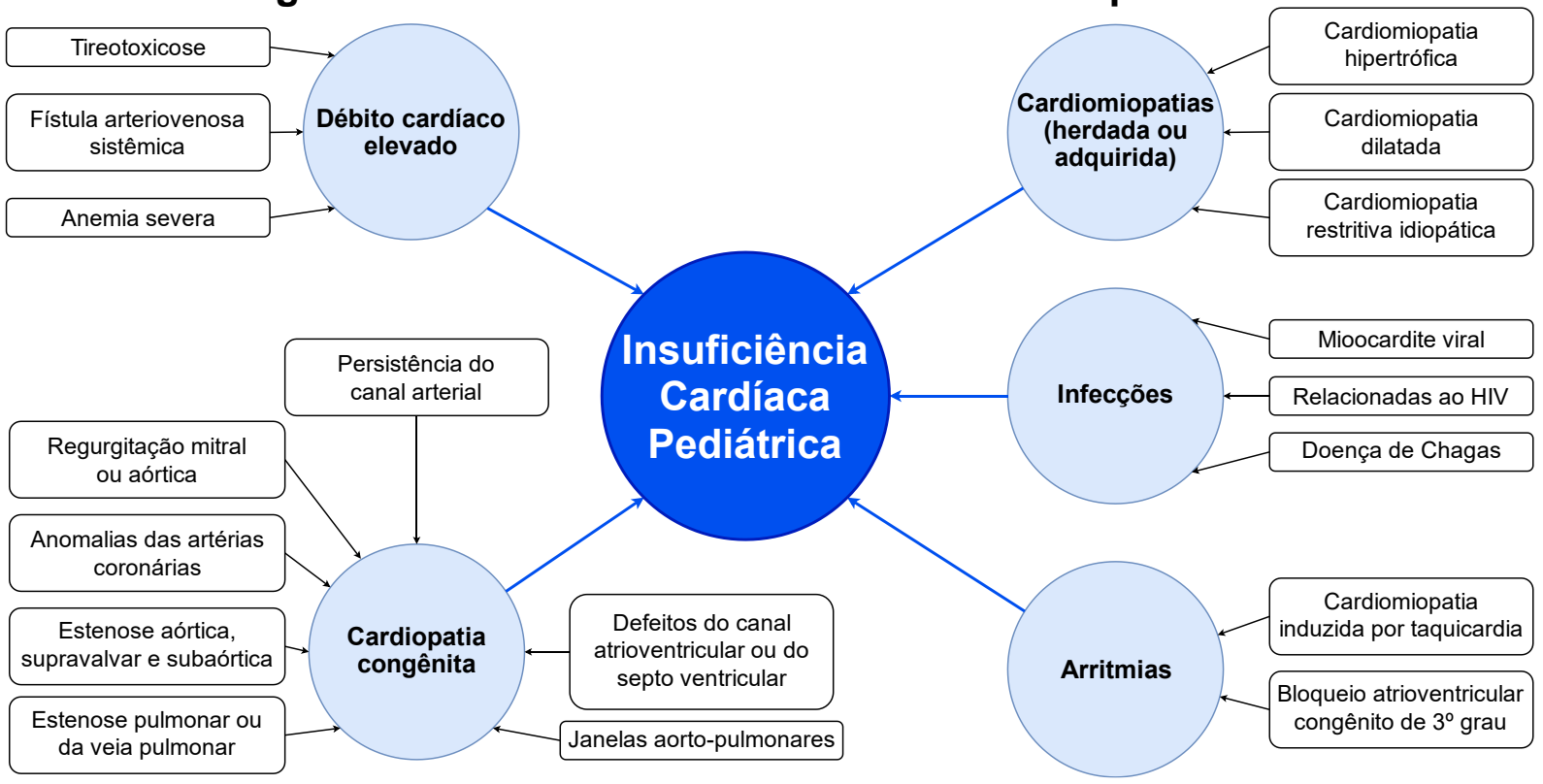

Fonte: Adapatado de Jayaprasad (2016) e Masarone et al. (2017).

Dentre as cinco principais causas de insuficiência cardíaca infantil, pode-se destacar dois que apresentam a maior incidência. A primeira causa é a cardiopatia congênita que afeta $8 \%$ crianças nascidas o que corresponde entre $25 \%$ a $75 \%$ de todos os pacientes pediátricos com IC. A segunda causa mais incidente é a cardiomiopatia com 1,3 casos a cada 10000 bebês entre zero e um ano. Sabe-se que 90\% das crianças afetadas pela cardiomiopatia terão o agravante da dilatação do ventrículo, o que leva a um risco de morte em até cinco anos ou 31 a $46 \%$ de ser submetido a transplante cardíaco (TOWBIN et al., 2006). Além das duas primeiras causas mundiais de IC infantil, pode-se destacar no Brasil as IC causadas por doenças infecciosas. Nos Estados Unidos, 1\% dos casos de IC infantil estavam relacionados ao vírus HIV, já no Brasil esta proporção é de 29,3\% (DAS, 2018).

Os tratamentos disponíveis para IC variam desde dietas e medicamentos até cirurgias e transplante. No caso dos transplantes, o número de doadores é inferior ao número de pacientes (Figura 14a). Em crianças a situação é pior, pois o tamanho do coração é um fator determinante (TJANG et al., 2008). Isto gera grandes filas e consequentemente o tempo de espera é longo, causando muitas mortes (Figura 14b). 
Uma possível solução para as filas de espera pelo órgão, tanto em adultos quanto em crianças, é utilização de um DAV. Há três formas principais de uso para um DAV: ponte para o transplante, ponte para a recuperação ou terapia de destino. As pontes para o transplante ou recuperação mostraram-se muito eficazes ao longo dos anos de desenvolvimento dos dispositivos (JAKOVLJEVIC et al., 2017). Recentemente, o uso de dispositivos a longo prazo também apresentou bons resultados, o que pode aumentar o uso dos DAV como terapia de destino (RAJU et al., 2017).
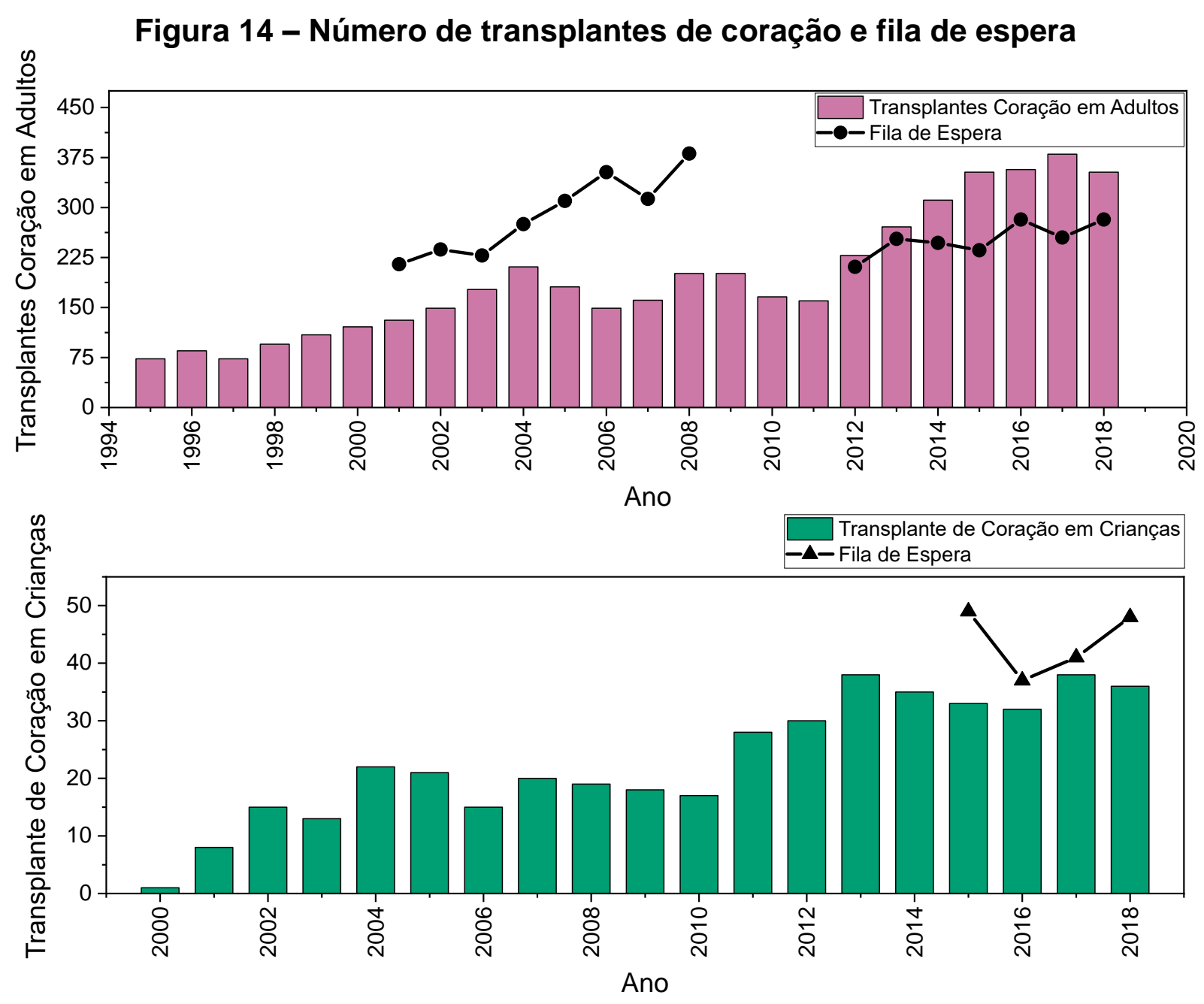

Fonte: Adaptado de Associação Brasileira de Transplante de Órgãos (2018).

\subsection{Os dispositivos de assistência ventricular}

O dispositivo de assistência ventricular (DAV) é um equipamento eletromecânico cuja função é auxiliar a circulação cardíaca através de bombeamento de sangue. A Figura 15 apresenta três DAVs: Thoratec PVAD (Figura 15a), Thoratec HeartMate II (Figura 15b); HeartWare LVAD (Figura 15c). 


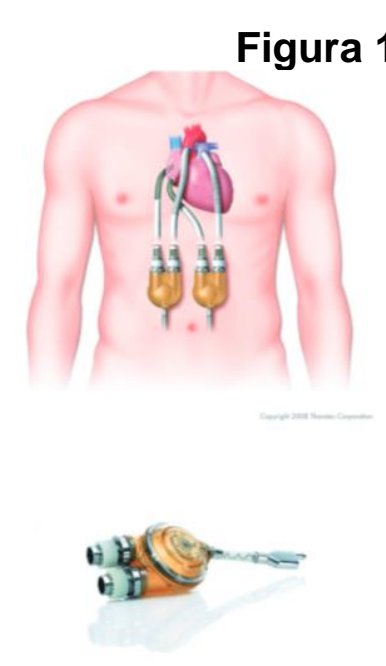

a)

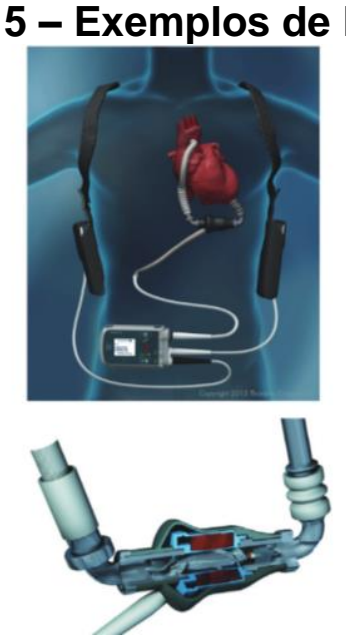

b)

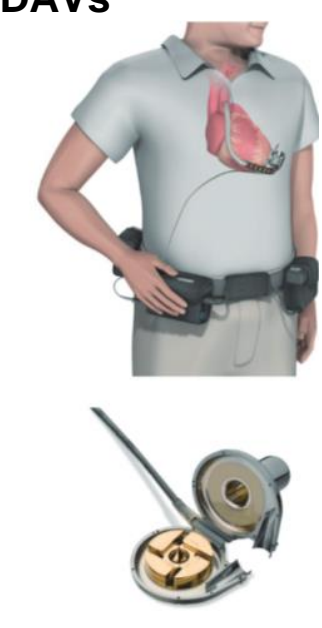

c)

Fonte: Adaptado de Prinzing et al. (2016).

Nos dispositivos pneumáticos o ar comprimido transfere a energia mecânica, em forma de pressão, para uma membrana (ou diafragma) que se move e por consequência transfere energia cinética para o sangue (Figura 16). No período de enchimento, o ar deixa câmara e a membrana recolhe-se no sentido do vácuo criado. Neste momento o sangue do ventrículo passa por uma válvula unidirecional na entrada da câmara de bombeamento do DAV. Após o enchimento da câmara de bombeamento, o ar comprimido adentra a câmara de ar e pressiona a membrana, aumentando a pressão do sistema e ejetando o sangue pela válvula unidirecional de saída em direção a veia aorta ou pulmonar (PIRBODAGHI et al., 2013). Portanto, o DAV pneumático reproduz mecanicamente a sístole e a diástole do coração biológico.

\section{Figura 16 - Mecanismo de funcionamento do DAV pneumático Corte Transversal do DAV Pneumático}
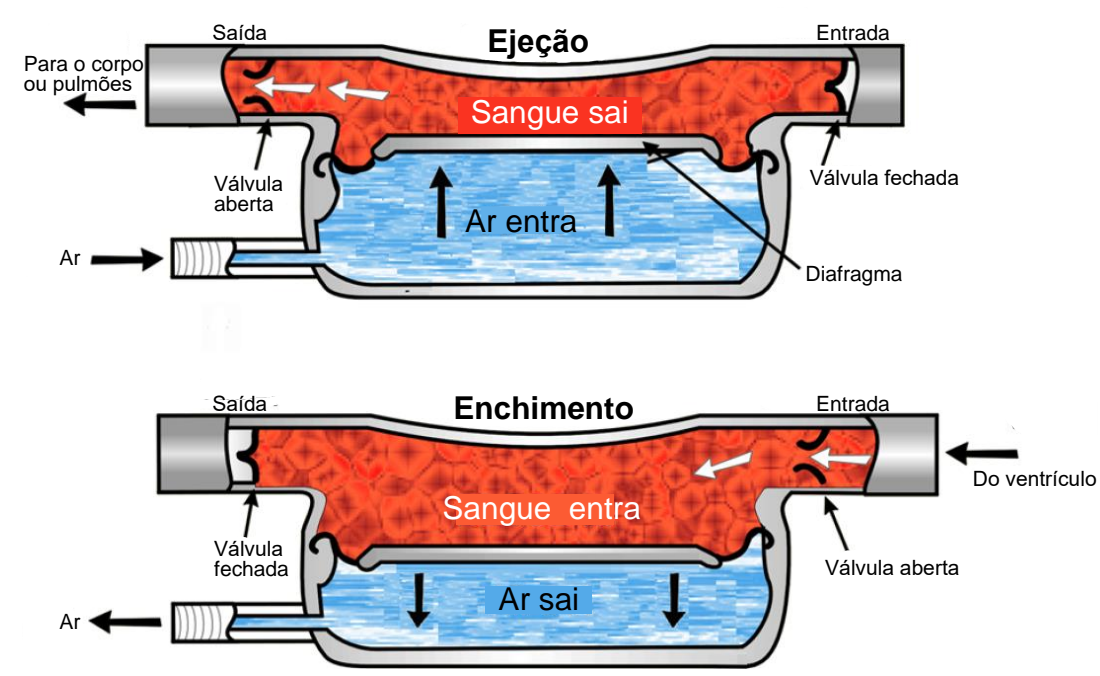

Fonte: Adaptado de Pirbodaghi et al. (2013). 
Usualmente o DAV substitui a função do ventrículo esquerdo (Figura 17a), pois é este que realiza a maior força de bombeamento, mas também é implantado no lado direito (Figura 17b) ou em ambos os lados (Figura 17c).

a)

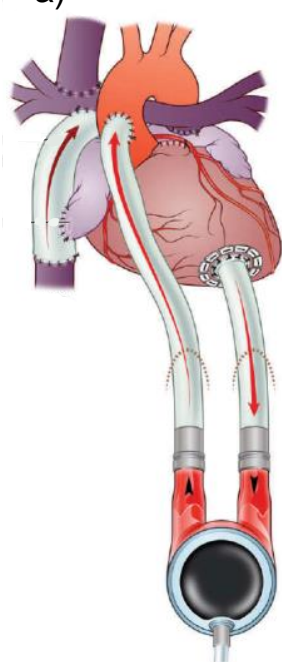

Fonte: Adaptado de Burrato et al. (2017). b)

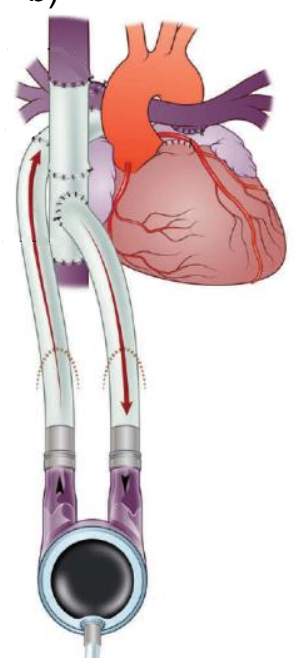

c)

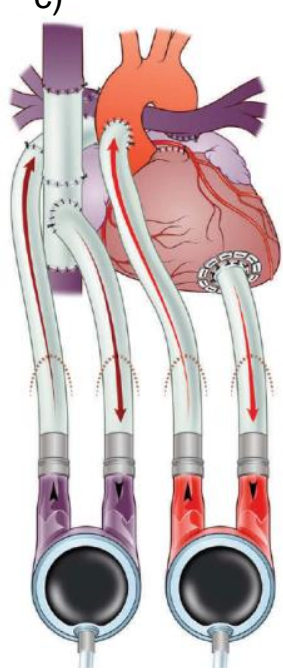

O primeiro dispositivo de assistência ventricular (Figura 18) foi implantado em 1963 quando o Dr. Domingo Santo Liotta, cirurgião cardíaco, o utilizou no ventrículo esquerdo de um paciente em choque cardiogênico.

Figura 18 - DAV concebido por Liotta

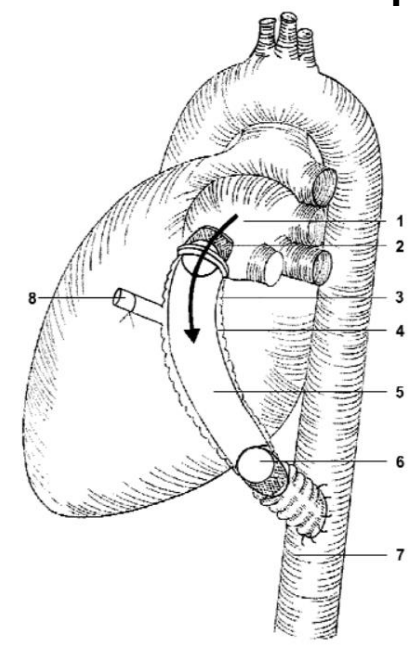

Fonte: Liotta (2002).

Após o sucesso do primeiro DAV e reconhecendo que outros pacientes poderiam se beneficiar deste tipo de terapia, o Instituto Nacional de Coração Pulmões 
e Sangue dos Estados Unidos (National Heart, Lung, and Blood Institute - NHLBI) estabeleceu o programa para desenvolvimento de novos DAVs em 1975 (TANG, OYER e MALLIDI, 2009).

Durante os anos 1970 e 1980 surgiram os DAVs que hoje são chamados de DAVs de primeira geração. As características principais destes dispositivos são: maior durabilidade, deslocamento positivo das bombas e o fluxo pulsátil (Figura 19). Testes clínicos mostraram que em $75 \%$ dos casos o paciente sobreviveu com o DAV até o transplante (TANG, OYER e MALLIDI, 2009).

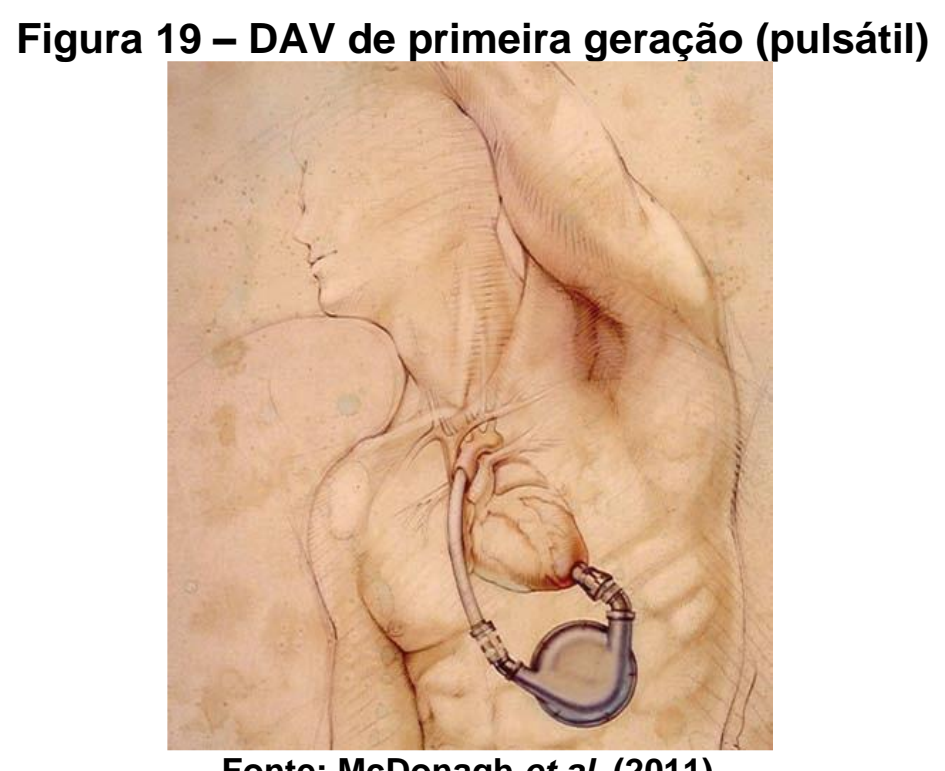

Fonte: McDonagh et al. (2011).

Em 1993 foi realizada a primeira cirurgia para implantação de um DAV na América Latina. O procedimento foi realizado no Instituto do Coração (InCor) em um paciente em estado terminal da doença de Chagas, no qual o DAV deu suporte à sua vida por cinco dias, até ser transplantado (UNIVERSIDADE DE SÃO PAULO (USP), 2012).

Também na década de 1990 o NHLBI abriu uma proposta para a criação de novos DAVs inovadores, cujo objetivo era melhorar a durabilidade e a capacidade de implantação. Surgiu neste momento a segunda geração de DAVs, caracterizada pelas bombas rotativas de fluxo axial (Figura 20), tamanho reduzido, ausência de válvulas e baixo ruído sonoro. Os DAVs de segunda geração apresentam desvantagens em relação ao DAVs de primeira geração, sendo elas a perfusão não pulsátil, eventos de sucção e sangramento gastrointestinal (TANG, OYER e MALLIDI, 2009). 


\section{Figura 20 - DAV de segunda geração (axial)}

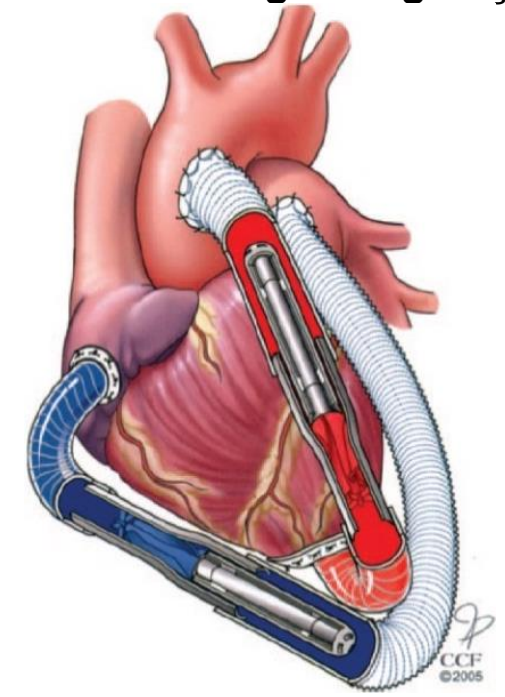

Fonte: Adaptado de Baldwin et al. (2006).

Por volta de 2010 surgiram os DAV de terceira geração, caracterizados por bombas centrífugas (Figura 21) e a ausência de rolamentos, que foram substituídos por ímãs. Acredita-se que sem rolamentos os dispositivos durem por mais tempo após o implante. Outro fator que pode beneficiar as bombas centrífugas é a curva de pressão por fluxo ser próxima ao linear o que permitiria menores rotações e consequentemente menos eventos de sucção (MCDONAGH et al., 2011).

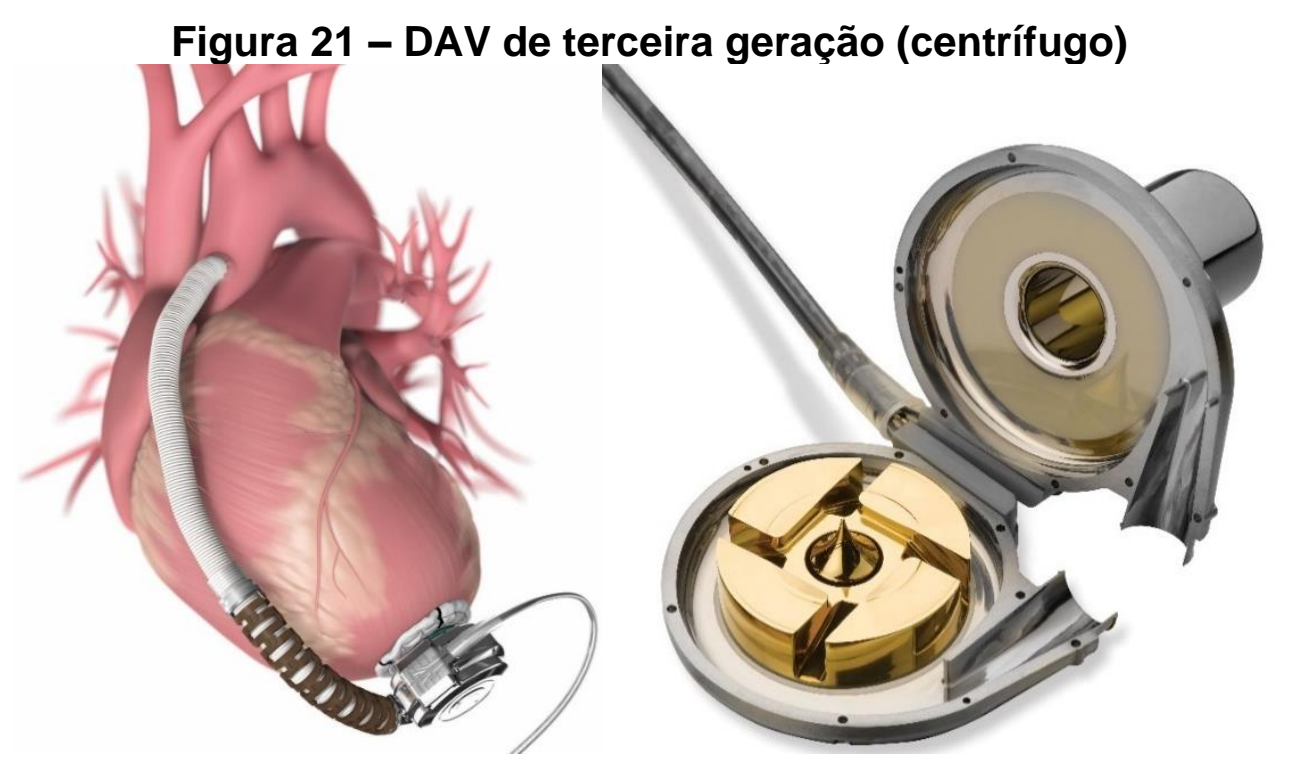

Fonte: HearWare (2019).

A Tabela 2 apresenta diversos DAVs de diferentes gerações com valores próximos de vazão com suas principais características construtivas. 
Tabela 2 - Comparação de DAVs de diferentes gerações

\begin{tabular}{c|c|c|c|c}
\hline Nome & Características & $\begin{array}{c}\text { Volume Deslocado } \\
(\mathbf{m L})\end{array}$ & $\begin{array}{c}\text { Rotação } \\
\text { (rpm) }\end{array}$ & $\begin{array}{c}\text { Vazão } \\
\text { (L/min) }\end{array}$ \\
\hline Thoratec PVAD & Pulsátil & 65 & - & 7 \\
Jarvik 2000 & Axial & - & 12000 & 7 \\
VentrAssist & Centrífugo & - & 3000 & 6 \\
\hline
\end{tabular}

Fonte: Adaptado de Tang, Oyer e Mallidi (2009).

O desenvolvimento de bombas rotativas de fluxo contínuo ocorreu de forma precipitada devido à falta de empenho da engenharia para com as bombas pulsáteis. Apesar da simplicidade das bombas rotativas, o corpo humano não está preparado para suportar tensões de cisalhamento constantes bem como tolerar a ausência de pulsos. A evolução das espécies favoreceu a evolução das bombas de deslocamento positivo com altas pressões e baixas tensões de cisalhamento (MOAZAMl et al., 2015). Desde os tempos de Aristóteles (384 - 322 a.C.) e Avicena (980 - 1037 d.C.) os estudiosos pesquisam sobre o pulso do sistema cardiovascular. Entretanto, só recentemente o movimento pulsátil com suas tensões cíclicas foi compreendido. As células endoteliais do corpo atuam na regulação dos vasos sanguíneos, provocando a produção de componentes químicos ao receberem estímulos mecânicos. Este processo é denominado mecanotransdução. Sem o fluxo pulsátil não há a produção de óxido nítrico e assim sendo, não há vasodilatação suficiente no corpo (Barić, 2014). Portanto, desenvolvimentos futuros devem aprimorar os DAVs de primeira geração ou adicionar pulsos às bombas rotativas. Outras vantagens e desvantagens dos tipos de DAVs são apresentadas na Tabela 4.

No que diz respeito aos DAV pediátricos (DAVP) o surgimento e utilização foi diferente. No início implantou-se DAVs de adultos em crianças com maior massa corporal, o que se mostrou efetivo. Em crianças maiores de 14 anos a sobrevida com um DAV estava na faixa de $90 \%$ dos casos, porém em crianças menores de 10 anos a probabilidade de sobrevivência era $38 \%$. A partir deste momento viu-se a necessidade da criação de dispositivos específicos para as necessidades das crianças (STILLER, ADACHI e FRASER JR, 2013). 
Tabela 3 - Comparação de DAVs de diferentes gerações

\begin{tabular}{|c|c|c|}
\hline Geração & Vantagens & Desvantagens \\
\hline $1^{\underline{a}}$ & $\begin{array}{l}\text { Pulsatilidade inerente e } \\
\text { semelhante ao coração; } \\
\text { Construção simples. }\end{array}$ & $\begin{array}{l}\text { Dimensões avantajadas; } \\
\text { Alguns casos: } \\
\text { Instalação paracorpórea e necessidade } \\
\text { de ar comprimido }\end{array}$ \\
\hline $2^{\mathrm{a}}$ & $\begin{array}{l}\text { Dimensões compactas; } \\
\text { Mobilidade para o paciente. }\end{array}$ & $\begin{array}{l}\text { Não possui pulsatilidade no escoamento } \\
\text { pois são bombas cinéticas; } \\
\text { Hemólise elevada; } \\
\text { Construcão complexa. }\end{array}$ \\
\hline
\end{tabular}

Em 2006, o NHLBI lançou um programa para pesquisa e desenvolvimento de dispositivos pediátricos para crianças de 2 a $25 \mathrm{~kg}$. O maior desafio da construção de um dispositivo pediátrico é a adequação em uma ampla faixa de tamanhos de pacientes, do recém-nascido ao adolescente, e no uso prolongado o dispositivo deve adaptar-se à demanda do paciente em crescimento. Ademais, em oposição às necessidades de suporte ao ventrículo esquerdo na IC adulta, os pacientes infantis com IC apresentam uma maior probabilidade de falha no ventrículo direito ou em ambos. Logo, há uma preocupação maior na adequação física (Figura 22) de um dispositivo biventricular em uma cavidade torácica pequena (BALDWIN et al., 2006).

\section{Figura 22 - Disposição de um DAV em um bebê}

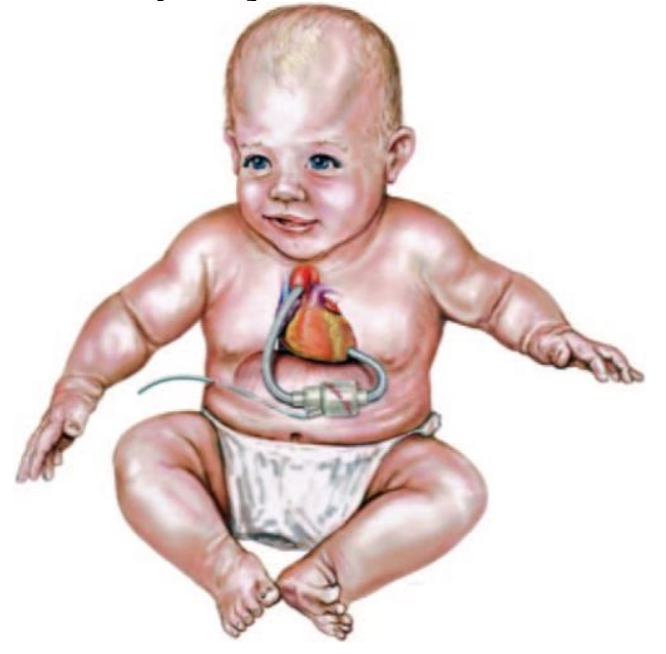

Fonte: Baldwin et al. (2006).

Atualmente, a FDA aprovou o uso de nove tipos de DAVPs, apresentados na 
Tabela 4, de todas as três gerações de dispositivos. Geralmente os DAVPs temporários são utilizados por dias ou semanas e os DAVPs de longo prazo são para pacientes que precisem de suporte mecânico por meses ou anos.

Tabela 4 - DAVPs aprovados pela FDA

\begin{tabular}{|c|c|c|c|c|}
\hline & Dispositivos & Restrições & Tipos de suporte & Bomba \\
\hline \multirow{4}{*}{ 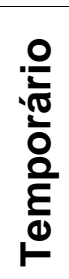 } & Centrimag & Nenhuma & Uni/biventricular & Centrífuga \\
\hline & Rotaflow & Nenhuma & Uni/biventricular & Centrífuga \\
\hline & TandemHeart pVAD & Não info. & Univentricular & Centrífuga \\
\hline & Impella 2.5/5.0 & Não info. & Univentricular & Axial \\
\hline \multirow{4}{*}{ 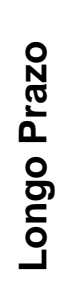 } & Berlin Heart EXCOR & Peso $>3 \mathrm{~kg}$ & Uni/biventricular & Pulsátil \\
\hline & HeartWare HVAD & Peso $\geq 15 \mathrm{~kg}$ & Uni/biventricular & Centrífuga \\
\hline & HeartMate II & Peso $\geq 30 \mathrm{~kg}$ & Univentricular & Axial \\
\hline & Syncardia Total Artificial Heart & $\mathrm{SC}>1,7 \mathrm{~m}^{2}$ & Biventricular & Pulsátil \\
\hline
\end{tabular}

Fonte: Adaptado de VanderPluym, Fynn-Thompson e Blume (2014).

Dentre os dispositivos apresentados, vale ressaltar o DAVP da Berlin Heart EXACOR. Este DAVP foi o único estudado prospectivamente em crianças e produziu uma gama de dispositivos com volumes sistólicos variados, para aplicações em pacientes com diferentes pesos (Figura 23) (VANDERPLUYM, FYNN-THOMPSON e BLUME, 2014).

Figura 23 - Gama de DAVs da Berlin Heart EXACOR
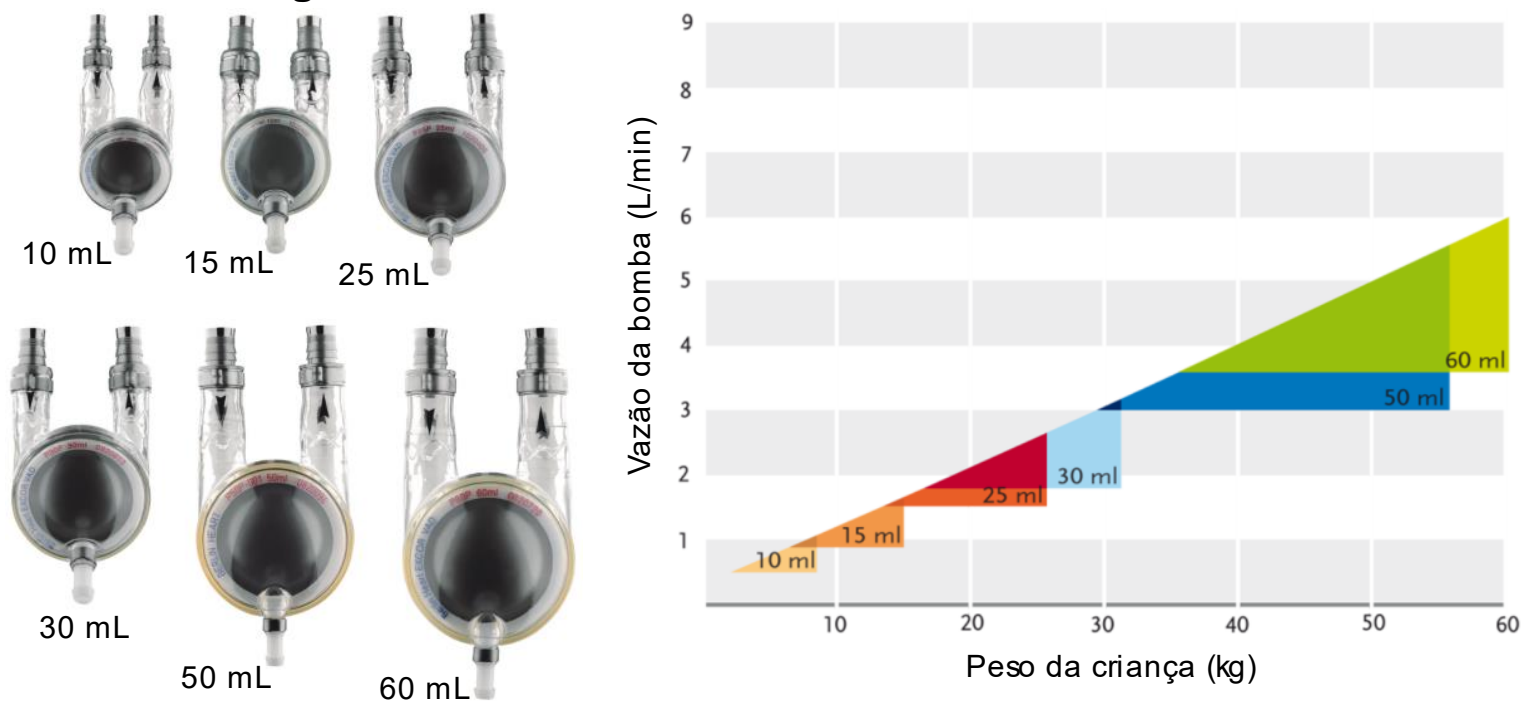

Fonte: Adaptado de Burki (2017), Fraser e Jaquiss (2013) e Berlin Heart (2018). 
Além do EXACOR, o Impella 2.5/5.0 (Figura 24a) destaca-se por possuir tamanho reduzido e a implantação intravascular. Já o Syncardia Total Artificial Heart (Figura 24b) é o único coração totalmente artificial aplicado em casos extremos, como nos casos de doença cardíaca congênita, insuficiência valvular e arritmias intratáveis (VILLA e MORALES, 2017).

A situação no Brasil é diferente da americana. A Sociedade Brasileira de Cardiologia (SBC) lançou em 2016 uma diretriz sobre assistência circulatória mecânica permitindo o uso de seis dispositivos temporários e três para longo prazo, indicados na Tabela 5 (AYUB-FERREIRA et al., 2016). Nesta diretriz não há menção sobre os dispositivos pediátricos no Brasil. Porém, pode-se inferir que há um modelo liberado para o uso pediátrico, o Berlin Heart EXCOR, projetado exclusivamente para crianças.

Tabela 5 - Dispositivos na diretriz de circulação mecânica da SBC

\begin{tabular}{|c|c|c|c|}
\hline & Dispositivo & Tipo de bomba & Suporte hemodinâmico \\
\hline 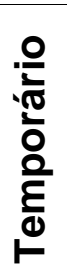 & $\begin{array}{l}\text { TandemHeart } \\
\text { Impella } 2.5 / 5.0 \\
\text { CentriMag } \\
\text { Berlin Heart EXCOR }\end{array}$ & $\begin{array}{l}\text { Centrífuga } \\
\text { Axial } \\
\text { Centrífuga } \\
\text { Pulsátil }\end{array}$ & $\begin{array}{c}4 \mathrm{~L} / \mathrm{min} \\
2,5 \text { e } 5,0 \mathrm{~L} / \mathrm{min} \\
\text { Até } 8 \text { a } 10 \mathrm{~L} / \mathrm{min} \\
\text { Até } 8 \mathrm{~L} / \mathrm{min}\end{array}$ \\
\hline 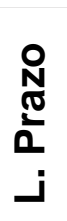 & $\begin{array}{l}\text { HeartMate } I^{*} \\
\text { Berlin Heart INCOR } \\
\text { HeartWare }^{*}\end{array}$ & $\begin{array}{c}\text { Axial } \\
\text { Axial } \\
\text { Centrífuga }\end{array}$ & $\begin{array}{l}\text { Até } 10 \mathrm{~L} / \mathrm{min} \\
\text { Até } 7 \mathrm{~L} / \mathrm{min} \\
\text { Até } 10 \mathrm{~L} / \mathrm{min}\end{array}$ \\
\hline
\end{tabular}

aprovado pela ANVISA. Fonte: Adaptado de Ayub-Ferreira et al. (2016).

Figura 24 - DAV intravascular e coração artificial

a)

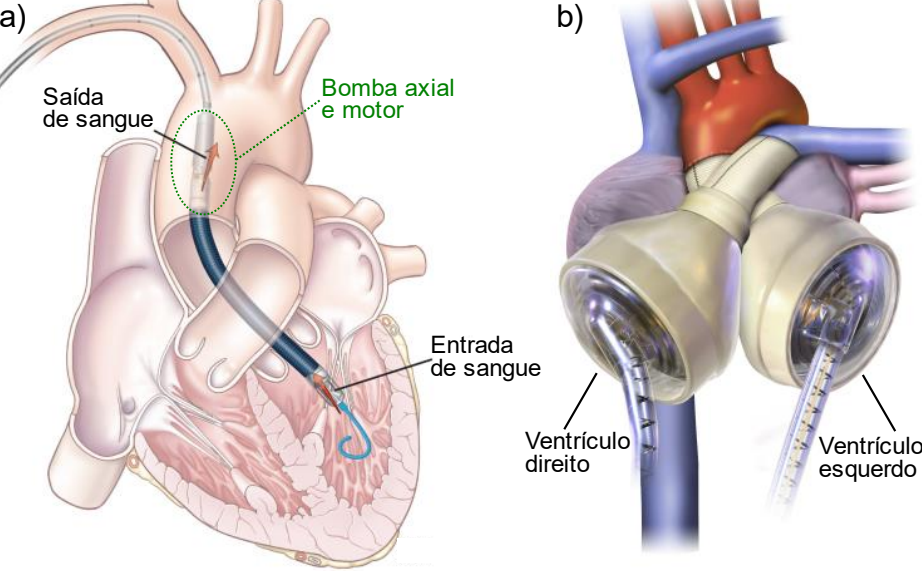

Fonte: Adaptado de Food and Drug Administration (FDA) (2016) e VanderPluym, FynnThompson e Blume (2014). 


\subsection{Desafios tecnológicos nos DAVs: análise do escoamento interno}

Os dispositivos de assistência ventricular (DAVs) não apresentam biocompatibilidade total e desta maneira sua utilização pode causar problemas no corpo do paciente (TCHANTCHALEISHVILI et al., 2014). Os principais problemas associados ao uso do DAV são a hemólise, a trombose, seguidos por sangramento, infecções e falha no dispositivo. A trombose é um estado no qual a coagulação do sangue ocorre dentro dos vasos sanguíneos com potencial obstrução do fluxo (KEY, MAKRIS e LILLICRAP, 2017). Por sua vez, a hemólise, também chamada de hematólise, eritrólise ou eritrocitólise, é a destruição prematura das hemácias por rompimento da membrana das células (JAMESON et al., 2018). Por tratar-se de um método invasivo, as infecções ocorreriam em consequência de contaminações por agentes etiológicos diversos, seja pré, per ou pós cirúrgico.

Na maioria das vezes, o DAV é instalado no lado esquerdo do coração (Figura 17c), pois é o mais utilizado, uma vez que o lado direito do coração apresenta menor índice de problemas relacionados ao bombeamento para os pulmões. De qualquer forma, os dispositivos e os contratempos associados são os mesmos, o que muda é o local de aplicação (BURKI e ADACHI, 2017).

O sangue bombeado por um dispositivo mecânico está sujeito a condições reológicas diferentes das encontradas no corpo humano e também há o contato com superfície não biológicas (plásticos e metais). Segundo Koliopoulou et al. (2016), este estado não natural resulta na ativação de plaquetas causando a trombose e na destruição de eritrócitos causando a hemólise. Devido ao tamanho dos DAVs pulsáteis, dificilmente ocorre uma trombose suficientemente grande para o bloqueio do fluxo. Entretanto, nos dispositivos mais modernos de fluxo contínuo a chance de trombose é maior, pois as bombas são menores (TCHANTCHALEISHVILI et al., 2014). De toda maneira, tanto o deslocamento de um pequeno coágulo, por menor que seja, quanto uma baixa taxa de eritrócitos no paciente, podem trazer consequências severas à manutenção da vida.

As causas de trombose e hemólise no DAV podem incluir: baixa anticoagulação, terapia antiplaquetária inadequada, ativação das plaquetas devido ao material do dispositivo ou tensão de cisalhamento elevada, diminuição do fluxo sanguíneo, infecção, inflamação, alta pressão na saída do DAV, e em alguns casos a hemorragias causadas pela síndrome de von Willebrand adquirida de forma 
comórbida. Todos estes fatores são apresentados na Figura 25 (LINDENFELD e KEEBLER, 2015).

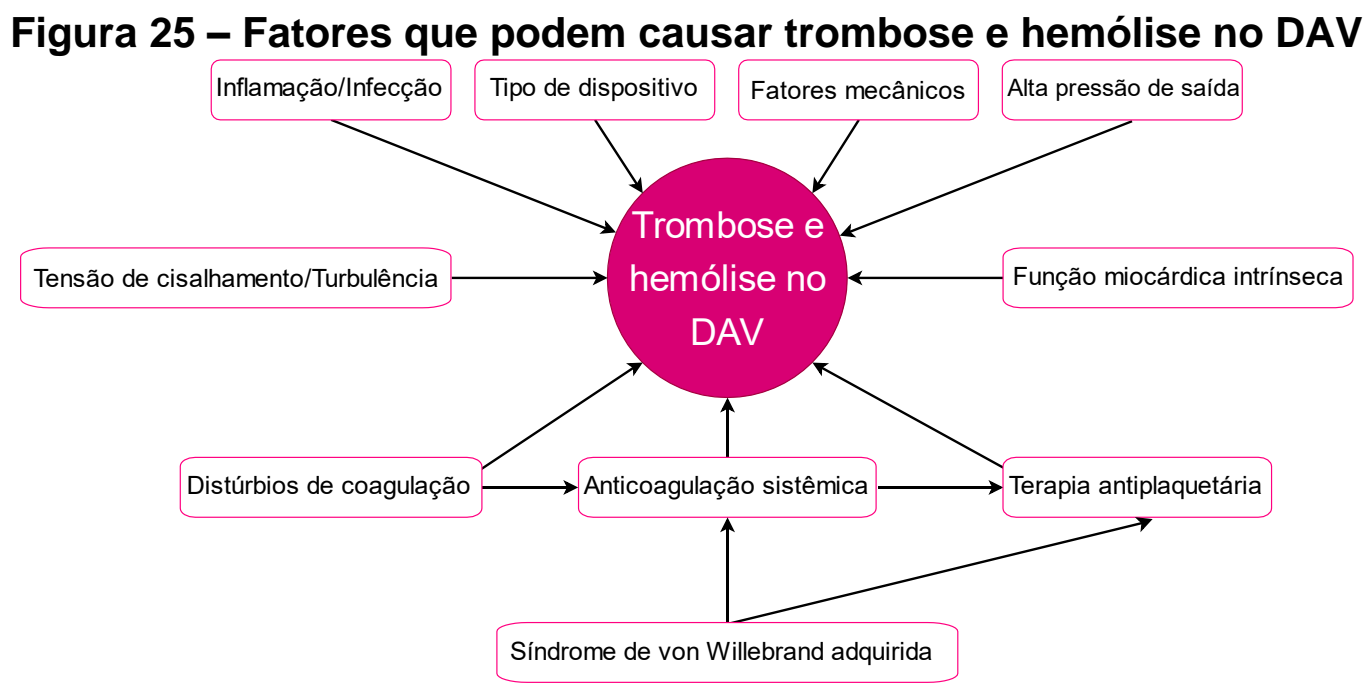

Fonte: Adaptado de Stehlik, Johnson e Selzman (2015).

Dentre estes inúmeros fatores, na engenharia de um DAV destacam-se os fatores mecânicos e os fenômenos físicos, por exemplo, a turbulência e as tensões de cisalhamento. Deutsch et al. (2006) relacionou o tempo de exposição com a tensão de cisalhamento e a hemólise em DAV em duas situações. Na primeira situação a destruição das células ocorreu em tempos maiores que $0,1 \mathrm{~ms}$ e com tensões próximas a $1000 \mathrm{~Pa}$. Na segunda situação, a lise celular ocorre a $100 \mathrm{~s}$ com tensão na ordem de $150 \mathrm{~Pa}$. Isto é preocupante na região próxima às válvulas do DAV (Figura 26).

Figura 26 - Taxa de cisalhamento na parede do DAV de $50 \mathrm{~mL}$ da Penn State

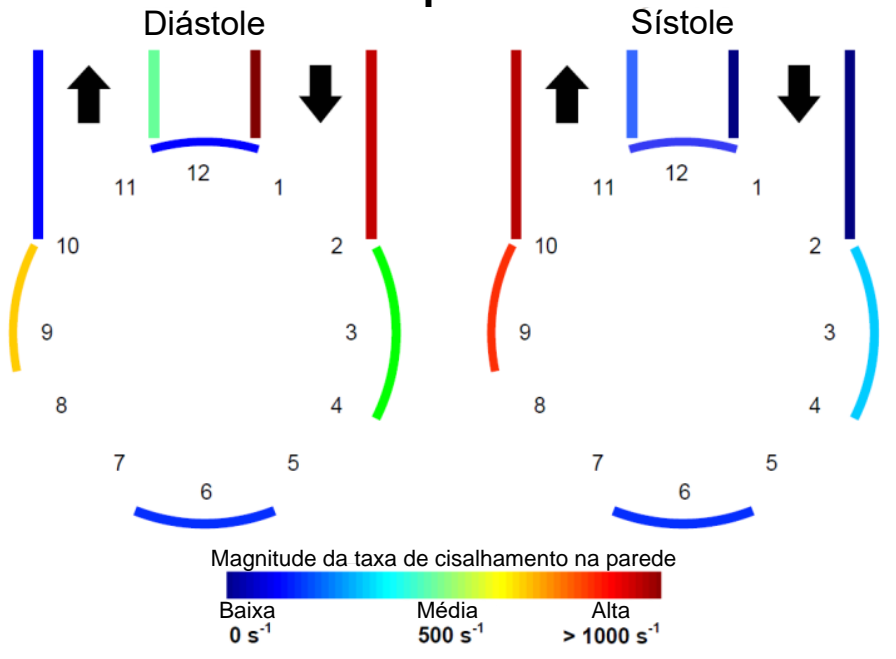

Fonte: Adaptado de Hochareon (2003). 
Um dos fatores desencadeantes da trombose seriam as zonas de estagnação que podem ser correlacionadas com as taxas de cisalhamento. Hochareon et al. (2004) apontou uma correlação entre o depósito de coágulos em DAV e regiões de fluxo sujeitas a uma taxa de cisalhamento menor que $200 \mathrm{~s}^{-1}$. Nanna et al. (2011) descreve um valor um pouco diferente: $500 \mathrm{~s}^{-1}$. A Figura 27b apresenta os valores da taxa de cisalhamento na parede do dispositivo em um ponto para diferentes tempos nos ciclos, para três frequências cardíacas medidos com PIV no plano a $5 \mathrm{~mm}$ da parede frontal do dispositivo, na região iii na direção da seta laranja (Figura 27a). Navitsky, Deutsch e Manning (2013) seguiram pelo mesmo caminho e pesquisaram a relação do formato da parede frontal com regiões de recirculação que provocariam as taxas de tensões de cisalhamento abaixo de $500 \mathrm{~s}^{-1}$. DAVs com domo (Figura 28a) e sem domo (Figura 28b) apresentaram tensões diferentes (Figura 28c). Em todos os casos referidos, os dispositivos utilizados eram pulsáteis.

\section{Figura 27 - Plano de medição PIV e taxas de tensão de cisalhamento}
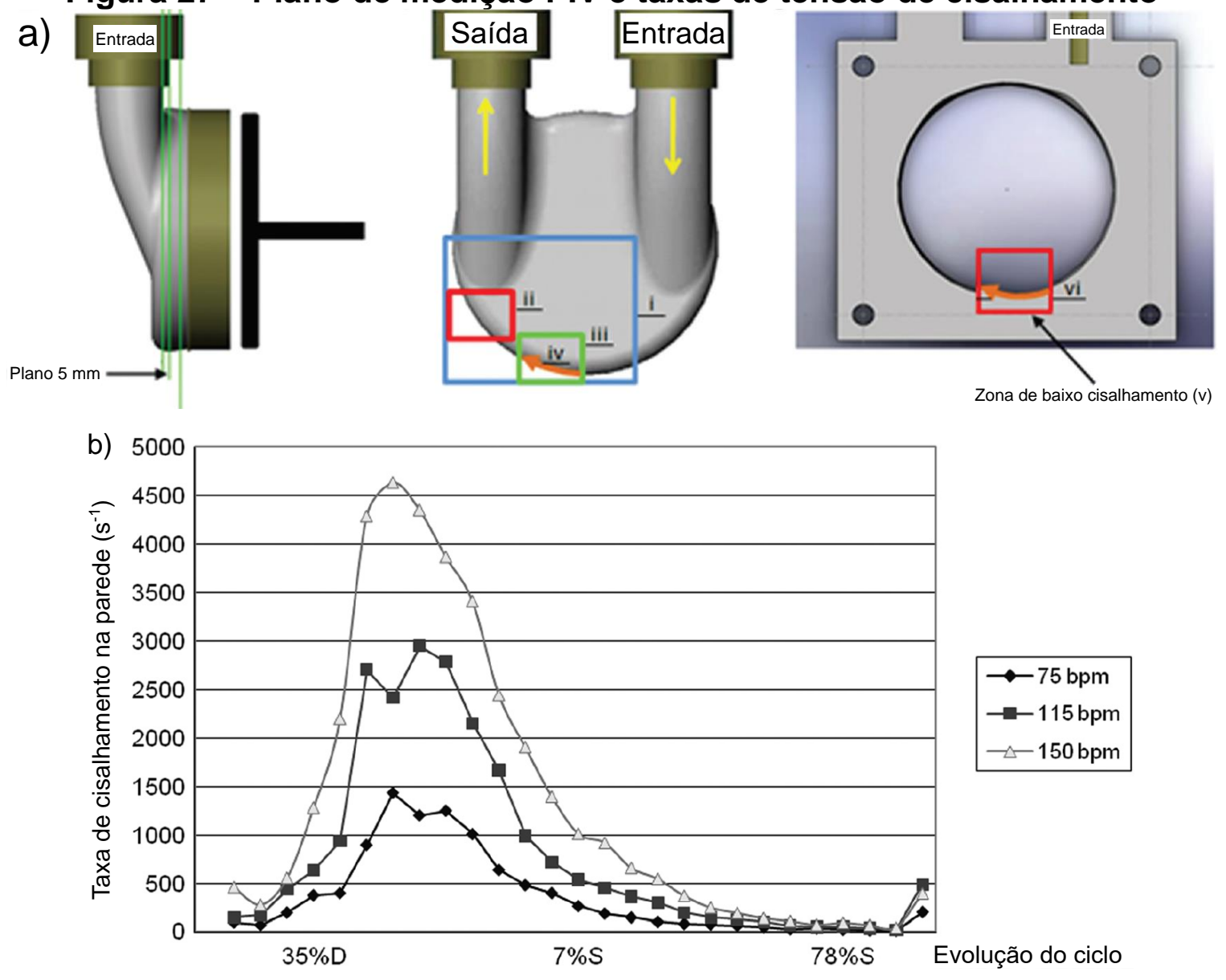

$D$ é diástole e $S$ é sístole

Fonte: Adaptado de Nanna et al. (2011). 
Vs e taxas de cisalhamento

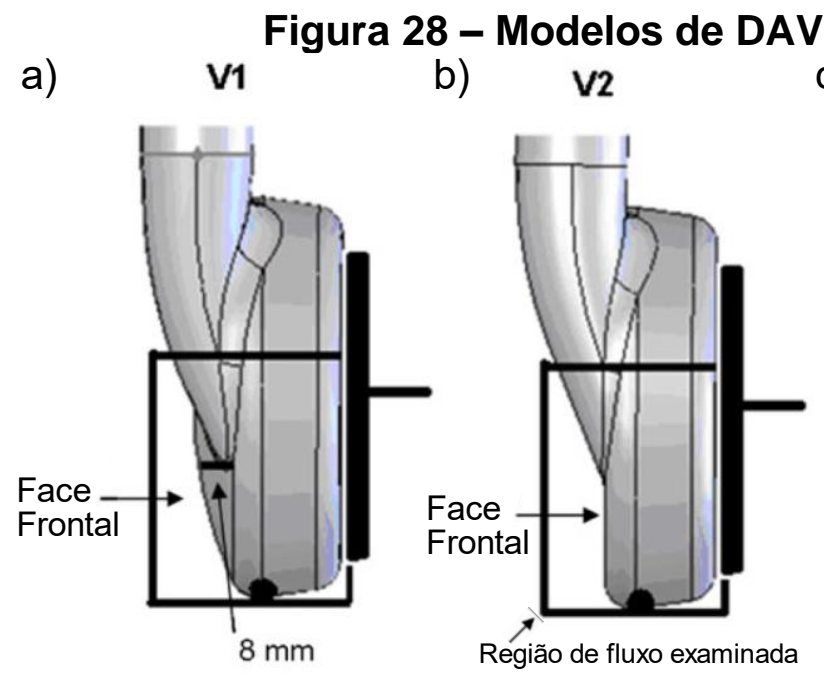

a)
)

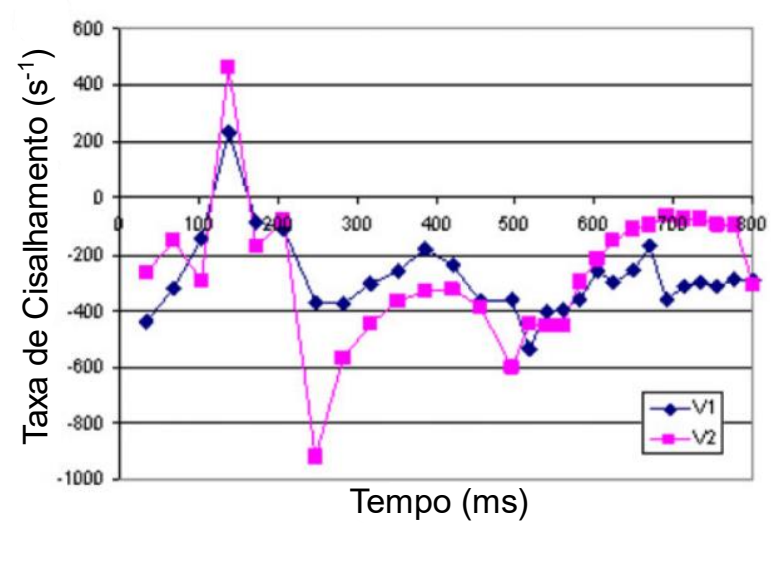

Fonte: Adaptado de Navitsky, Deutsch e Manning (2013).

\subsubsection{As tensões de cisalhamento}

Os três estados físicos básicos da matéria são: sólido, líquido e gasoso. No estudo da mecânica dos fluidos cria-se, por conveniência, um grupo com os líquidos e gases chamado de fluidos. As diferenças entre os fluidos e sólidos é justificável pela estrutura molecular e pelo movimento de partículas, mas uma definição relacionada à deformação exprime melhor esta diferença entre os estados físicos. Um fluido se deforma continuamente sob a ação de tensões de cisalhamento. Ao contrário de um sólido, que se deforma minimamente e atinge uma deformação máxima proporcional à tensão de cisalhamento. Portanto, nos sólidos a tensão de cisalhamento é proporcional à deformação e nos fluidos a tensão de cisalhamento é proporcional à taxa de deformação (GERHART, GERHART e HOCHSTEIN, 2016). As tensões ( $\sigma$ ) são definidas matematicamente como uma força $(F)$ atuando sobre uma área $(A)$ (Eq. (1)). Se a componente da força for normal à superfície, a tensão é denominada normal. Caso a força, ou sua componente, seja tangencial à superfície, será denominada cisalhamento (Figura 29).

$$
\sigma=\frac{F}{A}
$$


Figura 29 - Representação física das forças que atuam no fluido
Normal à superfice

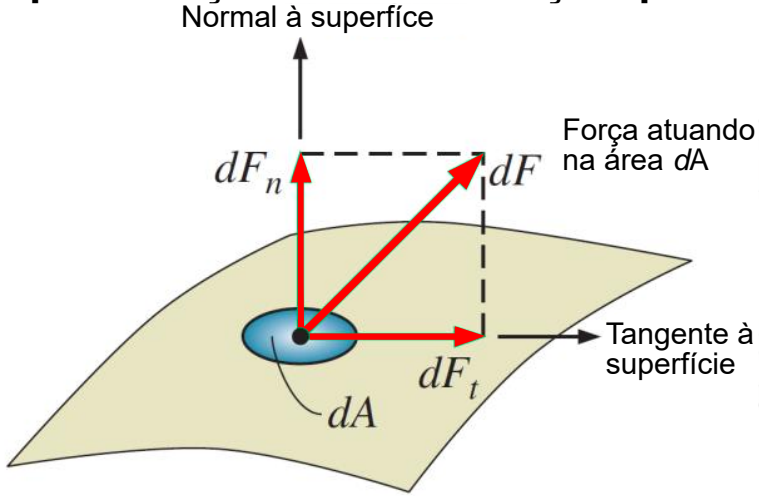

Fonte: Adaptado de Çengel e Cimbala (2017).

Em fluidos, especialmente os que estão em repouso, a tensão normal é denominada pressão. Quando o fluido se move a tensão de cisalhamento deixa de ser nula e passa a ser proporcional à velocidade em cada posição do fluido (MOTT e UNTENER, 2015).

Existem três tipos diferentes de tensões de cisalhamento utilizadas nos estudos de DAV. São elas: a tensão de cisalhamento viscosa, a tensão de cisalhamento de Reynolds, também chamada de tensão de cisalhamento turbulenta, e a tensão de cisalhamento viscosa turbulenta. Todas são discutidas nas subseções a seguir.

\subsubsection{Tensão de cisalhamento viscosa}

A tensão de cisalhamento viscosa ocorre em fluidos que se movem e estes fluidos são delimitados por uma ou mais superfícies. O cisalhamento viscoso consiste na deformação do fluido pela ação de uma força tangencial. A viscosidade, neste caso, atua como propriedade física resistente ao escoamento (ESCUDIER, 2017). Em um escoamento laminar unidirecional em um plano, a tensão de cisalhamento de um fluido newtoniano é dada por:

$$
\tau=\mu \dot{\gamma}=\mu \frac{d u}{d y}
$$

Sendo $\tau$ a tensão de cisalhamento viscosa no plano $\mathrm{xy}, \mu$ a viscosidade dinâmica do fluido, $\dot{\gamma}$ ou $d u / d y$ é a taxa de cisalhamento, $u$ a velocidade no sentido de $x$ (tangencial) e $y$ é a distância entre a região de velocidade zero e a região onde 
ocorre o cisalhamento (Figura 30).

Figura 30 - Representação física da tensão de cisalhamento viscosa

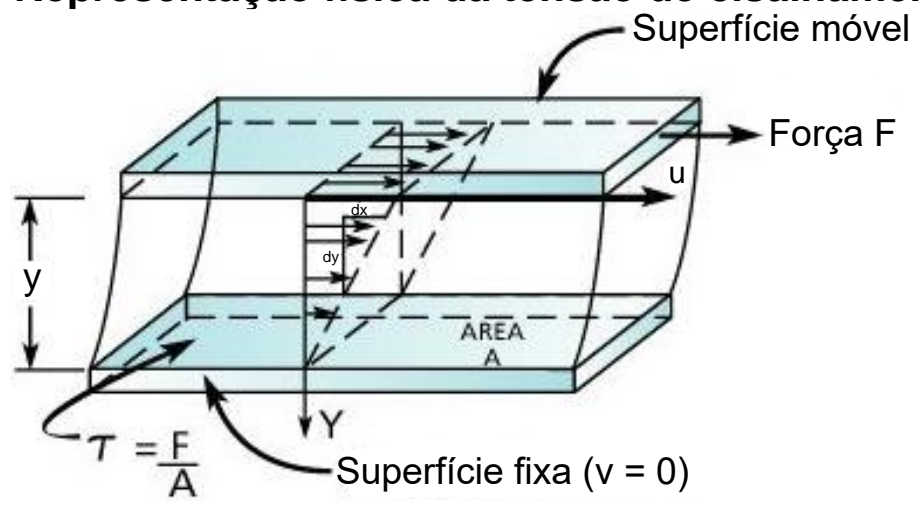

Fonte: Pump Fundamentals (2019).

Para um escoamento bidirecional no plano, nomeia-se a tensão de cisalhamento viscosa como VSS (Viscous Shear Stress) e a Eq. (2) torna-se:

$$
V S S=\mu\left(\frac{\partial u}{\partial y}+\frac{\partial v}{\partial x}\right)
$$

Sendo $v$ a velocidade no eixo $y$, e $\partial v / \partial x$ é sua derivada parcial em relação a $x$.

Nanna (2010) estimou a taxa de cisalhamento viscoso na parede do DAV em suas medições PIV utilizando a Eq. (2). O resultado desta estimativa é:

$$
\dot{\gamma}_{P I V}=\frac{d u}{d y}=\frac{u_{t}-u_{w}}{y_{t}-y_{w}}
$$

Em que $u_{t}$ é a componente de velocidade tangencial próxima a parede, $u_{W}$ é a velocidade na parede, $y_{t}$ é a distância entre $u_{t}$ e a parede e $y_{w}$ é a localização da parede.

Para o cálculo, considerou-se que não há escorregamento na parede $\left(u_{w}=0\right)$ e a parede estava na origem $\left(y_{w}=0\right)$. Desta forma a Eq. (4) torna-se:

$$
\dot{\gamma}_{P I V}=\frac{u_{t}}{y_{t}}
$$

Na mecânica dos fluidos, a camada limite exerce um papel fundamental, pois 
separa a região do fluido que possui velocidade menor, próxima a uma parede, da região do escoamento desenvolvido, longe de uma parede (Figura 31).

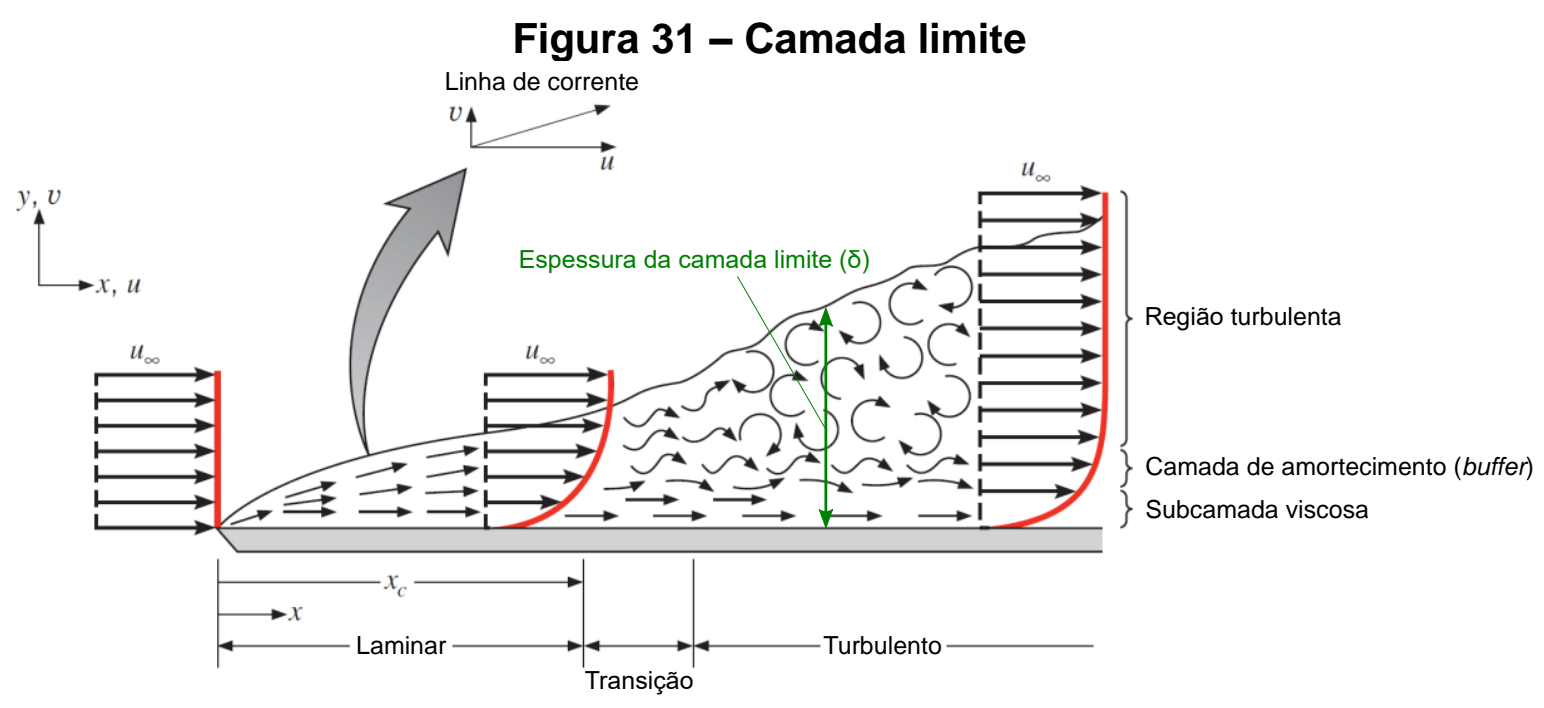

Fonte: Adaptado de Bergman e Lavine (2017).

Dentro da camada limite que fica próxima à parede, a vorticidade está diretamente relacionada com a tensão de cisalhamento (KHERADVAR e PEDRIZZETTI, 2012). Sendo a vorticidade bidimensional dada por:

$$
\vec{\omega}=\nabla \times \vec{v}=\left(\frac{\partial}{\partial x}, \frac{\partial}{\partial y}\right) \times(u, v)=\frac{\partial v}{\partial x}-\frac{\partial u}{\partial y}
$$

Em que $\vec{\omega}$ é o vetor vorticidade dada pelo rotacional $(\nabla x)$ do campo de velocidades ( $\overrightarrow{\mathrm{v}}$ ) (Figura 32). A vorticidade é uma medida de rotação de uma partícula de fluido e no caso bidimensional, representa um campo de rotação escalar (GUO e LI, 2010).

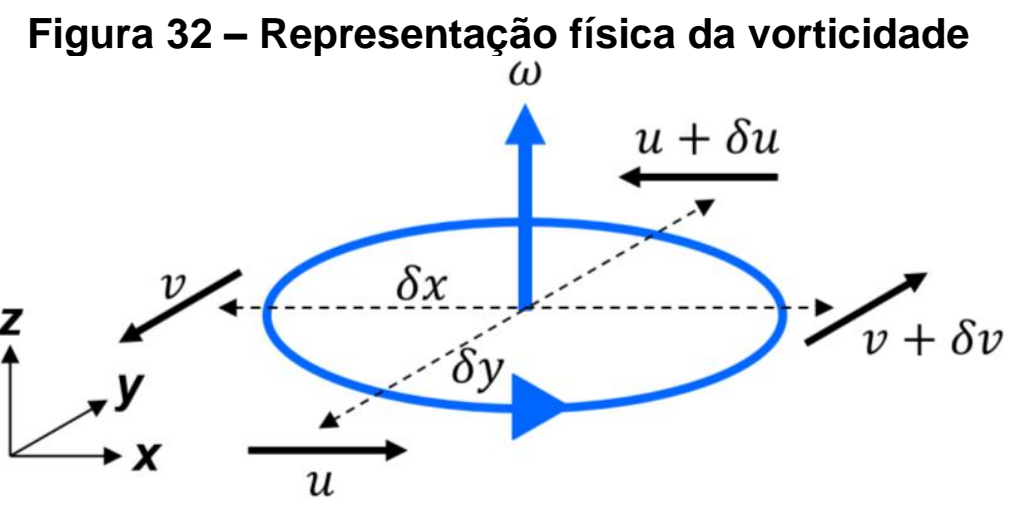

Fonte: Adaptado de Rodwell (2009). 
Todavia, a relação entre a vorticidade e a tensão de cisalhamento só é válida na parede $\left(\tau_{w}\right)$, ou seja, o escoamento deve ser considerado unidimensional e tangencial a parede. Portanto a relação entre a tensão e a vorticidade é dada por:

$$
\tau_{w}=\mu \omega
$$

Dentre os principais problemas da utilização da tensão de cisalhamento viscosa como estimativa para verificação de um DAV estão nas propriedades reológicas e ao tipo de escoamento que o fluido está sujeito.

O sangue é considerado um fluido não newtoniano devido à presença das células vermelhas no fluido. Entretanto, o plasma sanguíneo é considerado um fluido newtoniano e em grandes vasos e cavidades, por exemplo, os átrios e ventrículos, o sangue comporta-se como um fluido newtoniano. Os motivos para tal comportamento estão na homogeneidade e nas altas taxas de cisalhamento encontradas nestas condições (SOCHI, 2013).

Dentro do DAV o fluido comporta-se de maneira tridimensional devido ao movimento da membrana (BENK et al., 2011). Portanto a aplicação das equações uni e bidimensionais da tensão de cisalhamento viscosa não são suficientes para fornecer um valor adequado do escoamento.

Outro fator também relacionado ao tipo de escoamento é a turbulência. A expansão repentina do fluxo na entrada da câmara do DAV pode causar um escoamento turbulento (AL-AZAWY, TURAN e REVELL, 2015). As equações apresentadas nesta seção não levam em consideração o efeito da turbulência dentro do DAV, logo, deixa-se de considerar um efeito que pode alterar os valores das tensões.

Sabe-se que a hemólise pode ser causada pelo cisalhamento. Ao longo do tempo, buscou-se encontrar um valor bem definido que relacionasse o cisalhamento com a destruição das hemácias ou das plaquetas. Os limites para as tensões de cisalhamento viscosa pelo tempo de exposição do sangue nos dispositivos são apresentados na Figura 33 e Figura 34. Os autores citados na figura em questão, utilizaram métodos semelhantes ou diferentes e encontraram valores diversos nos limiares hemolíticos. Isto dificulta o trabalho dos engenheiros, no momento de 
dimensionar e analisar corretamente um DAV (GIARRA, 2009).

Figura 33 - Limites de VSS pelos tempos de exposição para hemácias

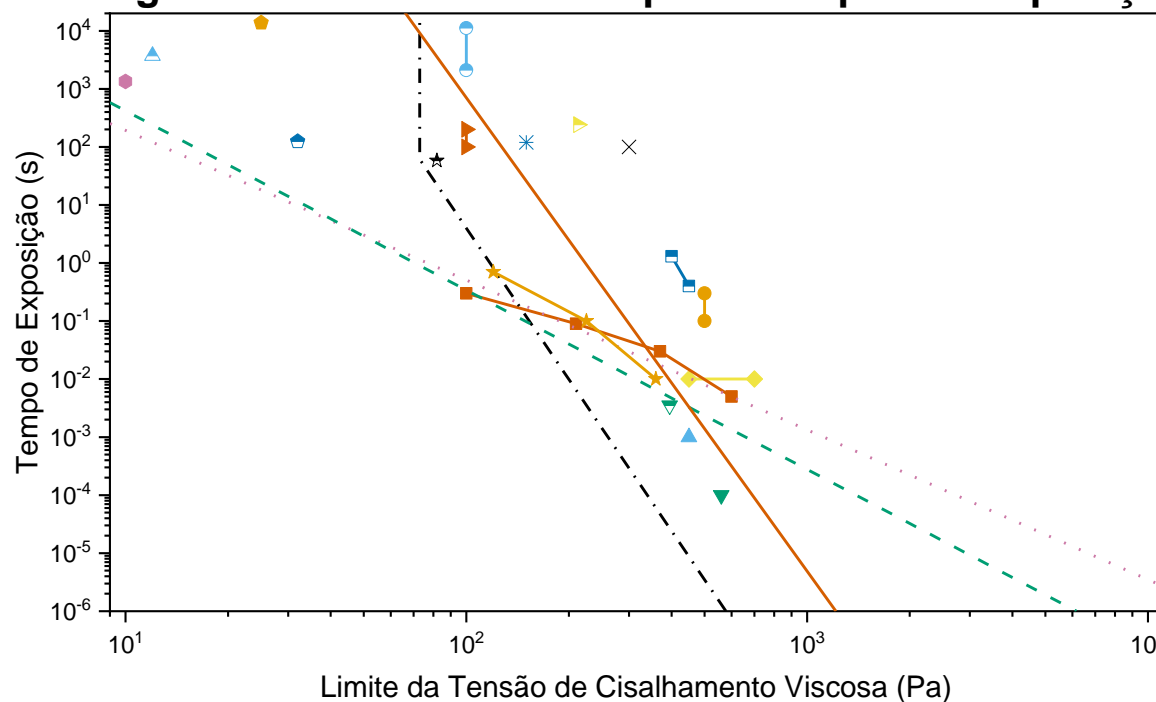

X Nevaril et al. (1968)

- Bacher e William

Williams, Hughes

- Keshaviah (1970)

* Leverett et al. (1972)

$\rightarrow-$ Sutera, Croce e Mehrjardi (1972)

- Nanjappa, Chang e Glomski (1973)

† Williams (1973)

- Lobowitz et al. (1974)

$\triangle$ Sandza et al. (1974)

$\nabla$ Lambert (1976)

Velker, Mclntire e Lynch (1977)

- Heuser e Opitz (1980)

Heuser e Opitz (1980)

- . - Tillmann et al. (1984)

$\star$ Wurzinger et al. (1985)

- Hashimoto (1989)

- - Giersiepen et al. (1990)

$\rightarrow$ Paul et al. (2003)

Limite da Tensão de Cisalhamento Viscosa $(\mathrm{Pa})$ Day (2008)

Fonte: Adaptado de Day (2008).

Figura 34 - Limites de VSS pelos tempos de exposição para plaquetas

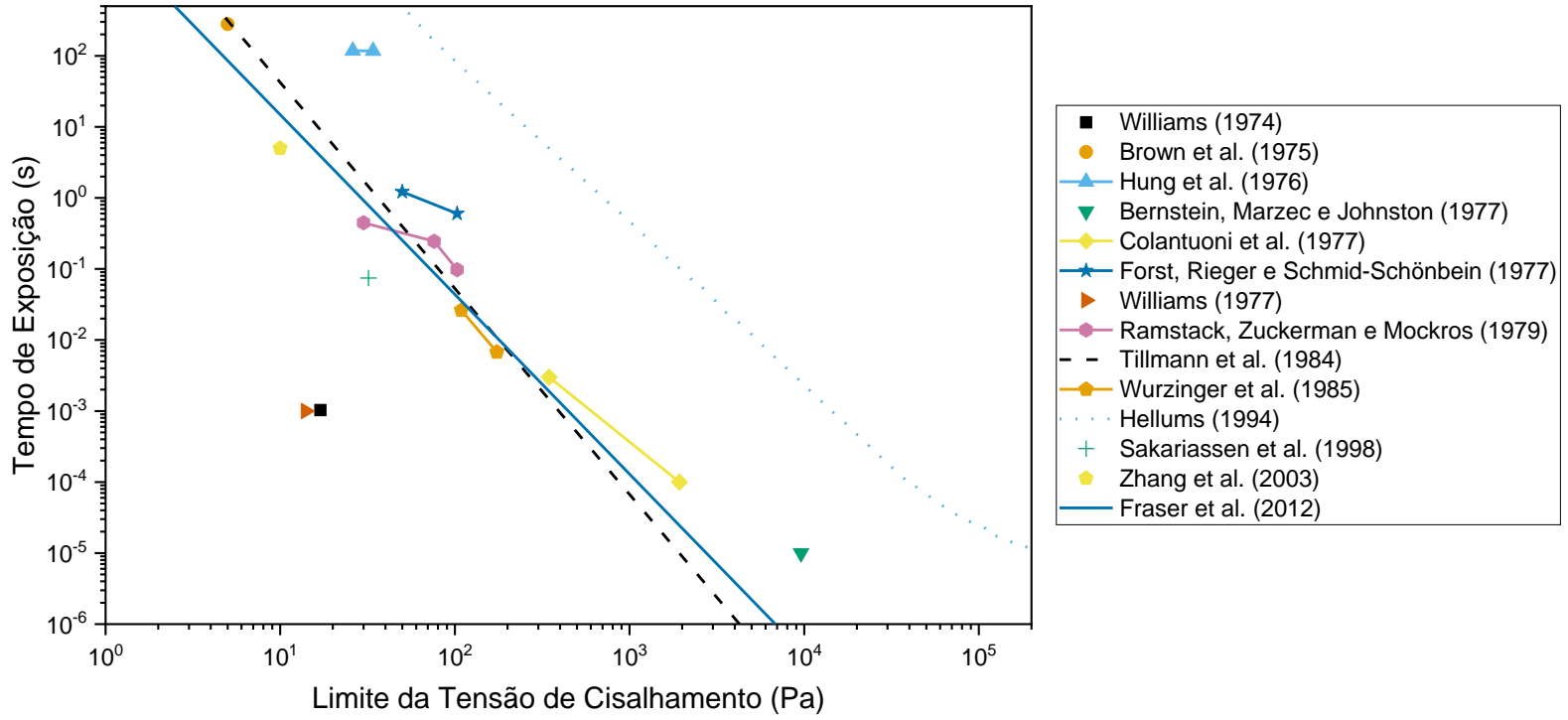

\subsubsection{Tensões de Reynolds}

As tensões de Reynolds, também chamadas de tensões turbulentas, estão relacionadas ao regime de escoamento turbulento. A turbulência é caracterizada pelo fluxo instável, irregular, aleatório e caótico, ou seja, o movimento do fluido é imprevisível. Observa-se também a formação de estruturas coerentes como os turbilhões, também chamados de redemoinhos ou vórtices (POPE, 2000). Osborne Reynolds demonstrou em seus experimentos de 1883 e 1895 a relação entre o tipo 
de fluxo a um parâmetro adimensional, mais tarde denominado número de Reynolds (Eq. (8)), além de outras importantes características da turbulência: a capacidade de transporte e mistura (Figura 35).

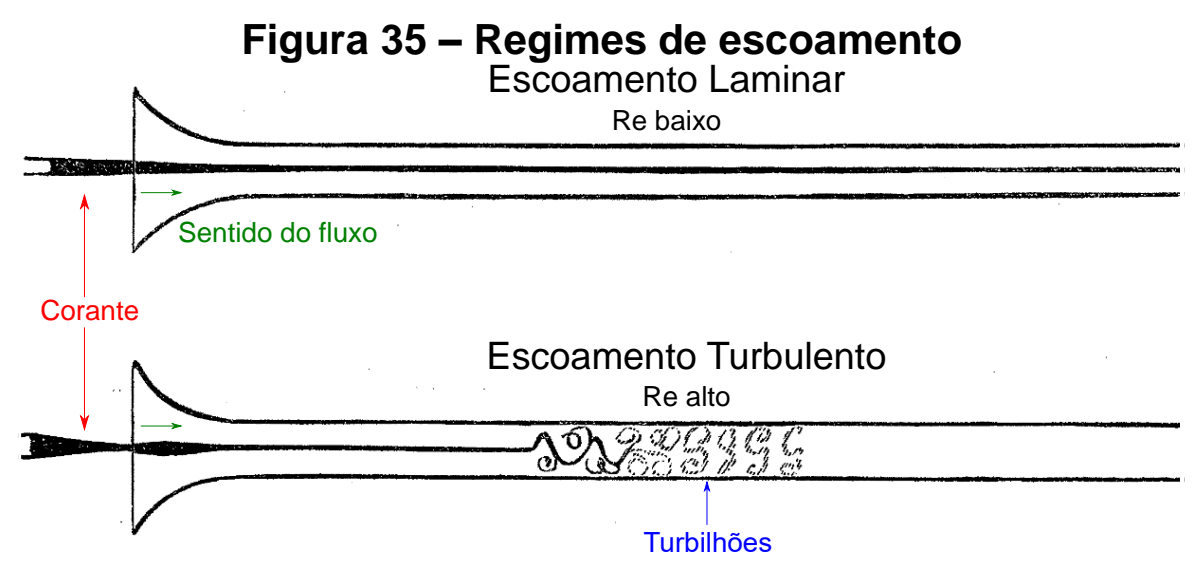

Fonte: Adaptado de Reynolds (1883).

$$
R e=\frac{u_{c} \cdot L \cdot \rho}{\mu}=\frac{u_{c} \cdot L}{v}
$$

Em que Re é o número de Reynolds, $u_{c}$ é a velocidade média característica do fluido, $L$ é o comprimento característico do fluxo, $\rho$ é a densidade do fluido e $v$ é a viscosidade cinemática do fluido. Considera-se $u \rho$ como as forças inerciais e $\mu / L$ como as forças viscosas.

As tensões turbulentas estão relacionadas com a decomposição de Reynolds da velocidade. Em um plano, a decomposição torna-se:

$$
\begin{gathered}
u=\bar{u}+u^{\prime} \\
v=\bar{v}+v^{\prime}
\end{gathered}
$$

Em que $u$ e $v$ são as velocidades instantâneas medidas, $\bar{u}$ e $\bar{v}$ são as velocidades médias e $u^{\prime}$ e $v^{\prime}$ são as flutuações das velocidades, todos nas direções $\mathrm{x}$ e y respectivamente. A velocidade média é obtida pela média temporal e a flutuação é considerada o elemento turbulento.

A partir da velocidade e da densidade do fluido, pode-se calcular a tensão normal de Reynolds (Reynolds Normal Stress - RNS) e a tensão de cisalhamento de 
Reynolds (Reynolds Shear Stress - RSS) (BALDWIN et al., 1993). Desta forma:

$$
\begin{gathered}
R N S_{x}=\overline{\rho u^{\prime} u^{\prime}}=\frac{\rho}{N} \sum_{1}^{N}\left(u^{\prime}\right)^{2} \\
R N S_{y}=\overline{\rho v^{\prime} v^{\prime}}=\frac{\rho}{N} \sum_{1}^{N}\left(v^{\prime}\right)^{2} \\
R S S=\overline{\rho u^{\prime} v^{\prime}}=\frac{\rho}{N} \sum_{1}^{N} u^{\prime} v^{\prime}
\end{gathered}
$$

Em que $N$ é o número de imagens ou pares de imagens de campos da amostra. Baldwin et al. (1993) utilizou um fluido viscoelástico análogo ao sangue com $\rho=1750$ $\mathrm{kg} / \mathrm{m}^{3}$ e seguindo o mesmo princípio, Rowlands et al. (2018) utilizou um fluido de densidade $\rho=1720 \mathrm{~kg} / \mathrm{m}^{3}$.

Os valores de maior interesse para o dimensionamento e avaliação de um DAV são os valores máximos das tensões de Reynolds (ROWLANDS et al., 2018). De acordo com Baldwin et al. (1993), estes valores podem ser calculados pelas Equações (14) e (15):

$$
\begin{gathered}
R S S_{\text {max }}=\sqrt{\left(\frac{R N S_{x}-R N S_{y}}{2}\right)^{2}+R S S^{2}} \\
R N S_{\text {max }}=\frac{R N S_{x}+R N S_{y}}{2}+R S S_{\text {max }}
\end{gathered}
$$

As tensões de Reynolds, por representarem a componente turbulenta do escoamento, possuem grande importância. Isto porque podem ser o fator responsável pelo trauma das hemácias. De acordo com a fenomenologia da turbulência o trauma dos eritrócitos está relacionado ao tamanho dos turbilhões, à tensão de cisalhamento turbulenta (RSS) e ao tempo de exposição que as células vermelhas permanecem nessas regiões (PINOTTI, 2000). Sabe-se que os DAV geram turbulência e os valores 
das tensões de Reynolds são de grandezas maiores que as tensões de cisalhamento viscosas (ROWLANDS et al., 2018).

Pode-se marcar os pontos para os limites das tensões de Reynolds em função tempo de exposição nos DAVs (Figura 36). Semelhante às tensões viscosas, os valores encontrados pelos autores citados na figura para o RSS estão distribuídos em uma ampla faixa.

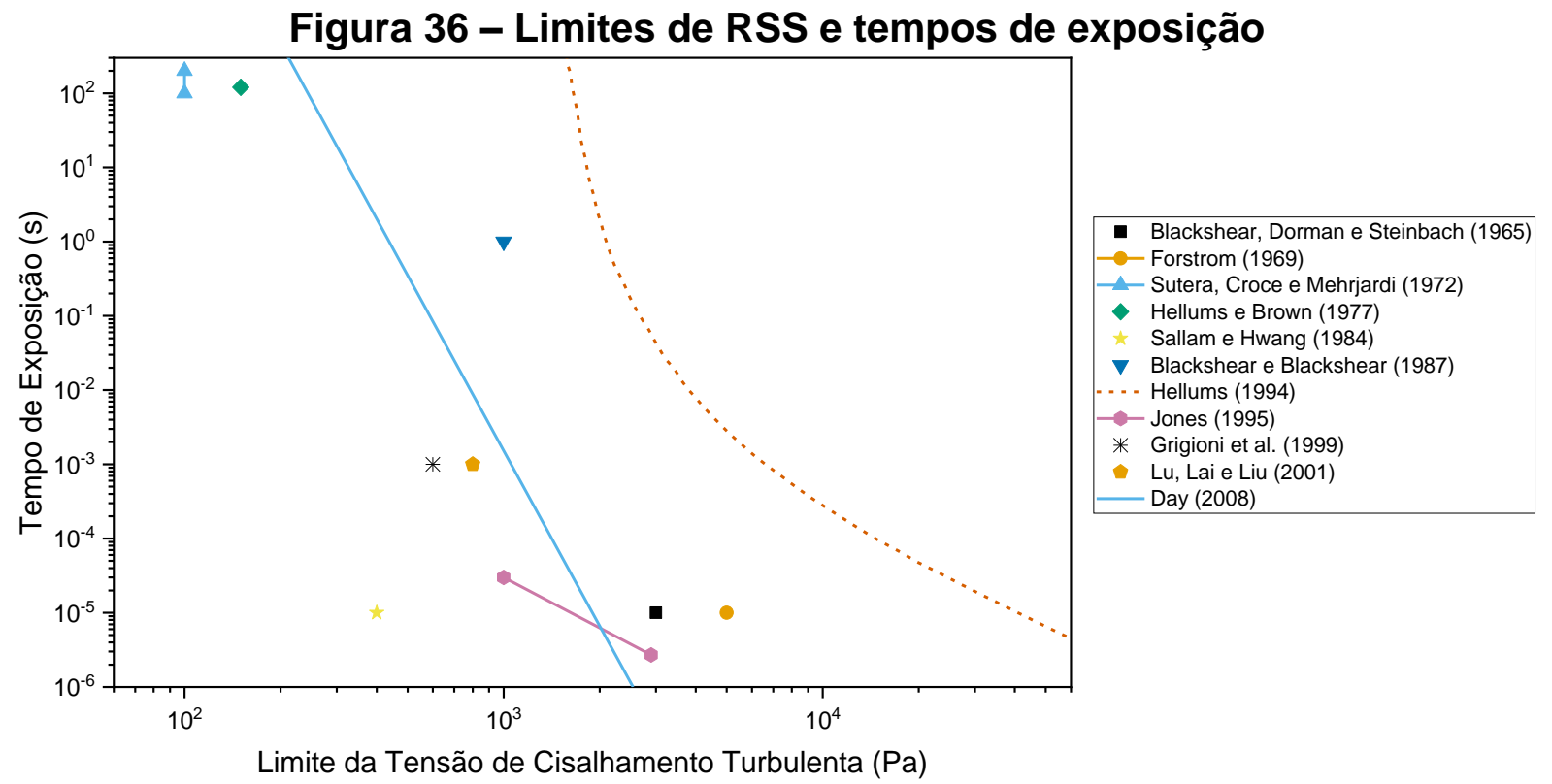

Fonte: Adaptado de Day (2008).

As tensões de Reynolds não são tensões propriamente ditas, pois não exercem força em uma determinada área do fluido. Na realidade, as tensões de Reynolds são fluxos de momento decorrentes da turbulência (BRENNEN, 2016). Portanto, por não representar as ações físicas no fluido os valores encontrados não representam a realidade do escoamento.

\subsubsection{Tensão de cisalhamento viscosa turbulenta}

Uma alternativa para as tensões viscosas e de Reynolds é a tensão de cisalhamento viscosa turbulenta (Turbulent Viscous Shear Stress - TVSS). Neste caso, a TVSS engloba o termo viscoso e o termo turbulento, caracterizando totalmente o escoamento (JONES, 1995). Para aplicar a TVSS deve-se assumir a teoria estatística da turbulência proposta por Taylor (1935). Nesta teoria, propõe-se a isotropia da turbulência, ou seja, as propriedades estatísticas não variam nos pontos 
do fluido com as transformações das coordenadas dos eixos. O conceito de homogeneidade foi acrescido posteriormente e garante que as translações arbitrárias das coordenadas dos eixos não alterarão as propriedades estatísticas (MONIN e YAGLOM, 1971). Outro acréscimo à teoria de Taylor foi o equilíbrio estatístico, ou seja, os valores médios da turbulência são independentes do tempo (BATCHELOR, 1959).

Com todas as considerações, a equação da TVSS para um escoamento bidimensional é dada por:

$$
T V S S=\mu \sqrt{S_{x y} S_{x y}}
$$

Sendo $S_{x y}$ a taxa de flutuação da tensão.

Fluxos turbulentos são essencialmente dissipativos devido às tensões de cisalhamento viscosas, que estão relacionadas ao movimento do fluido. Com o movimento há a deformação, e pela lei de conservação da energia, a energia interna do fluido aumenta com a diminuição da energia cinética turbulenta do fluido (TENNEKES e LUMLEY, 1972). Surge assim a taxa de dissipação turbulenta $(\varepsilon)$, parâmetro importante para dimensionamento do escoamento, calculado por:

$$
\varepsilon=2 \frac{\mu}{\rho} \overline{S_{x y} S_{x y}}
$$

Substituindo-se a Eq. (17) na Eq. (16) chega-se a:

$$
T V S S=\sqrt{\frac{\rho \mu \varepsilon}{2}}
$$

Dentre todos os termos da Eq. (18), o termo da dissipação de energia turbulenta ( $\varepsilon$ e é o mais complexo de medir utilizando os as técnicas experimentais disponíveis pois o $\varepsilon$ está relacionado aos menores turbilhões (YEN et al., 2014). O PIV apresenta limitações na resolução espacial de medição, ou seja, o equipamento é incapaz de medir várias escalas de turbulência ao mesmo tempo, especialmente as menores escalas. Uma solução para este problema é a utilização do método Large Eddy PIV 
proposto por Sheng, Meng e Fox (2000). Este método é baseado nas ideias do Large Eddy Simulation (LES), um modelo CFD. No LES um dos objetivos é a redução do custo computacional baseado na filtragem das menores escalas nas equações de Navier-Stokes. Este filtro passa baixa pode ser uma média temporal ou espacial o que garante a resolução dos turbilhões das maiores escalas e a modelagem dos turbilhões das escalas ignoradas. Consequentemente, o método Large Eddy PIV é uma opção para o cálculo, pois este método pressupõe que não há a necessidade da medida PIV chegar nas menores escalas. As derivadas espaciais das velocidades são calculáveis e os demais termos fora das duas componentes resolvidas são aproximados sem que haja discrepância aos fenômenos observados (SHENG, MENG e FOX, 2000).

Pela teoria de Kolmogorov (1941), a energia cinética turbulenta (Turbulent Kinect Energy - TKE) é a energia cinética média associada aos turbilhões de escoamento com número de Reynolds elevado. A TKE é gerada por um mecanismo de produção nas maiores escalas de turbulência. Posteriormente esta energia é transferida para as escalas menores que transferem para escalas ainda menores até ser dissipada pelo efeito viscoso, formando uma cascata. A maior escala de turbulência é conhecida como a escala integral $(\kappa)$ e a menor escala é chamada de escala de Kolmogorov $\left(\kappa_{\eta}\right)$ (POPE, 2000). Matematicamente a TKE, válida para um plano é exposta na Eq. (19). A Figura 37a exibe a cascata do espectro de energia de Kolmogorov e a Figura 37b exibe a TKE, ambas aplicadas ao LES e ao Large Eddy PIV.

$$
T K E=\frac{1}{2}\left(\overline{\left(u^{\prime}\right)^{2}}+\overline{\left(v^{\prime}\right)^{2}}\right)
$$
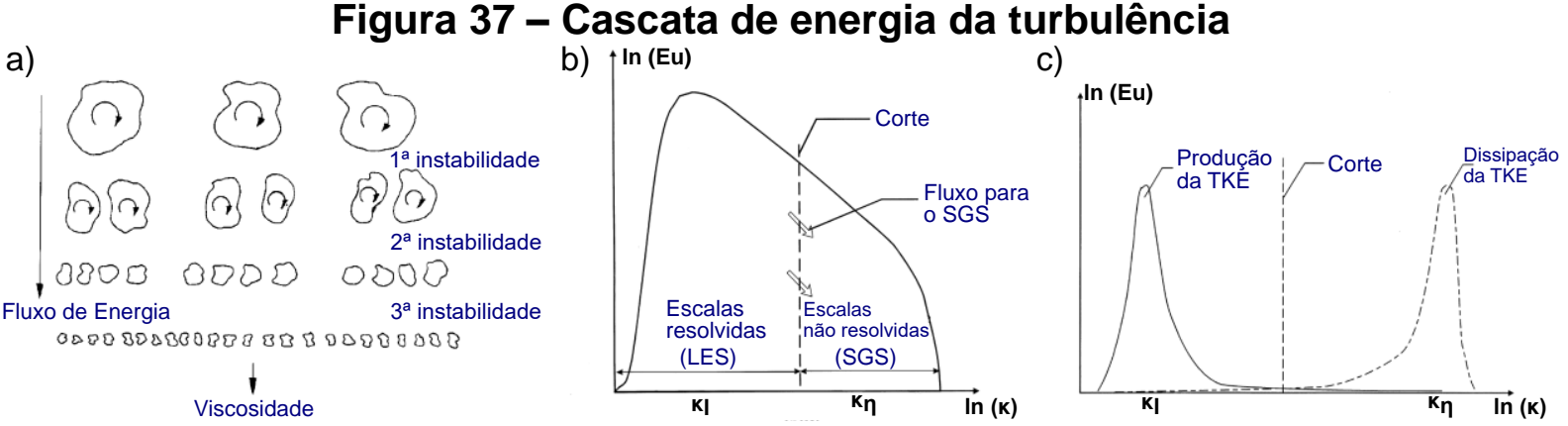

Fonte: Adaptado de Davidson (2004) e Sheng, Meng e Fox (2000).

Desta forma, as escalas resolvidas (do tamanho do grid) pela técnica PIV, irão 
transferir a energia para as escalas não resolvidas, ou escalas sub-grid (sub-grid scales - SGS). Utilizando as Eq. (9) e (10) da decomposição das velocidades e aplicando o filtro passa baixa nas equações da continuidade e de Navier-Stokes para um fluido incompressível em um plano obtêm-se:

$$
\begin{gathered}
\frac{\partial \bar{u}_{\imath}}{\partial x_{i}}=0 \\
\frac{\partial \overline{u_{l}}}{\partial t}+\frac{\partial}{\partial x_{j}}\left(\bar{u}_{\imath} \bar{u}_{J}\right)=-\frac{\partial \bar{p}}{\partial x_{i}}+\frac{\mu}{\rho} \frac{\partial^{2} \overline{u_{\imath}}}{\partial x_{j} \partial x_{j}}-\frac{\partial \tau_{i j}}{\partial x_{j}}
\end{gathered}
$$

Em que $\bar{p}$ é a pressão média e $\tau_{i j}$ é o tensor das tensões SGS e deve ser modelado. O tensor das tensões SGS é definido pela Eq. (29).

$$
\tau_{i j}=\overline{u_{\imath}^{\prime} u_{\jmath}^{\prime}}-\overline{u_{i}} \overline{u_{j}}
$$

Multiplicando a Eq. (21) por $\bar{u}_{i}$ chega-se a:

$$
\frac{\partial}{\partial t}(T K E)+\overline{u_{j}} \frac{\partial}{\partial x_{j}}(T K E)=\frac{\partial}{\partial x_{j}}\left(-\bar{p} \bar{u}_{j}+\frac{\mu}{\rho} \frac{\partial}{\partial x_{j}}(T K E)-\tau_{i j} \bar{u}_{i}\right)-\frac{\mu}{\rho} \frac{\partial \bar{u}_{i} \partial \bar{u}_{i}}{\partial x_{j} \partial x_{j}}+\tau_{i j} \overline{S_{i j}}
$$

O termo $\tau_{i j} \overline{S_{l j}}$ é a dissipação no turbilhão e relaciona a TKE transportada das escalas resolvidas para o SGS, portanto:

$$
\varepsilon \approx\left\langle\varepsilon_{S G S}\right\rangle=-2\left\langle\tau_{i j} \overline{S_{l \jmath}}\right\rangle
$$

Os chevrons indicam a média de conjunto e são a essência do método Large Eddy PIV. Entretanto, para obter o valor da taxa de dissipação ainda é necessário modelar o tensor das tensões SGS. Sheng, Meng e Fox (2000) propõem quatro alternativas para esta modelagem, a saber: o modelo de Smagorinsky, o modelo da similaridade, o modelo do gradiente e o modelo dinâmico. Devido às pequenas diferenças entre os resultados apresentados para os modelos no PIV, Li, Lo e Lu (2010), Yen et al. (2014) e Davis (2018) optaram pelo modelo de Smagorinsky (1963). 


$$
\tau_{i j}=-C_{S}^{2} \Delta^{2}\left|\sqrt{2 \overline{S_{l \jmath} S_{l \jmath}}}\right| \overline{S_{l \jmath}}
$$

Sendo $C_{s}$ a constante de Smagorinsky, cujo valor é $0,17, \Delta$ é a distância entre dois pontos medidos.

Para um fluido incompressível com escoamento bidimensional, a taxa de flutuação da tensão está na escala resolvida, logo, seu cálculo é dado por:

$$
\overline{S_{x y}}=\frac{1}{2}\left(\frac{\partial v}{\partial x}-\frac{\partial u}{\partial y}\right)
$$

Para correlacionar a tensão de Reynolds e diminuir o custo computacional, a Eq. (18) da TVSS é reescrita como:

$$
T V S S=\sqrt{R S S \mu S_{x y}}=\sqrt{R S S \frac{\mu}{2}\left(\frac{\partial v}{\partial x}+\frac{\partial u}{\partial y}\right)}=\sqrt{R S S \frac{V S S}{2}}
$$

\subsubsection{Regiões de estagnação no DAV}

Nos dispositivos pediátricos podem ocorrer zonas de estagnação do fluido, devido à baixa velocidade encontrada em regiões do DAVP. Estas regiões de estagnação promovem a deposição de células sanguíneas danificadas e são mais propensas à adesão de plaquetas, desencadeando a formação de trombos, pois não há turbulência suficiente para movimentar as células (WEISS et al. 2012). Portanto, identificar e prevenir áreas de estagnação são importantes no desenvolvimento de um DAV (MANNING et al., 2008).

Os métodos de identificação de regiões de estagnação em DAVs são baseados no conceito de ativação das plaquetas após o contato prolongado com um material não biológico, ou seja, baseiam-se no tempo. Este contato prolongado é modelado de duas maneiras distintas, ambas para facilitar o emprego das técnicas ópticas de medição, como a anemometria laser Doppler (Laser Doppler anemometry - LDA) e o PIV. A primeira técnica é chamada de volume da zona de estagnação (Volume of Stagnation Zone - VSZ) e relaciona o tempo de exposição à baixas velocidades no 
DAV, principalmente em regiões próximas à parede. Para tanto, estipulou-se que velocidades abaixo de $0,01 \mathrm{~m} / \mathrm{s}$ formariam trombos no dispositivo (OBIDOWSKI et al. 2018). No PIV bidimensional a técnica VSZ resume-se a planos com áreas de estagnação que passam por filtros para excluir vetores ou áreas cujos valores de velocidade forem maiores que $0,01 \mathrm{~m} / \mathrm{s}$.

Já a segunda modelagem consiste na avaliação da taxa de cisalhamento na parede dos DAVs. De acordo com Baldwin et al. (1994), um jato na diástole deve ser forte para produzir o fluxo rotacional característico do coração. Desta forma, Navitsky, Deutsch e Manning (2013) estipularam que taxas de cisalhamento abaixo de 500/s seriam as mais propensas à formação dos trombos em dispositivos feitos de poliuretano (HUBBELL e MCINTIRE, 1986). Após a obtenção dos campos de velocidades pela técnica PIV um algoritmo aplica a Eq. (5) nas imagens a fim de obterse os campos de taxa de cisalhamento. A Figura 38 apresenta a taxa de cisalhamento normalizada para o experimento de Navitsky, Deutsch e Manning (2013) obtida por PIV. A normalização foi feita baseada no valor de 500/s, portanto valores menores que este estão na faixa de -1 a 1.

Figura 38 - Taxa de cisalhamento normalizada na parede de dois DAVs

(a)

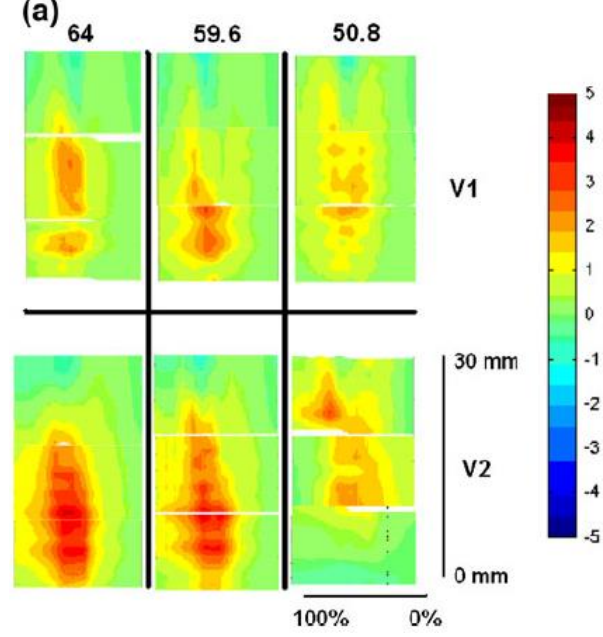

(b)

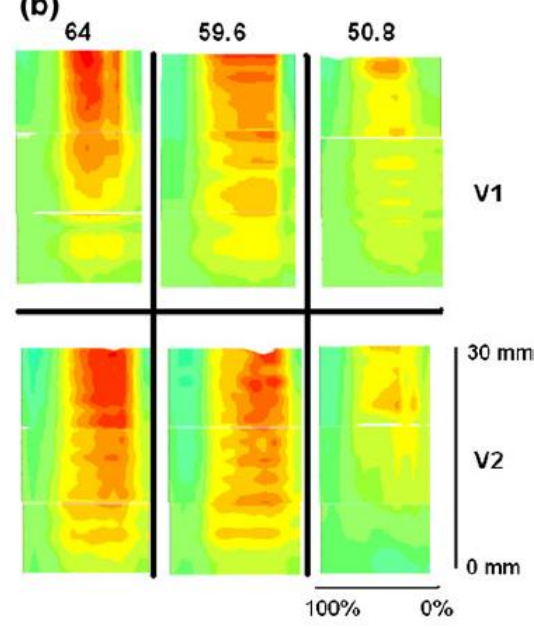

a) Diástole e b) Sístole dos modelos V1 e V2 de DAV na região de saída da bomba Fonte: Navitsky, Deutsch e Manning (2013).

\subsection{Velocimetria por imagens de partículas (PIV)}

A velocimetria por imagens de partículas (Particle Image Velocimetry - PIV) é uma técnica de medição quantitativa relativamente moderna. As bases do PIV surgiram no final do século XIX com o aparecimento da câmera fotográfica que 
passava a registrar eventos em meio físico. O movimento dos fluidos era capturado pelas câmeras através de partículas adicionadas ao escoamento. Posteriormente as fotos eram comparadas na linha do tempo do experimento. Em 1904, Ludwig Prandtl adicionou partículas de hematita em seu canal d'água e fotografou diferentes modelos para estudar o escoamento (RAFFEL et al., 2018). Todavia, não era possível obter informações quantitativas. Com o avanço da tecnologia da computação e das câmeras, Adrian e Yao (1985) criaram o PIV como é conhecido hoje.

A técnica PIV consiste na gravação de imagens do fluido com partículas traçadoras que são carregadas durante o escoamento. Para tanto, o experimento deve possuir acesso óptico para as câmeras e as partículas traçadores devem adequar-se ao fluido para não alterar as propriedades reológicas e não interferir na extração da velocidade. A região de interesse é então iluminada por um plano laser e a câmera geralmente é posicionada perpendicularmente à folha de luz (Figura 39). As partículas traçadoras espalham a luz no sensor do tipo CCD (charge-coupled device - dispositivo de carga acoplada) ou CMOS (complementary metal-oxidesemiconductor - semicondutor de metal-óxido complementar) da câmera cujo foco está no plano iluminado (TROPEA, YARIN e FOSS, 2007). As imagens gravadas são transferidas para um computador onde são processadas. Com uma câmera, o PIV é capaz de determinar duas componentes de velocidade (2C) no plano (2D). Caso utilize-se duas ou mais câmeras, a técnica torna-se estereoscópica ou tomográfica, permitindo a obtenção de três componente de velocidade, no plano e campos completamente 3D, respectivamente ( $\mathrm{LYNCH}, 2015)$.

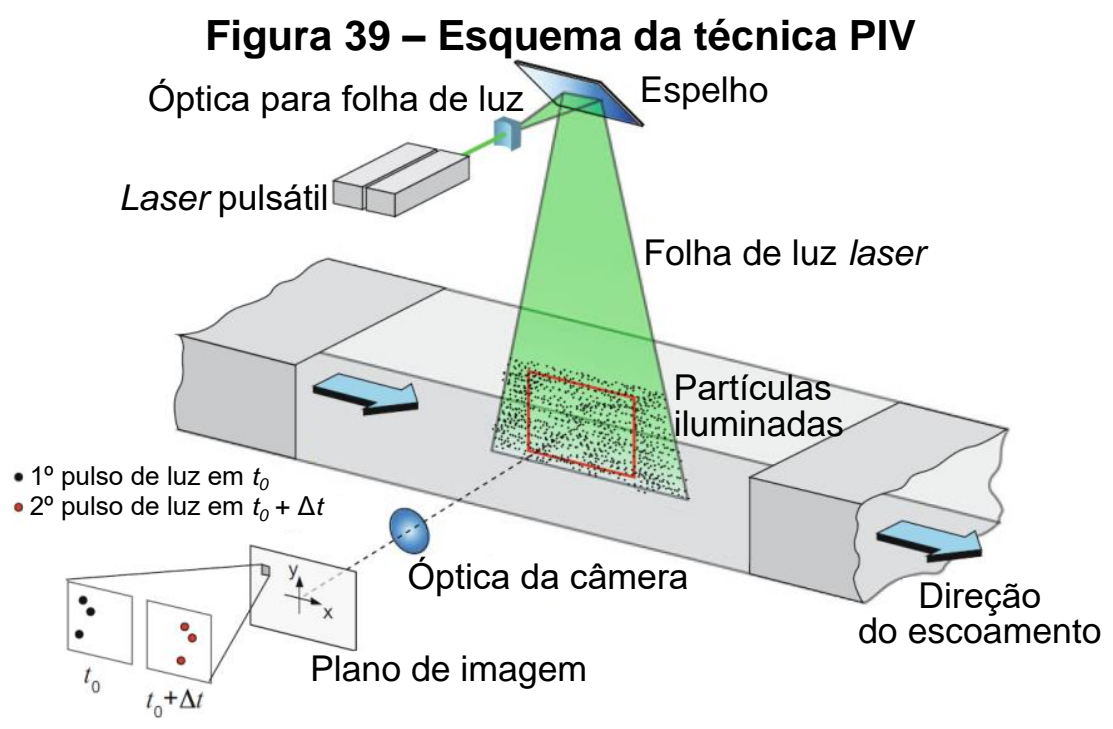

Fonte: Adaptado de Raffel et al. (2018). 


\subsubsection{Princípio de funcionamento PIV}

O princípio de funcionamento PIV 2D pode ser divido em seis etapas (Figura 40).

Figura 40 - Princípio de funcionamento PIV 2D

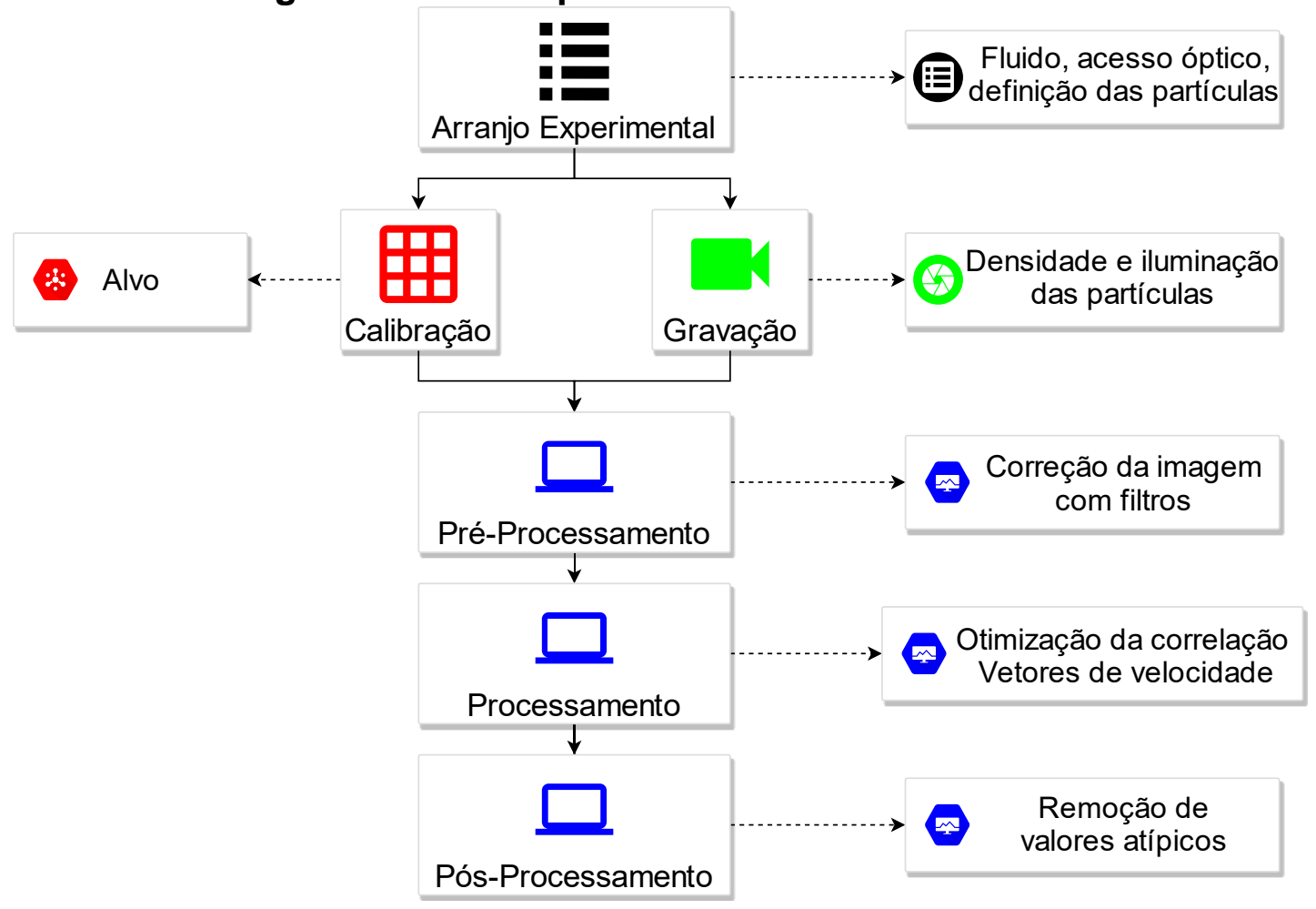

No arranjo experimental, deve-se determinar qual partícula é mais adequada para representar corretamente o escoamento do fluido estudado, com densidade compatível e tamanho suficiente para representar as escalas de movimento desejadas ou permitidas. As partículas também devem espalhar a luz de forma eficiente, considerando-se o índice de refração do fluido (Figura 41a e b). Outra preocupação no arranjo experimental está no acesso óptico que não deve produzir distorções na imagem gravada. No que diz respeito à iluminação, os lasers mais utilizados são: lâmpadas de íons de argônio, Nd:YAG (granada de alumínio com ítrio dopada com neodímio) e Nd:YLF (fluoreto de lítio ítrio dopado com neodímio). Os sistemas com argônio são menos utilizados devido à baixa taxa repetição do laser. O Nd:YAG apresenta maiores energias por pulso que os demais tipos de lasers, e taxa de repetição, maior que o sistema com argônio. Todavia, o sistema com Nd:YLF apresenta a maior taxa de repetição, porém com menos energia que o Nd:YAG. A 
óptica do laser é importante para produzir uma folha fina de luz na região de interesse. Além dos fatores já citados anteriormente, outros dois que possuem bastante relevância no arranjo experimental, o sincronizador e o computador. O primeiro controla os tempos de iluminação e gravação (Figura 41c) e o segundo envia os sinais e salva as imagens (HU, 2018).

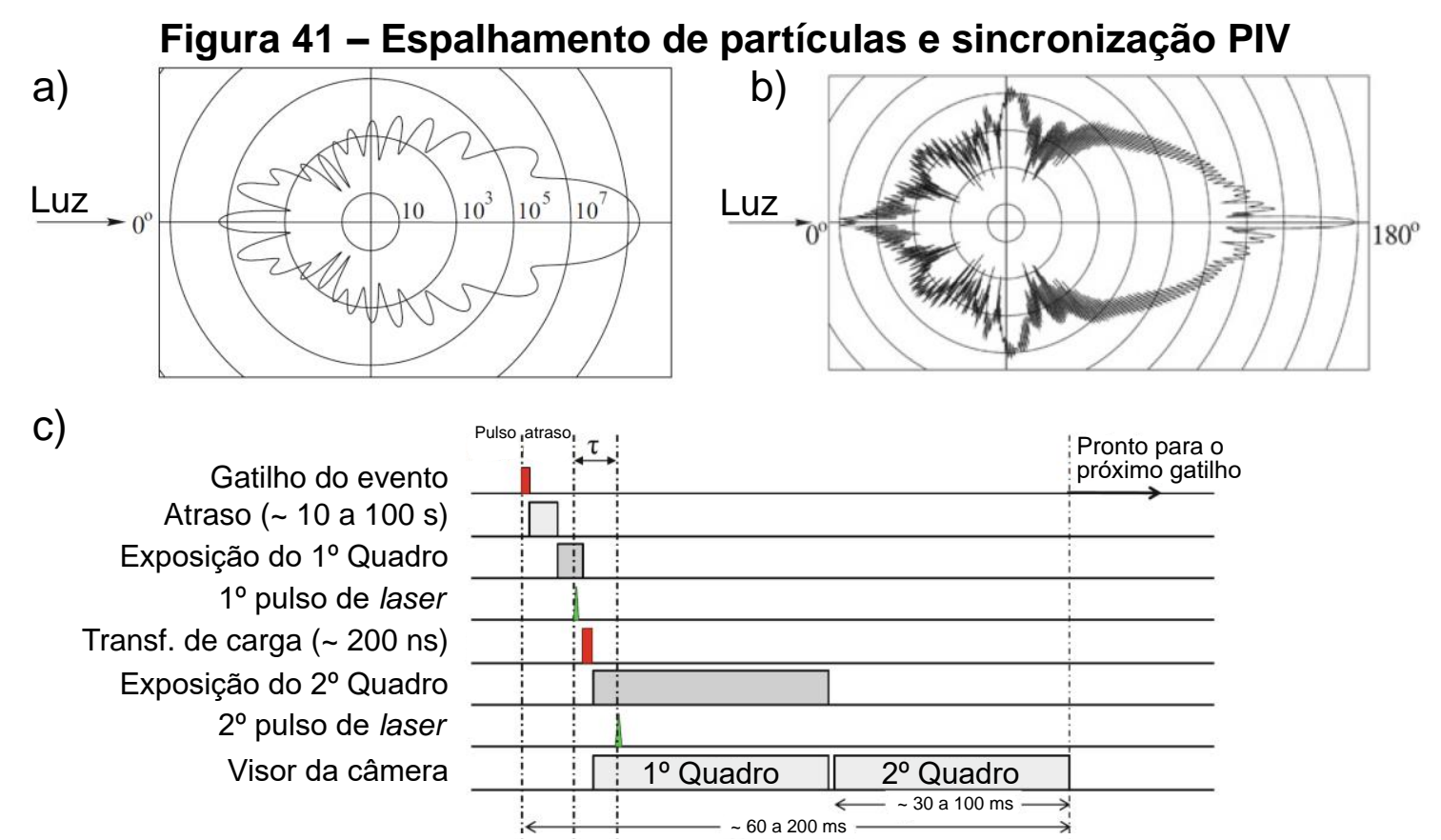

a) Espalhamento de uma partícula de óleo de $1 \mu \mathrm{m}$ em ar; b) partícula de vidro de $10 \mu \mathrm{m} \mathrm{em}$ água; c) exemplo de sincronização de laser e câmeras. Fonte: Adaptado de Raffel et al. (2018).

O processo de calibração inicia com a fixação de um alvo de calibração no experimento, dentro da linha de visão, ou linha de visada (line of sight - LoS), da câmera (Figura 42a). Geralmente o alvo de calibração consiste em pontos com diâmetro conhecido distribuídos a distâncias pré-determinadas, tanto na vertical quanto na horizontal. O próximo passo da calibração consiste no ajuste do foco da lente (Figura 42b). O objetivo deste passo é evitar distorções causadas, por exemplo, pela mudança do índice de refração entre o ar e uma um cilindro de quartzo. $O$ terceiro passo, ocorre no computador, com a identificação do alvo (Figura 42c). O quarto e último passo da calibração consiste na função de mapeamento do alvo, que correlaciona a medida real com as dimensões virtuais da imagem (Figura 42d). A título de exemplo, a distância entre dois pontos do alvo de calibração é $10 \mathrm{~mm}$ e na imagem, esta distância corresponde a 10 px. A informação espacial fornecida pela calibração será utilizada, após a gravação, para processar as imagens (ADRIAN e WESTERWEEL, 2011). 
Figura 42 - Procedimentos para a calibração

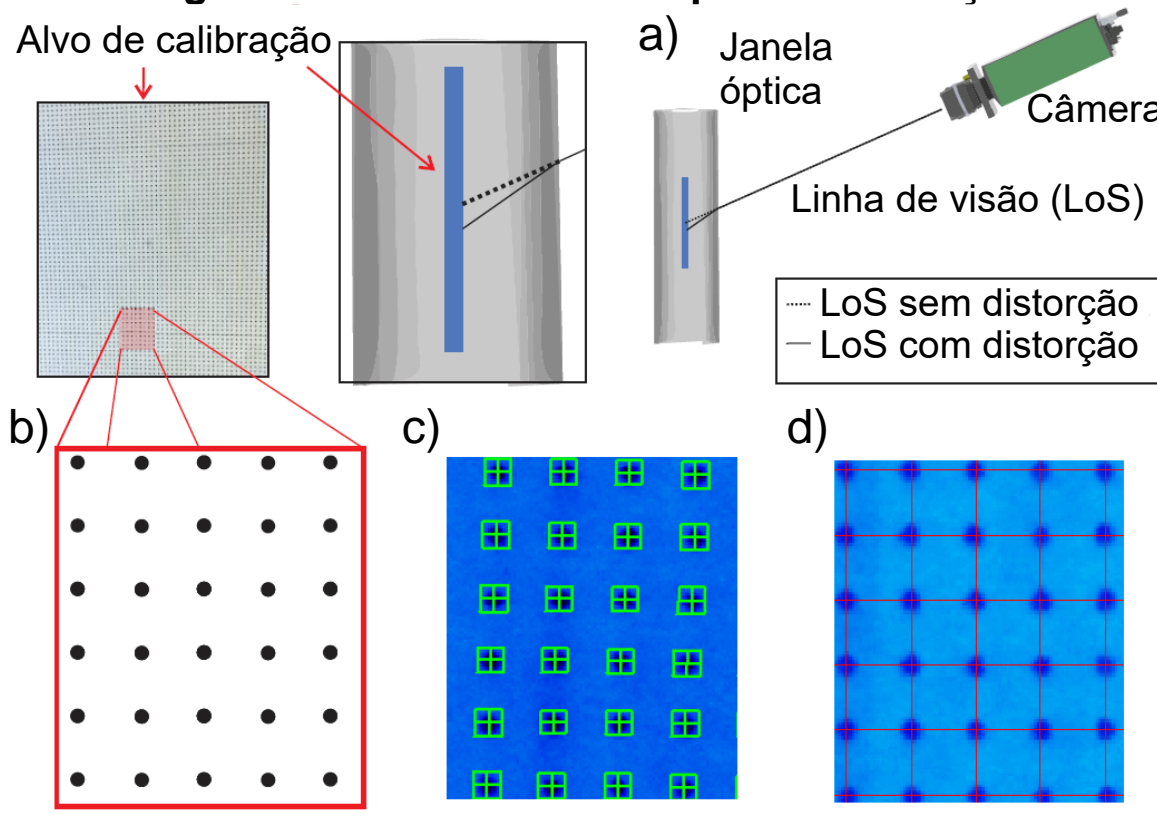

Fonte: Adaptado de Amaral (2017).

$\mathrm{Na}$ gravação, grande parte dos experimentos PIV são gravados no modo double frame/single exposure (Figura 43), ou seja, um par de imagens gravadas em sequência. Neste caso, cada par de imagens é utilizado para determinar a velocidade. (RAFFEL et al. 2018).

Figura 43 - Modo de gravação double frame/single exposure
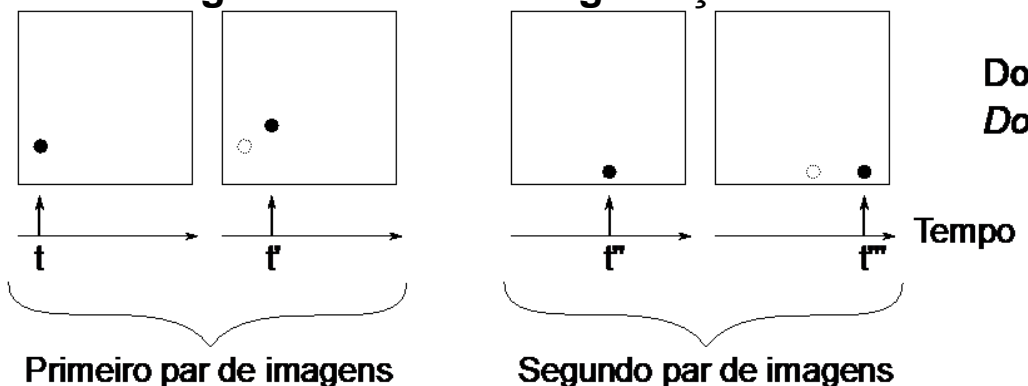

Dois Quadros/Única Exposição

Double Frame/Single Exposure

Primeiro par de imagens

Segundo par de imagens

Fonte: Adaptado de Raffel et al. (2018).

A resolução em PIV é definida como a relação entre dois espaços diferentes. Por exemplo, a relação entre o espaço físico e o espaço do tempo é denominada resolução temporal. No PIV existem três tipos principais de resolução: espacial, que se subdivide em sistema de imagem e sistema PIV; temporal e bit (Figura 44). A resolução espacial estabelece a conexão do espaço físico e do espaço da imagem. No sistema de imagem, a correlação ocorre entre as distâncias reais, fornecidas pela calibração, com as dimensões da imagem em pixels (px), ou vice-versa, proporcionando resoluções do tipo $\mathrm{mm} / \mathrm{px}$. Já a resolução espacial no sistema PIV 
correlaciona um vetor velocidade com uma medida real ou medida na imagem. A título de exemplo, pode-se correlacionar um vetor velocidade com a janela de interrogação utilizada no processamento PIV, gerando uma resolução espacial em 1/px. Como mencionado anteriormente, a resolução temporal está associada ao espaço físico e ao tempo e usualmente é medida na frequência do escoamento e da gravação. Já a resolução bit correlaciona valores analógico com valores digitais, no caso do PIV, isto traduz-se como a intensidade de luz que chega ao sensor da câmera e como este sensor transforma esta informação em diferentes níveis. No caso de câmeras coloridas, a resolução bit também é a relação entre o espalhamento de luz e as cores. A resolução exigida para um experimento, seja ela qual for, pode ser muito maior que a resolução disponível no sistema. No caso de um escoamento turbulento a resolução temporal necessária para resolvê-lo pode estar muito aquém da frequência de gravação da câmera (ADRIAN e WESTERWEEL, 2011).

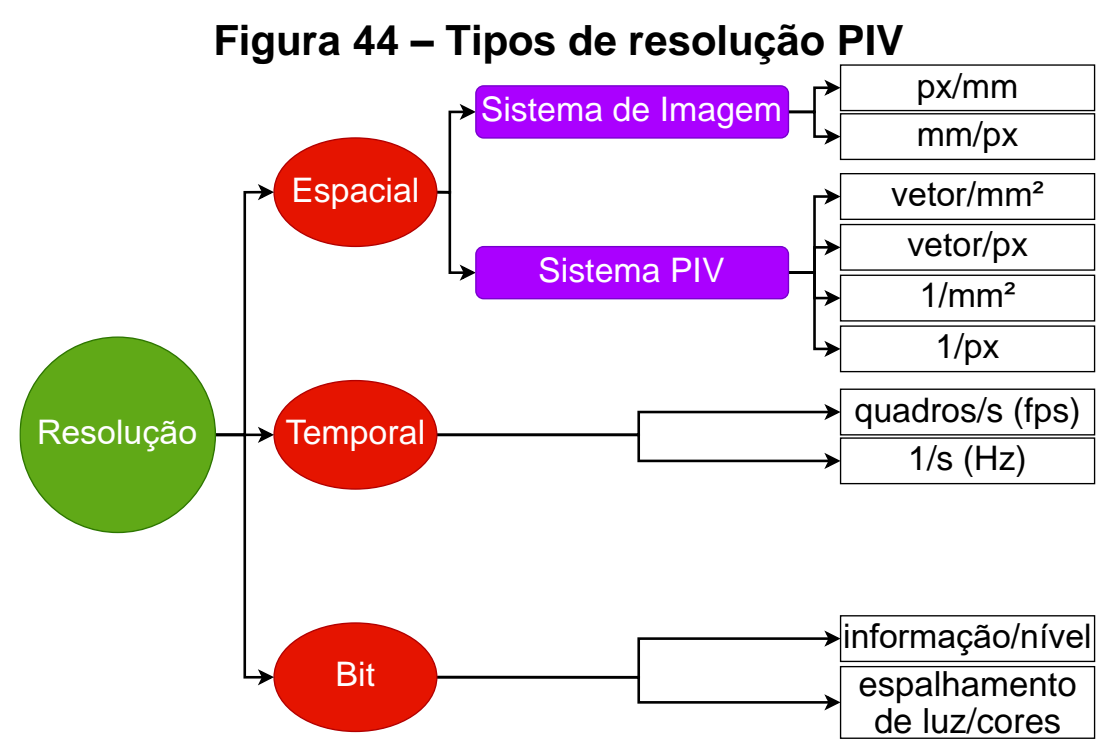

O tipo de sensor da câmera, CCD ou CMOS, também influencia nas resoluções. Os sensores CMOS incorpora amplificadores, conversores analógicodigital e muitas vezes processamento adicional, além de produzir menos calor. Geralmente os sensores CCD não possuem tais incorporações, mas não sofrem com o ruído estrutural presente nestes componentes. A câmeras mais antigas do tipo CCD possuem resoluções temporal muito menores quando comparadas às câmeras mais modernas CMOS. Entretanto, os sensores CCD apresentam resolução bit muito maior e resolução espacial ligeiramente maior que os sensores CMOS (RAFFEL et al. 2018).

O pré-processamento PIV é utilizado para remover ruídos das imagens desde 
o início dos anos 90 (REEVES, 1995). Ruído em PIV é tudo aquilo que está na imagem, mas não é partícula. Portanto, o pré-processamento remove o ruído para que apenas as partículas sejam utilizadas para determinar o campo de velocidade. Nesta etapa, pode-se corrigir a intensidade luminosa das imagens que varia ao decorrer do experimento, a presença de objetos estacionários no escoamento e a movimentação de objetos como bolhas, membranas, rotores, entre outros (COWEN e MONISMITH, 1997). Entretanto, o pré-processamento não adiciona informações após a gravação do experimento, apenas remove ou reorganiza as informações já existentes e diminui o custo computacional da etapa seguinte (FINCHAM e SPEDDING, 1997). As correções se dão por meio de filtros digitais (HONKANEN e NOBACH, 2005)

A Figura 45 retrata a intensidade de uma única partícula sem nenhum tratamento (Figura 45a), com pré-processamento por filtros digitais do tipo gaussiano (Figura 45b), valor eficaz (Root Mean Square - RMS) (Figura 45c) e Subtract Sliding Minimum (SSM) (Figura 45d), todos com tamanho de 3x3 pixels. O filtro gaussiano é utilizado para suavizar a partícula, mas não é capaz de remover a intensidade de fundo na imagem. Já o filtro RMS remove grande parte da iluminação de fundo e cria um pico de intensidade proeminente. O filtro SSM também remove o ruído de fundo de imagem, porém afeta a intensidade das partículas ao produzir um pico de intensidade mais largo (MOURA, 2017).

\section{Figura 45 - Intensidade de uma partícula com e sem pré-processamento}

a)

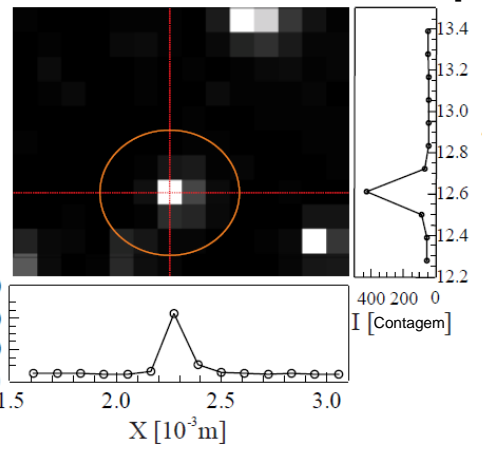

c)

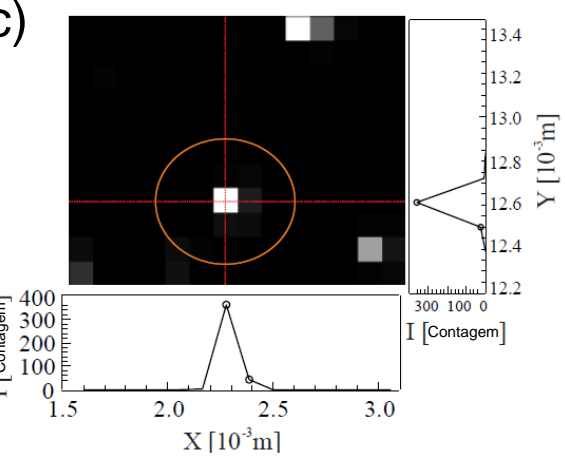

b)
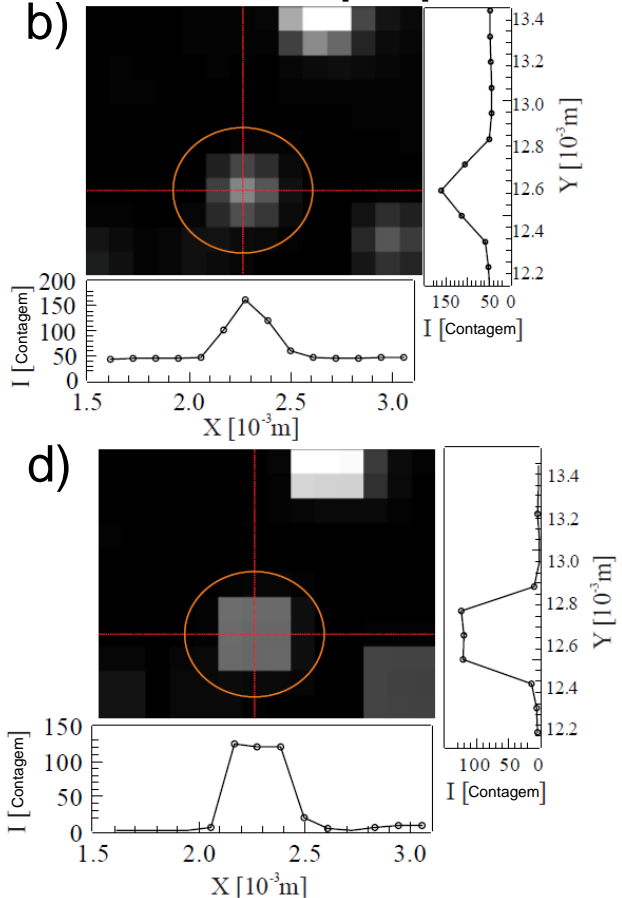

Fonte: Adaptado de Moura (2017). 
$\mathrm{Na}$ Figura 46, observa-se a aplicação do pré-processamento em uma imagem completa (Figura 46a). Inicialmente, o filtro digital detecta a borda (Figura 46b) por meio de gradientes na imagem e posteriormente remove o fundo (Figura 46c) de um objeto estacionário, através de um filtro mediano.

\section{Figura 46 - Exemplo de pré-processamento}

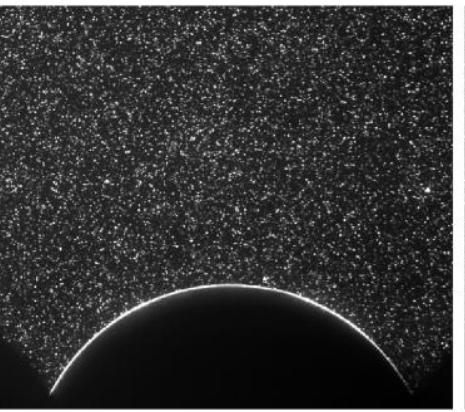

Imagem crua

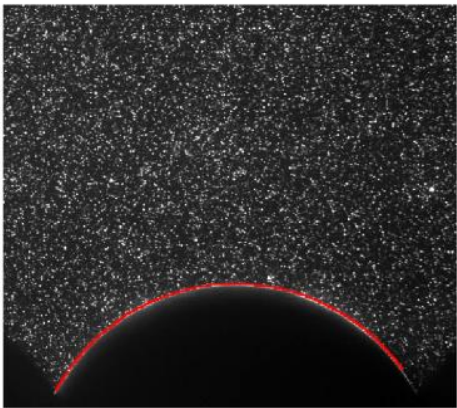

Detecção da borda

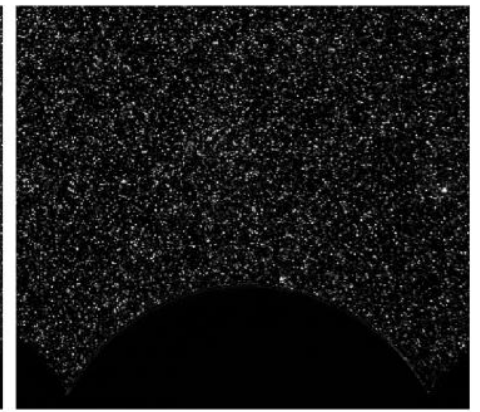

Fundo removido

Fonte: Adaptado de Universidade de Aberdeen (2008).

O processamento fornece os vetores e campos de velocidade e outras grandezas físicas relacionadas à velocidade (Figura 47), tudo isso mediante o uso de algoritmos (ADRIAN e WESTERWEEL, 2011).

Figura 47 - Processamento de imagens PIV

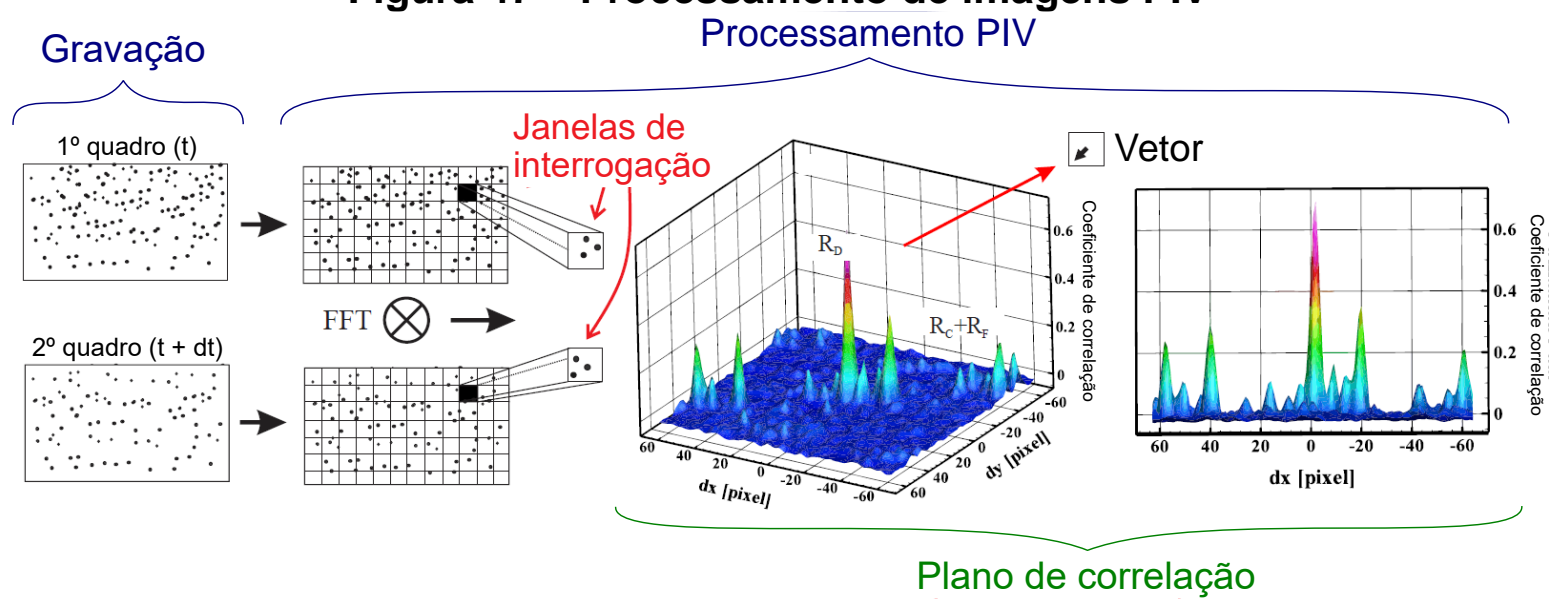

Fonte: Adaptado de Amaral (2017).

O deslocamento das partículas no PIV habitualmente é estimado por um algoritmo baseado na correlação cruzada padrão (Standard Cross Correlation - SCC) de duas janelas de interrogação, que são regiões delimitadas dentro da imagem, de dois tempos consecutivos. Este cálculo possui alto custo computacional, logo, com o propósito de facilitar o cálculo e diminuir o tempo despendido, as imagens são submetidas à transformada rápida de Fourier (fast Fourier transform - FFT) que 
converte as janelas de interrogação do domínio espacial para o domínio da frequência. Qualquer FFT produzirá uma imagem de números complexo, que se pode dividir em duas imagens: uma com a parte real (magnitude) e outra com a parte imaginária (fase) (GONZALEZ e WOODS, 2008).

A correlação cruzada entre duas funções é equivalente ao produto escalar de suas transformadas de Fourier. Posteriormente, este produto passará por uma transformada inversa de Fourier (inverse Fourier Transform - IFT) para retornar ao domínio espacial e produzir o plano de correlação da SCC. A magnitude da imagem contém a maior parte da informação, porém, a fase é importante pois sem ela a reconstrução da imagem geraria um domínio espacial errado. O processo para realizar a SCC é apresentado na Figura 48. Os picos resultantes da SCC são os indicadores de melhor adequação à relação cruzada, sendo o maior pico o melhor resultado (BHATTACHARYA, CHARONKO e VLACHOS, 2018).

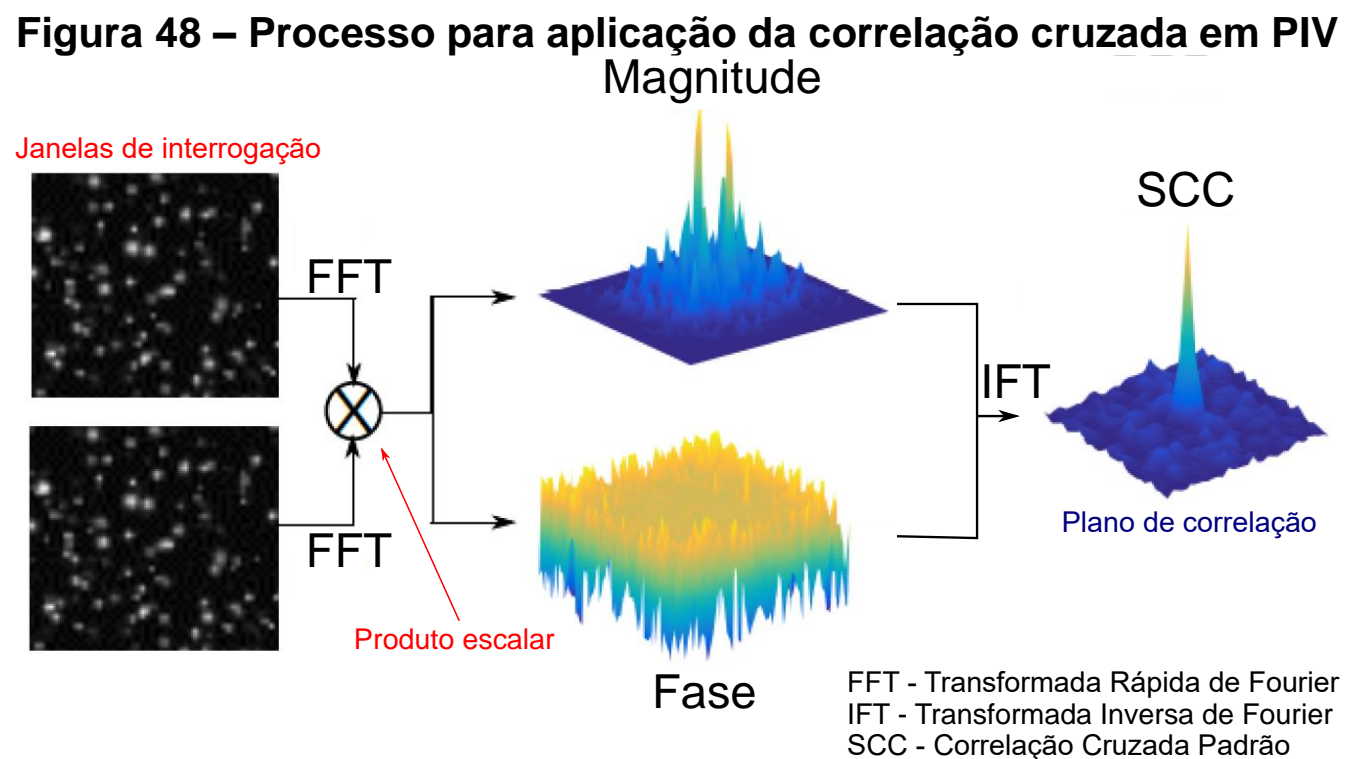

Fonte: Adaptado de Bhattacharya, Charonko e Vlachos (2018).

O plano de correlação $(R)$ da SCC representa todas as probabilidades de todas as correlações cruzadas possíveis entre quadros de imagens consecutivos (Figura 49a). O maior pico no plano de correlação corresponde a maior probabilidade de deslocamento de partículas ( $R_{D}$, Figura $49 \mathrm{~d}$ ). É este pico que será utilizado para determinar o vetor velocidade (Figura 49e). Os outros picos de $R_{D}$ são outras probabilidades de deslocamento, que aparecem devido à problemas na gravação (Figura 49f). Já os demais picos são as somatórias das correlações média do fundo ( $R c$, Figura $49 b)$ e da correlação correspondente à flutuação aleatória ( $R_{F}$, Figura $\left.49 c\right)$, 
ambos são considerados ruídos. Portanto, a equação (28) rege o plano de correlação.

$$
R=R_{C}+R_{F}+R_{D}
$$

Figura 49 - Plano de correlação

a)

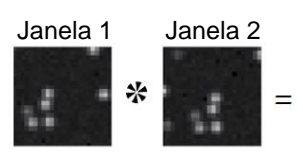

b)

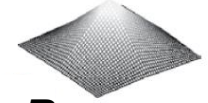

$R_{C}$

e)

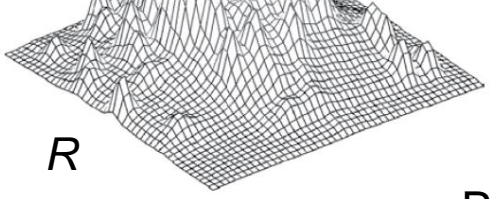

Pico de maior prob. $\left(R_{D}\right)$ c)

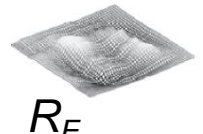

d)

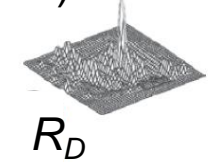

f)

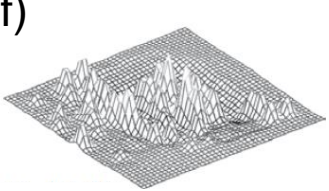

Resto de $R_{D}$ Fonte: Adaptado de Discetti e laniro (2017).

As correções do pré-processamento impactam diretamente no plano de correlação. Por exemplo, a imagens normalizadas (Figura 50b) de um experimento PIV apresentam um pico mais estreito quando comparada à imagens originais (Figura 50a) no momento do SCC. O pico produzido após o pré-processamento aumenta as possibilidades de deteç̧ão correta na correlação cruzada e diminui erros (DEEN et al., 2010).
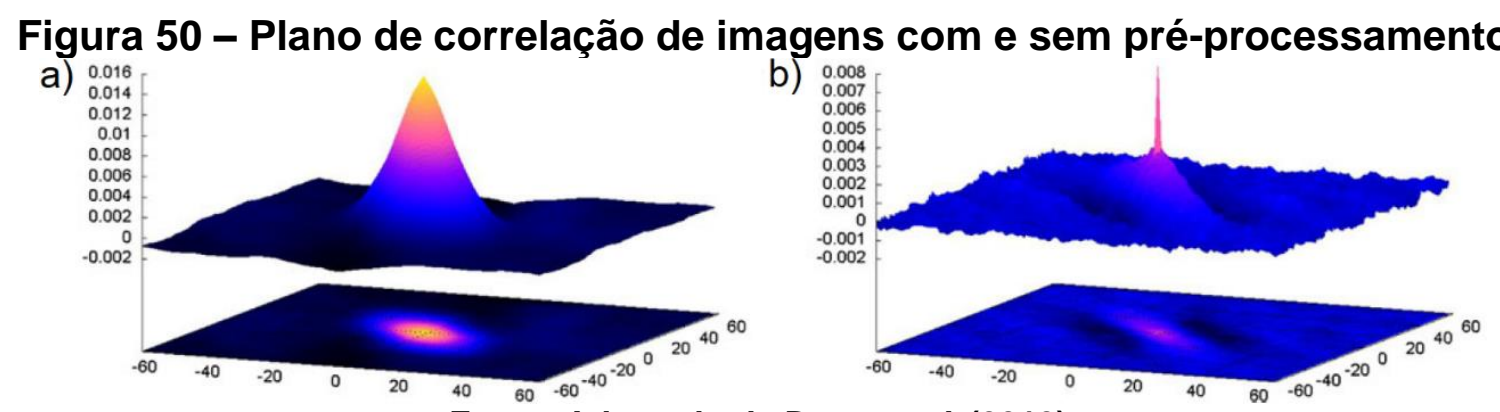

Fonte: Adaptado de Deen et al. (2010).

O pós-processamento PIV comumente remove as disparidades observadas, suaviza e valida os vetores brutos, todos após a correlação cruzada. O pósprocessamento é, em vista disso, necessário antes de qualquer análise das informações fornecidas pelo PIV (GARCIA, 2011). Na Figura 51 têm-se um exemplo de pós-processamento de um modelo ventricular esquerdo, com sua respectiva imagem bruta (Figura 51a), campos pós-processados (Figura 51b) e resíduos com os 
vetores espúrios (Figura 51c).

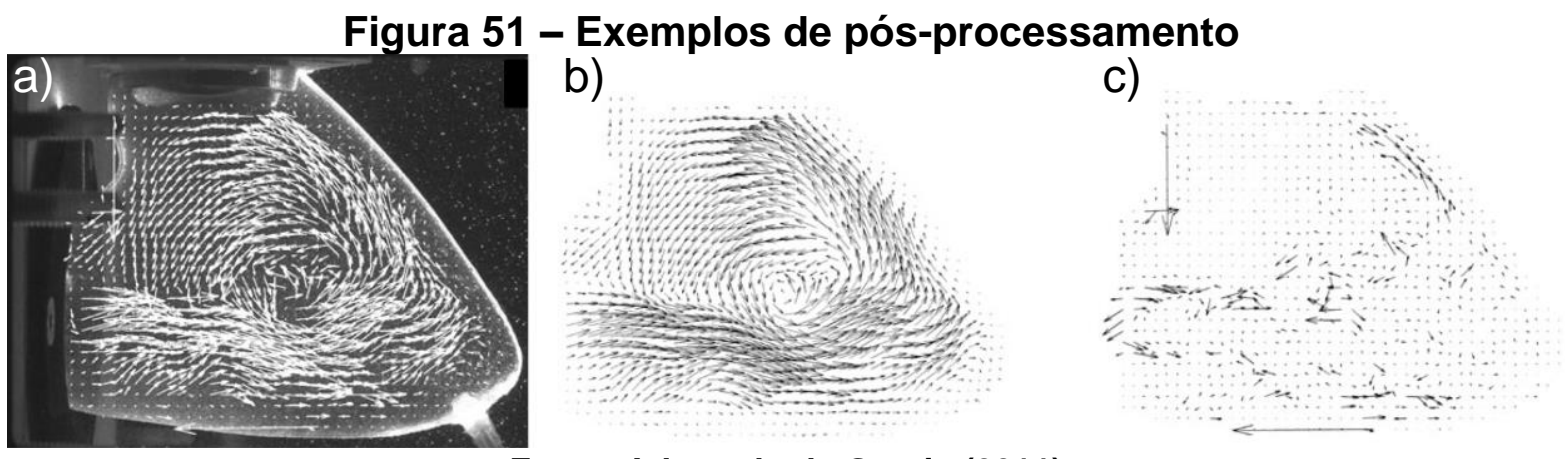

Fonte: Adaptado de Garcia (2011).

Os campos de velocidade sem ruídos apresentam coerência espacial pois seus vetores possuem tamanhos condizentes com a janela de interrogação e com as janelas vizinhas. O ruído, presente nas medidas reais, gera vetores espúrios que interferem nesta coerência espacial e uma das maneiras para diminuir o seu efeito nos campos de velocidade consiste na aplicação de filtros espaciais locais e/ou globais. A mesma abordagem é válida para a coerência temporal. A grande vantagem dos filtros espaciais e temporais consiste na simplicidade de implantação, no entanto, grupos de vetores falsos podem permanecer após a aplicação dos filtros (SCIACCHITANO, 2014).

O PIV possui desvantagens em relação às técnicas mais simples de medição de velocidade como anemômetros e tubos de Pitot como o alto preço dos equipamentos necessários à medição. Entretanto, a grande vantagem do PIV sobre os demais é a não intrusão do equipamento no fluxo. Ademais, o PIV trouxe aos experimentalistas a capacidade de determinar o gradiente de velocidade $\partial \mathrm{u} / \partial \mathrm{x}$, graças às câmeras de alta velocidade. Isto permitiu medições de fenômenos transientes, como a turbulência. Estruturas de fluxo antes invisíveis às demais técnicas passaram a ser vistas de forma quantitativa, iniciando um novo olhar à turbulência. Outro ponto positivo para o PIV é a medição de um plano ou volume velocidades instantaneamente, ao contrário do anemômetro de fio quente e dos sistemas LDA que realizam medidas pontuais (TROPEA, YARIN e FOSS, 2007).

\subsubsection{Medidas resolvidas no tempo}

O termo PIV resolvido no tempo (time-resolved particle image velocimetry, TR- 
PIV) foi cunhado pela primeira vez por Vogel e Lauterborn (1988), pouco anos após o surgimento do PIV. A ideia era unir os campos de velocidade obtidos pelo PIV com a evolução temporal obtida pela velocimetria laser (laser Doppler anemometry, LDA). Para tanto, Vogel e Lauterborn (1988) montaram uma câmera com tambor rotativo e um obturador óptico-acústico no facho laser, permitindo a gravação de imagens a 10 $\mathrm{kHz}$. Como resultado, obtiveram as velocidades em torno das bolhas de cavitação na faixa de 2 a $30 \mathrm{~m} / \mathrm{s}$ (Figura 52).

Figura 52 - Evolução temporal das velocidades de uma bolha de cavitação

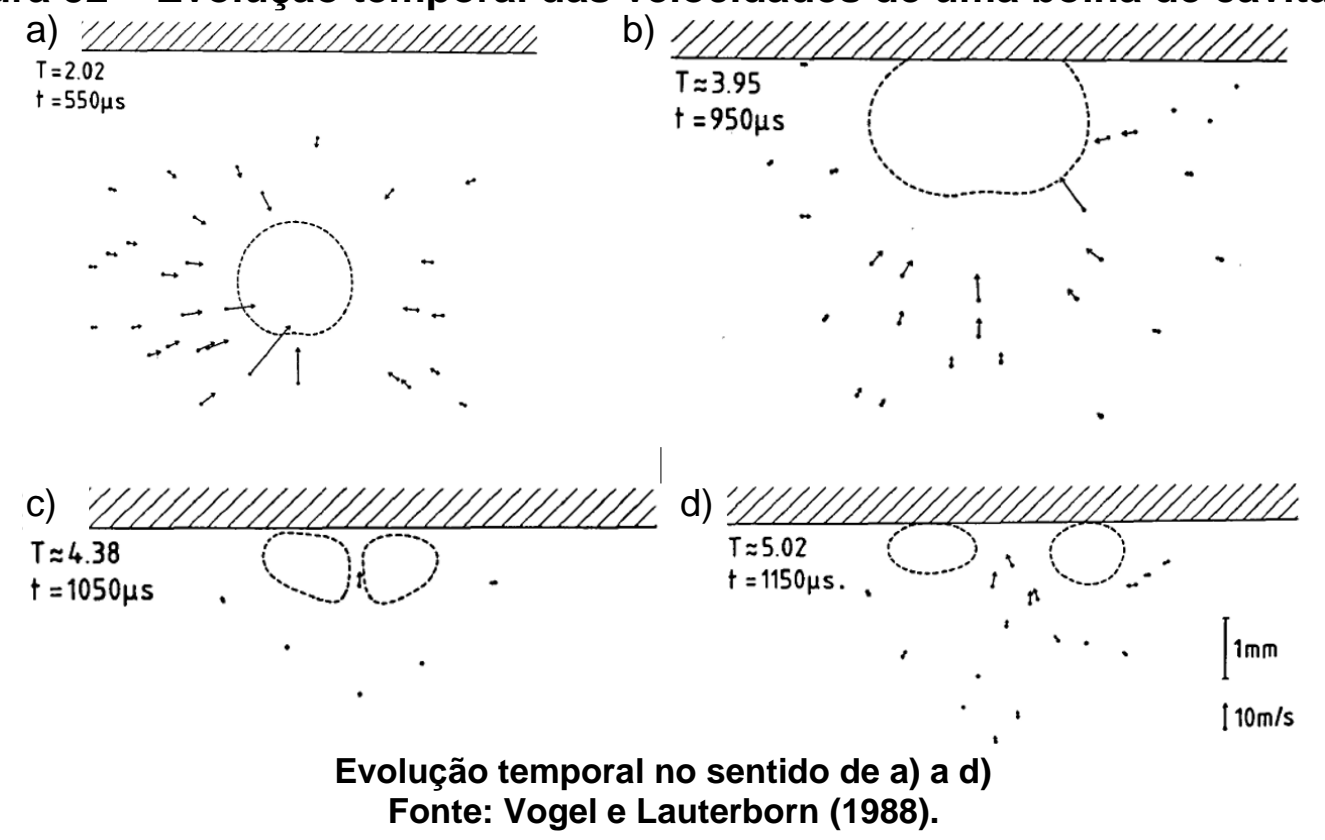

Atualmente, define-se o TR-PIV como um subtipo de medição PIV em que a aquisição das imagens ocorre em uma taxa próxima à escala de tempo das flutuações que ocorrem no fluxo medido. Isto possibilita a análise espacial e temporal (ou da frequência) do movimento do fluido ( $\mathrm{LYNCH}, 2015)$. As câmeras mecânicas ficaram no passado, e foram substituídas pelas câmeras digitais de alta velocidade com sensores CMOS. Da mesma forma, os lasers baseados em lâmpadas foram substituídos por lasers com tecnologia de estado sólido de alta repetição (SCIACCHITANO, SCARANO e WIENEKE, 2012).

A regra para definir o que é considerado resolvido no tempo ou não se baseia no teorema de amostragem de Nyquist-Shannon (LYNCH, PRÖBSTING e SCARANO, 2014). Em processamento de sinais, o teorema da amostragem estabelece a ligação entre os sinais contínuos e os sinais discretos no tempo. De acordo com esse teorema, a taxa de amostragem, apesar de discreta, deve ser 
suficiente para capturar todas as informações de um sinal (SHANNON, 1998).

A capacidade de correlacionar o espaço e o tempo permite a observação e quantificação de estruturas coerentes em escoamentos medidos com o TR-PIV. Além disso, a alta taxa de aquisição permite classificar as frequências dominantes nas flutuações da velocidade. Em ambos os casos, pode-se relacionar as estruturas coerentes e as flutuações de velocidade à turbulência, como no caso de um vórtice de von Kármán em uma Gurney flap (Figura 53a). Outra forma de aplicação do TRPIV consiste no uso da informação da correlação espaço-tempo nas equações de Navier-Stokes a fim de obter-se o gradiente de pressão, por exemplo em uma camada limite (Figura 53b). Por fim, TR-PIV também é utilizado em estimativas aeroacústicas e em fluxos com cisalhamento turbulento (LYNCH, 2015). Por exemplo, a Figura 53c apresenta a densidade de energia do TR-PIV sobreposta a do anemômetro de fio quente em um jato e a Figura 53d apresenta a evolução temporal da vorticidade próxima à parede.

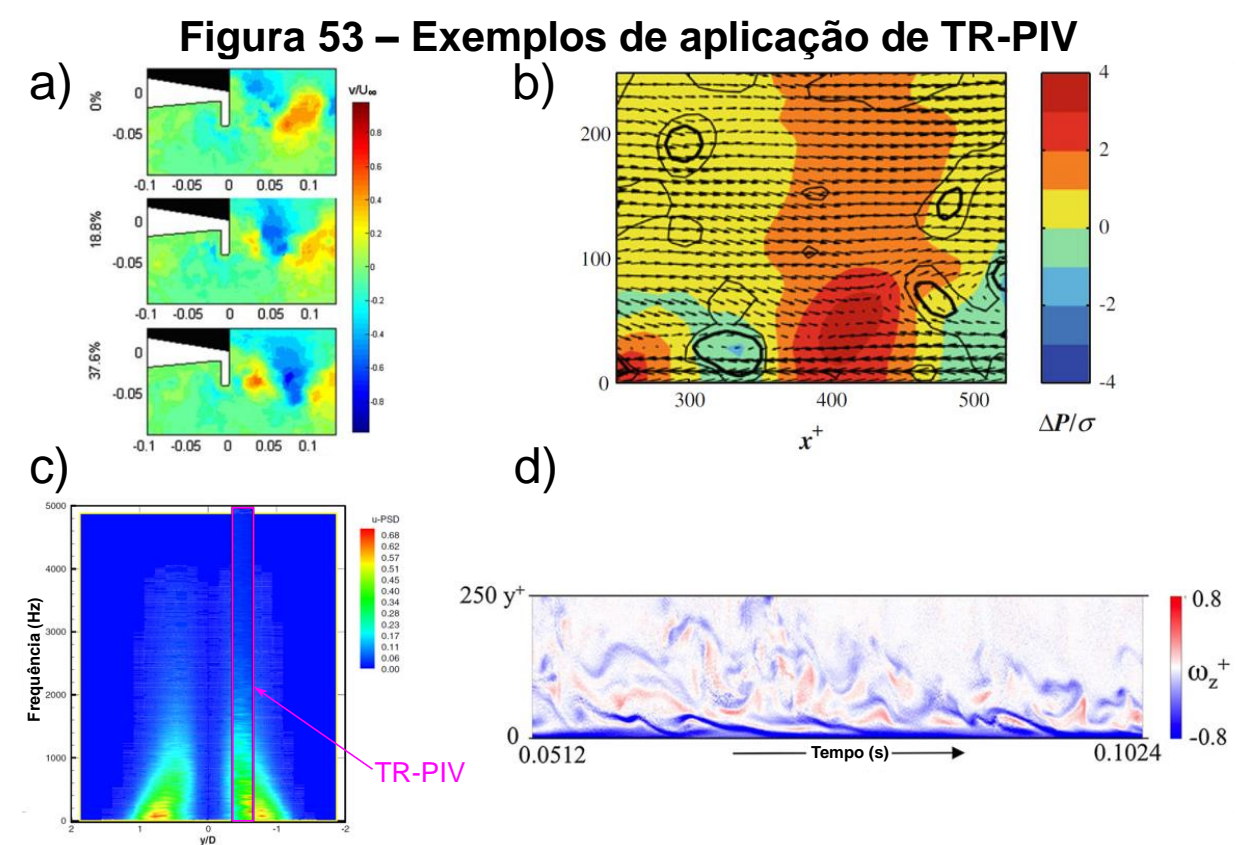

Fonte: Adaptado de Troolin, Longmire e Lai (2006), Ghaemi, Ragni e Scarano (2012), Wernet (2007) e Willert (2015).

No TR-PIV, as imagens podem ser gravadas no modo single frame/single exposure, que é a gravação de um único quadro exposto a um único tempo de exposição. Neste caso, as velocidades são extraídas em sequência e não em pares como no modo double frame. Com o advento das câmeras CMOS de alta velocidade não há mais o problema encontrado nas câmeras mecânicas, pois o obturador não 
permanece aberto tempo suficiente para criar as linhas de emissão (streaklines) na imagem (Figura 54) (RAFFEL et al., 2018).

Figura 54 - Tipos de gravação single frame

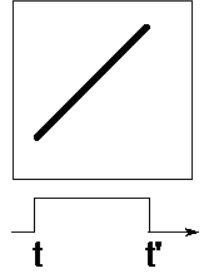

Único Quadro/Única Exposição com linhas de emissão

Single Frame/Single Exposure with streaklines
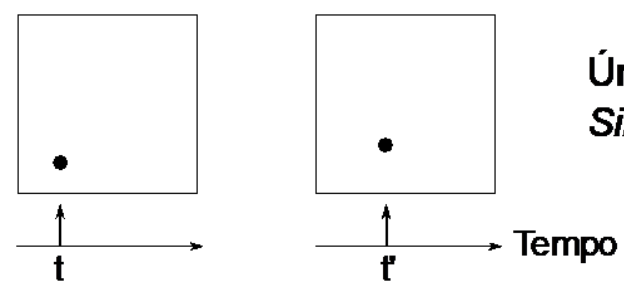

Único Quadro/Única Exposição

Single Frame/Single Exposure

Fonte: Adaptado de Raffel et al. (2018).

\subsubsection{Aplicações de PIV em DAV}

O grande problema que assola os pacientes com DAV é a formação de trombos e a hemólise do sangue. No decorrer da evolução do DAV, várias formas de medição foram empregadas com o objetivo de estimar a velocidade e posteriormente as tensões de cisalhamento, que estariam diretamente ligadas aos coágulos (HOCHAREON et al. 2004). Para atingir o grau de detalhamento desejado, técnicas de medição quantitativas foram empregadas para observar o fenômeno.

As primeiras medições de velocidade e de tensões de cisalhamento em DAVs ocorreu no final dos anos 1980. Tarbell et al. (1986) utilizou um equipamento LDA para medir em oito pontos as velocidades médias e suas flutuações, além de estimativas das tensões de cisalhamento na parede. Baldwin et al. (1988) também estimou as taxas de cisalhamento na parede utilizando um anemômetro de filme quente. Posteriormente, obtiveram medidas das velocidades médias (BALDWIN et al., 1989), campos de velocidades (JIN e CLARK, 1993) e tensões de Reynolds (BALDWIN et al., 1990) através do LDA. A técnica LDA foi mais utilizada pois não era invasiva ao escoamento e não era dependente da orientação, como a anemometria de filme quente. Entretanto, o LDA também possui as suas desvantagens, a saber: medições pontuais, dados não contínuos, e a precisão das medidas é altamente dependente do alinhamento dos feixes emitidos e refletidos (ALBRETCH et al. 2003). 
A noção destes problemas e a popularização do PIV no final dos anos 1990 permitiu a Hochareon et al. (2004) medir os campos de velocidade média (CVM) e taxas de cisalhamento próximas à parede (wall sher rate - WSR). A grande vantagem do PIV em relação ao LDA é o cálculo instantâneo do gradiente de velocidades em um plano. Em seu experimento, Hochareon et al. (2004) mediu sete planos, divididos em três profundidades $f$ (frontal), $m$ (média) e $r$ (traseira) em três áreas denominadas 5, 6 e 7 como apresentadas nas vistas do DAV da Universidade Estadual da Pensilvânia (Pennsylvania State University, PSU ou mais comumente Penn State) da Figura 55. O campo de velocidades resultante da penetração do jato de entrada na diástole precoce (Figura 55b) e a taxa de cisalhamento na parede com diferentes janelas de interrogação (Figura 55c).

\section{Figura 55 - CVM e WSR no DAV de $50 \mathrm{ml}$ da Penn State}

a)

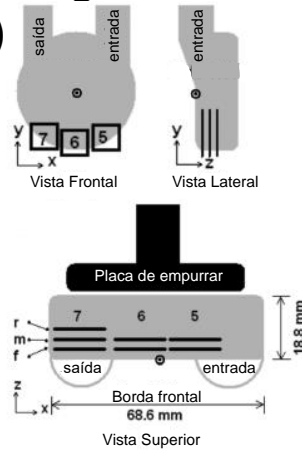

b)

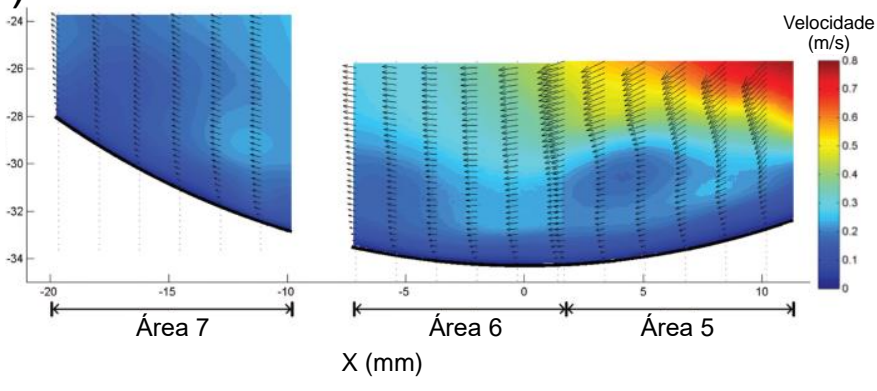

c)

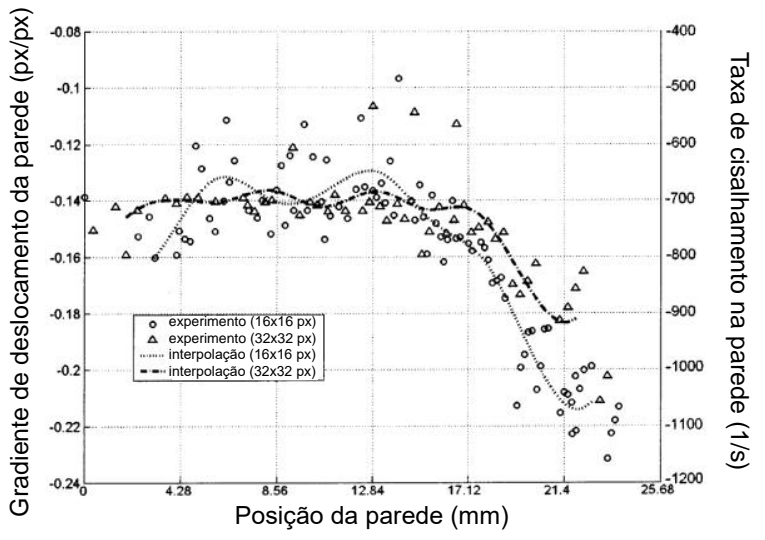

Fonte: Adaptado de Hochareon et al. (2004) e Hochareon et al. (2004).

O jato de entrada é responsável por lavar o DAV, pois adiciona um movimento rotacional e as diferente janelas de interrogação apresentaram poucas diferenças nos resultados das taxas de cisalhamento na parede (HOCHAREON et al., 2004).

O próximo avanço nas medições PIV ocorreu com a medição da energia cinética turbulenta (TKE). Na Figura 56a têm-se a TKE para 60 bpm e na Figura 56b para 75bpm, ambas no início da diástole. Da TKE infere-se como está a mistura do 
fluido que acabou de entrar no DAV com o fluido que permaneceu na câmara após a injeção (OLEY et al., 2005).
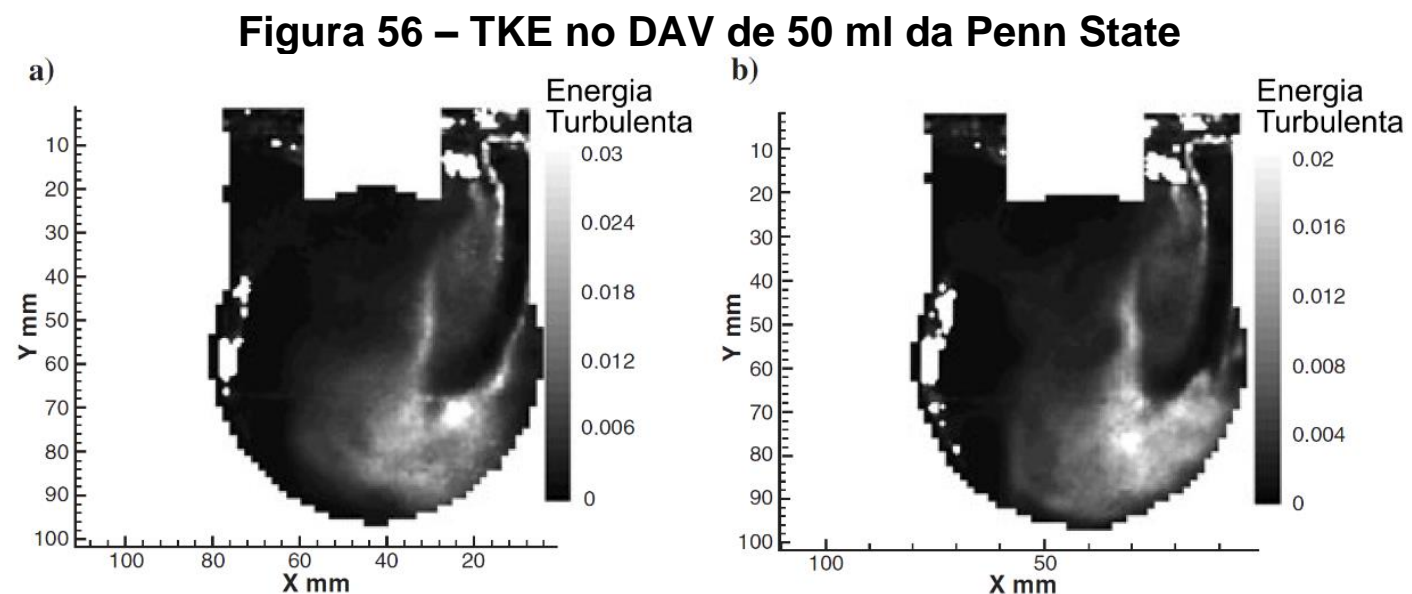

Fonte: Adaptado de Oley et al. (2005).

O primeiro DAVP medido com PIV também foi da Penn State. Roszelle et al. (2008) mediu as velocidades próximas à parede (near wall velocity - NWV) e o WSR de um DAVP de $12 \mathrm{ml}$. As folhas de luz medidas estão marcadas para os planos paralelos (Figura 57a) e perpendiculares ao diafragma (Figura 57b).

a)

\section{Figura 57 - Planos PIV do DAVP de 12 ml da Penn State}

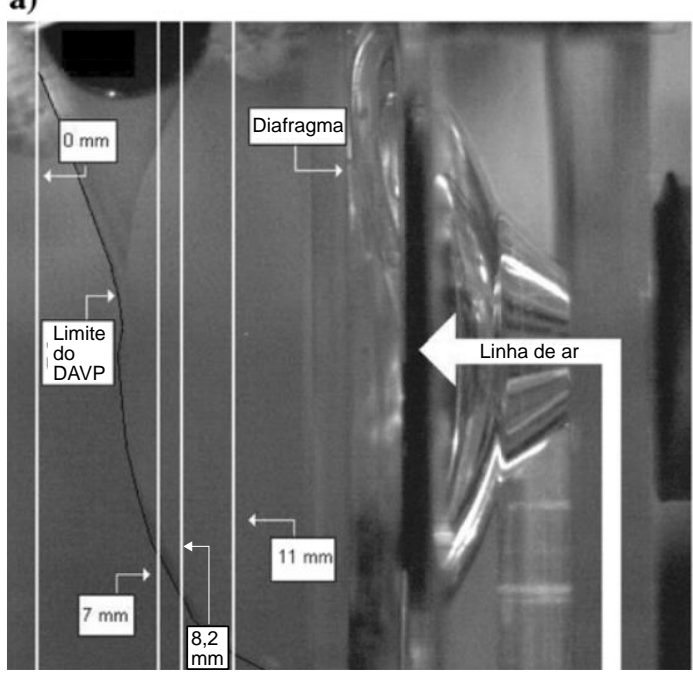

Fonte: Adaptado de Roszelle, Deutsch e Manning (2010).

b)

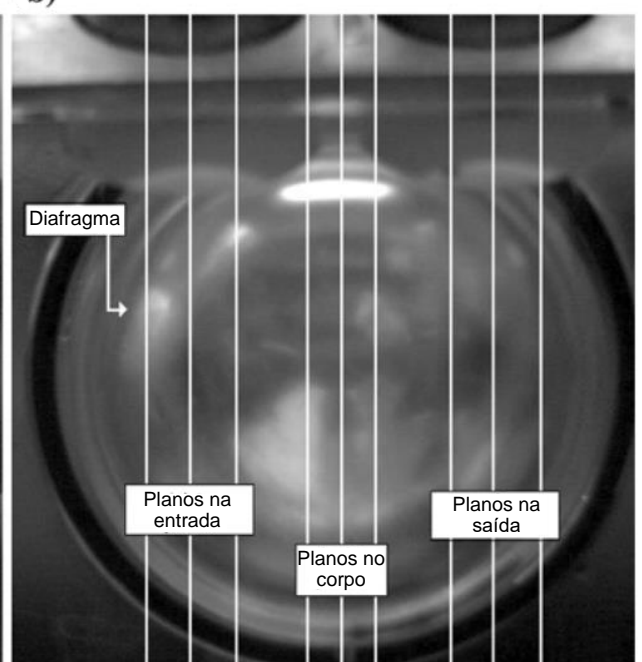

As velocidades encontradas para o plano paralelo $8,2 \mathrm{~mm}$ (Figura 58a) e para os planos perpendiculares ao diafragma na entrada do DAVP em 3,75 mm (Figura 58b), 7,5 mm (Figura 58c) e 11,25 mm (Figura 58d) demonstram também o efeito das válvulas e do diafragma nas medidas PIV. 
Figura 58 - Velocidades próximas à parede no DAVP da Penn State

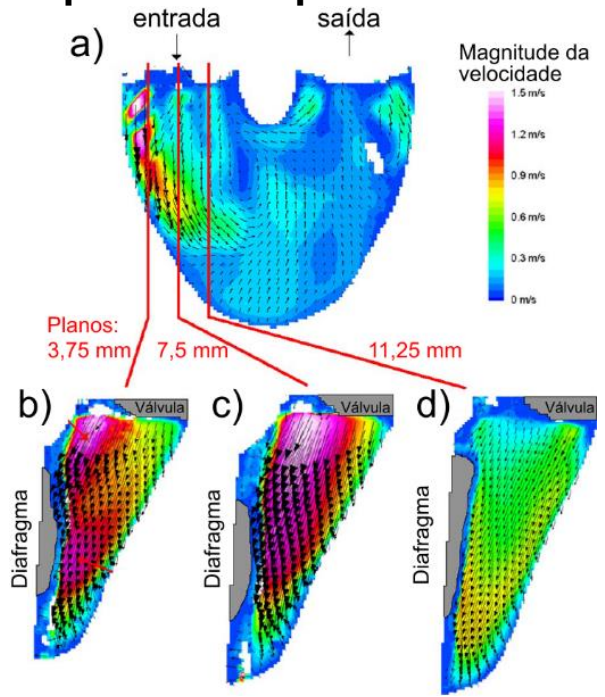

Fonte: Adaptado de Roszelle, Deutsch e Manning (2010).

Outras contribuições da Penn State estão na taxa de cisalhamento na parede, que estaria relacionado à formação de trombos e à hemólise e o potencial de susceptibilidade de formação de trombos (Thrombus Susceptibility Potential - TSP). As taxas de cisalhamento são baseadas na tensão de cisalhamento viscoso, como apresentada na Eq. (5). A Figura 59 apresenta os planos paralelos (a) e perpendiculares (b) medidos por Topper et al. (2014). A evolução do WSR (Figura 59c) durante a diástole ( $0 \%$ a $62 \%$ do ciclo) foi normalizado para $500 \mathrm{~s}^{-1}$ nos planos perpendiculares de $19,5 \mathrm{~mm}$ a $50,8 \mathrm{~mm}$. O plano medido vai de $\mathrm{y}=0$ a $\mathrm{y}=30 \mathrm{~mm}$ e $z=0$ a $z=-10 \mathrm{~mm}$.

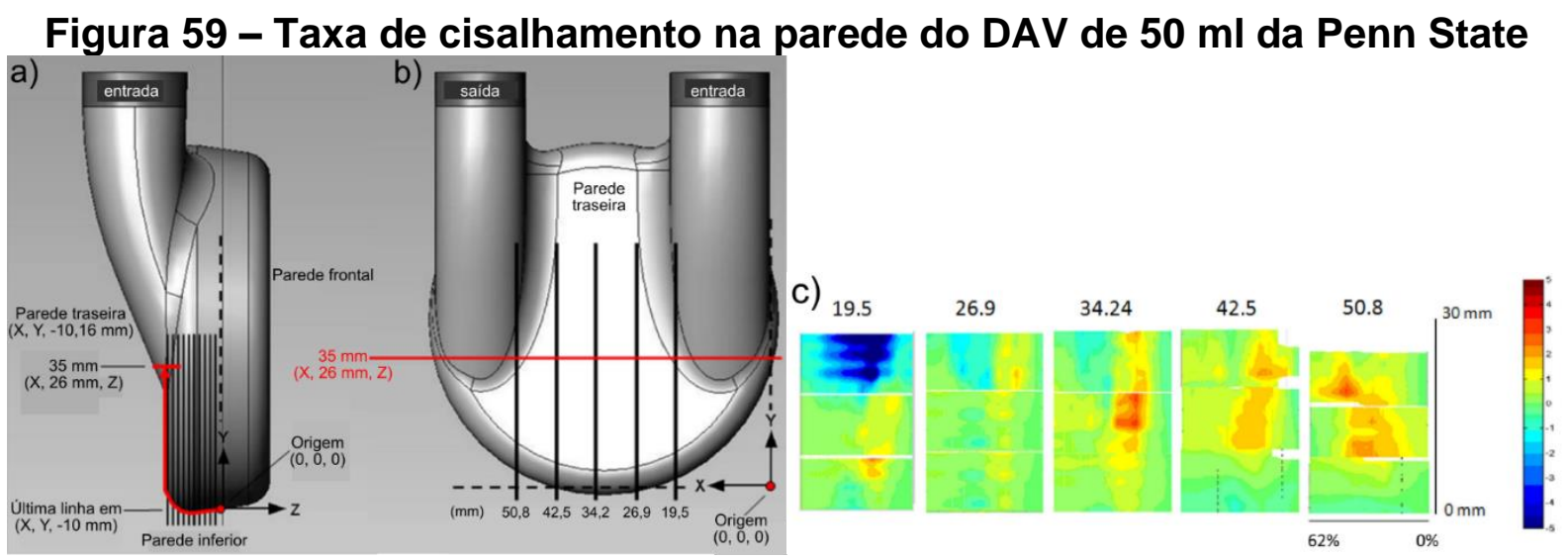

Fonte: Adaptado de Topper et al. (2014).

O TSP é um método quantitativo para determinar a probabilidade de formação de trombos, ou seja, é um valor entre $0 \%$ e $100 \%$, e foi adaptado para o PIV por 
Navitsky (2012). A equação do TSP é dada por:

$$
T S P=1-\sum_{0}^{N} \frac{\Delta t \cdot \gamma_{w}}{\gamma_{c u t o f f} \cdot t_{c r i t}} \cdot \frac{e^{\left(\frac{\gamma_{w}-\gamma_{\text {pico }}}{\gamma_{\text {cutoff }}-\gamma_{\text {pico }}}\right)}-1}{e-1}
$$

Em que Né o número de passos de tempo do ciclo cardíaco, $\Delta t$ é o tempo entre os quadros de imagens gravados, por exemplo 56 ms (TOPPER et al., 2014); $\gamma_{w}$ é a taxa de cisalhamento na parede, $Y_{\text {pico }}$ é o valor limite para deposição de trombos, 500 $\mathrm{s}^{-1}$ valor padrão para os DAVs da Penn State; Ycutoff é o valor de corte definido experimentalmente como $1000 \mathrm{~s}^{-1}$ pois a partir deste valor a deposição de plaquetas é inibida; por fim, $t_{c r i t}$ é o dobro de $\Delta t$ e foi assim definido para reduzir erros entre os passos de tempo (Navitsky, Deutsch e Manning, 2012).

A Universidade Tecnológica de Łódź (UTŁ ou Politechnika Łódzka) contribuiu para o desenvolvimento de DAVs com a visualização de zonas de estagnação a partir das velocidades médias do PIV. A estas zonas estaria associada a formação de trombos. Já a Universidade de São Paulo (USP) contribuiu com as tensões de cisalhamento turbulentas, que conforme mencionado anteriormente apresentam uma outra perspectiva ao escoamento. A Figura 60a apresenta a porcentagem de zonas de estagnação (ZE) em um DAVP de $45 \mathrm{ml}$ no período de enchimento e ejeção. Por sua vez, na Figura 60b pode-se observar o RSS no DAVP do InCor de $30 \mathrm{ml}$ a 80 bpm.

\section{Figura 60 - Percentual de estagnação e tensão de cisalhamento turbulenta}

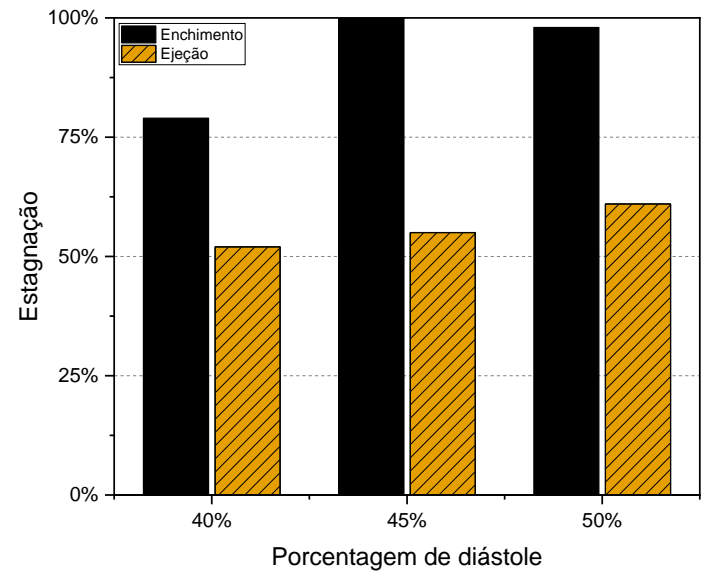

a)

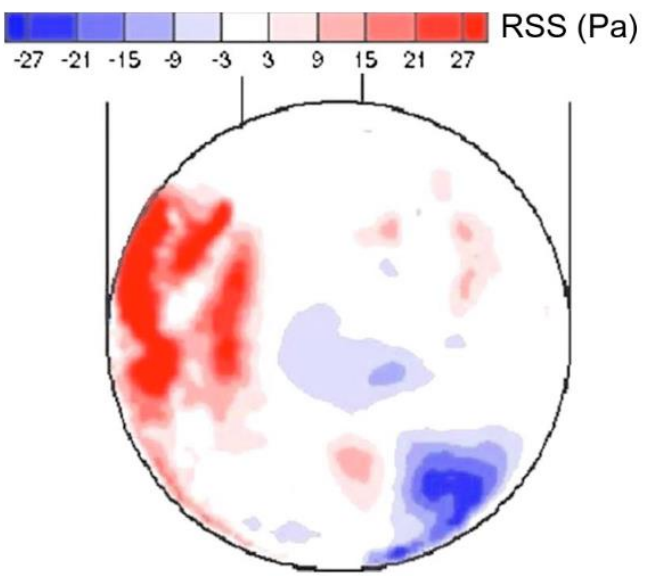

b)

Fonte: Adaptado de Witkowski et al. (2017) e Ferrara et al. (2010). 
A Tabela 6 apresenta as referências de medições PIV nos três grandes centros de pesquisa: Penn State, USP e Łódź.

Tabela 6 - Histórico das medições PIV em DAVs pneumáticos

\begin{tabular}{|c|c|c|c|c|}
\hline Local & Fonte & $\begin{array}{l}\text { DAV } \\
\text { (mL) }\end{array}$ & $\begin{array}{l}\text { Frequência } \\
\text { (bpm) }\end{array}$ & $\begin{array}{l}\text { Parâmetros } \\
\text { PIV }\end{array}$ \\
\hline \multirow{14}{*}{ 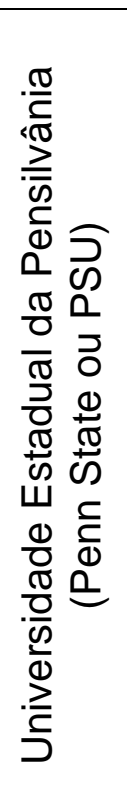 } & Hochareon (2004) & 50 & 75 & CVM, WSR \\
\hline & Oley et al. (2005) & 50 & 60,75 e 90 & CVM, TKE \\
\hline & Kreider et al. (2006) & 50 & 75 & CVM \\
\hline & Manning et al. (2008) & 12 & 86 & NWV e WSR \\
\hline & Cooper et al. (2008) & 12 & 75 & NWV e WSR \\
\hline & Roszelle et al. (2008) & 12 & 50 e 70 & NWV e WSR \\
\hline & Cooper et al. (2010) & 12 & 50 & NWV e WSR \\
\hline & Roszelle, Deutsch e Manning (2010) & 12 & 75 & NWV e WSR \\
\hline & Roszelle et al. (2011) & 12 & 75 & NWV e WSR \\
\hline & $\begin{array}{l}\text { Schönberger, Deutsch e Manning } \\
\text { (2012) }\end{array}$ & 12 & 75 & NWV e WSR \\
\hline & Nanna et al. (2011) & 50 & 75,115 e 150 & NWV e WSR \\
\hline & Navitsky, Deutsch e Manning (2012) & 50 & 75 & $\begin{array}{r}\text { NWV, WSR e } \\
\text { TSP }\end{array}$ \\
\hline & Topper et al. (2014) & 50 & 75 & \\
\hline & Caimi et al. (2017) & 12 & 75 & CVM \\
\hline \multirow{3}{*}{ 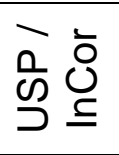 } & Ferrara, Muramatsu e Cestari (2004) & $30^{*}$ & 30 & CVM \\
\hline & Christensen et al. (2005) & $30^{*}$ & 60 e 100 & CVM e RSS \\
\hline & Ferrara et al. (2010) & 30 & 80,100 e 120 & CVM e RSS \\
\hline \multirow{2}{*}{ 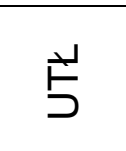 } & Witkowski et al. (2017) & $\begin{array}{l}30 \\
45\end{array}$ & $30,40,50$ & CVM e ZE \\
\hline & Obidowski et al. (2018) & 45 & 60 & CVM e ZE \\
\hline
\end{tabular}

${ }^{*}$ dados retirados de Ferrara 2010.

Nos casos apresentados acima, pouco ou nenhum foco é dado aos ruídos do PIV. Distorções e espalhamento de luz devido à geometria complexa do DAV, préprocessamento para aprimorar as imagens, movimento $3 \mathrm{D}$ do fluido dentro do DAV, e sombra da membrana são, na maior parte dos trabalhos, ignorados. Os trabalhos de Cooper et al. (2008), Roszelle et al. (2008) e Roszelle, Deutsch e Manning (2010) há marcações de regiões em que a reflexão do DAV (Figura 61a) afeta o algoritmo PIV (Figura 61b), a tridimensionalidade do escoamento é importante para compreender a rotação desenvolvida dentro do DAV (Figura 61c e d) e o movimento da válvula de entrada que compromete a correlação do PIV (Figura 61e e f). Apesar disso, nenhum dos autores propõe uma alternativa para solucionar tais problemas, apenas comentam a existência e no máximo os erros que acompanham tais ruídos. 
Figura 61 - Ruídos nas imagens PIV no DAVP de 12 ml da Penn State

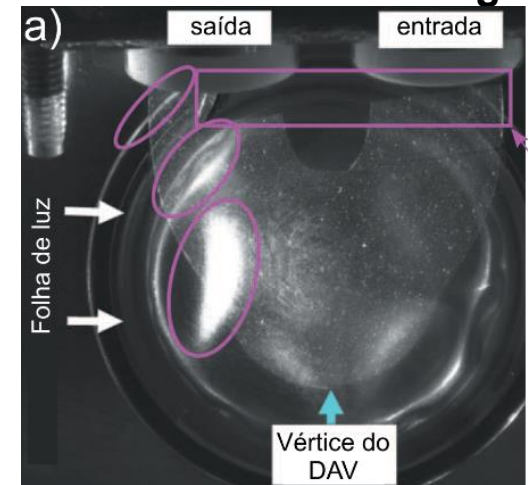

b)
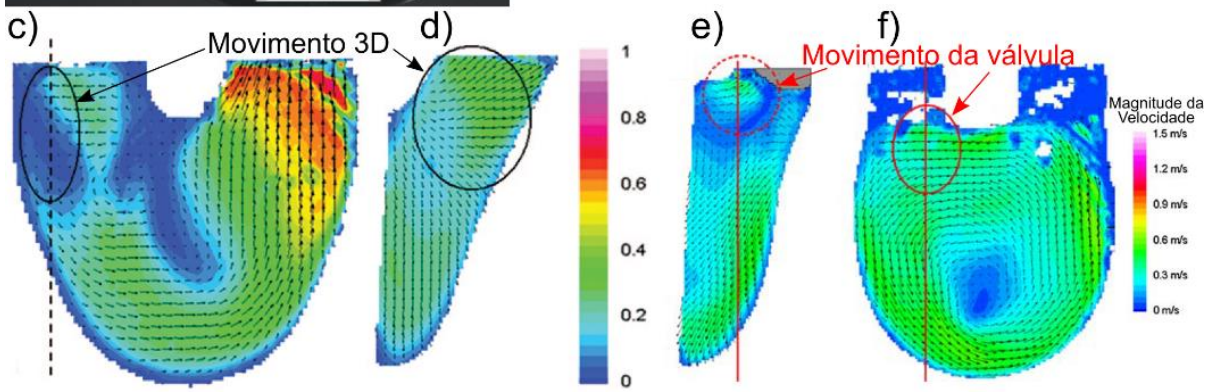

Fonte: Adaptado de Cooper et al. (2008), Roszelle et al. (2008) e Roszelle, Deutsch e Manning (2010).

\subsubsection{Ruído no PIV}

As medições não são perfeitas, portanto apresentam erros que interferem nos resultados obtidos. No PIV há várias fontes prováveis de erros, como o escoamento, a gravação, o cálculo da velocidade e a física (Figura 62). Usualmente, divide-se o erro em dois tipos: sistemático e aleatório. O erro sistemático está ligado a um efeito de uma grandeza durante as medições. Conhecendo-se este efeito, pode-se corrigir o problema (INMETRO, 2012). No PIV os erros sistemáticos estão presentes na montagem e gravação das imagens. Por exemplo, uma placa de calibração fora de foco ou mal posicionada induzirá a um erro sistemático. Neste caso, é mais prático corrigir o problema relacionado a calibração do que acrescentar um fator de correção ao resultado da medida (WIENEKE, 2017).

No que lhe concerne, o erro aleatório está associado à variação dos valores observados no decorrer da medição. Seu valor tende a zero com o aumento do número de medidas e com a aplicação da estatística nestes valores, por exemplo, a média (INMETRO, 2012). Na técnica PIV, os erros aleatórios estão associados ao ruído, movimento de partículas para fora do plano, alta ou baixa concentração de traçadores, gradientes de deslocamento que não acompanham a taxa de gravação dos quadros, entre outros (AMARAL, 2017). Contudo, estes erros aleatórios podem 
passar despercebidos.

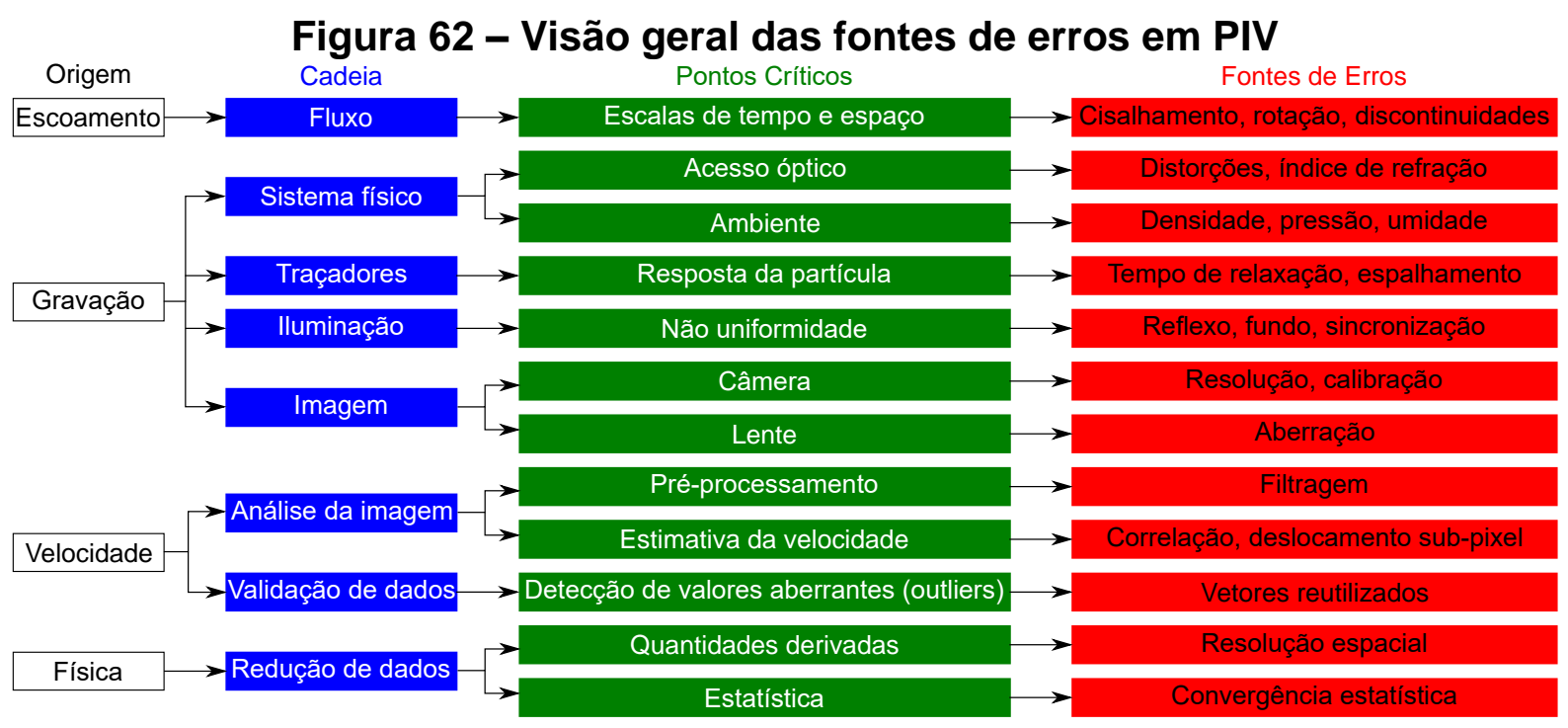

Fonte: Adaptado de Wieneke (2017).

Em uma medição ideal, com iluminação uniforme e invariável, além de partículas isométricas e distribuídas de forma homogênea, só haveria um pico máximo no SCC. Este pico indicaria o deslocamento correto das partículas na janela de interrogação sem nenhum erro (SCHARNOWSKI, SCIACCHITANO e KÄHLER, 2019). Nos experimentos reais, sujeitos a todos os tipos de interferências, também podem alcançar uma alta probabilidade de detecção válida (Valid Detection Probability - VDP) correspondente ao deslocamento médio real. Keane e Adrian (1992) afirmaram que um único pico de correlação era formado se houvessem um número de partículas na janela de interrogação $\left(N_{I}\right)$ maior que seis partículas.

$$
N_{I} \geq 6
$$

Acrescenta-se ao número de partículas dentro da janela de interrogação, outros quatro fatores que interferem no VDP, a saber: movimento no plano $\left(F_{I}\right)$, movimento para fora do plano $\left(F_{0}\right)$, gradientes de deslocamento $\left(F_{\Delta}\right)$ e ruído na imagem $\left(F_{\sigma}\right)$. Todos estes cinco erros podem criar outros picos secundários no plano de correlação e gerar incertezas à medição.

Para uma gravação do tipo double frame/single exposure, o número efetivo de imagens de partículas é dado por: 


$$
N_{I} F_{I} F_{O} \geq 6
$$

Esta relação não é suficiente pois não leva em conta as partículas que não são correlacionadas e que geram os picos de correlação secundários. Por exemplo, experimentos que possuem iluminação otimizada para alta resolução espacial, produzem altos deslocamentos de partículas entre as imagens e planos de laserfinos. O primeiro está ligado à incerteza do movimento no plano e o segundo à incerteza do movimento para fora do plano. Desta maneira, mesmo com valores acima de seis para o número efetivo de imagens, conseguido pelo aumento de $N_{I}$ na Eq. (31), os fatores Fı e Fo serão muito baixos para produzir um bom pico de correlação (SCHARNOWSKI, SCIACCHITANO e KÄHLER, 2019).

Uma proposta para solucionar este problema está no uso do número médio de imagens de partículas por pixel $\left(N_{p p p}\right)$ :

$$
N_{I}=N_{p p p} \cdot D_{I}^{2}
$$

Onde $D_{I}$ é o valor da aresta de uma janela quadrada em pixel. Não há um valor bem definido para nenhuma das três variáveis presentes na Eq. (32), porém, na Figura 63 são apresentados valores de $N_{p p p}$ e $F_{O}$ com curvas de $D_{I}$ e $N_{I}$ para VDP de 95\%.

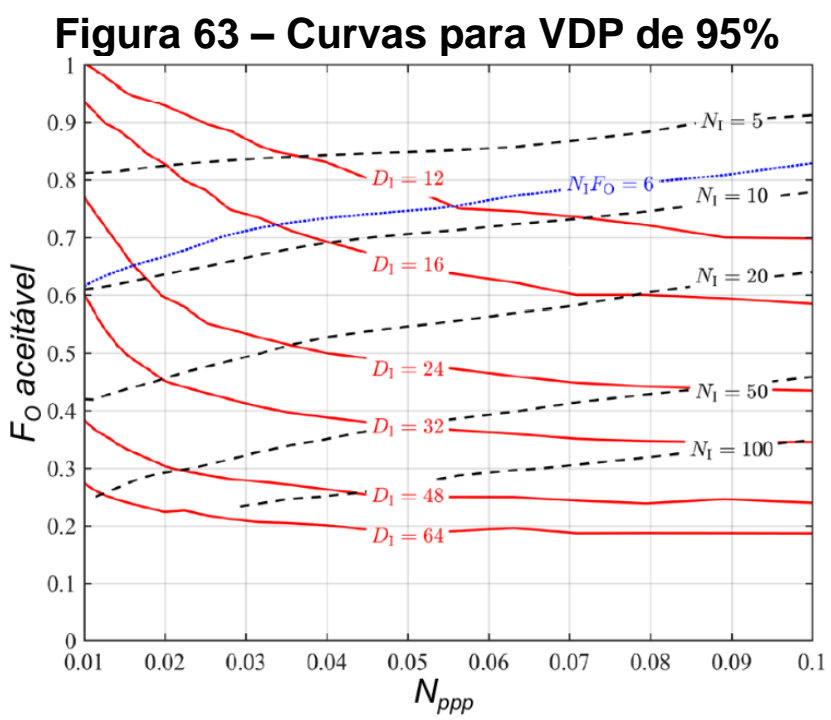

Fonte: Adaptado de Scharnowski, Sciacchitano e Kähler (2019).

Outro fator que também está associado ao erro aleatório é o diâmetro das partículas na imagem gravada. A Figura 64 exibe seis curvas que correlacionam o 
diâmetro da partícula com o erro. Cada curva corresponde a um tamanho de janela de interrogação, variando de 16 a 64 px² em um único ou múltiplos passes de correlação. Em todas as curvas o $\mathrm{N}_{\mathrm{ppp}}$ é constante.

Figura 64 - Relação do diâmetro da partícula na imagem com o erro aleatório

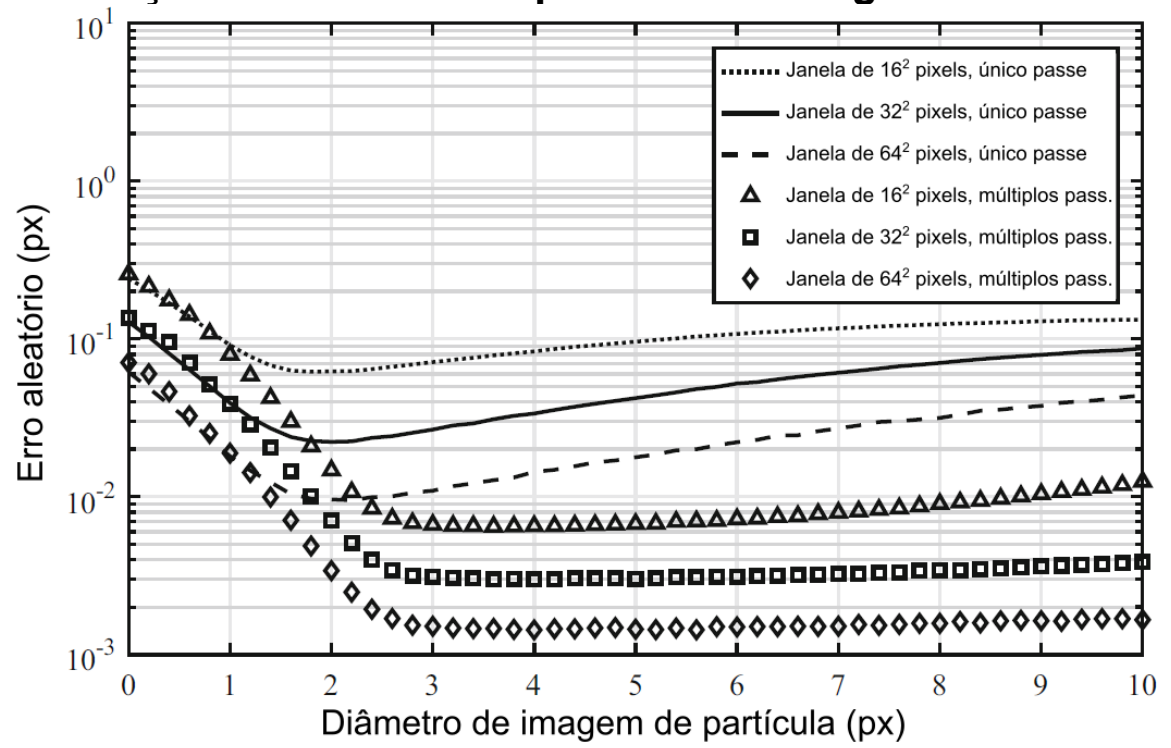

Fonte: Adaptado de Raffel et al. (2018).

Percebe-se na Figura 64 que janelas de interrogação maiores possuem um erro menor tanto para um único ou para múltiplos passes. Isto ocorre devido à relação do número de partículas por janela, ou seja, janelas de interrogação maiores possuem mais partículas e a estatística final produzirá uma melhor convergência. Todas as curvas possuem um valor mínimo, que está entre 1,5 e 3 pixels. Para os processamentos de único passe os valores do erro são maiores, mas o valor mínimo é alcançado antes das curvas de múltiplos passes (RAFFEL et al., 2018).

As funções de correlação cruzada fornecem medidas estatística de melhor correspondência, portanto produzem informações úteis acerca das imagens. Seguindo este princípio, a Figura 65 exibe o comportamento da relação entre diâmetro das partículas e o erro aleatório, para dois tipos de correlação: SCC e correlação de fase robusta (Robust Phase Correlation-RPC). Todas as curvas possuem $N_{I}=0,05$ partículas $/$ pixel $^{2}$. Analisando as curvas, constata-se que o valor mínimo delas está entre 1,5 e 3 pixels, semelhante ao observado na Figura 64. As curvas do RPC apresentam um erro ligeiramente menor, tal como o crescimento do erro do RPC após o valor mínimo, quando comparado ao SCC.

Este crescimento nas curvas após o valor mínimo, tanto na Figura 64 quanto 
na Figura 65, está vinculado na determinação do centro da partícula pelo algoritmo. Partículas maiores apresentam maior dispersão no momento da demarcação do centro das mesmas, aumentando a incerteza final. Idealmente, as imagens PIV devem possuir um diâmetro de partícula dentre este intervalo para produzir dados mais confiáveis (DISCETTI e IANIRO, 2017).

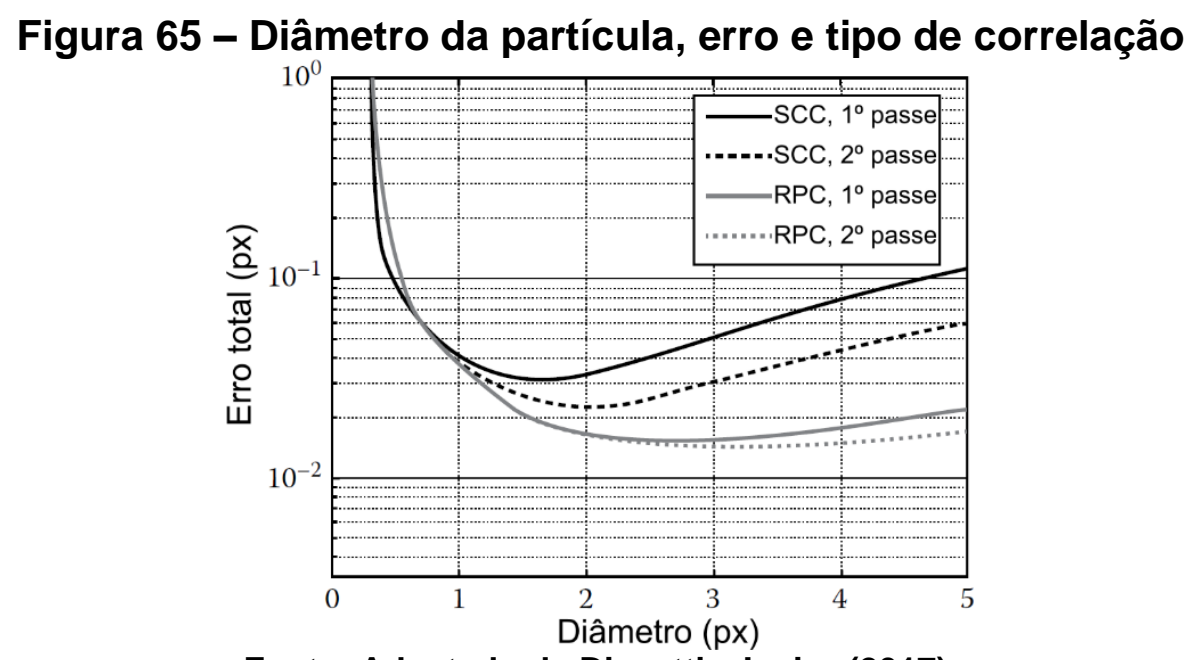

Fonte: Adaptado de Discetti e laniro (2017).

Dividindo-se uma curva de erro total em duas componentes, erro sistemático e erro aleatório (Figura 66) constata-se que a parte sistemática possui maior influência no total apenas em imagens com partículas menores que 0,5 px. Nos demais diâmetros o erro aleatório é preponderante.

Figura 66 - Diâmetro da partícula e erro aleatório e sistemático

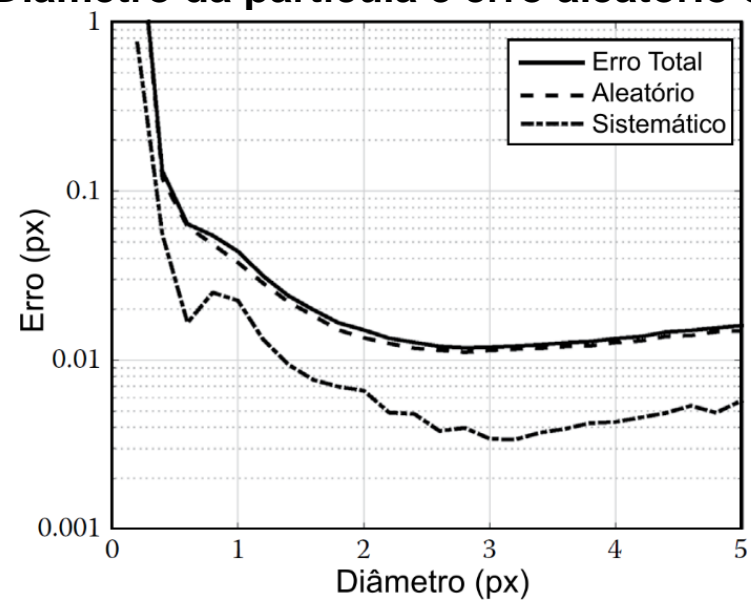

Fonte: Adaptado de Discetti e laniro (2017).

Os ruídos do PIV podem minimizar se os aspectos apresentados anteriormente forem levados em conta durante a calibração e gravação, mas mesmo com este 
cuidado ainda restarão fontes ruidosas. Para tanto, há um método que permite avaliar a incerteza das medições PIV após a correlação as imagens, chamado de relação sinal-ruído (Signal-to-Noise Ratio - SNR). O SNR utilizado em imagens representa um valor físico da sensibilidade e subsequentemente da qualidade de uma imagem. No PIV, o SNR estabelece a precisão e a incerteza da correlação utilizada nas imagens, seja ela cruzada (SCC), de fase (RPC) ou outra. Um dos métodos de cálculo do SNR é chamado de relação do pico primário (Primary Peak Ratio - PPR) e é obtido pelo plano de correlação (XUE, CHARONKO e VLACHOS, 2014).

O PPR é definido como a razão entre o valor do pico máximo $\left(C_{\max }\right)$ pelo segundo pico mais alto $\left(C_{2}\right)$, conforme a equação:

$$
P P R=\frac{C_{\max }}{C_{2}}
$$

Neste caso, $C_{\max }$ representa o sinal e o $C_{2}$ o ruído. A Figura 67 representa graficamente os picos utilizados no cálculo do SNR pelo PPR no plano de correlação.

Figura 67 - Representação gráfica do SNR no plano de correlação C Sinal: pico primário

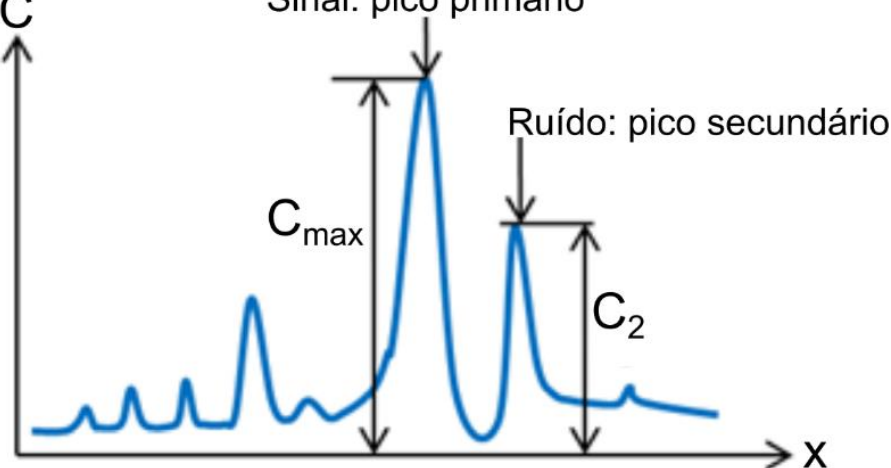

Fonte: Adaptado de Xue, Charonko e Vlachos (2014). 



\section{METODOLOGIA}

Nesta seção estão os detalhes relacionados ao desenvolvimento do experimento e da técnica de medição utilizada.

\subsection{O dispositivo de assistência ventricular pediátrico (DAVP) do Instituto do Coração (InCor)}

O dispositivo de assistência ventricular pediátrico (DAVP) do Instituto do Coração (InCor) possui uma unidade de bombeamento com formato próximo ao de uma calota esférica para a câmara unida a outra calota esférica para a antecâmara, com dois canais acoplados, onde ficam as válvulas de entrada e saída (Figura 68). As calotas esféricas também são denominadas câmara sanguínea (câmara) e câmara pneumática (antecâmara), de acordo como fluido que ocupa o seu volume interno. As câmaras são separadas por um diafragma, por vezes denominada membrana, confeccionada de material elástico. O dispositivo possui dimensões aproximadas de $65 \mathrm{~mm}$ no diâmetro externo, $59 \mathrm{~mm}$ no diâmetro interno e $21 \mathrm{~mm}$ no diâmetro externo dos canais valvulares. O DAVP possui capacidade para ejetar até $30 \mathrm{~mL}$ de sangue por batimento e sua implantação pode ocorrer no lado esquerdo, direito ou em ambos os lados do coração de forma paracorpórea, ou seja, o dispositivo permanece externo ao corpo enquanto a ligação deste com o coração é realizada por meio de cânulas.

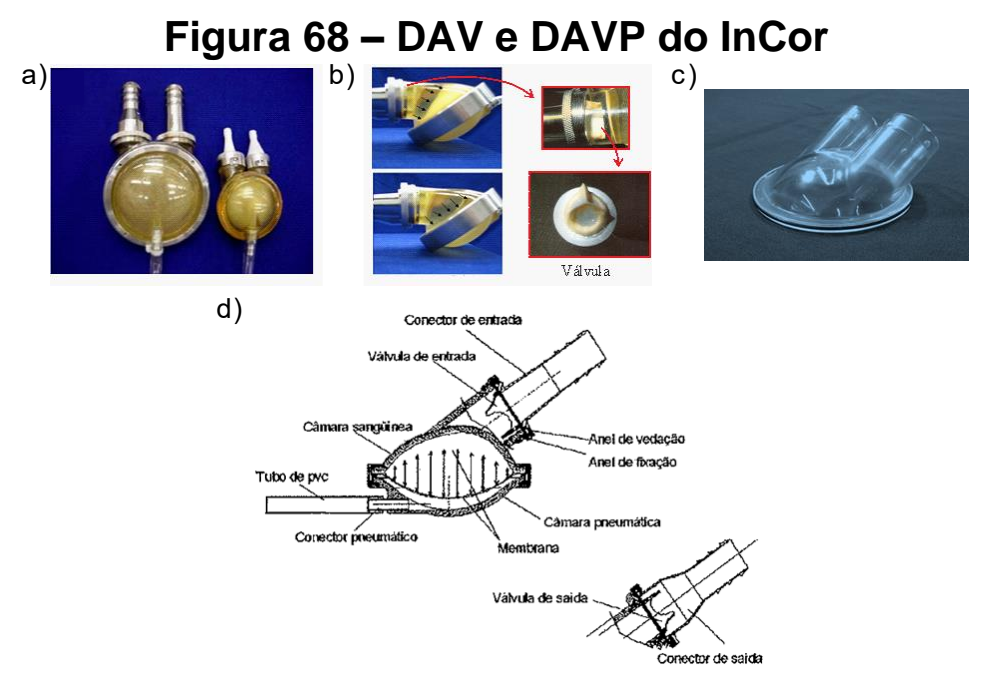

(a) DAV desenvolvido na Bioengenharia do InCor para adultos (DAV-InCor) e crianças (DAVPInCor); (b) Vista lateral do DAV-Incor com movimento da membrana flexível e detalhe da válvula; (c) Câmara sanguínea do DAVP; (d) Partes construtivas do DAV/DAVP. Fonte: Adaptado de Galantier (2007), Cestari (2017) e Ferrara (2005). 
A carcaça do dispositivo é feita de poliuretano (PU) vegetal transparente rígido, adequado para a inspeção visual permanente, revestido de uma camada de elastômero termoplástico de poliuretano (ChronoFlex® $A R$ ), um material biocompatível e bioresistente (ADVANSOURCE BIOMATERIALS, 2011). O diafragma é composto por poliuretano flexível reforçado internamente com uma tela ou carregada com grafeno, ambos para conferir maior resistência e durabilidade durante as expansões e contrações. A fim de garantir que os materiais da unidade de bombeamento sejam os mesmos, o diafragma é revestido com o mesmo elastômero termoplástico de poliuretano utilizado na carcaça para evitar reações adversar no sangue. Por sua vez, as válvulas de entrada e saída, são do mesmo modelo, 21AJ501 produzido pela St. Jude Medical com diâmetro interno de 16,7 mm (ST. JUDE MEDICAL, 2012). Esta válvula artificial possui dois folhetos (Figura 69b) que produzem três regiões por onde o sangue pode escoar. Os ângulos de abertura e fechamento dos folhetos são 59ํ e 85으 (Figura 69c). As demais partes construtivas da válvula estão marcadas na Figura 69a.

Figura 69 - Detalhes da válvula 21 AJ-501

a)

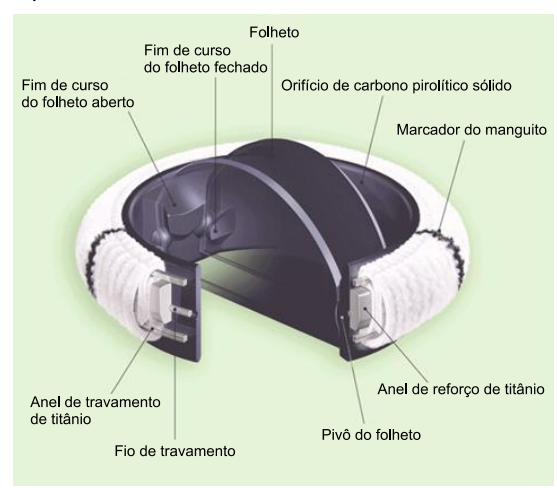

b)

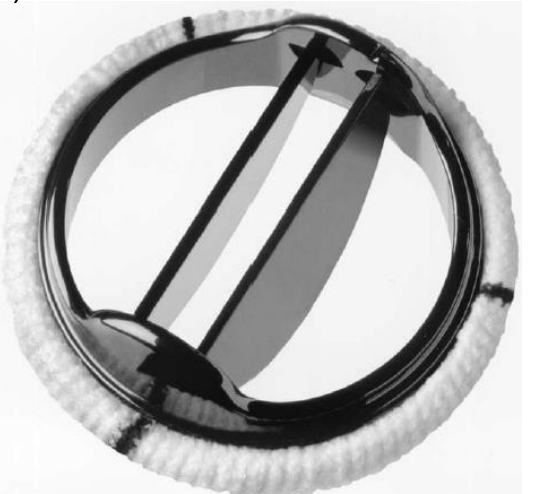

c)

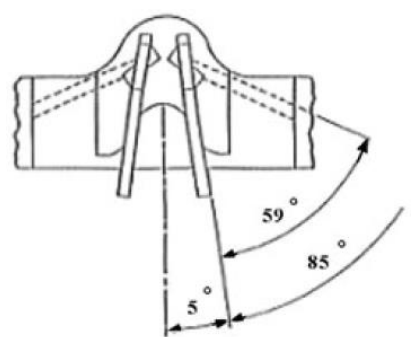

a) Detalhes construtivos de uma válvula de dois folhetos, b) St Jude Medical Regent, c) Ângulos de fechamento e aberta da válvula Regent. Fonte: Jaron et al. (2008), Bach et al. (2002) e Akutsu e Matsumoto (2010).

As válvulas apoiam-se sobre bases de aço inoxidável titânio. Estas bases possuem rosca onde parafusam-se os conectores, também de titânio, que ligam o DAVP ao paciente. Novamente, as partes metálicas recebem um banho de elastômero termoplástico de poliuretano. A estanqueidade do dispositivo é garantida por anéis de vedação, instalados entre cada um dos conectores e suas respectivas bases. As cânulas e o tubo pneumático são de policloroeteno (PVC) flexível, revestidas internamente com material biocompatível quando há contato com o sangue. 
A fim de facilitar as medições PIV e evitar refrações e reflexões da folha laser que pudessem causar erros nas medições, a geometria externa do DAVP foi alterada de um formato de calota esférica para uma cunha (Figura 70). A cunha possui faces retas e garantem que a folha de luz laser incida perpendicularmente por qualquer lado. Internamente a geometria da câmara sanguínea foi mantida, assim como toda a geometria da câmera pneumática. O material escolhido para a fabricação desta cunha foi o poliuretano transparente (Polytek® Poly-Optic $\AA$ 1411), devido às suas propriedades ópticas, por exemplo, transparência óptica na faixa do espectro visível, resistência a danos causados por laser, índice de refração próximo a 1,49 e transmitância na ordem de 90\% (POLYTEK DEVELOPMENT CORP., 2019). Além disso, este poliuretano possui boa usinabilidade, densidade de $1070 \mathrm{~kg} / \mathrm{m}^{3}$ e dureza Shore D80. A Tabela 7 apresenta um resumo de cada material empregado na fabricação do DAVP.

Tabela 7 - Materiais empregados no DAVP do InCor e no DAVP utilizado no PIV

\begin{tabular}{|c|c|c|c|}
\hline & Componente & Material & Medidas de interesse \\
\hline \multirow{5}{*}{ 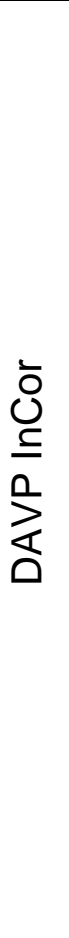 } & $\begin{array}{l}\text { Carcaça do } \\
\text { dispositivo }\end{array}$ & $\begin{array}{l}\text { Poliuretano revestido com } \\
\text { material biocompatível }\end{array}$ & $\begin{array}{l}\text { Diâmetro externo: } 65 \mathrm{~mm} \\
\text { Diâmetro interno: } 59 \mathrm{~mm} \\
\text { Diâmetro externo dos } \\
\text { canais valvulares: } 21 \mathrm{~mm}\end{array}$ \\
\hline & Diafragma & $\begin{array}{l}\text { Poliuretano, grafeno ou tela } \\
\text { interna, revestidos com } \\
\text { material biocompatível }\end{array}$ & - \\
\hline & Válvulas & $\begin{array}{l}\text { Folhetos e anel interno de } \\
\text { carbono pirolítico. } \\
\text { Estrutura do anel de titânio } \\
\text { e revestimento de tecido. }\end{array}$ & $\begin{array}{l}\text { Diâmetro do anel: } 21 \mathrm{~mm} \\
\text { Diâmetro interno da } \\
\text { válvula: } 16,7 \mathrm{~mm} \\
\text { Área do orifício: } 2,06 \mathrm{~cm}^{2} \\
\text { Área efetiva do orifício: } \\
1,51 \mathrm{~cm}^{2}\end{array}$ \\
\hline & $\begin{array}{l}\text { Base das válvulas } \\
\text { e conectores }\end{array}$ & Titânio & - \\
\hline & $\begin{array}{l}\text { Cânulas e tubo } \\
\text { pneumático }\end{array}$ & PVC flexível & \\
\hline \multirow{2}{*}{ 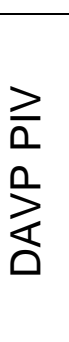 } & $\begin{array}{l}\text { Carcaça do } \\
\text { dispositivo }\end{array}$ & Poliuretano transparente & $\begin{array}{l}\text { Cunha } \\
\text { Altura: } 90,7 \mathrm{~mm} \text {; } \\
\text { Largura: } 81,7 \mathrm{~mm} \text {; } \\
\text { Comprimento: } 110,4 \mathrm{~mm} \text {. }\end{array}$ \\
\hline & Diafragma & $\begin{array}{l}\text { Poliuretano carregado com } \\
\text { grafeno }\end{array}$ & - \\
\hline
\end{tabular}




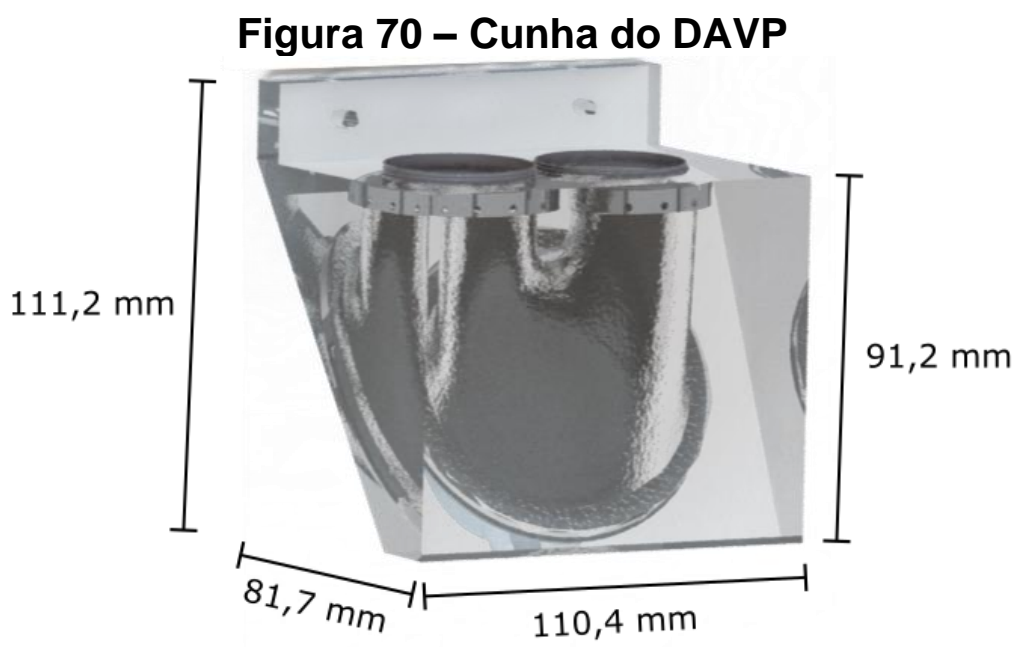

\subsection{O circuito de circulação simulada}

Por questões éticas e pela sensatez, os DAVs devem ser testados antes da utilização em seres humanos. A Food and Drug Administration (FDA), agência americana responsável pela saúde pública, estabelece que os DAVs sejam testados in vitro e in vivo. Os testes mais comuns in vitro e in vivo são os circuitos de circulação simulada (mock circulation loops - MCL) e os modelos animais, respectivamente. Ademais, os modelos numéricos, apesar de serem testes in silico, são úteis pois apresentam vantagens em relação aos outros dois (Tabela 8) e podem prever comportamentos antes dos experimentos. Na prática, todos os três modelos são utilizados para o desenvolvimento de DAVs (OCHSNER, 2014).

Neste trabalho, os experimentos com o DAVP foram realizados em um circuito de circulação simulada.

Esse circuito é vital para testar e desenvolver DAVs, válvulas cardíacas, corações artificiais, pulmões artificiais, enxertos vasculares e bombas de balão intraaórtico. Os modelos de circulação simulada apresentam vários níveis de complexidade, sempre buscando igualar os parâmetros hidrodinâmicos humanos, por exemplo, o débito cardíaco, as pressões sanguíneas, a pulsatilidade do fluxo, a resistência e inércia do fluxo, a contração atrial, os circuitos pulmonar e sistêmico, a inserção de dispositivos cardiovasculares, os defeitos no septo, a regurgitação das válvulas, a complacência (uma medida da resistência de um órgão oco ao recuo às suas dimensões originais com a remoção de uma força compressiva ou distensiva), entre outros. Os valores de frequência, fluxo e pressão fornecidos pelos MCLs são 
registrados por sensores. Todavia, para a FDA os MCLs não substituem os testes in vivo (GREGORY, 2009).

Tabela 8 - Vantagens e desvantagens dos testes de DAVs

\begin{tabular}{|c|c|c|c|}
\hline & Modelo Numérico & Circulação Simulada & Modelos Animais \\
\hline 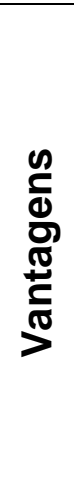 & $\begin{array}{l}\text { Ampla gama de } \\
\text { complexidade; } \\
\text { Repetibilidade absoluta; } \\
\text { Controle absoluta; } \\
\text { Alta flexibilidade e } \\
\text { modularidade; } \\
\text { Interpretação dos resultados } \\
\text { mais fácil; } \\
\text { Fácil compartilhamento. }\end{array}$ & $\begin{array}{l}\text { Ampla gama de } \\
\text { complexidade; } \\
\text { Alta repetibilidade; } \\
\text { Alto controle; } \\
\text { Modelagem completa } \\
\text { (p. ex., regurgitação } \\
\text { da válvula). }\end{array}$ & $\begin{array}{l}\text { Comportamento } \\
\text { fisiológico inerente; } \\
\text { Próximo ao ambiente } \\
\text { clínico. }\end{array}$ \\
\hline 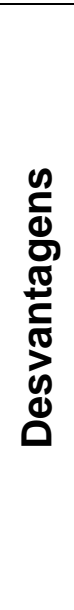 & $\begin{array}{l}\text { Muitos aspectos fisiológicos } \\
\text { são negligenciados; } \\
\text { Modelagem (p. ex., } \\
\text { turbulência, deslocamento } \\
\text { das ondas); } \\
\text { O hardware do VAD não } \\
\text { pode ser testado (apenas o } \\
\text { modelo numérico do VAD } \\
\text { pode ser testado). }\end{array}$ & $\begin{array}{l}\text { Pode ser complexo; } \\
\text { Modelagem (p. ex., } \\
\text { sensibilidade de pré- } \\
\text { carga do ventrículo); } \\
\text { A interpretação dos } \\
\text { resultados pode ser } \\
\text { difícil; } \\
\text { Efeitos indesejados } \\
\text { presentes (por } \\
\text { exemplo, golpe de } \\
\text { aríete da válvula). }\end{array}$ & $\begin{array}{l}\text { Demorado; } \\
\text { Eticamente } \\
\text { problemático. } \\
\text { Baixa repetibilidade; } \\
\text { Baixo controle } \\
\text { (patologia difícil de } \\
\text { modelar); } \\
\text { Resultados } \\
\text { específicos para } \\
\text { mamíferos. }\end{array}$ \\
\hline
\end{tabular}

Fonte: Adaptado de Ochsner, (2014).

O MCL utilizado nos experimentos possui acionamento eletropneumático e um circuito hidráulico. Durante os experimentos, a frequência foi controlada por um gerador de pulsos, cuja função é estabelecer a frequência de batimentos por minuto (bpm) do DAVP. Na ejeção do DAVP, o ar comprimido passa por um regulador de pressão e um capacitor pneumático até chegar na válvula solenoide 5/2 vias (Figura 71). O gerador de pulsos produz um sinal que muda a posição da válvula solenoide. Quando a tensão elétrica atinge zero volts $(0 \mathrm{~V})$, a bomba de vácuo succiona o ar da câmara pneumática do DAVP até atingir $-10 \mathrm{mmHg}$ de pressão estática, auxiliando o retorno do diafragma e o enchimento do dispositivo até o final da diástole. No início da sístole a tensão elétrica sobe para $12 \mathrm{~V}$, permanecendo assim até o final do período e permitindo a passagem do ar comprimido para encher a câmara do DAVP até atingir $240 \mathrm{mmHg}$ de pressão estática. 


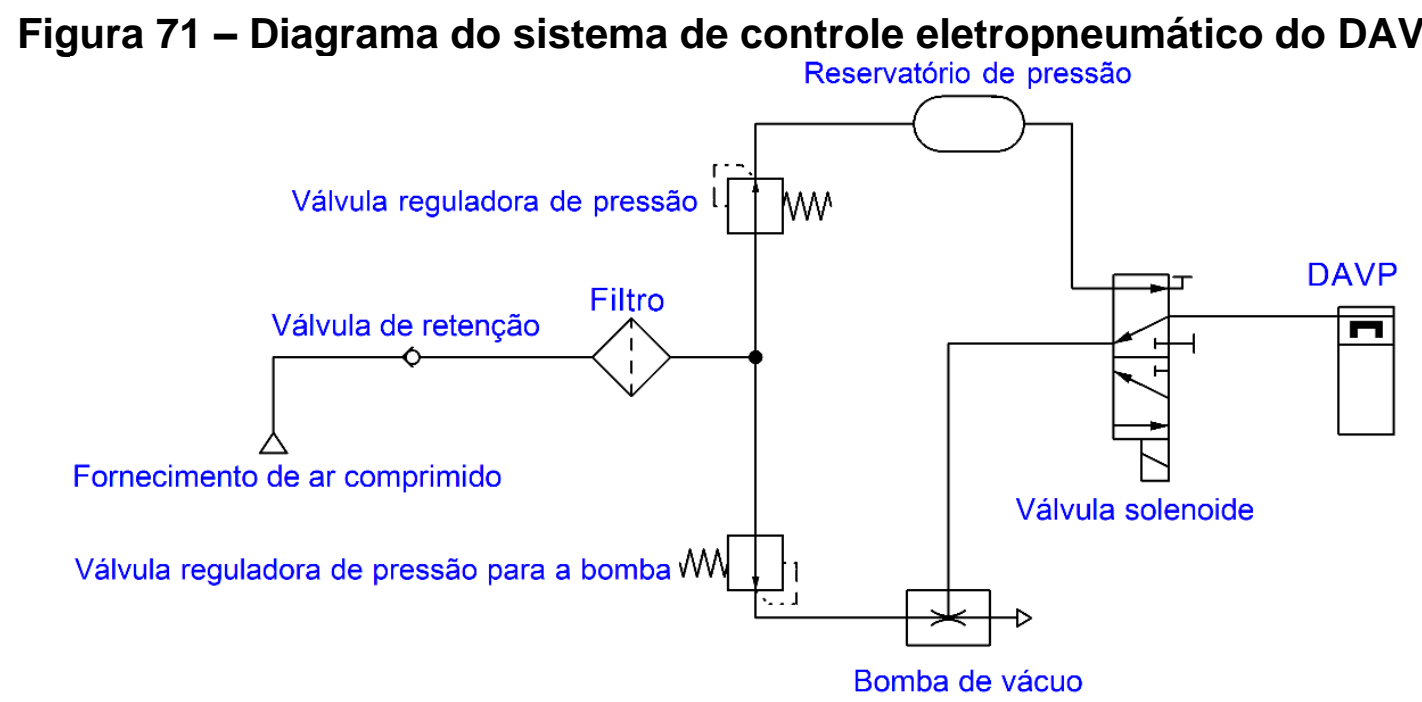

Os tempos de permanência em cada via da válvula determinam a duração da sístole e da diástole do DAVP, ou seja, o gerador de pulsos também controla a duração das duas fases do ciclo. Por exemplo, em $70 \mathrm{bpm}$ um ciclo possui um período de 857 ms e para que a sístole seja equivalente à um terço deste ciclo, a sua duração deve ser $260 \mathrm{~ms}$. O gerador de pulsos utilizado é capaz de reproduzir frequências entre 30 a 150 bpm com total controle da duração da sístole, 10\% a 100\% de duração, em toda a faixa. Os sinais de frequência foram registrados utilizando um sistema de aquisição DataQ DI-720 (DATAQ INSTRUMENTS, 2014).

O sistema hidráulico do MCL utilizado nos experimentos foi desenvolvido buscando atender as condições fisiológicas, em especial, as pressões sanguíneas, a complacência, a resistência hidráulica e a contração atrial para a circulação sistêmica de um adulto ou criança.

O MCL, ilustrado na Figura 72, possui uma câmara de complacência que simula o átrio esquerdo, permitindo a reprodução das grandezas fisiológicas das pressões entre 0 a $20 \mathrm{mmHg}$, tendo mantido durante o experimento uma pré-carga de $5 \mathrm{mmHg}$. A entrada do DAVP é conectada através de uma cânula à câmara de complacência atrial e sua saída é conectada a câmara arterial, que permite reproduzir as grandezas fisiológicas das pressões aórtica entre 10 a $250 \mathrm{mmHg}$, tendo mantido durante o experimento uma pós-carga sistólica de $120 \mathrm{mmHg}$ e diastólica de $80 \mathrm{mmHg}$. A saída desta câmara é conectada a um reservatório aberto para a atmosfera, representando o volume sistêmico de sangue. Entre estas câmaras é utilizado um clamp de Hoffman para ajustar a resistência sistêmica a passagem do sangue. A pressão pneumática foi medida por um transdutor de pressão e a pressão aórtica por um manômetro. 
Figura 72 - Esquema do MCL utilizado nos experimentos do DAVP

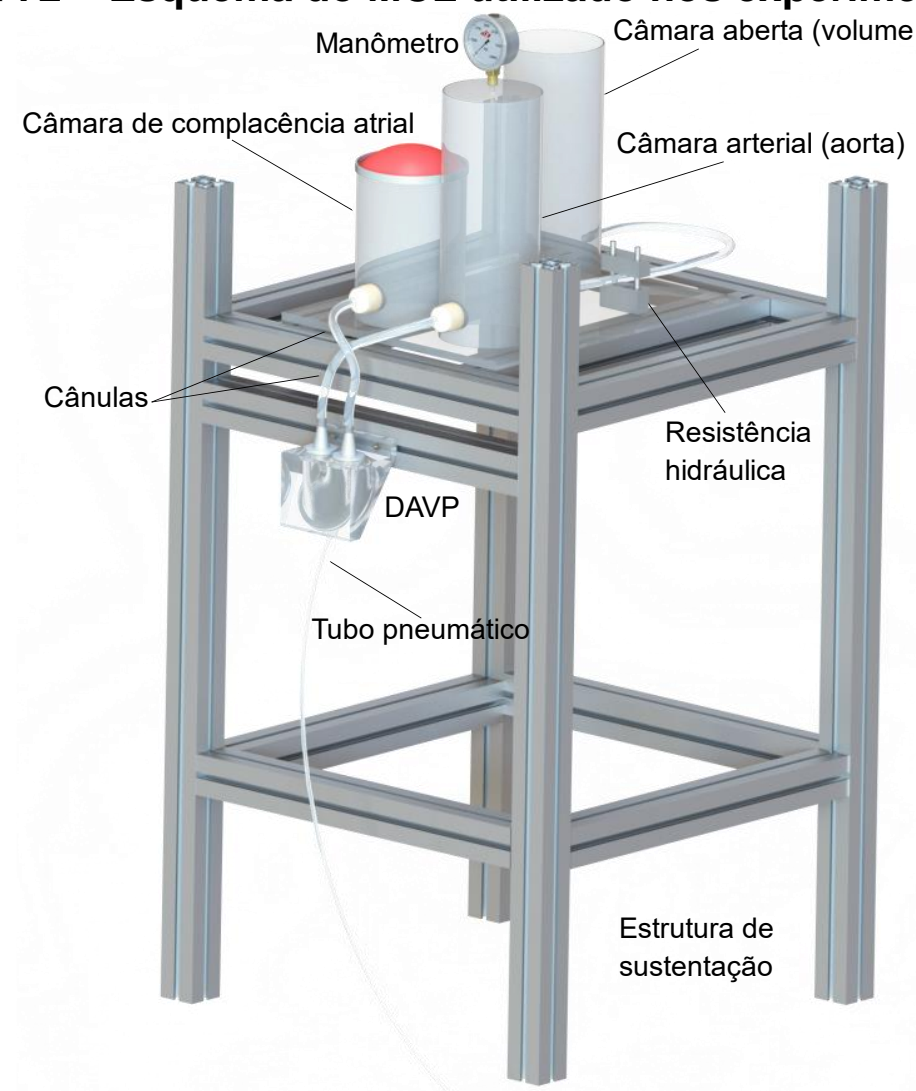

Outros parâmetros configurados no $\mathrm{MCL}$ foram a frequência de batimento do DAVP em 70 bpm e a duração sistólica de 260 ms (30\% do ciclo), ambas mantidas constantes em todos os casos. Além disso, o tempo entre o final da diástole e o início da sístole, chamado de atraso diastólico final (End Diastolic Delay - EDD), foi utilizado. No caso de dispositivos eletromecânicos, o atraso ocorre devido à diferença entre a ação do sinal elétrico na válvula solenoide e a inércia mecânica do fluido dentro do dispositivo (GALLAGHER, 2017). Portanto, o EDD é calculado como o tempo entre o momento em que sinal elétrico do solenoide atinge o valor $12 \mathrm{~V}$ - definido como o início do período - e o momento que a pressão da câmara sanguínea começa a subir. O EDD foi pensando para prolongar a durabilidade do dispositivo e do sistema, acomodando a inércia entre as câmaras sanguínea e pneumática no momento do sinal elétrico (ZHU et al., 2019). O mesmo raciocínio é válido para o atraso sistólico final. Os valores de EDD e atraso sistólico final utilizados foram $44 \mathrm{~ms}$ e $14 \mathrm{~ms}$ respectivamente.

Após a configuração de todos os parâmetros no sistema de circulação simulada, foi possível traçar as curvas de pressão, vazão e tensão elétrica do 
dispositivo de maneira semelhante ao Diagrama de Wiggers do coração humano (Figura 73). As pressões da aorta, do átrio esquerdo e das câmaras sanguínea e pneumática estão na parte superior do gráfico. Logo abaixo, está a curva de vazão do dispositivo e na parte inferior do gráfico está a tensão elétrica da válvula solenoide que controla a ação do ar comprimido e do vácuo na câmara pneumática. As linhas pretas verticais e tracejadas representam as mudanças entre os períodos do ciclo e a linha vermelhas verticais e tracejadas representam as mudanças na pressão após 0 início do novo período. Assim sendo, $\Delta \mathrm{t}_{1}$ representa o EDD e $\Delta \mathrm{t}_{2}$ representa o atraso sistólico final.

Figura 73 - Diagrama de Wiggers do DAVP do InCor
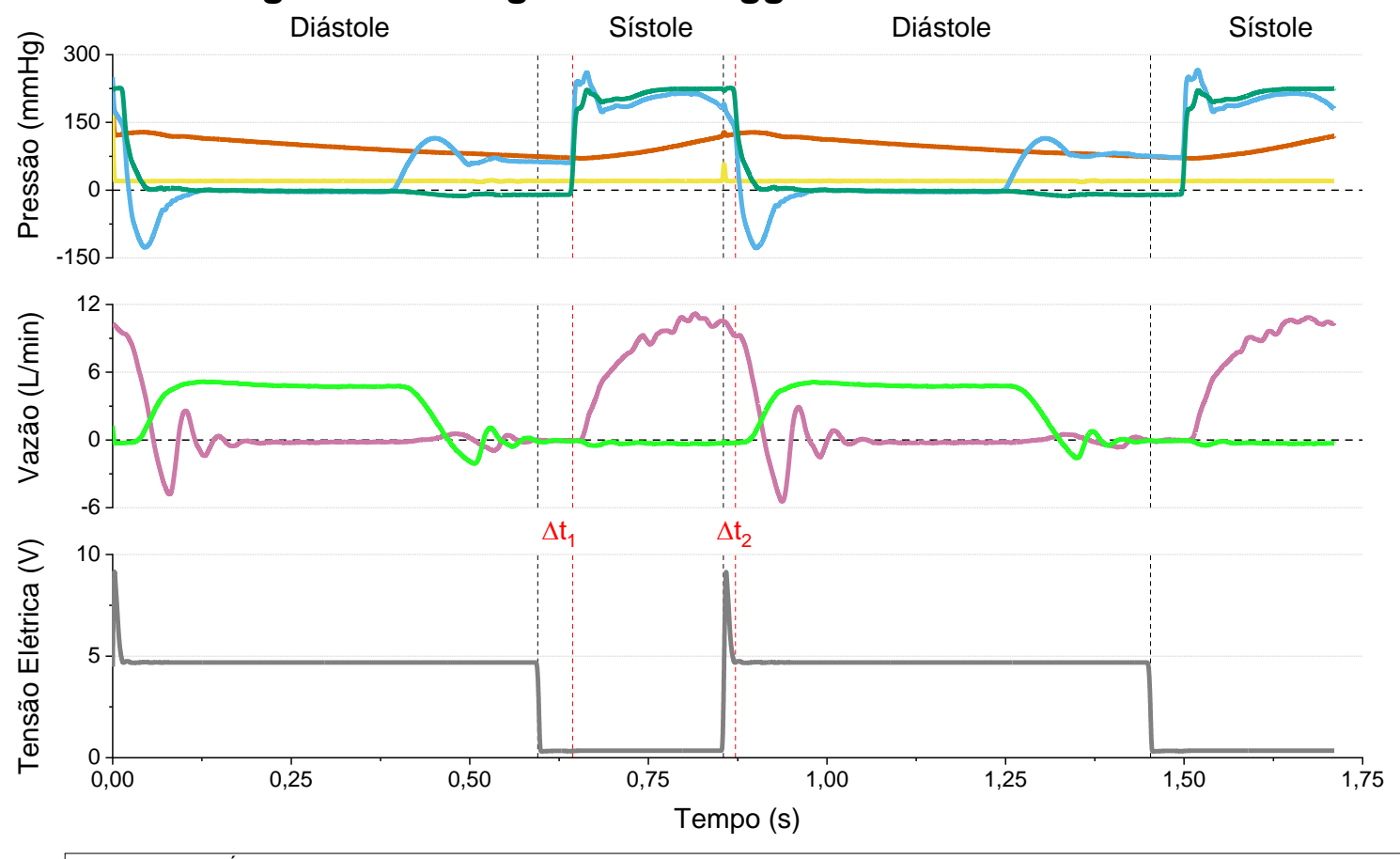

— Aorta — Átrio esquerdo — Câmara sanguínea —Câmara pneumática — Saída do DAVP — Entrada do DAVP — Solenoide

Observa-se também na Figura 73 o efeito das válvulas mecânicas na pressão e na vazão. Na curva de pressão da câmara sanguínea há um pico logo após a marcação de $\Delta \mathrm{t}_{1}$ que logo cai para a pressão normal de sístole. A causa deste pico está no momento de fechamento da válvula de entrada do DAVP. Quando a pressão se eleva no início da sístole, a válvula de folheto duplo da entrada do dispositivo se fecha, mas logo em seguida abre novamente, semelhante a um efeito ricochete, e por fim fecha-se definitivamente. Este fenômeno observado durante o fechamento da válvula causa os picos na pressão, mais aparentes na sístole, mas também presente no fechamento da válvula de saída durante a diástole (KINI et al., 2001). Já na vazão 
o fenômeno mais aparente é regurgitação das válvulas mecânicas. Dá-se o nome de regurgitação ao fluxo que segue em sentido contrário ao esperado, sendo dividido em dois períodos nas válvulas: fechamento e vazamento. O período de fechamento (Figura 74B) propicia o retorno de fluido pelas válvulas, geralmente ao fim de um período do ciclo de batimento, quando as válvulas estão se fechando. Já o período de vazamento (Figura 74C) ocorre após o fechamento das válvulas e o fluido que não deveria escoar por elas acaba fluindo pelas fendas entre os folhetos e as sedes (DAVIS, 2018). O efeito da regurgitação é mais visível entre as mudanças de período dos batimentos e está sempre presente neste tipo de válvula mecânica (FLACHSKAMPF et al., 1991).

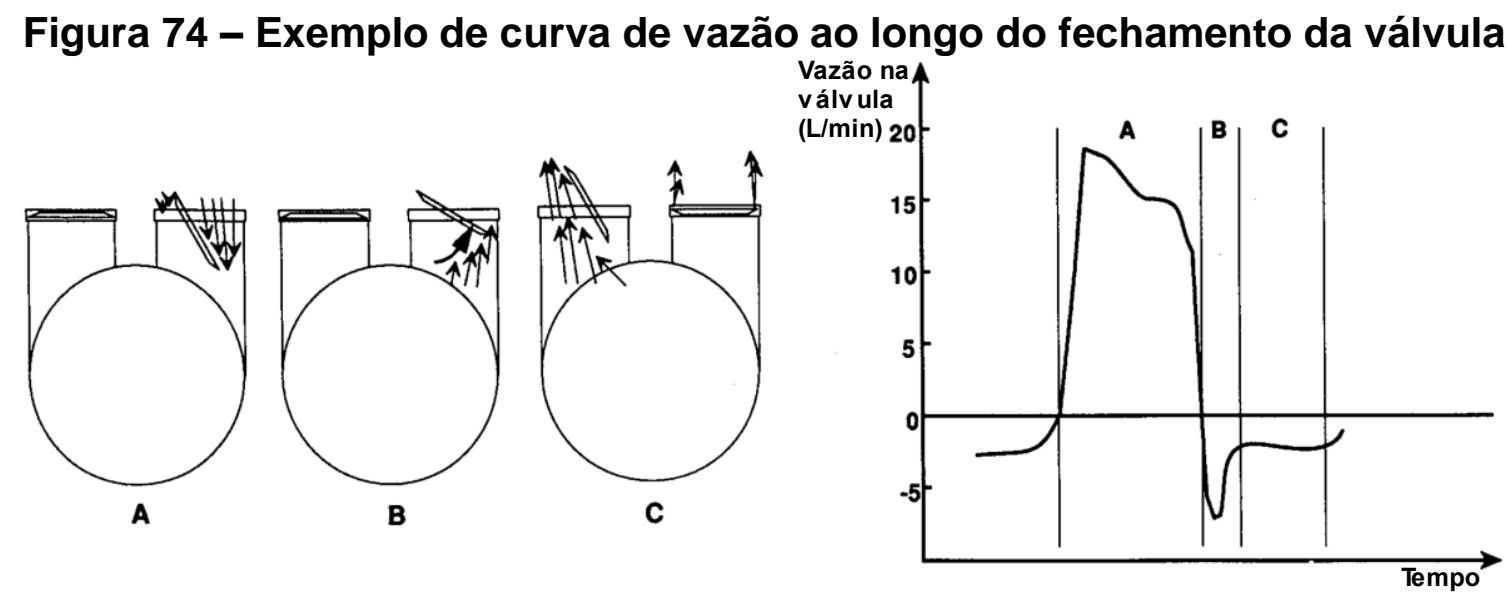

Fonte: Adaptado de Lamson et al. (1993).

O fluxo interno dentro das bombas é complexo, depende do tempo e possui tridimensionalidade. Portanto, o tipo de escoamento dentro do DAVP do InCor é importante para a análise pois conhecendo se o regime é laminar, de transição ou turbulento, determinadas variáveis tornam-se mais interessantes do que outras. Por exemplo, no regime laminar não é tão interessante medir parâmetros relacionados à turbulência como as tensões turbulentas. Diante disto, os parâmetros adimensionais independentes fornecem mais detalhes sobre as condições do escoamento, destacando-se o número de Reynolds (Re), já apresentado na Eq. (8) e o número de Strouhal (St):

$$
S t=\frac{f L}{u_{c}}
$$


Em que $f$ é a frequência, $L$ é o comprimento característico e $u_{c}$ é a velocidade média característica do escoamento. Assim como o número de Reynolds é importante para determinar o tipo de escoamento, o número de Strouhal descreve mecanismos de fluxo oscilante, como ocorre no DAVP. Ademais, dispositivos diferentes possuem formas de onda semelhante, sendo suficientes estes dois parâmetros adimensionais para compará-los. A maior turbulência dos dispositivos é encontrada durante o enchimento, como afirmado por Bachmann et al. (2000), logo, o comprimento característico é igual ao diâmetro da válvula de entrada $\left(\mathrm{d}_{\mathrm{e}}\right)$ e o período característico (T) é definido como:

$$
T=\frac{D_{\%}}{f}
$$

Sendo $\mathrm{D} \%$ o valor da diástole percentualmente no ciclo do dispositivo. Sabe-se que a vazão de enchimento $(Q)$ é função da frequência de batimento e do volume sistólico (VS), bem como também é função da velocidade característica pela área em que essa velocidade passa. Sendo assim:

$$
\begin{gathered}
Q=f \cdot V S \\
Q=D_{\%} \cdot u_{c} \cdot\left(\frac{\pi \cdot d_{e}^{2}}{4}\right)
\end{gathered}
$$

Substituindo a Eq. (36) na Eq. (37), encontra-se o valor de $u_{c}$ :

$$
u_{c}=\frac{4 \cdot f \cdot V S}{\pi \cdot d_{e}^{2} \cdot D_{\%}}
$$

Substituindo as variáveis uc, L e T encontradas nas Eq. (35) e Eq. (38) nas equações de número de Reynolds (Eq. (8)) e de Strouhal (Eq. (34)) chega-se a:

$$
R e=\frac{4 \cdot f \cdot V S}{v \cdot \pi \cdot d_{e} \cdot D_{\%}}
$$




$$
S t=\frac{4 \cdot V S}{\pi \cdot d_{e}^{3}}
$$

A duração sistólica nos experimentos a 70 bpm no DAVP foi de $260 \mathrm{~ms}$, o que representa $30 \%$ de todo o ciclo. O diâmetro de entrada é dado pela válvula: $16,4 \mathrm{~mm}$. A viscosidade cinemática do sangue é $3,8 \times 10^{-6} \mathrm{~m}^{2} / \mathrm{s}$. Com isto, o Re e St foram calculados para o dispositivo que é comparado com outros modelos na Tabela 9.

Tabela 9 - Valores de Re e St para os dispositivos incluindo o DAVP InCor
\begin{tabular}{l|r|r|r}
\hline Tamanho do dispositivo & Reynolds & Strouhal & Frequência (bpm) \\
\hline Penn State $70 \mathrm{~mL}$ & 2482 & 8,3 & 70 \\
\hline Penn State $50 \mathrm{~mL}$ & 1054 & 4,5 & 70 \\
\hline Penn State $15 \mathrm{~mL}$ & 1567 & 45,3 & 70 \\
\hline Yonsei $34 \mathrm{~mL}$ & 1500 & 7,7 & 70 \\
\hline InCor $30 \mathrm{~mL}$ & 1026 & 8,7 & 70 \\
\hline Toyobo $20 \mathrm{~mL}$ & 988 & 6,3 & 70 \\
\hline Berlin Heart $12 \mathrm{~mL}$ & 785 & 8,8 & 70 \\
\hline MEDHOS-HIA 10 mL & 655 & 7,4 & 70 \\
\hline
\end{tabular}

Fonte: Adaptado de Bachmann et al. (2000) e Deutsch et al. (2006).

O dispositivo mais próximo em dimensões ao DAVP do InCor é o Yonsei 34 $\mathrm{mL}$. Comparando ambos, as diferenças não são consideráveis, mas o DAVP do InCor possui número de Reynolds menor e número de Strouhal maior.

\subsection{Aquisição dos dados}

O sistema PIV é composto pelo escoamento com partículas traçadoras, iluminação, gravação, calibração e processamentos. O fluido utilizado foi uma mistura de $60 \%$ de soro fisiológico com $40 \%$ de glicerina. Ao fluido foram adicionadas partículas de poliamida com $30 \mu \mathrm{m}$ de diâmetro. Este líquido possui propriedades como viscosidade dinâmica de 3,3 × 10-3 Pa.s, densidade de $1100 \mathrm{~kg} / \mathrm{m}^{3}$ e índice de refração de 1,41. Estas propriedades do fluido utilizado são bem próximas aos valores encontrados no sangue: viscosidade dinâmica entre $(3 \sim 4) \times 10^{-3}$ Pa.s e densidade de $1060 \mathrm{~kg} / \mathrm{m}^{3}$ (GOSLINGA, 1984).

Prosseguindo, o sistema de iluminação utilizado consistia de um laser de estado sólido bombeado por diodo (Diode-Pumped Solid-State - DPSS) do tipo 
Nd:YLF (Neodymium-doped Yttrium Lithium Fluoride ou fluoreto de ítrio e lítio dopado com neodímio) com duplicador de frequência (geração de segundo harmônico), alta taxa de repetição e dupla cavidade (Litron Lasers Ltd, LDY304). As características do laser são: comprimento de onda $527 \mathrm{~nm}$, taxa de repetição (frequência) de 0,2 a 20 $\mathrm{kHz}$, energia de $30 \mathrm{~mJ}$ a $1 \mathrm{kHz}$ e diâmetro do faixo de $5 \mathrm{~mm}$ com divergência menor que 3 mrad (LITRON LASERS, 2016).

Para criar o plano iluminado no DAVP utilizou-se um conjunto de ópticas planas apenas na primeira cabeça do laser, já que as medições foram realizadas em single frame. Ademais, a frequência do laser foi configurada para $3250 \mathrm{~Hz}$ produzindo uma energia de aproximadamente 12,6 mJ (Figura 75a).
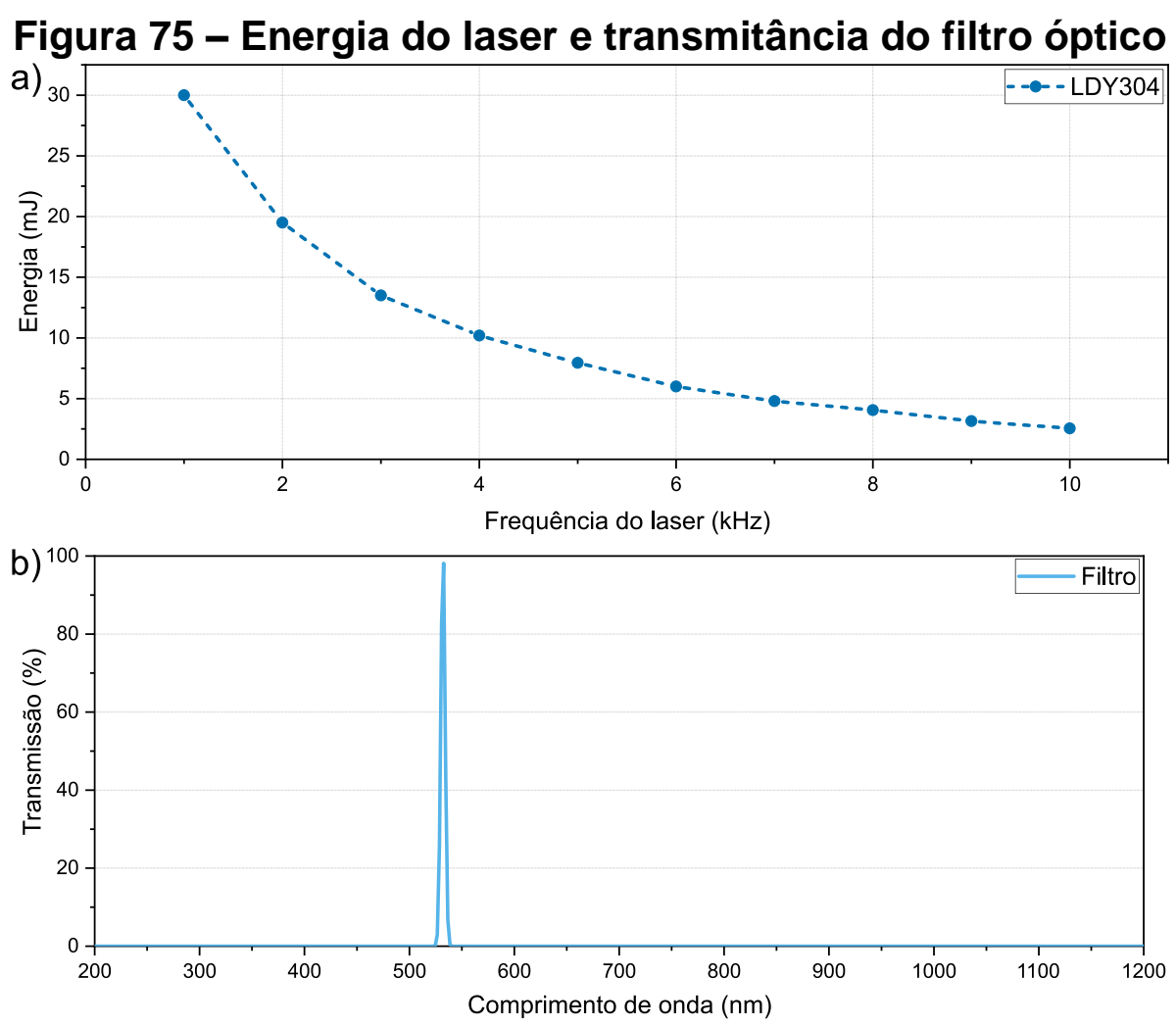

Fonte: Adaptado de Litron Lasers (2016) e Edmund Optics (2017).

Para gravar as imagens, utilizou-se uma câmera do tipo CMOS (Vision Research, Phantom ${ }^{\circledR}$ Miro $®$ R311) com tamanho do sensor de 1280 x 800 px, sensor com dimensões de 25,6 x 16,0 mm e 1 Mpx, tempo de exposição mínimo de $1 \mu \mathrm{s}$ e frequência máxima na maior resolução de 3200 fps (VISION RESEARCH, 2016). Um conjunto de lente e filtros foram utilizados para evitar ruídos. A objetiva, possui as seguintes propriedades como ângulo de visão de 23,3ํㅡ, abertura mínima de f/32, 
distância focal mínima de 0,313 m e máxima de 0,58 m e magnificação variando de 1:1 a 1:4 (Macro) (SIGMA CORPORATION, 2012). O filtro utilizado é do tipo passa banda de $532 \mathrm{~nm}$ revestido com uma superfície dura, com largura à meia altura (Full Width at Half Maximum - FWHM) de $5 \mathrm{~nm}$, absorbância (absorbance ou Optical Density - OD) com valor mínimo de 4 e transmitância mínima maior que $85 \%$, como observado na Figura 75b (Edmund Optics Inc., 532nm CWL, 50mm Dia., Hard Coated OD 4.0 5nm Bandpass Filter) (EDMUND OPTICS, 2017).

A câmera registra as imagens em sua memória interna, que a $3250 \mathrm{~Hz}$ e 1280 $x 800$ px de tamanho de sensor consegue armazenar aproximadamente 2,3 segundos. Posteriormente, as imagens são transferidas da memória da câmera para o disco rígido onde serão processadas.

A calibração foi realizada por meio de pontos com tamanho e distâncias conhecidas a fim de obter-se a resolução do experimento em $\mathrm{px} / \mathrm{mm}$. $\mathrm{O}$ alvo de calibração também foi utilizado para compensar as distorções ópticas causadas pela geometria interna do dispositivo. Entretanto, o presente trabalho não irá detalhar esse procedimento uma vez que o mesmo está vinculado ao pedido de patente na agência USP de inovação (AUSPIN) pelo identificador CC-PI-2019-0077.

Para sincronizar o laser, a câmera e o DAVP utilizou-se um gerador de pulsos e atraso (Berkeley Nucleonics Corp (BNC), Model 575) com amplitude de 0 a 1000 segundos e resolução de 250 os (BERKELEY NUCLEONICS CORP (BNC), 2013). O sistema de circulação simulada envia um sinal, na forma de onda quadrada, quando a pressão máxima foi atingida pelo diafragma. Este sinal é recebido pelo gerador de pulsos e atraso e então envia o sinal para os disparos do laser e subsequentemente da câmera, dentro dos intervalos especificados (Figura 76).

Figura 76 - Sincronização do experimento

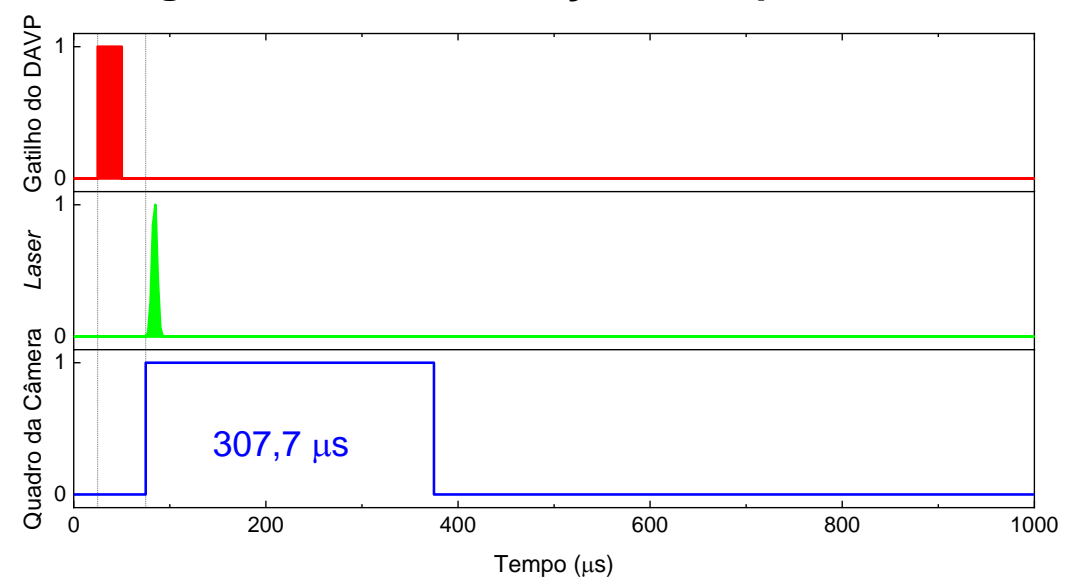




\subsection{Processamento dos dados}

O pré-processamento PIV foi realizado de acordo com os procedimentos na Figura 77. A imagem bruta passa pelo filtro espacial de desvio padrão de $3 \times 3$ pixels. O intuito deste filtro é remover o ruído de fundo e excluir as partículas que estavam fora da faixa, neste caso, as partículas maiores que 3 px de diâmetro. Depois disso aplicou-se três vezes o filtro gaussiano de $3 \times 3$ pixels considerando o desvio padrão $(\sigma)$ igual a 0,3. Este filtro foi utilizado para melhorar o formato da partícula na imagem. Em seguida, o filtro de subtração pelo mínimo local (subtraction sliding minimum) de $50 \times 50$ pixels foi aplicada a imagem. A função deste filtro é remover a iluminação de fundo da imagem. Após este passo, para evitar uma contribuição desigual de luminosidade das partículas mais iluminadas com relação às mais escuras, o método apresentado por Shavit, Lowe e Steinbuck (2007) como limite de intensidade (intensity capping) foi utilizado. O último passo do pré-processamento consistiu em outro filtro gaussiano de $3 \times 3$ pixels e $\sigma=1$.

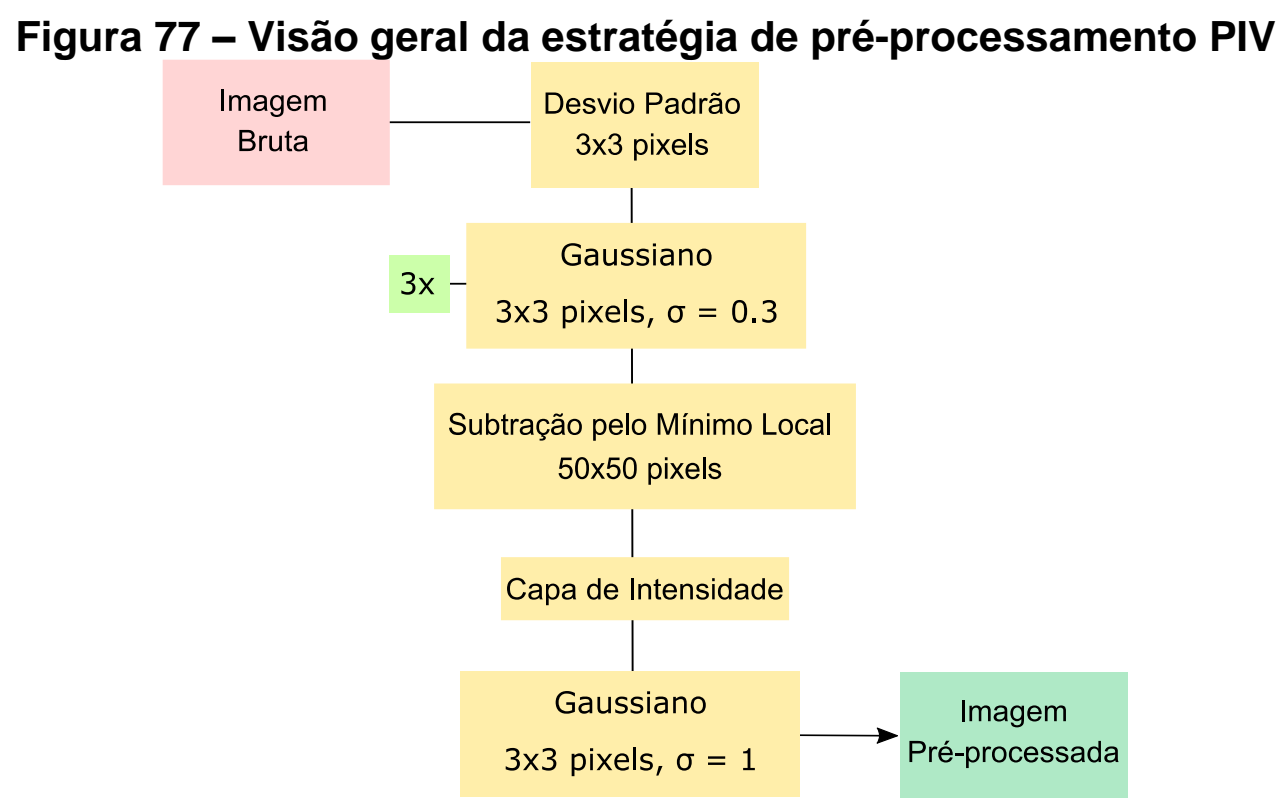

O processamento e pós-processamento PIV utilizado é apresentado na Figura 78. As estratégias da análise multigrid propostas por Scarano (2002) e Kim e Sung (2006) em que o tamanho da janela de interrogação é progressivamente diminuído, foi utilizado. Esse processo elimina a restrição de regra de um quarto. Na correlação, a standard cross correlation (SCC) foi analisada com método de deformação da 
imagem e o tamanho da janela de interrogação inicial e final foi de 32 e 15 pixels com $25 \%$ de sobreposição para todos os casos. Em relação ao método de deformação, a função de interpolação cardinal baseada na função sinc (HALL, 1979) foi adotada para reconstruir os valores da imagem em localizações de subpixel. Nesse caso, foi definido o número de iteração mínimo e máximo de 2 e 3, respectivamente. Na análise multigrid, foram utilizados 4 passos na interrogação em que a resolução espacial de cada passo (tamanho da janela por $25 \%$ de sobreposição) foi gradativamente diminuída em $25 \%$

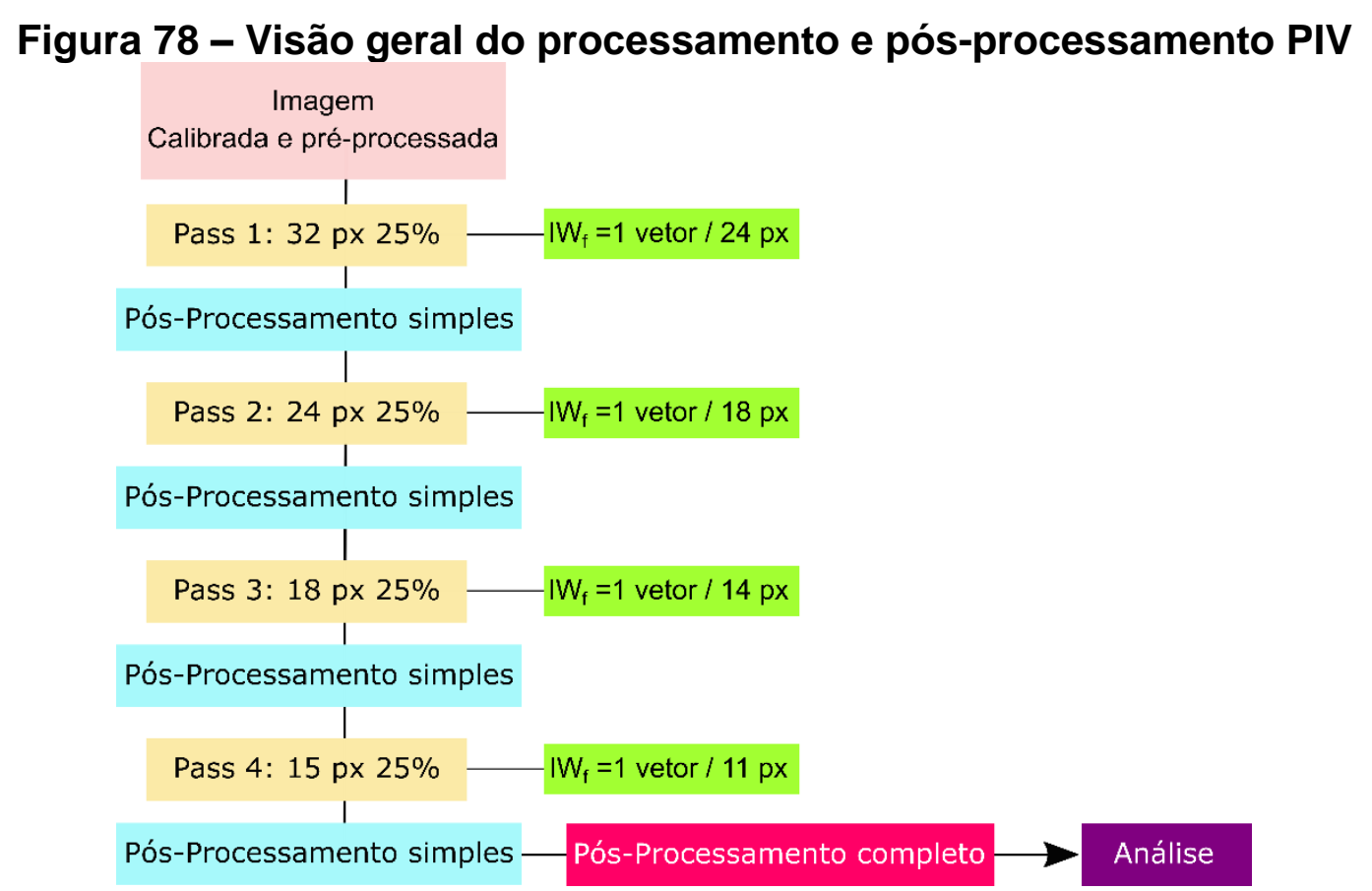

No final de cada passo, um pós-processamento simples foi utilizado para eliminar os outliers evitando instabilidades e propagação de ruído na abordagem multigrid. Nesse pós-processamento simples, a abordagem desenvolvida por Westerweel e Scarano (2005) foi usado para reduzir principalmente os outliers nos campos. Baseado na análise dos autores, um limiar de remoção de 2 (adequado para detectar vetores falsos) em uma vizinhança de $3 \times 3$ pixels foi utilizado. Além disso, todos as velocidades com $\mathrm{SNR}<1,2$ foram excluídos e interpolados pela média da vizinhança.

No pós-processamento completo, todos as velocidades com $\mathrm{SNR}<1,3$ foram excluídos e uma interpolação baseada na abordagem shape-preserving piecewise cubic spline interpolation (FRITSCH e CARLSON, 1980) foi usada. Além disso, foi 
utilizado o método do desvio absoluto médio (Median Absolute Deviation, MAD) em uma vizinhança $3 \times 3$ de janelas de interrogação para identificar outliers. Nesse caso, são considerados outliers os valores de velocidade na janela de interrogação maior do que 3 vezes a escala MAD. Essa escolha é baseada nas observações de (MILLER, 1991). Mais precisamente, a escala MAD é definida pela Equação (41) em que $b=$ 1,4826 (HUBER e RONCHETTI, 2009). Os outliers identificados pela abordagem MAD são excluídos e uma interpolação baseada na abordagem shape-preserving piecewise cubic spline interpolation foi usada. Um filtro temporal baseado no desvio padrão também foi utilizado para remover valores espúrios. Em uma análise prévia, foi observado que um outlier era detectado se seu valor fosse três vezes o desvio padrão da vizinhança com um núcleo igual a três vezes o intervalo para uma mesma janela de interrogação.

$$
M A D=b \cdot M_{i}\left(\left|x_{i}-M_{j}\left(x_{j}\right)\right|\right)
$$

\subsection{Análise dos dados}

O fluxo dentro do DAV apresenta comportamento periódico, variando entre períodos de sístole e diástole. Dentre esses períodos, ocorrem as variações ciclo a ciclo, que alteram os valores das velocidades em determinados instantes. Soma-se a isto outros fatores como o ruído PIV e a turbulência que são processos estocásticos, ou seja, possuem várias variáveis aleatórias que as governam. Em resumo, as velocidades instantâneas medidas pela técnica PIV nunca são iguais entre as sístoles e as diástoles de um mesmo experimento. Para diminuir a incerteza das medições, idealmente não se deve discutir um único evento em um determinado momento ou posição, mas sim a valores médios dentro de um único intervalo de tempo, denominado média temporal, ou valores médios de muitos sistemas idênticos em um mesmo instante de tempo, denominado média de conjunto (YAMAMOTO, 2015). Enquanto a média temporal está diretamente ligada a experimentos, pois nem sempre é viável repeti-lo múltiplas vezes, a média de conjunto está relacionada com a função densidade de probabilidade. A Figura 79 representa graficamente um exemplo de sistemas $(1,2, \ldots, N)$ da variável $x$ em função do tempo com as respectivas médias temporal e de conjunto. 
Figura 79 - Representação da média temporal e da média de conjunto

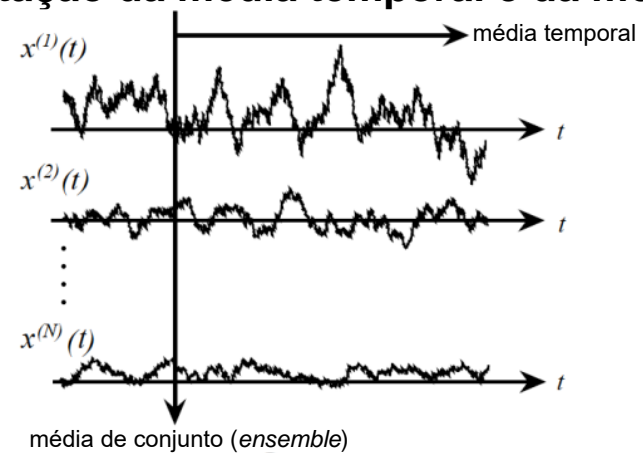

Fonte: Adaptado de Yamamoto (2015).

Neste trabalho apenas as médias temporais são utilizadas, denotadas pelo sinal diacrítico mácron $\left({ }^{-}\right.$) acima da variável, por exemplo, ū. A média de conjunto não foi calculada pois o número de ciclos necessários para se obter um valor confiável era muito superior ao espaço disponível em disco rígido.

O experimento montado com o DAVP, o circuito de circulação simulada e a aquisição de dados por PIV permite a obtenção de inúmeros resultados. Determinados resultados apresentam mais informações sobre o escoamento que outros, desta maneira deve-se estabelecer os parâmetros experimentais. Neste trabalho, a frequência de batimento do DAVP foi constante, $70 \mathrm{bpm}$, para todos os casos. Além disso, três planos de medição foram escolhidos. O plano frontal, mais afastado do diafragma, o plano médio e o plano traseiro. Estes planos possuem um ângulo de 36응 em relação ao diafragma e as distâncias estão representadas na Figura 80. No DAVP moldado dentro da cunha, este plano torna-se paralelo a face do dispositivo, facilitando o arranjo perpendicular entre o plano laser e a linha de visão da câmera.

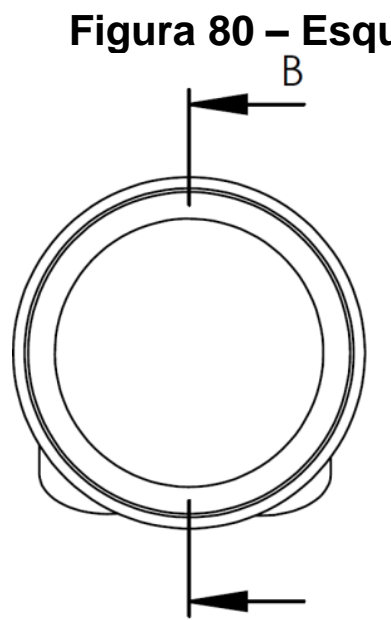

B

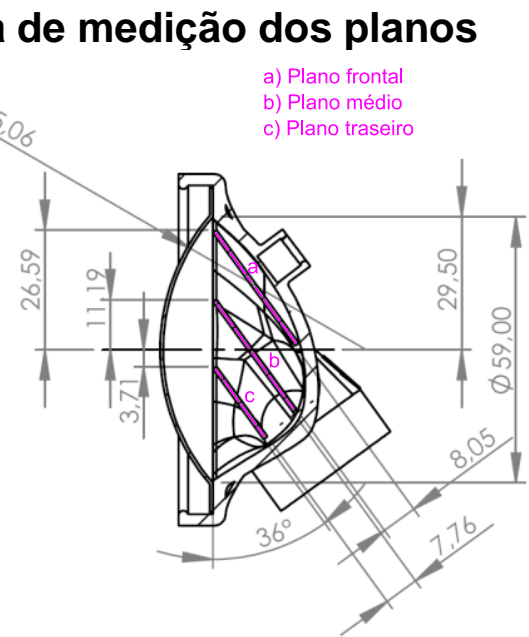

SEÇÃO B-B

Fonte: Instituto do Coração (2019). 
Mantidos o batimento do dispositivo a $70 \mathrm{bpm}$ e os planos de medição (frontal, médio e traseiro), a variável experimental modificada foi o ângulo da válvula de entrada: $0^{\circ}$ e $30^{\circ}$. O ângulo de $30^{\circ}$ foi escolhido devido ao seu uso no DAV e DAVP da Penn State, o que possibilita uma comparação entre velocidades e tensões encontradas neste trabalho (HOCHAREON et al., 2004; KREIDER et al., 2006; MANNING et al., 2008; NANNA et al., 2011; NAVITSKY, DEUTSCH e MANNING, 2013). Estes ângulos são medidos na vista superior tomando como base o eixo horizontal, tangente ao ponto máximo do diafragma ou no caso do DAVP dentro da cunha, paralelo a face dianteira (Figura 81).

a)

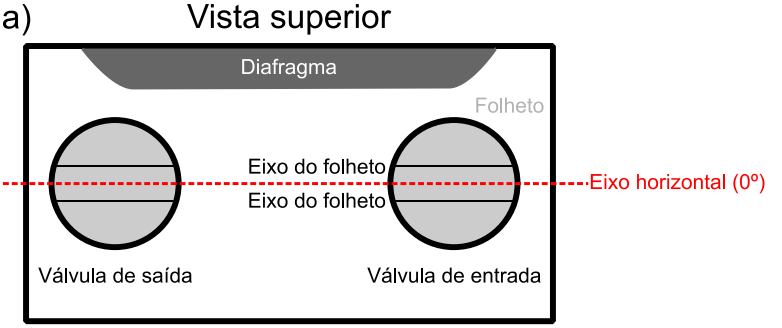

Figura 81 - Posição da válvula de entrada do DAV

b)

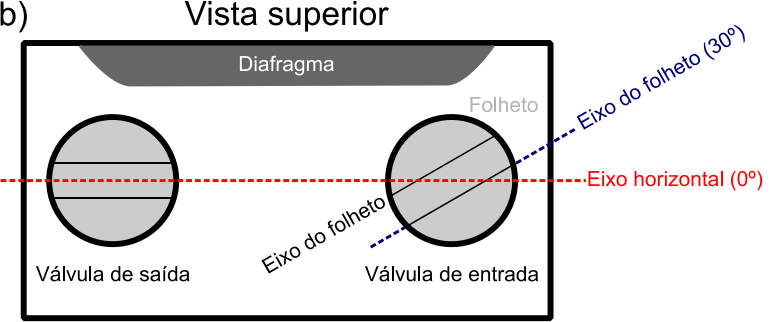

Durante os experimentos, vários ciclos do DAVP foram gravados com a técnica TR-PIV, todavia, nem todas as partes do ciclo possuem o mesmo nível de interesse. Uma prática comum em experimentos que utilizam PIV especialmente aqueles que não são capazes de gravar todo o ciclo, consiste na determinação de uma faixa de tempo de interesse. Em medições ópticas de DAV destacam-se dois trabalhos que estabeleceram faixas de tempo de interesse. O primeiro, de Jin e Clark (1993), dividiu o ciclo do DAV em seis tempos, a saber: $t_{1} 0$ início da ejeção, t2 o pico da ejeção, t $t_{3} 0$ intervalo entre a ejeção e o enchimento, $t_{4} 0$ enchimento, t 50 pico de enchimento e t6 o fim do enchimento. Os tempos foram baseados nas diferenças de pressão causadas pelo diafragma e pelas condições das válvulas, ou seja, uma delas aberta ou ambas fechadas. Por exemplo, t3 é definido como o momento em que ambas as válvulas do DAV estão fechadas em um ciclo isovolumétrico. Vale ressaltar que o início da sístole e da diástole nem sempre correspondem ao início da ejeção e do enchimento, respectivamente, pois as mudanças de pressão são mais rápidas quando comparado ao tempo necessário para retirar o fluido da inércia. A Figura 82a apresenta a divisão temporal do ciclo na curva da pressão e na curva de vazão. O segundo trabalho, de Navitsky, Deutsch e Manning (2013), dividiu o ciclo em oito partes, definidas como 
$7 \%, 35 \%, 64 \%$ e $92 \%$ da sístole e da diástole (Figura 82b). Novamente, a ideia é avaliar a evolução de cada parte do ciclo, com crescimento, pico, região de estabilização e decaimento. Baseado em ambos, o presente trabalho dividiu o ciclo em seis partes, três para a sístole e outras três para a diástole, a saber:
a) $t_{1}$, definida pela região de $0 \%$ a $20 \%$ da diástole, ou início do enchimento;
b) t2, definida pela região de $20 \%$ a $40 \%$ da diástole, ou o pico do enchimento;
c) $t_{3}$, definida pela região de 50 a $70 \%$ da diástole, ou final do enchimento.
d) $\mathrm{t}_{4}$, definida pela região de $0 \%$ a $20 \%$ da sístole, ou seja, início da ejeção;
e) $t_{5}$, definida pela região de $20 \%$ a $40 \%$ da sístole, ou o pico da ejeção;
f) t6, definida pela região de 80 a $100 \%$ da sístole, ou final da ejeção;

a)

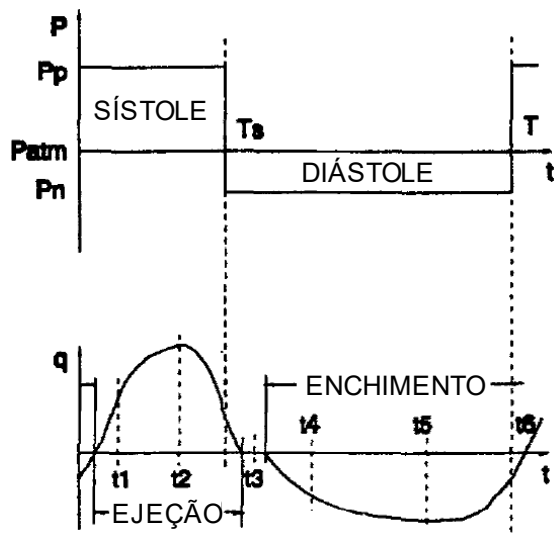

Figura 82 - Divisão temporal do ciclo do DAV

b)

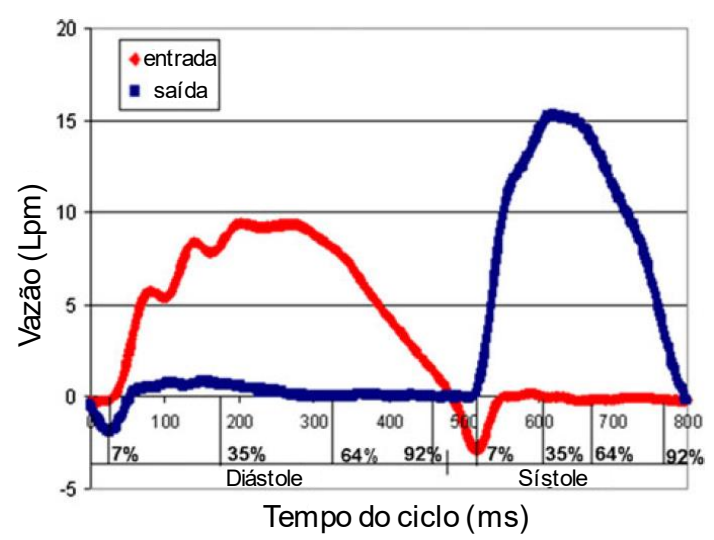

Fonte: Adaptado de Jin e Clark (1993), Navitsky, Deutsch e Manning, (2013).

Nos seis intervalos definidos serão extraídas oito variáveis médias (temporal) nos campos: velocidade em x ( $\bar{u})$, velocidade em y $(\bar{v})$, magnitude de velocidade $(|\bar{U}|)$, o valor eficaz da magnitude da velocidade $(|\bar{U}|$ rms $)$, a tensão de cisalhamento viscosa $(\overline{V S S})$, a tensão de cisalhamento de Reynolds $(\overline{R S S})$, a tensão de Reynolds máxima $\left(\overline{R S S_{\max }}\right)$ e a tensão de cisalhamento viscosa turbulenta $(\overline{T V S S})$. Complementando, outras três variáveis instantâneas com a respectiva evolução temporal são apresentadas: velocidade em $\times(\mathrm{u})$, velocidade em y $(\mathrm{v})$ e magnitude de velocidade $(|\mathrm{U}|)$. Contudo, essas variáveis não são apresentadas em todo o campo, nove pontos (P1 a P9) na região superior do dispositivo (Figura 83) foram escolhidos, sendo três na entrada, três no meio e três na saída, todas no plano médio.

A tensão de cisalhamento viscosa turbulenta (VSS) instantânea também é 
apresentada em determinados intervalos. Além disso, a abordagem do pseudorastreamento foi utilizada no VSS e RSS instantâneos. O pseudo-rastreamento (pseudo-tracking) é uma aproximação matemática considerada válida pois utilizou-se o TR-PIV, mas a aplicação da técnica de velocimetria por rastreamento de partículas (Particle Tracking Velocimetry, PTV) provavelmente resultaria em dados melhores. No PTV sabe-se exatamente, por meio de algoritmos, se uma partícula está dentro do plano ou se outra partícula foi iluminada devido à reflexão. Sem esta dúvida sobre o plano da partícula, elimina-se uma forma de ruído na correlação de imagens.

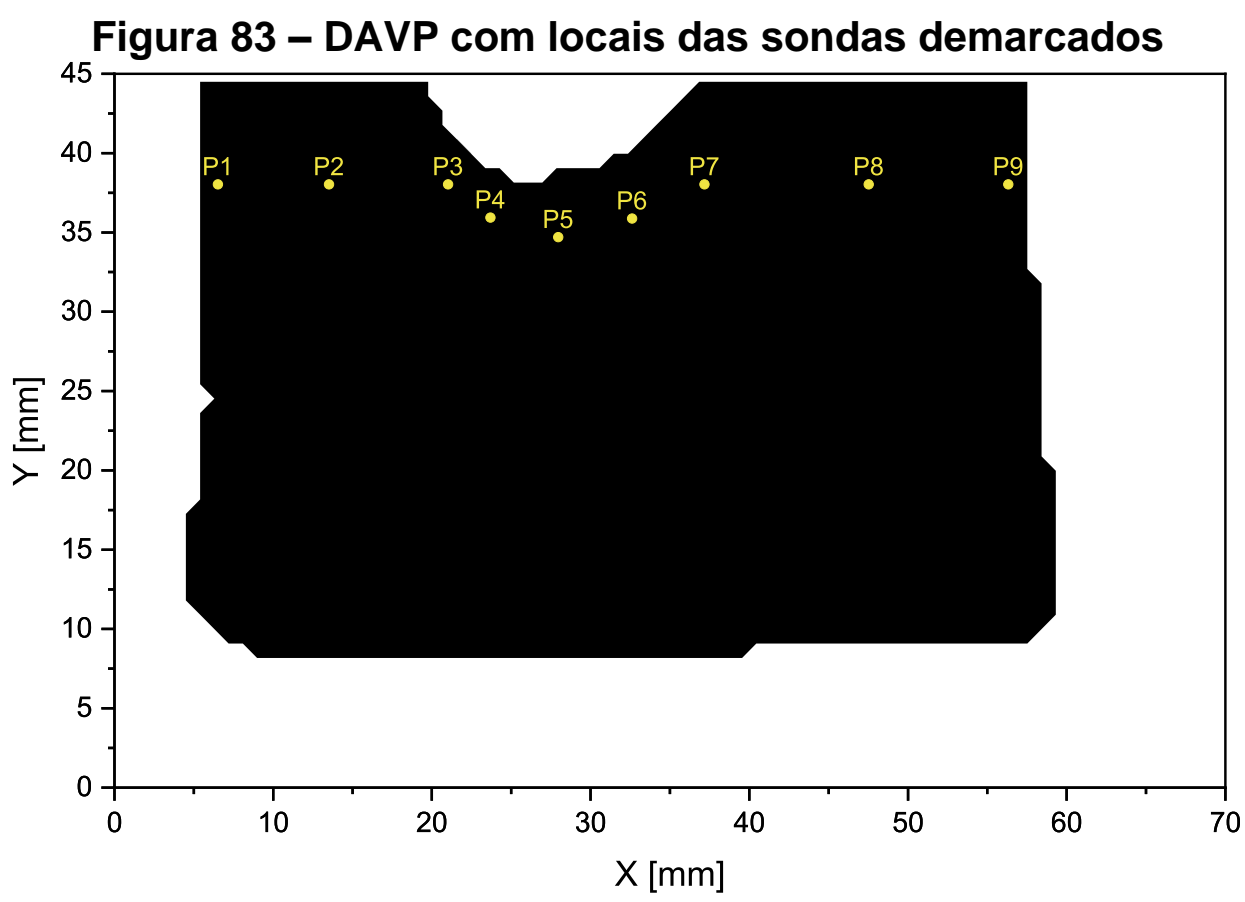




\section{RESULTADOS E DISCUSSÃO}

Neste capítulo os resultados obtidos pela técnica PIV são apresentados para dois casos, em 70 bpm nos três planos de medição. Também são discutidos os efeitos dos resultados nas diferentes frequências de batimento e comparados com os valores obtidos na literatura.

\subsection{Efeito da posição de válvula}

Imediatamente abaixo são apresentados os resultados para os experimentos de 70 bpm com as válvulas a $0^{\circ}$ e $30^{\circ}$ nos seis intervalos previamente mencionados.

\subsubsection{Intervalo de 0 a $20 \%$ da diástole ( $\left.t_{1}\right)$}

O efeito da posição da válvula de entrada no intervalo de 0 a $20 \%$ da diástole pode ser comparado analisando a média temporal das velocidades para 0 e e $30^{\circ}$ no plano frontal (Figura 84), médio (Figura 85) e traseiro (Figura 86). Vale destacar que as linhas tracejadas no campo apresentam limites em que os resultados são ruidosos mesmo após a filtragem no pós-processamento PIV. Nesse caso, a região interna a esse limite possui resultados com um SNR maior do que 1.3 e alta coerência espacial dos parâmetros medidos como detalhado na Seção 3.4.

Iniciando a análise pela velocidade média horizontal ( $\bar{u})$, observou-se regiões com velocidades negativas $(\sim-0,3 \mathrm{~m} / \mathrm{s})$ em todos os planos. Isto indica que o fluido está se movendo da direita para a esquerda, ocupando o espaço deixado pelo retorno do diafragma. No plano frontal (Figura 84a), está localizada a maior região com velocidades negativas entre todos os planos. Todavia, no plano traseiro não houve um predomínio das regiões com velocidades negativas, ao contrário, a região com velocidades positivas $(\sim 0,2 \mathrm{~m} / \mathrm{s})$ é maior para 0 ㅇ (Figura $86 \mathrm{a}$ ) e $30^{\circ}$ (Figura $86 \mathrm{~b}$ ). Isto sugere que nesta pequena região delimitada pelas paredes do dispositivo e pelo diafragma, o fluido que entrou acaba retornando. Outra hipótese baseia-se na tridimensionalidade do escoamento, ou seja, o fluido que se moveu para a direita deixa o plano traseiro em direção a outro plano.

Na velocidade média vertical $(\overline{\mathrm{v}})$, também há um predomínio das velocidades negativas. No plano frontal é clara a disparidade entre os valores de $\bar{v}$ para $0^{\circ}$ e $30^{\circ}$. 
No primeiro (Figura $84 \mathrm{c}$ ), há uma região de $-0,3 \mathrm{~m} / \mathrm{s}$ próximo à válvula de entrada. Já no segundo (Figura 84d), não há uma região bem definida e os valores variam de 0,05 a $-0,1 \mathrm{~m} / \mathrm{s}$. No plano médio, as duas posições de válvula exibiram campos médio semelhantes. No plano traseiro, a situação é a inversa do plano frontal. O campo para $30^{\circ}$ (Figura $86 \mathrm{~d}$ ) apresentou uma região maior e bem definida de velocidade negativas, ao passo que para $0^{\circ}$ (Figura $86 \mathrm{c}$ ) essa região foi menos intensa. A estas regiões bem definidas de velocidades negativas dá-se o nome de jato diastólico.

Figura 84 - Campos de velocidades $\left(0^{\circ}\right.$ e $\left.30^{\circ}\right)$ no plano frontal no intervalo $t_{1}$
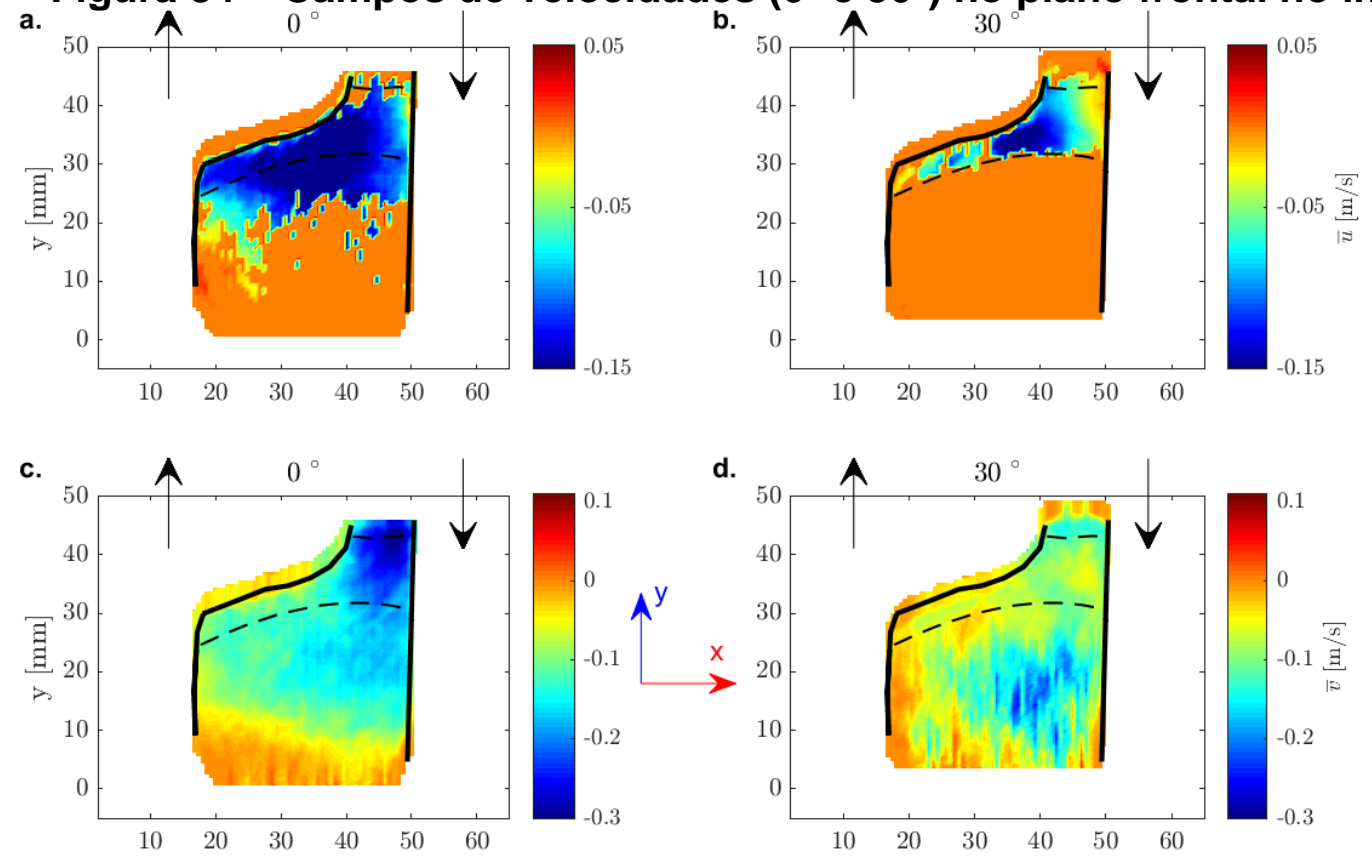

d.
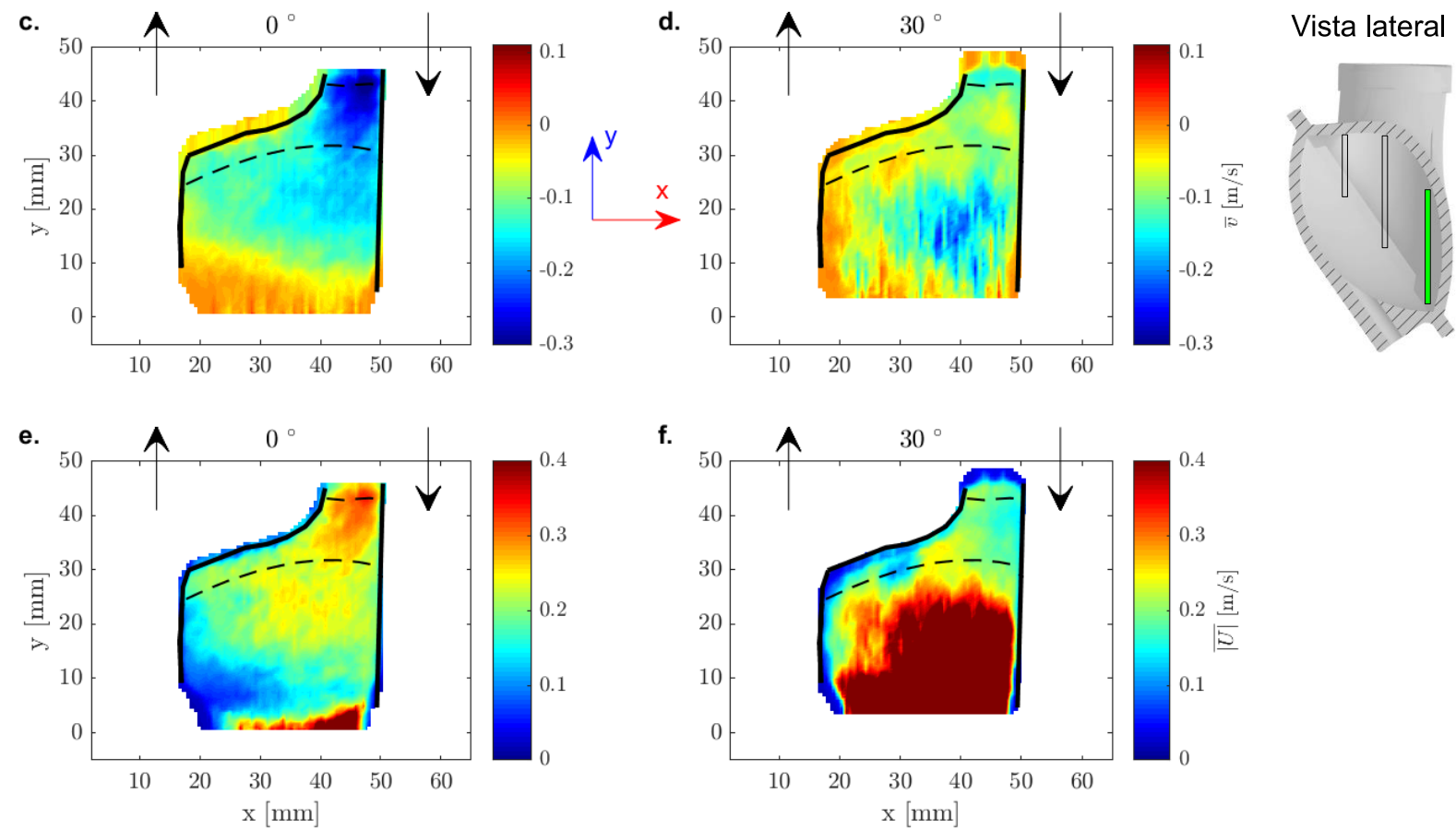

Além disso, observa-se na saída do dispositivo, no plano médio, uma região com valores positivos de $\bar{v}$ para $0^{\circ}$ que não é vista para $30^{\circ}$. Nesta pequena região, 0 fluido está saindo do DAVP em um momento em que a válvula estaria fechada. Ao examinar a velocidade na saída do DAVP, percebe-se em alguns intervalos uma região com velocidades que não condizem com o ideal, indicando uma possível 
regurgitação na região das válvulas. A regurgitação é o nome dado para o escoamento anormal, no qual o fluido escoa no sentido contrário ao que deveria. Nas válvulas mecânicas a regurgitação é dividida em duas fases: fluxo reverso durante o fechamento da válvula e vazamento após o fechamento. Como afirmado por Fung (1984), um coração normal não apresenta regurgitação e no caso de DAVs, este fenômeno reduz a eficiência do dispositivo. A análise da regurgitação em válvulas mecânicas ocorre através das velocidades, obtidas por ecocardiografia Doppler, LDA ou PIV; e da pressão, por meio de cateteres com medidores de pressão. A quantificação da regurgitação é importante pois estaria relacionada a hemólise, trombose e cavitação (MANNING et al., 2003). Dimensionar a regurgitação é importante pois desta maneira pode-se definir se o efeito deste fenômeno é mínimo e, portanto, aceitável ou se é elevado e prejudicial ao paciente.

\section{Figura 85 - Campos de velocidades $\left(0^{\circ}\right.$ e $\left.30^{\circ}\right)$ no plano médio no intervalo $t_{1}$}

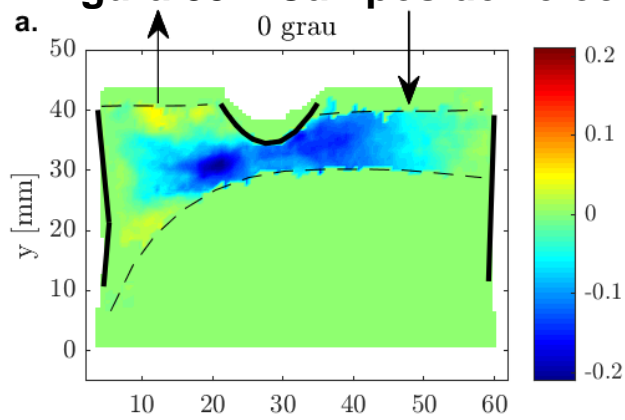

b.
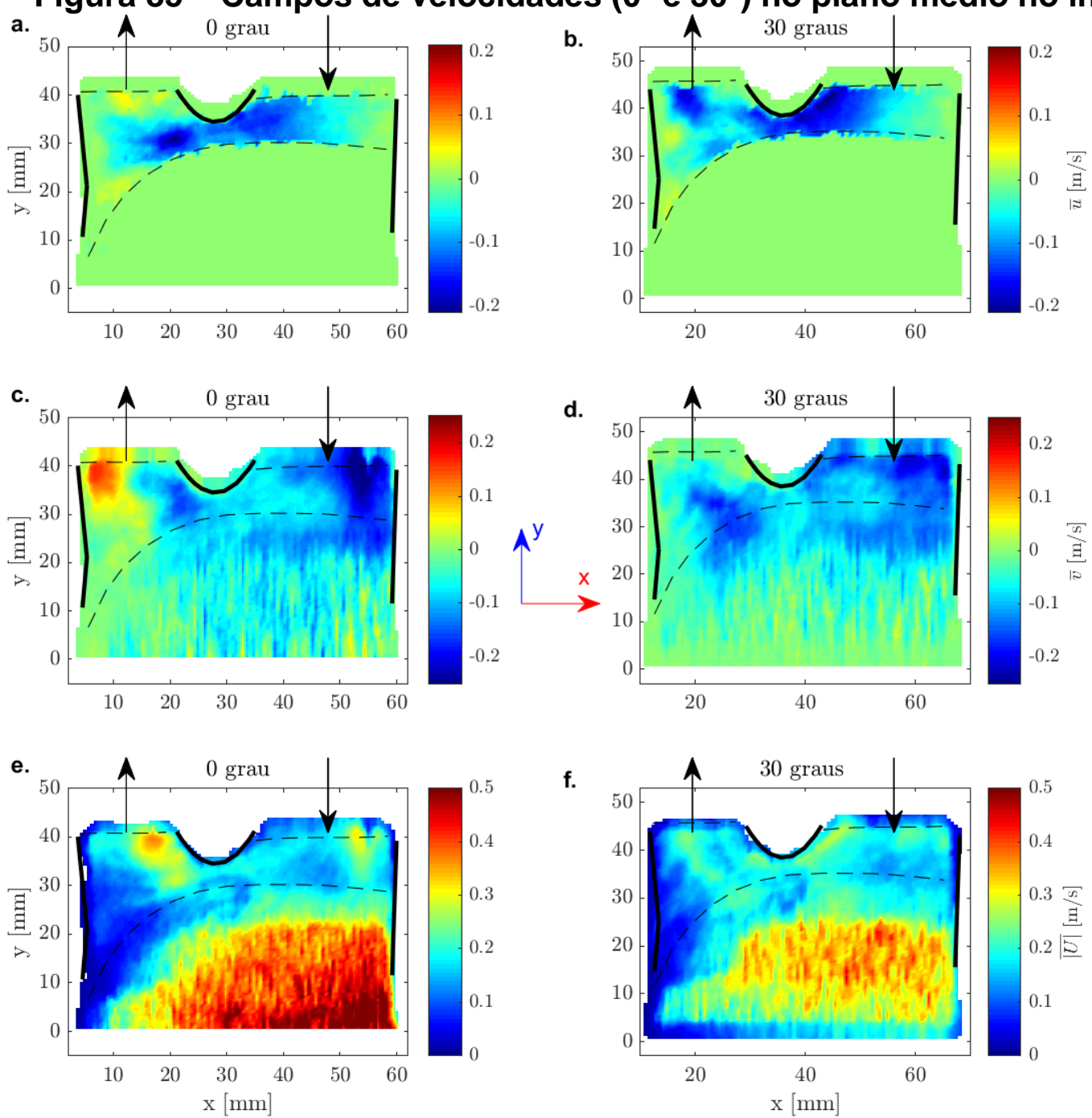
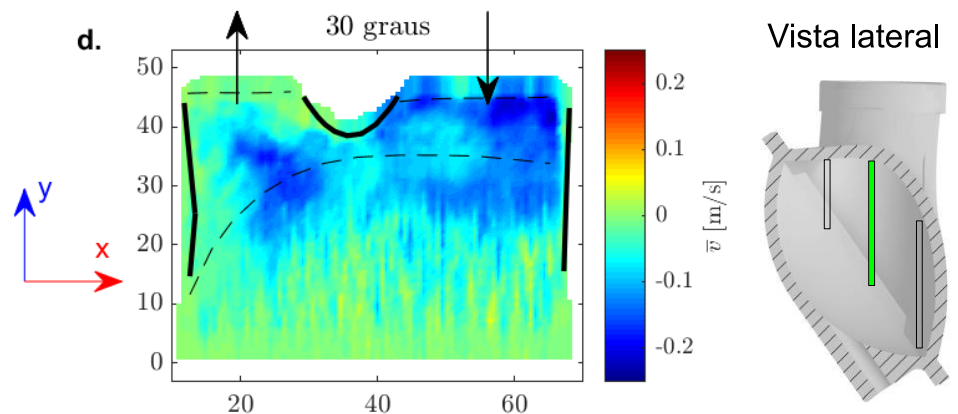

f.

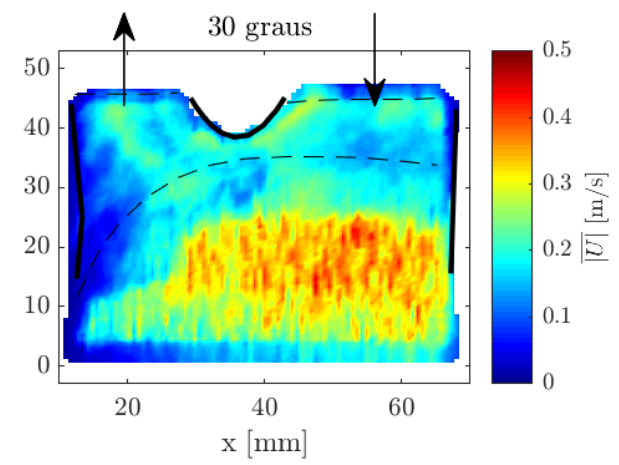


Figura 86 - Campos de velocidades $\left(0^{\circ}\right.$ e $\left.30^{\circ}\right)$ no plano traseiro no intervalo $t_{1}$
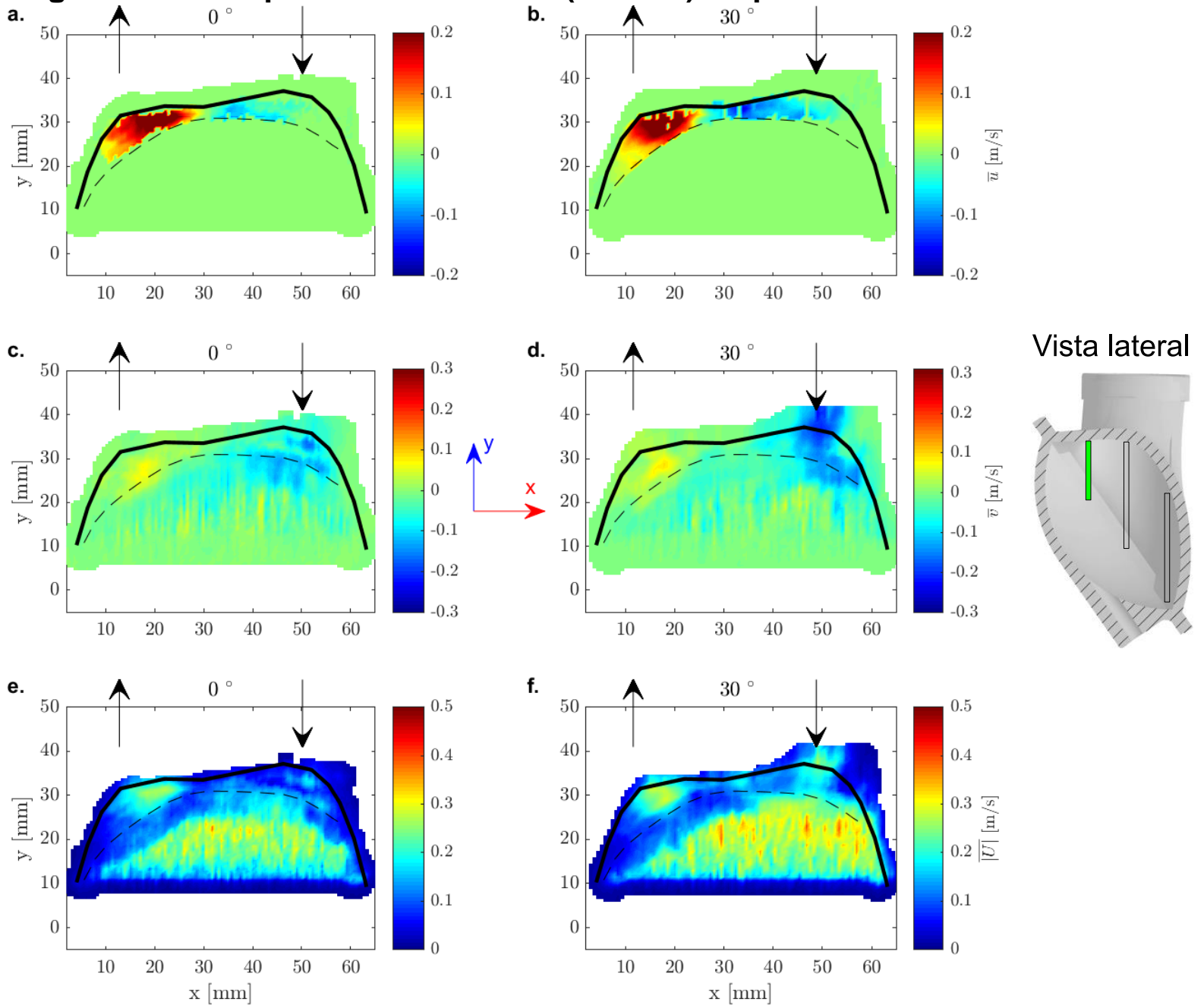

Nos experimentos apresentados nesta dissertação, os planos laser utilizado na técnica PIV não possuía altura suficiente para observar regiões próximas às válvulas o que não permite afirmar com toda a certeza sobre a regurgitação. Por outro lado, estudos sobre regurgitação de válvulas de duplo folheto da St. Jude Medical realizados por Flachskampf et al. (1991), Meyer et al. (2001), Bach et al. (2002) e Manning et al. (2003) afirmam que a válvula 21AJ-501 geralmente apresenta regurgitação trivial a leve. Esse comportamento pode ser observado na evolução temporal da componente vertical (v) na Figura 87, no plano médio. Os valores encontrados de $\mathrm{v}$ na sonda P1 e P2 mostram bem como há regurgitação até $40 \mathrm{~ms}$ para ambas as posições da válvula. Todavia, nota-se velocidades maiores no período de regurgitação para a posição $0^{\circ}$ em $\mathrm{P} 1$, como também é evidenciado no campo médio. A evolução temporal das demais componentes de velocidade para os nove pontos da sonda destacados na seção 3.5 são apresentados no Apêndice $A$. 
Figura 87 - Evolução temporal de $v$ na saída do DAVP no plano médio em $t_{1}$
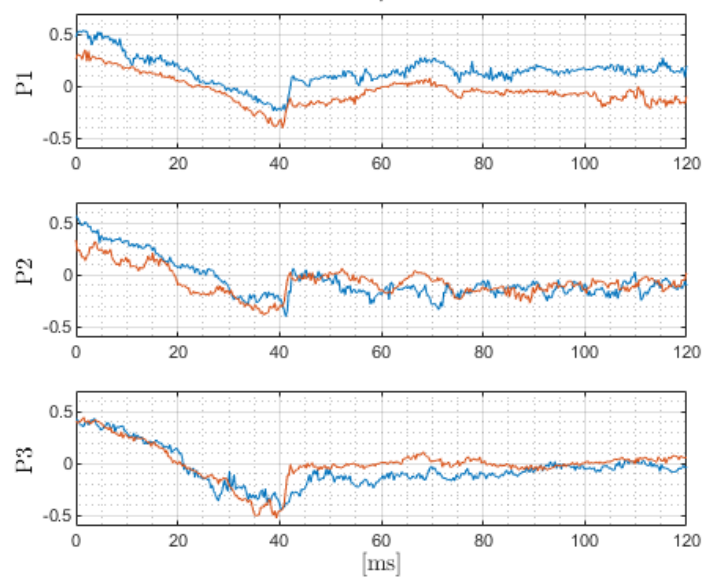

Azul - 0; vermelho - 30응

Prosseguindo com a análise da regurgitação, a Figura 88 expõe as pressões e vazões medidas para o intervalo em questão. A pressão na câmara sanguínea possui dois decaimentos. O primeiro dentro do atraso sistólico final e o segundo, mais íngreme do que o primeiro, acompanhando o comportamento da membrana representada pela pressão da câmara pneumática. A vazão medida após a válvula de saída possui valores negativos em aproximadamente $60 \mathrm{~ms}$ (10\% da diástole), ou seja, a regurgitação foi confirmada. $O$ atraso entre a regurgitação observada na Figura 87 e Figura 88 deve-se ao percurso do escoamento que é medido antes pelo PIV e depois passa pelo medidor de vazão gerando um atraso de $44 \mathrm{~ms}$ (7\%).

Figura 88 - Curvas de pressão e vazão para o intervalo $t_{1}$

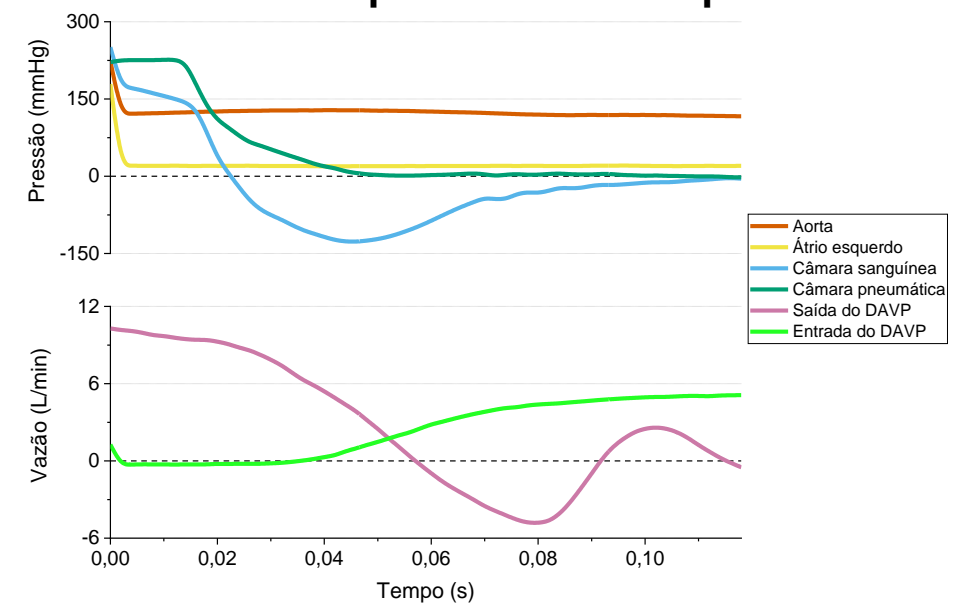

A magnitude da velocidade média (|Ū|) apresenta comportamentos distintos para as duas posições de válvula em todos os planos. Como os valores de $\bar{v}$ são maiores que os valores de ū, a sua influência na magnitude é maior. Isto foi observado 
no plano frontal para $0^{\circ}$ (Figura $84 \mathrm{e}$ ), onde há uma região bem definida que seguiu a geometria do dispositivo logo abaixo da válvula de entrada. O mesmo ocorre no plano médio para $0^{\circ}$ (Figura 85e) e no plano traseiro para 30 (Figura 86f). Os demais campos, apresentaram comportamentos praticamente homogêneos.

Ao analisar os três planos em conjunto percebe-se que a tridimensionalidade do escoamento possui um papel importante. A princípio, neste intervalo, a mudança no ângulo da válvula de entrada alterou a presença do jato diastólico. Esclarecendo, o jato diastólico que fora observado para $0^{\circ}$ no plano médio não foi visto para $30^{\circ}$ no mesmo plano, bem como a situação inversa ocorreu no plano traseiro.

As tensões médias para este intervalo, nos planos frontal (Figura 89), médio (Figura 90) e traseiro (Figura 91) são apresentadas a seguir.

\section{Figura 89 - Campos de tensões $\left(0^{\circ}\right.$ e $\left.3^{\circ}\right)$ no plano frontal no intervalo $t_{1}$}
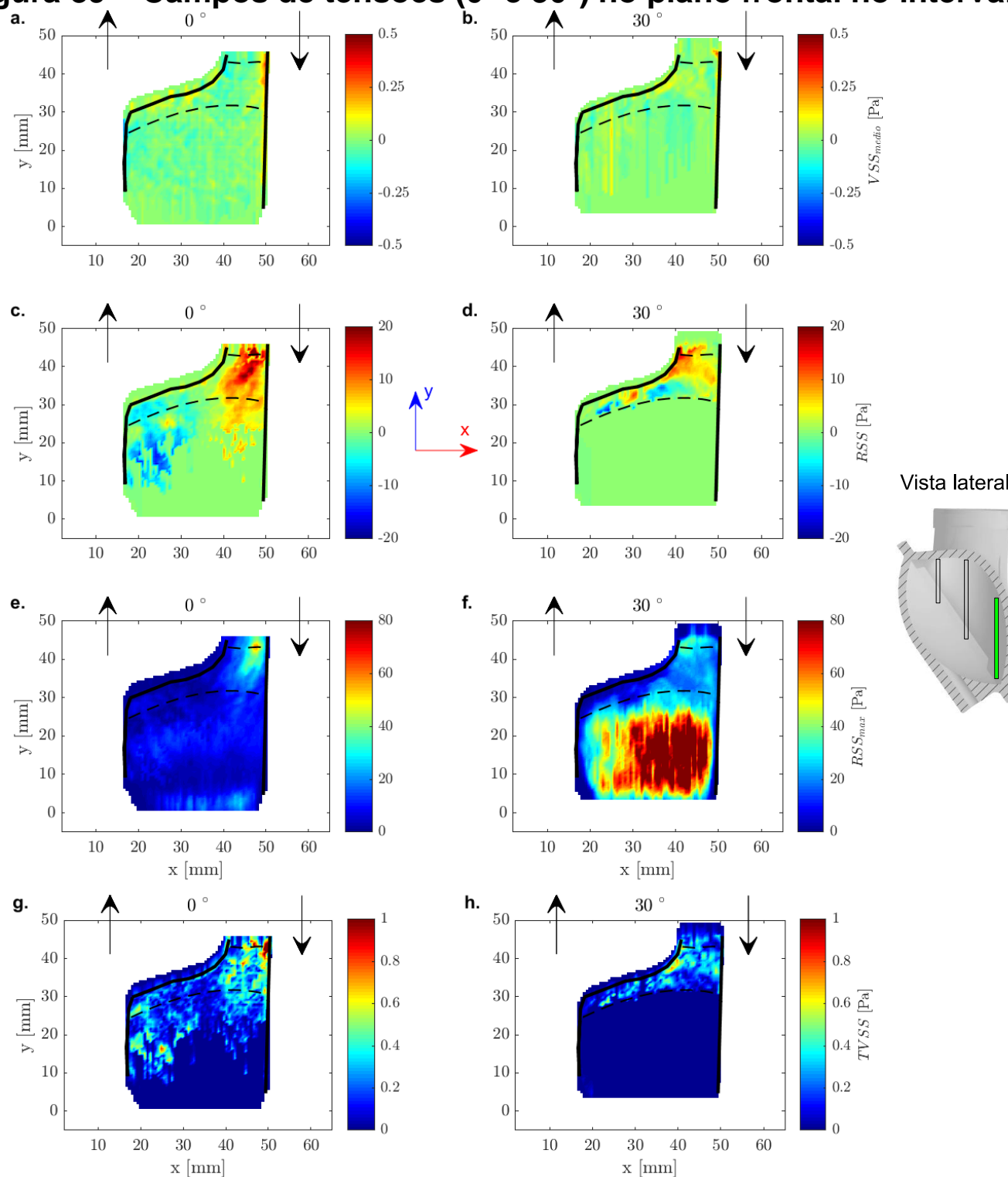
Figura 90 - Campos de tensões para a válvula em $0^{\circ}$ e $30^{\circ}$ no intervalo $t_{1}$

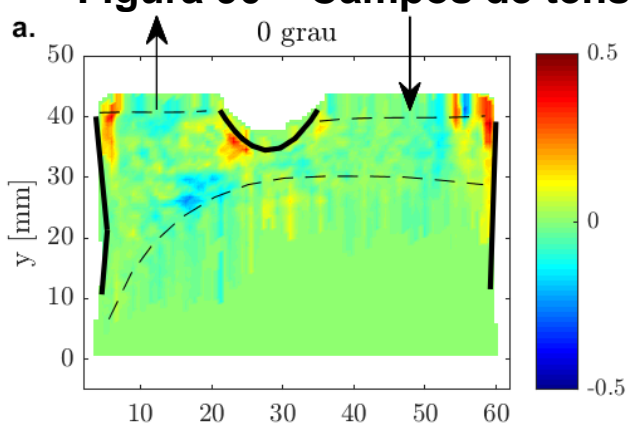

b.
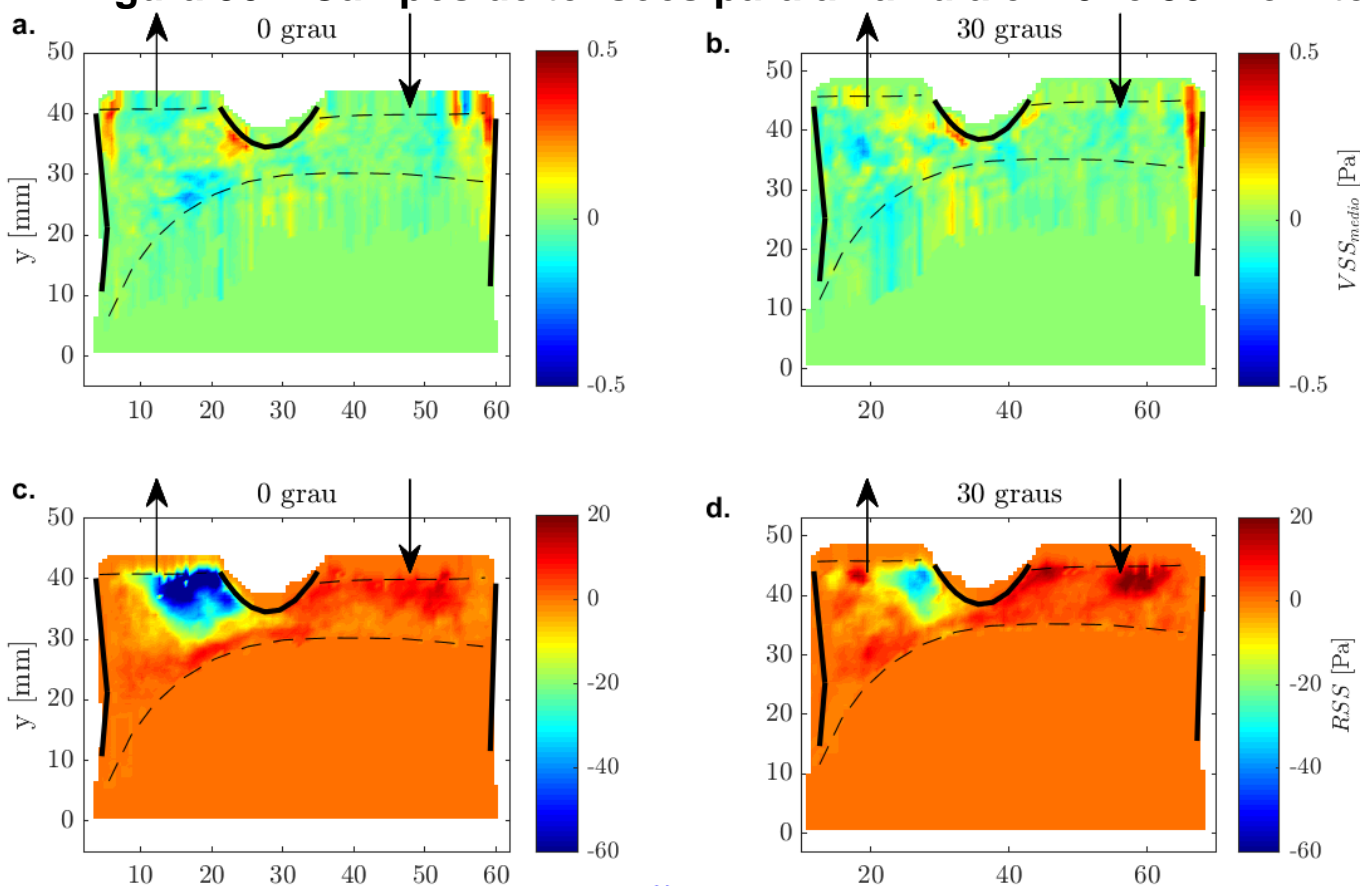

d.

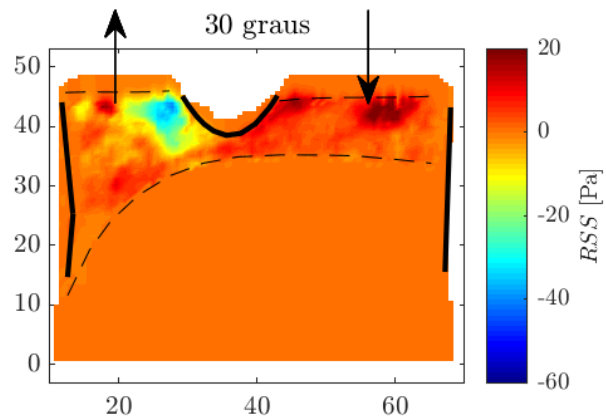

Vista lateral

e.

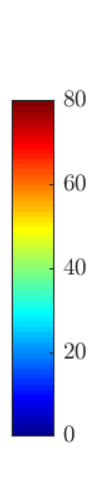

$\uparrow^{\mathrm{y}} \mathrm{x}$
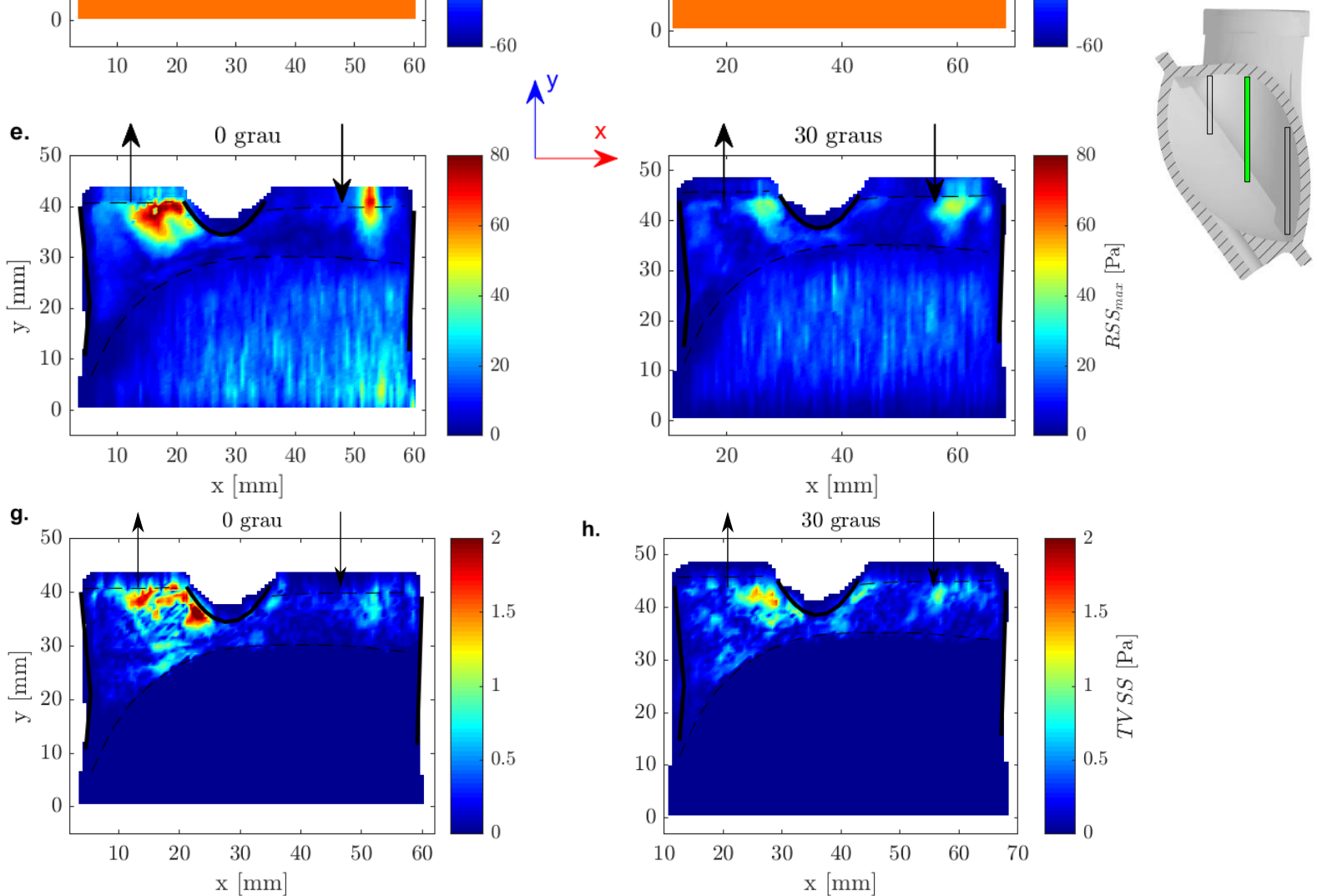

h.

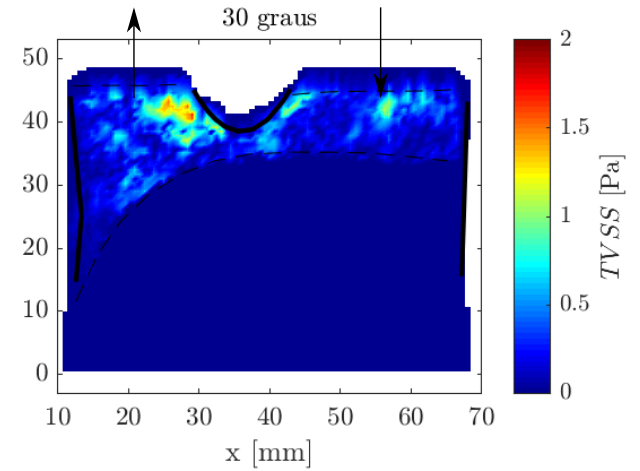


Figura 91 - Campos de tensões $\left(0^{\circ}\right.$ e $\left.30^{\circ}\right)$ no plano traseiro no intervalo $t_{1}$
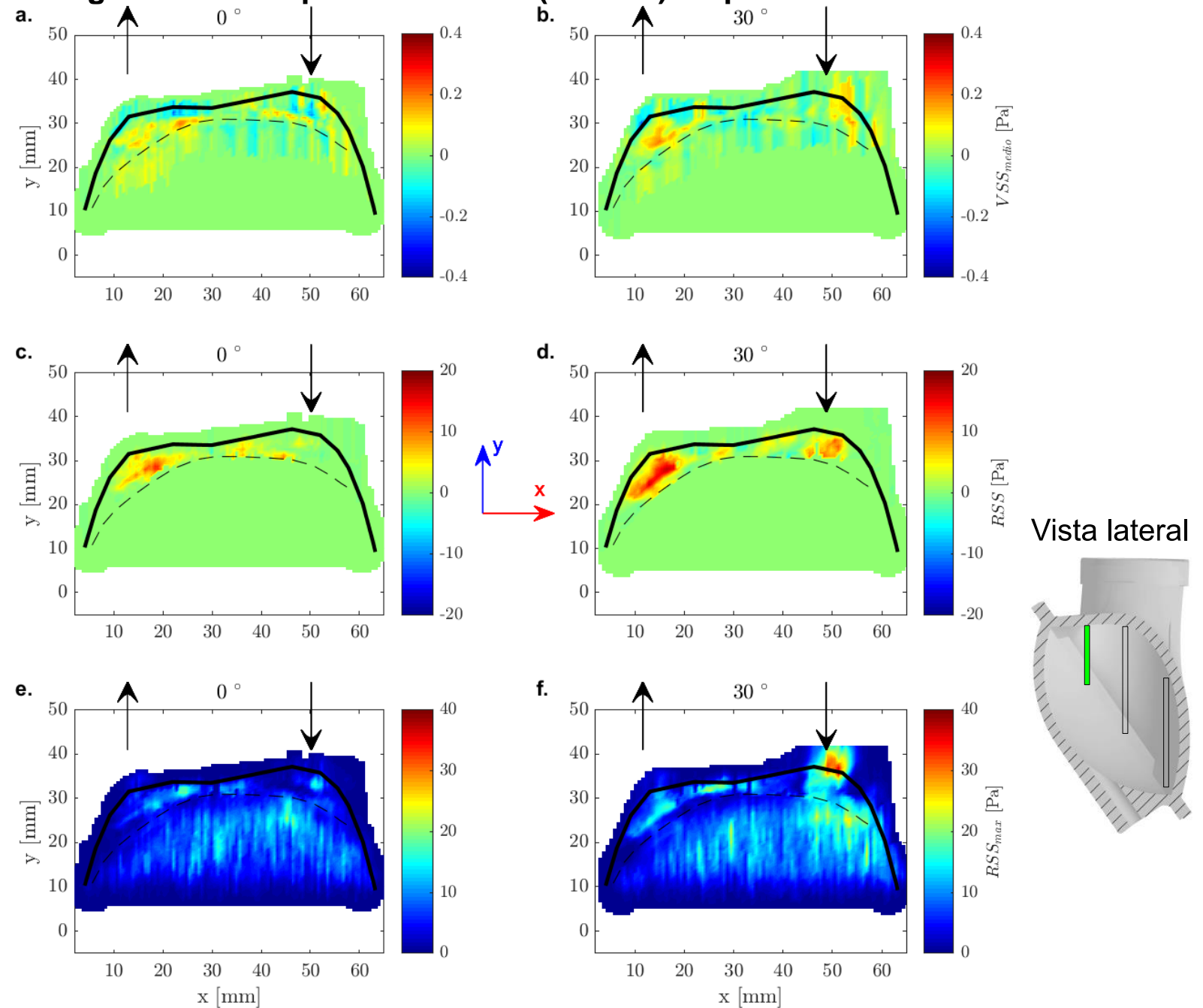

f.
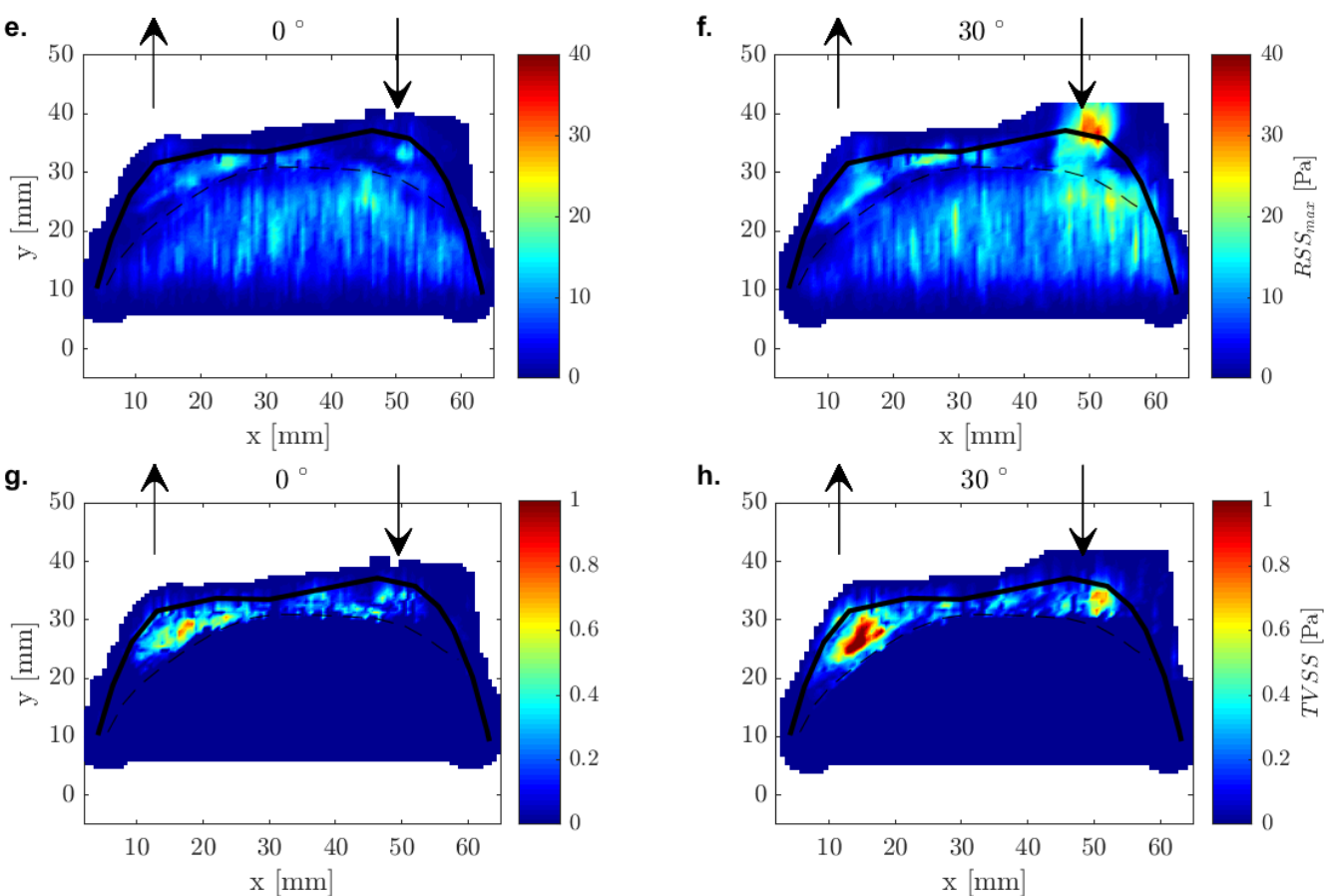

A média temporal da tensão de cisalhamento viscoso $(\overline{V S S})$ concentra-se principalmente na parede direita próximo a entrada nos campos do plano frontal e médio. Para 0 (Figura 89a), a região de pico é maior no plano frontal, estendendo-se por toda a parede direita do dispositivo. Para 30ํㅡ (Figura 89b), a região de máximos não é tão extensa. Já no plano médio, ocorre o contrário. A região de pico de $\overline{V S S}$ para $30^{\circ}$ (Figura 90b) é mais extensa que a região de pico para 0 (Figura 90a). Os campos de $\overline{V S S}$ (Figura $91 \mathrm{a}$ e b) do plano traseiro não apresentaram tensões na parede direita. 
Traçando uma linha em $Y=40 \mathrm{~mm}\left(0^{\circ}\right)$ e $Y=45 \mathrm{~mm}\left(30^{\circ}\right)$ no plano médio e calculando a evolução temporal de VSS nas regiões próximas à parede e às válvulas (Figura 92) observam-se valores na ordem de $1 \mathrm{~Pa}$, ou seja, o dobro do valor encontrado para a média. Além do mais, pequenas regiões de altas tensões são igualmente encontradas na curvatura entre as válvulas no campo médio e uma região de tensões maiores na parede superior esquerda apenas é observada quando a válvula está na posição $0^{\circ}$. Esse comportamento é mais um indício de que há vazamento na válvula de saída causado pela regurgitação, como discutido anteriormente.

Figura 92 - Evolução temporal de VSS próximo à parede no plano médio em $\mathbf{t}_{1}$
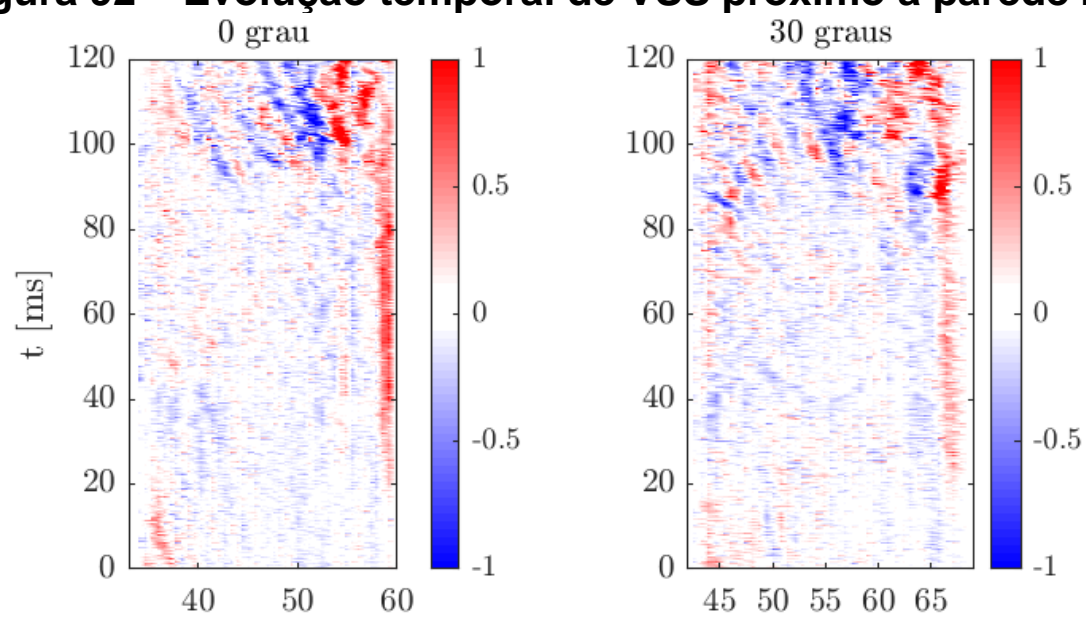

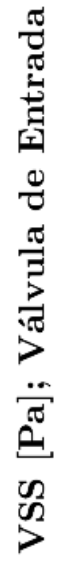
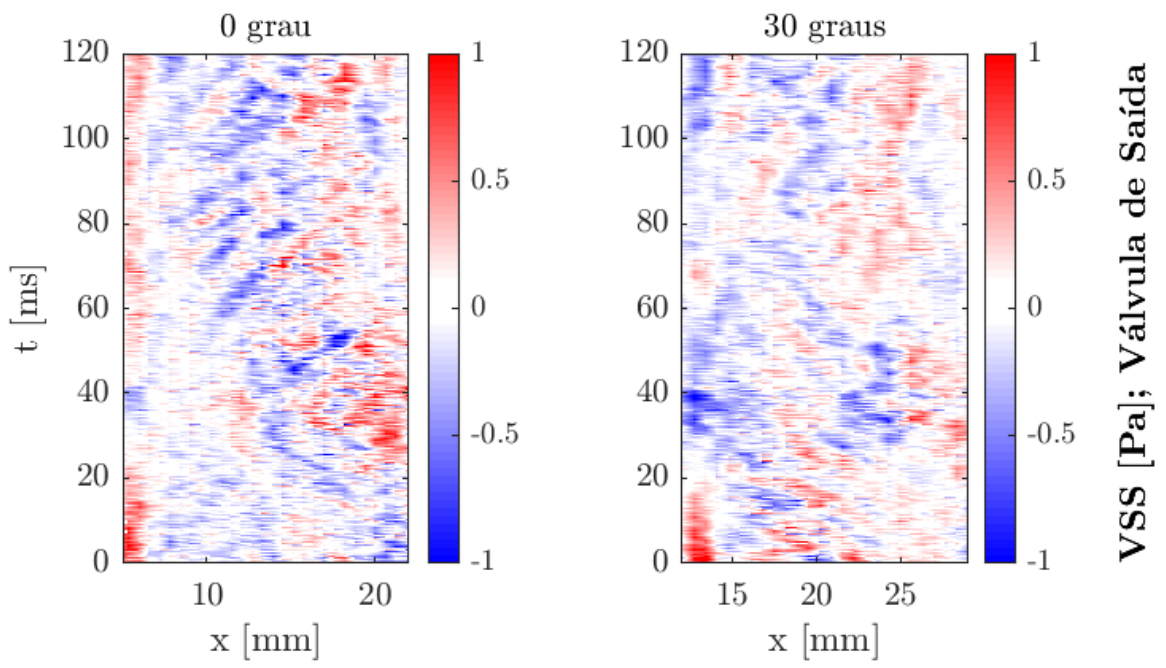

Vista lateral

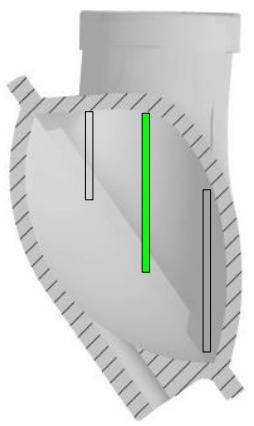

A tensão de cisalhamento de Reynolds (RSS), apresentaram valores maiores na entrada do dispositivo para o plano frontal e na saída do DAVP para os planos médio e traseiro. O campo com maior relevância de RSS ocorreu para $0^{\circ}$ no plano 
frontal (Figura 89c). Neste campo observa-se a região com valores positivos (20 Pa) e outra com valores negativos (-20 Pa), no espaço deixado pelo diafragma.

Os campos de RSS $S_{\max }$ exibiram regiões de máximos bem peculiares. Nos planos cujas magnitude de velocidade estavam mais nítidos, os valores de RSS max foram ressaltados, principalmente no centro dos jatos diastólicos (Figura 89e, Figura 90e, Figura $90 f$ e Figura 91f).

A tensão de cisalhamento viscosa turbulenta (TVSS), por conter VSS e RSS, expôs campos com regiões mais próxima à RSS. Contudo os valores encontrados nas regiões de pico possuem escala mais próxima a VSS $(\sim 0,5 \mathrm{~Pa})$.

Comparando as tensões encontradas para $0^{\circ}$ e $30^{\circ}$, nota-se que a intensidade dos campos de $0^{\circ}$ é maior em todas as tensões no plano frontal e médio. Já no plano traseiro os campos para $30^{\circ}$ apresentam intensidade maior.

Considerando as medidas como pseudo-estacionárias, ou seja, uma aproximação ou hipótese matemática. Esta aproximação é conveniente quando um experimento contém processos regidos por escalas de tempo muito diferentes entre si. No presente trabalho o escoamento proporcionado por um batimento do DAVP e o fenômeno da turbulência apresentam escalas temporais diferentes. Esta hipótese torna-se mais forte quanto maior forem as diferenças entre as escalas temporais, ou seja, isto é, os processos rápidos se encontram em estado estacionário no momento das medições. Assim posto, a energia cinética turbulenta (TKE) para o intervalo de 0 a $20 \%$ da diástole é exibida na Figura 93 no plano médio. No CFD a modelagem da turbulência é uma forma de evitar a simulação numérica direta (Direct Numerical Simulation, DNS) que apresenta um custo computacional muito elevado. Dentro da modelagem da turbulência, utiliza-se o TKE pois esta propriedade é de fácil obtenção e está diretamente relacionada ao fluxo.

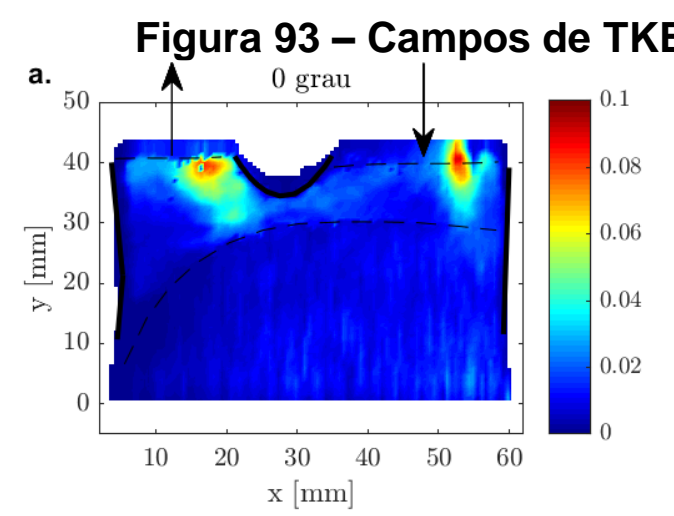

b.

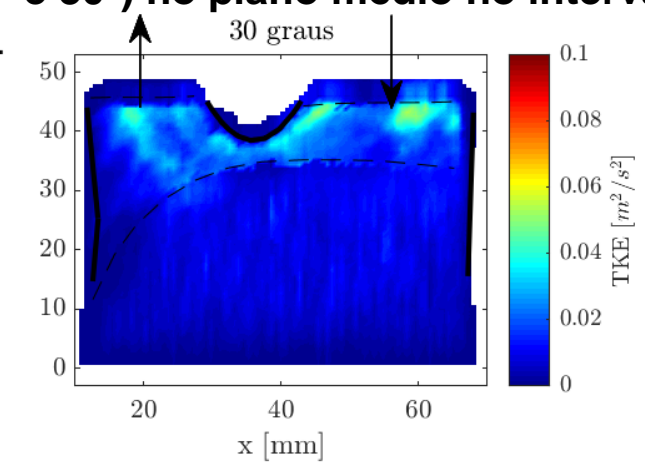

Vista lateral 
No escoamento, regiões com altos valores de cisalhamento estão associadas à produção de turbulência, logo o comportamento do campo de TKE é semelhante ao campo de RSS max: altos valores estão presentes na entrada e saída do DAVP. Para $0^{0}$, os valores são maiores em todo o campo comparado ao campo para 30․ Percebese também uma estrutura semelhante a um pequeno jato na entrada do campo para 0 ‥

\subsubsection{Intervalo de 20 a $40 \%$ da diástole ( $\left.t_{2}\right)$}

No segundo intervalo ( $\mathrm{t}_{2}$ ), que compreende $20 \%$ a $40 \%$ da diástole, a região sem ruído é maior uma vez que o diafragma recuou consideravelmente em relação ao o intervalo anterior. Os campos médios de velocidade para o plano frontal (Figura 94), médio (Figura 95) e traseiro (Figura 96) são apresentados abaixo.

Figura 94 - Campos de velocidades $\left(0^{\circ}\right.$ e $\left.30^{\circ}\right)$ no plano frontal no intervalo $t_{2}$

a.

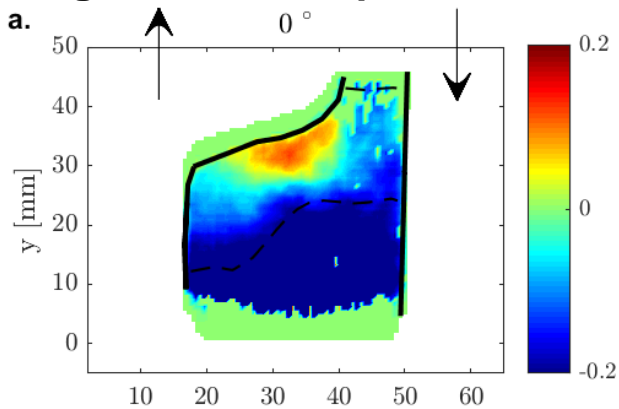

c.
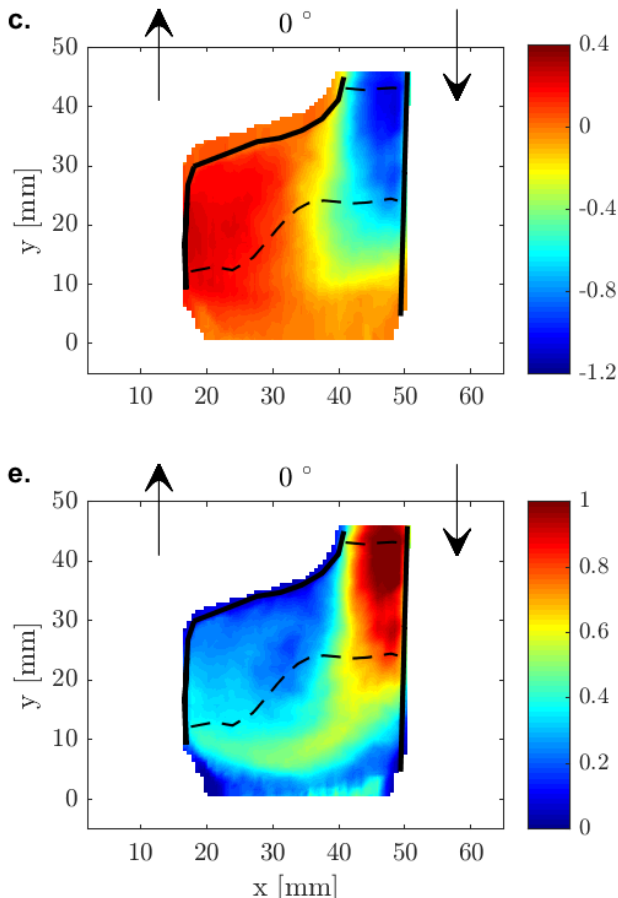

b.

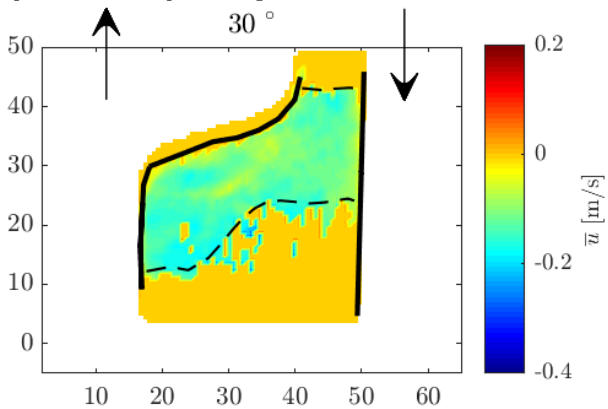

d.

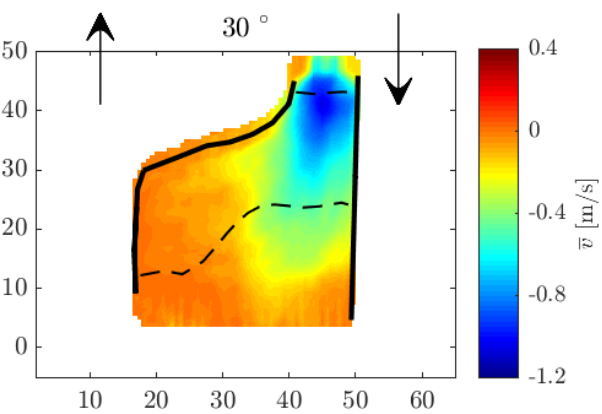

f.

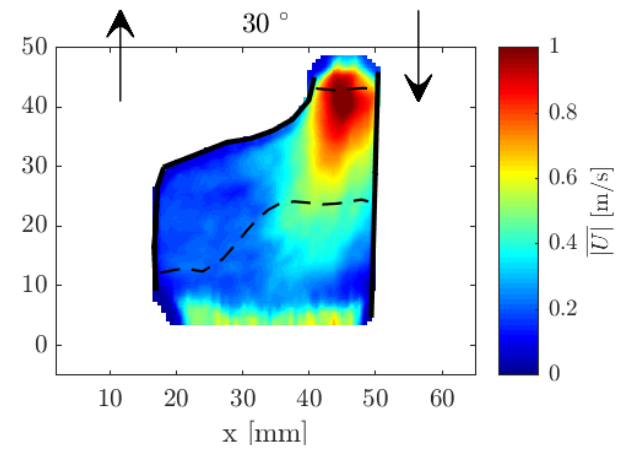

Vista lateral

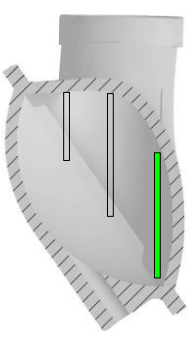


A média temporal da velocidade horizontal (ū) revelou uma região positiva entre as válvulas de entrada e saída do dispositivo que começa pequena no plano frontal e cresce até o plano traseiro para $0^{\circ}$ (Figura 94a, Figura 95a e Figura 96a). Para $30^{\circ}$, ù possui um campo homogêneo no plano frontal (Figura 94b); duas regiões com picos positivos de velocidade no plano médio (Figura 95b); e uma grande região com valores positivos no plano traseiro (Figura 96b). Ademais, na Figura 95b, há duas regiões com sentidos de velocidade opostos, logo abaixo da válvula de entrada. Este fenômeno pode ser mais um indício de que o fluido está se movimentando na componente $z$.

Figura 95 - Campos de velocidades ( $0^{\circ}$ e $\left.30^{\circ}\right)$ no plano médio no intervalo $t_{2}$

a.

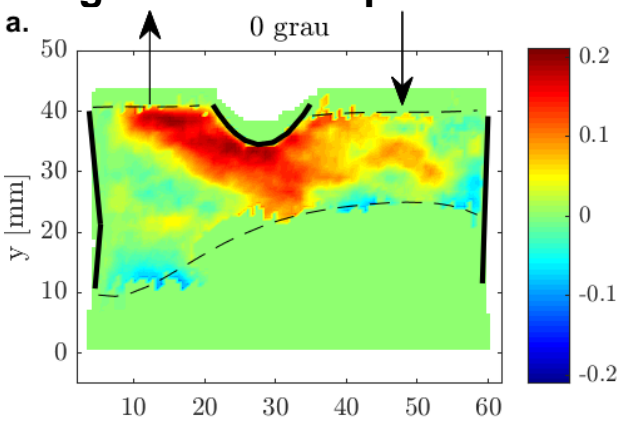

c.
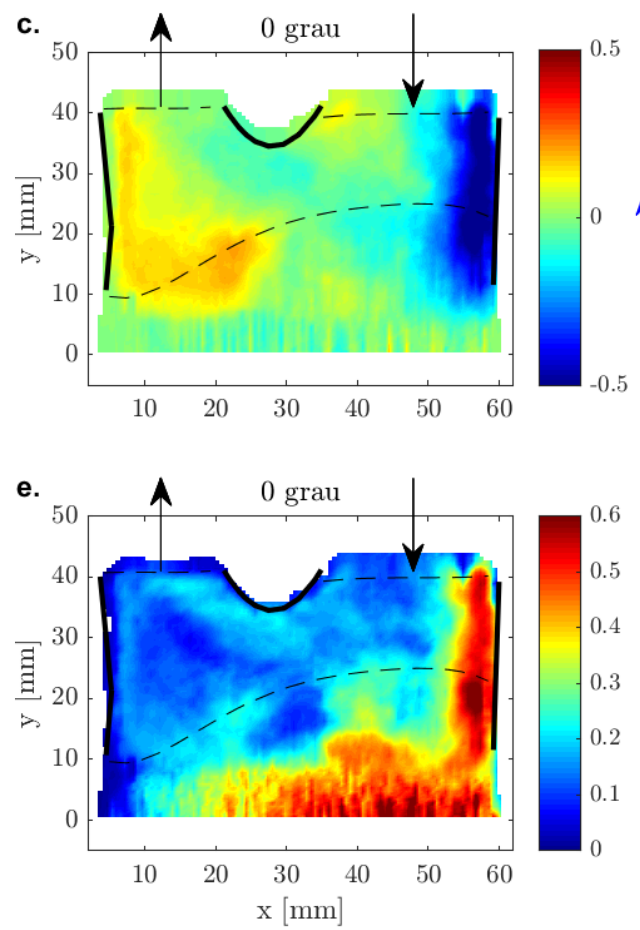

b.
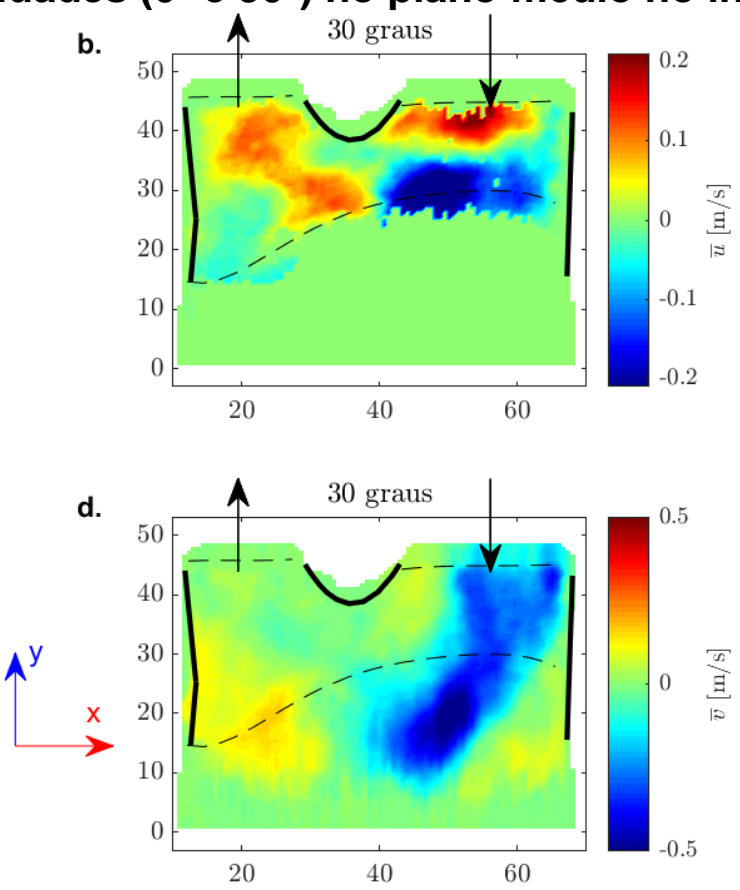

f.

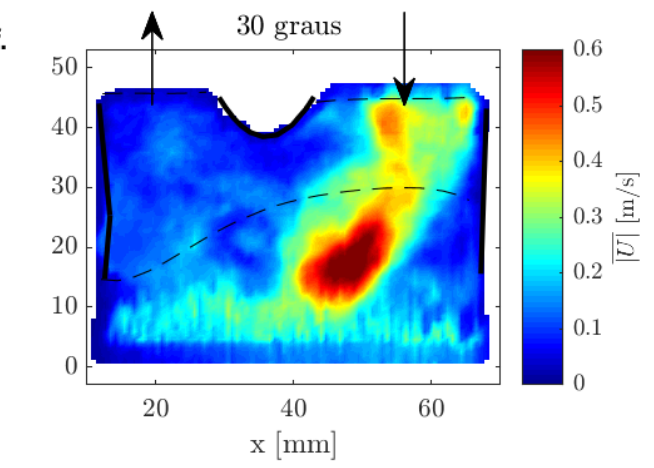

Vista lateral

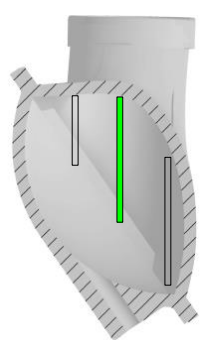


Figura 96 - Campos de velocidades $\left(0^{\circ}\right.$ e $\left.30^{\circ}\right)$ no plano traseiro no intervalo $t_{2}$
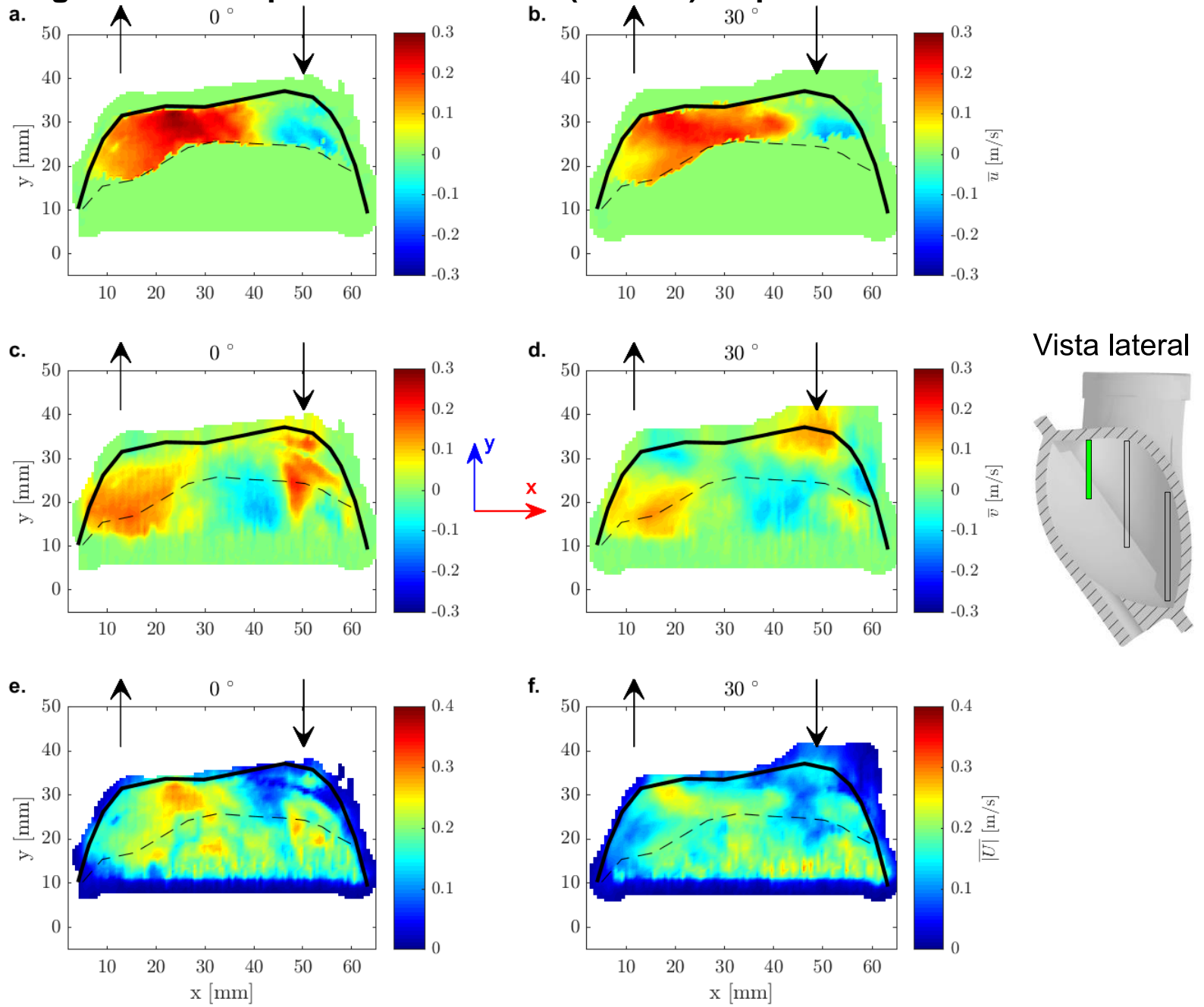

Em relação à média temporal da velocidade vertical $(\bar{v})$ é possível identificar o jato diastólico nos planos frontal e médio. Analisando o plano médio, percebeu-se que a região do jato diastólico com velocidades em torno de $-1 \mathrm{~m} / \mathrm{s}$ é maior para $0^{\circ}$ (Figura 94c) do que para $30^{\circ}$ (Figura 94d). Passando para o plano médio, os jatos diastólicos possuem tamanhos similares e velocidades em torno de $-0,5 \mathrm{~m} / \mathrm{s}$. Todavia o contorno do jato diastólico diferiu. Para 0 (Figura 95c), o jato seguiu e esteve mais próximo da parede direita do dispositivo, sem mudanças de direção. Já o jato diastólico para $30^{\circ}$ (Figura 95d) se distribuiu pela entrada e à medida que avançou, afastou-se da parede externa e moveu-se em direção ao local antes ocupado pela membrana na região central da DAVP. Também é evidente em $\bar{v}$ os valores positivos na região inferior esquerda do DAVP, que em $0^{\circ}$ prolonga-se até a válvula de saída. Na evolução temporal de $v$ (Figura 97), confirma-se que este prolongamento da região positiva é a regurgitação observada em $\mathrm{P} 1$. A região à esquerda do dispositivo com velocidades 
positivas, ou seja, em direção à saída do DAVP, também estiveram presentes no plano traseiro. Neste plano, as velocidades positivas foram predominantes para $0^{\circ}$ (Figura 96c) e $30^{\circ}$ (Figura 96d).

Figura 97 - Evolução temporal de u e v na saída do DAVP no plano médio em $t_{2}$

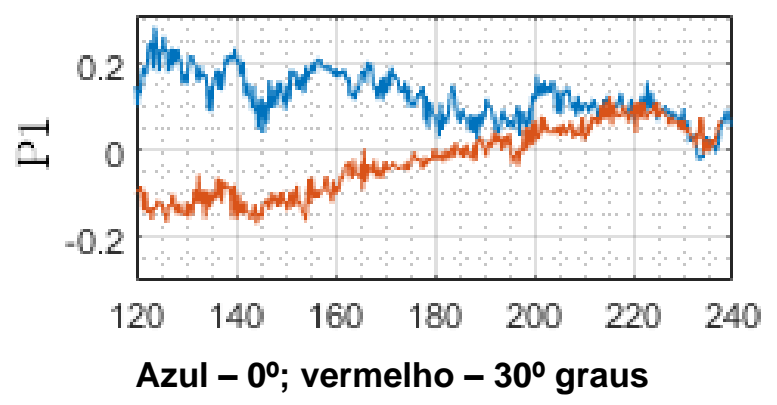

Ao longo dos planos está clara a presença de regiões com movimentos opostos de $\bar{u}$ e $\bar{v}$. Estas estruturas estariam relacionas a própria geometria interna do DAVP e neste instante, a quase metade do enchimento, resta pouco volume desocupado pelo diafragma para preencher. Como a diástole ainda não terminou, o fluido que sobe e move-se para a direita tende a ser empurrado para baixo pelo jato diastólico. Contudo, este movimento não está bem definido e a tridimensionalidade do escoamento altera o plano em que estas estruturas ocorrem.

Os campos de magnitude da velocidade média (|Ū|) apresentaram os contornos do jato diastólico para o plano frontal (Figura 94e e Figura 94f) e médio (Figura 95e e Figura 95f). Além disso, regiões com valores mais elevados de $|\bar{U}|$ foram observadas nos limites da geometria interna do dispositivo, como por exemplo, na Figura 94e e Figura 96f.

Os campos de tensões são apresentados para os planos frontal (Figura 98), médio (Figura 99) e traseiro (

Figura 100). Na tensão de cisalhamento viscosa $(\overline{V S S})$, percebe-se um aumento nos valores próximo à parede direita nos planos frontal e médio. Esta elevação nas tensões está diretamente relacionada ao aumento dos perfis dos jatos e de suas respectivas velocidades. É importante ressaltar o efeito dos limites do jato diastólico em $\overline{V S S}$. No plano médio para 30 (Figura 99b), as tensões máximas deixaram a parede direita e seguiram o contorno do jato, que mudou de direção. Já no plano traseiro para $30^{\circ}($

Figura 100b), surgiu, pela primeira vez, uma tensão elevada na parede 
esquerda do dispositivo. Esta nova região estaria relacionada à parede superior que limita o escoamento.

Figura 98 - Campos de tensões ( $0^{\circ}$ e $\left.30^{\circ}\right)$ no plano frontal no intervalo $t_{2}$
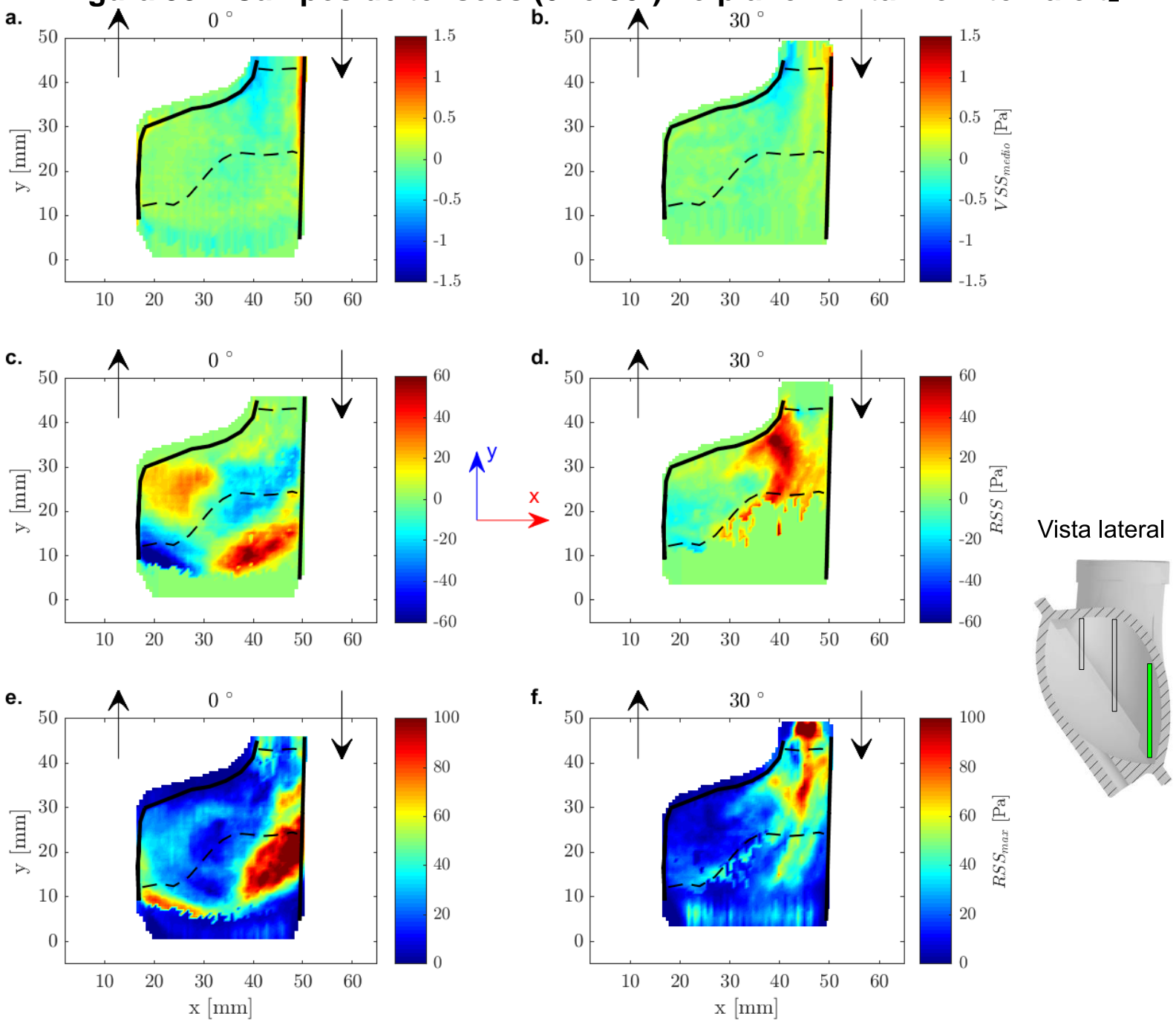

f.
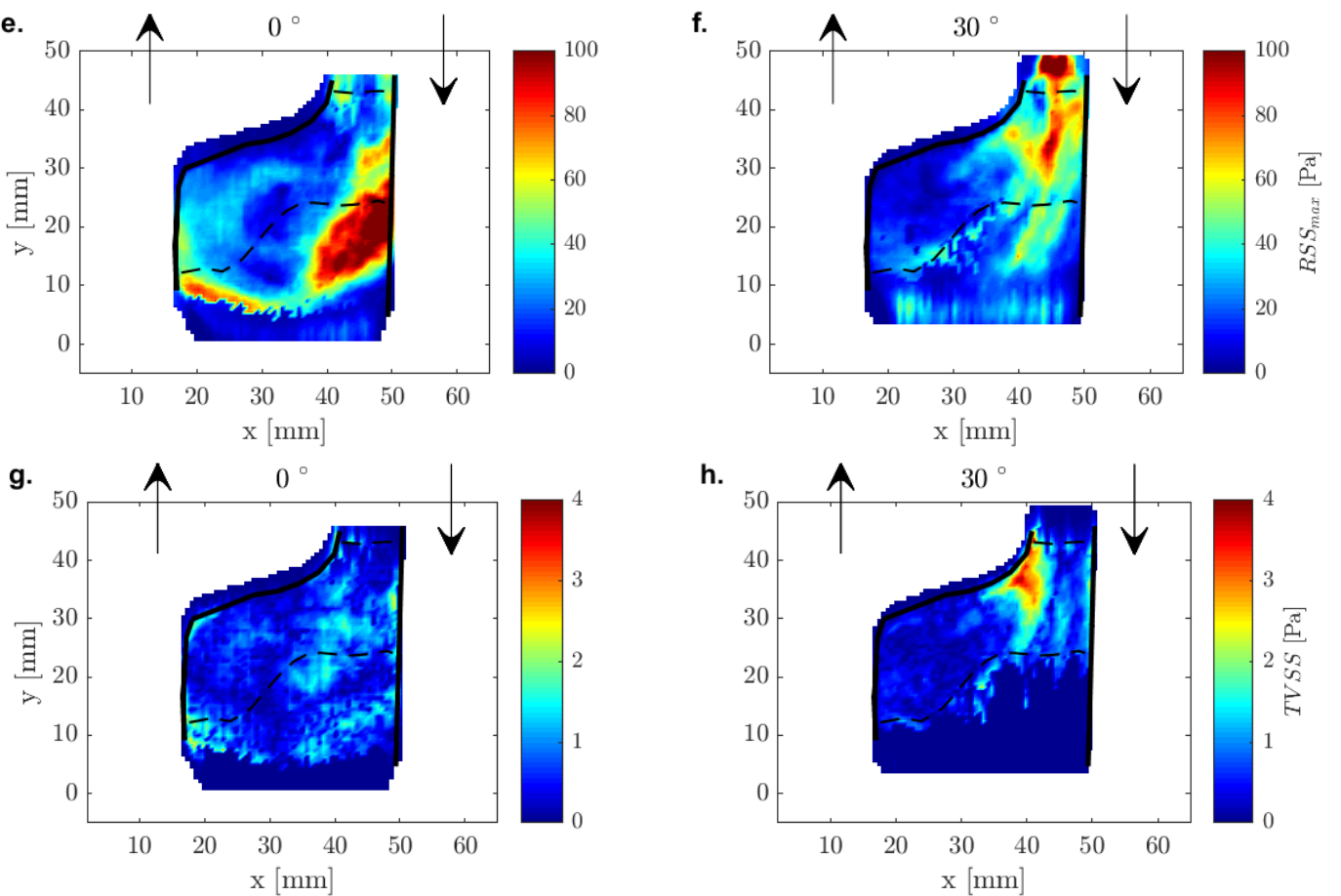
Figura 99 - Campos de tensões ( $0^{\circ}$ e $\left.30^{\circ}\right)$ no plano médio no intervalo t2

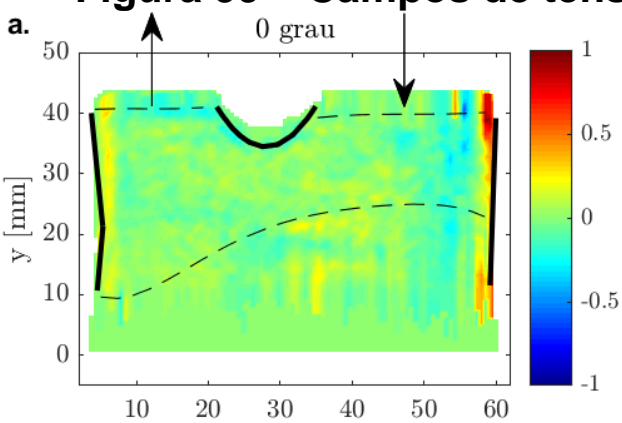

b.
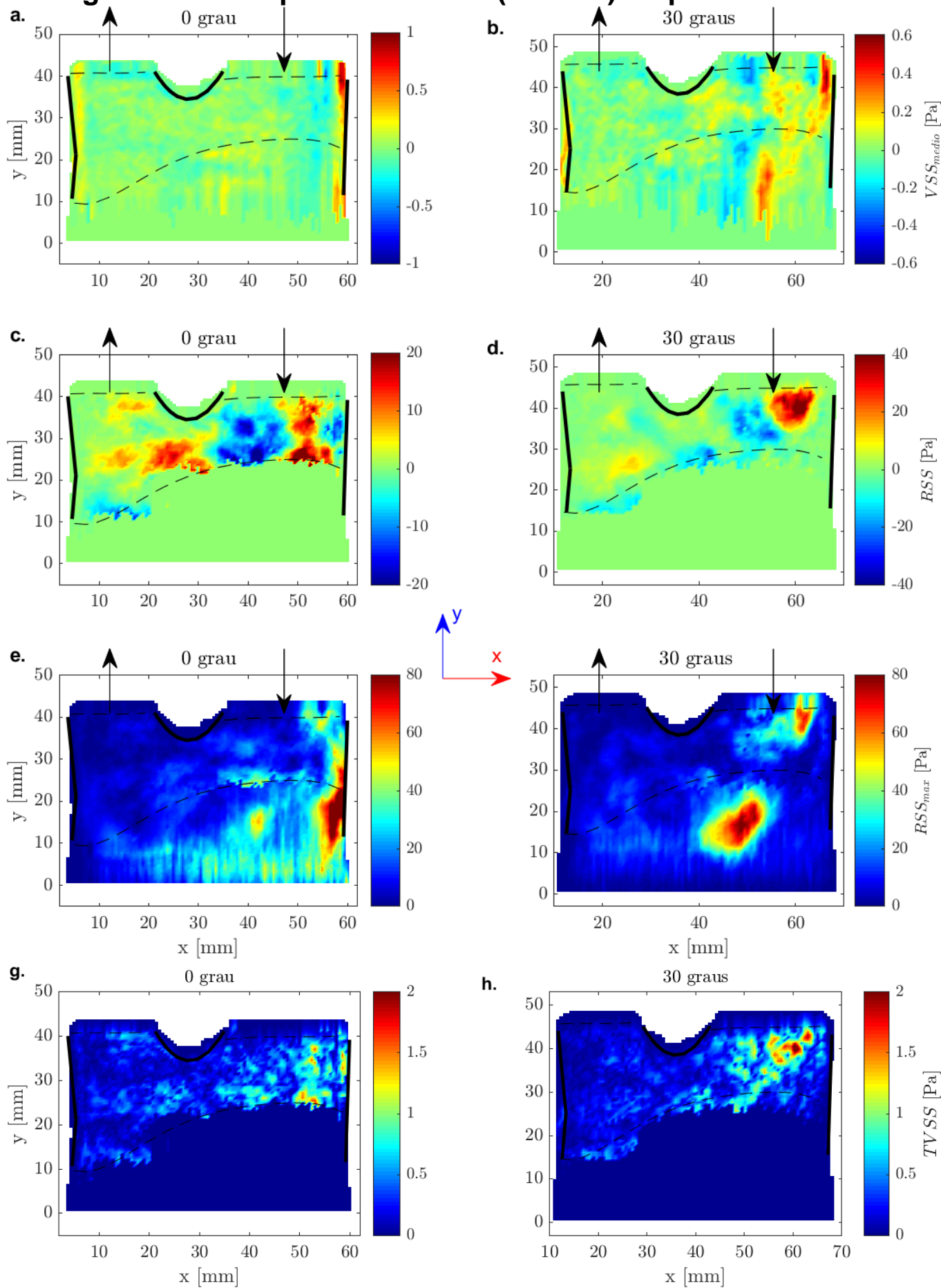

d.

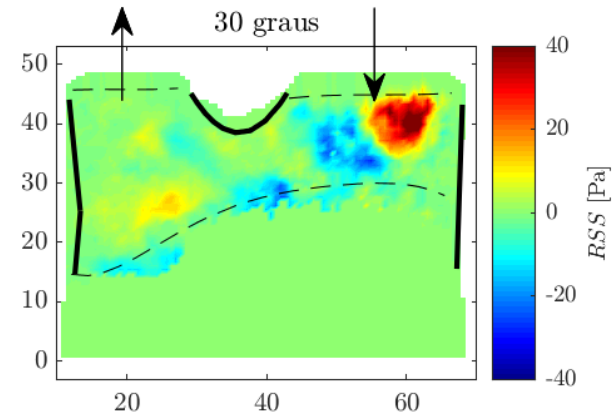

$\stackrel{\uparrow^{y}}{\longrightarrow}$
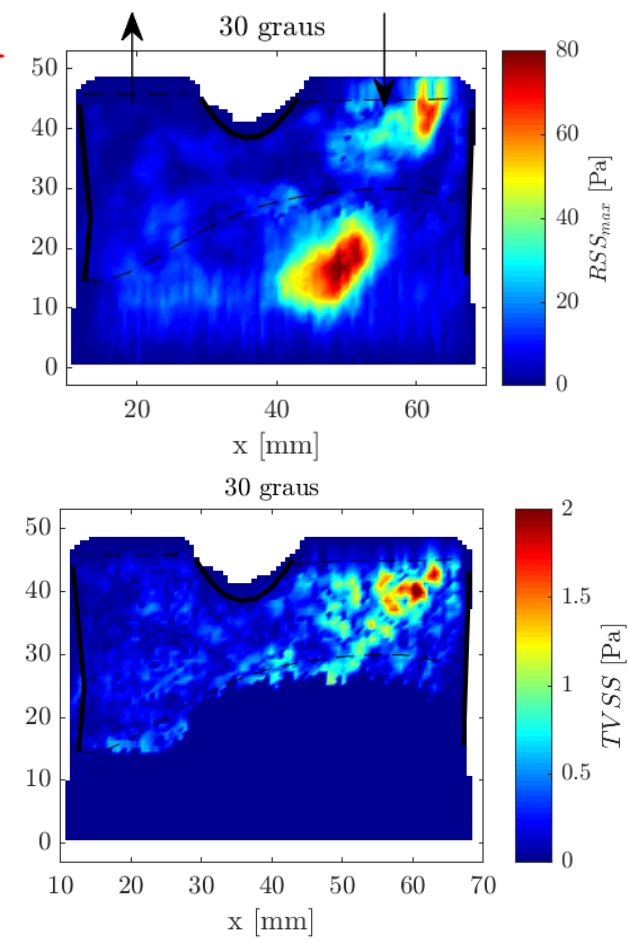

Vista lateral

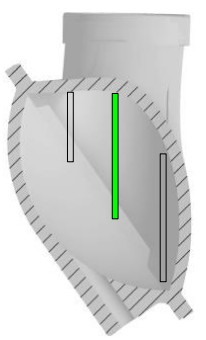


Figura 100 - Campos de tensões $\left(0^{\circ}\right.$ e $\left.30^{\circ}\right)$ no plano traseiro no intervalo t2

a.

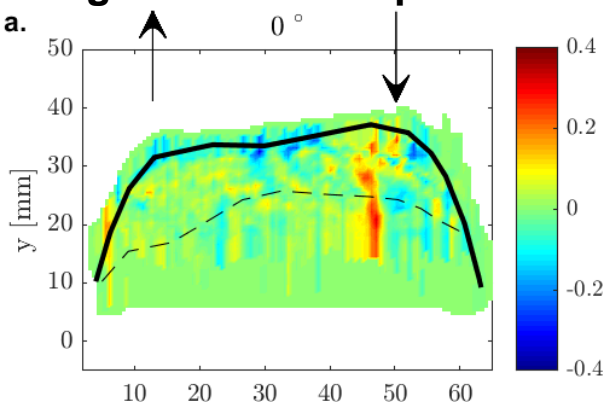

c.

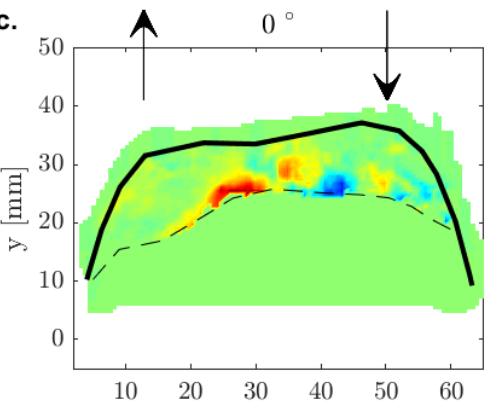

e.
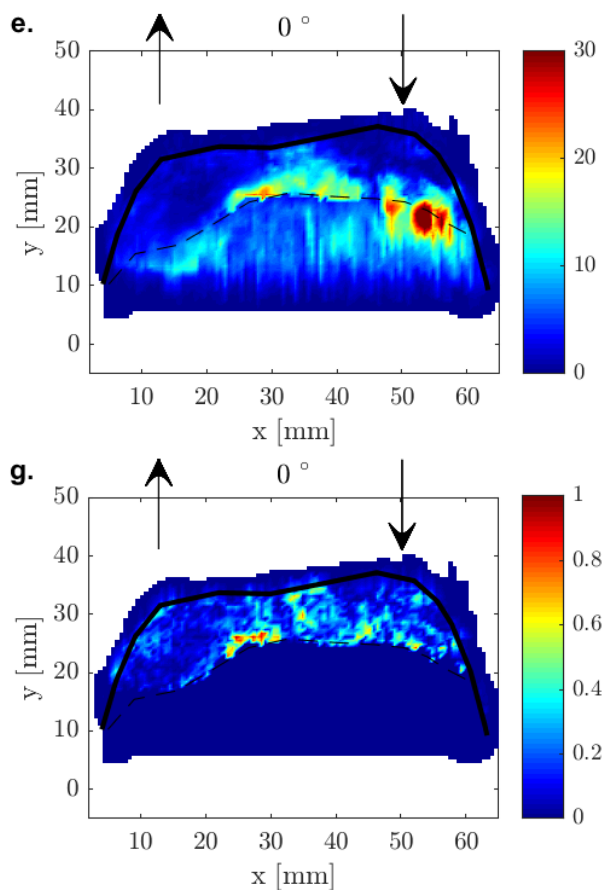

b.

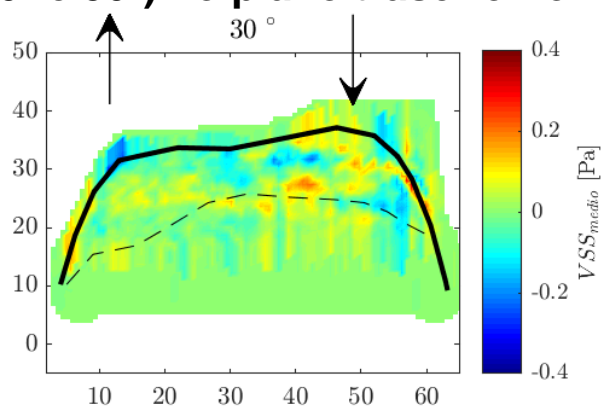

d.

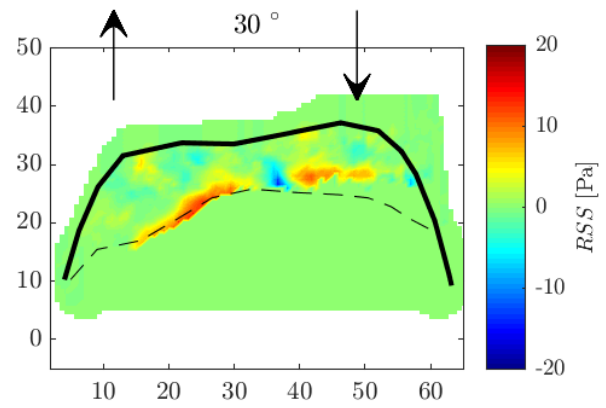

f.

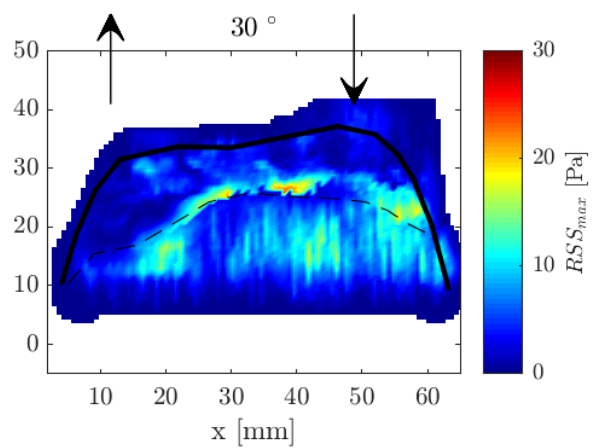

h.

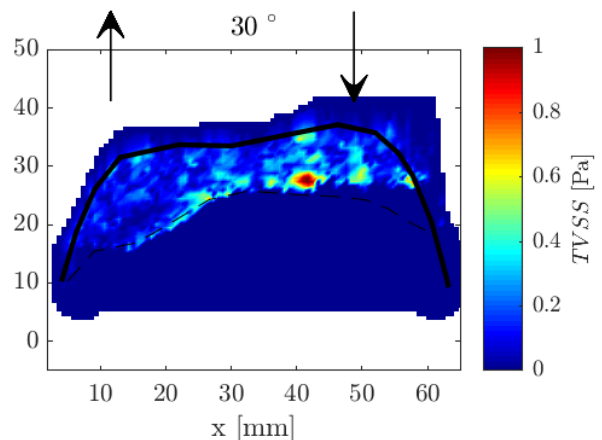

Vista lateral

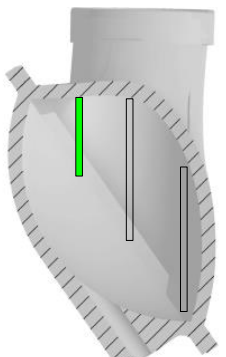

A evolução temporal de VSS para o plano médio (Figura 101), avaliada em $Y=$ $40 \mathrm{~mm}\left(0^{\circ}\right)$ e $\mathrm{Y}=45 \mathrm{~mm}\left(30^{\circ}\right)$, exibe regiões muito próximas à parede de entrada com valores de $1 \mathrm{~Pa}$ durante todo o intervalo. Para $0^{\circ}$ as faixas de $1 \mathrm{~Pa}$ são bem nítidas, ao contrário de $30^{\circ}$ que exibe uma faixa que intercala regiões de $1 \mathrm{~Pa}$ com $0 \mathrm{~Pa}$. Por outro lado, a parede de saída para $30^{\circ}$ muda o sentido do VSS, de -0,5 Pa para 0,5 $\mathrm{Pa}$ enquanto $0^{\circ}$ permanece positivo durante todo o intervalo. 
Figura 101 - Evolução temporal de VSS próximo à parede no plano médio em $\mathrm{t}_{2}$
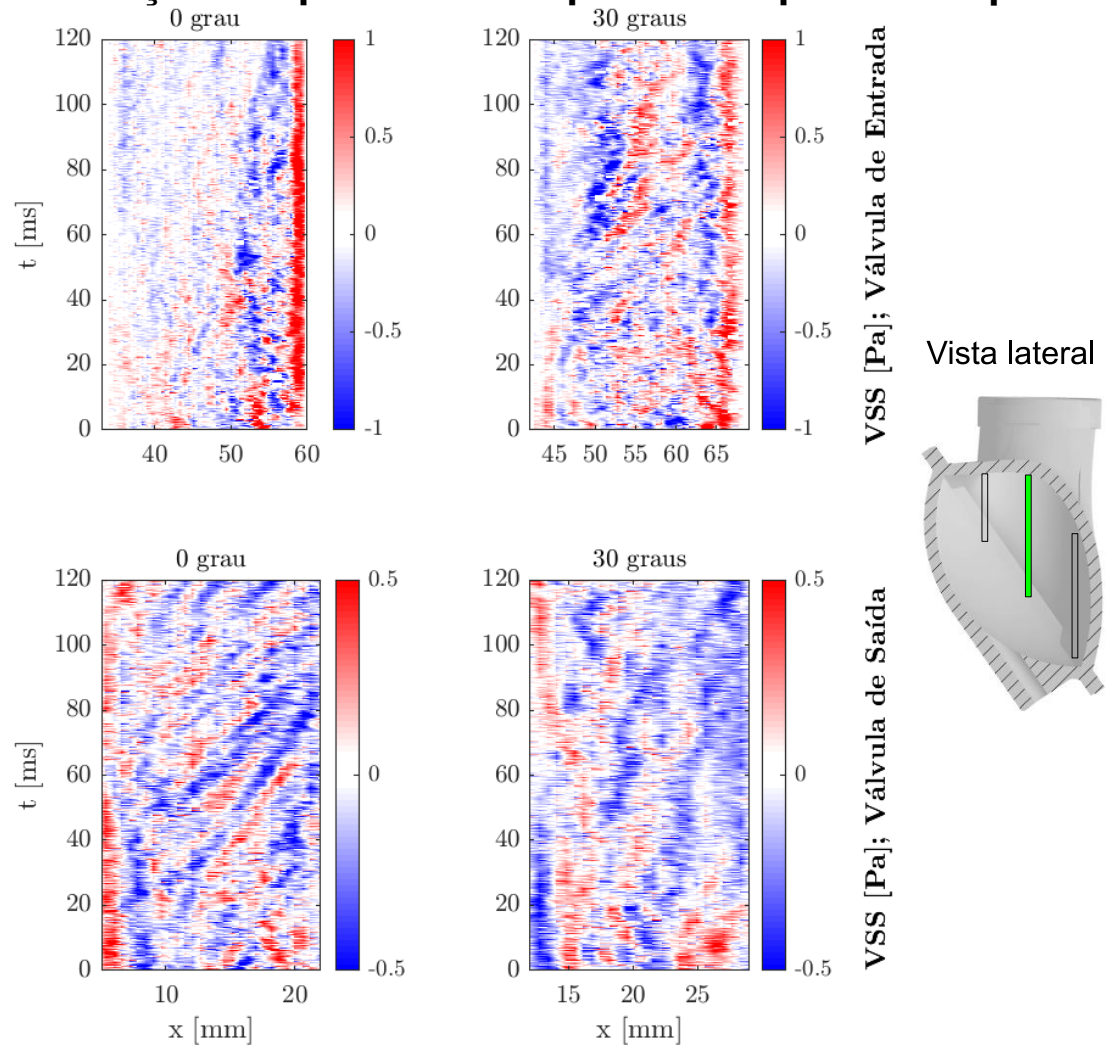

O RSS para $0^{\circ}$ exibe um comportamento com valores máximos e mínimos distribuídos por todo o campo, no plano frontal (Figura 98c) e médio (Figura 99c). Provavelmente, isto se deve à mudança de sentido em ū. Os campos para $30^{\circ}$ no plano frontal e médio possuíram uma zona bem definida de altos valores de RSS na entrada do DAVP.

O TKE (Figura 102) para o intervalo de 20 a $40 \%$ da diástole novamente apresentou comportamento semelhante ao observado no RSS max. Valores acima de $0,15 \mathrm{~m}^{2} / \mathrm{s}^{2}$ estão dentro do jato diastólico para 0ำ e 30․ Como o cisalhamento foi maior neste intervalo, a produção de turbulência também foi.

Figura 102 - Campos de TKE ( $0^{\circ}$ e $\left.30^{\circ}\right)$ no plano médio no intervalo t 2

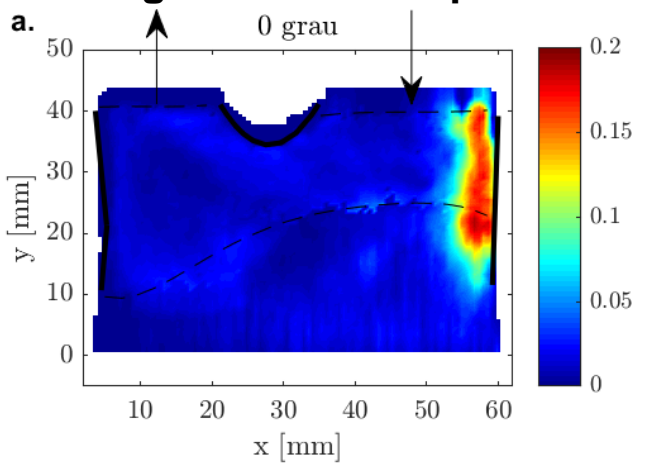

b.

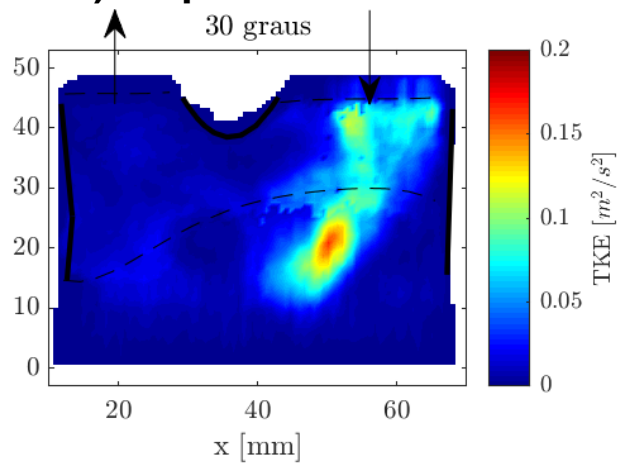

Vista lateral

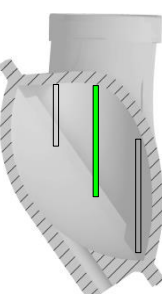




\subsubsection{Intervalo de 50 a $70 \%$ da diástole ( $\left.t_{3}\right)$}

As características dos escoamentos no intervalo de 50 a $70 \%$ da diástole para as posições da válvula ( $0^{\circ}$ e $\left.30^{\circ}\right)$ são apresentadas na Figura 103, Figura 104 e Figura 105 para os planos frontal, médio e traseiro respectivamente.

Neste período, a membrana desocupa a área central do DAVP e toda a região de análise se tornou visível. A média temporal da velocidade horizontal ( $\bar{u}$ ) apresentaram nos três planos para $0^{\circ}$ e $30^{\circ}$ comportamentos semelhantes. Na parte superior dos campos, os valores foram mais altos e positivos, indicando movimento para a direita. Já na parte inferior valores negativos foram encontrados, ou seja, movimentos para a esquerda. Avaliando o plano frontal em direção ao traseiro, as regiões de valores máximos aumentaram e as regiões negativas diminuíram.

Figura 103 - Campos de velocidades $\left(0^{\circ}\right.$ e $\left.30^{\circ}\right)$ no plano frontal no intervalo $t_{3}$

a.

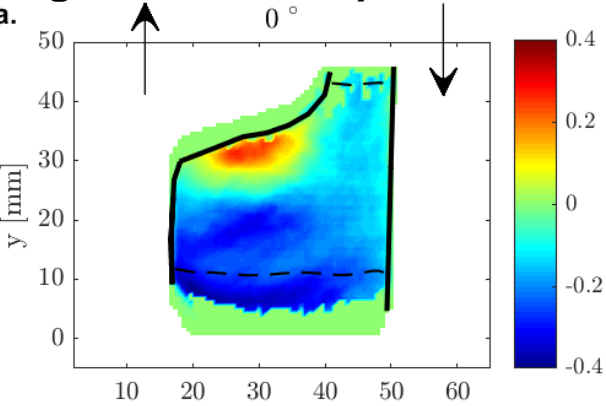

c.

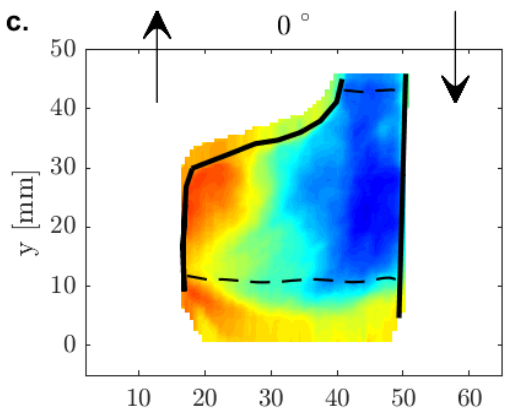

e.

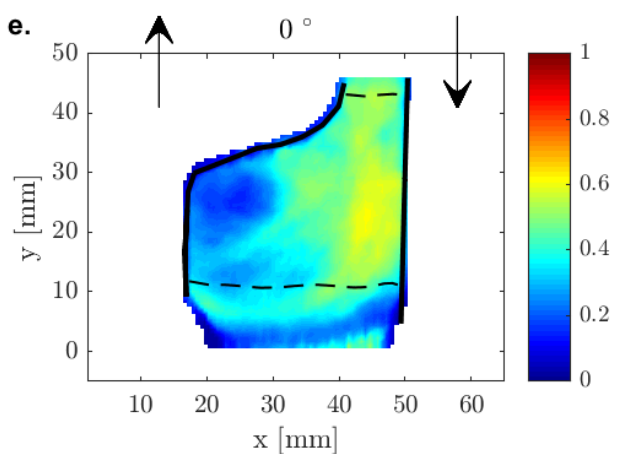

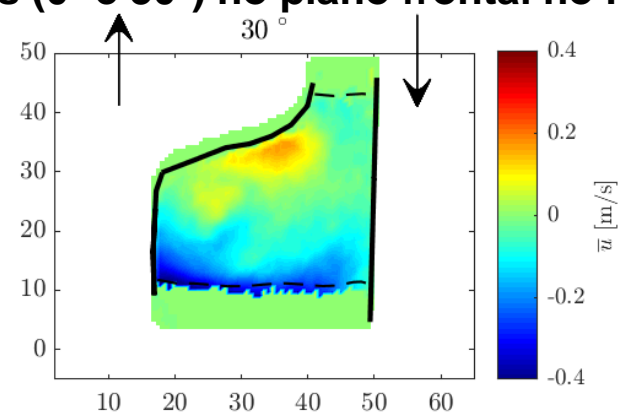

d.

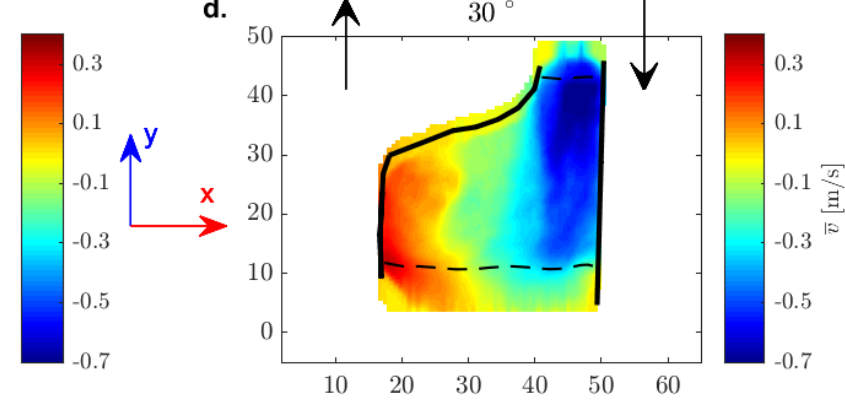

f.

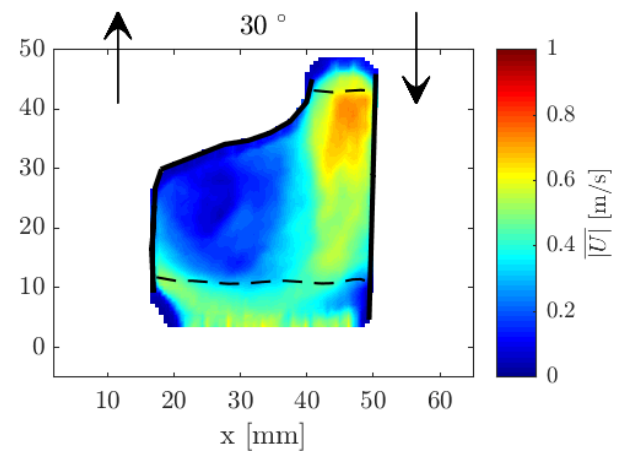

Vista lateral

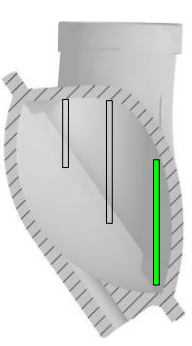


Figura 104 - Campos de velocidades $\left(0^{\circ}\right.$ e $\left.30^{\circ}\right)$ no plano médio no intervalo $t_{3}$
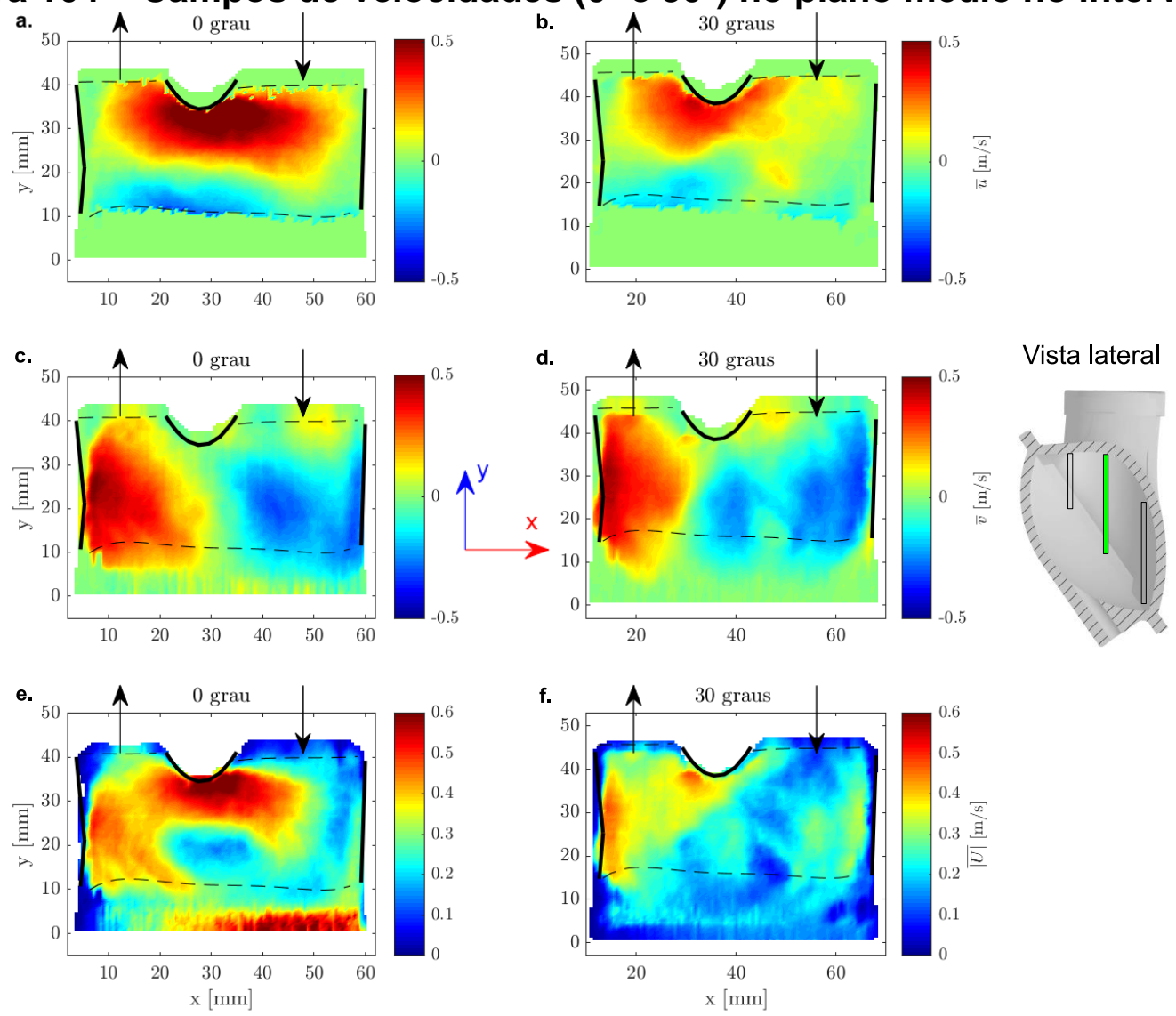

Figura 105 - Campos de velocidades ( $\left(0^{\circ}\right.$ e $\left.3^{\circ}\right)$ no plano traseiro no intervalo $t_{3}$
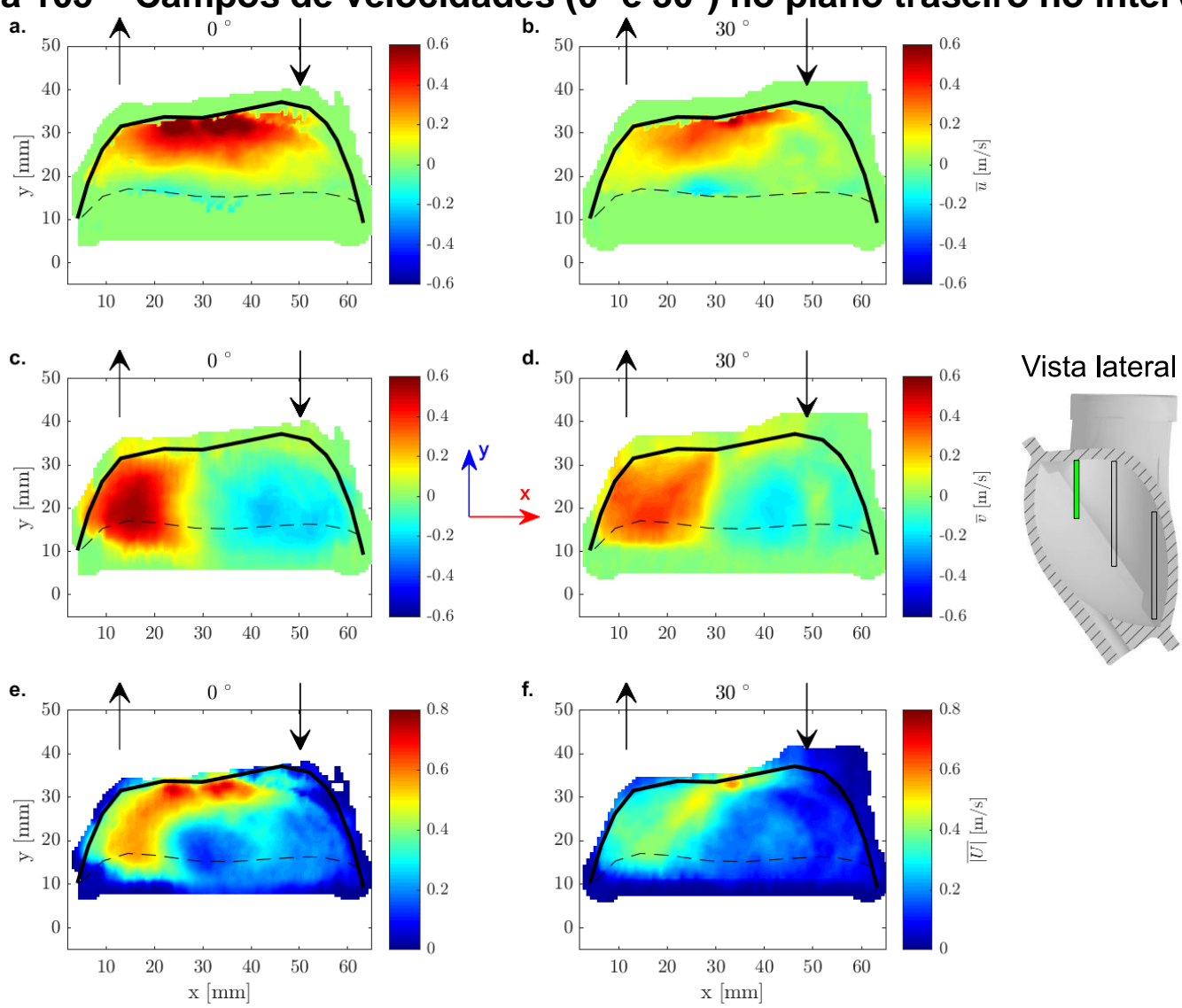
Um comportamento semelhante também foi observado nos campos da média temporal da velocidade vertical $(\overline{\mathrm{v}})$. Uma zona de velocidades negativas persiste na parede direita, ao mesmo tempo que surge uma zona na parede esquerda com sentido oposto. Desta vez, no plano frontal as regiões com velocidades negativas são maiores e vão diminuindo gradativamente nos outros planos.

Focando na magnitude média (|Ū|), observa-se, principalmente no plano médio, um grande movimento rotacional cujo centro é próximo ao centro geométrico da seção transversal. No plano frontal, percebeu-se apenas a parte inferior deste grande vórtice, bem como no plano traseiro, é nítida apenas a parte superior. O movimento tridimensional é mais intenso nesse momento, pois a membrana já deixou o plano médio e neste instante $o$ jato diastólico predominou no plano frontal. Esta grande estrutura vortical observada nos planos é importante pois promove a lavagem do dispositivo. A lavagem é essencial e evita regiões de estagnação no dispositivo que tendem a formar trombos.

A Figura 106 exibe a disparidade entre a intensidade da magnitude de velocidade $(|\mathrm{U}|)$ entre $0^{\circ}$ e $30^{\circ}$ na região entre as válvulas no plano médio. Isto é claro em P5 e P6 onde $0^{\circ}$ varia entre 0,4 e $0,8 \mathrm{~m} / \mathrm{s}$ e $30^{\circ}$ fica entre 0,2 e $0,4 \mathrm{~m} / \mathrm{s}$.

Figura 106 - Evolução temporal de u e e $\underset{|W|}{|U|} \mid$ entre as válvulas do DAVP em t3
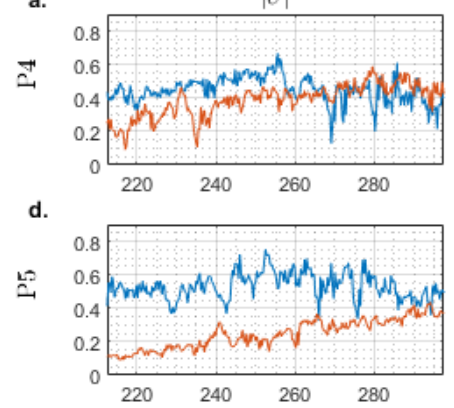

g.

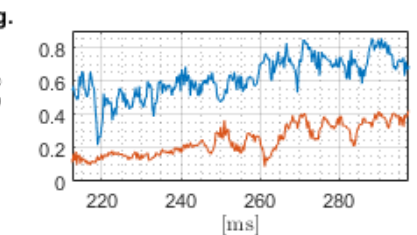

Azul - 0; vermelho - $30^{\circ}$ graus

As tensões médias são exibidas a seguir para os planos frontal (Figura 107), médio (Figura 108) e traseiro (Figura 109). 
Figura 107 - Campos de tensões $\left(0^{\circ}\right.$ e $\left.30^{\circ}\right)$ no plano frontal no intervalo $t_{3}$
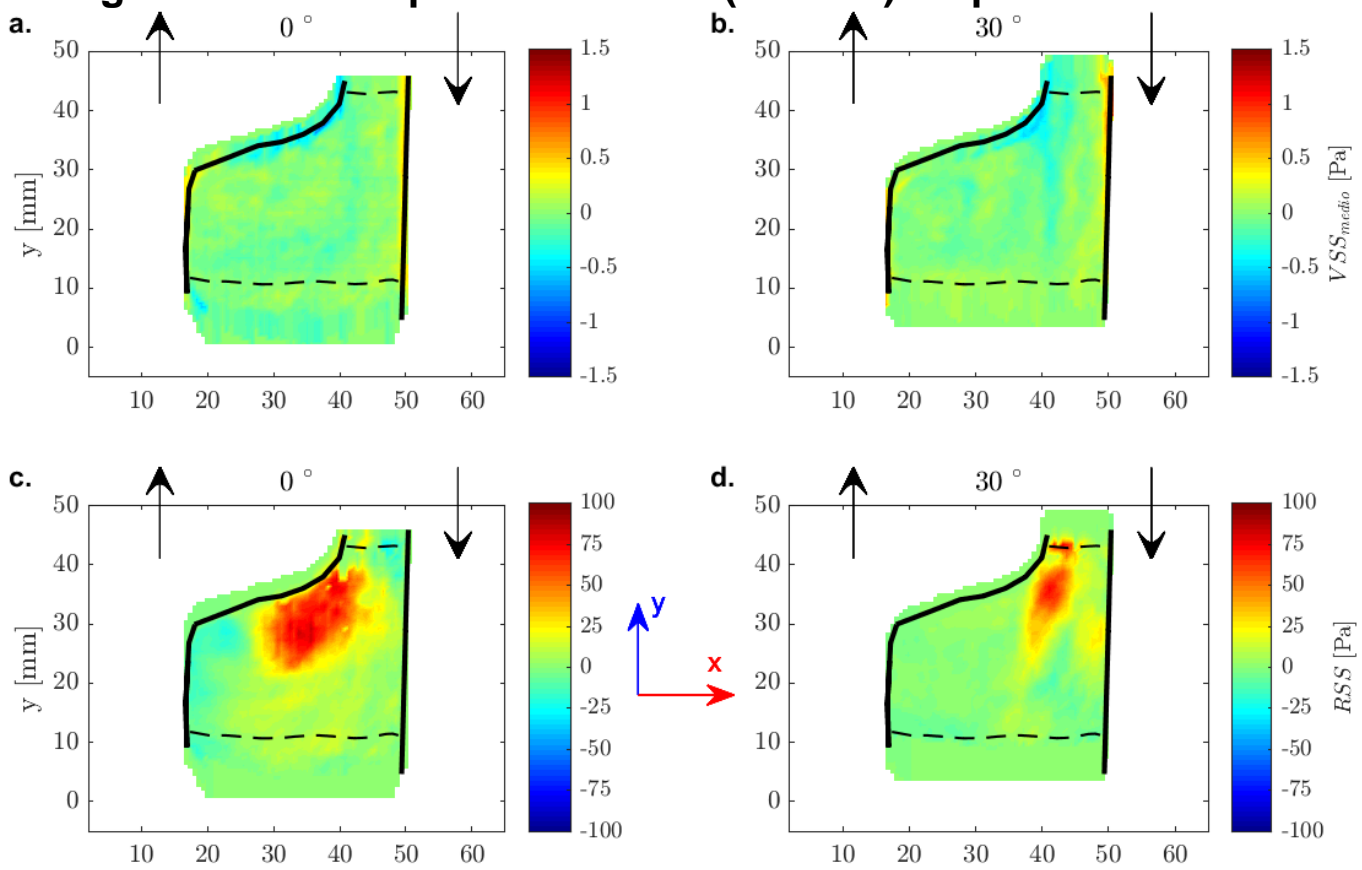

Vista lateral

e.
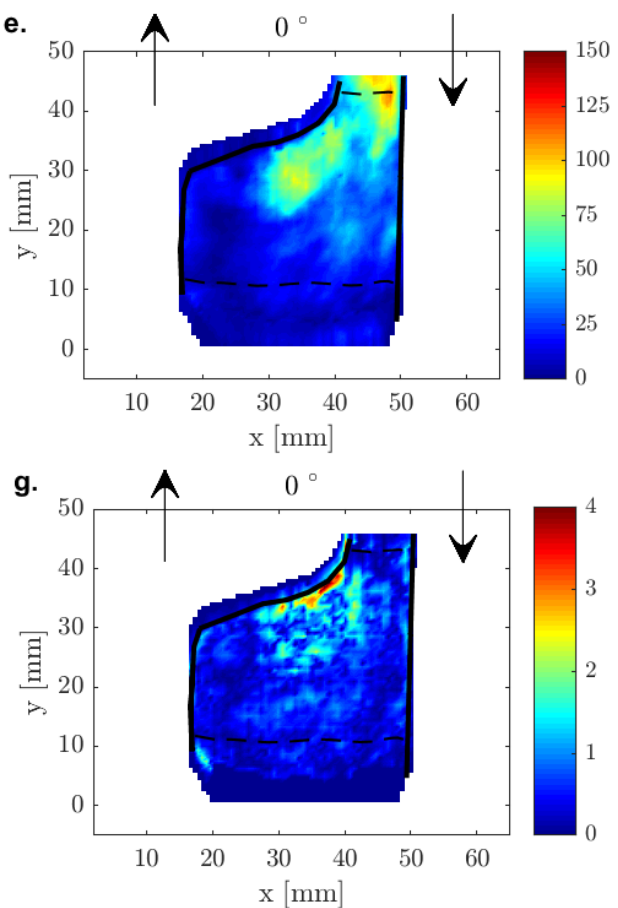

f.

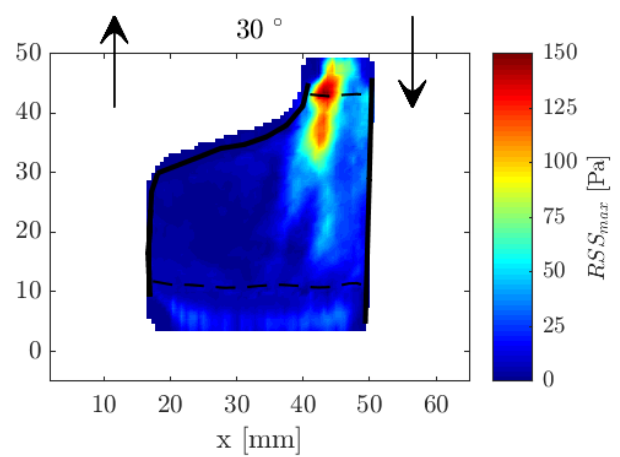

h.

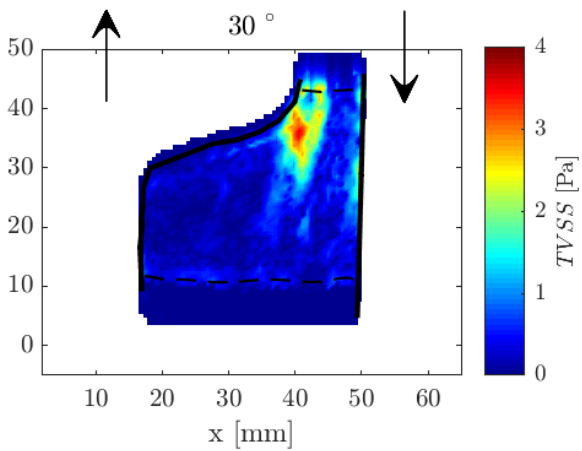

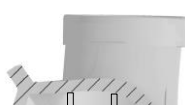


Figura 108 - Campos de tensões $\left(0^{\circ}\right.$ e $\left.30^{\circ}\right)$ no plano médio no intervalo t3
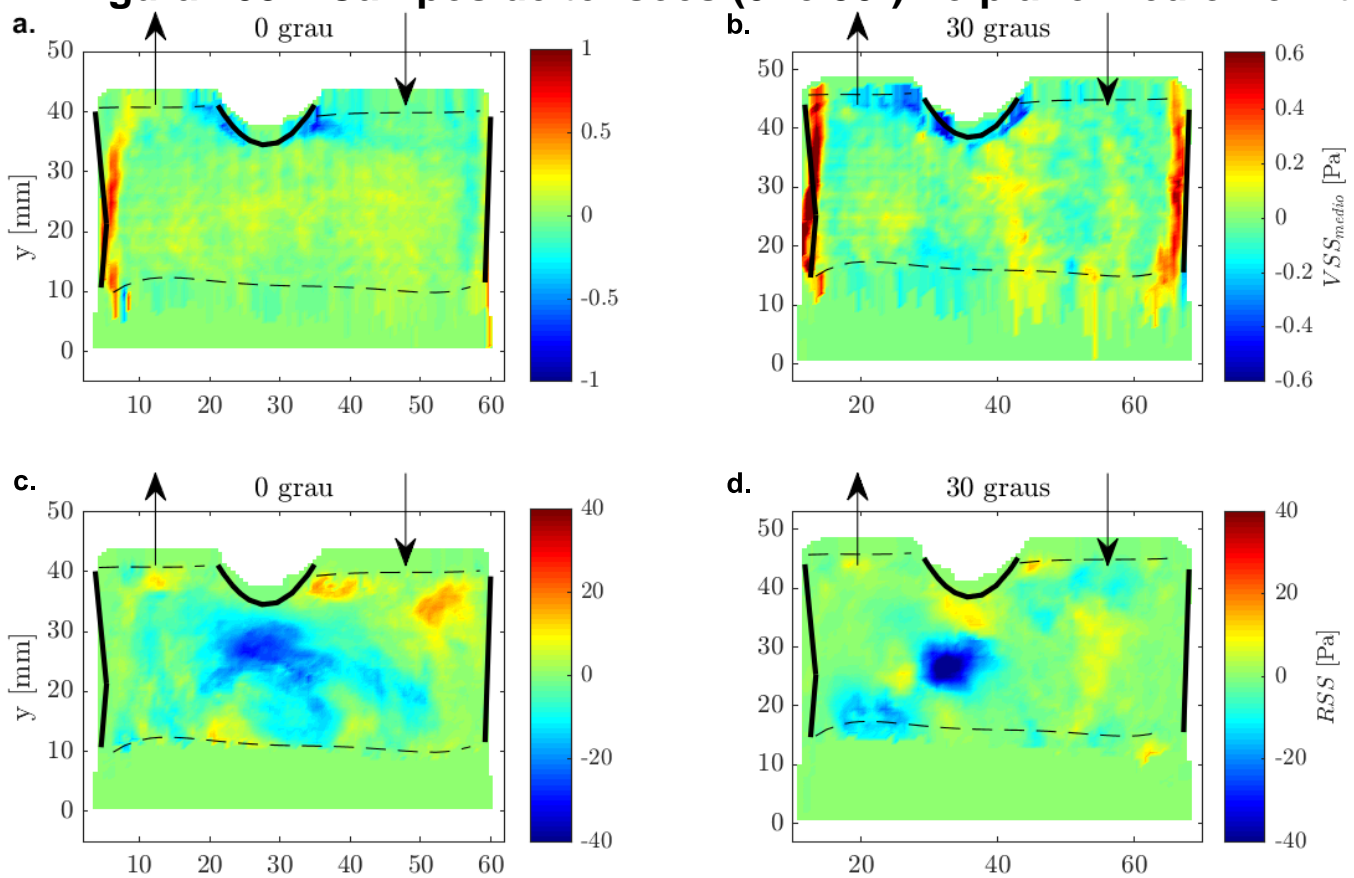

Vista lateral

e.
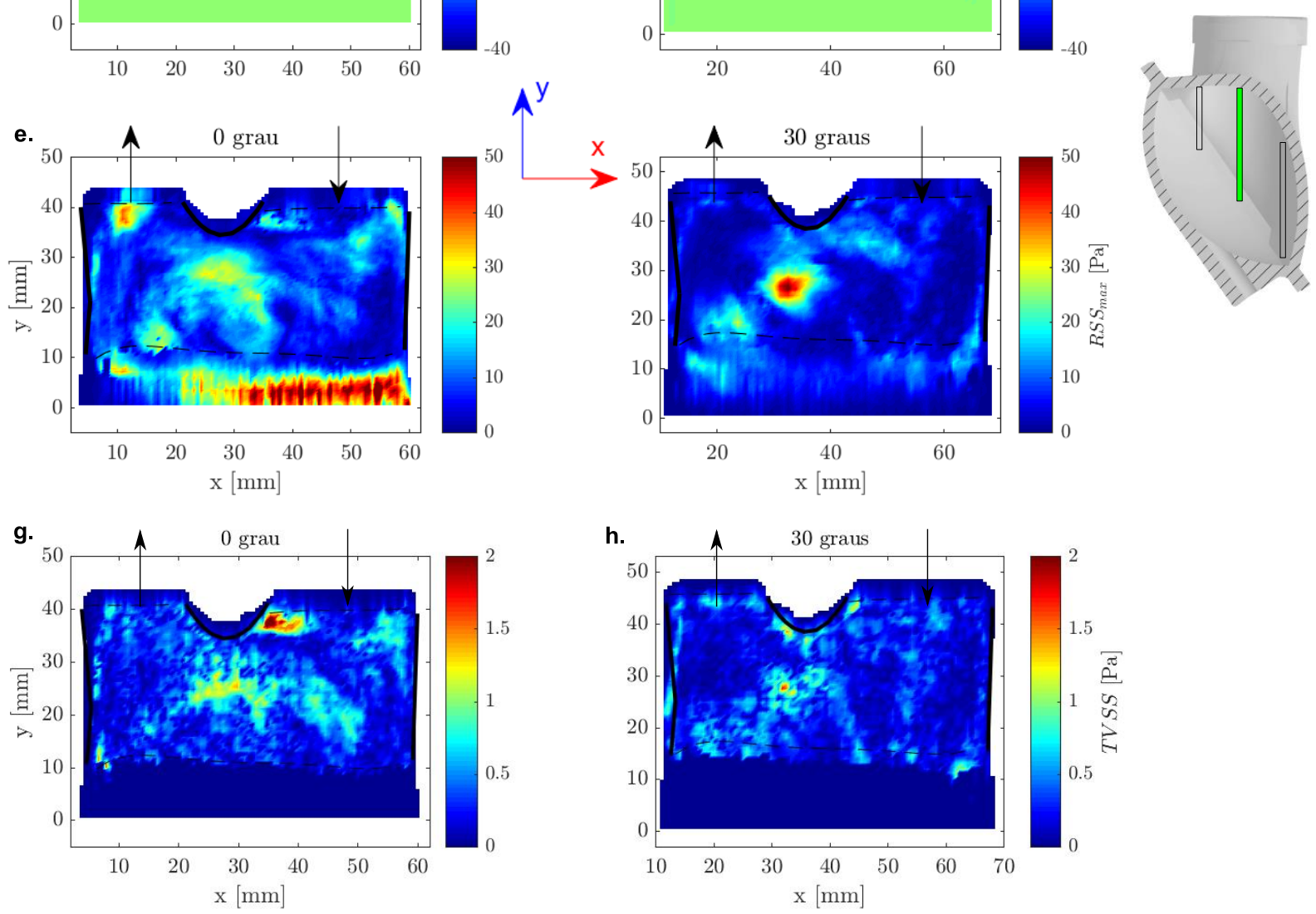
Figura 109 - Campos de tensões $\left(0^{\circ}\right.$ e $\left.30^{\circ}\right)$ no plano traseiro no intervalo $t_{3}$

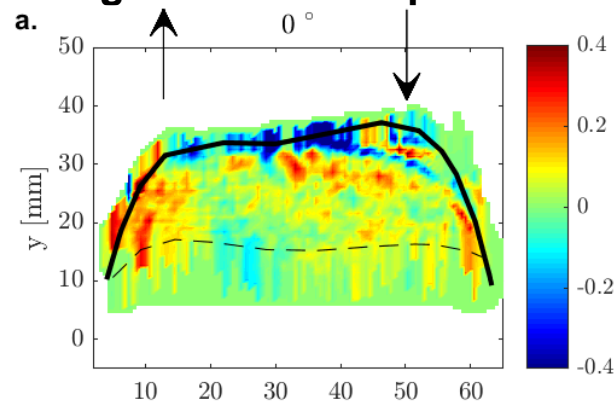

b.

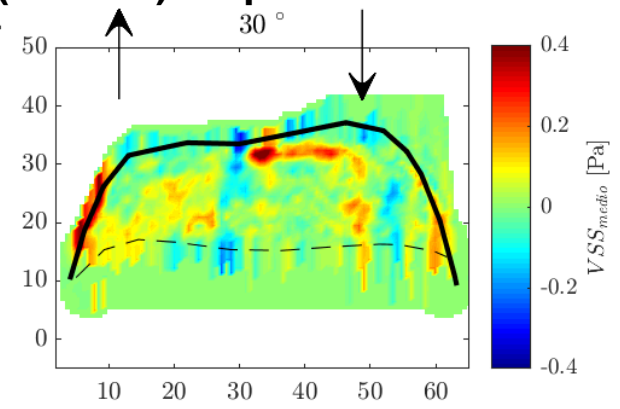

.

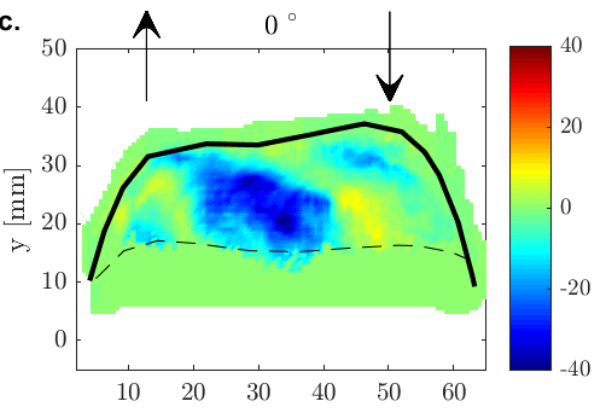

e.

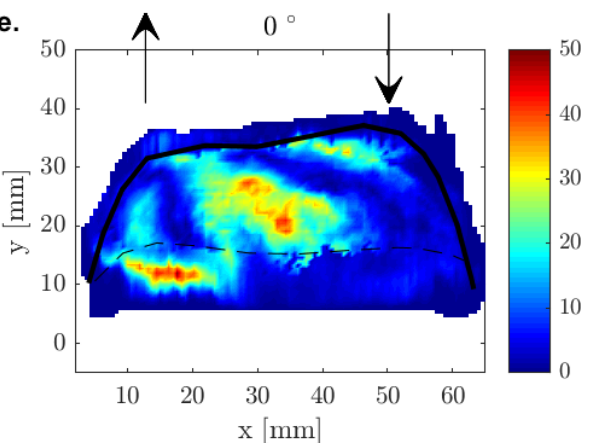

g.

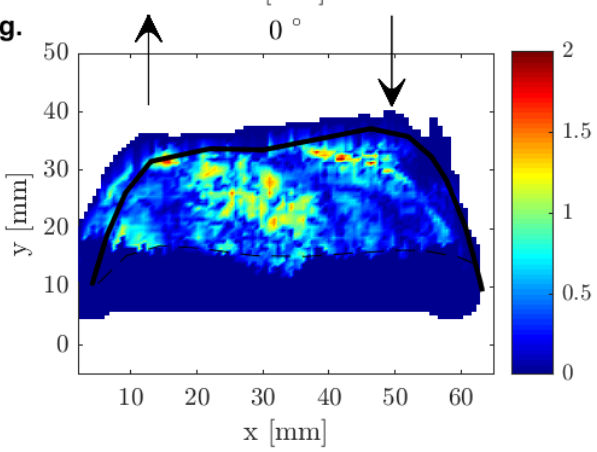

d.

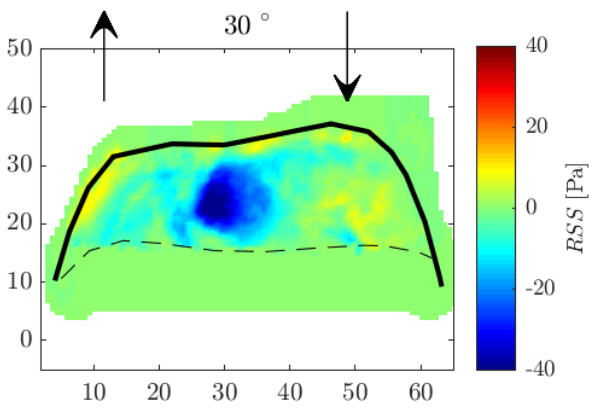

f.

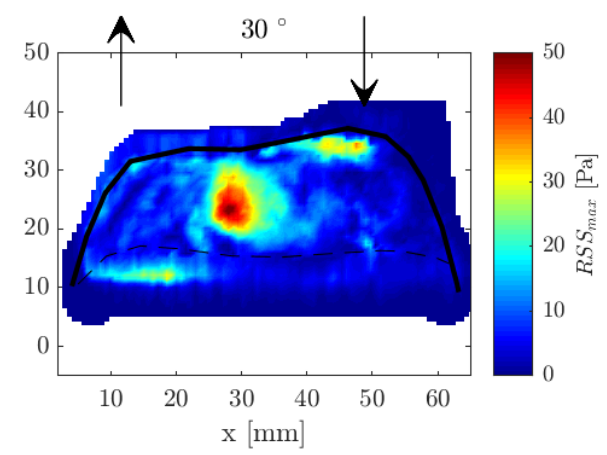

h.

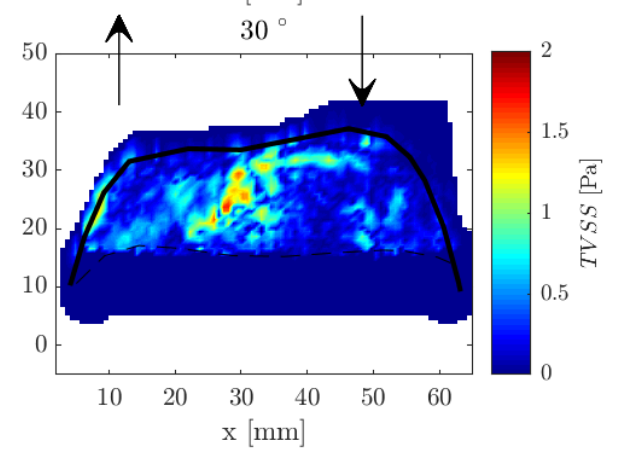

Vista lateral

O movimento rotacional condicionou o fluxo para mais próximo de todas as paredes. Isto criou uma faixa de $\overline{V S S}$ na parede esquerda e direita. Os valores máximos permaneceram os mesmos de t2. Para o plano traseira houve ainda uma terceira região de máximos, na parede superior entre as válvulas de entrada e saída (mais nítido na Figura 109b).

A evolução de VSS temporal no plano médio (Figura 110) nas linhas $Y=40$ $\mathrm{mm}\left(0^{\circ}\right)$ e $\mathrm{Y}=45 \mathrm{~mm}\left(30^{\circ}\right)$ diferem para os dois ângulos de posicionamento da válvula 
de entrada. No caso $0^{\circ}$, o VSS na parede direita é positivo no início do intervalo e torna-se negativo do meio para o final do intervalo. Como os valores negativos e positivos são relativamente próximos, contribuíram para a média nula observada na Figura 108a. Já no caso 30ํㅡㄹ a tensão permanece positiva. Na saída nota-se tensões mais baixas e numa faixa mais estreita quando se compara $0^{\circ}$ e $30^{\circ}$.

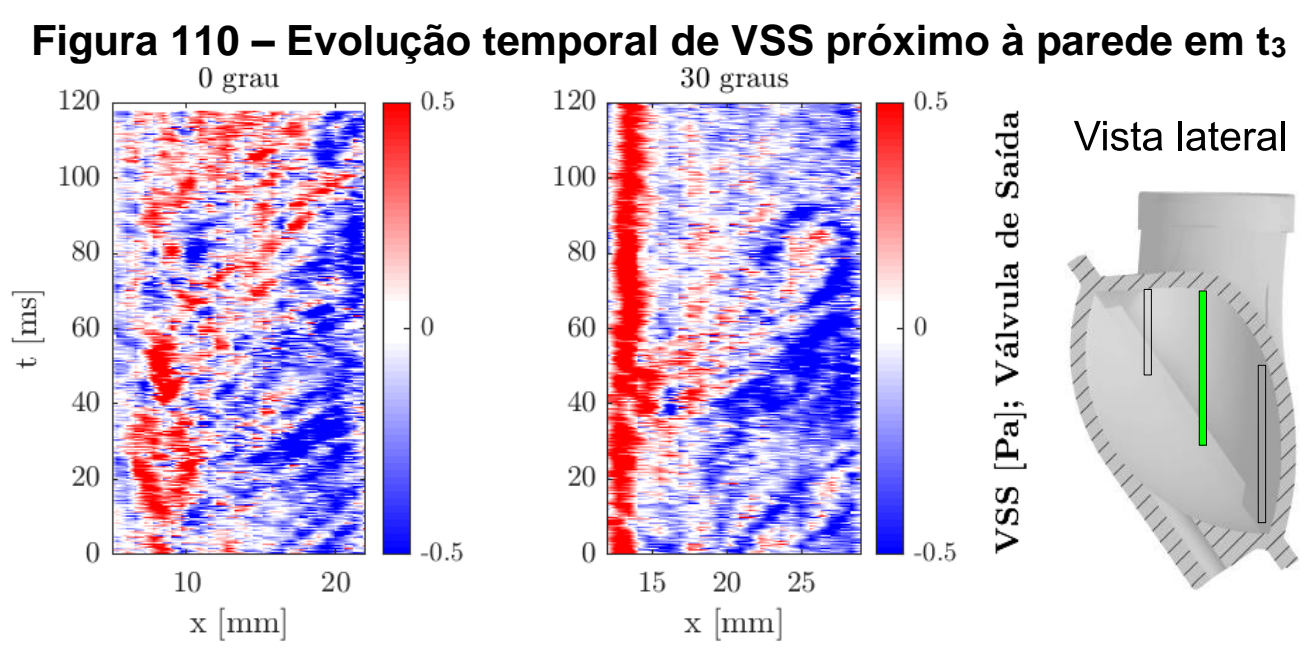

Os valores de RSS e RSS max foram altos no plano frontal e estavam dentro da região do jato diastólico. Já nos planos médio e traseiro, os valores de RSS foram

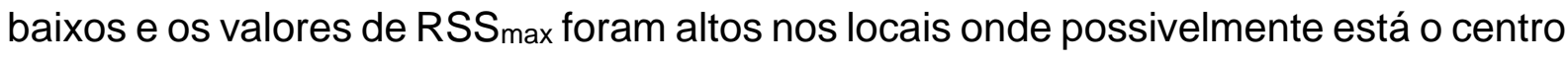
do grande vórtice. A flutuação das velocidades instantâneas u e v são, provavelmente, a causa primária destas regiões com tensões mínimas e máximas de RSS e RSS max, respectivamente.

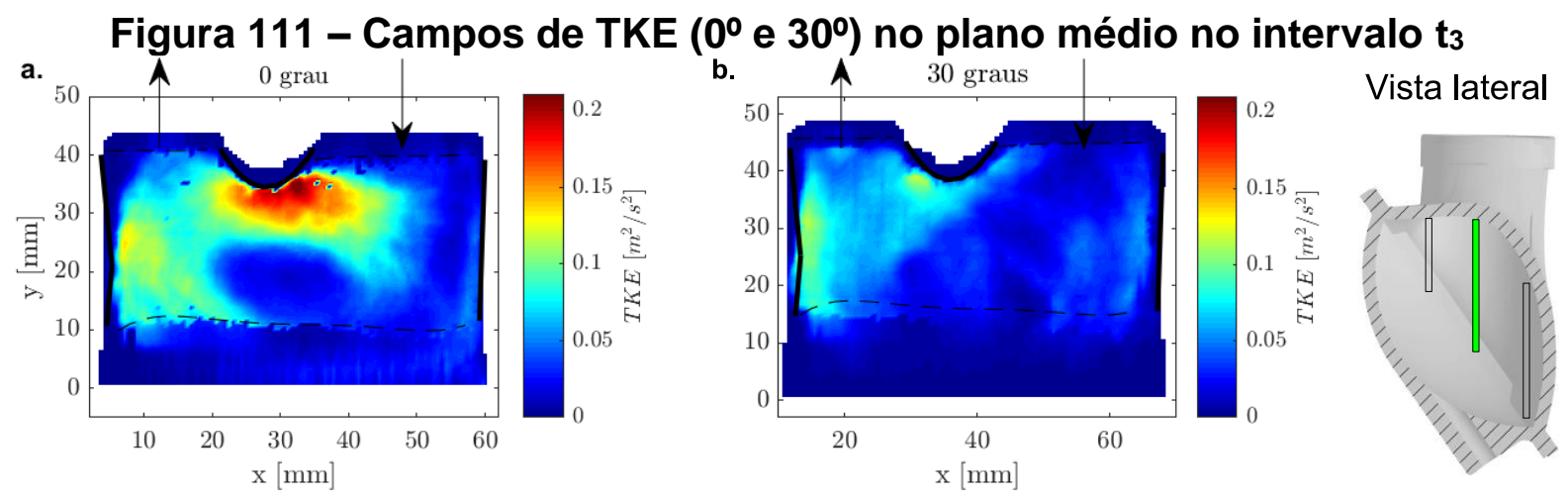

O TKE para o intervalo t3 não apresentou semelhanças ao RSS max no plano médio, como fora observado nos intervalos $t_{1}$ e t2. No campo (Figura 111) para $0^{\circ} a$ região mais intensa está concentrada entre as válvula, além de uma região com 
valores em torno de $0,1 \mathrm{~m}^{2} / \mathrm{s}^{2}$ que envolve grande parte do vórtice de lavagem do DAVP. Para o caso 30, o TKE concentrou-se na parede esquerda e não ultrapassou $0,1 \mathrm{~m}^{2} / \mathrm{s}^{2}$. Infere-se nesta situação que o caso $0^{\circ}$ teve pouca intervenção das tensões na produção da turbulência, ao passo que o caso $30^{\circ}$ teve grande influência de VSS na turbulência gerada dentro do dispositivo.

\subsubsection{Intervalo de 0 a $20 \%$ da sístole ( $\left.t_{4}\right)$}

As características dos escoamentos no intervalo de 0 a $20 \%$ da sístole para a posição da válvula a $0^{\circ}$ e $30^{\circ}$ são apresentadas para os três planos na (Figura 112, Figura 113 e Figura 114).

Figura 112 - Campos de velocidades $\left(0^{\circ}\right.$ e $\left.30^{\circ}\right)$ no plano frontal no intervalo $t_{4}$

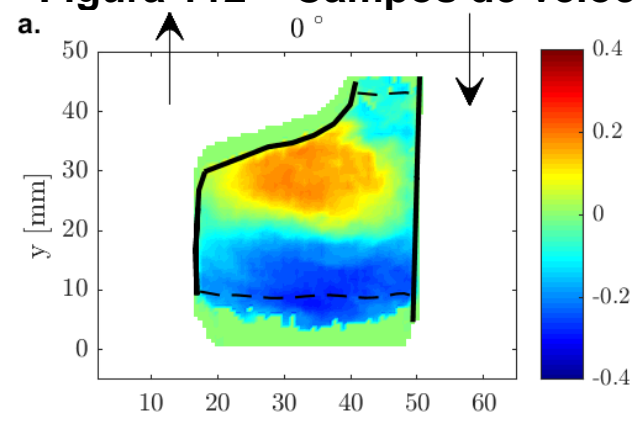

b.

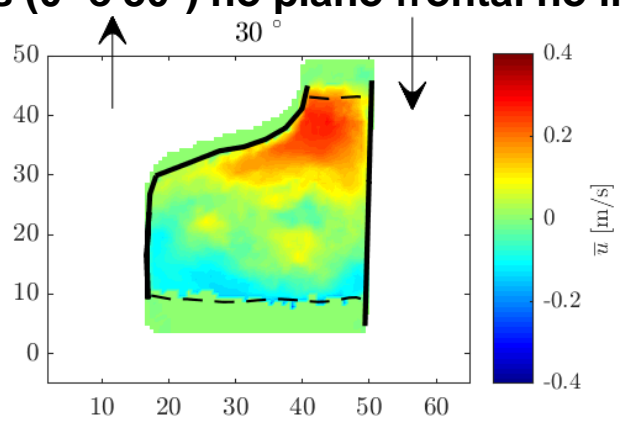

c.
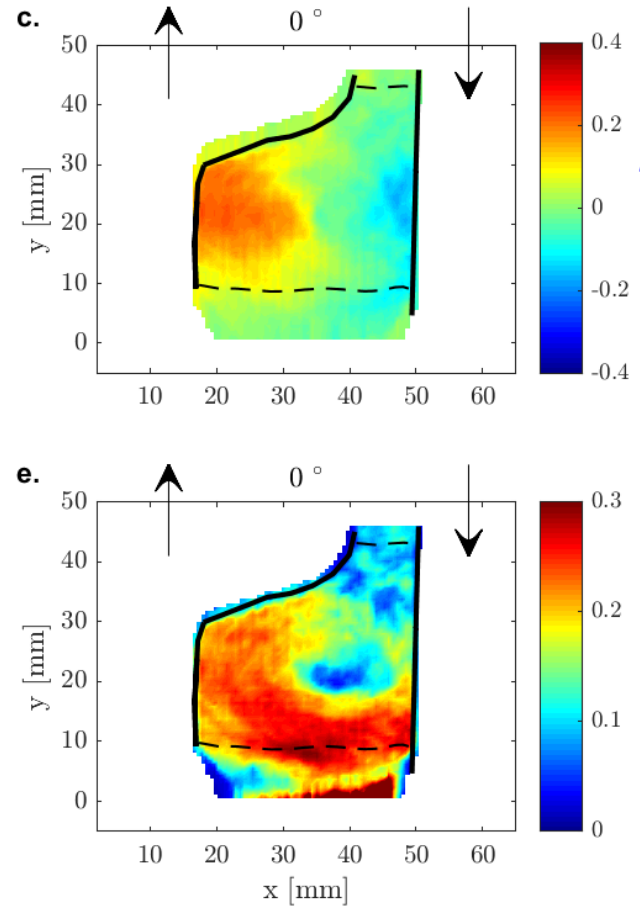

d.

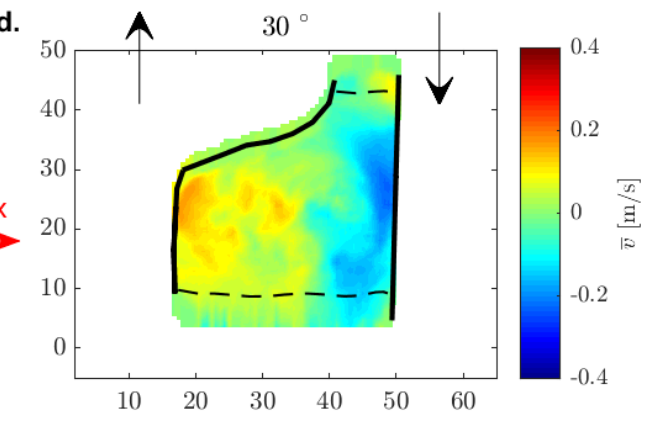

f.

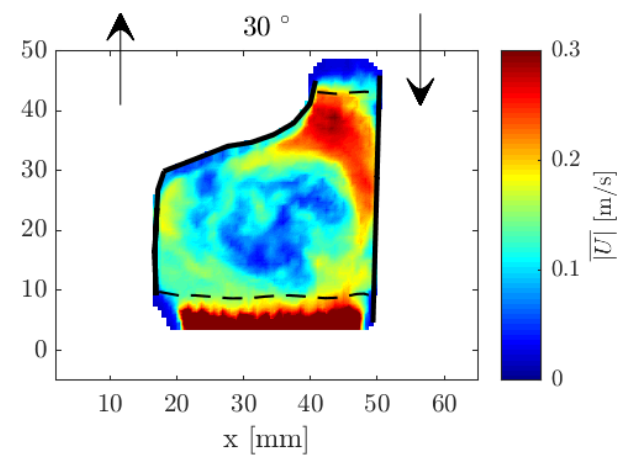

Vista lateral

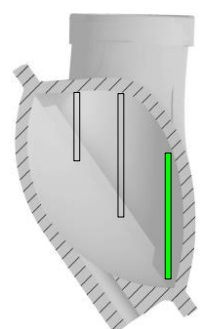


Figura 113 - Campos de velocidades ( $0^{\circ}$ e $\left.30^{\circ}\right)$ no plano médio no intervalo $t_{4}$
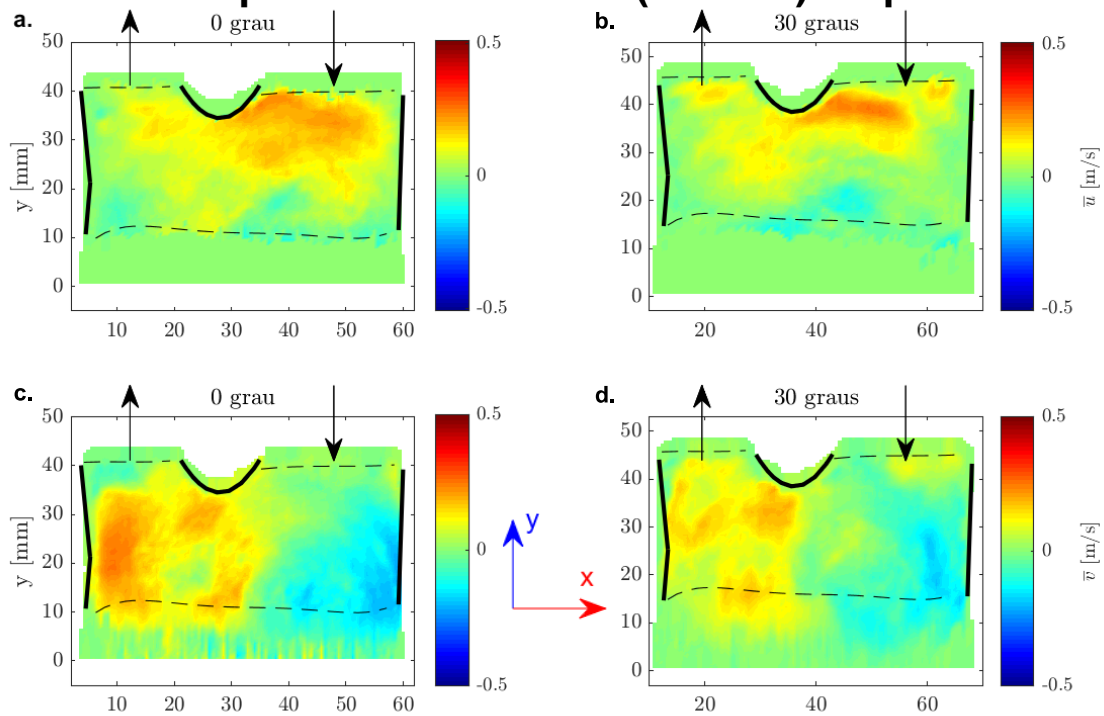

Vista lateral
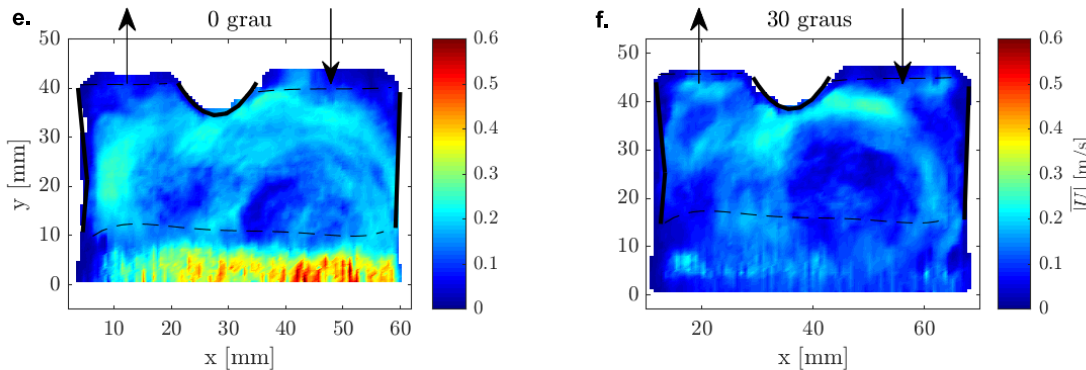

Figura 114 - Campos de velocidades ( $0^{\circ}$ e $\left.30^{\circ}\right)$ no plano traseiro no intervalo $t_{4}$
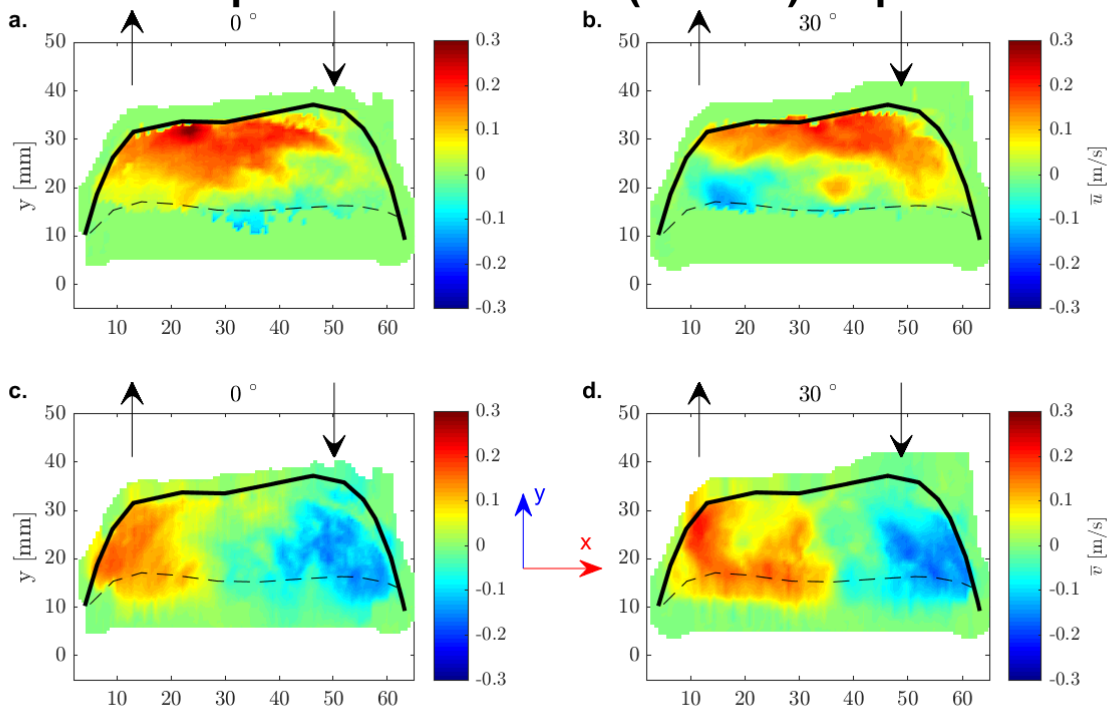

Vista lateral
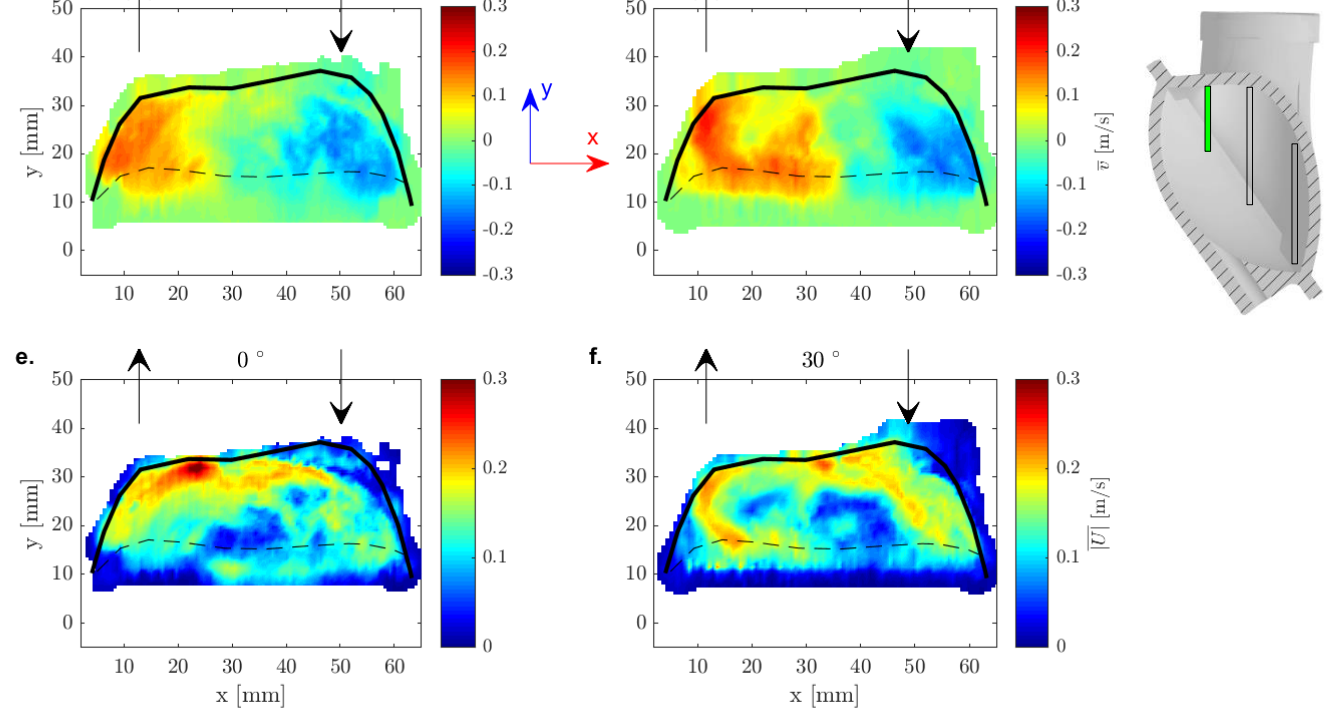
No início da sístole, o movimento rotacional induzido pela entrada de fluido permanece. A velocidade horizontal ( $\bar{u})$ e vertical $(\bar{v})$ apresentaram semelhanças aos campos observados na metade final da diástole $\left(t_{3}\right)$. As regiões com sentidos opostos de velocidade estão nos mesmos locais, tanto para ū quanto para $\bar{v}$, mas a intensidade reduziu consideravelmente nas duas posições de válvulas.

A velocidade instantânea vertical ( $v$ na Figura 115a) na região de saída do dispositivo é igual entre as duas posições de válvulas na sonda $\mathrm{P} 1$ e diferente nas sondas P2 e P3 no plano médio. Em P2 a intensidade de v é maior para 30ํe em P3 ocorre o contrário. Os campos médios sugerem que há uma leve regurgitação na válvula de entrada, confirmada por v Figura 115b. Há fluxo positivo no meio da região de entrada, representada pela sonda P8 para a válvula a 30, e na parede externa direita, representada pela sonda P9 para a válvula a 0 .

\section{Figura 115 - Evolução temporal de v no plano médio em $\mathrm{t}_{4}$}

P1

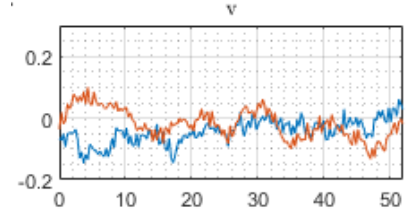

P2

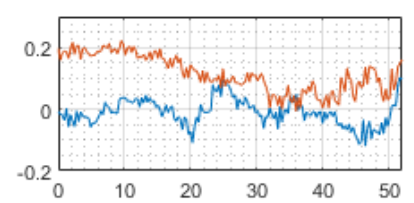

P3

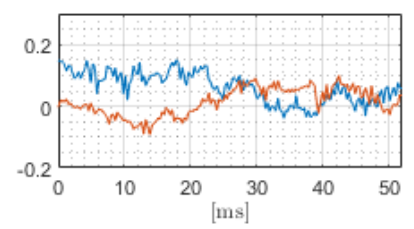

P7

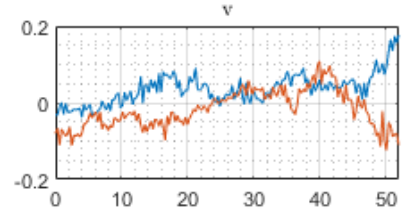

P8

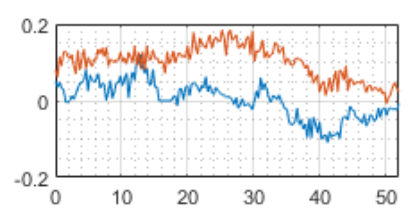

P9

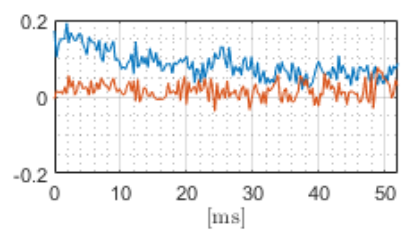

Azul - 0; vermelho - 30 graus

$\mathrm{Na}$ magnitude da velocidade destacou-se novamente o grande turbilhão no DAVP, desta vez menos intenso, o que condiz com a análise das componentes da velocidade. O centro do vórtice deslocou-se para a direita do dispositivo. Vale ressaltar a diferença entre a região da coroa circular que possuía velocidades em torno de 0,5 $\mathrm{m} / \mathrm{s}$ em t3 e agora possuem velocidades perto de $0,2 \mathrm{~m} / \mathrm{s}$ nas duas posições de válvula. Em $0^{\circ}$, a região de lavagem é bem maior do que para $30^{\circ} \mathrm{em}$ todos os planos. Analisando a tridimensionalidade do fluido, percebe-se que no plano frontal a região de lavagem possuía maior intensidade neste intervalo do que os demais planos. 
As tensões para o intervalo t4 são exibidas logo abaixo para o plano frontal (Figura 116), médio (Figura 117) e traseiro (Figura 118).
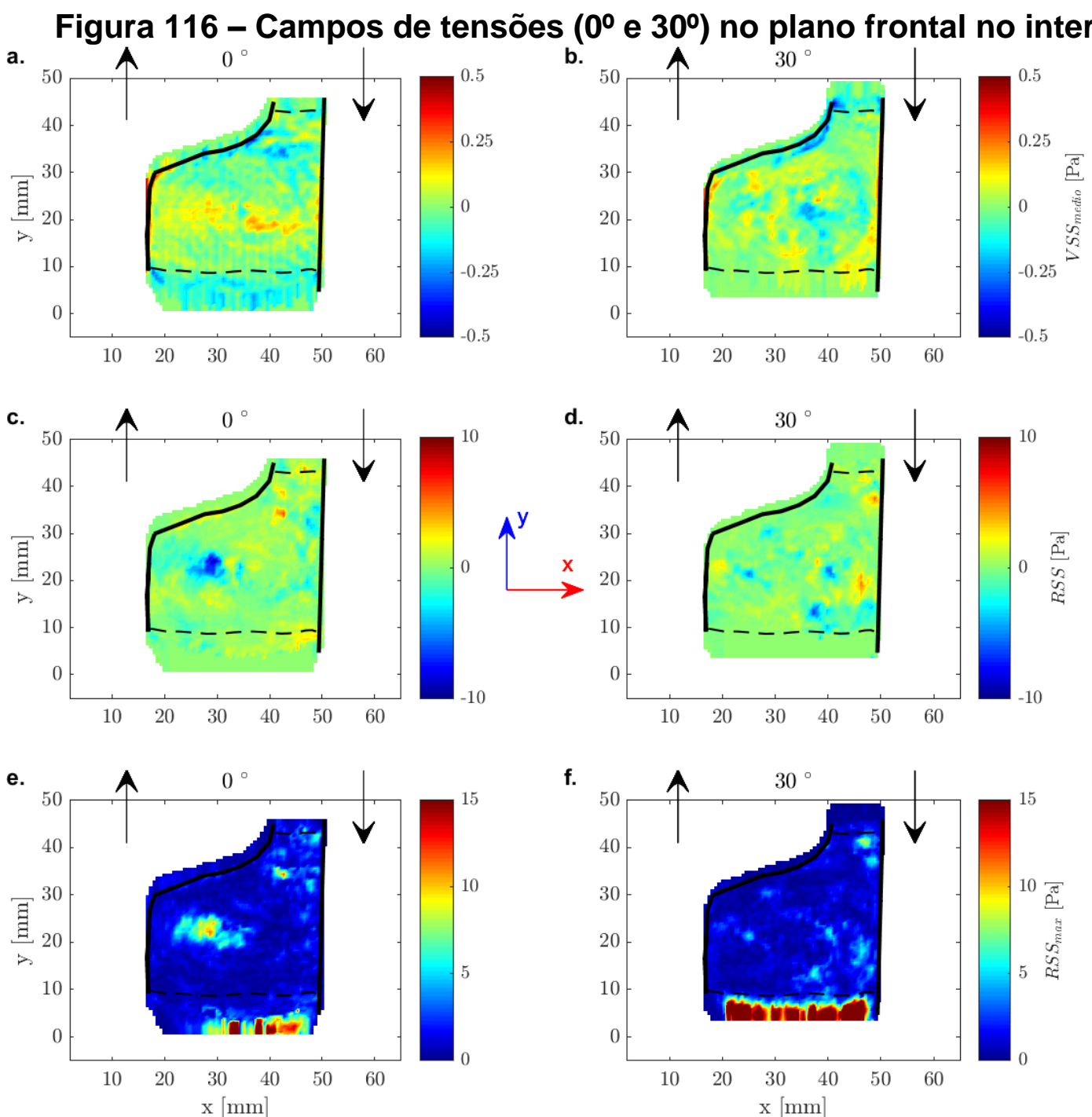

f.
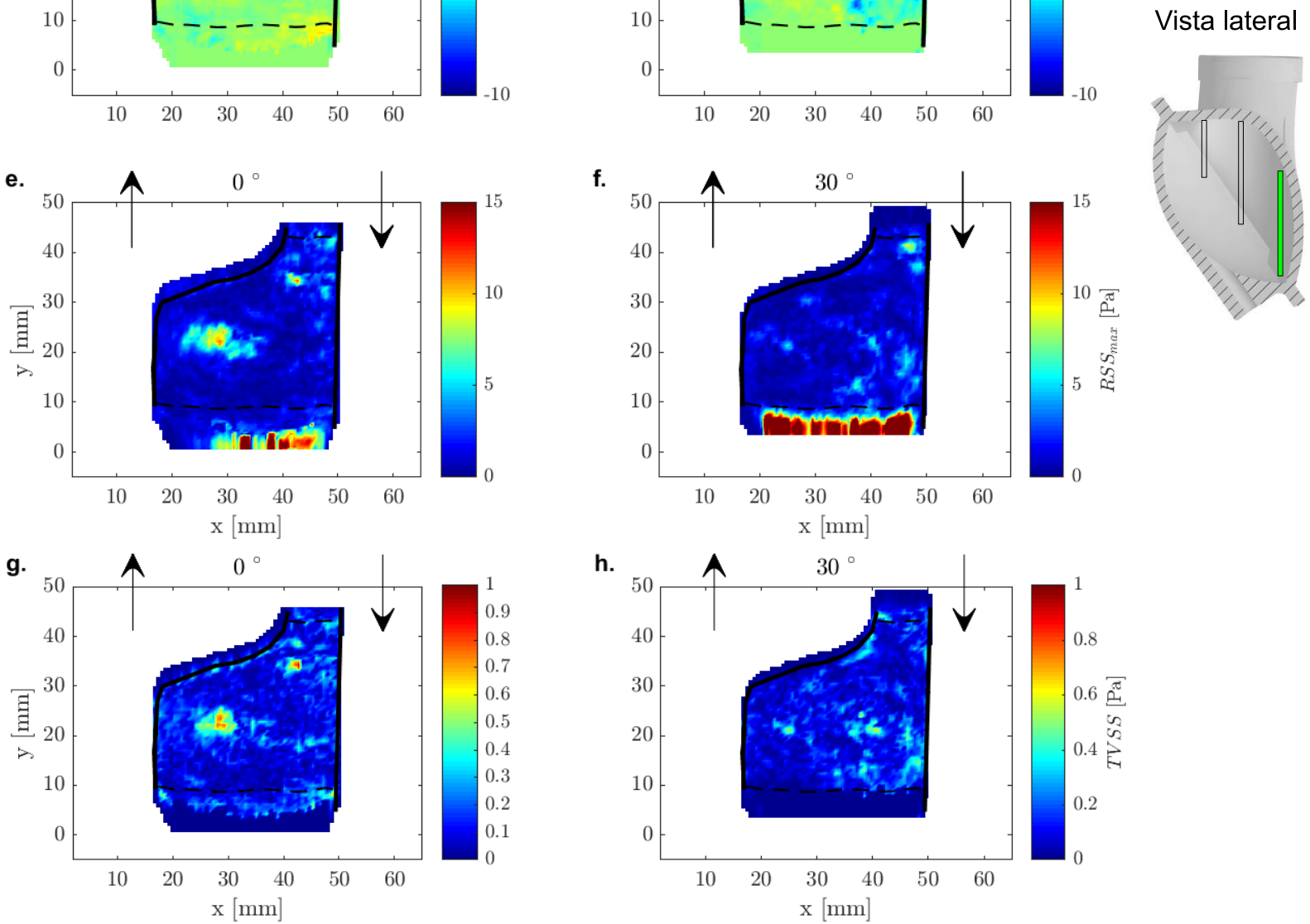
Figura 117 - Campos de tensões ( $0^{\circ}$ e $\left.30^{\circ}\right)$ no plano médio no intervalo $t_{4}$
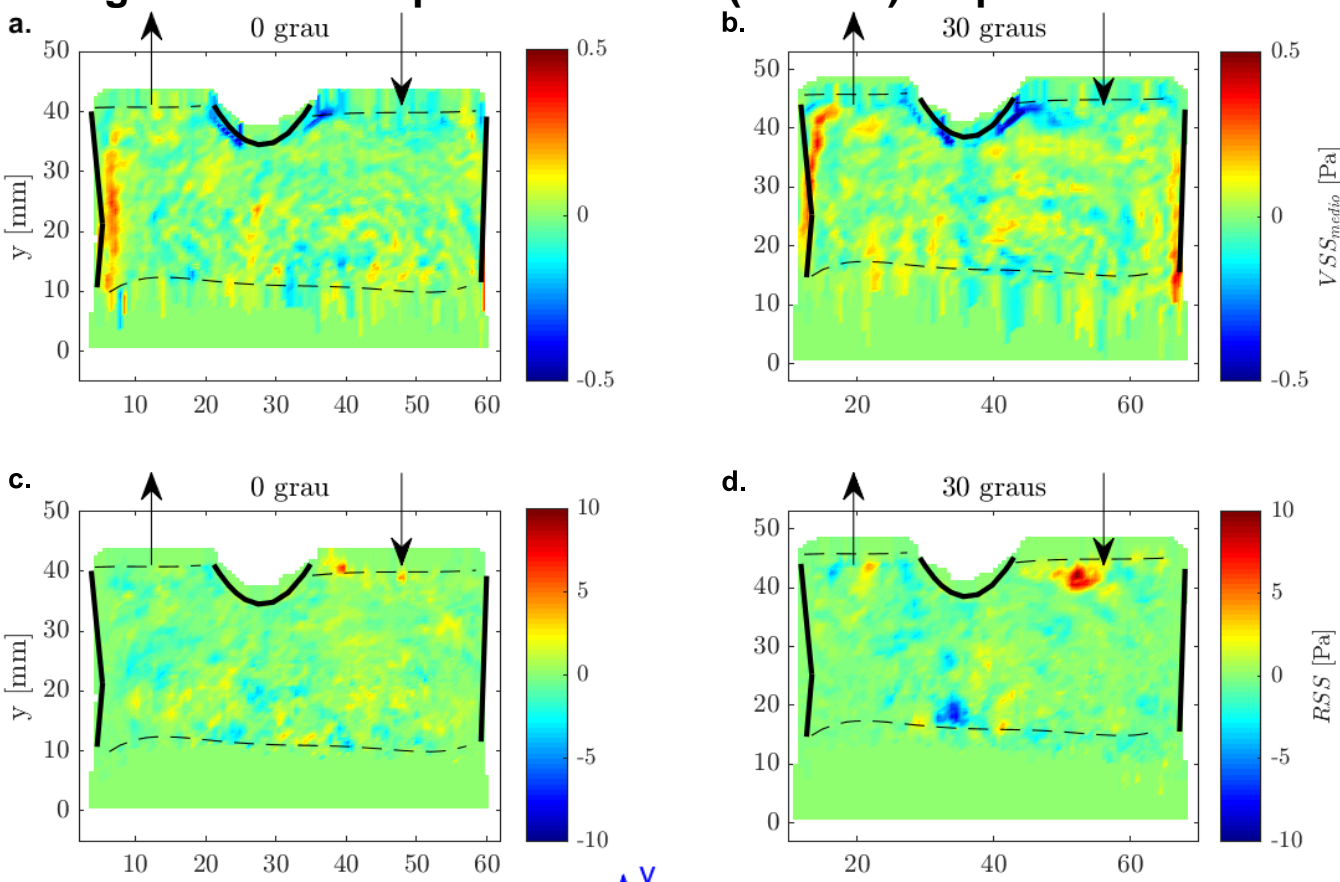

Vista lateral

e.

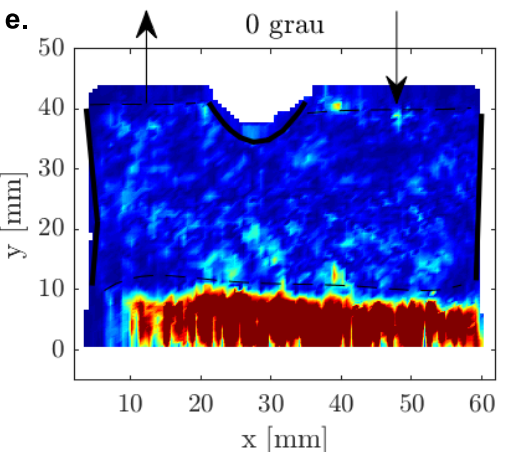

$A^{y}$
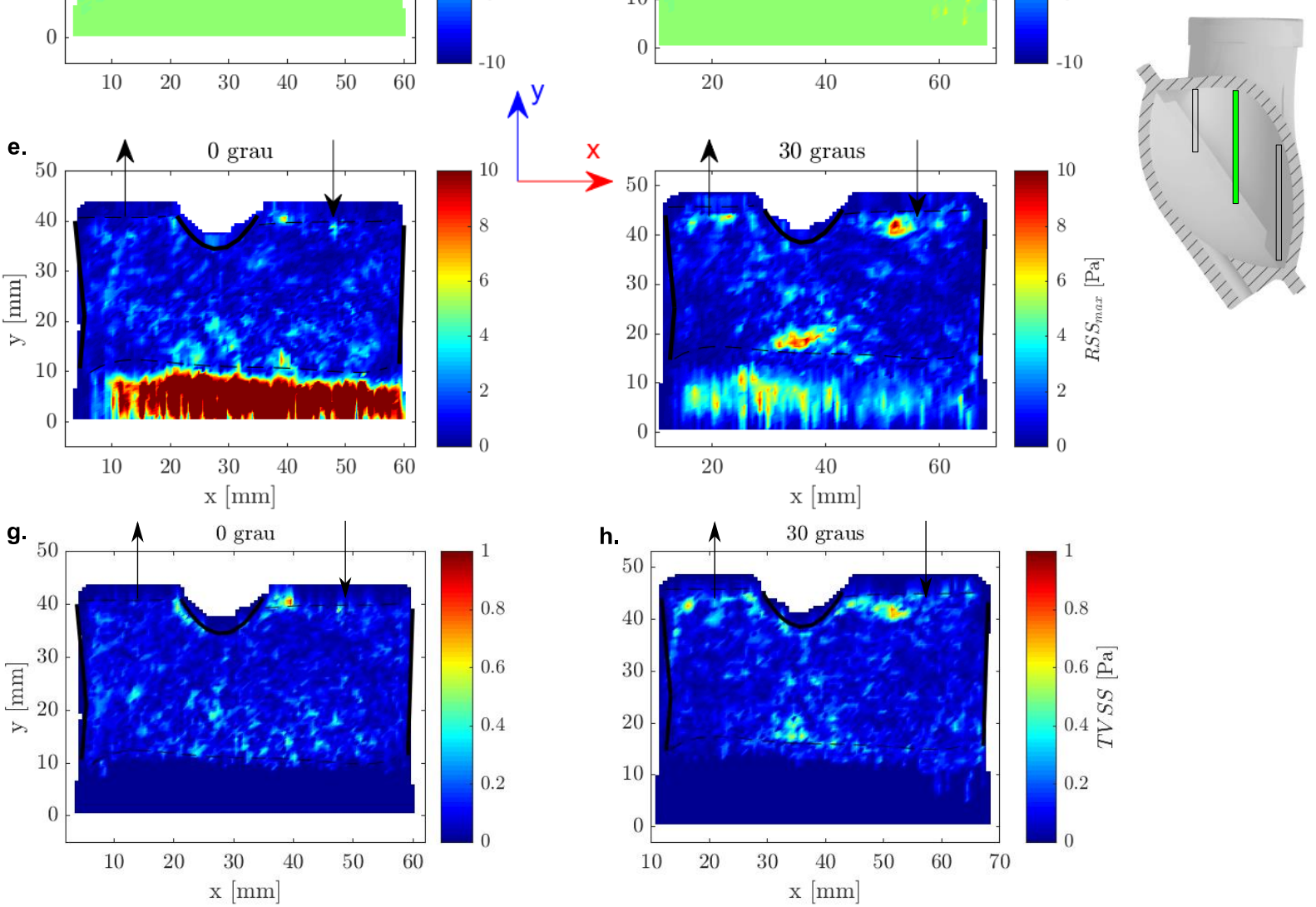
Figura 118 - Campos de tensões ( $0^{\circ}$ e $\left.30^{\circ}\right)$ no plano traseiro no intervalo $t_{4}$

a.

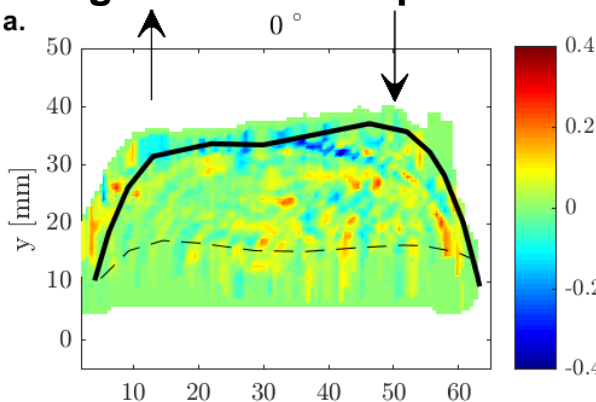

c.

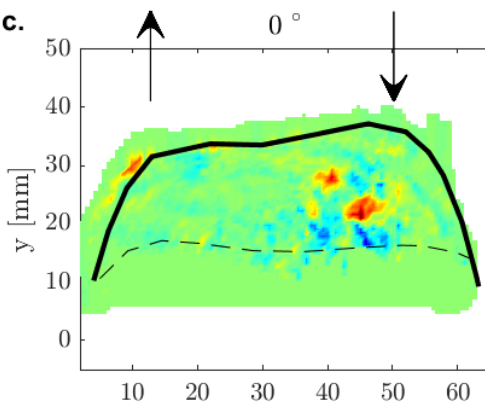

e.
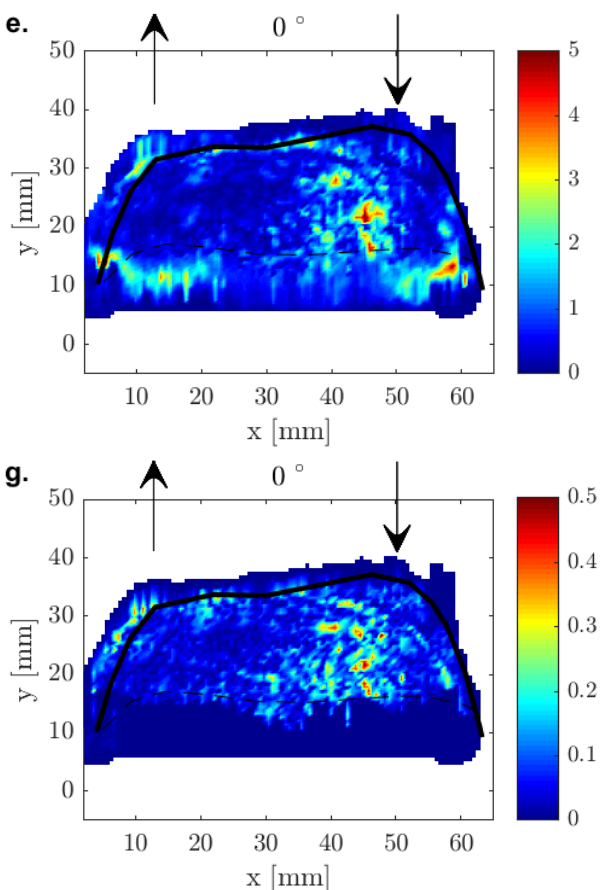

b.

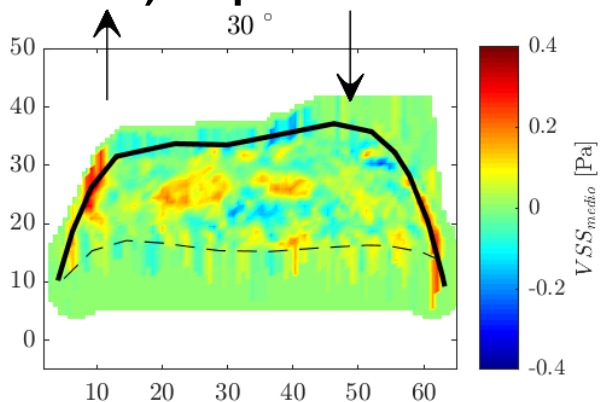

d.

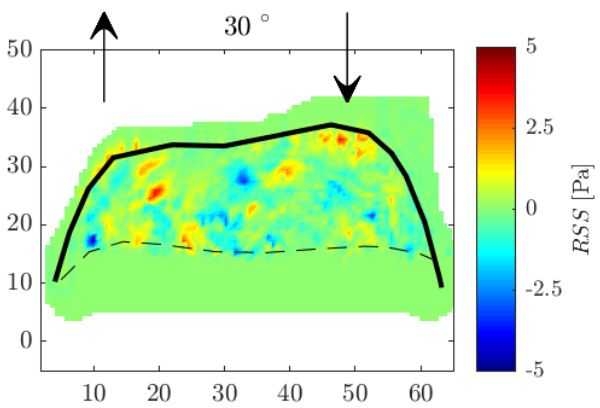

f.

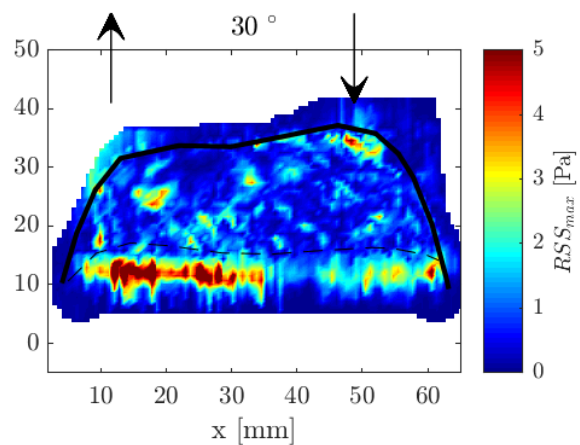

h.

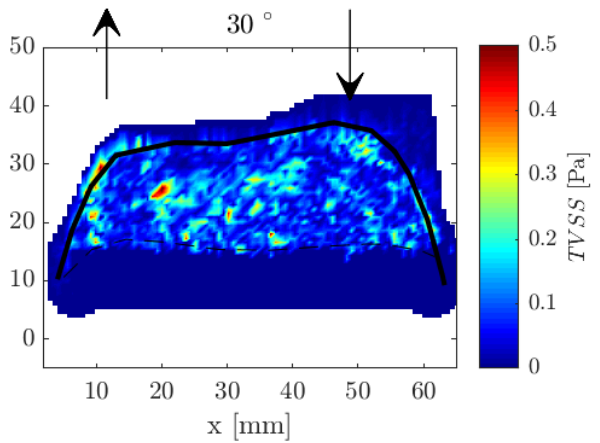

Vista lateral

O ápice do $\overline{V S S}$ neste intervalo ainda é a parede esquerda para ambos, e o mínimo está concentrado na curvatura entre as válvulas. Os valores de pico também reduziram, de $1 \mathrm{~Pa}$ para 0,5 $\mathrm{Pa}$ em $0^{\circ}$ e de 0,6 Pa para 0,5 $\mathrm{Pa}$ em $30^{\circ}$ na mudança de intervalos. Nos planos frontal e traseiro ainda há uma faixa de $\overline{V S S}$ na parede direita. 
De modo geral, os campos de $\overline{V S S}$ para $30^{\circ}$ foram mais intensos.

Para as demais tensões, RSS, RSS max e TVSS, os valores foram muito próximos a $0 \mathrm{~Pa}$ com pequenos pontos sobressaindo sobre os demais. Como o padrão rotacional se manteve, poucas flutuações nas velocidades foram observadas.

A energia cinética turbulenta (TKE) deste intervalo foi fracamente influenciada pelas tensões (Figura 119) em ambas as posições de válvula. Destaca-se as regiões vermelhas com valores na ordem de $0,04 \mathrm{~m}^{2} / \mathrm{s}^{2}$, o menor valor máximo observado até o momento, indicando que o TKE está se dissipando.
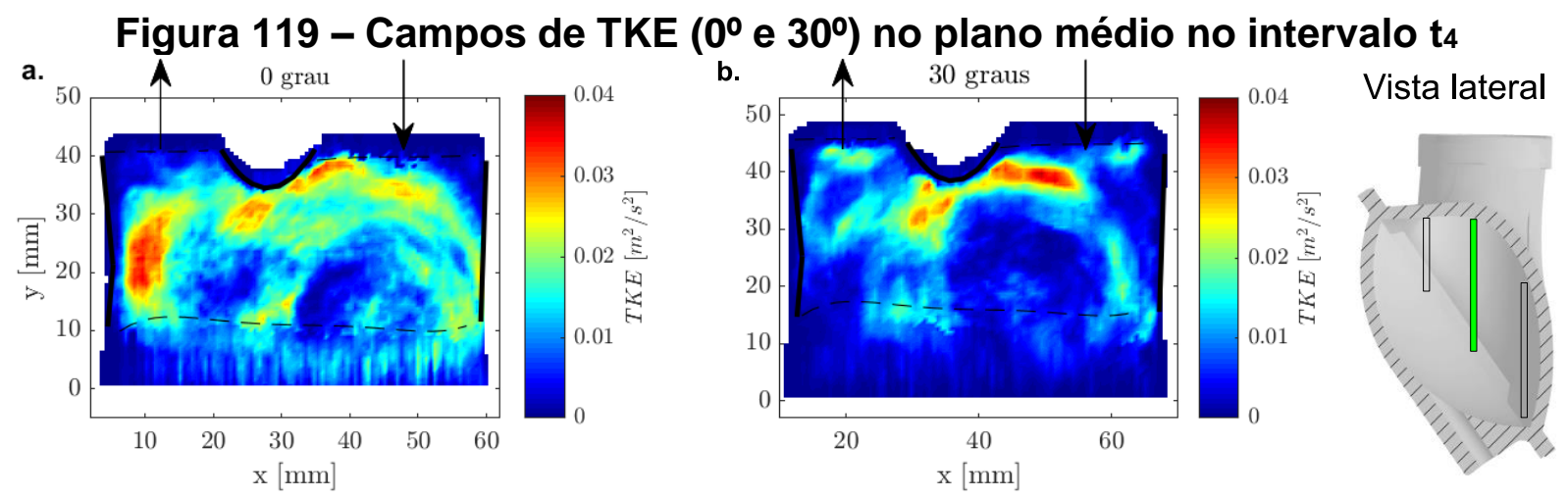

\subsubsection{Intervalo de 20 a $40 \%$ da sístole ( $\left.t_{5}\right)$}

As propriedades dos escoamentos no intervalo de 20 a $40 \%$ da sístole para dois ângulos de válvula, $0^{\circ}$ e 30ํㅡㄹ são expostos na Figura 120, Figura 121 e Figura 122. Neste período o diafragma esteve visível apenas no plano traseiro, diferindo do intervalo de 20 a $40 \%$ da diástole (t2), pois as curvas de enchimento e esvaziamento da câmara pneumática não são iguais.

As velocidades horizontais médias $(\overline{\mathrm{u}})$ tiveram suas regiões de concentração dos ápices mantidas, mas os valores reduziram. A exceção está no plano traseiro para 0 (Figura 122a). Neste campo as velocidades que eram positivas tornaram-se negativas.

Em $\bar{v}$ surge uma grande zona de velocidade positivas $(\sim 0,5 \mathrm{~m} / \mathrm{s})$ na saída do dispositivo. A velocidade vertical instantânea (v), no plano médio (Figura 123), reforça o crescimento das velocidades com picos de $0,75 \mathrm{~m} / \mathrm{s}$. Nesta situação não há como afirmar a presença de um jato sistólico, pois a velocidade em y está bem distribuída e homogênea. 
Na magnitude da velocidade (|Ū|) percebe-se que a lavagem permaneceu neste intervalo. A estrutura do grande vórtice é mais evidente nos planos frontal e traseiro. Já no plano médio, pouco se vê desta estrutura. Agora, praticamente na metade da sístole, a tendência do fluxo é mover-se para próximo da parede de saída e aumentar o volume ejetado. Nota-se também que a intensidade nos campos para 0ำ foram maiores.

Figura 120 - Campos de velocidades $\left(0^{\circ}\right.$ e $\left.30^{\circ}\right)$ no plano frontal no intervalo $t_{5}$

a.

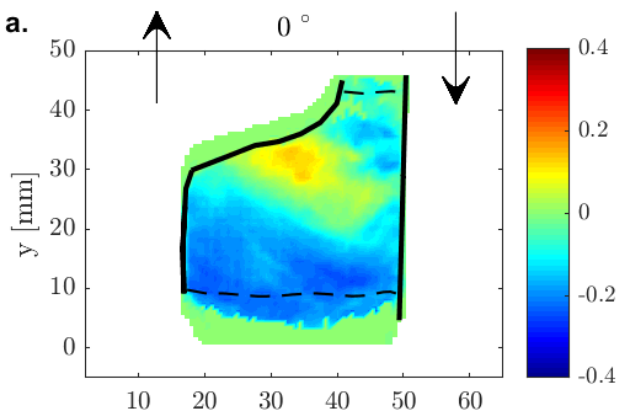

c.

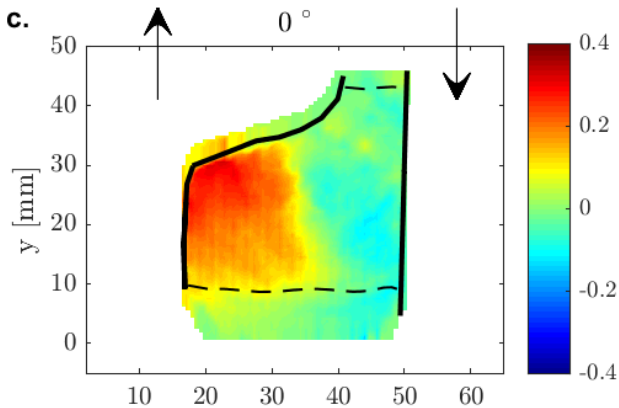

e.

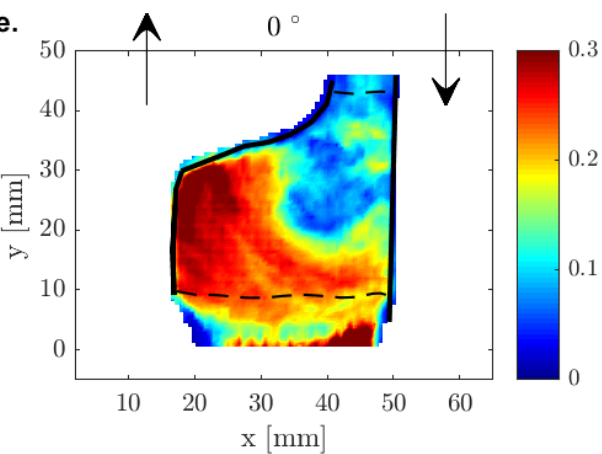

b.

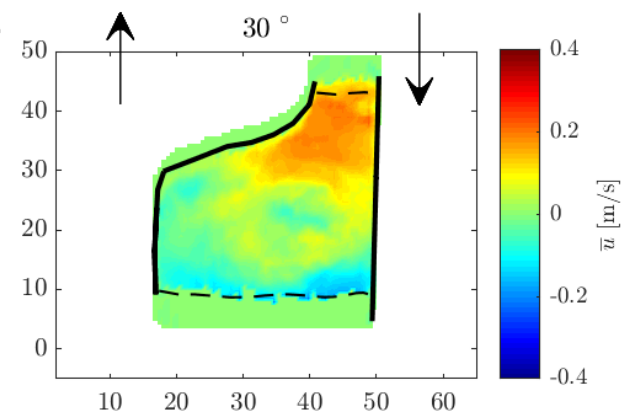

d.

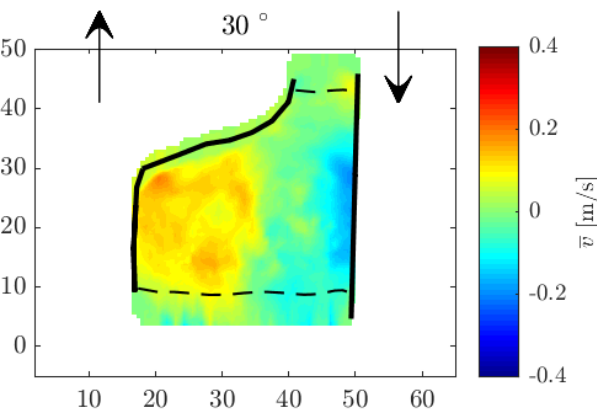

f.

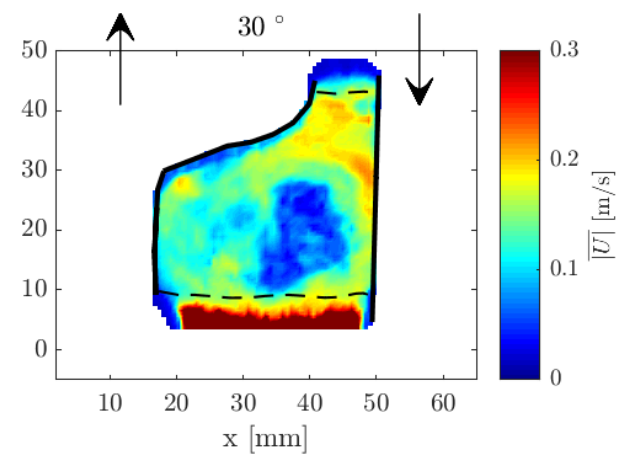

Vista lateral

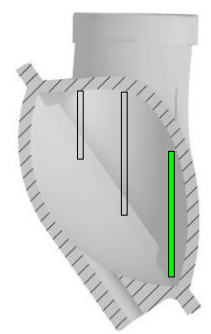


Figura 121 - Campos de velocidades $\left(0^{\circ}\right.$ e $\left.30^{\circ}\right)$ no plano médio no intervalo t5
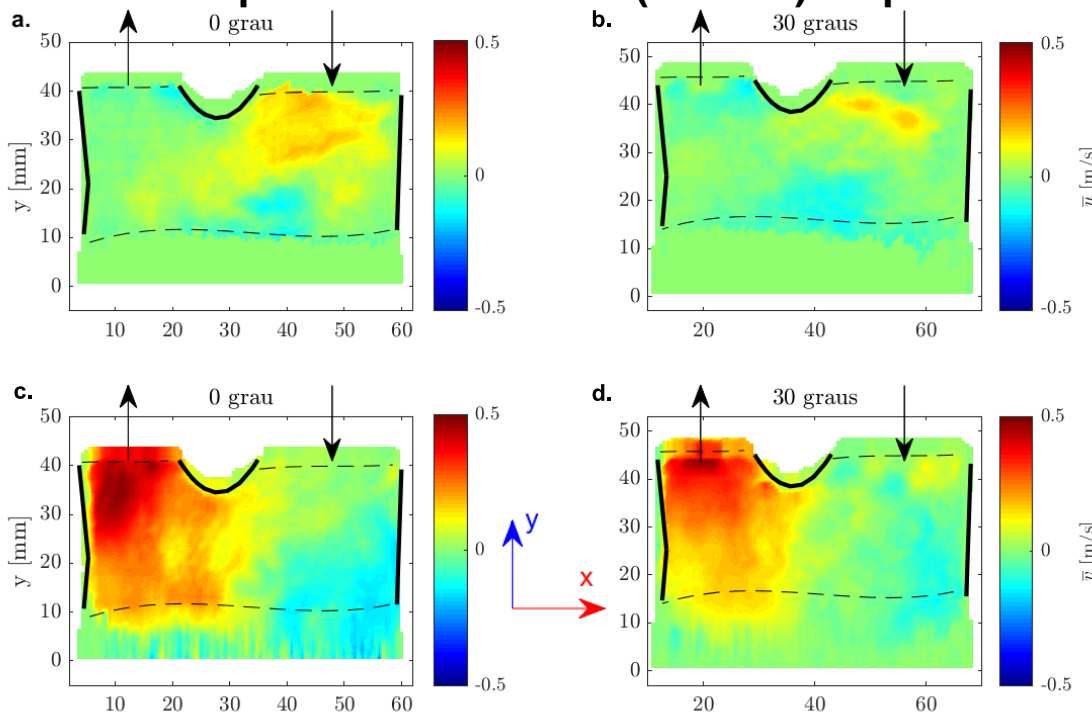

Vista lateral
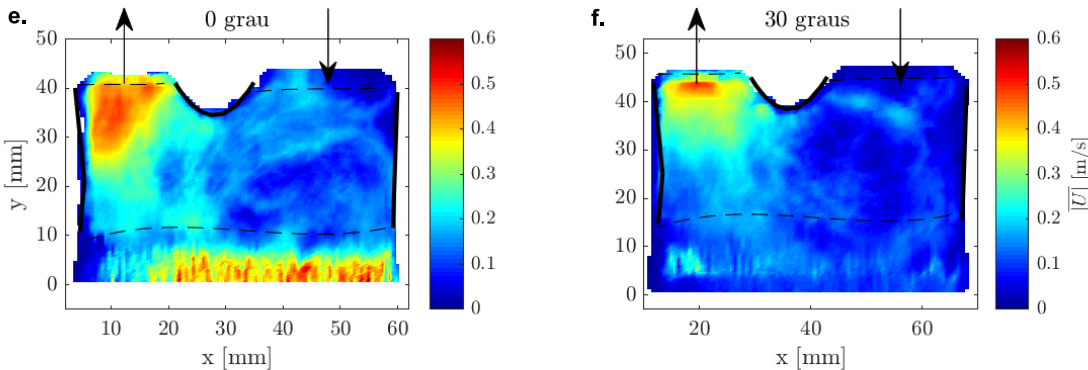

Figura 122 - Campos de velocidades $\left(0^{\circ}\right.$ e $\left.30^{\circ}\right)$ no plano traseiro no intervalo $t_{5}$
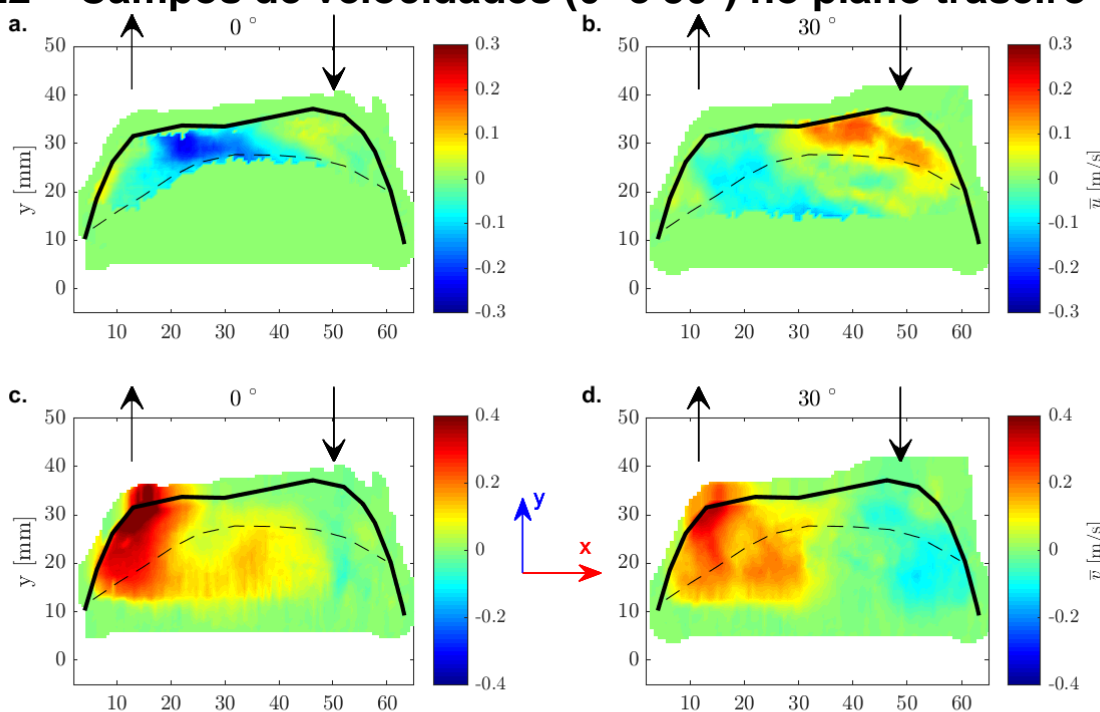

Vista lateral
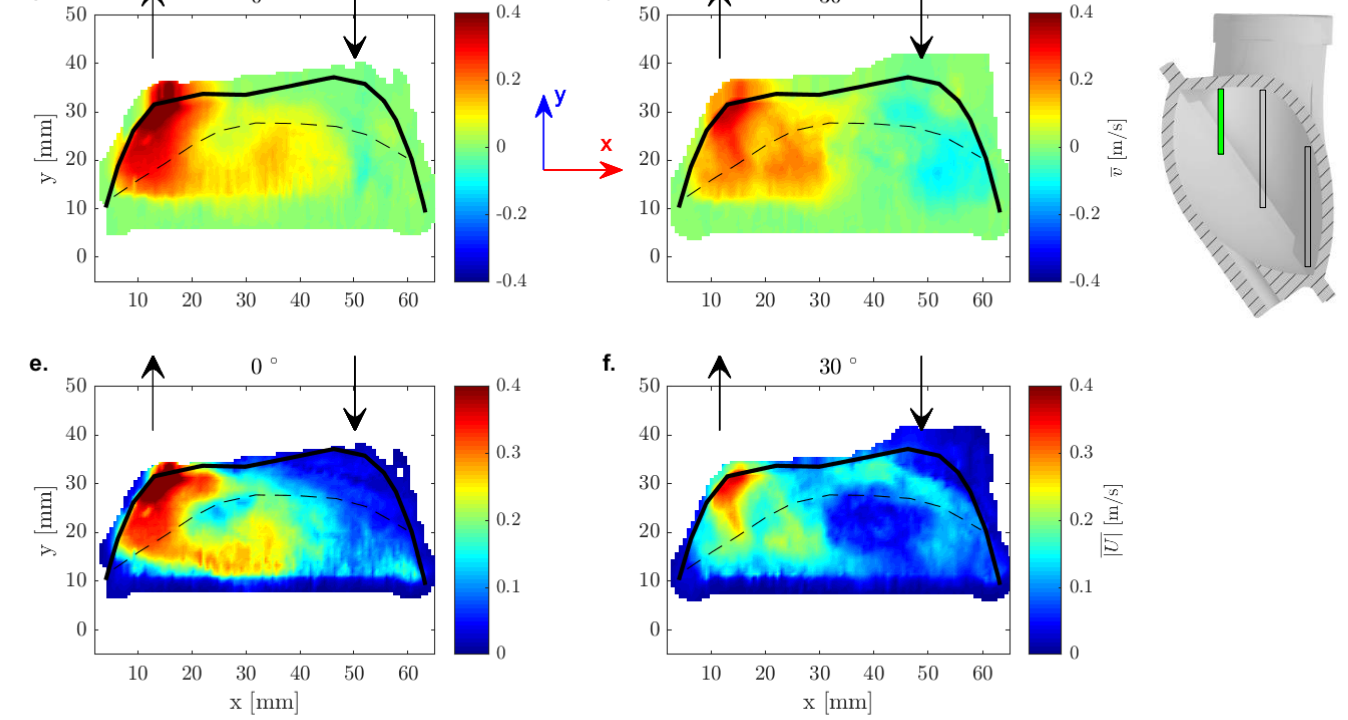
Figura 123 - Evolução temporal de $v$ na entrada do DAVP no plano médio em t5
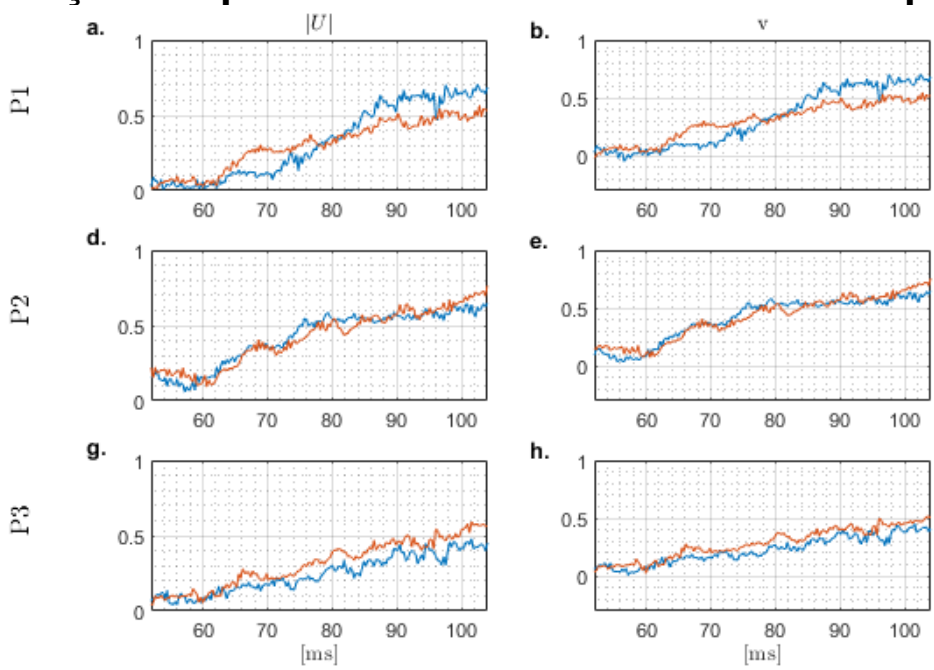

Azul - 0; vermelho - 30 graus

Nos campos médios não há como inferir sobre a regurgitação na válvula de entrada, devido à discrepância entre os valores do lado esquerdo do dispositivo com o lado direito. Ao analisar a Figura 124, em especial as sondas P7 e P9, constata-se a clara regurgitação quando a válvula de entrada está posicionada a 0 .. mesmo não se pode afirmar quando a posição muda para $30^{\circ}$ pois os valores positivos são muito próximos de $0 \mathrm{~m} / \mathrm{s}$.

Figura 124 - Evolução temporal de v na entrada do DAVP no plano médio em t5

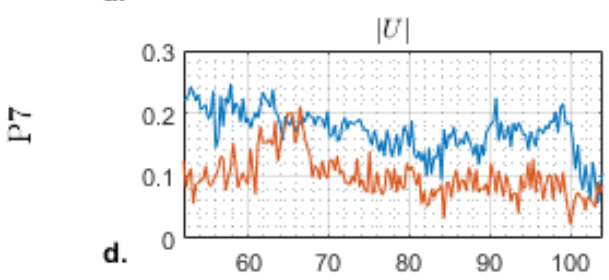

b.
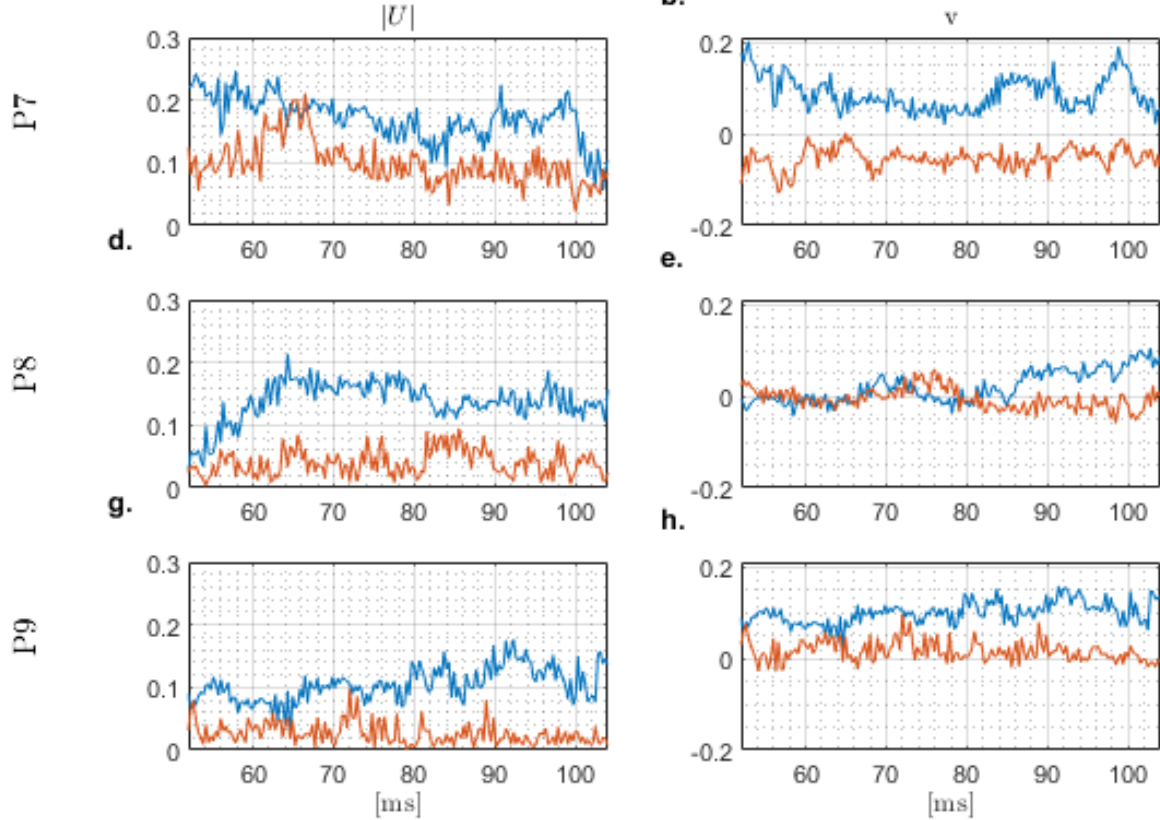

h.

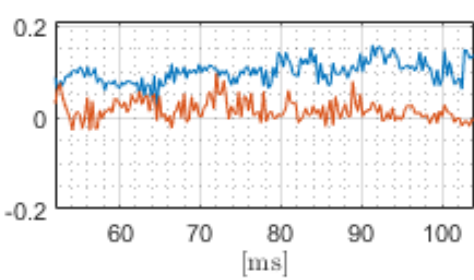

Azul - $0 \circ$; vermelho - $30^{\circ}$ graus

Os campos de tensões para o intervalo t5 são apresentados a seguir na Figura 
125, Figura 126 e Figura 127.

$\mathrm{Na}$ tensão de cisalhamento viscosa $(\overline{V S S})$ os valores máximos concentraramse na parede esquerda mantendo 0,6 Pa. Para 30, ainda há regiões de máximos na parede esquerda, como visto no plano frontal (Figura 125b) e traseiro (Figura 127b).

Já a tensão de cisalhamento de Reynolds (Figura 126b) é bem homogênea, excetuando-se a saída do dispositivo que exibe entre -10 Pa (plano frontal) e $-30 \mathrm{~Pa}$ (plano médio). O mesmo ocorre para RSS max (Figura 126c) e TVSS (Figura 126d) que exibem campos praticamente nulos, exceto na saída do DAVP, onde ocorreram regiões de máximos.

Figura 125 - Campos de tensões ( $0^{\circ}$ e $\left.30^{\circ}\right)$ no plano frontal no intervalo t5
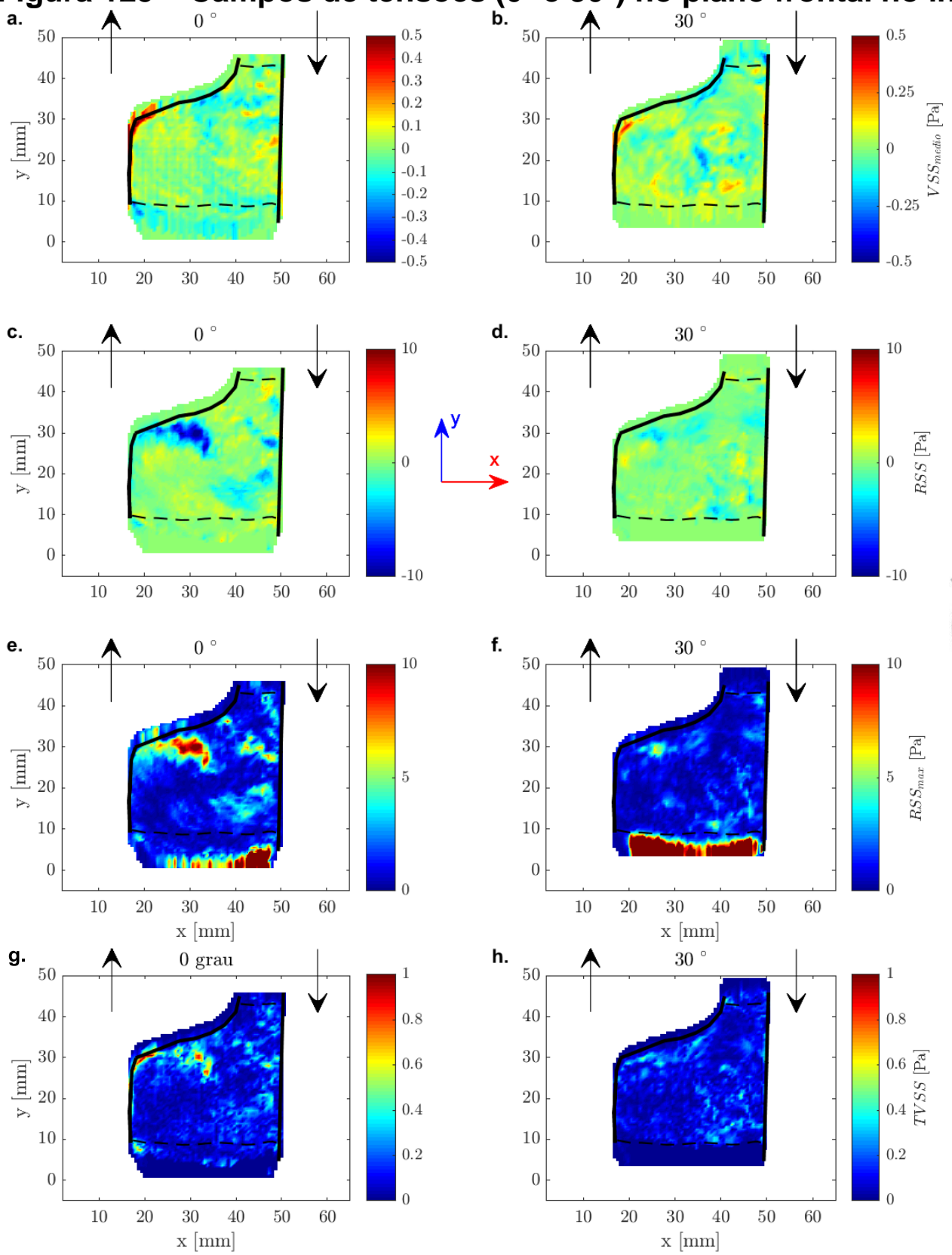

Vista lateral

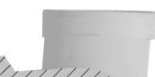


Figura 126 - Campos de tensões $\left(0^{\circ}\right.$ e $\left.30^{\circ}\right)$ no plano médio no intervalo t5
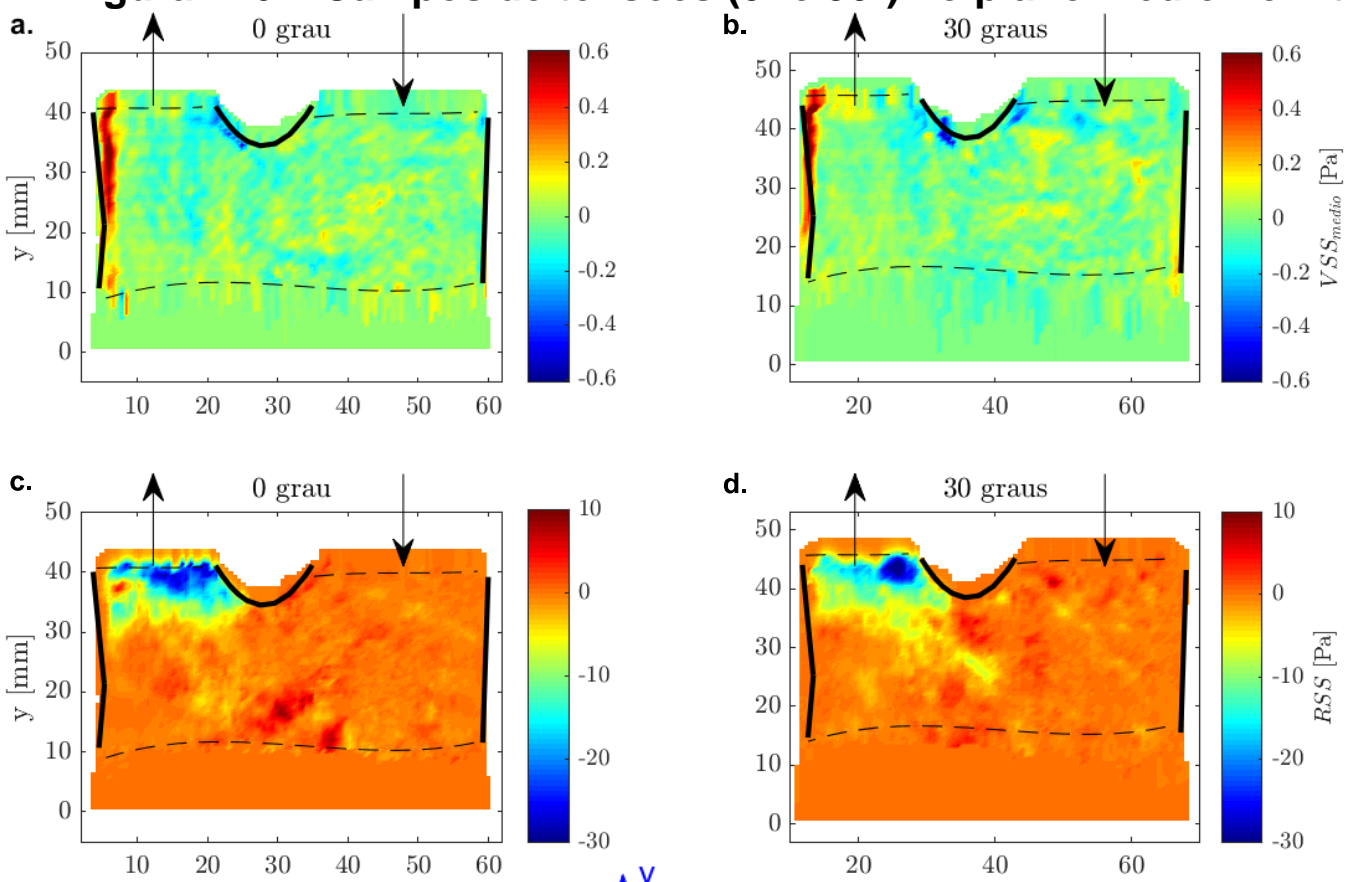

Vista lateral

e.
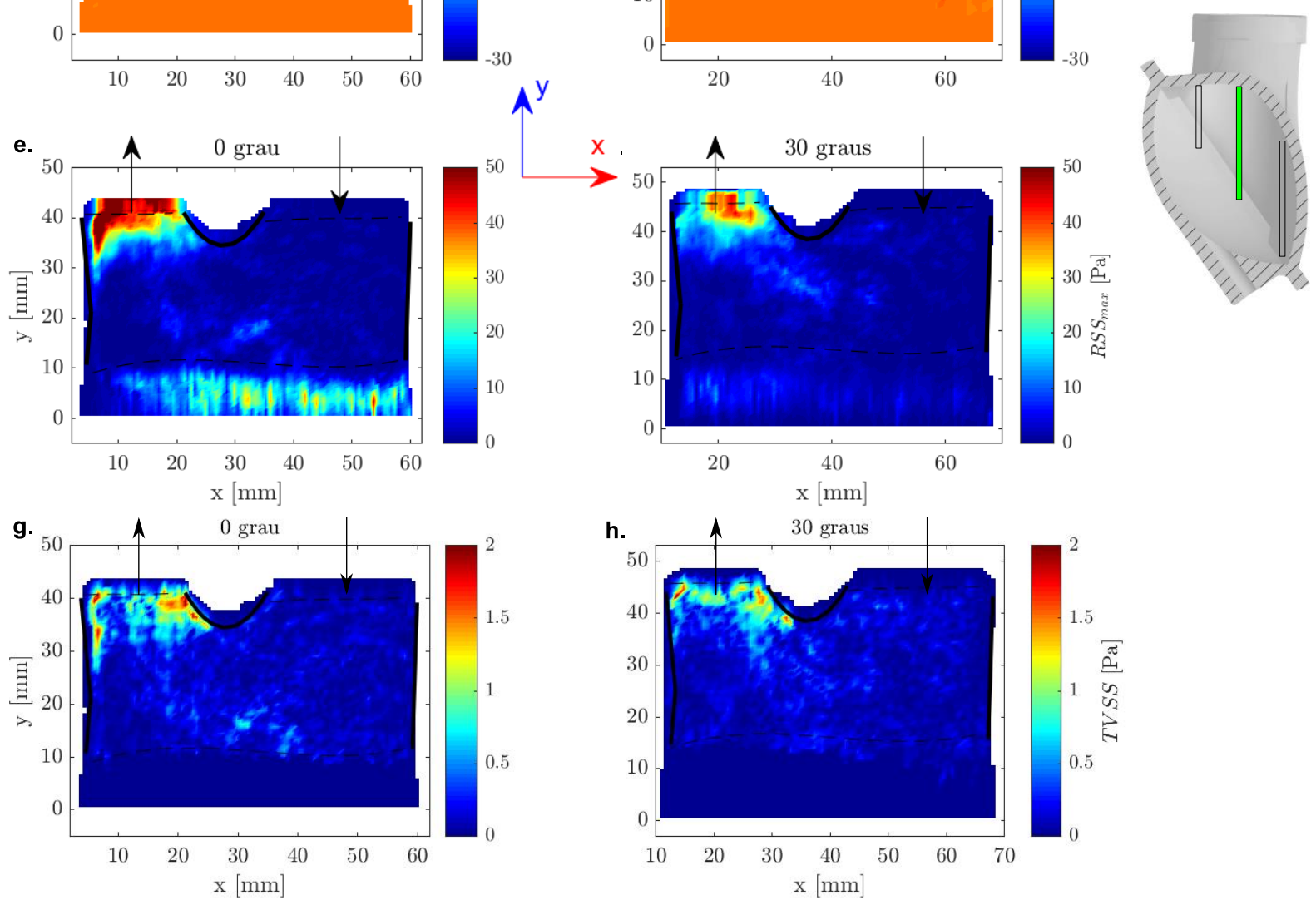
Figura 127 - Campos de tensões $\left(0^{\circ}\right.$ e $\left.30^{\circ}\right)$ no plano traseiro no intervalo t5
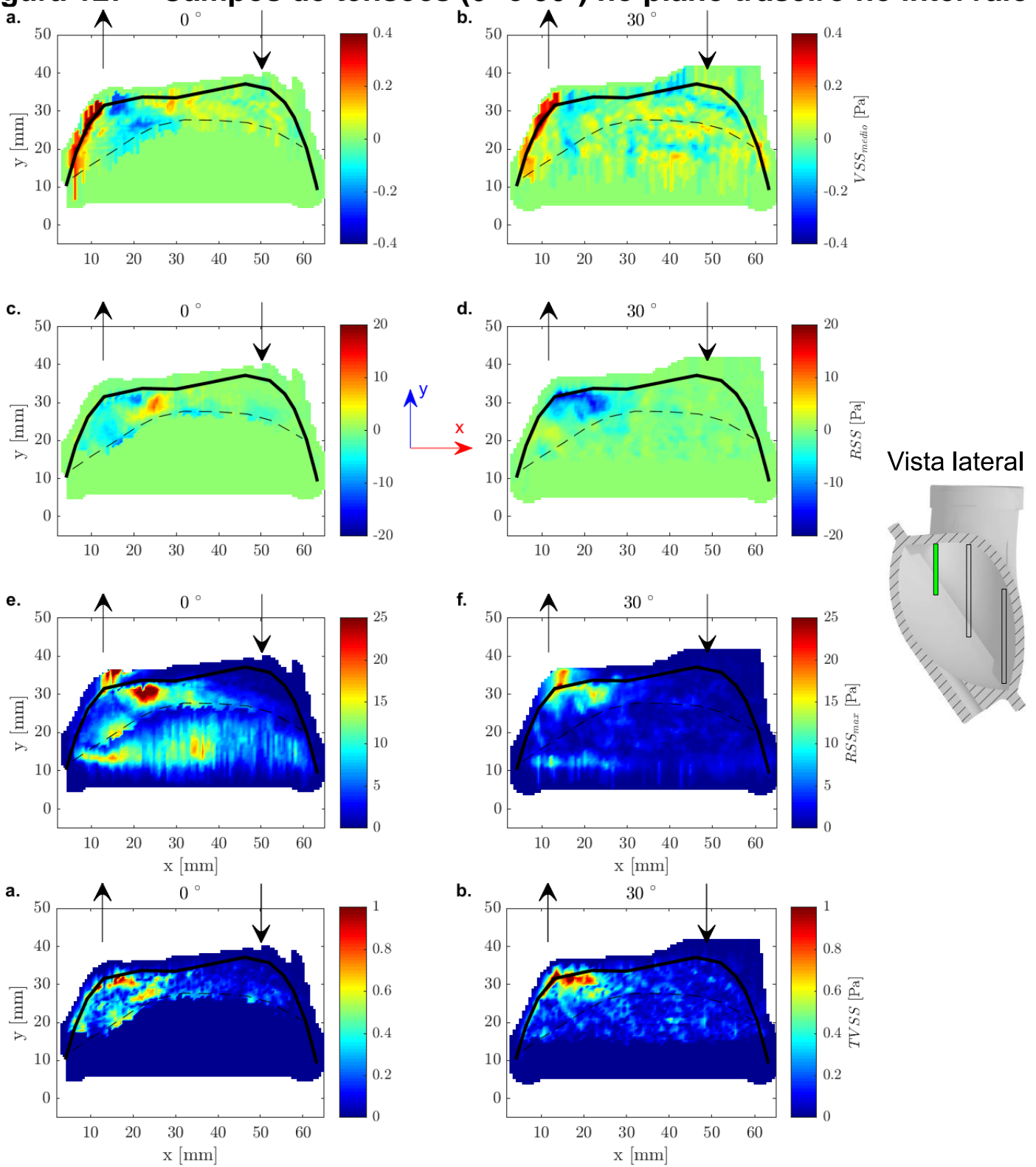

Os campos de TKE deste intervalo apresentam forma semelhante à magnitude de velocidade (|Ū|) e às tensões máximas de Reynolds (RSS max) no plano médio. Isto é, a concentração do ápice de energia está na válvula de saída.

Figura 128 - Campos de TKE ( $0^{\circ}$ e $\left.30^{\circ}\right)$ no plano médio no intervalo t5
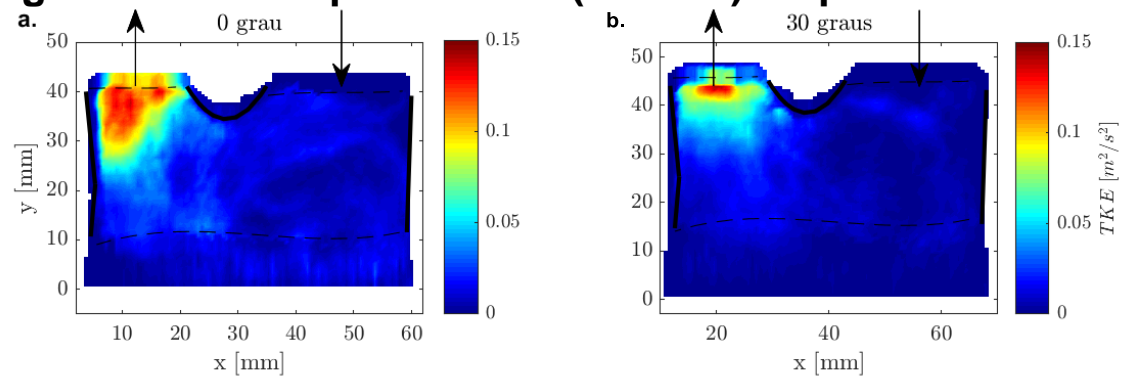

Vista lateral

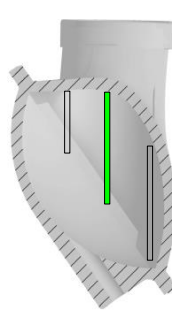




\subsubsection{Intervalo de $80 \%$ a $100 \%$ da sístole ( $\left.t_{6}\right)$}

As propriedades dos escoamentos no intervalo de $80 \%$ a $100 \%$ da sístole para dois ângulos de válvula, ํㅡ e 30ำ, são expostos na Figura 129, Figura 130 e Figura 131. Neste instante de tempo, a membrana já atingiu seu apogeu de pressão e volume e torna-se perceptível em todos os campos.

A componente de velocidade $(\bar{u})$ teve o seu sentido alterado e agora todo o fluxo move-se em direção à saída. Em $\bar{v}$, a intensidade máxima dobrou na mesma região de t5 no plano médio. Avaliando a magnitude da velocidade (|Ū|), o escoamento ficou concentrado na válvula de saída. O progresso temporal de Ū e de v (Figura 132) no plano médio condizem com o observado nos campos médios. Ambos apresentam valores altos, mas que começaram a decair, de $1 \mathrm{~m} / \mathrm{s}$ para $0,4 \mathrm{~m} / \mathrm{s}$.

Figura 129 - Campos de velocidades $\left(0^{\circ}\right.$ e $\left.30^{\circ}\right)$ no plano frontal no intervalo $t_{6}$

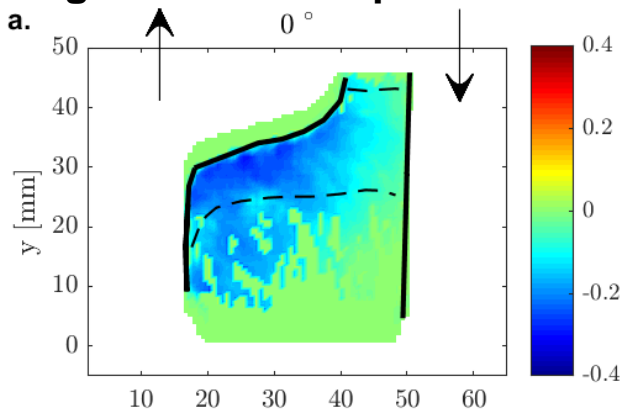

b.

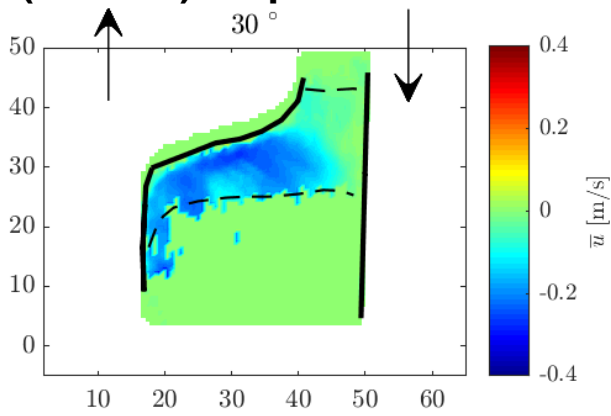

c.
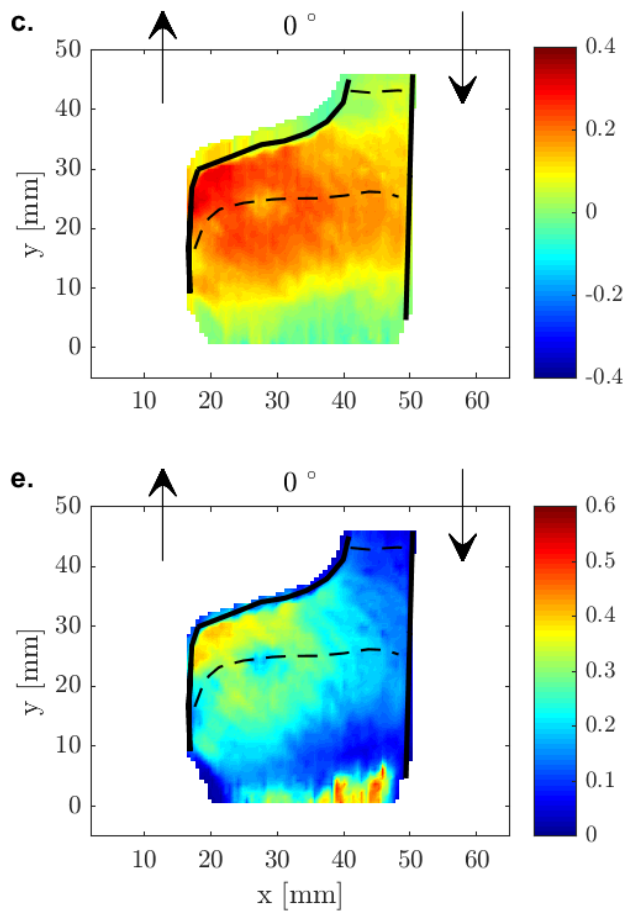

d.

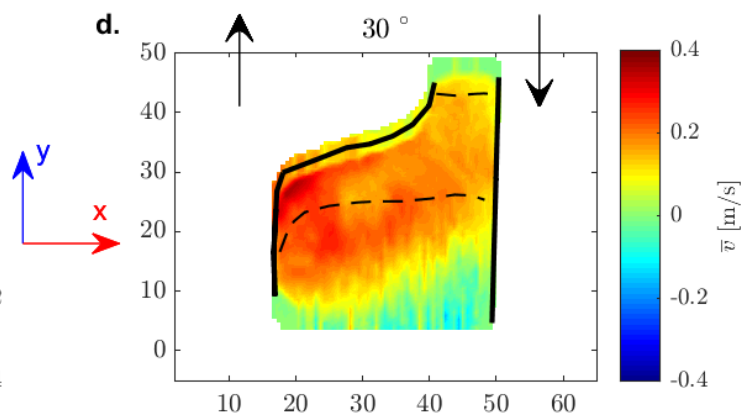

f.

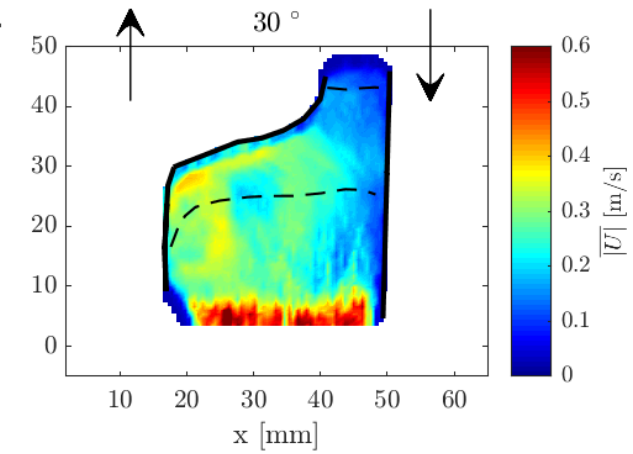

Vista lateral

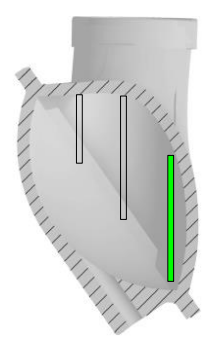


Figura 130 - Campos de velocidades ( $0^{\circ}$ e $\left.30^{\circ}\right)$ no plano médio no intervalo t6
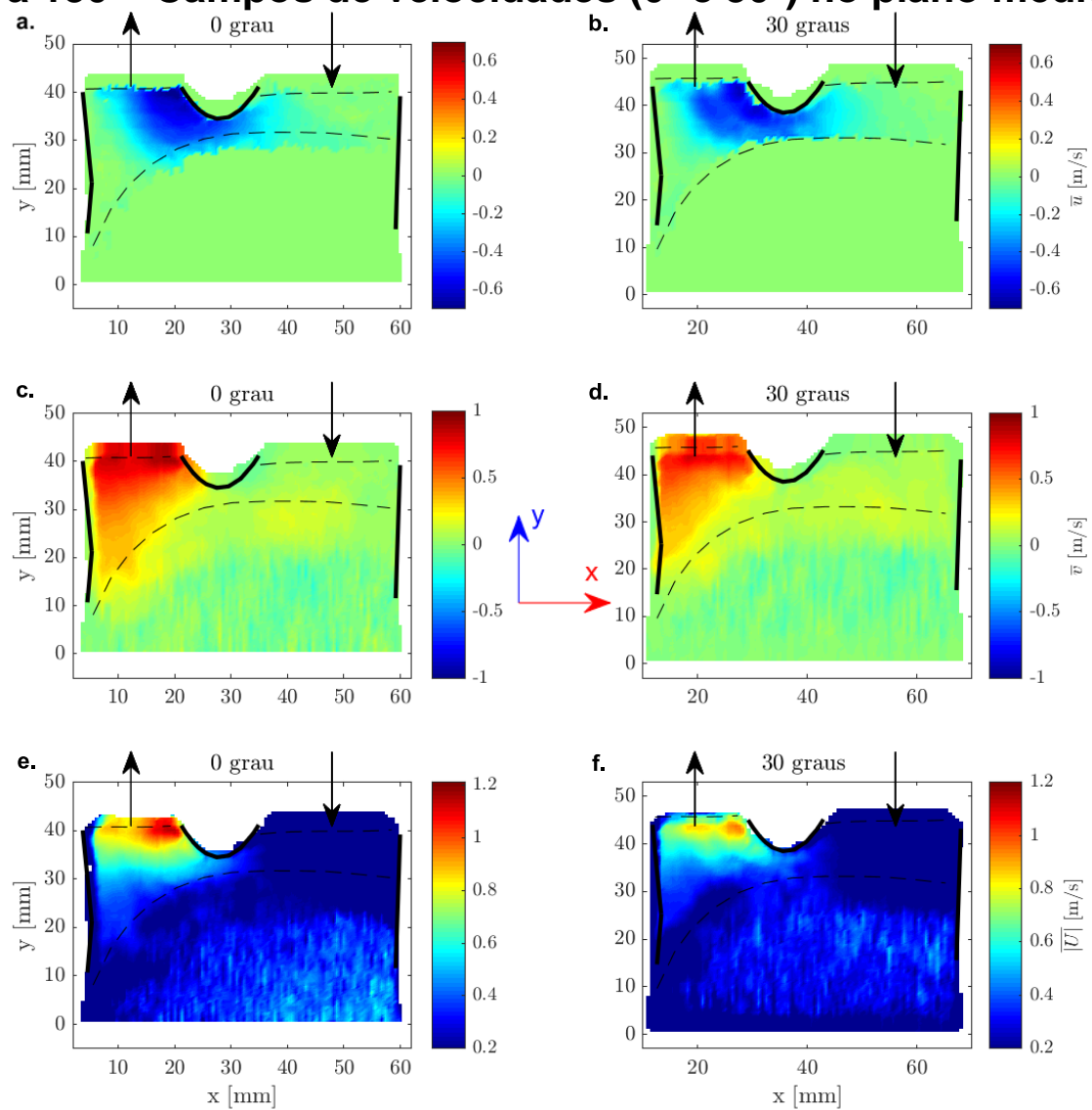

Figura 131 - Campos de velocidades $\left(0^{\circ}\right.$ e $\left.30^{\circ}\right)$ no plano traseiro no intervalo t6
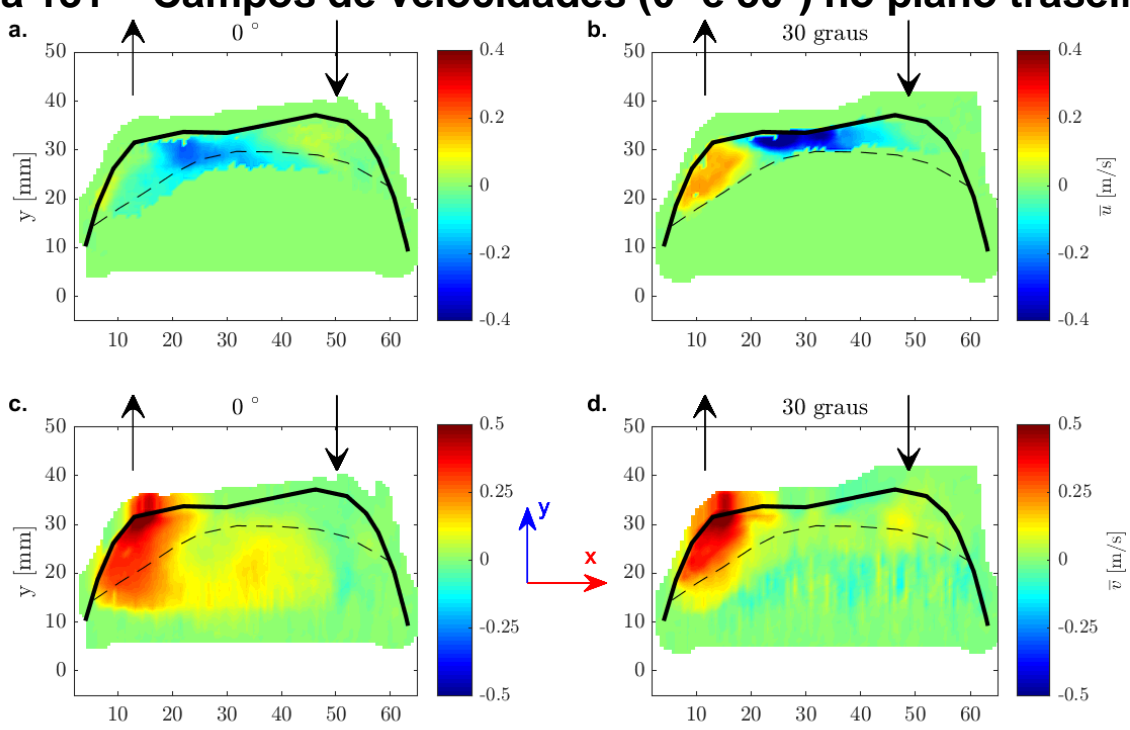

Vista lateral
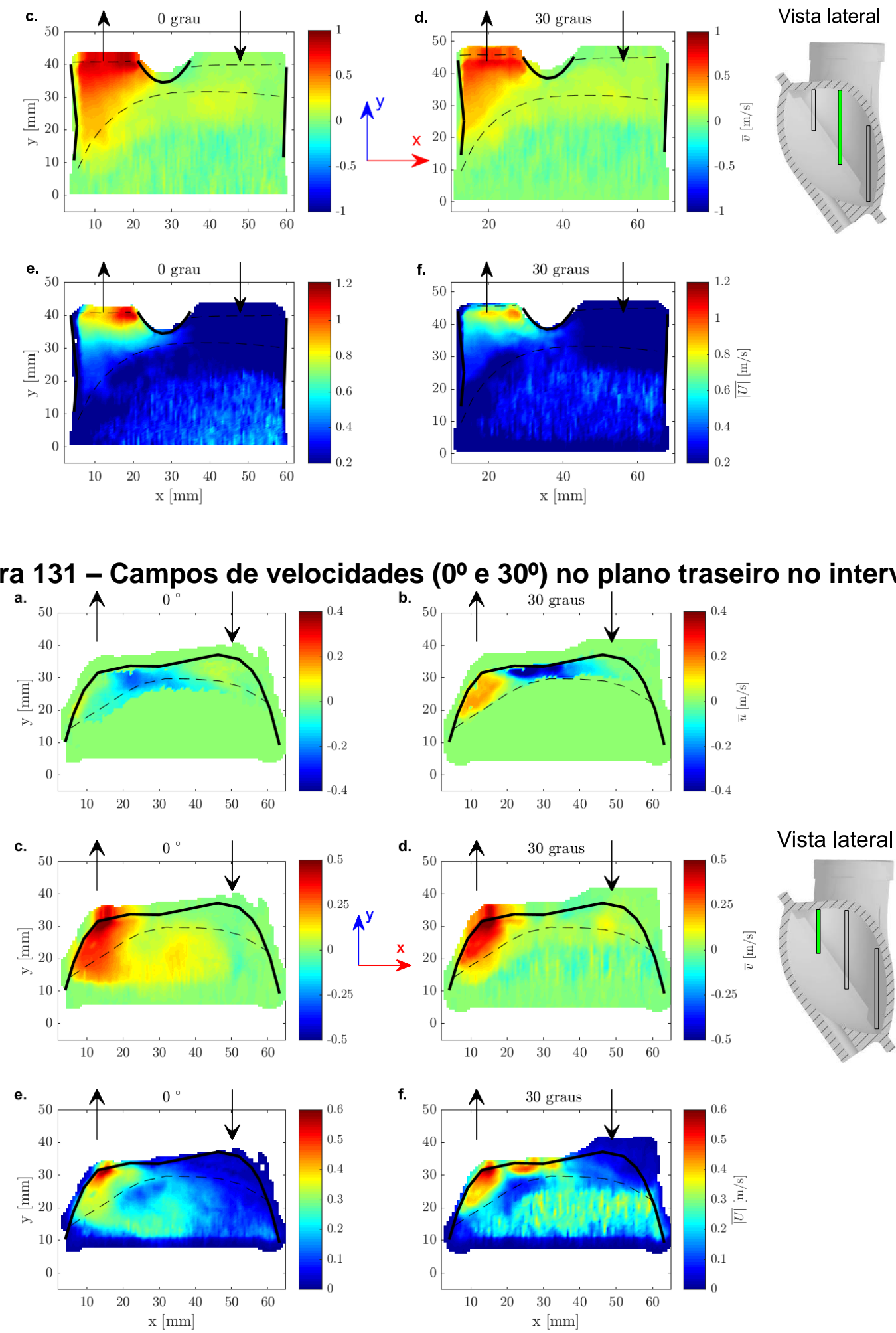
Figura 132 - Evolução temporal de |U| e v na saída do DAVP no plano médio
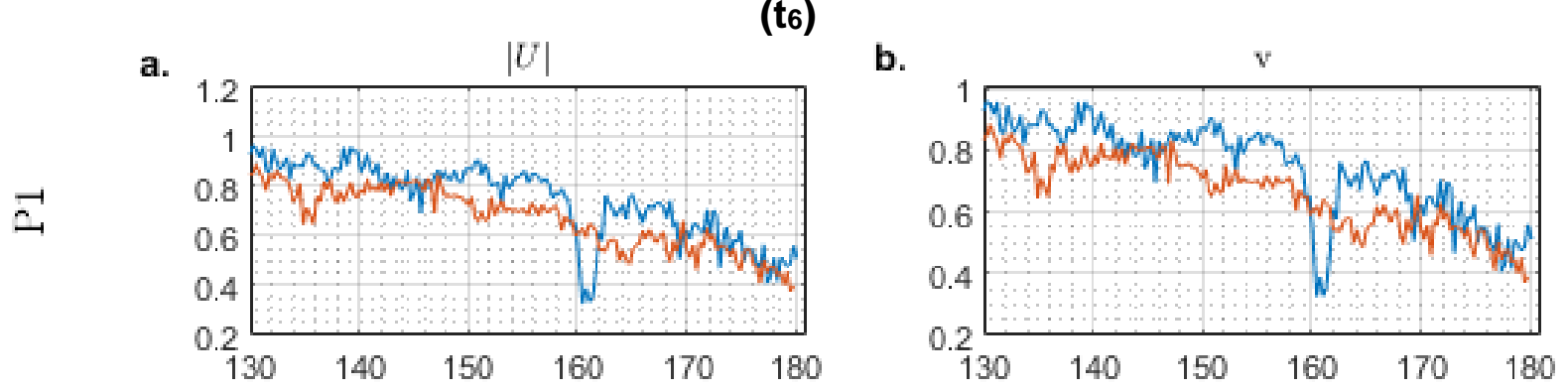

d.

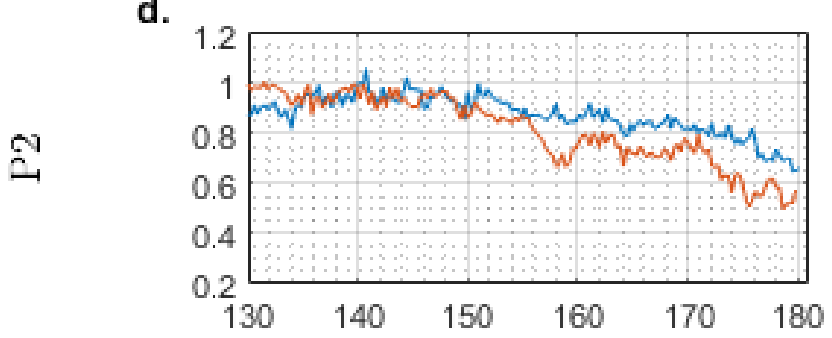

e.

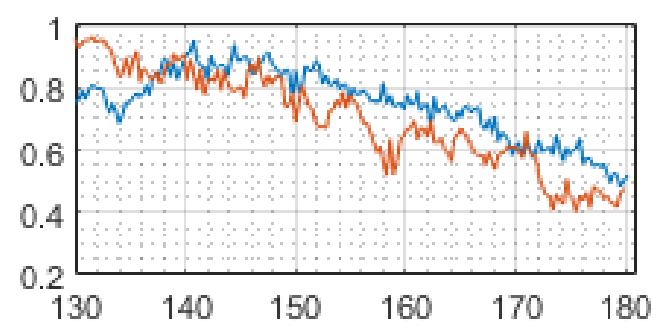

g.

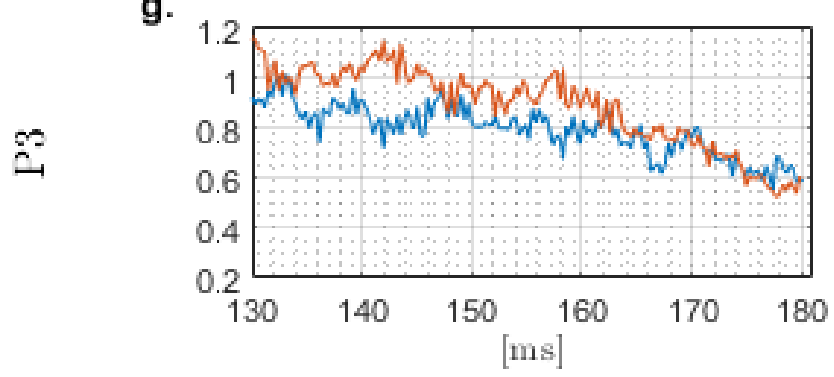

h.

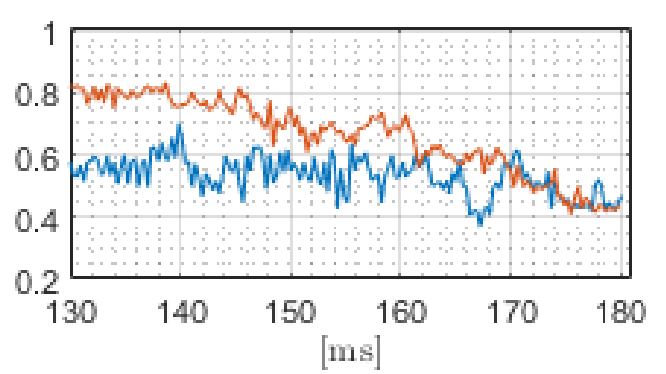

Azul - 0; vermelho - $30^{\circ}$ graus

A seguir, analisou-se as quatro tensões para o plano frontal (Figura 133), médio (Figura 134) e traseiro (Figura 135) no intervalo t6.

Nos campos de tensões, pode-se observar um aumento na região que está sujeita ao cisalhamento viscoso (Figura 134a) na parede esquerda próxima à válvula de saída. Igualmente surgem valores de $\overline{V S S}$ mais altos na curvatura entre as válvulas, mais perceptível no plano frontal (Figura 133a). Já no cisalhamento de Reynolds o campo é praticamente nulo, com pequenas regiões logo acima da membrana destoando do demais valores. Os campos de RSS $\max$ diferem entre 0ำ e 30․ O campo em que a válvula não está rotacionada, mal se vê valores elevados, ao contrário de $30^{\circ}$ que possui uma grande região com tensões próximas a $40 \mathrm{~Pa}$ no campo médio (Figura 134f) e traseiro (Figura 135f). No TVSS destacam-se as regiões logo acima da membrana, análogo ao observado em RSS. Isto ocorre pois os valores de RSS são pelo menos dez vezes maiores que os valores de $\overline{V S S}$, pesando mais no cálculo de TVSS. Neste intervalo, todas as tensões foram mais intensas para $30^{\circ}$. 
Figura 133 - Campos de tensões $\left(0^{\circ}\right.$ e $\left.30^{\circ}\right)$ no plano frontal no intervalo t6

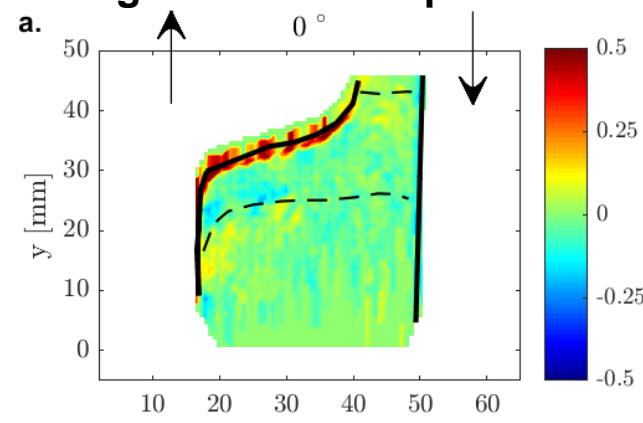

b.

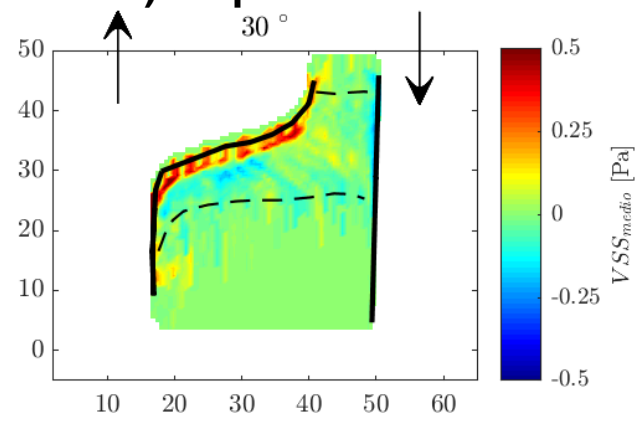

c.
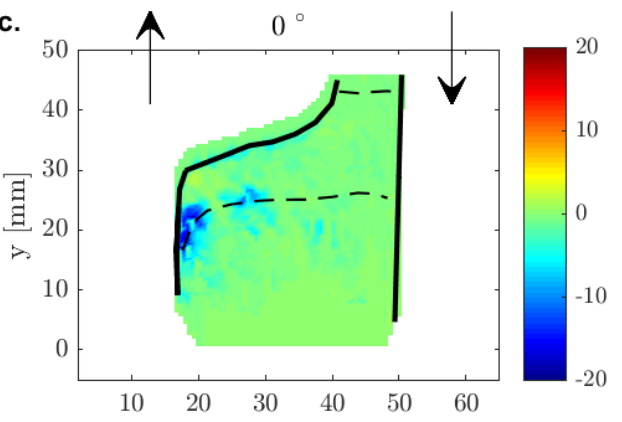

d.

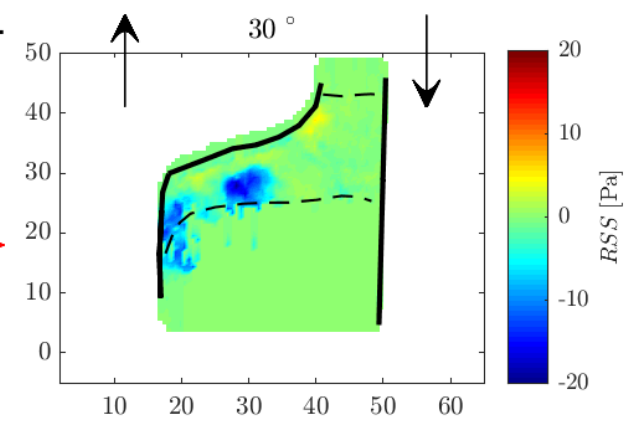

Vista lateral

e.

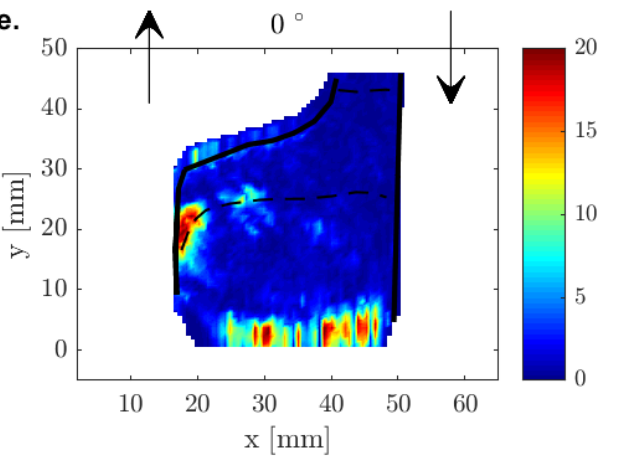

f.
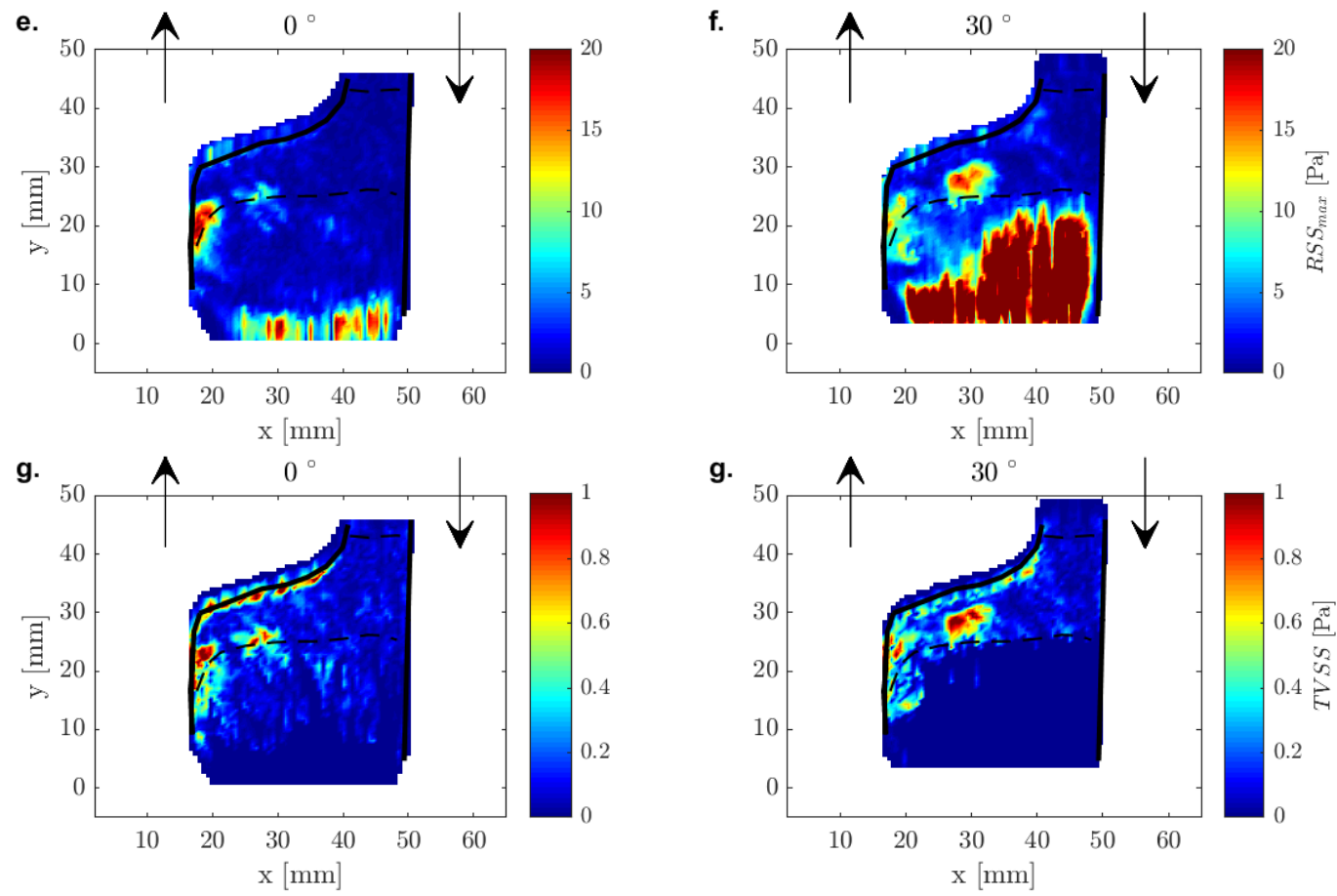

g.

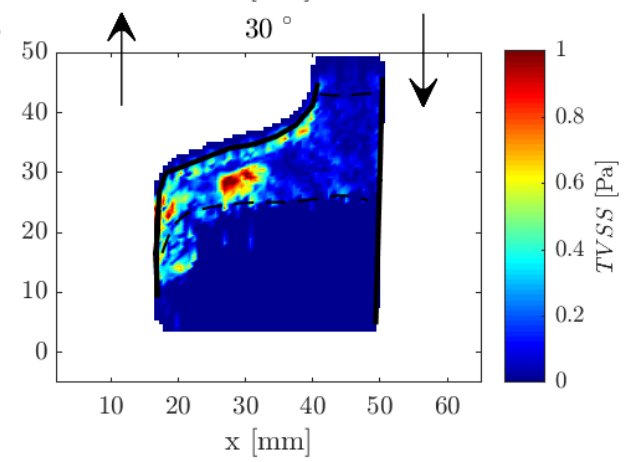


Figura 134 - Campos de tensões ( $0^{\circ}$ e $\left.30^{\circ}\right)$ no plano médio no intervalo t6
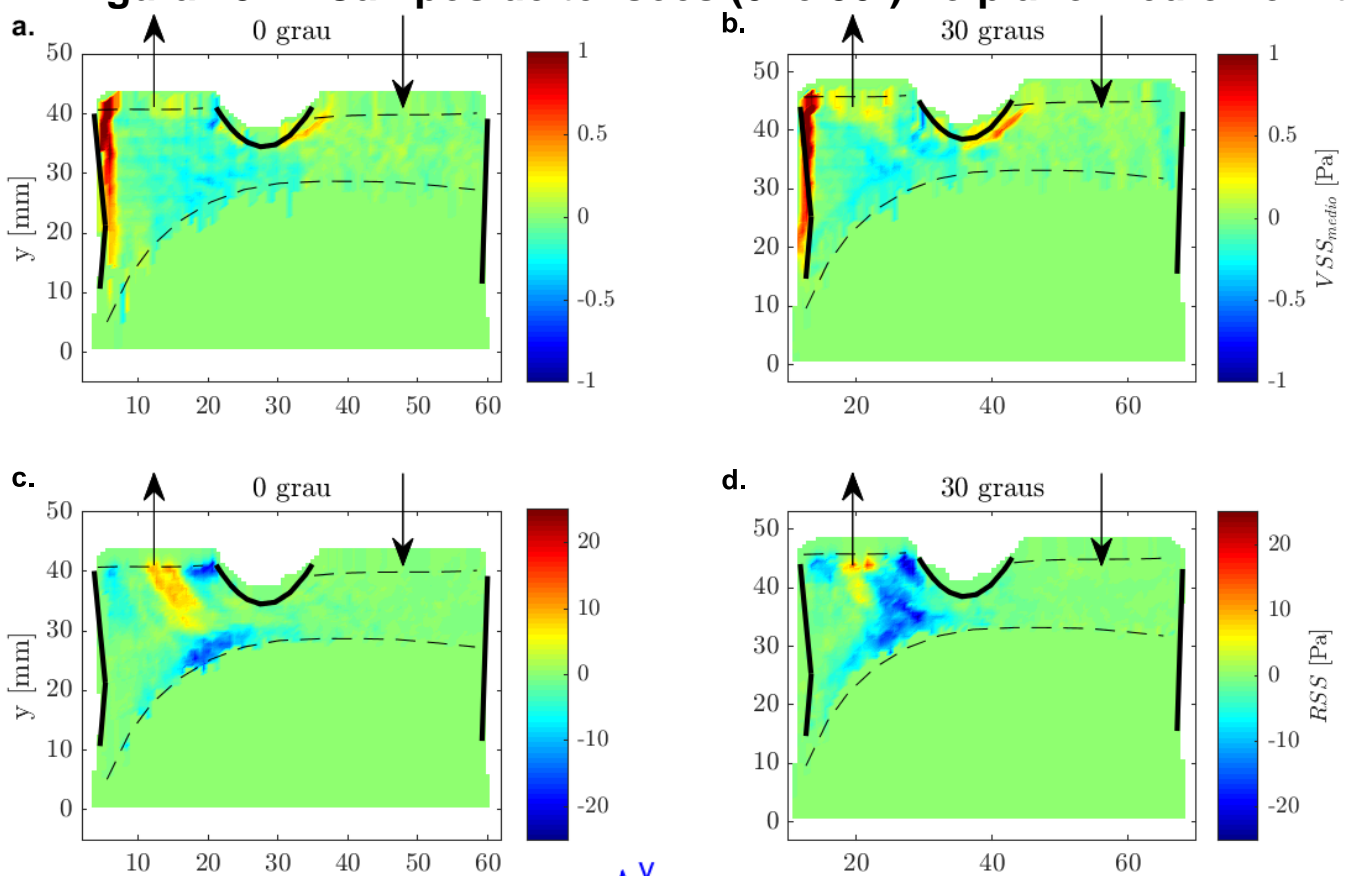

Vista lateral

e.
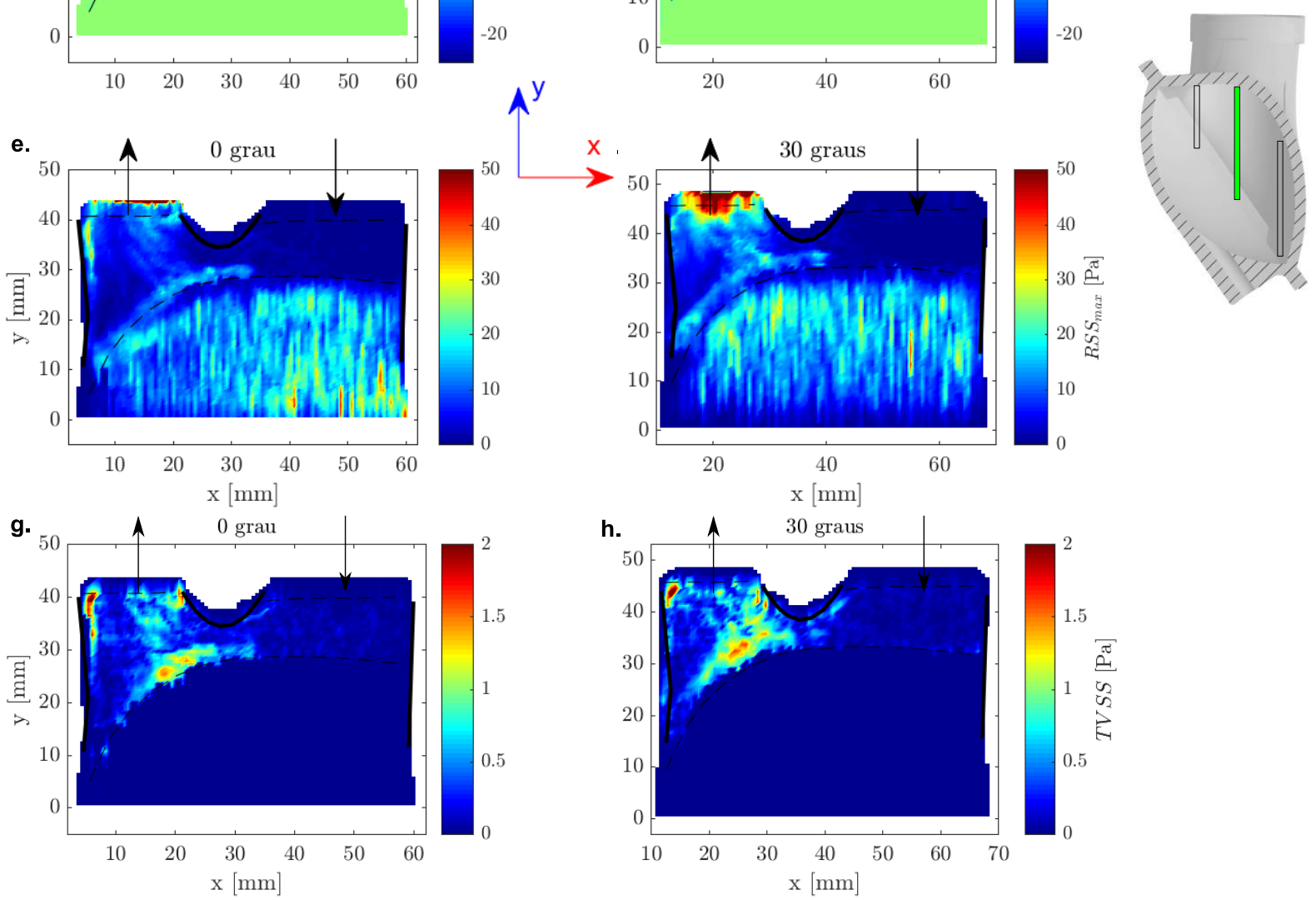
Figura 135 - Campos de tensões $\left(0^{\circ}\right.$ e $\left.30^{\circ}\right)$ no plano traseiro no intervalo t6
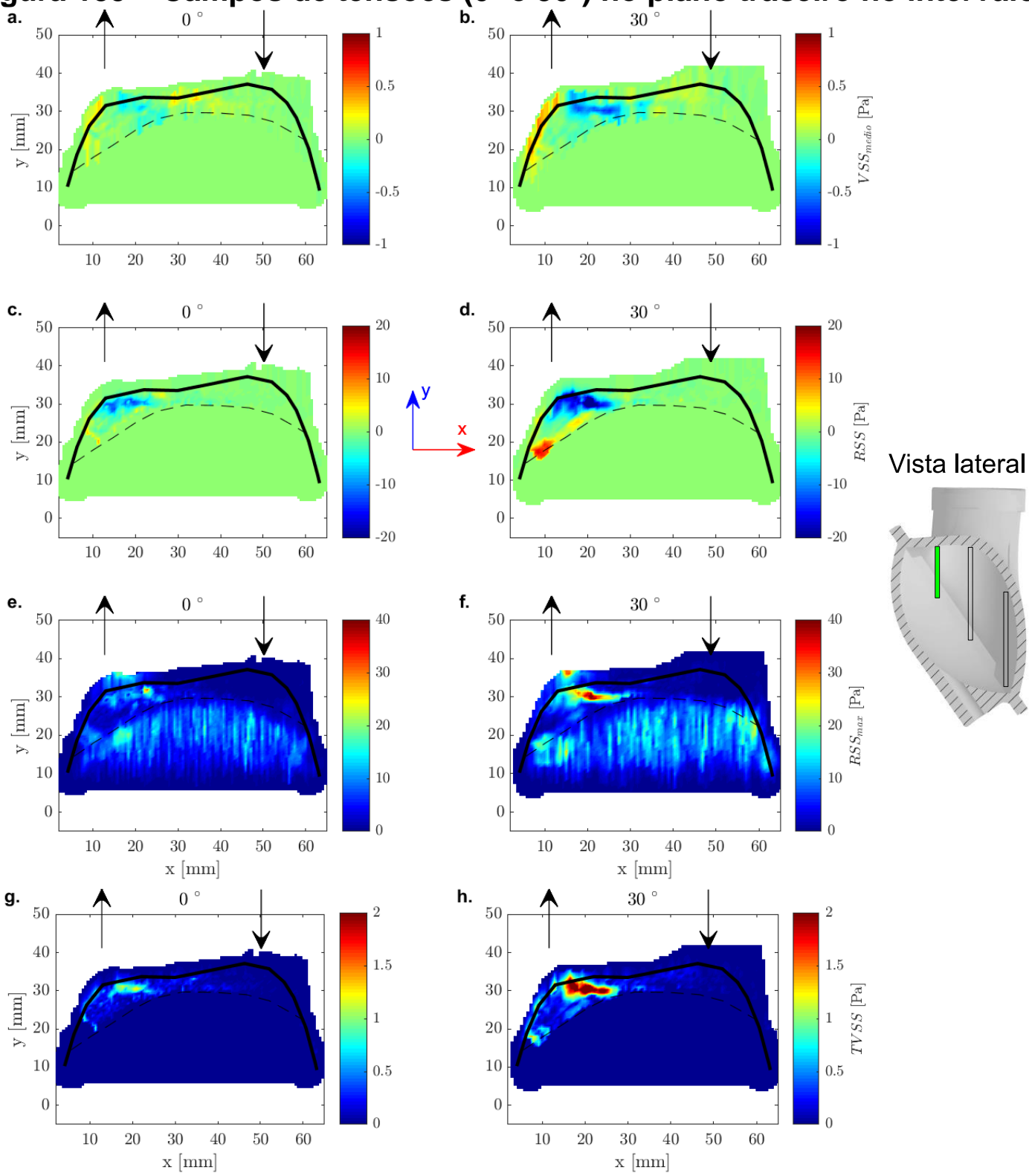

O desfecho da sístole é também o apogeu da energia cinética turbulenta. Neste intervalo surge uma pequena região com valores acima de $0,6 \mathrm{~m}^{2} / \mathrm{s}^{2}$ para a válvula de entrada a $0^{\circ}$. Também neste intervalo ocorre o auge da energia para $30^{\circ}$.

Figura 136 - Campos de TKE (0 e 30) no plano médio no intervalo t6
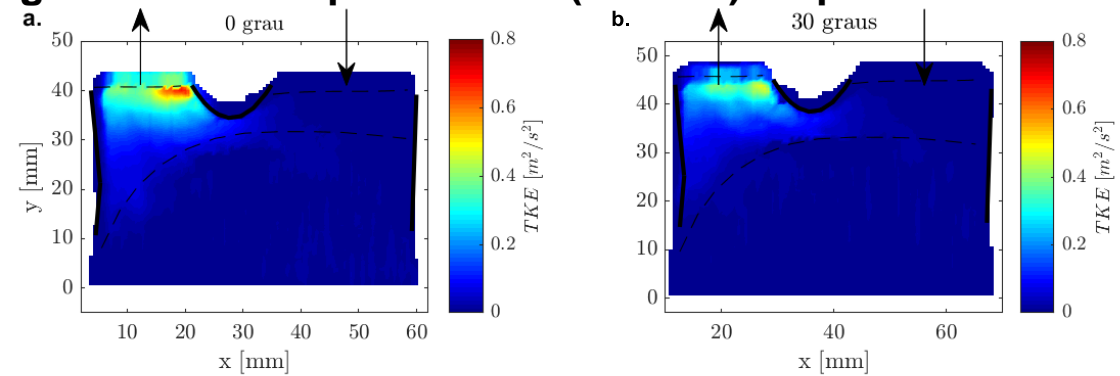

Vista lateral

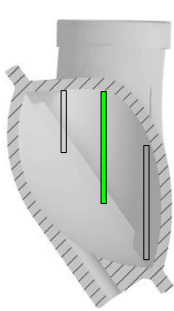


A Tabela 10 apresenta um resumo comparando os seis intervalos analisados e os dois ângulos da válvula de entrada, $0^{\circ}$ e 30ㅜ em relação às estruturas do escoamento, velocidades e regurgitação. Também há uma comparação entre os dois ângulos de válvula para um ciclo completo do DAVP ao final da tabela.

\begin{tabular}{|c|c|c|c|c|}
\hline Intervalo & Ângulo & Estruturas no escoamento & Velocidades & Regurgitação \\
\hline \multirow[b]{2}{*}{$\mathrm{t}_{1}$} & $0^{\circ}$ & Nenhuma & Superiores & Sim (saída) \\
\hline & $30^{\circ}$ & Nenhuma & Inferiores & Sim (saída) \\
\hline \multirow{2}{*}{ t2 } & $0^{\circ}$ & Jato diastólico & Análogas & Sim (saída) \\
\hline & $30^{\circ}$ & Jato diastólico & Análogas & Não \\
\hline \multirow{2}{*}{$t_{3}$} & $0^{\circ}$ & Vórtice & Superiores & Não \\
\hline & $30^{\circ}$ & Vórtice & Inferiores & Não \\
\hline \multirow{2}{*}{$\mathrm{t}_{4}$} & $0^{\circ}$ & Vórtice & Análogas & Sim (entrada) \\
\hline & $30^{\circ}$ & Vórtice & Análogas & Sim (entrada) \\
\hline \multirow{2}{*}{$\mathrm{t}_{5}$} & $0^{\circ}$ & Nenhuma & Superiores & Sim (entrada) \\
\hline & $30^{\circ}$ & Nenhuma & Inferiores & Não \\
\hline \multirow{2}{*}{$t_{6}$} & $0^{\circ}$ & Nenhuma & Superiores & Não \\
\hline & $30^{\circ}$ & Nenhuma & Inferiores & Não \\
\hline Geral & $\begin{array}{r}0 \\
30\end{array}$ & $\begin{array}{r}\text { Maior vórtice (lavagem) } \\
\text { Jato diastólico deslocado }\end{array}$ & $\begin{array}{r}\text { Superiores } \\
\text { Inferiores }\end{array}$ & $\begin{array}{l}\text { Maior } \\
\text { Menor }\end{array}$ \\
\hline
\end{tabular}

Já a Tabela 11 apresenta uma comparação entre os ângulos de entrada ( $0^{\circ} \mathrm{e}$ $\left.30^{\circ}\right)$ das tensões analisadas e do TKE, novamente para os seis intervalos avaliados e para o ciclo como um todo.

Tabela 11 - Resumo comparando as tensões e energia cinética turbulenta

\begin{tabular}{|c|c|c|c|c|c|c|}
\hline Intervalo & Ângulo & VSS & RSS & RSS $_{\max }$ & TVSS & TKE \\
\hline$t_{1}$ & $\begin{array}{r}0^{\circ} \\
30^{\circ}\end{array}$ & $\begin{array}{r}\text { Superior } \\
\text { Inferior }\end{array}$ & $\begin{array}{r}\text { Superior } \\
\text { Inferior }\end{array}$ & $\begin{array}{l}\text { Superior } \\
\text { Inferior }\end{array}$ & $\begin{array}{l}\text { Superior } \\
\text { Inferior }\end{array}$ & $\begin{array}{l}\text { Superior } \\
\text { Inferior }\end{array}$ \\
\hline \multirow[b]{2}{*}{ t2 } & $0^{\circ}$ & Inferior & Superior & Análogo & Inferior & Superior \\
\hline & $30^{\circ}$ & Superior & Inferior & Análogo & Superior & Inferior \\
\hline \multirow{2}{*}{$t_{3}$} & $0^{\circ}$ & Inferior & Superior & Análogo & Superior & Superior \\
\hline & $30^{\circ}$ & Superior & Inferior & Análogo & Inferior & Inferior \\
\hline $\mathrm{t}_{4}$ & $\begin{array}{r}0^{\circ} \\
30^{\circ}\end{array}$ & Inferior & $\begin{array}{l}\text { Inferior } \\
\text { r }\end{array}$ & Inferior & Inferior & Inferior \\
\hline \multirow[b]{2}{*}{$t_{5}$} & $\begin{array}{r}30= \\
0\end{array}$ & $\begin{array}{l}\text { Superior } \\
\text { Superior }\end{array}$ & $\begin{array}{l}\text { Superior } \\
\text { Superior }\end{array}$ & $\begin{array}{l}\text { Superior } \\
\text { Superior }\end{array}$ & Superior & Superior \\
\hline & $30^{\circ}$ & Inferior & Inferior & Inferior & Inferior & Inferior \\
\hline \multirow{2}{*}{ t6 } & $0^{\circ}$ & Inferior & Inferior & Inferior & Inferior & Superior \\
\hline & $30^{\circ}$ & Superior & Superior & Superior & Superior & Inferior \\
\hline Geral & $\begin{array}{r}0= \\
30 \text { o }\end{array}$ & $\begin{array}{l}\text { Superior } \\
\text { Inferior }\end{array}$ & $\begin{array}{l}\text { Superior } \\
\text { Inferior }\end{array}$ & $\begin{array}{l}\text { Superior } \\
\text { Inferior }\end{array}$ & $\begin{array}{l}\text { Superior } \\
\text { Inferior }\end{array}$ & $\begin{array}{l}\text { Superior } \\
\text { Inferior }\end{array}$ \\
\hline
\end{tabular}




\subsection{Evolução temporal das tensões viscosa e de Reynolds}

Os valores médios das tensões de cisalhamento viscosa e de Reynolds são frequentemente utilizadas para determinar se há a formação de trombos em um determinado local do dispositivo dentro de um intervalo do ciclo. Porém, para determinar se há a hemólise no sangue que passou pelo DAV é necessário determinar a evolução temporal das tensões a que uma partícula, que representaria um eritrócito ou plaqueta, esteve sujeita, considerando uma abordagem lagrangiana. Nesta abordagem, são lançadas partículas imaginárias em um campo medido pelo PIV. O progresso desta partícula no escoamento é avaliado na escala de tempo, ou seja, nas diferenças de velocidade entre os campos PIV. Os métodos baseados nesta abordagem são chamados de pseudo-rastreamento (pseudo-tracking), pois as trajetórias das partículas não estão disponíveis no momento da medição, mas são construídas em um momento posterior (GENT, SCHRIJER e OUDHEUSDEN, 2018). A abordagem torna-se especialmente válida para este trabalho devido à resolução temporal obtida pelo TR-PIV. No presente trabalho tem-se, portanto, uma aproximação da trajetória realizada por esta partícula no plano apesar da consciência do movimento tridimensional do fluxo no dispositivo.

Além da evolução temporal instantânea, deve-se contabilizar o efeito das tensões nesta partícula durante a sua passagem pelo dispositivo, ou seja, deve-se integrar a área sob a curva da tensão por tempo. Nesse contexto, comparou-se o valor encontrado da somatória com os valores limítrofes definidos pela literatura (Figura 33 e Figura 36).

Primeiramente, neste estudo para encontrar a evolução temporal de uma partícula no escoamento, selecionou-se o lugar geométrico e o instante inicial em que uma partícula seria "criada" e liberada no escoamento. Após a "criação" desta partícula, ela seguiu a trajetória determinada pelo vetor velocidade fornecido pelo campo de velocidades instantâneo e bidimensional do PIV. No intervalo seguinte, o ponto final do deslocamento anterior é utilizado como o novo ponto inicial do vetor seguinte, novamente calculado baseada no campo de velocidades instantâneo do PIV, até que a partícula saísse do dispositivo ou entrasse em uma região com muito ruído. Regiões consideradas ruidosas são: diafragma, limites do DAVP como válvulas e paredes.

Dez pontos iniciais foram selecionados em dois instantes diferentes, no início 
da sístole e da diástole para os dois ângulos de válvula. Escolheu-se o início de cada período do ciclo de batimento como instantes de partida das partículas pois observouse poucas diferenças no escoamento entre $0^{\circ}$ e $30^{\circ}$ nestes instantes. $O$ início geométrico dos pontos quando a válvula de entrada estava a $0^{\circ}$ (pontos $A, C, E, G$ e I) não são os mesmos dos pontos $30^{\circ}$ (pontos $B, D, F, H$ e J) porque a posição da câmara foi ligeiramente alterada. As informações iniciais dos pontos estão na Tabela 12.

\begin{tabular}{|c|c|c|c|}
\hline Ponto & Início geométrico $(\mathrm{mm})$ & Início temporal & Ângulo da válvula \\
\hline $\mathrm{A}$ & $(95,70)$ & $0 \%$ da diástole & $0^{\circ}$ \\
\hline B & $(95,70)$ & $0 \%$ da diástole & $30^{\circ}$ \\
\hline C & $(14,53)$ & $0 \%$ da diástole & $0^{\circ}$ \\
\hline D & $(24,53)$ & $0 \%$ da diástole & $30^{\circ}$ \\
\hline $\mathrm{E}$ & $(16,30)$ & $0 \%$ da diástole & 0 \\
\hline $\mathrm{F}$ & $(30,40)$ & $0 \%$ da diástole & $30^{\circ}$ \\
\hline G & $(15,35)$ & 0\% da sístole & 0 \\
\hline $\mathrm{H}$ & $(28,35)$ & $0 \%$ da sístole & $30^{\circ}$ \\
\hline I & $(88,60)$ & $0 \%$ da sístole & 0 \\
\hline$J$ & $(90,60)$ & 0\% da sístole & $30^{\circ}$ \\
\hline
\end{tabular}

O ponto A representa bem a evolução do jato diastólico para $0^{\circ}$, pois durante todo o tempo permanece muito próximo à parede externa de entrada por quase toda a metade inicial da diástole (Figura 137a). A partícula cobriu uma distância de aproximadamente $35 \mathrm{~mm}$ (Figura 137b) em 46\% da diástole. Esperava-se valores maiores de VSS devido à proximidade com a parede e ao intervalo do ciclo, entretanto a partícula não esteve próxima o suficiente da parede para atingir tais magnitudes, resultando em um VSS máximo de 0,06 Pa e com área de 6,5 Pa.ms (Figura 137c). O mesmo vale para o RSS que seguiu o comportamento observado nos campos de tensões médios para o intervalo e manteve-se baixo, entre 0,5 e $6 \mathrm{~Pa}$ resultando em uma área de 208 Pa.ms.

O ponto $B$ (Figura 138) também representa bem o jato diastólico para $30^{\circ}$. No início a partícula segue verticalmente para em direção ao fundo do DAVP. Após 30 instantes de tempo a trajetória da partícula muda de vertical para diagonal, bem como ocorreu na magnitude média Ū (Figura 95). Esta trajetória permanece até que a partícula chegue próxima ao fundo do dispositivo, onde permanecerá boa parte do 
tempo. Após 150 instantes de tempo já no período da sístole a partícula segue em direção à válvula de saída e deixa o dispositivo após $80 \%$ da sístole. Neste trajeto a partícula percorreu quase $100 \mathrm{~mm}$ (Figura 138b) no dispositivo e produziu um VSS máximo de $0,08 \mathrm{~Pa}$, o maior observado entre as partículas. A área total de VSS foi 12,2 Pa.ms (Figura 138c). O máximo valor de RSS ficou ligeiramente acima de $10 \mathrm{~Pa}$ com área de 669,7 Pa.ms (Figura 138d).

Já o ponto $\mathrm{C}$ representa a regurgitação na saída durante a diástole para 0응 (Figura 139a). Pouco após a marca de $40 \%$ da diástole, a partícula deixou o dispositivo, percorrendo quase $12 \mathrm{~mm}$ (Figura 139b). O VSS (Figura 139c) e RSS (Figura 139d) do percurso são menores que os encontrados no ponto $A$.

$A$ intenção do ponto $D$ era exibir o caminho de uma partícula regurgitada na saída para $30^{\circ}$. Entretanto, o local de origem que foi escolhido para ser próximo ao caso para $0^{\circ}$ resultou em uma partícula que sobe em direção à válvula de saída, mas que fica retida na parede com grande curvatura entre as válvulas (Figura 140a). Com isto a partícula percorreu $17 \mathrm{~mm}$ (Figura 140b) e sofreu pouco com as tensões cujas áreas foram de 3,0 Pa.ms para o VSS (Figura 140c) e 41,6 Pa.ms para o RSS (Figura 140d).

Figura 137 - Evolução temporal do ponto A
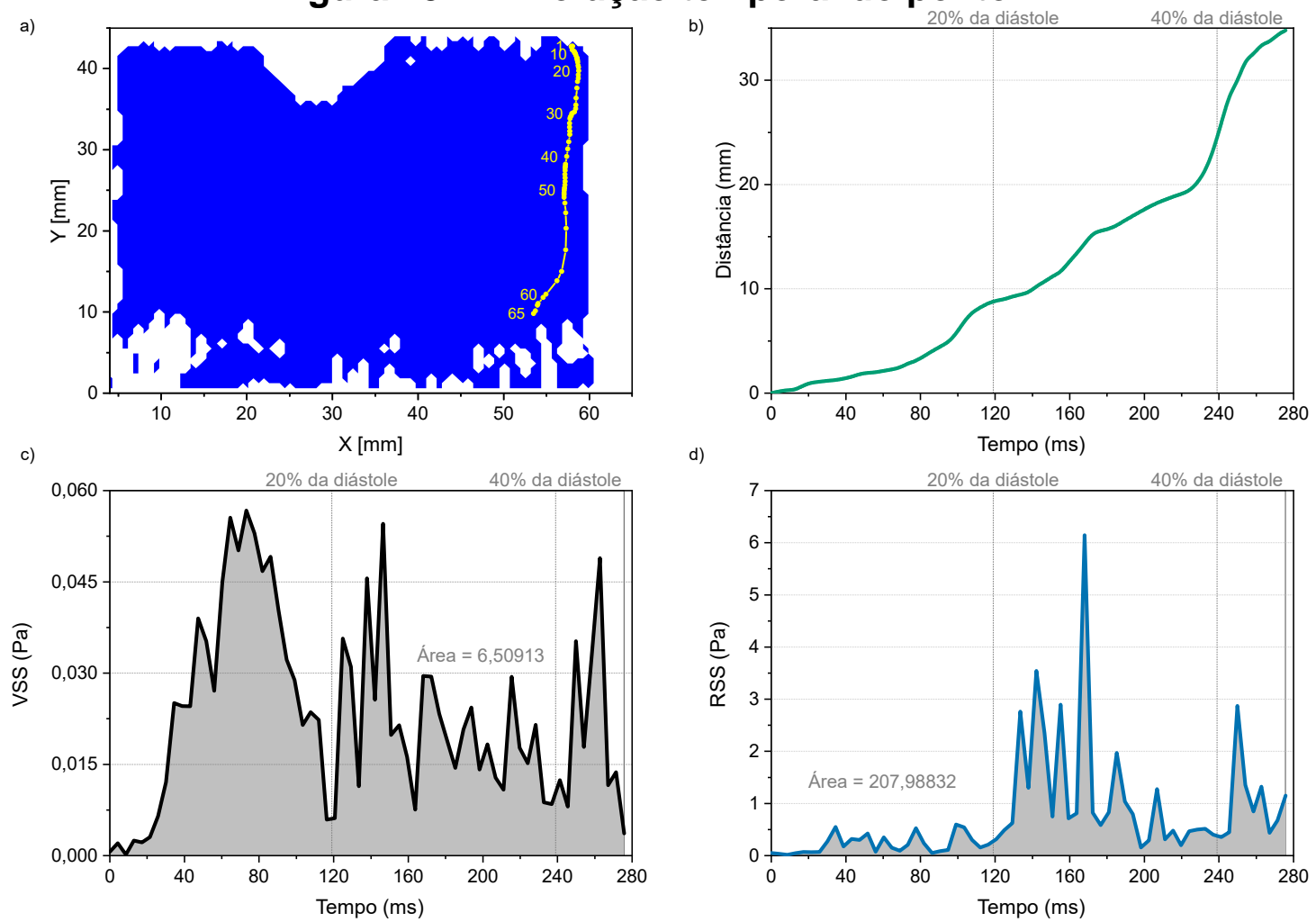
Figura 138 - Evolução temporal do ponto B
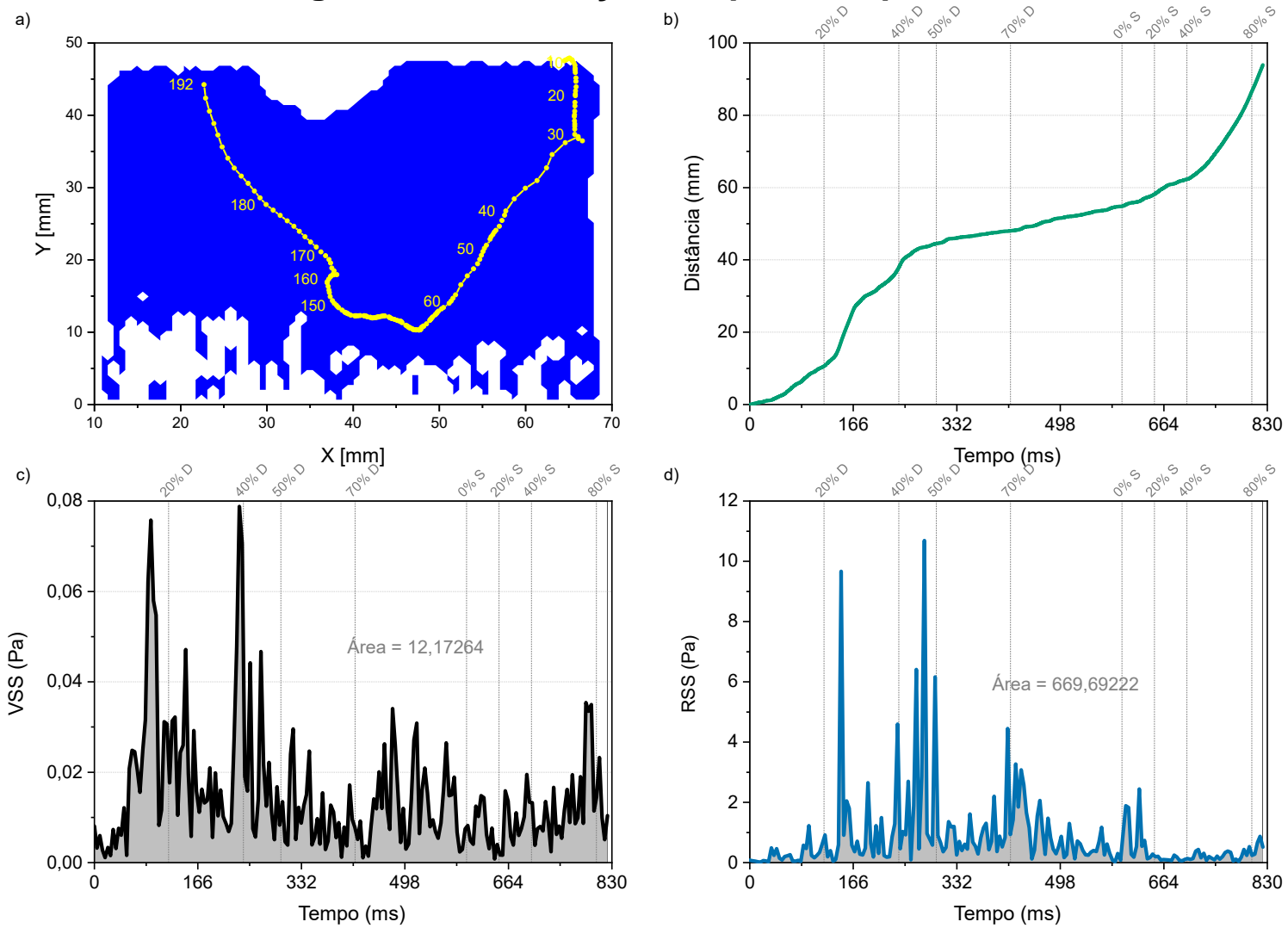

Figura 139 - Evolução temporal do Ponto C
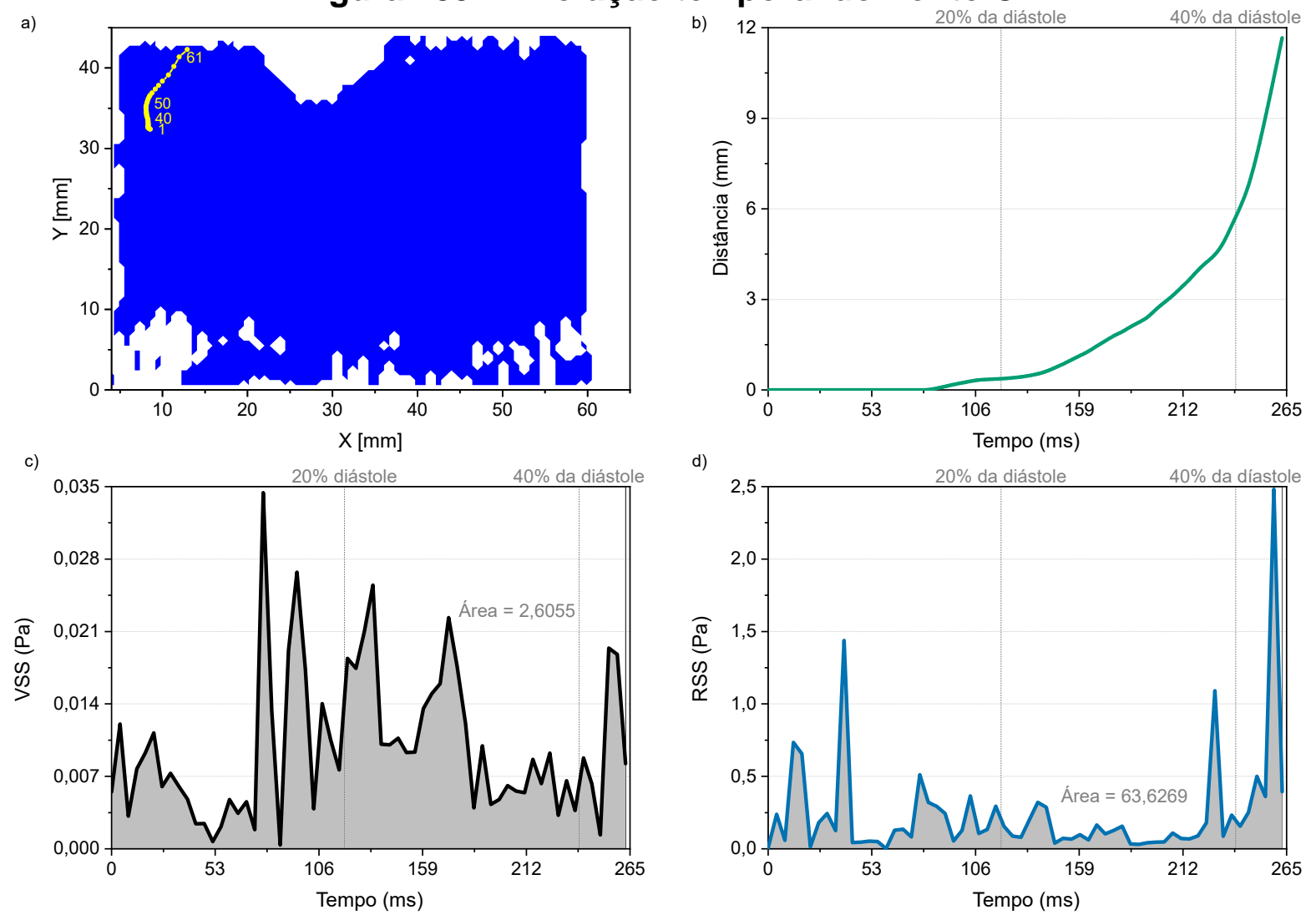
Figura 140 - Evolução temporal do Ponto D
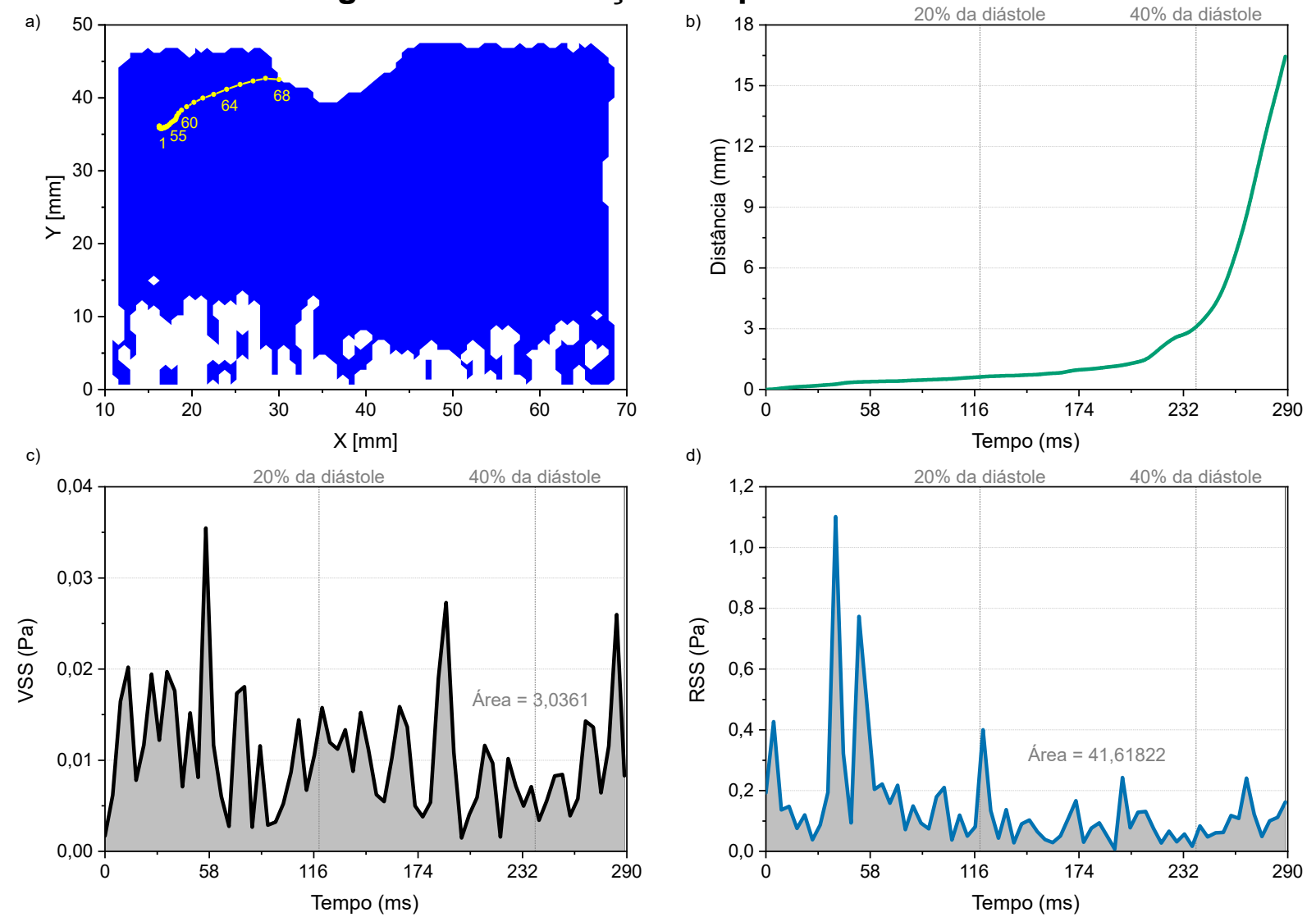

$\mathrm{O}$ ponto $\mathrm{E}$ representa uma partícula que passou pela grande lavagem do dispositivo para a válvula a 0 . Nos instantes iniciais esta partícula quase não se movimenta, devido à pouca ação do escoamento no lado esquerdo do dispositivo já que 0 jato diastólico adentra pela direita (Figura 141a). Em 40\% da diástole 0 movimento cresce e a partícula adentra o grande vórtice observado nas magnitudes da velocidade média Ū. Já no início da sístole, a partícula move-se em direção à saída, mas assim como ocorreu no ponto $\mathrm{D}$, acaba batendo na parede e lá permanece. $\mathrm{O}$ resultado deste percurso são $120 \mathrm{~mm}$ deslocados em quase um segundo (Figura 141b). O VSS atingiu valores na ordem de 0,07 Pa resultando em uma área de 15,6 Pa.ms (Figura 141c). Por sua vez, o RSS ultrapassou 22,5 Pa de máxima em uma área de 1248,6 Pa.ms (Figura 141d).

$\mathrm{O}$ ponto $\mathrm{F}$ também representa a lavagem do dispositivo, mas desta vez para $30^{\circ}$. Neste caso, tem-se o maior tempo em que uma partícula permaneceu no dispositivo: 1,5 segundos. $O$ trajeto segue 0 grande vórtice, entretanto devido às menores velocidade observadas para $30^{\circ}$ a partícula não consegue seguir rumo à 
válvula de saída durante a sístole. Desta maneira, ela permanece no dispositivo durante outro ciclo, semelhante ao volume sistólico final do coração humano. No início da segunda diástole, a partícula é empurrada para o fundo do dispositivo onde perdura até pouco depois do início da segunda sístole. Neste instante, o diafragma surge na região onde está a partícula e ela se perde, terminando com o trajeto (Figura 142a). A distância que a partícula percorreu foi próxima de $100 \mathrm{~mm}$ (Figura 142b), com uma área de VSS de 14,3 Pa.ms (Figura 142c). Já o RSS alcançou o maior pico entre todos os pontos, aproximadamente $33 \mathrm{~Pa}$ e como consequência a maior área: 2647,9 Pa.ms (Figura 142d).

O ponto $G$ representa uma célula no decorrer da sístole, que sai do meio para o fundo do dispositivo e segue para cima em direção a região de saída para $0^{\circ}$ (Figura 143a). Do início ao fim do percurso, a partícula percorre 20,3 mm em $168 \mathrm{~ms}$, ou seja, foi necessário 65\% da sístole para a partícula de sair do DAVP (Figura 143b). A tensão de cisalhamento viscosa (VSS) é muito baixa durante todo o percurso, atingindo valores próximos a 0,015 $\mathrm{Pa}$, o que resultou em uma área sob a curva de 0,9 Pa.ms (Figura 143c). O mesmo é válido para as tensões de cisalhamento de Reynolds que quase atingiram 1,8 Pa de máximo e resultaram em uma área de 36,3 Pa.ms (Figura 143d).

Figura 141 - Evolução temporal do Ponto E
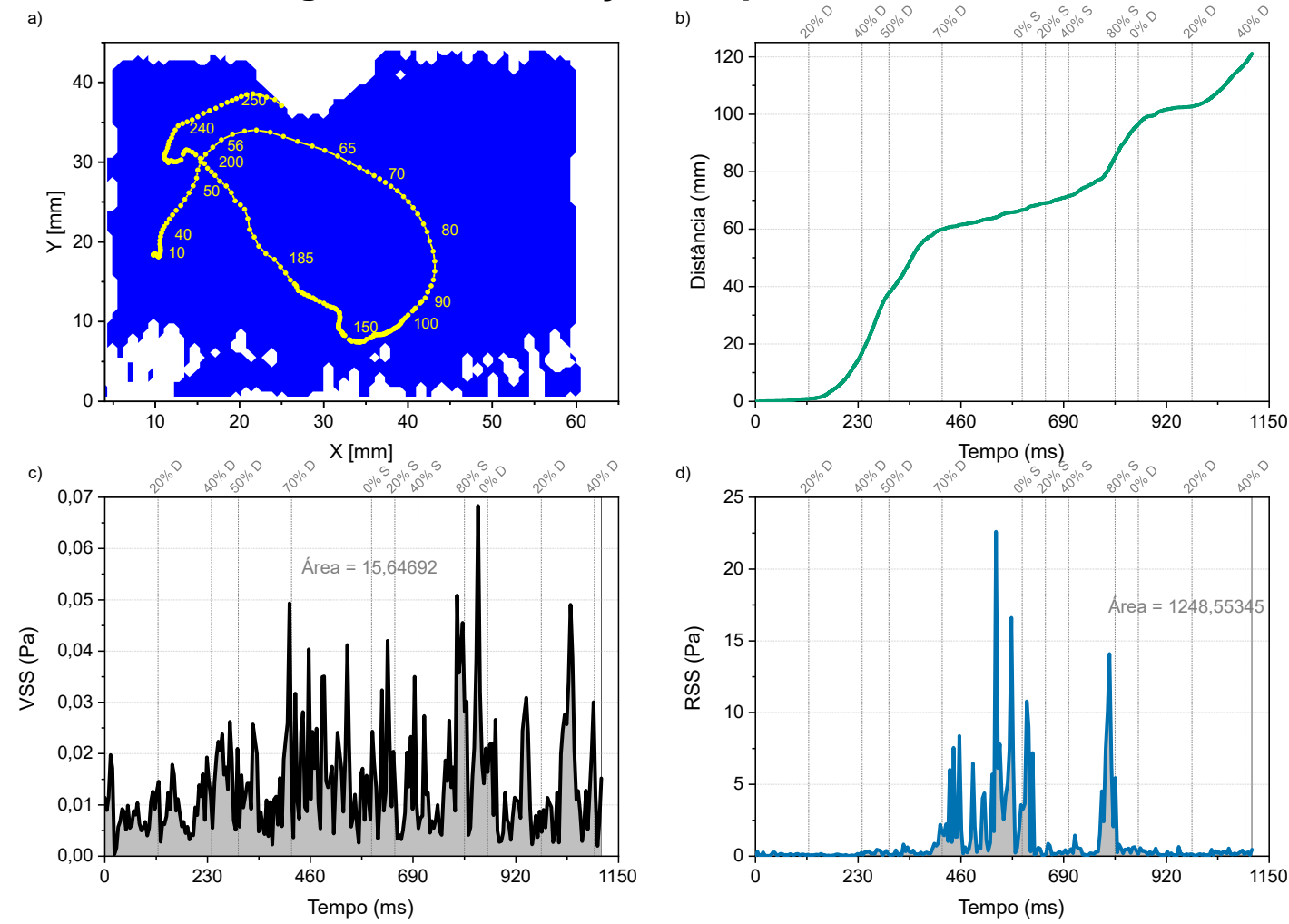
Figura 142 - Evolução temporal do Ponto F
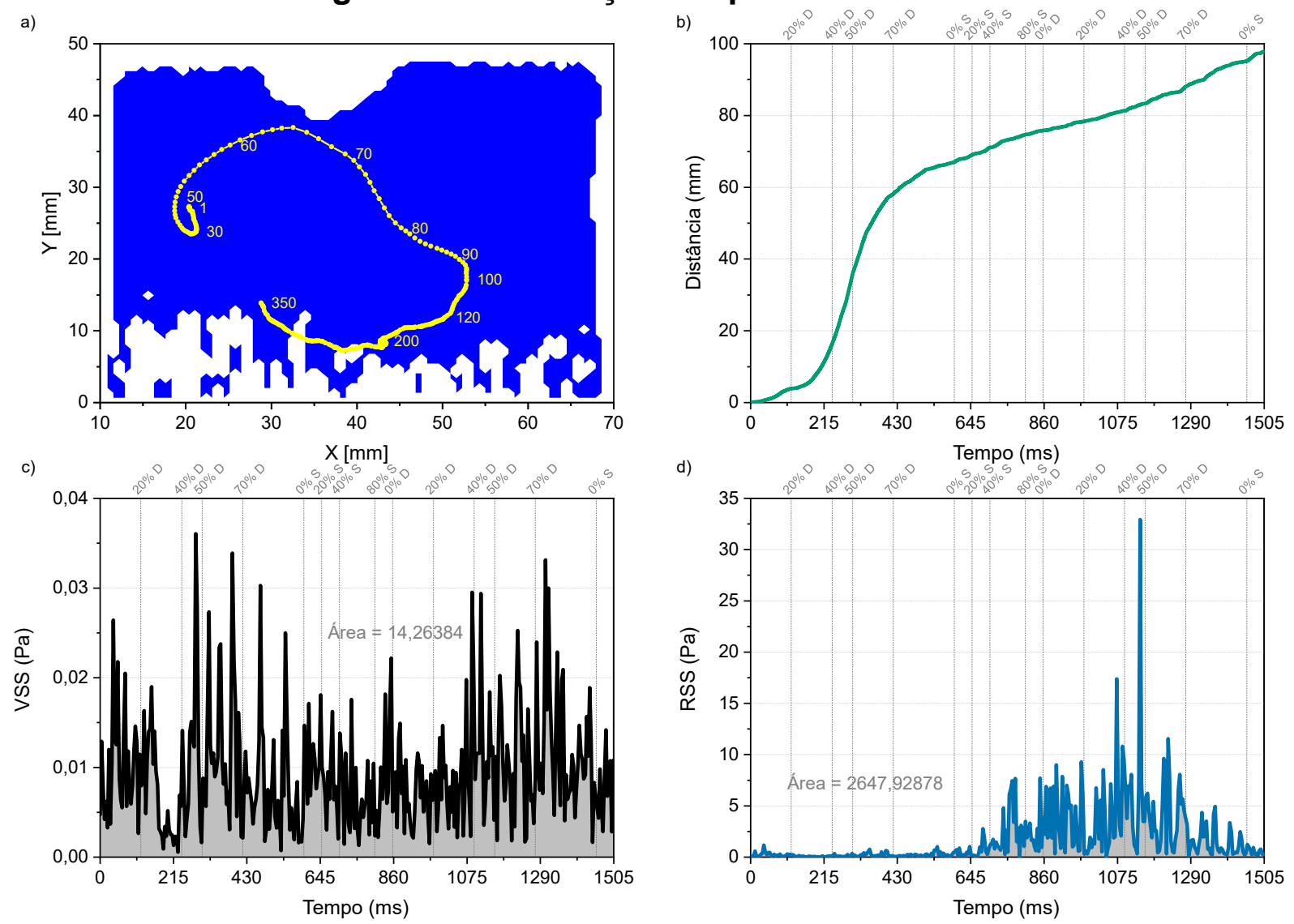

Figura 143 - Evolução temporal do Ponto G
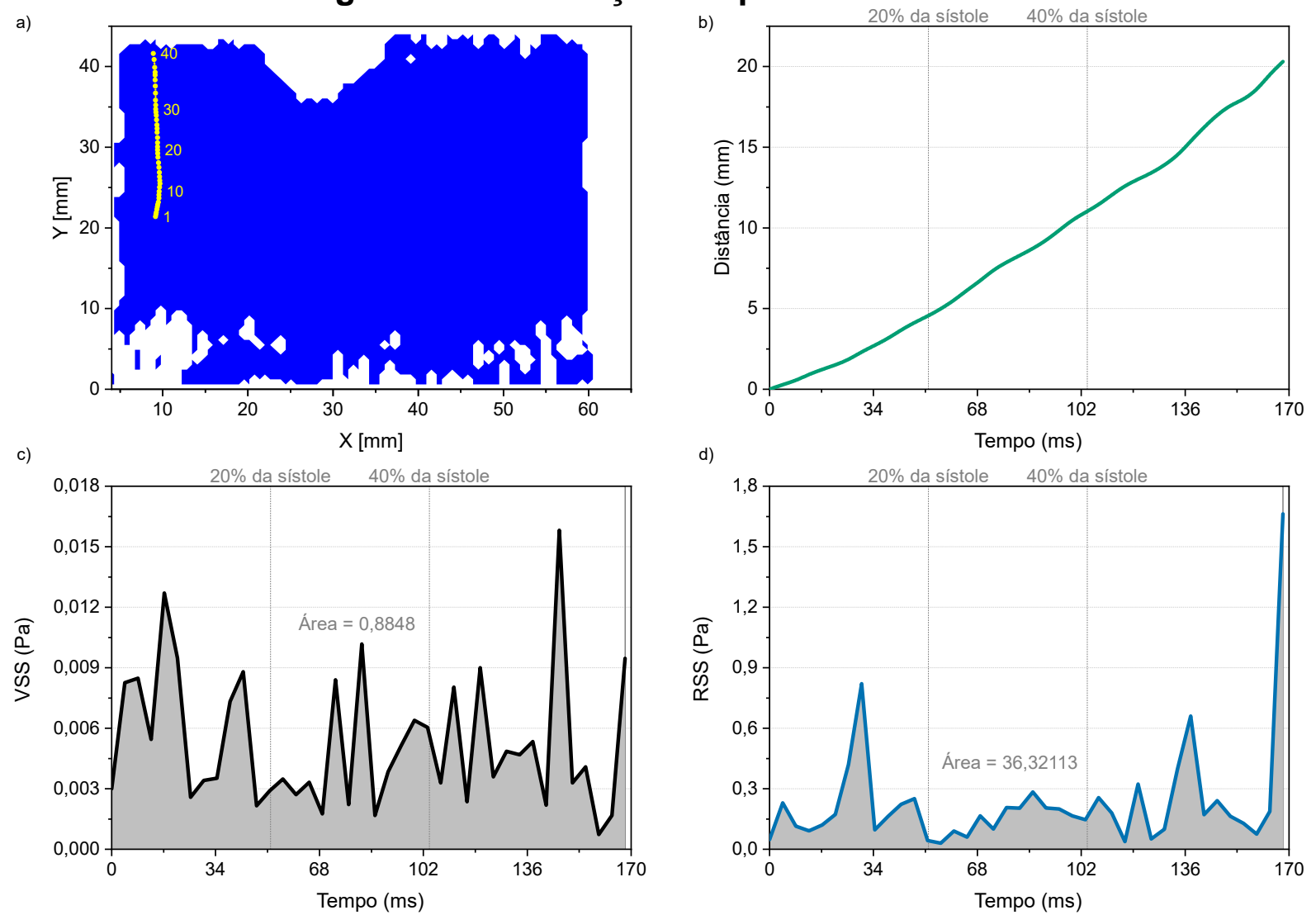
$\mathrm{O}$ ponto $\mathrm{H}$ é a representação da sístole para $30^{\circ}$. O comportamento desta partícula é semelhante ao que fora observado no ponto $\mathrm{G}$. Os valores encontrados foram ligeiramente maiores para $30^{\circ}$, muito devido à pequena curva observada no trajeto do ponto $\mathrm{H}$ (Figura 144a). A distância total foi $23 \mathrm{~mm}$ (Figura 144b) com valores de tensões baixos sendo a área de VSS igual a 1,5 Pa.ms (Figura 144c) e a área de RSS igual a 39,3 Pa.ms (Figura 144d).
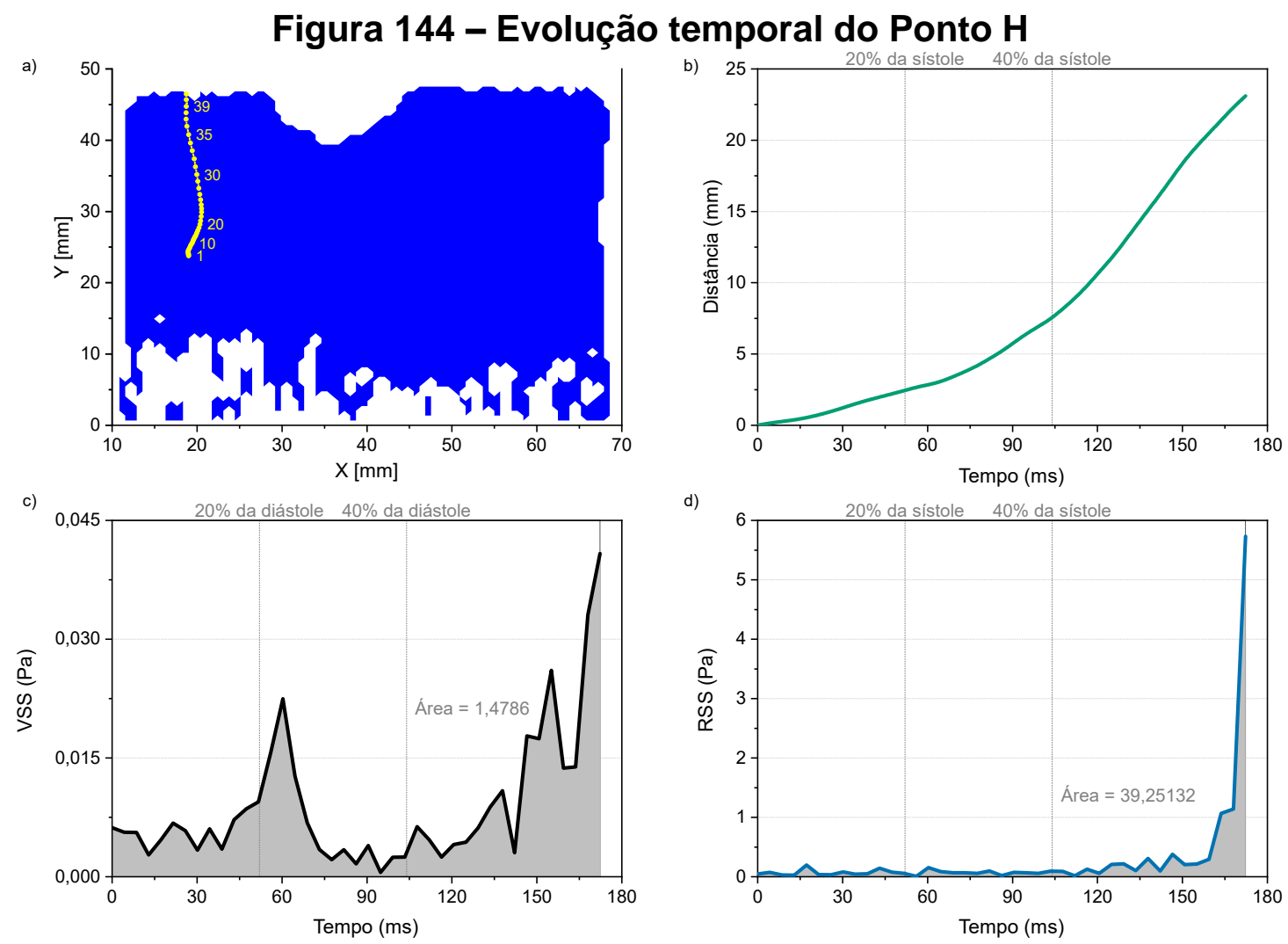

O ponto I, por outro lado, representa uma partícula regurgitada na entrada durante a sístole para $0^{\circ}$. Ela foi "liberada" logo abaixo da válvula de entrada do dispositivo e por lá permaneceu pouco tempo (Figura 145a). Com isso a partícula percorreu 16,5 mm em pouco mais de 120,6 ms (Figura 145b). A região de entrada do DAVP do InCor possui VSS muito semelhantes às encontradas na saída produzindo uma área integrada de 1 Pa.ms (Figura 145c). O RSS não possui valores elevados portanto, a área resultante da curva foi 10,5 Pa.ms (Figura 145d). Novamente, o VSS e o RSS não são preocupantes.

O ponto $\mathrm{J}$ corresponde a uma partícula regurgitada para a válvula posicionada

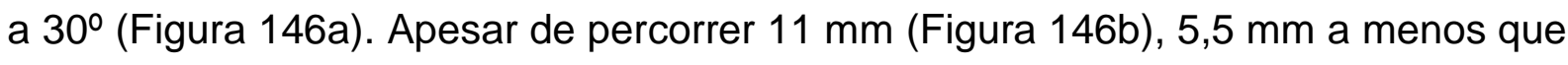
o ponto I, a somatória das tensões foi maior. A área de VSS alcançou 1,4 Pa.ms 
(Figura 146c) e a área de RSS atingiu 22,5 Pa.ms (Figura 146d). Estes valores refletem um aumento de $40 \%$ para VSS e $114 \%$ para RSS em relação ao ponto I.

Figura 145 - Evolução temporal do Ponto I
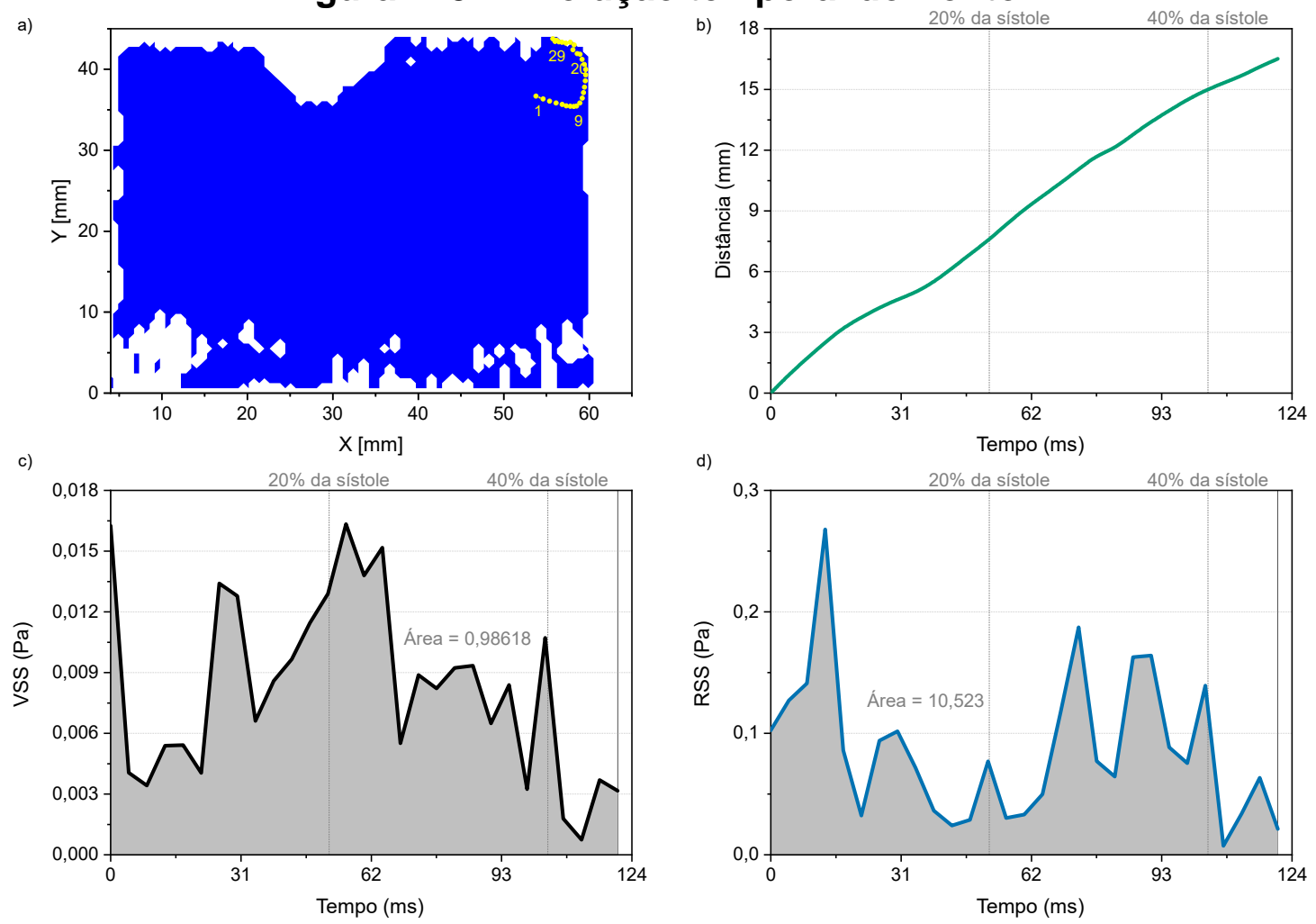

Figura 146 - Evolução temporal do Ponto J
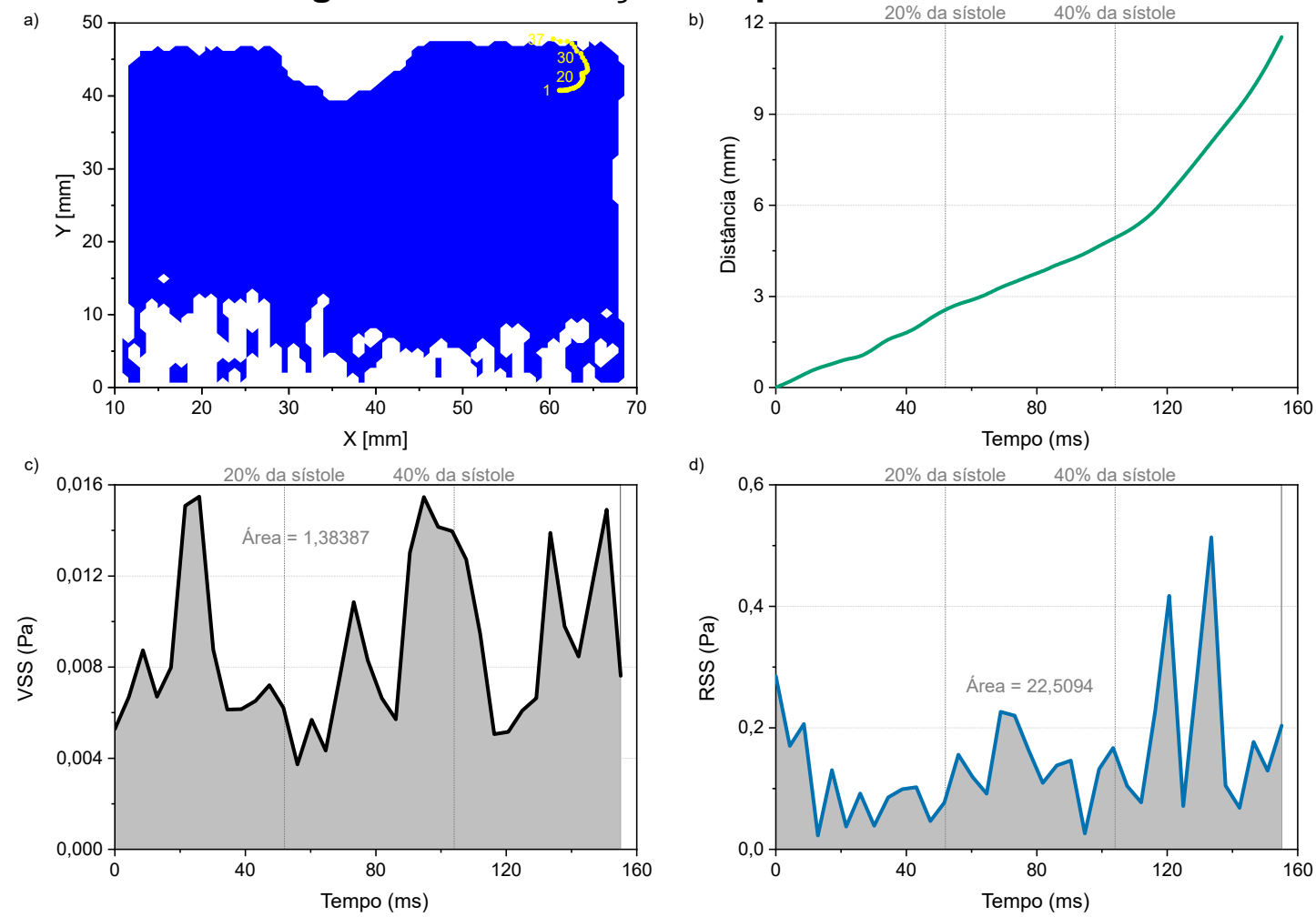


\subsection{Discussão}

As condições de operação de um DAV pulsátil influenciam nos padrões da fluidodinâmica e possivelmente nos danos causados ao sangue, como a formação de trombos e a hemólise, no interior do dispositivo. A investigação das condições de operação torna-se, portanto, necessária para determinar pontos ideais de funcionamento e para fornecer indícios às terapias medicamentosas de anticoagulação. Espera-se que três condições de operação de um DAV seriam as grandes responsáveis pela deterioração sanguínea: os efeitos físicos do diafragma e/ou das válvulas, a taxa de pulsação (ou frequência de batimento) e a duração sistólica (XU et al., 2015). Todavia, faz necessário o uso de grandezas físicas para comparar as diferentes condições avaliadas, como por exemplo, as velocidades e as tensões de cisalhamento.

Os resultados encontrados no presente estudo sugerem que a mudança no ângulo da válvula mecânica na entrada induz uma mudança no escoamento interno do DAVP. Ou seja, por possuir dois folhetos, a válvula produz três regiões por onde o sangue pode escoar. Os perfis de velocidade de válvulas de dois folhetos são medidos com LDA e PIV desde o início do milênio por Liu, Lu e Chu (2000) e mais tarde por Lee, Tatsumi e Taenaka (2009 e 2010). Essas medidas concentravam-se nos perfis de apenas um dos folhetos ou de uma área após a saída das válvulas, o que nem sempre representava os detalhes do escoamento mais próximo e em cada região por onde o fluido poderia passar. Os perfis de velocidade da válvula 21AJ-501, utilizada nas medições PIV, foram medidos com LDA por Bazan et al. (2013) a $30 \mathrm{~mm}$ a montante e a 8,20 e $32 \mathrm{~mm}$ a jusante do centro válvula (Figura 147). Após o fluido passar pela válvula, o escoamento apresenta três picos de velocidade, dois deles são semelhantes e ocorrem entre o anel da válvula e o folheto mais próximo. O último pico de velocidade ocorre entre os dois folhetos. As velocidades encontradas são próximas nas três regiões a jusante, com um leve aumento nas regiões próximas ao anel. Ao desenvolver-se, o escoamento tende a retornar ao perfil anterior a passagem pela válvula. Devido ao perfil de velocidade produzido pelas válvulas, o ângulo de instalação de ambas é importante no desenvolvimento do fluxo dentro do DAVP e na cânula de saída do dispositivo. Pequenas mudanças nos ângulos de instalação podem causar mudanças significativas nas velocidades, tensões e no padrão rotacional do fluido. 
Neste contexto, a presente dissertação encontrou diferenças nos jatos diastólicos e consequentemente nas tensões para os dois ângulos de válvula de entrada analisados, a saber, $0^{\circ}$ e $30^{\circ}$ na Seção 4.1. Para 0ㅜㅇ o jato é mais intenso e vertical, ao contrário de 30ำ, em que o jato foi menos intenso e deslocou-se da parede de entrada. Percebeu-se também, que os jatos diastólicos são visíveis nos planos frontal e traseiro em intervalos distintos. Como decorrência, as tensões foram afetadas, em especial a tensão de cisalhamento viscosa (VSS). Na parede direita, logo abaixo da válvula de entrada, o VSS foi maior para a posição de válvula em que o jato esteve mais próximo, ou seja, $0^{\circ}$.

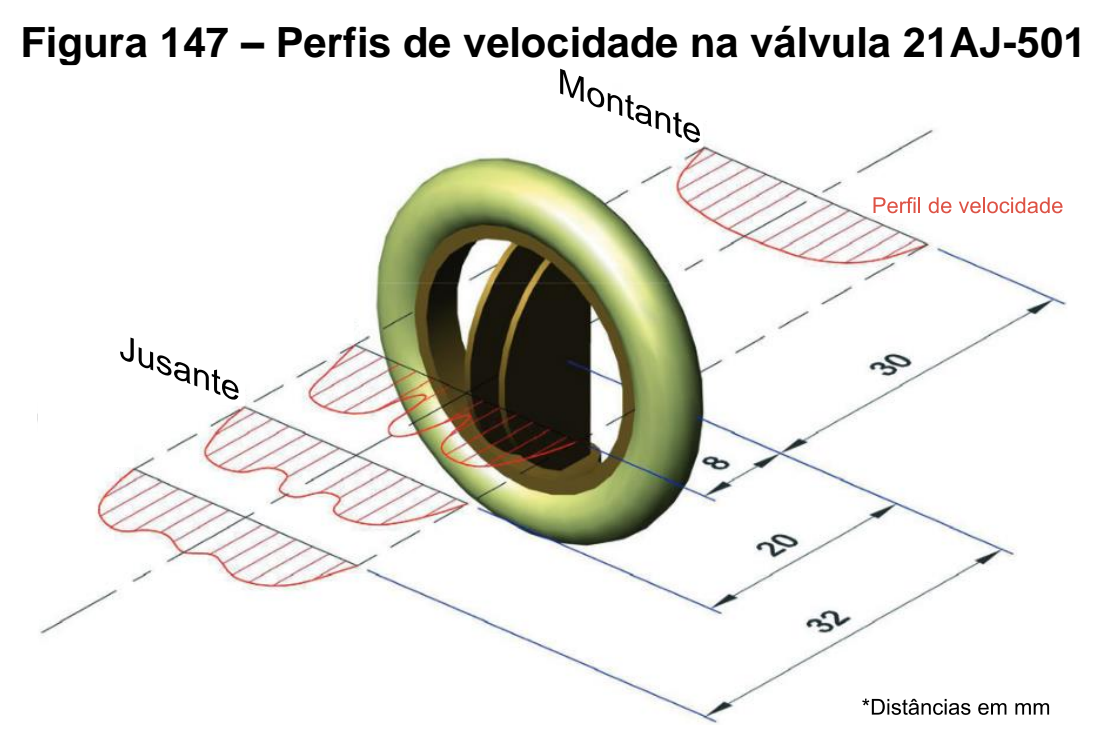

Fonte: Adaptado de Bazan et al. (2013).

Prosseguindo, a velocidade é um parâmetro interessante pois, geralmente é obtido primeiro pelas técnicas experimentais, como o PIV. Todavia deve-se ter cautela na determinação das velocidades. Devido ao movimento do diafragma, que perpassa o plano de medição PIV no início da diástole e no fim da sístole, surgem reflexões de luz. A reflexão causa regiões de maior intensidade na imagem que podem levar a erros no cálculo da velocidade pelo PIV. Outro contratempo causado pelo diafragma consiste na sua sombra no plano de medição. A sombra pode causar perda de informação sobre o escoamento nesta região, devido à baixa luminosidade nas partículas. Estas adversidades foram solucionadas no presente trabalho através do pré-processamento PIV e da máscara dinâmica, ambos mencionados na Seção 3.4. Outro fator que deve ser levado em conta é a tridimensionalidade do escoamento dentro no DAV. Usualmente a técnica PIV é 2D, portanto a terceira componente não 
é medida e seus efeitos na fluidodinâmica são desconhecidos (COOPER et al., 2008). A partir das velocidades calculam-se as demais grandezas físicas.

A tensão de cisalhamento é o fator mais utilizado no desenvolvimento de DAVs visto sua relação direta com a formação de trombos e a hemólise. No fluxo laminar, a tensão de cisalhamento é função única da viscosidade e depende das derivadas espaciais do campo instantâneo de velocidade. Ou seja, a tensão de cisalhamento laminar é viscosa. No escoamento turbulento, o conceito de cisalhamento pode assumir duas definições, a saber, a tensão viscosa instantânea ou a tensão estatística definida pela decomposição de Reynolds, também chamada de tensor das tensões de Reynolds. Esta dualidade no conceito do cisalhamento turbulento cria confusão na interpretação da literatura e muitas vezes está relaciona à falta de informação sobre qual dos conceitos foi utilizado. O uso incorreto da definição leva a grandes erros pois a tensão de cisalhamento viscosa é uma expressão de uma grandeza real, função de uma força real em uma área real. Por outro lado, a tensão de Reynolds é um valor estatístico não relacionado a uma grandeza física, sendo assim um artefato matemático da turbulência e de ordem de grandeza maior que a tensão de cisalhamento viscosa (GE et al., 2008). Os danos causados ao sangue são modelados como funções da tensão de cisalhamento, viscosa ou turbulenta, pelo tempo de residência do sangue a esta tensão. Tensões muito baixas estão relacionadas à ativação de plaquetas e a formação de trombos, assim como tensões elevadas estão relacionadas a lise de eritrócitos e plaquetas. Ao analisar os resultados dos campos médios e instantâneos da Seção 4.1, nota-se que a escala de VSS foi bem menor que a escala de RSS. Por exemplo, os valores máximos de VSS estiveram na ordem de 1,5 Pa enquanto os valores máximos de RSS/RSS max foram cem vezes maiores. A tensão de cisalhamento viscosa turbulenta (TVSS) foi utilizada com o intuito de considerar a componente viscosa e turbulenta ao mesmo tempo. Com isto, os campos médios encontrados apresentaram comportamentos semelhantes aos campos de RSS/RSS max, mas com valores ligeiramente maiores que VSS ( 4 Pa de máximo).

No caso dos trombos, curtos tempos de residência a baixas tensões são suficientes para iniciar a cadeia de formação. Deste modo, estipula-se uma faixa para a taxa da tensão de cisalhamento em que a deposição de trombos é praticamente certa: 0 a 250 s$^{-1}$ (DEUTSCH et al., 2006). Para Navitsky et al. (2013) o valor mínimo para não formar trombos é $500 \mathrm{~s}^{-1}$. Considerando a viscosidade do sangue e do fluido utilizado nos testes como muito próximas e com valor igual a $3 \times 10^{-3}$ Pa.s, chega-se 
a seguinte conversão: $250 \mathrm{~s}^{-1}$ é $0,75 \mathrm{~Pa}$ e $500 \mathrm{~s}^{-1}$ é 1,5 Pa. Estes valores são especialmente interessantes nas regiões próximas à parede. Devido à condição de não escorregamento, o cisalhamento tende a nulidade conforme as tensões se aproximem da parede, levando a deposição de trombos. Determinar a parede não é uma tarefa fácil devido à geometria complexa com curvatura acentuada no interior do DAV. Além disso há o grande gradiente de velocidade dentro da camada limite provocado pela pulsatilidade da bomba. Em ambos os casos, estas limitações dificultam o aumento da resolução na região da parede e aumentam a incerteza na medição (NANNA et al., 2011). Ainda assim, na maior parte dos intervalos a tensões nas paredes estão entre 0,8 e $1 \mathrm{~Pa}$.

Algumas regiões já são reconhecidas por seus padrões de taxas de cisalhamento. A parede externa próxima à entrada é uma região onde não há a formação de trombos porque o jato diastólico possui taxa de cisalhamento acima de $500 \mathrm{~s}^{-1}$. A exceção encontra-se no final desta região, próxima ao "fundo" do DAV, onde a tridimensionalidade do escoamento pode causar uma diminuição nos valores da taxa próximo a parede. Por outro lado, a parede externa próxima à saída apresenta comportamento inverso ao primeiro caso. Os valores não estão próximos a $500 \mathrm{~s}-1$, excetuando-se a ejeção durante a sístole. Isto está diretamente relacionado à regurgitação da válvula de saída que reduz a eficiência do batimento e atrapalha 0 sentido normal do escoamento. Um terceiro local de destaque é a região inferior do DAV, onde normalmente as tensões são menores durante todo o ciclo (COOPER et al., 2010).

Outros trabalhos como os de Oley et al. (2005) e Nanna et al. (2011) investigaram as taxas de cisalhamento em frequências de batimento distintas enquanto Cooper et al. (2010) comparou a duração da diástole, em todos os casos para avaliar em qual condição há menos deposição de trombos nos dispositivos. Os resultados apontam para batimentos mais acelerados e menor duração diastólica. Os batimentos acelerados aumentam as tensões de cisalhamento e a menor duração diastólica está relacionada ao desenvolvimento da vorticidade no fluido. O escoamento rotacional é bom pois promove a lavagem da parede do DAV e evita a cadeia de formação dos trombos (NAVITSKY et al., 2013). Nas condições investigadas pelos autores, o batimento e a duração diastólica foram mantidos constantes, 70 bpm e 50\% de duração no ciclo, respectivamente, então não se pode concluir nada sobre estas duas variáveis neste trabalho. 
No outro lado da linha de crescimento das tensões de cisalhamento está a hemólise, cuja relação com o tempo de exposição é fundamental. A hemólise pode ocorrer nos glóbulos vermelhos, leucócitos e plaquetas. A maior parte da literatura estipula valores máximos de tensões e tempos de exposição a que estão sujeitas as células antes de romperem, tanto para cisalhamento viscoso quanto para 0 cisalhamento de Reynolds (Figura 33 e Figura 36). As plaquetas são as mais sensíveis às tensões de cisalhamento do que as células vermelhas, possuindo um limite para a lise na ordem de $10 \mathrm{~Pa}$ (Figura 34). O escoamento no corpo do DAVP provavelmente não é hemolítico, devido aos fatores apresentados na Seção 2.3 e considerando apenas a evolução temporal das tensões viscosas (VSS). Analisando os casos investigados na Seção 4.2 através da abordagem pseudo-tracking e inserindo-os nas figuras dos limiares de tensões encontrados na literatura, percebe-se que nenhum ponto está à direita das linhas. Ou seja, os pontos investigados não estão acima do que cada autor definiu como o limite de VSS para as hemácias (Figura 148) e plaquetas (Figura 149). Contudo, no caso das plaquetas, os pontos B, E e F estão acima de $10 \mathrm{~Pa}$, ou seja, hemorragias podem ocorrer no paciente.

Figura 148 - Pontos da evolução temporal nos limites de VSS para hemácias

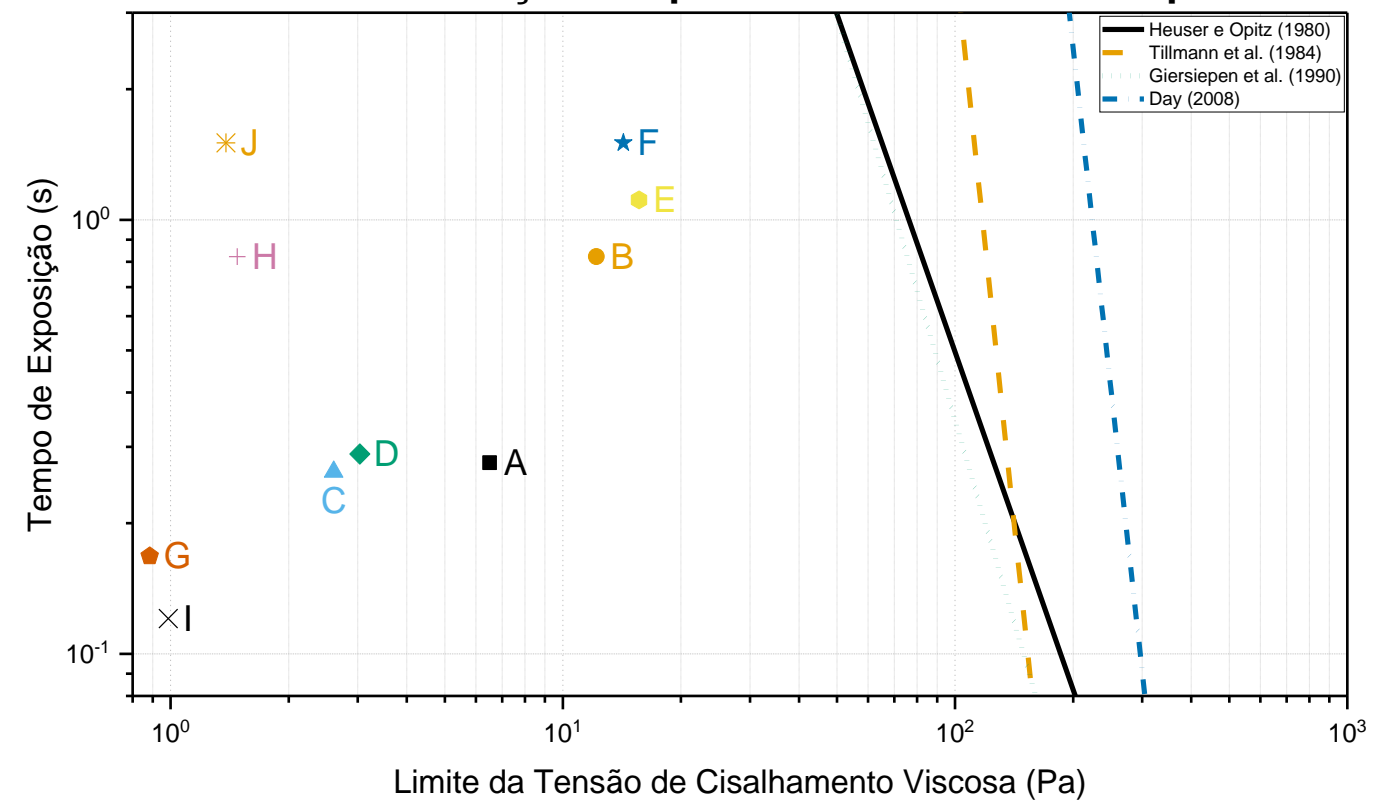

Já na tensão de Reynolds a situação é diferente, pois três dos dez pontos estão acima do limite. Dois destes pontos ( $B$ e F) pertencem ao caso em que a válvula está posicionada à $30^{\circ}$ e o último ponto $(\mathrm{E})$ pertence ao caso da válvula à 0 ‥ Como o efeito da turbulência no mecanismo físico da hemólise ainda não é bem compreendido e o 
RSS representa um tensor e não uma ação física no fluido, é possível que estes três pontos que ultrapassaram o limite estejam com medidas ruidosas (JHUN et al., 2018). O ponto $B$ representa uma partícula que entra no dispositivo durante o jato diastólico passando pela região inferior do DAVP e sai durante a sístole. Os pontos E e F representam as lavagens no dispositivo e em ambos as partículas também passam pela região inferior do DAVP. É sabido que na região inferior do DAVP a membrana é visível em grande parte do escoamento, bem como a reflexão e distorção da luz neste local são maiores. Portanto, a membrana gera dados ruidosos que influenciam nos cálculos de RSS. Isto posto, não há como afirmar que há hemólise devido ao RSS no dispositivo.

Figura 149 - Pontos da evolução temporal nos limites de VSS para plaquetas

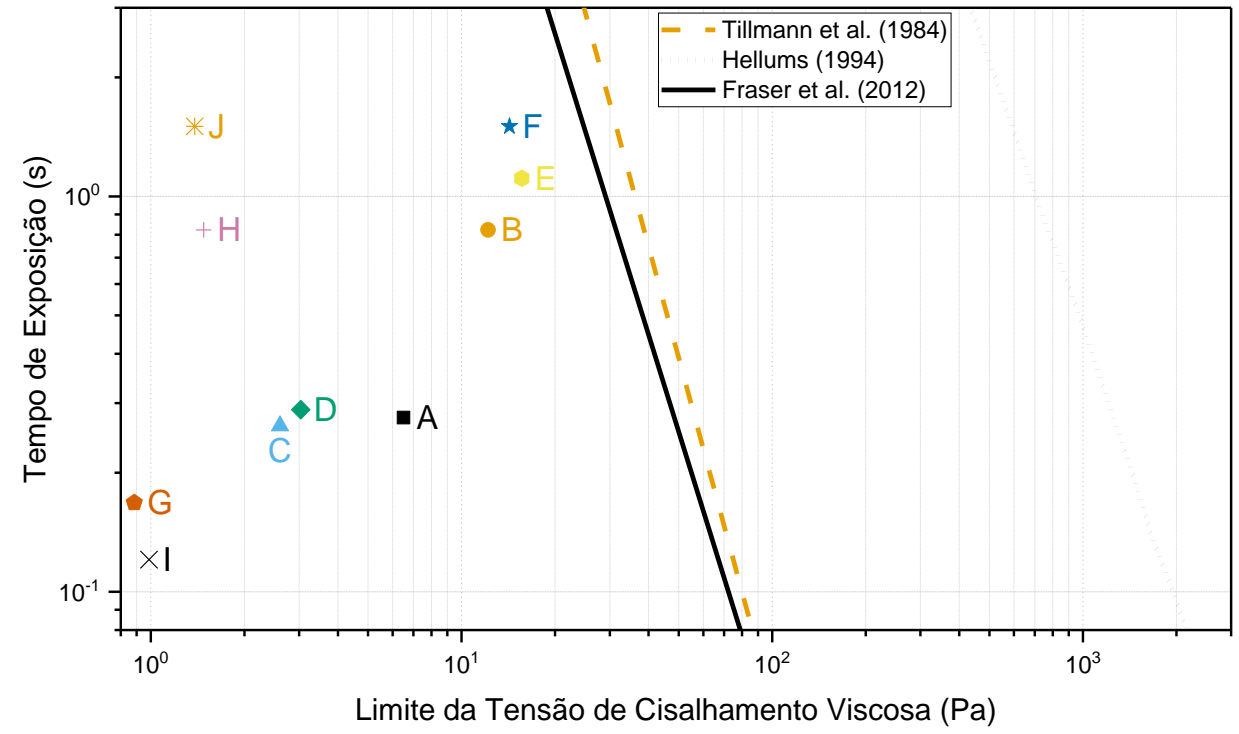

Figura 150 - Pontos da evolução temporal nos limites de RSS

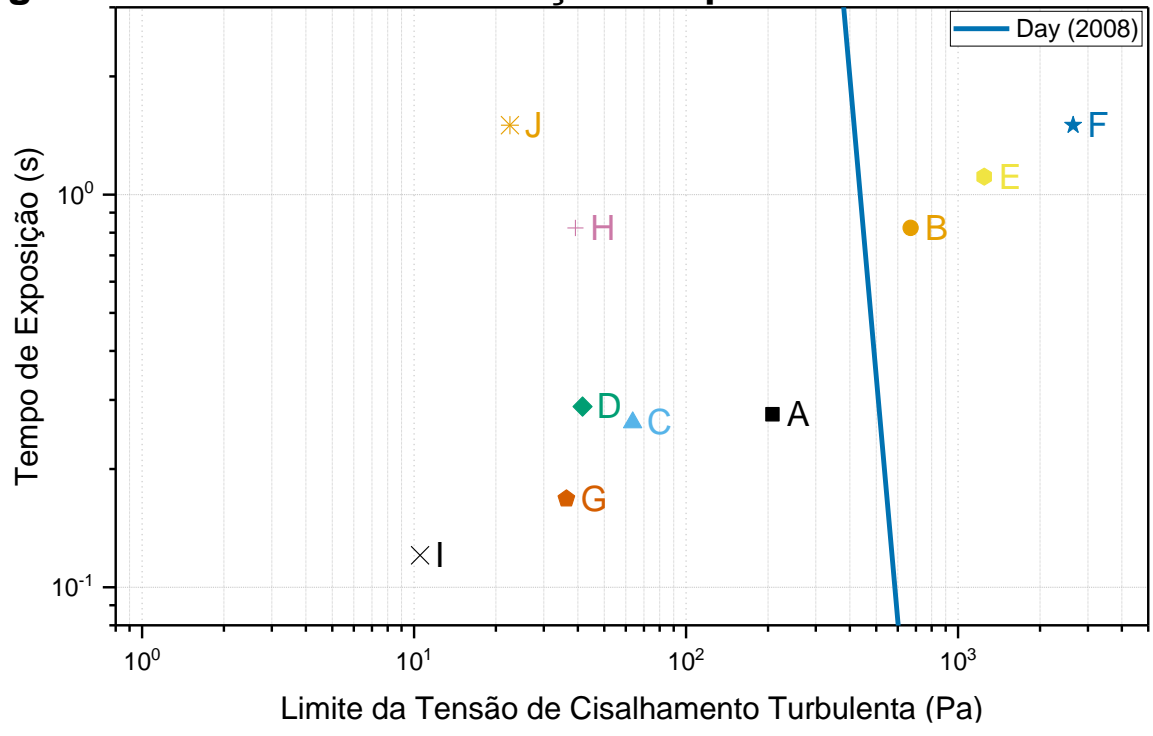


As regiões próximas às válvulas são outros locais que em algumas situações são hemolíticas devido aos altos valores encontrados (DEUTSCH et al., 2006). A cavitação gerada pelo fechamento das válvulas é reconhecida como a causa principal da hemólise nos DAVs. Quando a válvula fecha, a pressão na região a jusante da válvula diminui repentinamente para valores abaixo no ponto de pressão de vapor do sangue. Neste momento de baixa pressão surgem bolhas de cavitação que quando chegarem a uma região de maior pressão irão colapsar (implodir) produzindo ondas de choque que erodem superfícies sólidas, como a própria válvula e/ou o DAV, e destroem as células próximas. Outras causas de hemólise consistem nas altas tensões de cisalhamento no fluxo a jusante das válvulas e a regurgitação. Neste caso, a lise das células ocorre devido ao diferencial de pressão (LEE, TATSUMI e TAENAKA, 2009). Nas medições PIV, apenas observou-se a regurgitação presente na região das válvulas dentro do DAVP, sendo que não houveram medições nas cânulas e não foram realizadas medições de pressão nessas regiões. Portanto, pouco pode ser dito sobre a hemólise neste caso.

Quando a tensão de Reynolds é utilizada para determinar se há ou não a hemólise no dispositivo, a intensidade turbulenta ou a energia cinética turbulenta (TKE) tornam-se parâmetros comparativos entre os experimentos. Todavia, a maior parte do TKE calculado é proveniente da variação ciclo a ciclo, ou batimento a batimento, e esta variação aparecerá nos resultados como uma "pseudo-turbulência" sem a possibilidade de ser separada das demais partes constituintes do TKE. Definir um único "tempo de coincidência" nos fluxos instáveis também leva a erros nos cálculos dos tesões de Reynolds (OLEY et al., 2005). Outro fato percebido nos experimentos sugere que o DAVP não está num regime turbulento, mas aproxima-se mais de um regime de transição ou mesmo laminar. Logo, o cálculo de TKE não se mostrou interessante. O valor eficaz, contudo, apresentou resultados interessante e por ser uma medida estatística não depende da teoria turbulenta.

Diminuir as tensões para evitar a hemólise é também favorecer o surgimento de trombos, ou seja, apenas uma condição de funcionamento bem delimitada é a ideal para evitar qualquer tipo de danos ao sangue.

O diafragma do DAV é um componente de extrema importância para o entendimento da fluidodinâmica, visto que sua expansão e contração fornecem movimento ao fluido. Logo, todas as grandezas físicas são afetadas pelo movimento do diafragma. Como não há uma região de preferência para iniciar e finalizar a 
expansão e retração da membrana, partes do diafragma podem interferir nos ciclos do DAV. Durante o enchimento, caso uma parte do diafragma permaneça inflada na região próxima à válvula de entrada ocorrerá uma obstrução no fluxo. O mesmo é válido para a ejeção. Uma obstrução próxima à válvula de saída leva a um aumento nas tensões de cisalhamento com consequente separação do fluxo próximo à região inflada. Esta situação é observada no DAVP do InCor durante a sístole e a diástole. Tomando como exemplo o instante em que os períodos chegam a $40 \%$ não se vê a membrana na sístole ao passo que ela está presente neste instante na diástole.

Para comparar os resultados encontrados para o DAVP do InCor com outro dispositivo, escolheu-se o DAVP da Penn State analisado por Cooper et al. (2008). O dispositivo em questão é pneumático, possui volume deslocado de $12 \mathrm{~mL}$ a $75 \mathrm{bpm}$ com duração sistólica de $42,5 \%$ do ciclo, restando $57,5 \%$ para diástole. Em um de seus experimentos, Cooper et al. (2008) utilizou uma válvula mecânica de folheto duplo da CarboMedics. Logo percebe-se que o DAVP da Penn State é menor, $12 \mathrm{~mL}$ contra $30 \mathrm{~mL}$; a frequência utilizada no experimento foi ligeiramente maior, 75 bpm versus 70 bpm; e os períodos do ciclo não possuem mesma duração. Por outro lado, ambos os dispositivos são pneumáticos e utilizaram válvulas de folheto duplo, apesar de o autor afirmar que sua válvula CarboMedics possua uma regurgitação duas vezes maior que as válvulas da St. Jude Medical.

Retomando ao experimento de Cooper et al. (2008), o equipamento PIV utilizado foi do tipo Nd:YAG fornecendo $120 \mathrm{~mJ} /$ pulso no comprimento de onda de 532 $\mathrm{nm}$ com uma largura de pulso de $10 \mathrm{~ns}$. Os dados foram obtidos em três planos paralelos ao diafragma a $7 \mathrm{~mm}, 8,2 \mathrm{~mm}$ e $11 \mathrm{~mm}$ a partir do ponto mais extremo das válvulas (igual a Figura 57a). A câmera utilizada para gravação PIV era do tipo CCD com tamanho de sensor de 1000 x 1016 pixels com espaçamento de $9 \mu \mathrm{m} / \mathrm{pixe}^{2}$ a 30 $\mathrm{Hz}$ com tempo de abertura do obturador de $225 \mu \mathrm{s}$. A resolução espacial da câmera ficou na ordem de $58 \mu \mathrm{m} /$ pixel. O processamento de imagens foi realizado com janelas de interrogação inicial de 32 × 32 pixels e uma janela final de 16 × 16 pixels.

Os resultados PIV para a válvula CarboMedics no plano de $7 \mathrm{~mm}$ são apresentados na Figura 151 e no plano de $11 \mathrm{~mm}$ na Figura 152. Cada figura representa um instante diferente do ciclo: 250 ou 300, 400, 550 e 700 ms, sendo equivalente a $54 \%$ ou $65 \%$ e $87 \%$ da diástole, $26 \%$ e $71 \%$ da sístole nesta ordem.

A válvula, aparentemente, está na posição de $90^{\circ}$ em relação ao diafragma devido a presença de três jatos diastólicos distintos (Figura 151a), como discutido 
previamente nos perfis de velocidade das válvulas de folheto duplo. $\mathrm{O}$ autor não especifica o ângulo utilizado nos experimentos, mas um ângulo de $90^{\circ}$ não é algo comum. Além dos jatos diastólicos, há a presença de regurgitação na válvula aórtica, ressaltada pelos ovais pretos. Essas áreas onde ocorre a regurgitação aparentam possuir maior tamanho proporcionalmente ao dispositivo do que as áreas de regurgitação no DAVP do InCor.

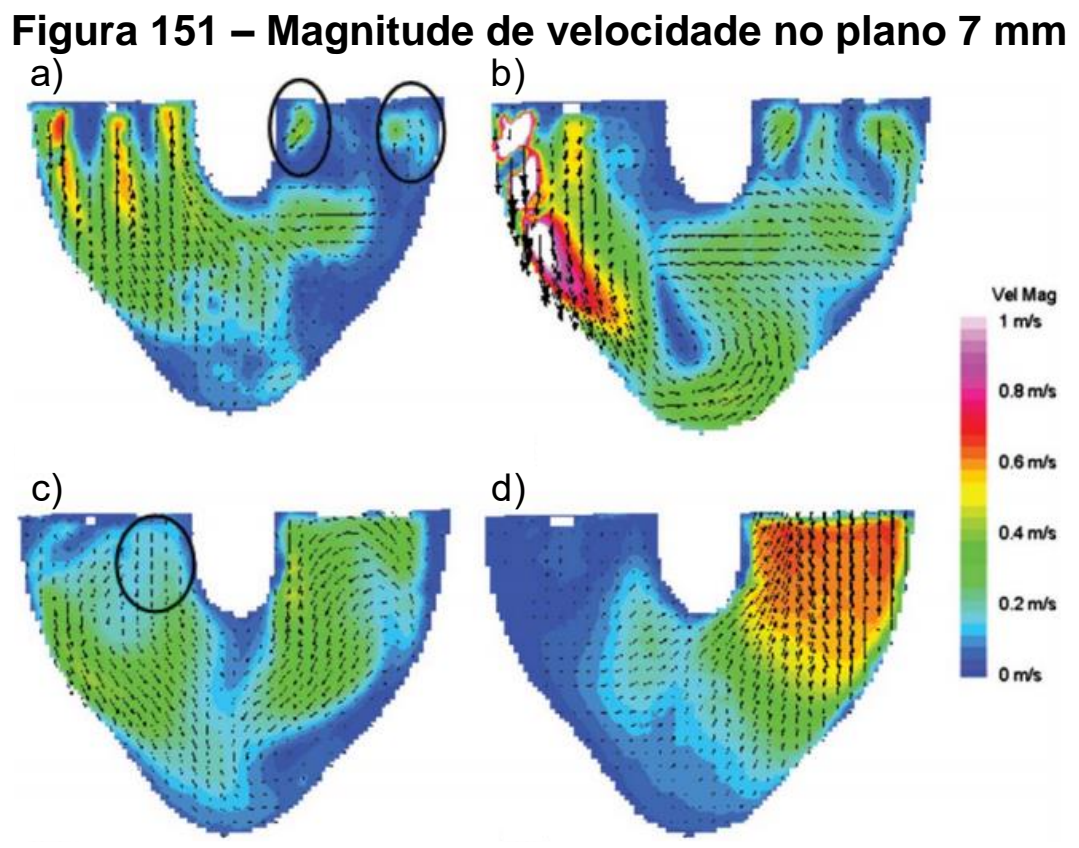

Fonte: Adaptado de Cooper et al. (2008)

Figura 152 - Magnitude de velocidade no plano $11 \mathrm{~mm}$

a)

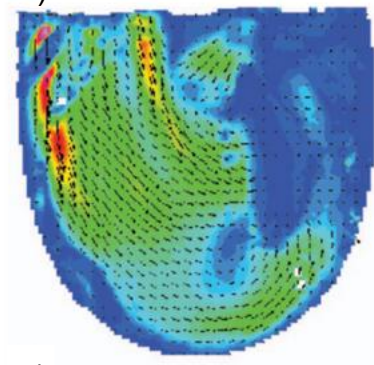

c)

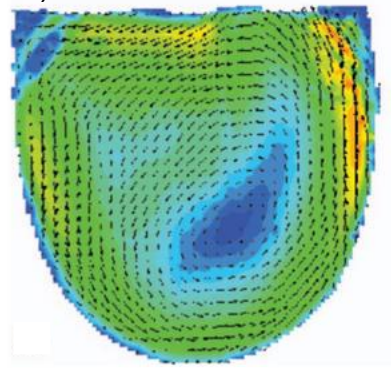

b)

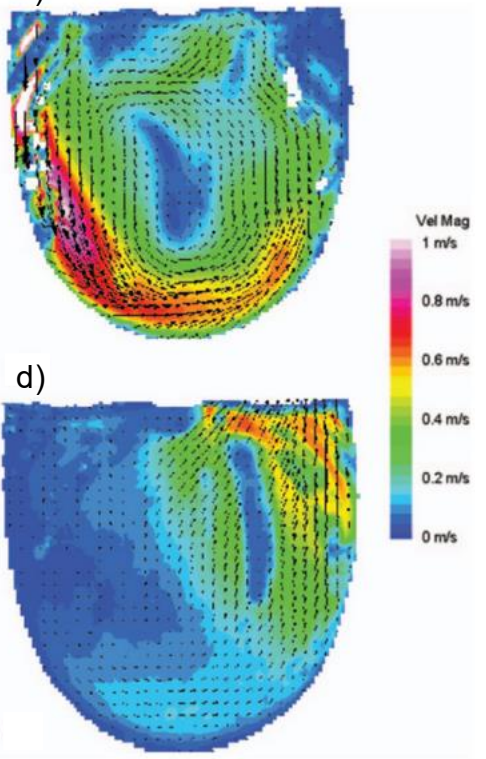

Fonte: Adaptado de Cooper et al. (2008) 
No final da diástole, o escoamento move-se para as paredes externas do DAVP, tanto no plano de $7 \mathrm{~mm}$ (Figura 151b) quanto no plano de $11 \mathrm{~mm}$ (Figura 152b). Neste momento ainda é possível observar regurgitação no plano de $7 \mathrm{~mm}$. A tendência do escoamento é criar um rotacional próximo ao centro do dispositivo, mas neste momento a regurgitação e a tridimensionalidade do escoamento não permitem o desenvolvimento completo do rotacional. Comparando o observado com o DAVP do InCor, no intervalo de $50 \%$ a $70 \%$ da diástole, quando ocorre a regurgitação, observada na evolução temporal das sondas, a velocidade máxima é $0,2 \mathrm{~m} / \mathrm{s}$ para ambos os casos. Já no DAVP da Penn State o pico é $0,4 \mathrm{~m} / \mathrm{s}$.

Nas Figura 151c e Figura 152c, a $26 \%$ da sístole, a velocidade reduz, mas 0 fluxo rotacional permanece, em especial no plano de $11 \mathrm{~mm}$. Já no plano de $7 \mathrm{~mm}$ a rotação reduz e a válvula começar a abrir, liberando a passagem. Uma pequena regurgitação é observada na válvula de entrada (círculo preto). O fenômeno observado é muito semelhante ao que ocorre no fluxo do DAVP do InCor no mesmo período.

Finalmente, a $71 \%$ da sístole, o jato deixa o DAV de forma praticamente uniforme em ambos os planos (Figura 151d e Figura 152d). Mais uma vez 0 comportamento é muito parecido, sendo a diferença encontrada nos picos de velocidade: $1 \mathrm{~m} / \mathrm{s}$ para o dispositivo da Penn State e 0,8 para o dispositivo do InCor. Provavelmente isto está ligado à frequência de batimento. Uma frequência maior tende a produzir maiores velocidades. 


\section{CONCLUSÃO}

Esta dissertação de mestrado teve como objetivo analisar as características do escoamento do dispositivo de assistência ventricular (DAVP) desenvolvido pelo Instituto do Coração (InCor) utilizando as velocidades e tensões obtidas pela velocimetria por imagem de partículas resolvida no tempo (TR-PIV).

Iniciando a comparação entre as posições da válvula de entrada pelo enchimento, fica claro que todos os parâmetros analisados, velocidade e tensões médias e instantâneas, foram maiores para $0^{\circ}$. Os valores mais elevados nas tensões são um bom indício de que provavelmente não há trombose no dispositivo. Entretanto, os altos valores produziram um lado negativo: a regurgitação na válvula de saída. A energia cinética turbulenta (TKE) calculada também foi maior para $0^{\circ}$, mostrando que há mais turbulência neste caso.

No segundo intervalo, $0 \%$ a $20 \%$ da diástole ( $\left.\mathrm{t}_{2}\right)$, vê-se a diferença entre as estruturas dos jatos diastólicos. $O$ jato para $0^{\circ}$ é vertical enquanto o jato para $30^{\circ}$ inicia vertical e depois inclina em direção ao centro do dispositivo. Para a válvula a $0^{\circ}$, o RSS, VSS instantâneo e TKE continuam maiores do que os parâmetros medidos para 30 ㅇ. É importante salientar que a regurgitação na saída permanece para 0 enquanto já findou em $30^{\circ}$. No RSS max é difícil definir qual das duas posições de válvula teve os maiores valores. A válvula de entrada a $30^{\circ}$ alcançou números maiores em VSS e TVSS.

No intervalo final da diástole, $50 \%$ a $70 \%$ ( $\mathrm{t}_{3}$ ), os maiores valores dos parâmetros analisados alternam entre $0^{\circ}$ e $30^{\circ}$. Para a válvula a $0^{\circ}$, quatro parâmetros foram maiores, a saber, as velocidades, RSS, TVSS e TKE. Para $30^{\circ}$, têm-se apenas $\overline{V S S}$ e VSS acima da condição $0^{\circ}$. Novamente, para o RSS $\max$ não há uma definição de qual condição é maior, mas nota-se que os apogeus das tensões se concentram em regiões diferentes dos campos. Para $0^{\circ}$ a região mais intensa de $\mathrm{RSS}_{\max }$ está na região do grande vórtice, o que condiz com a visível lavagem observada na magnitude de velocidade média $(|\overline{\mid}|)$. Para $30^{\circ}$, a região mais intensa ocorreu no centro do vórtice que é pouco visível em $|\bar{U}|$. Outro fator de interesse neste intervalo é o término da regurgitação na válvula de saída para $0^{\circ}$.

As velocidades no início da sístole exibem a lavagem no dispositivo, neste momento com menos intensidade para as duas posições de válvula. Assim como fora observado logo no começo do enchimento, fica claro que há regurgitação, desta vez 
na válvula de entrada para $0^{\circ}$ e $30^{\circ}$. Esta afirmação só se torna clara com as velocidades instantâneas obtidas pelas três sondas posicionadas na entrada do DAVP. Em t4, todas as tensões avaliadas foram ligeiramente superiores para $30^{\circ}$. A turbulência, medida indiretamente pelo TKE foi mais uma vez maior para $0^{\circ}$.

No pico da ejeção encontra-se a ampla superioridade de valores para $0^{\circ} \mathrm{em}$ todos os parâmetros analisados. Na velocidade média vertical ( $\bar{v}$ ) e na magnitude média das velocidades $(|\bar{U}|)$ a região que concentra os maiores valores é claramente maior para $0^{\circ}$, indicando que grande parte do fluido já deixa o dispositivo. Em contrapartida, a regurgitação na entrada para 0ำ permanece, enquanto para $30^{\circ}$ já cessou.

No final da sístole, a magnitude média das velocidades (|Ū|) ainda apresenta valores superiores para 0 . Entretanto, todas as tensões avaliadas foram levemente maiores para $30^{\circ}$. Não há mais indícios de regurgitação na entrada para $0^{\circ}$ e o TKE continuou superior para $0^{\circ}$.

Olhando para todo o ciclo têm-se, de um modo geral, velocidades e tensões maiores em quase todo o ciclo do dispositivo para a válvula de entrada posicionada a $0^{\circ}$. A turbulência também foi superior para $0^{\circ}$ em todos os intervalos, vide os valores de TKE. Por outro lado, para $0^{\circ}$ a regurgitação, considerando entrada e saída, esteve presente em dois terços do ciclo enquanto notou-se o mesmo efeito em apenas um terço do ciclo para 30․

Em alternativa, a análise do pseudo-rastreamento apresentou os efeitos de VSS e RSS nas partículas lançadas no escoamento, representadas pelos pontos A a J. Em VSS, os pontos para 30 foram moderadamente maiores que os respectivos pontos para $0^{\circ}$, o que fez com que eles se aproximassem mais dos limiares hemolíticos. De toda forma, nenhum dos dez pontos ultrapassou quaisquer dos limites estabelecidos pela literatura. No RSS, observou-se três pontos cujos valores ultrapassaram o limite estabelecido, sendo dois para $30^{\circ}$ e um para $0^{\circ}$. Todavia, como afirmado na Seção 4.3, o ruído da região inferior do dispositivo, local em que o diafragma esteve visível a maior parte do tempo, tenha causado os altos valores de RSS. Conclui-se neste caso que os efeitos de VSS e RSS não são expressivos nos pontos lançados considerando a abordagem lagrangiana.

Salienta-se ainda, o movimento tridimensional do escoamento dentro do dispositivo. Sem a análise da terceira componente não há como afirmar que um fenômeno que fora observado em apenas uma das posições de válvula não esteja 
ocorrendo na outra posição.

Considerando toda a perspectiva fluidodinâmica e o fato de velocidades e tensões não tão elevadas mais elevada serem benéficas em um dispositivo pulsátil, a válvula de entrada posicionada a $0^{\circ}$ mostrou-se a melhor opção. Neste ângulo de válvula de entrada o jato diastólico e o vórtice responsável pela lavagem do dispositivo foram mais intensos. O mesmo pode-se dizer sobre as tensões encontradas no dispositivo, especialmente a tensão viscosa (VSS), cujos valores estiveram na faixa de 0,75 Pa a 1,5 Pa. Já a válvula de entrada a 30 mostrou-se melhor apenas no item que trata sobre regurgitação. Neste caso, o escoamento foi fracamente menos prejudicial ao fluido, pois a regurgitação interfere na eficiência da bomba.

Vale ressaltar que as escolhas para o uso da válvula de entrada a $0^{\circ}$ ou $30^{\circ}$ foram tomadas estritamente baseadas nos efeitos fluidodinâmicos observados e suas consequências nos parâmetros analisados (velocidades e tensões). Caso experimentos biológicos sejam conduzidos, a escolha da posição de válvula pode variar. Os experimentos biológicos são essenciais para determinar a correlação entre os parâmetros e os potenciais riscos ao sangue do paciente. Por exemplo, a maior regurgitação observada a $0^{\circ}$ pode não ser danosa ao sangue, ao passo que os valores de $10 \mathrm{~Pa}$ na tensão viscosa para as plaquetas, que foram desconsiderados, podem levar a danos irreversíveis.

Sugere-se, como trabalhos futuros, a medição de outros batimentos do DAVP; outros ângulos de válvula de entrada para avaliar os possíveis efeitos; investigar a taxa da tensão de cisalhamento viscosa (VSS) na parede; reconstruir o campo de pressão com as medidas TR-PIV; medir com um sistema PIV estereoscópico ou tomográfico para obter a terceira componente de velocidade do escoamento e desta forma avaliar como é o seu comportamento; processamento PTV para melhorar o rastreamento das partículas; outras abordagens de medição, por exemplo, o ultrassom (Echo-PIV) para encontrar efeitos similares aos observados neste trabalho; testes biológicos utilizando sangue de animais a fim de correlacionar a formação de trombos e/ou hemólise com o que fora observado nas posições da válvula de entrada. Para mais, pode-se avaliar a interação fluido-estrutura e fluido-material por meio de simulações numéricas (CFD) e aplicar a otimização topológica no dispositivo. 



\section{REFERÊNCIAS}

ADRIAN, R. J.; WESTERWEEL, J. Particle image velocimetry. Cambridge: Cambridge University Press, 2011. 586 p. ISBN 9780521440080.

ADRIAN, R. J.; YAO, C.-S. Pulsed laser technique application to liquid and gaseous flows and the scattering power of seed materials. Applied Optics, v. 24, n. 1, p. 4452, 1 jan. 1985. https://doi.org/10.1364/AO.24.000044.

ADVANSOURCE BIOMATERIALS. ChronoFlex AR. Wilmington, p. 2. 2011. Datasheet.

AKHRAS, F.; RICKARDS, A. F. The relationship between QT interval and heart rate during physiological exercise and pacing. Japanese heart journal, v. 22, n. 3, p. 345351, maio 1981.

AKUTSU, T.; MATSUMOTO, A. Influence of three mechanical bileaflet prosthetic valve designs on the three-dimensional flow field inside a simulated aorta. Journal of Artificial Organs, v. 13, n. 4, p. 207-217, dez. 2010. https://doi.org/10.1007/s10047010-0519-7.

AL-AZAWY, M. G.; TURAN, A.; REVELL, A. Investigating the Use of Turbulence Models for Flow Investigations in a Positive Displacement Ventricular Assist Device. IFMBE Proceedings, v. 45, p. 395-398, 2015. DOI: 10.1007/978-3-319-11128-5.

ALBRECHT, H.-E. et al. Laser Doppler and Phase Doppler Measurement Techniques. Berlim: Springer, 2003. 738 p. ISBN 978-3-642-08739-4.

ALMOND, C. S. et al. Berlin Heart EXCOR Pediatric Ventricular Assist Device for Bridge to Heart Transplantation in US Children. Pediatric Cardiology, Boston, $p$. 1702-1711, 23 abr. 2013. DOI: 10.1161/CIRCULATIONAHA.112.000685.

AMARAL, R. D. L. Quality Analysis of 2D-2C and 2D-3C F-PIV Measurements of the Liquid Phase Velocity in a Bubble Column. Universidade Estadual de Campinas. Campinas, p. 178. 2017. 
AMERICAN HEART ASSOCIATION (AHA). What is Heart Failure? American Heart Association (AHA). Dallas, p. 2. 2015.

ASSOCIAÇÃO BRASILEIRA DE TRANSPLANTE DE ÓRGÃOS. Registro Brasileiro de Transplantes: Dimensionamento dos Transplantes no Brasil e em cada estado(2011-2018). Associação Brasileira de Transplante de Órgãos (ABTO). São Paulo, p. 100. 2018.

AUNE, E. et al. Normal reference ranges for left and right atrial volume indexes and ejection fractions obtained with real-time three-dimensional echocardiography. European Journal of Echocardiography, Toensberg, v. 10, p. 738-744, 2009. doi:10.1093/ejechocard/jep054.

AYUB-FERREIRA, S. M. et al. Diretriz de Assistência Circulatória Mecânica da Sociedade Brasileira de Cardiologia. Arquivos Brasileiros de Cardiologia, Rio de Janeiro, v. 107, n. 2 Supl. 2, p. 1-33, ago. 2016. ISSN 0066-782X. DOI: 10.5935/abc. 20160128.

BACH, D. S. et al. Hemodynamics and Early Clinical Performance of the St. Jude Medical Regent Mechanical Aortic Valve. The Annals of Thoracic Surgery, v. 74, n. 6, p. 2003-2009, dez. 2002. https://doi.org/10.1016/S0003-4975(02)04034-1.

BACHER, R. P.; WILLIAMS, M. C. Hemolysis in capillary flow. Journal of Laboratory and Clinical Medicine, v. 76, n. 3, p. 485-496, set. 1970.

BACHMANN, C. et al. Fluid Dynamics of a Pediatric Ventricular Assist Device. Artificial Organs, 24, n. 5, maio 2000. 362-372. https://doi.org/10.1046/j.15251594.2000.06536.x.

BALDWIN, J. et al. Mean Flow Velocity Patterns Within a Ventricular Assist Device. ASAIO Transactions, v. 35, n. 3, p. 429-432, 1 jul. 1989. ISSN 0889-7190.

BALDWIN, J. T. et al. Hot-Film Wall Shear Probe Measurements Inside a Ventricular Assist Device. Journal of Biomechanical Engineering, v. 110, n. 4, p. 326-333, 1 nov. 1988. doi:10.1115/1.3108449. 
BALDWIN, J. T. et al. Estimation of Reynolds stresses within the Penn State left ventricular assist device. ASAIO Transactions, v. 36, n. 3, p. M274-M278, jul. 1990.

BALDWIN, J. T. et al. Determination of Principal Reynolds Stresses in Pulsatile Flows After Elliptical Filtering of Discrete Velocity Measurements. Journal of Biomechanical Engineering, University Park, v. 115, n. 4A, p. 396-403, nov. 1993. doi:10.1115/1.2895503.

BALDWIN, J. T. et al. LDA Measurements of Mean Velocity and Reynolds Stress Fields Within an Artificial Heart Ventricle. Journal of Biomechanical Engineering, v. 116, n. 2, p. 190-200, 1 maio 1994. doi:10.1115/1.2895719.

BALDWIN, J. T. et al. The National Heart, Lung, and Blood Institute Pediatric Circulatory Support Program. Circulation, v. 113, p. 147-155, 2006. DOI: 10.1161/CIRCULATIONAHA.105.571422.

BARIć, D. Why pulsatility still matters: a review of current knowledge. Croatian Medical Journal, Zagreb, v. 55, p. 609-620, 2014. doi: 10.3325/cmj.2014.55.609.

BATCHELOR, G. K. The Theory of Homogeneous Turbulence. Londres: Cambridge University Press, 1959. 197 p. 3를 reimpressão.

BAZAN, O. et al. Laser Doppler anemometry measurements of steady flow through two bi-leaflet prosthetic heart valves. Revista Brasileira de Cirurgia Cardiovascular, 28, n. 4, 2013. 462-469. DOI: 10.5935/1678-9741.20130076.

BENK, C. et al. Three-dimensional flow characteristics in ventricular assist devices: Impact of valve design and operating conditions. The Journal of Thoracic and Cardiovascular Surgery, Freiburg, Vol. 142, n. 5, nov. 2011. p. 1019-1026. doi:10.1016/j.jtcvs.2011.01.058.

BERGMAN, T. L.; LAVINE, A. S. Fundamentals of Heat and Mass Transfer. 8a Danvers: John Wiley \& Sons, 2017. 966 p. ISBN 978-1-119-32042-5.

BERKELEY NUCLEONICS CORP (BNC). BNC model 575. San Rafael, p. 4. 2013. 
Datasheet.

BERLIN HEART. EXCOR Pediatric The Ventricular Assist Device for Children. Berlin Heart. Berlim, p. 12. 2018. Catálogo de Produto.

BERNSTEIN, E. F.; MARZEC, U.; JOHNSTON, G. G. Structural correlates of platelet functional damage by physical forces. Transactions - American Society for Artificial Internal Organs, 23, abr. 1977. 617-620.

BHATTACHARYA, S.; CHARONKO, J. J.; VLACHOS, P. P. Particle image velocimetry (PIV) uncertainty quantification using moment of correlation (MC) plane. Measurement Science and Technology, v. 29, n. 11, p. 115301, nov. 2018.

BLACKSHEAR, P. L. J.; DORMAN, F. D.; STEINBACH, J. H. SOME MECHANICAL EFFECTS THAT INFLUENCE HEMOLYSIS. Transactions - American Society for Artificial Internal Organs, Minneapolis, v. XI, p. 112-117, abr. 1965.

BLACKSHEAR, P. L.; BLACKSHEAR, G. L. Mechanical Hemolisis. In: SKALAK, R.; CHIEN, S. Handbook of Bioengineering. [S.I.]: McGraw-Hill, 1987. ISBN 9780070577831.

BOUDOULAS, H. et al. Linear Relationship Between Electrical Systole, Mechanical Systole, and Heart Rate. Chest, v. 80, n. 5, p. 613-617, nov. 1981.

BRENNEN, C. E. An Internet Book on Fluid Dynamics. Pasadena: Dankat Publishing, $2016 . \quad$ Disponivel em: <http://brennen.caltech.edu/FLUIDBOOK/FLUIDBOOK.htm>.

BROWN, C. H. . I. et al. Response of human platelets to shear stress. Transactions American Society for Artificial Internal Organs, 21, n. 1, abr. 1975. 35-39.

BURATTO, E. et al. Ventricular assist devices for the failing univentricular circulation. Expert Review of Medical Devices, v. 14, n. 6, p. 449-459, 2017. https://doi.org/10.1080/17434440.2017.1332523. 
BURKI, S.; ADACHI, I. Pediatric ventricular assist devices: current challenges and future prospects. Vascular Health and Risk Management, Houston, v. 13, p. 177185, 15 maio 2017. http://dx.doi.org/10.2147/VHRM.S82379.

CAIMI, A. et al. Toward the Virtual Benchmarking of Pneumatic Ventricular Assist Devices: Application of a Novel Fluid-Structure Interaction-Based Strategy to the Penn State 12 cc Device. Journal of Biomechanical Engineering, Milão, Vol. 139, ago. 2017. p. 081008. DOI: $10.1115 / 1.4036936$.

ÇENGEL, Y. A.; CIMBALA, J. M. . Fluid Mechanics: Fundamentals and Applications. 4ª . ed. Nova lorque: McGraw-Hill Education, 2017. 1024 p. ISBN 9781259696534.

CESTARI, I. A. Dispositivo de assistência ventricular: suporte circulatório em pacientes pediátricos. Faculdade de Medicina da Universidade de São Paulo. São Paulo, p. 77. 2017. Tese de Livre Docência.

CHRISTENSEN, K. T. et al. PIV Study of Flow Within a Pediatric Ventricular Assist Device. 35th AIAA Fluid Dynamics Conference and Exhibit, Toronto, p. 1-8, 6-9 jun. 2005. AIAA 2005-5003.

CHUNG, C. S.; KARAMANOGLU, M.; KOVÁCS, S. J. Duration of diastole and its phases as a function of heart rate during supine bicycle exercise. American Journal of Physiology-Heart and Circulatory Physiology, v. 287, n. 5, p. H2003-H2008, jun. 2004. doi:10.1152/ajpheart.00404.2004.

COLANTUONI, G. et al. The Response of Human Platelets to Shear Stress at Short Exposure Times. Transactions of the American Society for Artificial Internal Organs, 23, 1977. 626-630.

COOPER, B. T. et al. The 12 cc Penn State Pulsatile Pediatric Ventricular Assist Device: Fluid Dynamics Associated With Valve Selection. Journal of Biomechanical Engineering, v. 130, p. 041019-1 - 041019-14, 2008. DOI: 10.1115/1.2939342.

COOPER, B. T. et al. The Influence of Operational Protocol on the Fluid Dynamics in the 12 cc Penn State Pulsatile Pediatric Ventricular Assist Device: The Effect of End- 
Diastolic Delay. Artificial Organs, v. 34, n. 4, p. E122-E133, 2010. doi:10.1111/j.1525-1594.2009.00852.x.

COWEN, E. A.; MONISMITH, S. G. A hybrid digital particle tracking velocimetry technique. Experiments in Fluids, v. 22, p. 199-211, 1997.

DAS, B. B. Current State of Pediatric Heart Failure. Children, Hollywood, v. 5, n. 88, p. 16, 2018. doi:10.3390/children5070088.

DATAQ INSTRUMENTS. DI-720 and DI-730 Series. Akron, p. 16. 2014.

DAVIDSON, P. A. Turbulence An Introduction for Scientists and Engineers. Oxford: Oxford University Press, 2004. 657 p. ISBN 0198529481.

DAVIS, K. Numerical and Experimental Investigation of the Hemodynamics of an Artificial Heart Valve. Stellenbosch University. Stellenbosch, p. 130. 2018. Dissertação de Mestrado.

DAY, S. A Novel Magnetically Levitated Axial Flow Left Ventricular Assist Device. Rochester Institute of Technology. Skaneateles Falls, p. 37. 2008. Apresentação EMBS Health Tech Symposium Spring 2008.

DEEN, N. G. et al. On image pre-processing for PIV of single- and two-phase flows over reflecting objects. Experiments in Fluids, v. 49, p. 525-530, 2010. DOI 10.1007/s00348-010-0827-y.

DEUTSCH, S. et al. Experimental Fluid Mechanics of Pulsatile Artificial Blood Pumps. The Annual Review of Fluid Mechanics, v. 38, p. 65-86, 2006. doi: 10.1146/annurev.fluid.38.050304.092022.

DISCETTI, S.; IANIRO, A. Experimental Aerodynamics. Boca Raton: CRC Press, 2017. 454 p. ISBN 978-1-4987-0401-4.

EDMUND OPTICS. Techspec Filtes. Barrington, p. 8. 2017. Catálogo. 
ESCUDIER, M. Introduction to Engineering Fluid Mechanics. Nova lorque: Oxford University Press, 2017. 577 p. ISBN 978-0-19-871987-8.

FERRARA, E. Velocimetria de Imagens de Partículas Aplicada ao Estudo de um Ventrículo Artificial Pediátrico. Universidade de São Paulo. São Paulo, p. 211. 2005.

FERRARA, E. et al. Particle-Image Velocimetry Study of a Pediatric Ventricular Assist Device. Journal of Biomechanical Engineering, v. 132, n. 7, p. 071004-1 - 0710046, maio 2010. doi:10.1115/1.4001252.

FERRARA, E.; MURAMATSU, M.; CESTARI, I. A. Particle Image Velocimetry Applied to Study of a Ventricular Assist Device. 5th Iberoamerican Meeting on Optics and 8th Latin American Meeting on Optics, Lasers, and Their Applications, v. 5622, p. 18-23, 2004. doi: 10.1117/12.589331.

FINCHAM, A. M.; SPEDDING, G. R. Low cost, high resolution DPIV for measurement of turbulent fluid flow. Experiments in Fluids, v. 23, p. 449-462, 1997.

FLACHSKAMPF, F. A. et al. Patterns of Normal Transvalvular Regurgitation in Mechanical Valve Prostheses. Journal of the American College of Cardiology, 18, n. 6, 15 nov. 1991. 1493-1498. https://doi.org/10.1016/0735-1097(91)90680-8.

FOOD AND DRUG ADMINISTRATION (FDA). Temporary Ventricular Support Device: Impella Ventricular Support Systems. [S.I.], p. 38. 2016.

FORST, R.; RIEGER, H.; SCHMID-SCHÖNBEIN, H. Die Stimulation menschlicher Blutplättchen unter dem Einfluss hoher Schubspannungen in einer Rohströdmung. Tagung der Gesellschaft für Mikrozirkulation, Munique, 1977.

FORSTROM, R. J. A new measure of erythrocyte membrane strength: the jet fragility test. University of Minnesota. Minneapolis. 1969.

FRASER JR., C. D.; JAQUISS, R. D. B. The Berlin Heart EXCOR Pediatric ventricular assist device: history, North American experience, and future directions. Annals of the New York Academy of Sciences, v. 1291, p. 96-105, 2013. ISSN 0077-8923. doi: 
10.1111/nyas. 12144 .

FRASER, K. H. et al. A Quantitative Comparison of Mechanical Blood Damage Parameters in Rotary Ventricular Assist Devices: Shear Stress, Exposure Time and Hemolysis Index. Journal of Biomechanical Engineering, 134, ago. 2012. $081002-$ 1 - 081002-11. DOI: 10.1115/1.4007092.

FRITSCH, F. N.; CARLSON, R. E. Monotone Piecewise Cubic Interpolation. SIAM Journal on Numerical Analysis, 17, n. 2, abr. 1980. 238-246. http://www.jstor.org/stable/2156610.

FUNG, Y. C. Biodynamics: circulation. New York: Springer Science+Business Media, 1984. 404 p. ISBN 978-1-4757-3886-5.

GALANTIER, J. Avaliação do emprego clínico do dispositivo de assistência ventricular InCor como ponte para o transplante cardíaco. Faculdade de Medicina da Universidade de São Paulo. São Paulo, p. 76. 2007. Tese de Doutorado.

GALLAGHER, M. B. A Study of the Effect of Hematocrit on Weaning in the $12 \mathrm{cc}$ Penn State Pediatric Ventricular Assist Device. The Pennsylvania State University. State College, p. 277. 2017. Dissertação de Mestrado.

GARCIA, D. A fast all-in-one method for automated post-processing of PIV data. Experiments in Fluids, v. 50, p. 1247-1259, 2011. DOI 10.1007/s00348-010-0985-y.

GEMIGNANI, V. et al. Assessment of cardiologic systole and diastole duration in exercise stress tests with a transcutaneous accelerometer sensor. Computers in Cardiology 2008, v. 35, p. 153-156, 2008. ISSN 0276-6574. DOI: 10.1109/CIC.2008.4749000.

GENT, P. L. V.; SCHRIJER, F. F. J.; OUDHEUSDEN, B. W. V. Assessment of the pseudo-tracking approach for the calculation of material acceleration and pressure fields from time-resolved PIV: part I. Error propagation. Measurement Science and Technology, 045204, 7 mar. 2018. 1-14. https://doi.org/10.1088/1361-6501/aaa0a5. 
GERHART, P. M.; GERHART, A. L.; HOCHSTEIN, J. I. Munson, Young, and Okiishi's Fundamentals of Fluid Mechanics. 8a. ed. Danvers: Wiley, 2016. 777 p. ISBN 9781119080701.

GHAEMI, S.; RAGNI, D.; SCARANO, F. PIV-based pressure fluctuations in the turbulent boundary layer. Experiments in Fluids, v. 53, n. 6, p. 1823-1840, dez. 2012. DOI 10.1007/s00348-012-1391-4.

GIARRA, M. N. Shear Stress Distribution and Hemolysis Measurements in a Centrifugal Blood Pump. Rochester Institute of Technology. Rochester, p. 108. 2009. Dissertação de Mestrado.

GIERSIEPEN, M. et al. Estimation of shear stress-related blood damage in heart valve prostheses - in vitro comparison of 25 aortic valves. The International Journal of Artificial Organs, Aachen, v. 13, n. 5, p. 300-306, 1990.

GONZALEZ, R. C.; WOODS, R. E. Digital Image Processing. 3ㄹ. ed. Upper Saddle River: Pearson Prentice Hall, 2008. 954 p. ISBN 978-0-13-168728-8.

GOSLINGA, H. Blood Viscosity and Shock: The Role of Hemodilution, Hemoconcentration and Defibrination. Berlim: Spinger-Verlag, 1984. ISBN 978-3-54012620-1.

GREGORY, S. D. Simulation and development of a mock circulation loop with variable compliance. Queensland University of Technology. Brisbane City, p. 155. 2009. Dissertação de Mestrado.

GRIGIONI, M. et al. A discussion on the threshold limit for hemolysisrelated to Reynolds shear stress. Journal of Biomechanics, Roma, v. 32, n. 10, p. 1107-1112, 1999. https://doi.org/10.1016/S0021-9290(99)00063-9.

GUO, S.; LI, W. The Effect of Near-Wall Vortices on Wall Shear Stress in Turbulent Boundary Layers. Engineering, v. 2, p. 190-196, mar. 2010. doi:10.4236/eng.2010.23027. 
HALL, E. L. Computer Image Processing and Recognition. [S.I.]: Academic Press, 1979. 604 p. ISBN 9780123188502.

HALL, J. E. Guyton and Hall Textbook of Medical Physiology. 13ª ed. Philadelphia: Elsevier, 2016. 1097 p. ISBN 978-1-4557-7005-2.

HARRIS, L. C. et al. Duration of the phases of mechanical systole in infants and children. The American journal of cardiology, v. 14, n. 4, p. 448-455, 1964.

HASHIMOTO, S. Erythrocyte Destruction under Periodically Fluctuating Shear Rate: Comparative Study with Constant Shear Rate. Artificial Organs, Sagamihara, v. 13, n. 5, p. 458-463, 1989.

HEARTWARE. Image \& Video Library. HVAD, 2019. Disponivel em: $<$ https://www.heartware.com/resources>. Acesso em: 7 jun. 2019.

HELLUMS, J. D. 1993 Whitaker Lecture: Biorheology in Thrombosis Research. Annals of Biomedical Engineering, 22, $1994 . \quad 445-455$. https://doi.org/10.1007/BF02367081.

HELLUMS, J. D.; BROWN, C. H. Blood cell damage by mechanical forces. In: HWANG, N. H. C.; NORMANN, N. Cardiovascular Flow Dynamics and Measurements. [S.I.]: University Park Press, 1977. p. 799-823. ISBN 9780839109723.

HEUSER, G.; OPITZ, R. A Couette Viscometer for Short Time Shearing of Blood. Biorheology, v. 17, p. 17-24, 1980.

HOCHAREON, P. Development of Particle Image Velocimetry (PIV) for Wall Shear Stress Estimation within a 50cc Penn State Artificial Heart Ventricular Chamber. The Pennsylvania State University. State College, p. 208. 2003. Tese de Doutorado.

HOCHAREON, P. et al. Correlation of In Vivo Clot Deposition With the Flow Characteristics in the $50 \mathrm{cc}$ Penn State Artificial Heart: A Preliminary Study. ASAIO Journal, v. $50, \quad$ n. $6, \quad$ p. 537-542, 2004 ISSN DOI: 
10.1097/01.MAT.0000145694.40637.A.

HOCHAREON, P. et al. Fluid Dynamic Analysis of the $50 \mathrm{cc}$ Penn State Artificial Heart Under Physiological Operating Conditions Using Particle Image Velocimetry. Journal of Biomechanical Engineering, 126, n. 5, out. 2004. 585-593. https://doi.org/10.1115/1.1798056.

HOCHAREON, P. et al. Wall Shear-Rate Estimation Within the 50cc Penn State Artificial Heart Using Particle Image Velocimetry. Journal of Biomechanical Engineering, State College, v. 126, p. 430-437, ago. 2004. DOI: 10.1115/1.1784477.

HONKANEN, M.; NOBACH, H. Background extraction from double-frame PIV images. Experiments in Fluids, v. 38, p. 348-362, 2005. DOI 10.1007/s00348-004-0916-x.

HU, H. Lecture \#13: Particle Image Velocimetry Technique. lowa State University. Ames, p. 71. 2018. Lecture Notes.

HUBBELL, J. A.; MCINTIRE, L. V. Visualization and analysis of mural thrombogenesis on collagen, polyurethane and nylon. Biomaterials, v. 7, n. 5, p. 354-363, set. 1986. https://doi.org/10.1016/0142-9612(86)90006-2.

HUBER, P. J.; RONCHETTI, E. M. Robust Statistics. 2ª ed. Hoboken: Wiley, 2009. ISBN 9780470129906.

HUNG, T. C. et al. Shear-induced aggregation and lysis of platelets. Transactions American Society for Artificial Internal Organs, 22, n. 1, abr. 1976. 285-290.

INMETRO. Avaliação de dados de medição: Guia para a expressão de incerteza de medição - GUM 2008. Tradução de Antonio Carlos Baratto. Duque de Caxias: INMETRO/CICMA/SEPIN, 2012. 141 p. ISBN 978-85-86920-13-4.

INSTITUTO DO CORAÇÃO (INCOR). Montagem (003). Divisão de Bioengenharia. São Paulo. 2019. Relatório Interno.

JAKOVLJEVIC, D. G. et al. Left Ventricular Assist Device as a Bridge to Recovery for 
Patients With Advanced Heart Failure. Journal of The American College of Cardiology, Newcastle upon Tyne, v. 69, n. 15, p. 1924-1933, 2017. ISSN 0735-1097. http://dx.doi.org/10.1016/j.jacc.2017.02.018.

JAMESON, J. L. et al. Harrison's Principles of Internal Medicine. 20a․ ed. [S.I.]: McGraw-Hill Education, 2018. 3528 p. ISBN 978-1-25-964404-7.

JARON, D. et al. Materials Mechanical Heart Valve. Mechanical Heart Valve, $17 \mathrm{fev}$. 2008. Disponivel em: <http://www.pages.drexel.edu/ nag38/Materials.html>. Acesso em: 06 nov. 2019.

JAYAPRASAD, N. Heart Failure in Children. Heart Views, Kottayam, v. 17, p. 92-99, 2016. DOI: 10.4103/1995-705X.192556.

JHUN, C.-S. et al. Determination of Reynolds Shear Stress Level for Hemolysis. ASAIO Journal, 64, n. 1, jan. 2018. 63-69. doi: 10.1097/MAT.0000000000000615.

JIN, W.; CLARK, C. Experimental investigation of unsteady flow behaviour within a sac-type ventricular assist device (VAD). Journal of Biomechanics, v. 26, n. 6, p. 697-707, jun. 1993. https://doi.org/10.1016/0021-9290(93)90033-B.

JIN, W.; CLARK, C. Experimental Investigation of the Motions of the Pumping Diaphragm within a Sac-Type Pneumatically Driven Ventricular Assist Device. Journal Biomechanics, 27, n. 1, 1994. 43-55.

JONES, S. A. A Relationship Between Reynolds Stresses and Viscous Dissipation: Implications to Red Cell Damage. Annals of Biomedical Engineering, Baltimore, v. 23, p. 21-28, 1995. ISSN 0090-6964/95. doi:10.1007/bf02368297.

KATZ, A. M. Physiology of the Heart. 5․ ed. Filadélfia: Wolters Kluwer | Lippincott Williams \& Wilkins, 2011. 576 p. ISBN 978-1-60831-171-2.

KEANE, R. D.; ADRIAN, R. J. Theory of cross-correlation analysis of PIV images. Applied Scientific Research, v. 49, n. 3, p. 191-215, 1992. ISSN 1573-1987. https://doi.org/10.1007/BF00384623. 
KESHAVIAH, J. M. S. Thesis. University of Minnesota. Minneapolis. 1970.

KEY, N. S.; MAKRIS, M.; LILLICRAP, D. Practical Hemostasis and Thrombosis. 3a․ ed. Hoboken: Wiley \& Sons Inc., 2017. 477 p. ISBN 9781118344712.

KHERADVAR, A.; PEDRIZZETTI, G. Vortex Formation in the Cardiovascular System. London: Springer, 2012. 164 p. ISBN 978-1-4471-2287-6.

KIENLE, A. et al. Why do veins appear blue? A new look at an old question. Applied Optics, v. 35, n. 7, p. 1151-1160, 1 mar. 1996. doi:10.1364/ao.35.001151.

KIM, B. J.; SUNG, H. J. A further assessment of interpolation schemes for window deformation in PIV. Experiments in Fluids, 41, n. 3, 11 jul. 2006. 499-511. doi:10.1007/s00348-006-0177-y.

KINI, V. et al. Integrating Particle Image Velocimetry and Laser Doppler Velocimetry Measurements of the Regurgitant Flow Field Past Mechanical Heart Valves. Artificial Organs, 25, n. 2, 2001. 136-145.

KOLIOPOULOU, A. et al. Bleeding and thrombosis in chronic VAD therapy: focus on platelets. Current Opinion in Cardiology, Salt Lake City, v. 31, n. 3, p. 299-307, maio 2016. ISSN 0268-4705. DOI: 10.1097/HCO.0000000000000284.

KOLMOGOROV, A. N. Dissipation of energy in the locally isotropic turbulence. Proceedings of the Royal Society of London. Series A: Mathematical and Physical Sciences, v. 434, n. 1890, p. 15-17, 8 jul. 1991. ISSN 0962-8444. https://doi.org/10.1098/rspa.1991.0076.

KOLMOGOROV, A. N. The local structure of turbulence in incompressible viscous fluid for very large Reynolds numbers. Proceedings of the Royal Society of London. Series A: Mathematical and Physical Sciences, v. 434, n. 1890, p. 9-13, 8 jul. 1991. ISSN 0962-8444. https://doi.org/10.1098/rspa.1991.0075.

KREIDER, J. W. et al. The 50cc Penn State Left Ventricular Assist Device: A Parametric Study of Valve Orientation Flow Dynamics. ASAIO Journal, 52, n. 2, 
March-April 2006. 123-131. doi: 10.1097/01.mat.0000199750.89636.77.

LABROSSE, M. R. Cardiovascular mechanics. Boca Raton: CRC Press, 2019. 286 p. ISBN 9781138197237.

LAMBERT, J. Die Stimulation menschlicher Blutplättchen unter dem Einfluss hoher Schubspannungen in einer Rohstrdmung. RWTH Aachen University. Aachen. 1976. Tese de Doutorado.

LAMSON, T. et al. Relative Blood Damage in the Three Phases of a Prosthetic Heart Valve Flow Cycle. ASAIO Journal, 39, n. 3, jul. 1993. M626-M633.

LEE, H.; TATSUMI, E.; TAENAKA, Y. Experimental Study on the Reynolds and Viscous Shear Stress of Bileaflet Mechanical Heart Valves in a Pneumatic Ventricular Assist Device. ASAIO Journal, 55, n. 4, jul. 2009. 348-354. DOI: 10.1097/MAT.0b013e3181a793e0.

LEE, H.; TATSUMI, E.; TAENAKA, Y. Flow Visualization of A Monoleaflet and Bileaflet Mechanical Heart Valve in A Pneumatic Ventricular Assist Device Using A PIV System. ASAIO Journal, 56, n. 3 , maio 2010. 186-193. DOI: 10.1097/MAT.0b013e3181d68f83.

LEE, Y.; YANG, H.; YIN, Z. Outlier detection for particle image velocimetry data using a locally estimated noise variance. Measurement Science and Technology, Wuhan, v. 28, p. 12, jan. 2017. doi:10.1088/1361-6501/aa5431.

LEVERETT, L. B. et al. Red Blood Cell Damage by Shear Stress. Biophysical Journal, Houston, v. 12, n. 3, p. 257-273, 1972. doi 10.1016/S0006-3495(72)860855 .

LI, C.-P. et al. Turbulence Characteristics Downstream of a New Trileaflet Mechanical Heart Valve. ASAIO Journal, Tainan, Vol. 57, n. 3, 2011. p. 188-196. DOI: 10.1097/MAT.0b013e318213f9c2.

LI, C.-P.; LO, C.-W.; LU, P.-C. Estimation of Viscous Dissipative Stresses Induced by 
a Mechanical Heart Valve Using PIV Data. Annals of Biomedical Engineering, v. 38, n. 3, p. 903-916, mar. 2010. DOI: 10.1007/s10439-009-9867-y.

LIMA, F. E. T. et al. Perfil dos pacientes na Lista Única de Espera para transplante cardíaco no estado do Ceará. Arquivos Brasileiros de Cardiologia, Fortaleza, v. 95, n. 1, p. 79-84, 28 maio 2010. ISSN 0066-782X. http://dx.doi.org/10.1590.

LINDENFELD, J.; KEEBLER, M. E. Left Ventricular Assist Device Thrombosis: Another Piece of the Puzzle? JACC: Heart Failure, v. 3, n. 2, p. 154-158, 2015. ISSN 22131779. https://doi.org/10.1016/j.jchf.2014.12.001.

LIOTTA, D. Early Clinical Application of Assisted Circulation. Texas Heart Institute Journal, Buenos Aires, v. 29, n. 3, p. 229-230, 2002.

LITRON LASERS. LDY300 PIV Series: High Repetition Rate Lasers for TimeResolved PIV Applications. Warwickshire, p. 4. 2016. Datasheet.

LIU, J. S.; LU, P. C.; CHU, S. H. Turbulence Characteristics Downstream of Bileaflet Aortic Valve Prostheses. Transactions of the ASME, 122, n. 2, abr. 2000. 118-124. https://doi.org/10.1115/1.429643.

LU, P. C.; LAI, H. C.; LIU, J. S. A reevaluation and discussion on the threshold limit for hemolysisin a turbulent shear flow. Journal of Biomechanics, Taipei, v. 34, n. 10, p. 1361-1364, 8 maio 2001. https://doi.org/10.1016/S0021-9290(01)00084-7.

LUBOWITZ, H. et al. Shear-induced changes in permeability of human RBC to sodium. Transactions - American Society for Artificial Internal Organs, 20, n. 1, abr. 1974. 470-473.

LYNCH, K. Advances in Time-Resolved Tomographic Particle Image Velocimetry. Technische Universiteit Delft. Delft, p. 163. 2015. Tese de Doutorado.

LYNCH, K.; PRÖBSTING, S.; SCARANO, F. Temporal resolution of time-resolved tomographic PIV in turbulent boundary layers. 17th International Symposium on Applications of Laser Techniques to Fluid Mechanics, Lisboa, p. 12, 7-10 jul. 2014. 
MACEIRA, A. M. et al. Reference right ventricular systolic and diastolic function normalized to age, gender and body surface area from steady-state free precession cardiovascular magnetic resonance. European Heart Journal, Londres, v. 27, p. 2879-2888, 2006. doi:10.1093/eurheartj/ehl336.

MANNING, K. B. et al. Regurgitant Flow Field Characteristics of the St. Jude Bileaflet Mechanical Heart Valve under Physiologic Pulsatile Flow Using Particle Image Velocimetry. Artificial Organs, 27, n. 9, 23 ago. 2003. 840-846. https://doi.org/10.1046/j.1525-1594.2003.07194.x.

MANNING, K. B. et al. Flow Behavior Within the 12-cc Penn State Pulsatile Pediatric Ventricular Assist Device: An Experimental Study of the Initial Design. Artificial Organs, University Park, Vol. 36, n. 6, 2008. p. 442-452. doi:10.1111/j.15251594.2008.00565.x.

MARINHO, A.; CARDOSO, S. D. S.; ALMEIDA, V. V. D. Disparidades nas filas para transplantes de órgãos nos estados brasileiros. Cadernos de Saúde Pública, Rio de Janeiro, v. 26, n. 4, p. 786-796, abr. 2010. ISSN 1678-4464.

MASARONE, D. et al. Pediatric Heart Failure: A Practical Guide to Diagnosis and Management. Pediatrics and Neonatology, Nápolis, v. 58, p. 303-312, 2017. http://dx.doi.org/10.1016/j.pedneo.2017.01.001.

MASULLO, A.; THEUNISSEN, R. Improvement in universal PIV outlier detection by means of coherence adaptivity. 11TH INTERNATIONAL SYMPOSIUM ON PARTICLE IMAGE VELOCIMETRY - PIV15, Santa Barbara, p. 20, 14-16 set. 2015.

MCDONAGH, T. A. et al. Oxford Textbook of Heart Failure. Oxford: Oxford University Press, 2011. 641 p. ISBN 978-0-19-957772-9.

MEYER, R. S. et al. Laser Doppler Velocimetry and Flow Visualization Studies in the Regurgitant Leakage Flow Region of Three Mechanical Mitral Valves. Artificial Organs, 25, n. 4, abr. 2001. 292-299. https://doi.org/10.1046/j.15251594.2001.06700.x. 
MILLER, J. Short Report: Reaction Time Analysis with Outlier Exclusion: Bias Varies with Sample Size. Miller, J. (1991). Short Report: Reaction Time Analysis with Outlier ExThe Quarterly Journal of Experimental Psychology Section A, 43, n. 4, 1991. 907-912. doi:10.1080/14640749108400962.

MOAZAMI, N. et al. Does pulsatility matter in the era of continuous-flow blood pumps? The Journal of Heart and Lung Transplantation, Cleveland, v. 34, n. 8, p. 999-1004, ago. 2015. http://dx.doi.org/10.1016/j.healun.2014.09.012.

MONIN, A. S.; YAGLOM, A. M. Statistical Fluid Mechanics: Mechanics of Turbulence. Cambridge: The MIT Press, v. 1, 1971. 769 p. ISBN 0262130629.

MONIN, A. S.; YAGLOM, A. M. Statistical Fluid Mechanics: Mechanics of Turbulence. Cambridge: The MIT Press, v. 2, 1975. 874 p. ISBN 0-262-13098-X.

MOORE, K. L.; DALLEY, A. F.; AGUR, A. M. R. Clinically Oriented Anatomy. $8^{\text {a }}$. ed. Filadélfia: Wolters Kluwer, 2018. 2787 p. ISBN 9781496347213.

MOTT, R. L.; UNTENER, J. A. Applied Fluid Mechanics. $7^{a}$. ed. Upper Saddle River: Pearson, 2015. 531 p. ISBN 978-0-13-255892-1.

MOURA, H. L. D. Análise da qualidade de medidas F-PIV e da fluidodinâmica em coluna de. Universidade Estadual de Campinas. Campinas, p. 175. 2017. Tese de Doutorado.

NANJAPPA, B. N.; CHANG, H.-K.; GLOMSKI, C. A. Trauma of the erythrocyte membrane associated with low shear stress. Biophysical Journal, 13, n. 11, nov. 1973. 1212-1222.

NANNA, J. C. Beat Rate Implications on the Fluid Dynamics of a 50 cc Left Ventricular Assist Device. The Pennsylvania State University. State College, p. 158. 2010. Dissertação de Mestrado.

NANNA, J. C. et al. A Fluid Dynamics Study in a 50 cc Pulsatile Ventricular Assist Device: Influence of Heart Rate Variability. Journal of Biomechanical Engineering, 
v. 133 , p. $101002-1$ - 101002-10, out. 2011. DOI: 10.1115/1.4005001.

NAVITSKY, M. A. A Comparison of Thrombus Susceptibility for Two Pulsatile 50 cc Left Ventricular Assist Devices. The Pennsylvania State University. State College, p. 91. 2012. Dissertação de Mestrado.

NAVITSKY, M. A.; DEUTSCH, S.; MANNING, K. B. A Thrombus Susceptibility Comparison of Two Pulsatile Penn State $50 \mathrm{cc}$ Left Ventricular Assist Device Designs. Annals of Biomedical Engineering, v. 41, n. 1, p. 4-16, jan. 2013. DOI: 10.1007/s10439-012-0627-z.

NEVARIL, C. G. et al. Erythrocyte damage and destruction induced by shearing stress. Journal of Laboratory and Clinical Medicine, v. 71, p. 784-790, 1968.

OBIDOWSKI, D. et al. Methods for determination of stagnation in pneumatic ventricular assist devices. The International Journal of Artificial, v. 41, n. 10, p. 653-663, 2018. DOI: $10.1177 / 039139881$.

OCCHETTA, E. et al. Do electrical parameters of the cardiac cycle reflect the corresponding mechanical intervals as the heart rate changes? Europace, Novara, v. 12, p. 830-834, 2010. doi:10.1093/europace/euq068.

OCHSNER, G. M. Physiological Control of Left Ventricular Assist Devices. ETH Zurich. Zurique, p. 125. 2014. Tese de Doutorado.

OLEY, L. A. et al. Off-design Considerations of the 50cc Penn State Ventricular Assist Device. Artificial Organs, v. 29, n. 5, p. 378-386, 2005. https://doi.org/10.1111/j.1525-1594.2005.29064.x.

PAUL, R. et al. Shear Stress Related Blood Damage in Laminar Couette Flow. Artificial Organs, Aachen, v. 27, n. 6, p. 517-529, 2003.

PINOTTI, M. Is there Correlation between the Turbulent Eddies Size and Mechanical Hemolysis? Journal of the Brazilian Society of Mechanical Sciences, Belo Horizonte, v. 22, n. 4, p. 565-569, 2000. http://dx.doi.org/10.1590/S0100- 
73862000000400006.

PIRBODAGHI, T. et al. Physiologic and hematologic concerns of rotary blood pumps: what needs to be improved? Heart Failure Reviews, Berna, v. 19, n. 2, p. 259-266, 2014. DOI 10.1007/s10741-013-9389-4.

POLYTEK DEVELOPMENT CORP. Poly-Optic ${ }^{\circledR}$ 14-Series Casting Resins. Easton, p. 2. 2019. Boletim Técnico.

PONIKOWSKI, P. et al. Heart Failure: preventing disease and death worldwide. World Heart Failure Alliance. [S.I.], p. 35. 2014.

POPE, S. B. Turbulent Flows. Cambridge: Cambridge University Press, 2000. 771 p. ISBN 978-0-521-59125-6.

PRINZING, A. et al. Left ventricular assist devices-current state and perspectives. Journal of Thoracic Disease, v. 8, n. 8, p. E660-E666, 2016. http://dx.doi.org/10.21037/jtd.2016.07.13.

PRIOR, D. L.; GERCHE, A. L. The athlete's heart. Heart, Melbourne, v. 98, p. 947955, nov. 2012. doi:10.1136/heartjnl-2011-301329.

PUMP FUNDAMENTALS. About Fluids. Pump Fundamentals, 2019. Disponivel em: <https://www.pumpfundamentals.com/about_fluids.htm>. Acesso em: 8 jun. 2019.

RAFFEL, M. et al. Particle Image Velocimetry: A Practical Guide. $3^{a}$. ed. Cham: Springer, 2018. 668 p. ISBN 978-3-319-68851-0.

RAJU, S. et al. Long-term use of left ventricular assist devices: a report on clinical outcomes. Canadian Journal of Surgery, Toronto, v. 60, n. 4, p. 236-246, 2017. DOI: 10.1503/cjs.010016.

RAMSTACK, J. M.; ZUCKERMAN, L.; MOCKROS, L. F. Shear-Induced Activation of Platelets. Journal of Biomechanics, 12, n. 2, $1979 . \quad$ 113-125. https://doi.org/10.1016/0021-9290(79)90150-7. 
REEVES, M. Particle image velocimetry applied to internal combustion engine in-cylinder flows. Loughborough University. Loughborough, p. 157. 1995. Tese de Doutorado.

REYNOLDS, O. An Experimental Investigation of the Circumstances Which Determine Whether the Motion of Water Shall Be Direct or Sinuous, and of the Law of Resistance in Parallel Channels. Philosophical Transactions of the Royal Society of London, v. 174, p. 935-982, 1883. http://www.jstor.org/stable/109431.

REYNOLDS, O. On the Dynamical Theory of Incompressible Viscous Fluids and the Determination of the Criterion. Philosophical Transactions of the Royal Society of London, v. 186, p. 123-164, 1895. http://www.jstor.org/stable/90643.

RICKARDS, A. F.; NORMAN, J. Relation between QT interval and heart rate. New design of physiologically adaptive cardiac pacemaker. Heart, v. 45, n. 1, p. 56-61, 1981.

RODWELL, M. Atmospheric Variability: Extratropics. ECMWF Training Course 2009 - NWP-PR. [S.I.], p. 34. 2009.

ROONEY, J. A. Hemolysis Near an Ultrasonically Pulsating Gas Bubble. Science, v. 169, n. 3948, p. 869-871, 28 ago. 1970. DOI: 10.1126/science.169.3948.869.

ROSZELLE, B. N. et al. The 12 cc Penn State Pulsatile Pediatric Ventricular Assist Device: Flow Field Observations at a Reduced Beat Rate With Application to Weaning. ASAIO Journal, v. 54, p. 325-331, 2008. DOI: 10.1097/MAT.0b013e3181695cfe.

ROSZELLE, B. N. et al. Flow Visualization of a Pediatric Ventricular Assist Device During Stroke Volume Reductions Related to Weaning. Annals of Biomedical Engineering, v. 39, n. 7, p. 2046-2058, jul. 2011. DOI: 10.1007/s10439-011-0291-8.

ROSZELLE, B. N.; DEUTSCH, S.; MANNING, K. B. Flow Visualization of ThreeDimensionality Inside the 12 cc Penn State Pulsatile Pediatric Ventricular Assist Device. Annals of Biomedical Engineering, v. 38, n. 2, p. 439-455, fev. 2010. DOI: 10.1007/s10439-009-9842-7. 
ROWLANDS, G. W. et al. Characterizing the HeartMate II Left Ventricular Assist Device Outflow Using Particle Image Velocimetry. Journal of Biomechanical Engineering, University Park, v. 140, p. 071008-1 - 071008-13, jul. 2018. DOI: 10.1115/1.4039822.

SAKARIASSEN, K. S. et al. Shear-induced platelet activation and platelet microparticle formation in native human blood. Thrombosis Research, 92, n. 6, 15 dez. 1998. S33S41. https://doi.org/10.1016/S0049-3848(98)00158-3.

SALLAM, A. M.; HWANG, N. H. C. Human red blood cell hemolysis in a turbulent shear flow: Contribution of Reynolds shear stresses. Biorheology, Riyadh, v. 21, n. 6, p. 783-797, 1984. doi:10.3233/bir-1984-21605.

SANDZA, J. G. J. et al. Subhemolytlc trauma of erythrocytes: recognition and sequestration by the spleen as a function of shear. Transactions - American Society for Artificial Internal Organs, 20, n. 1, abr. 1974. 457-462.

SANTOS, I. D. S.; BITTENCOURT, M. S. Insuficiência cardíaca. Revista de Medicina, São Paulo, v. 87, n. 4, p. 224-231, out-dez 2008. ISSN 0034-8554.

SARNARI, R. et al. The systolic to diastolic duration ratio in children with normal cardiac function and its relation to heart rate, age and body surface area. Heart Views, v. 10, n. 1, p. 11-16, mar. 2009.

SAVARESE, G.; LUND, L. H. Global Public Health Burden of Heart Failure. Cardiac Failure Review, Estocolmo, v. 3, n. 1, p. 7-11, 2017. DOI: 10.15420/cfr.2016:25:2.

SCARANO, F. Iterative image deformation methods in PIV. Measurement Science and Technology, 13, n. 1, 23 nov. 2001. R1-R19. doi:10.1088/0957-0233/13/1/201.

SCHARNOWSKI, S.; SCIACCHITANO, A.; KÄHLER, C. J. On the universality of Keane \& Adrian's valid detection probability in PIV. Measurement Science and Technology, v. 30, p. 035203 1-8, 2019. https://doi.org/10.1088/1361-6501/aafe9d.

SCHÖNBERGER, M.; DEUTSCH, S.; MANNING, K. B. The Influence of Device 
Position on the Flow Within the Penn State $12 \mathrm{cc}$ Pediatric Ventricular Assist Device. ASAIO Journal, v. 58, p. 481-493, 2012. DOI: 10.1097/MAT.0b013e3182639a18.

SCHRÖDER, A. et al. Eulerian and Lagrangian views of a turbulent boundary layer flow using time-resolved tomographic PIV. Experiments in Fluids, v. 50, p. 10711091, 2011. DOI 10.1007/s00348-010-1014-x.

SCIACCHITANO, A. Uncertainty quantification in particle image velocimetry and advances in time-resolved image and data analysis. Technische Universiteit Delft. Delft, p. 241. 2014. (978-94-6186-353-9). Tese de Doutorado.

SCIACCHITANO, A.; SCARANO, F.; WIENEKE, B. Multi-frame pyramid correlation for time-resolved PIV. Experiments in Fluids, v. 53, p. 1087-1105, 2012. DOI 10.1007/s00348-012-1345-x.

SHANNON, C. E. Communication in the Presence of Noise. Proceedings of the IEEE, v. 86 , n. 2, p. 447-457, fev. 1998. DOI: 10.1109/JPROC.1998.659497.

SHAVIT, U.; LOWE, R. J.; STEINBUCK, J. V. Intensity Capping: a simple method to improve cross-correlation PIV results. Experiments in Fluids, 42, n. 2, 2007. 225240. doi:10.1007/s00348-006-0233-7.

SHENG, J.; MENG, H.; FOX, R. O. A large eddy PIV method for turbulence dissipation rate esti. Chemical Engineering Science, Manhattan, v. 55, p. 4423-4434, 2000.

SHINNEEB, A.-M.; BUGG, J. D.; BALACHANDAR, R. Variable threshold outlier identification in PIV data. Measurement Science and Technology, Windsor, Vol. 15, 23 jul. 2004. p. 1722-1732. doi:10.1088/0957-0233/15/9/008.

SIGMA CORPORATION. Sigma AF-MF Zoom Lens 105mm F2.8 EX DG MACRO. Kawasaki, p. 1. 2012. Datasheet.

SIQUEIRA, A. D. S. E.; SIQUEIRA-FILHO, A. G. D.; LAND, M. G. P. Análise do Impacto Econômico das Doenças Cardiovasculares nos Últimos Cinco Anos no Brasil. Arquivos Brasileiros de Cardiologia, Rio de Janeiro, p. 8, 2017. DOI 
10.5935/abc.20170068.

SKORUPSKA, K. Scriptorium \& Office: re-enchantment of work. Piet Zwart Institute. Roterdã, p. 101. 2017. Dissertação de Mestrado.

SMAGORINSKY, J. General Circulation Experiments With The Primitive Equations: I. The Basic Experiment. Monthly Weather Review, v. 91, p. 99-164, 1963. https://doi.org/10.1175/1520-0493(1963)0912.3.CO;2.

SOCHI, T. Non-Newtonian Rheology in Blood Circulation. Physics Fluid Dynamics, p. 1-26, 2013. arXiv:1306.2067v2.

SPITAELS, S. et al. The influence of heart rate and age on the systolic and diastolic time intervals in children. Circulation, v. 49, n. 6, p. 1107-1115, 1974.

ST. JUDE MEDICAL. Structural Heart U.S. Product Catalog. Saint Paul, p. 72. 2012. Catálogo.

STEHLIK, J.; JOHNSON, S. A.; SELZMAN, C. H. Gold Standard in Anticoagulation Assessment of Left Ventricular Assist Device Patients? How About Bronze. JACC: Heart Failure, v. 3, n. 4, p. 323-326, 2015. ISSN 2213-1779. https://doi.org/10.1016/j.jchf.2015.01.004.

STILLER, B.; ADACHI, I.; FRASER JR, C. D. Pediatric Ventricular Assist Devices. Pediatric Critical Care Medicine Journal, Freiburg, v. 14, n. 5, p. S20-S26, 2013. DOI: 10.1097/PCC.0b013e318292df5f.

SUTERA, S. P. Flow-Induced Trauma to Blood Cells. Circulation Research, 41, n. 1, jul. 1977. 2-8. https://doi.org/10.1161/01.RES.41.1.2.

SUTERA, S. P.; CROCE, P. A.; MEHRJARDI, M. Hemolysis and Subhemolytic Alterations of Human RBC Induced by Turbulent Shear Flow. American Society for Artificial Internal Organs, Saint Louis, v. XVIII, p. 335-341, 1972.

SUTERA, S. P.; MEHRJARDI, M. H. Deformation and fragmentation of human red 
blood cells in turbulent shear flow. Biophysical Journal, Saint Louis, v. 15, n. 1, p. 110, jan. 1975. doi: 10.1016/S0006-3495(75)85787-0.

TANG, D. G.; OYER, P. E.; MALLIDI, H. R. Ventricular Assist Devices: History, Patient Selection, and Timing of Therapy. Journal of Cardiovascular Translational Research, Stanford, v. 2, p. 159-167, 19 mar. 2009. DOI 10.1007/s12265-009-90985 .

TARBELL, J. M. et al. Pulsed Ultrasonic Doppler Velocity Measurements Inside a Left Ventricular Assist Device. Journal of Biomechanical Engineering, v. 108, n. 3, p. 232-238, 1 ago. 1986. doi:10.1115/1.3138608.

TAYLOR, G. I. Statistical Theory of Turbulence. Proceedings of the Royal Society of London. Series A-Mathematical and Physical Sciences, v. 151, n. 873, p. 421444, 2 set. 1935. https://doi.org/10.1098/rspa.1935.0158.

TCHANTCHALEISHVILI, V. et al. Evaluation and treatment of pump thrombosis and hemolysis. Annals of Cardiothoracic Surgery, v. 3, n. 5, p. 490-495, 2014. doi: 10.3978/j.issn.2225-319X.2014.09.01.

TENNEKES, H.; LUMLEY, J. L. A First Course in Turbulence. Cambridge: The MIT Press, 1972. 300 p. ISBN 978-0-262-20019-6.

TILLMANN, W. et al. In-vitro wall shear measurements at aortic valve prostheses. Journal of Biomechanics, 17, n. 4, 1984. 263-279. https://doi.org/10.1016/00219290(84)90137-4.

TJANG, Y. S. et al. Risk factor analysis in pediatric heart transplantation. The Journal of Heart and Lung Transplantation, v. 27, n. 4, p. 408-415, 2008. doi:10.1016/j.healun.2008.01.007.

TOPPER, S. R. et al. The Use of Fluid Mechanics to Predict Regions of Microscopic Thrombus Formation in Pulsatile VADs. Cardiovascular Engineering and Technology, University Park, Vol. 5, n. 1, mar. 2014. p. 54-69. DOI: 10.1007/s13239014-0174-x. 
TORNER, B. et al. Large eddy simulation in a rotary blood pump: Viscous shear stress computation and comparison with unsteady Reynolds-averaged Navier-Stokes simulation. The International Journal of Artificial Organs, Rostock, Vol. 41, n. 11, jun. 2018. p. 1-12. https://doi.org/10.1177/0391398818777697.

TOWBIN, J. A. et al. Incidence, Causes, and Outcomes of Dilated Cardiomyopathy in Children. Journal of the American Medical Association, v. 296, n. 15, p. 1867-1876, 18 out. 2006.

TROOLIN, D. R.; LONGMIRE, E. K.; LAI, W. T. Time resolved PIV analysis of flow over a NACA 0015 airfoil with Gurney flap. Experiments in Fluids, v. 41, p. 241-254, 2006. DOI 10.1007/s00348-006-0143-8.

TROPEA, C.; YARIN, A. L.; FOSS, J. F. Springer Handbook of Experimental Fluid Mechanics. Berlim: Springer, 2007. 1557 p. ISBN 978-3-540-25141-5.

UNIVERSIDADE DE SÃO PAULO (USP). 20 anos de Incor. Espaço Aberto, São Paulo, n. 138, maio 2012. Disponivel em: <http://www.usp.br/espacoaberto/?materia=20-anos-de-incor>. Acesso em: 7 jun. 2019.

UNIVERSITY OF ABERDEEN. SlugFlow: PIV Software. University of Aberdeen. Aberdeen, p. 1. 2008. Apresentação.

VANDERPLUYM, C. J.; FYNN-THOMPSON, F.; BLUME, E. D. Ventricular Assist Devices in Children: Progress With an Orphan Device Application. Challenges and Opportunities in Pediatric Heart Failure and Transplantation, Boston, p. 15301537, 8 abr. 2014. DOI: 10.1161/CIRCULATIONAHA.113.005574.

VELKER, J. A.; MCINTIRE, L. V.; LYNCH, E. C. Alteration of erythrocyte deformability due to shear stress as assessed by nuclepore filters. Transactions - American Society for Artificial Internal Organs, abr. 1977. 732-735.

VILLA, C. R.; MORALES, D. L. S. The Total Artificial Heart in End-Stage Congenital Heart Disease. Frontiers in Physiology, v. 8, p. 131, maio 2017. doi: 
10.3389/fphys.2017.00131.

VISION RESEARCH. Phantom Miro LAB-, LC- and R-Series Cameras. Wayne, p. 6. 2016. Datasheet.

VOGEL, A.; LAUTERBORN, W. Time-resolved particle image velocimetry used in the investigation of cavitation bubble dynamics. Applied Optics, v. 27, n. 9, p. 1869-1876, 1 maio 1988. doi: 10.1364/AO.27.001869.

WEISS, W. J. et al. Chronic In Vivo Testing of the Penn State Infant Ventricular Assist Device. ASAIO Journal, v. 58, p. 65-72, 2012. DOI: 10.1097/MAT.0b013e318239feb4.

WERNET, M. P. Temporally resolved PIV for space-time correlations in both cold and hot jet flows. Measurement Science and Technology, v. 18, p. 1387-1403, 2007. doi:10.1088/0957-0233/18/5/027.

WESTERWEEL, J.; SCARANO, F. Universal outlier detection for PIV data. Experiments in Fluids, 39, n. 6, 12 ago. 2005. 1096-1100. doi:10.1007/s00348-0050016-6.

WIENEKE, B. PIV Uncertainty Quantification and Beyond. Technische Universiteit Delft. Delft, p. 200. 2017. https://doi.org/10.4233/uuid:4ca8c0b8-0835-47c3-8523$12 f c 356768 f 3$.

WIGGERS, C. J. Modern Aspects of the Circulation in Health and Disease. Filadélfia: Lea \& Febiger, 1915. 376 p.

WILLERT, C. E. High-speed particle image velocimetry for the efficient measurement of turbulence statistics. Experiments in Fluids, v. 56, p. 1-17, 2015. DOI 10.1007/s00348-014-1892-4.

WILLIAMS, A. R. Shear-induced fragmentation of human erythrocytes. Biorheology, 10, n. 3, 1 set. 1973. 303-311. DOI: 10.3233/BIR-1973-10303. 
WILLIAMS, A. R. Release of serotonin from human platelets by acoustic microstreaming. The Journal of the Acoustical Society of America, 56, n. 5, nov. 1974. 1640-1643. https://doi.org/10.1121/1.1903490.

WILLIAMS, A. R. Intravascular mural thrombi produced by acoustic microstreaming. Ultrasound in Medicine \& Biology, 3, n. 2, 1977. 191-203. https://doi.org/10.1016/0301-5629(77)90071-0.

WILLIAMS, A. R.; HUGHES, D. E.; NYBORG, W. L. Hemolysis Near a Transversely Oscillating Wire. Science, v. 169, n. 3948, p. 871-873, 28 ago. 1970. DOI: 10.1126/science.169.3948.871.

WITKOWSKI, D. et al. Particle image velocimetry tests on pediatric 45-cc and 30-cc ventricle assist devices: effects of heart rate on VAD operation. The International Journal of Artificial Organs, v. 40, n. 10, p. 558-562, 2017. ISSN 0391-3988. https://doi.org/10.5301/ijao.5000618.

WORLD HEALTH ORGANIZATION. Global Health Estimates 2016: Deaths by Cause, Age, Sex, by Country and by Region, 2000-2016. Geneva. 2018.

WURZINGER, L. J. et al. "Shear Induced Platelet Activation" - A Critical Reappraisal. Biorheology, Aachen, v. 22, p. 399-413, 1985.

WURZINGER, L. J. et al. Platelet and Coagulation Parameters Following Millisecond Exposure to Laminar Shear Stress. Thrombosis and Haemostasis, v. 54, n. 02, p. 381-386, 1985. DOI: 10.1055/s-0038-1657744.

WURZINGER, L. J.; BLASBERG, P.; SCHMID-SCHBNBEIN, H. Towards a Concept of Thrombosis in Accelerated Flow: Rheology, Fluid Dynamics, and Biochemistry. Biorheology, Aachen, v. 22, p. 437-449, 1985.

$X U, Z$. et al. The Influence of Different Operating Conditions on the Blood Damage of a Pulsatile Ventricular Assist Device. ASAIO Journal, 61, n. 6, nov. 2015. 656-663. DOI: 10.1097/MAT.0000000000000261. 
XUE, Z.; CHARONKO, J. J.; VLACHOS, P. P. Particle image velocimetry correlation signal-to-noise ratio metrics and measurement uncertainty quantification. Measurement Science and Technology, v. 25, p. 115301 1-15, 2014. doi:10.1088/0957-0233/25/11/115301.

YAMAMOTO, Y. Fundamentals of Noise processes. Tóquio: FIRST, 2015. 1-33 p.

YEN, J.-H. et al. The effect of turbulent viscous shear stresson red blood cell hemolysis. Journal of Artificial Organs, New Taipei, v. 17, p. 178-185, 2014. DOI 10.1007/s10047-014-0755-3.

ZHANG, J.-N. et al. Duration of exposure to high fluid shear stress is critical in shearinduced platelet activation-aggregation. Thrombosis and Haemostasis, 90, n. 4, 2003. 672-678. DOI: 10.1160/TH03-03-0145.

ZHANG, W. et al. Relationship between heart rate and quiescent interval of the cardiac cycle in children using MRI. Pediatric radiology, v. 47, n. 12, p. 1588-1593, jul. 2017. DOI 10.1007/s00247-017-3918-6.

ZHU, S. et al. In vitro testing of an intra-ventricular assist device. Computer Assisted Surgery, 24, n. 1, 11 fev. 2019. 89-95. DOI: 10.1080/24699322.2018.1560099.

Колмогоров, А. Н. Локальная Структура Турбулентности в Несжимаемой Вязкой Жидкости При Очень Больших Числах Рейнольдса. Советская физика Успехи, v. 30, n. 4, p. 299, 1941. 10.3367/UFNr.0093.196711h.0476. 


\section{APÊNDICE A - EVOLUÇÃO TEMPORAL DA SONDAS P1 A P9 NOS SEIS INTEVALOS MEDIDOS}

Nesta seção estão todas as figuras das evoluções temporais das componentes de velocidade ( $u$ e v) e para a magnitude da velocidade $(|U|)$, avaliadas nas sondas P1, P2, P3 (válvula de saída), P4, P5, P6 (região entre as válvulas), P7, P8 e P9 (válvula de entrada) nos intervalos medidos ( $\mathrm{t}_{1}$ a $\mathrm{t}_{6}$ ).

a.

Figura 153 - Evolução temporal das velocidades em $t_{1}$ na válvula de saída
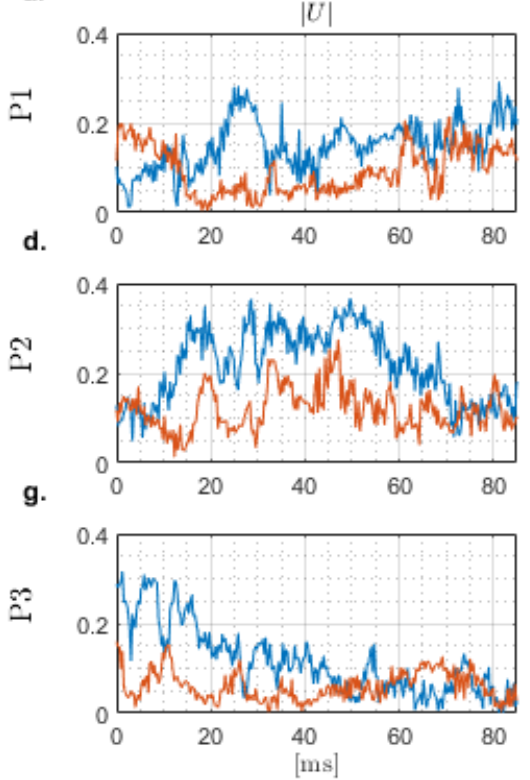

b.
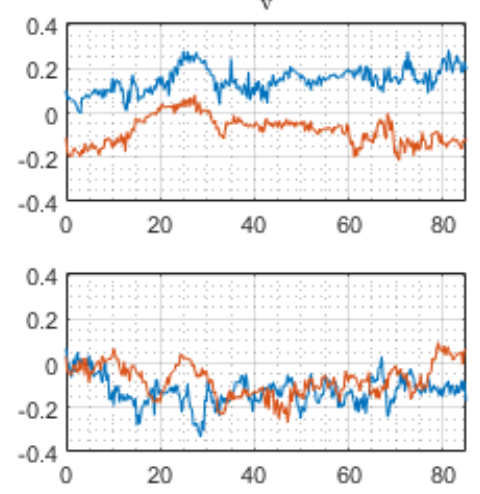

h.

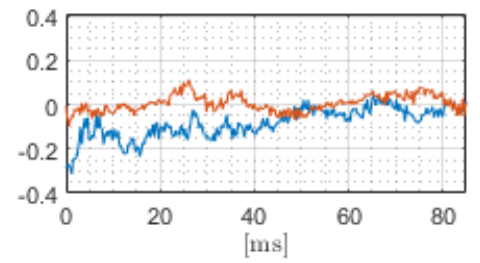

Azul - 0; vermelho - 30은

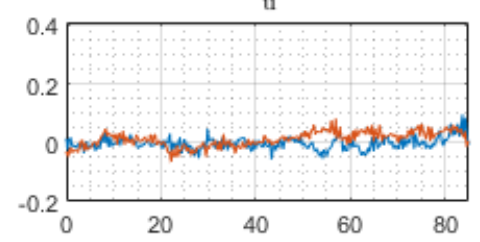

f.
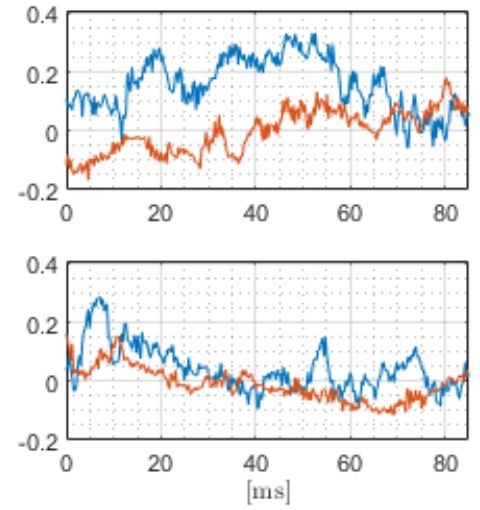

Figura 154 - Evolução temporal das velocidades em $t_{1}$ entre as válvulas
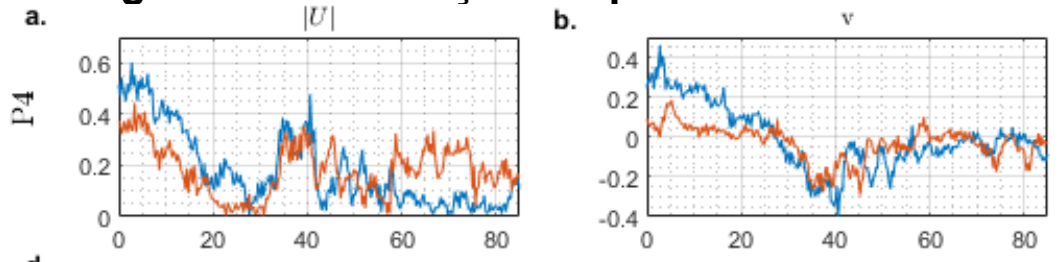

e.

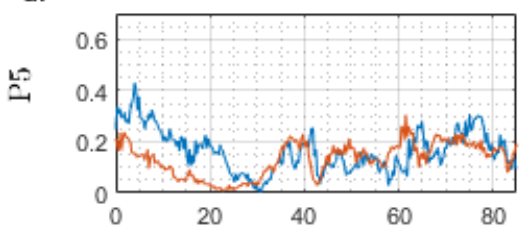

g.

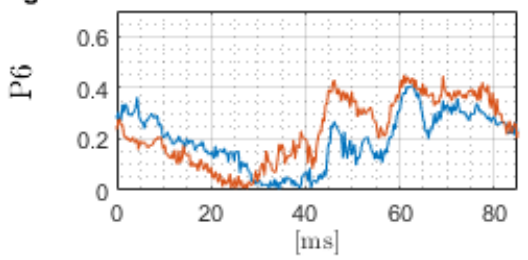

h.

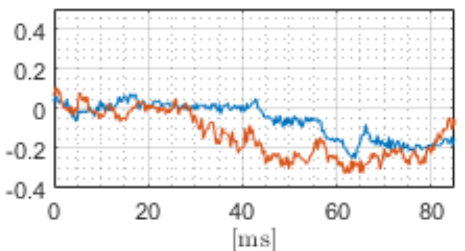

Azul - 0; vermelho - 30은

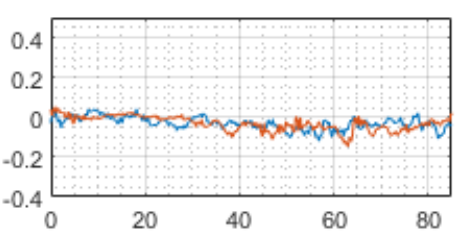

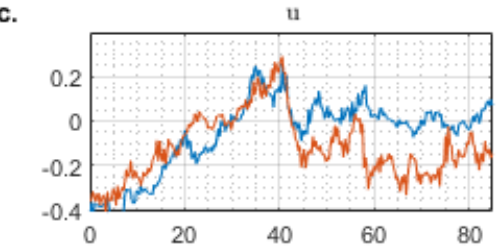

f.
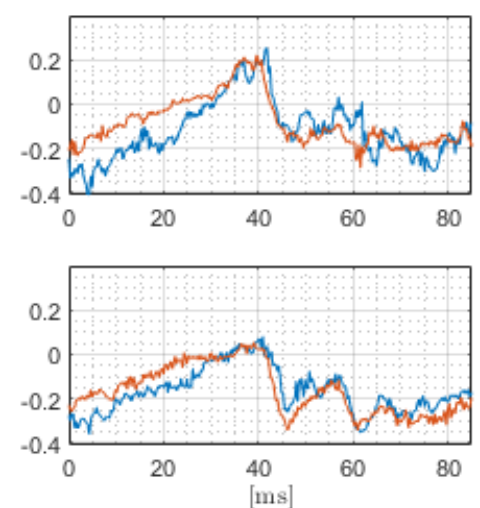
Figura 155 - Evolução temporal das velocidades em $\mathbf{t}_{1}$ na válvula de entrada
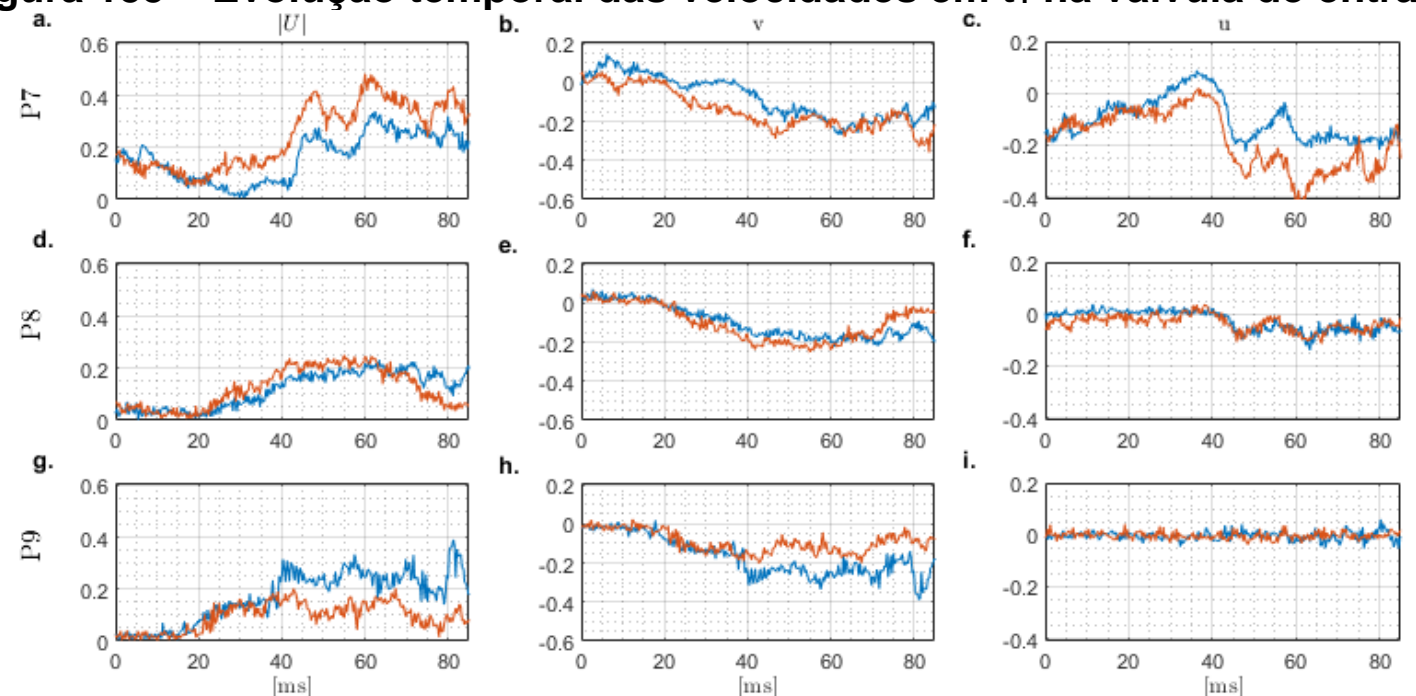

h.
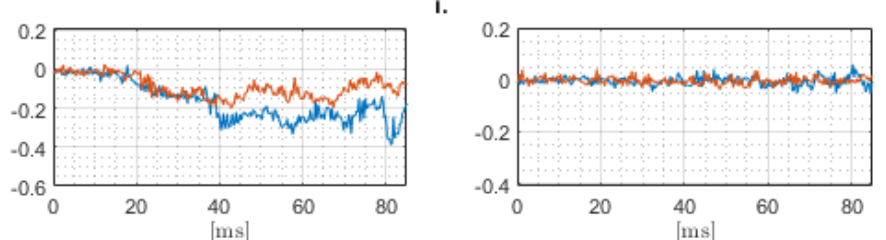

Azul - 0; vermelho - 30은

Figura 156 - Evolução temporal das velocidades em t2 na válvula de saída
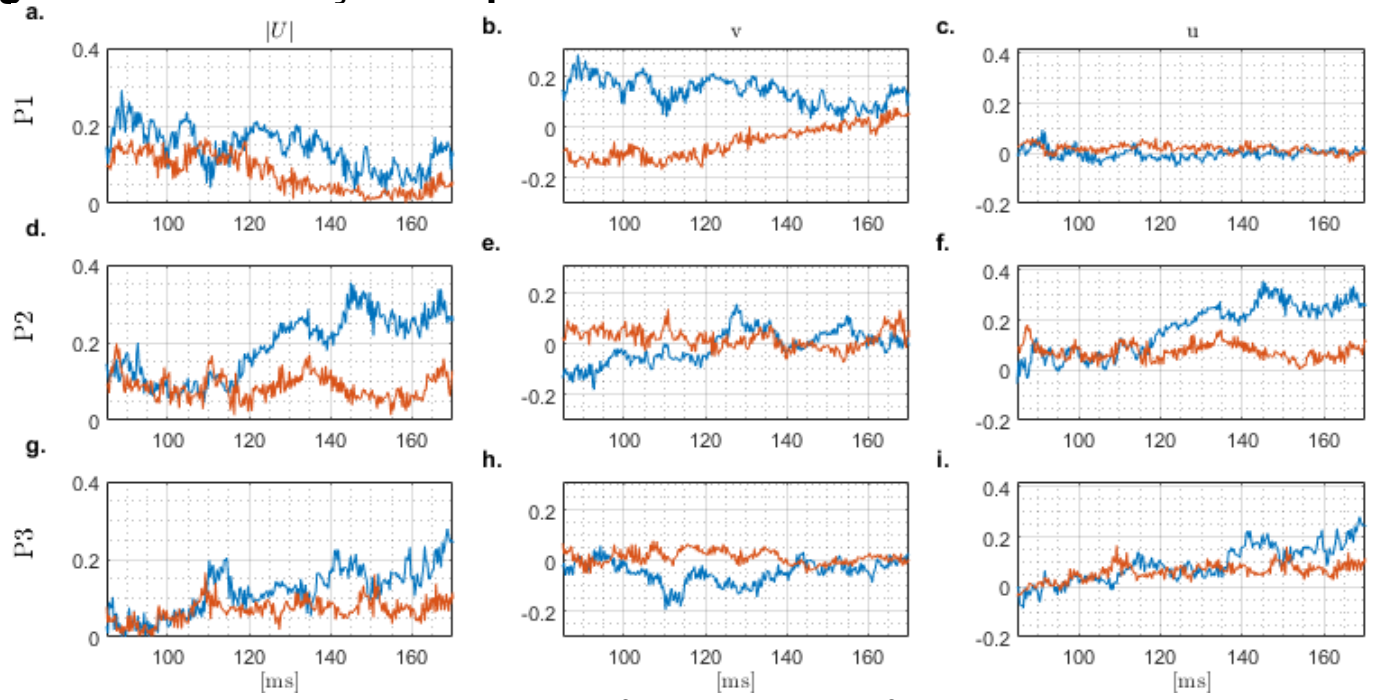

h.
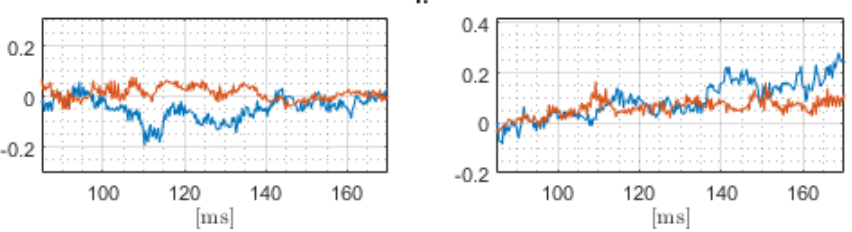

Azul - 0; vermelho - 30은

Figura 157 - Evolução temporal das velocidades em t $t_{2}$ entre as válvulas
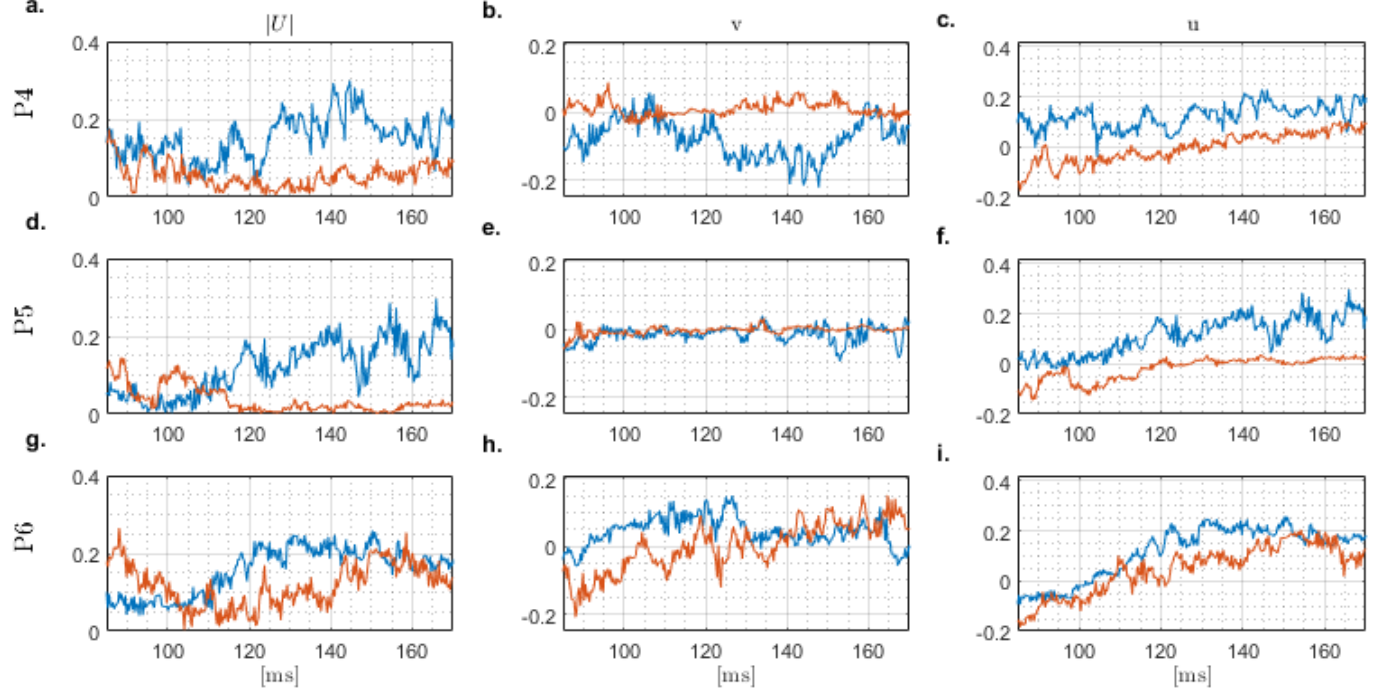

Azul - 0; vermelho - 30응 
Figura 158 - Evolução temporal das velocidades em $t_{2}$ na válvula de entrada
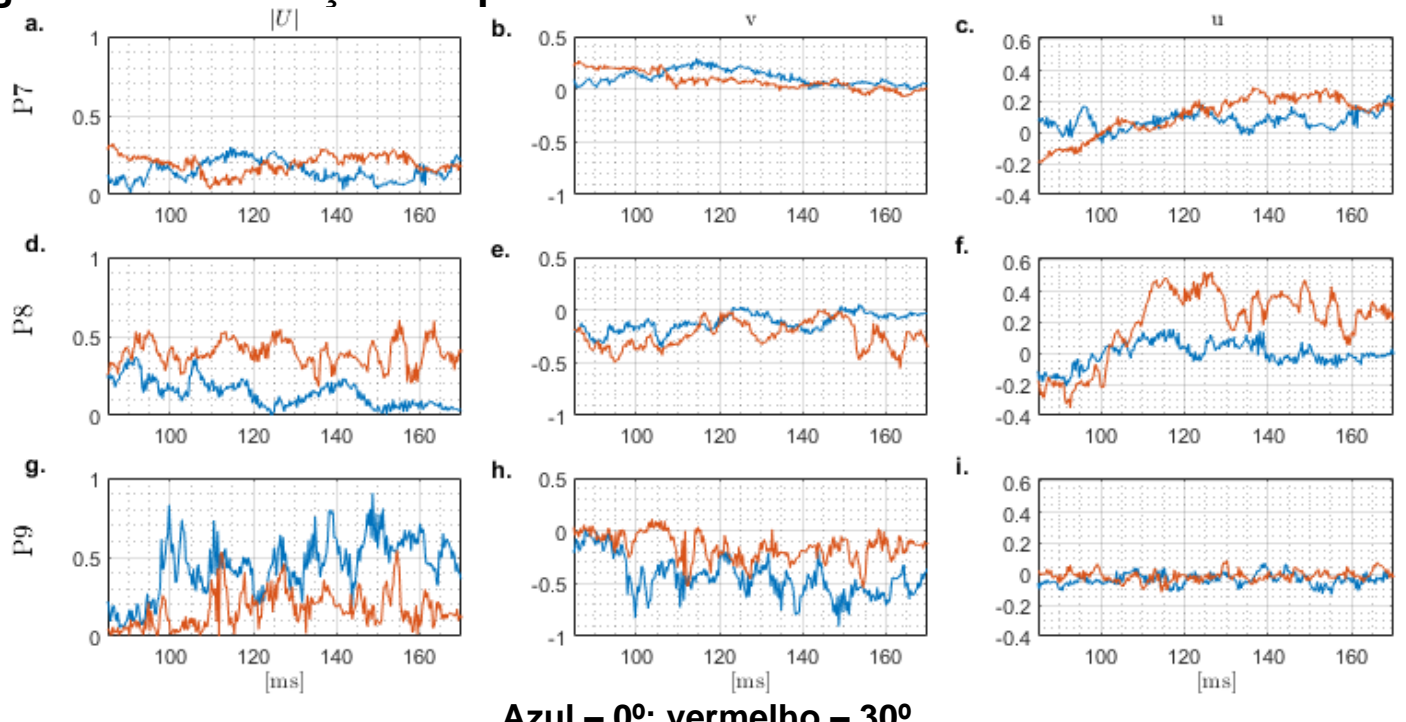

Azul - 0; vermelho - 30응

Figura 159 - Evolução temporal das velocidades em $t_{3}$ na válvula de saída
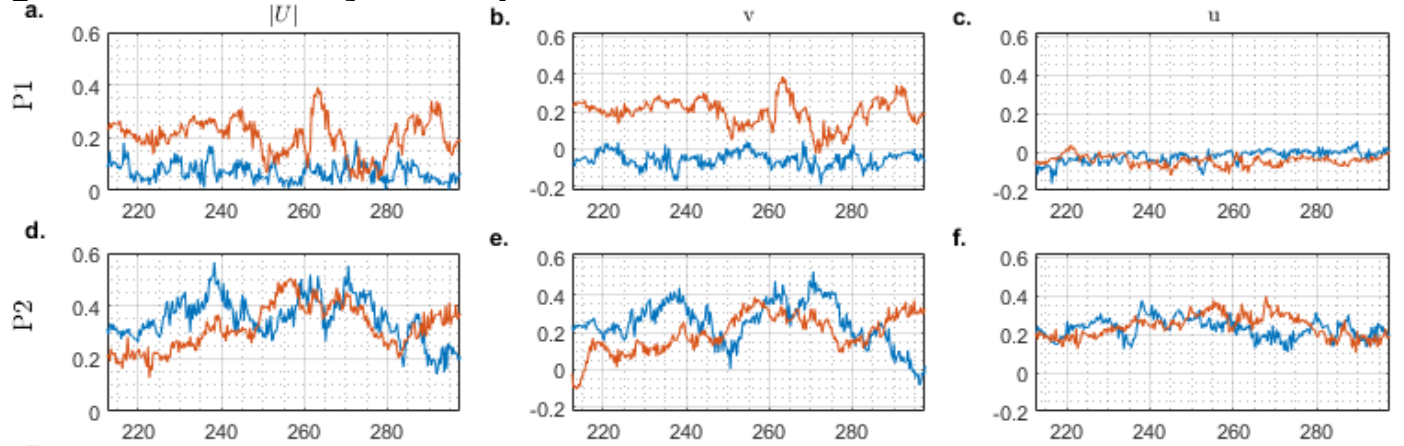

e.

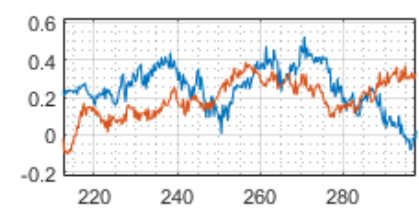

f.
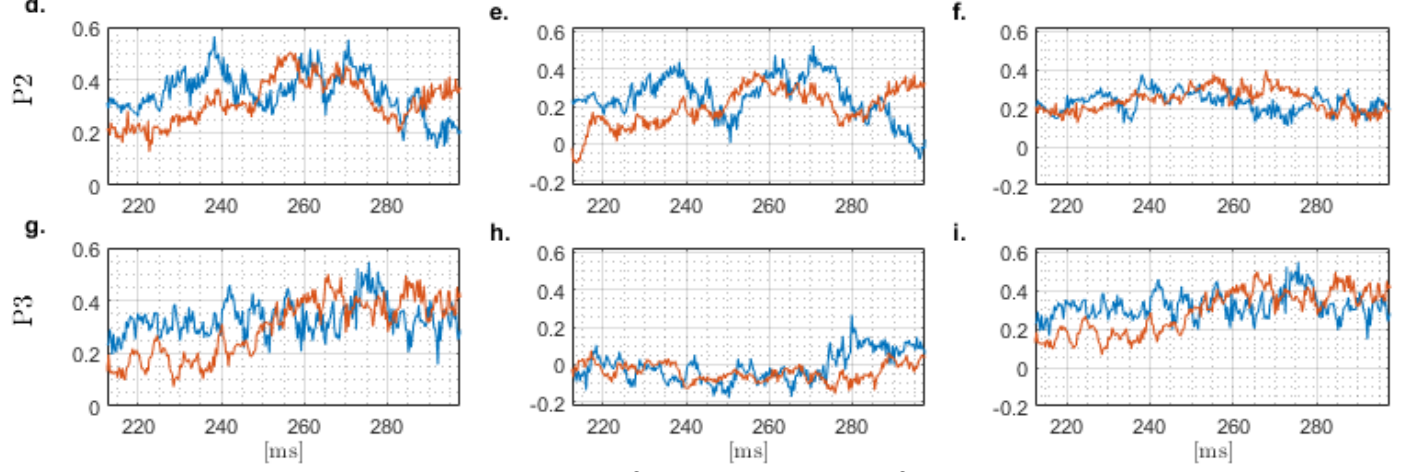

Azul - 0; vermelho - 30응

Figura 160 - Evolução temporal das velocidades em t3 entre as válvulas
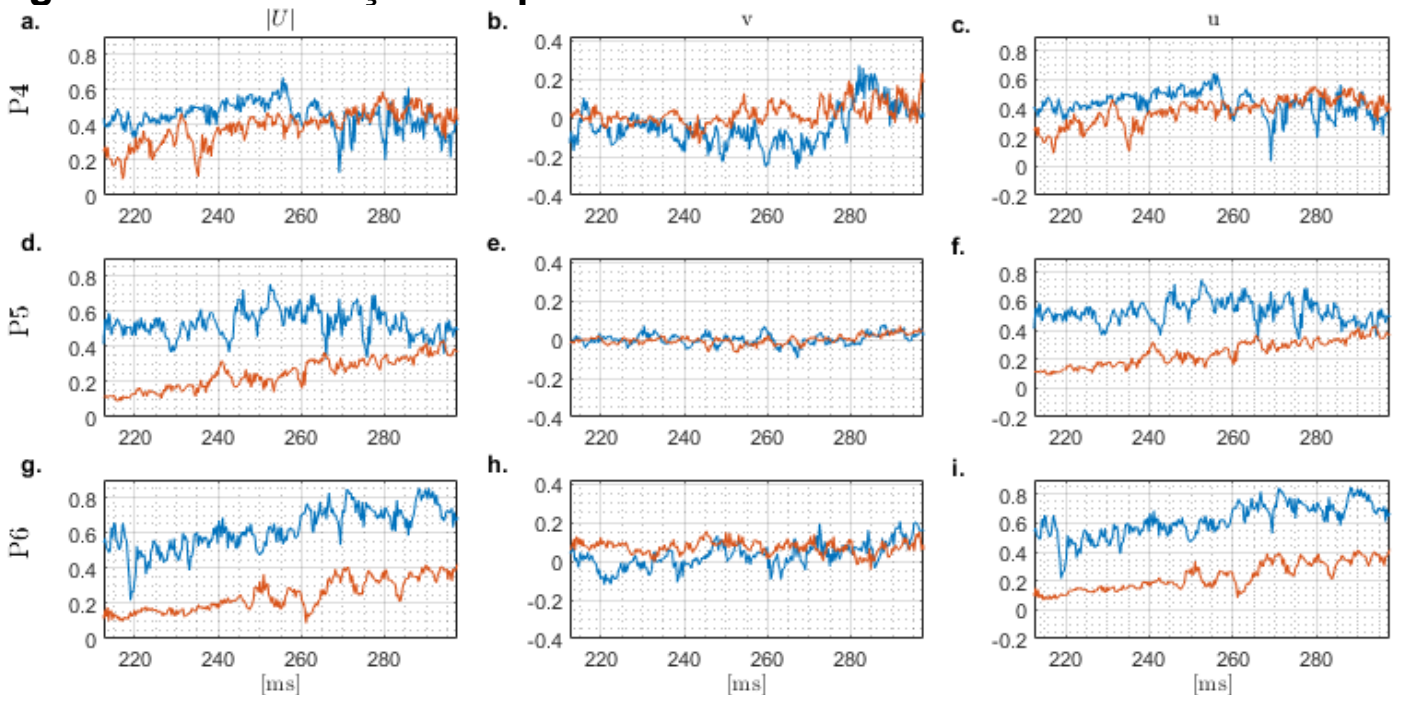

Azul - 0; vermelho - 30응 
Figura 161 - Evolução temporal das velocidades em t3 na válvula de entrada
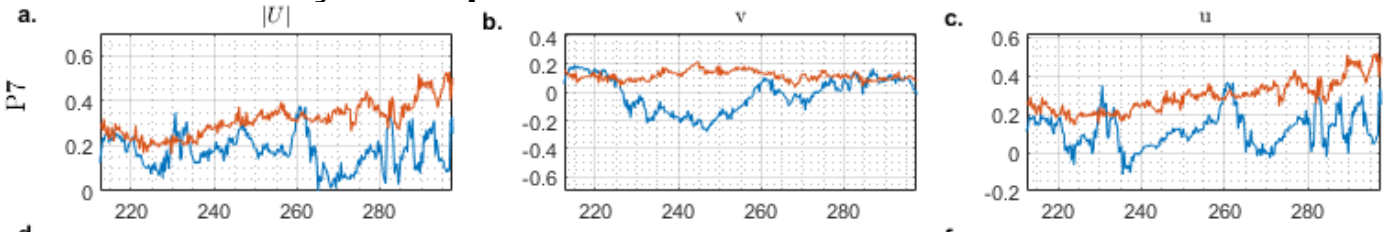

d.
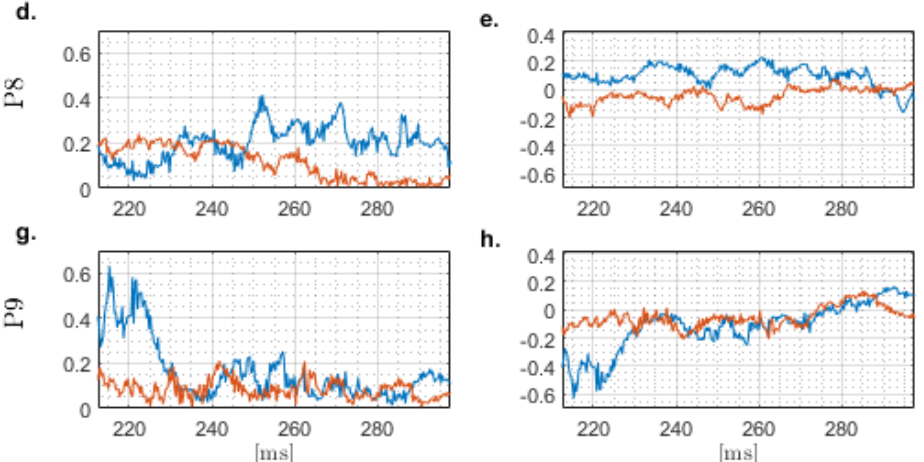

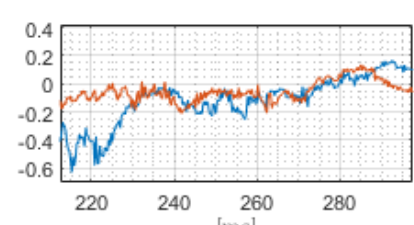

Azul - 0; vermelho - 30은

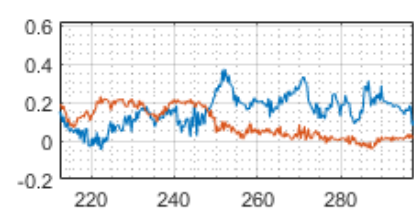

i.

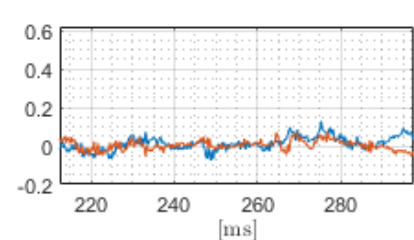

Figura 162 - Evolução temporal das velocidades em $t_{4}$ na válvula de saída
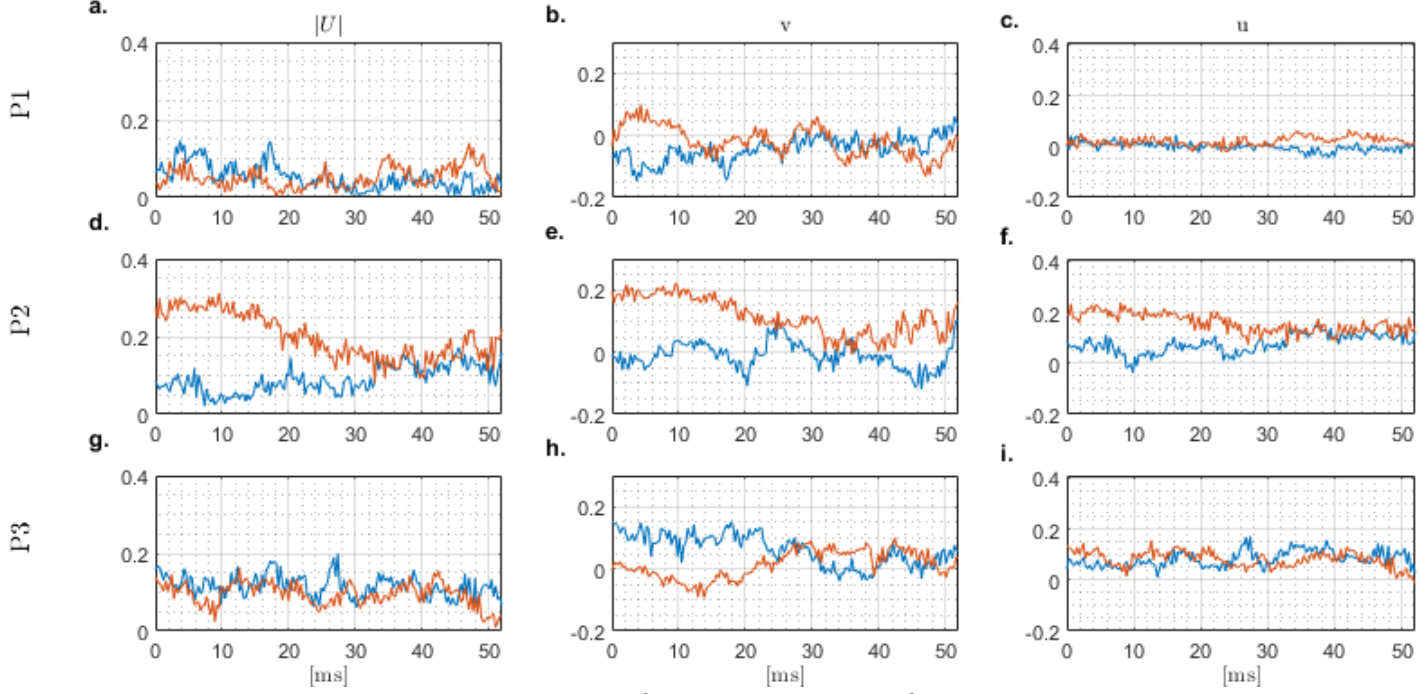

Azul - 0; vermelho - 30은

Figura 163 - Evolução temporal das velocidades em $\mathrm{t}_{4}$ entre as válvulas
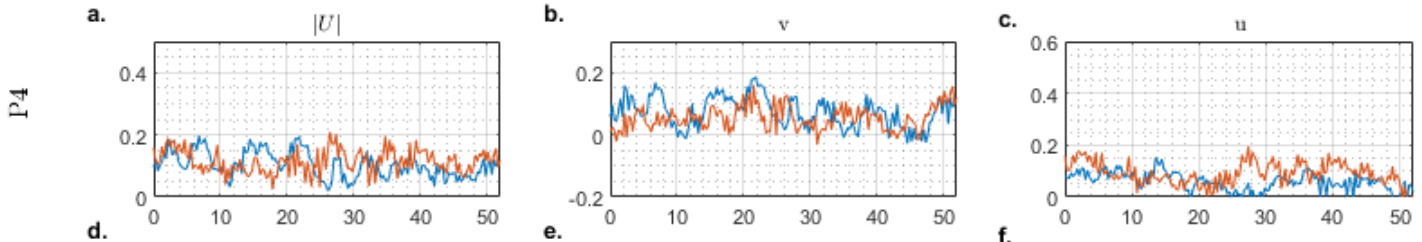

논
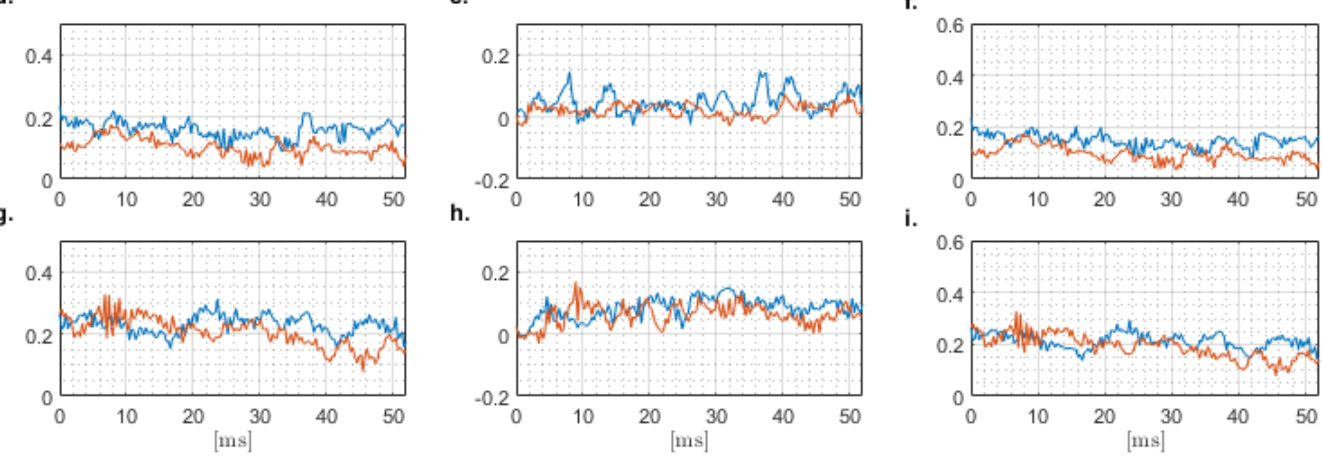

Azul - 0; vermelho - 30응

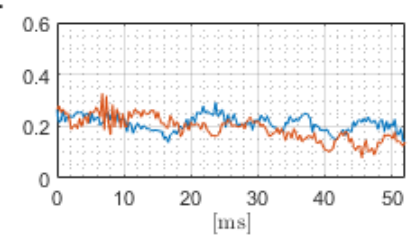


Figura 164 - Evolução temporal das velocidades em $t_{4}$ na válvula de entrada
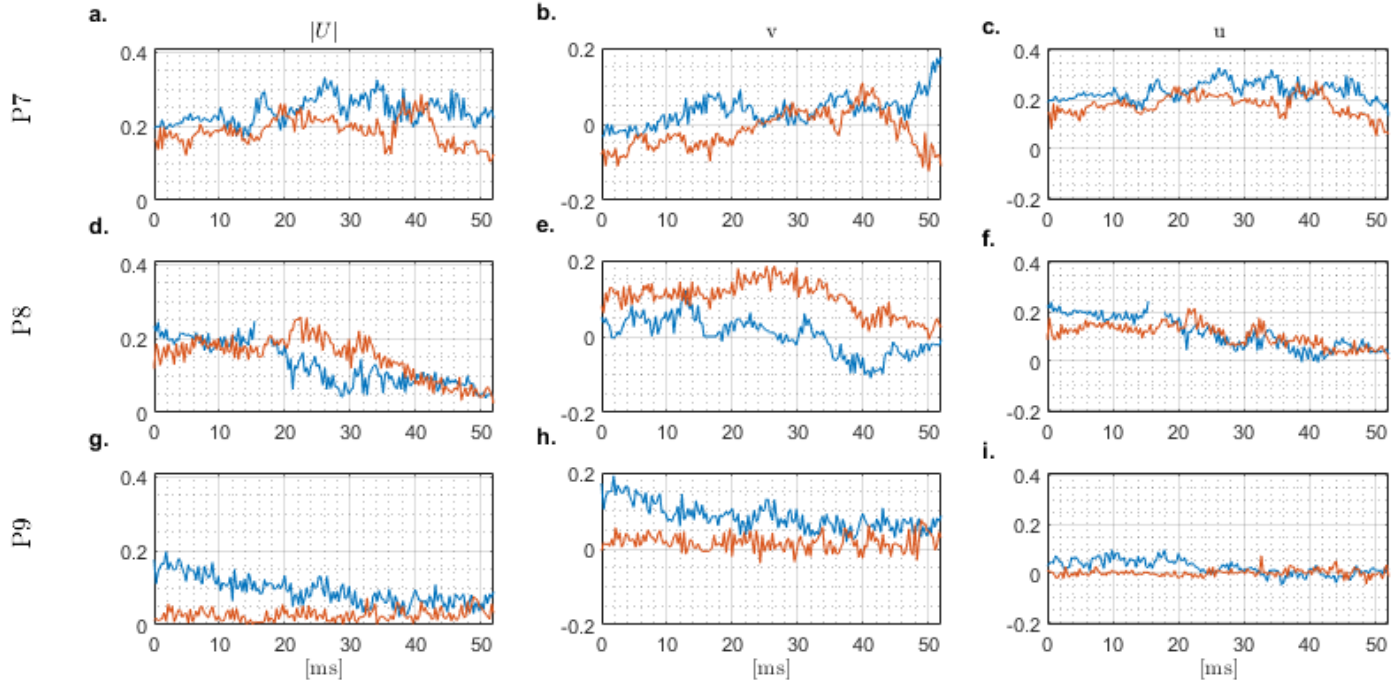

Azul - 0; vermelho - 30응

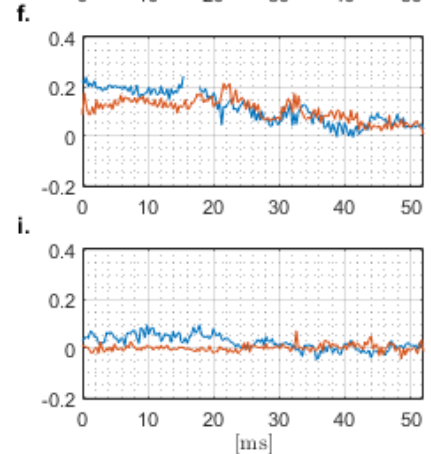

Figura 165 - Evolução temporal das velocidades em t 5 na válvula de saída
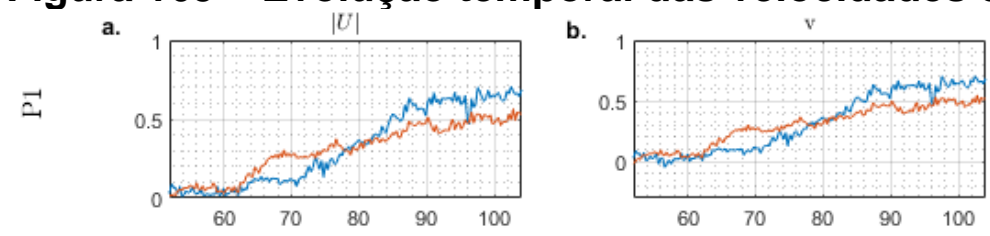

d.

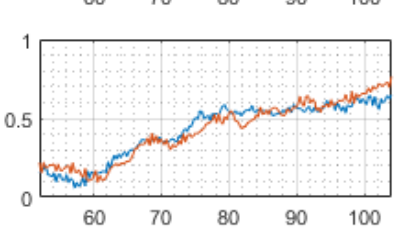

e.

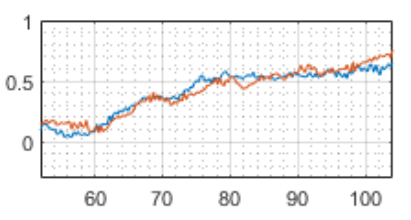

h.
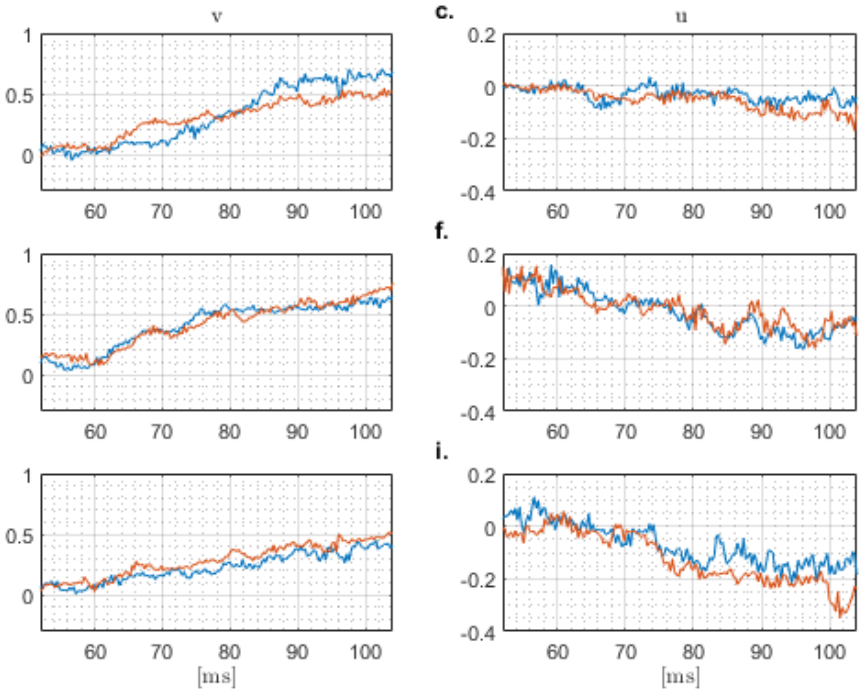

f.

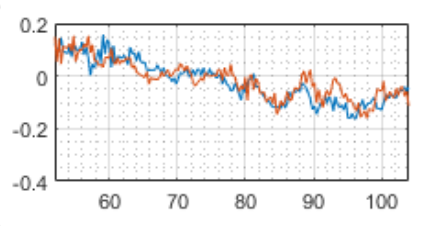

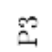

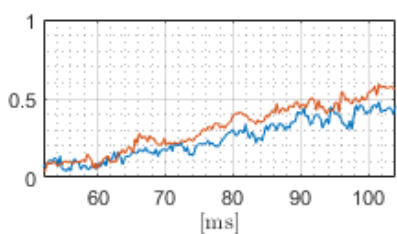

Azul - 0; vermelho - 30응

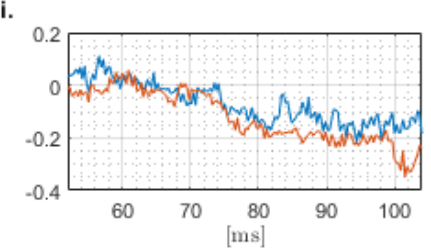

Figura 166 - Evolução temporal das velocidades em t5 entre as válvulas
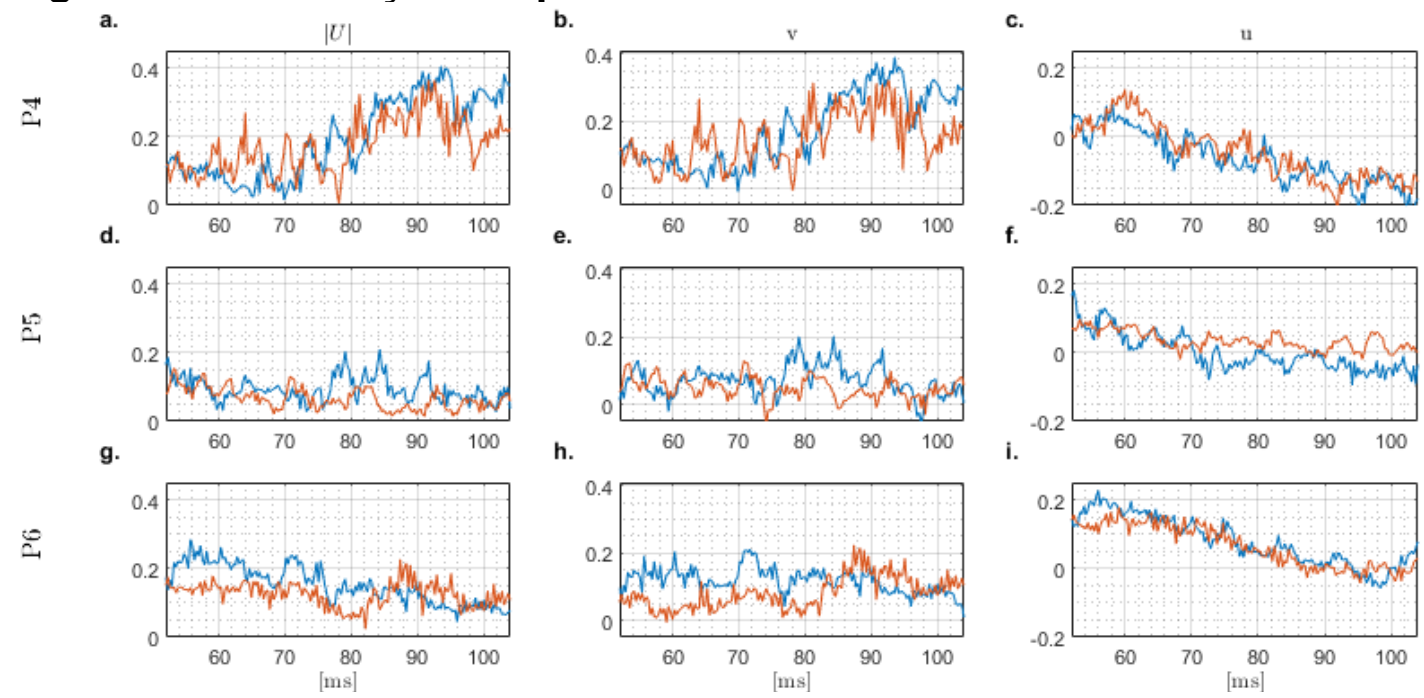
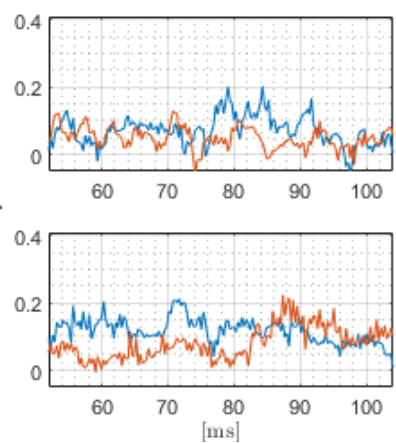

Azul - 0; vermelho - 30응

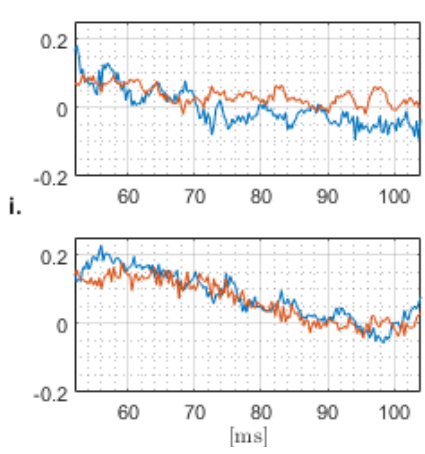


Figura 167 - Evolução temporal das velocidades em ts 5 na válvula de entrada
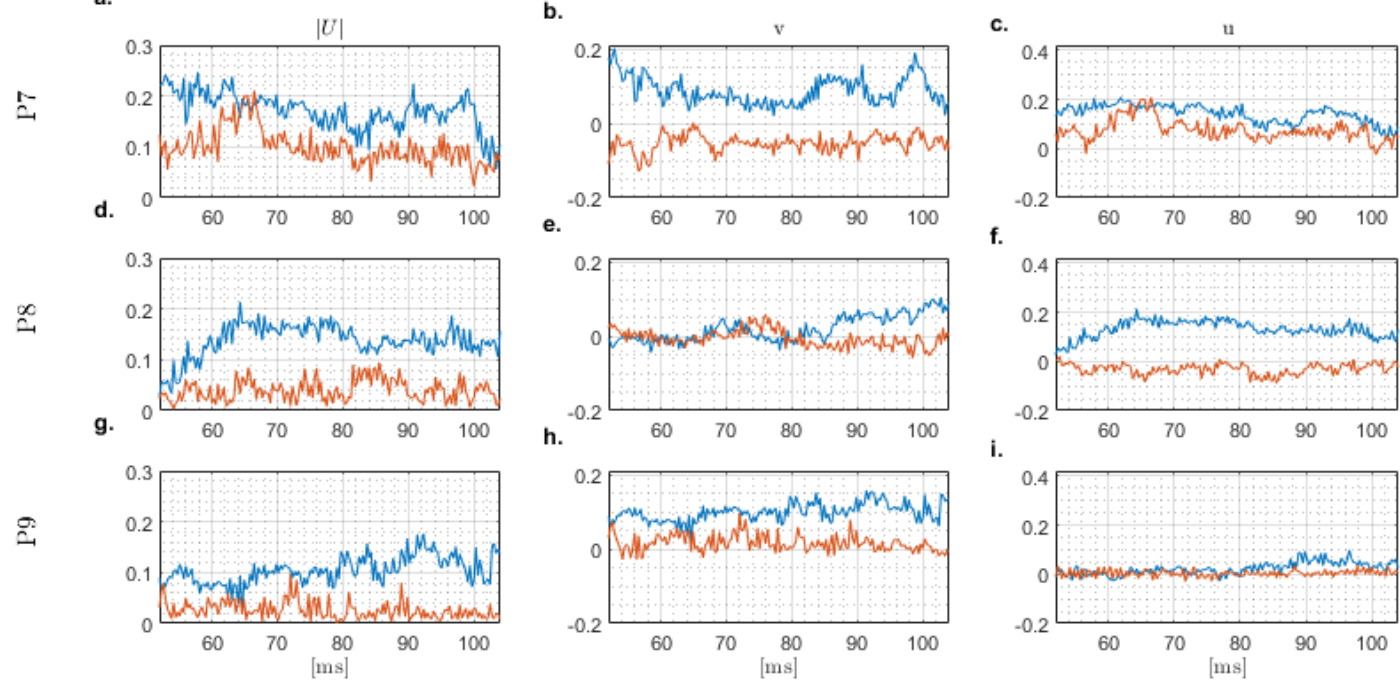

Azul - 0; vermelho - 30응

Figura 168 - Evolução temporal das velocidades em t6 na válvula de saída
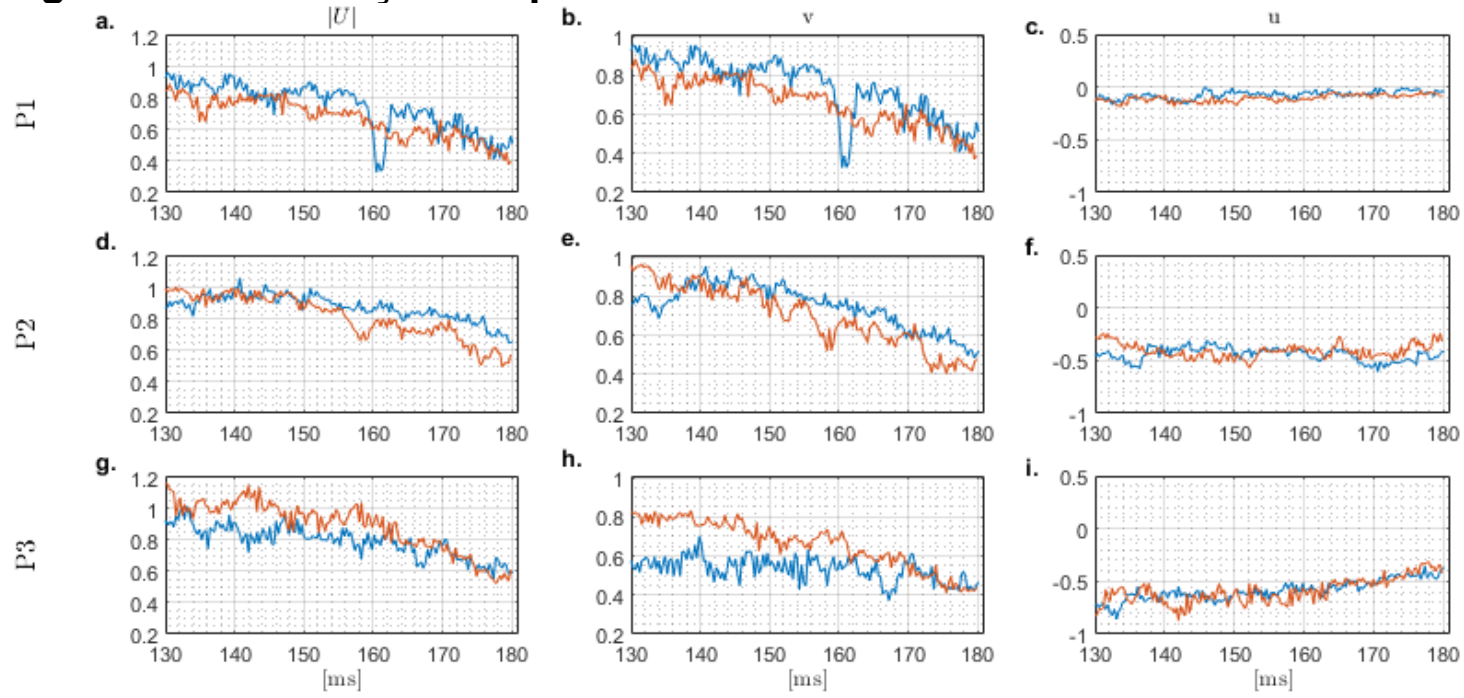

h.
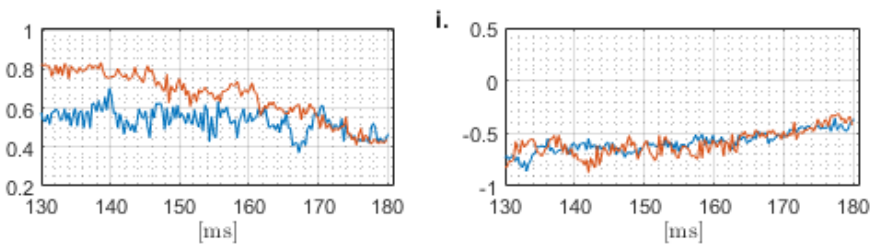

Azul - 0; vermelho - 30응

Figura 169 - Evolução temporal das velocidades em t6 entre as válvulas
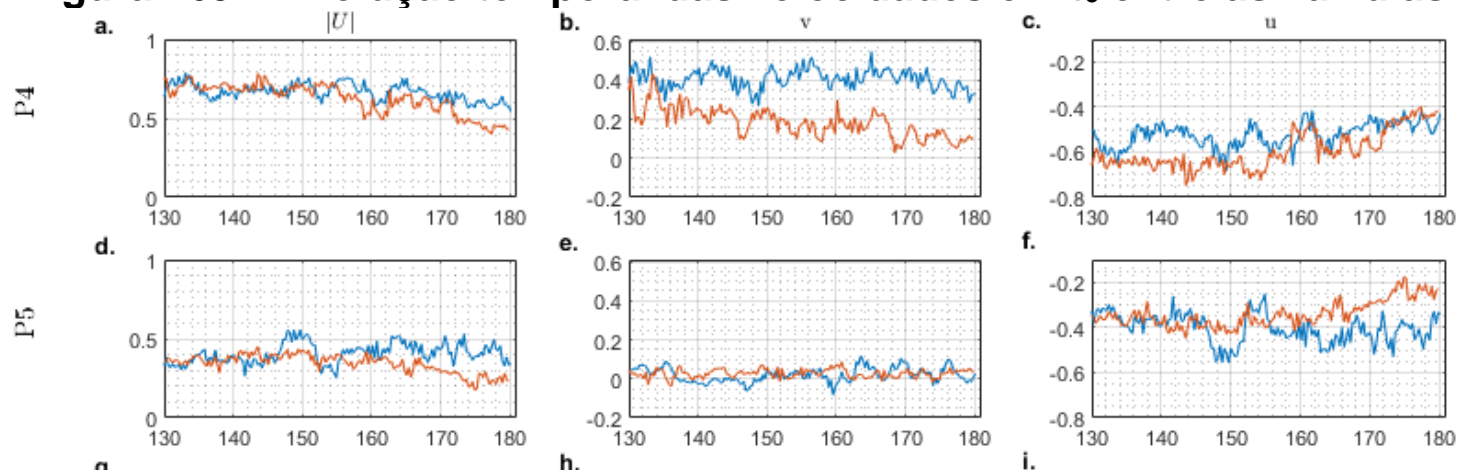

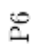

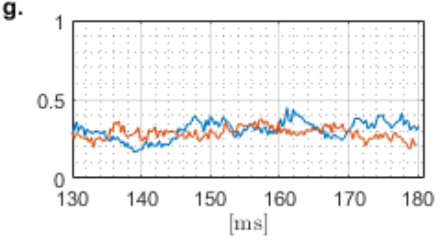

h.
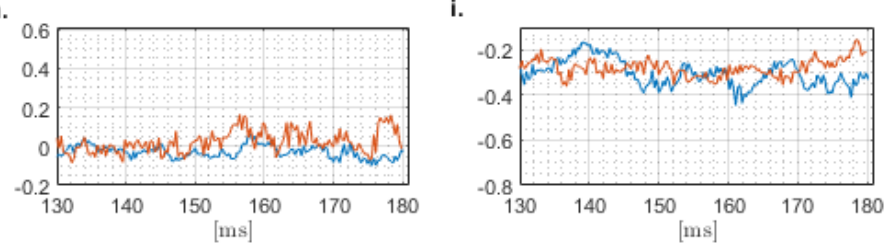

Azul - 0; vermelho - 30은 
Figura 170 - Evolução temporal das velocidades em t6 na válvula de entrada
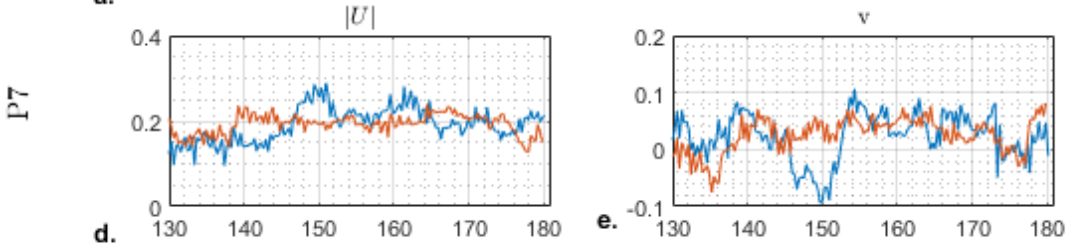

c.

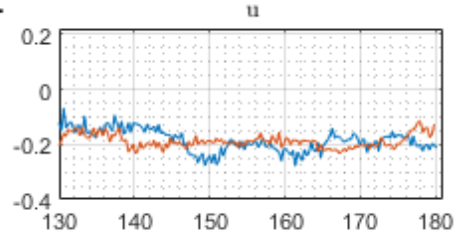

$\stackrel{\infty}{\sim}$
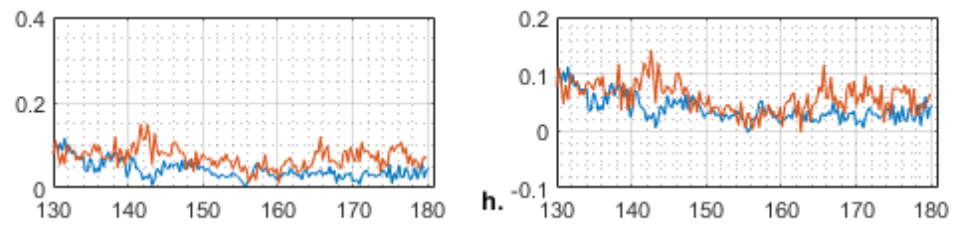

f.
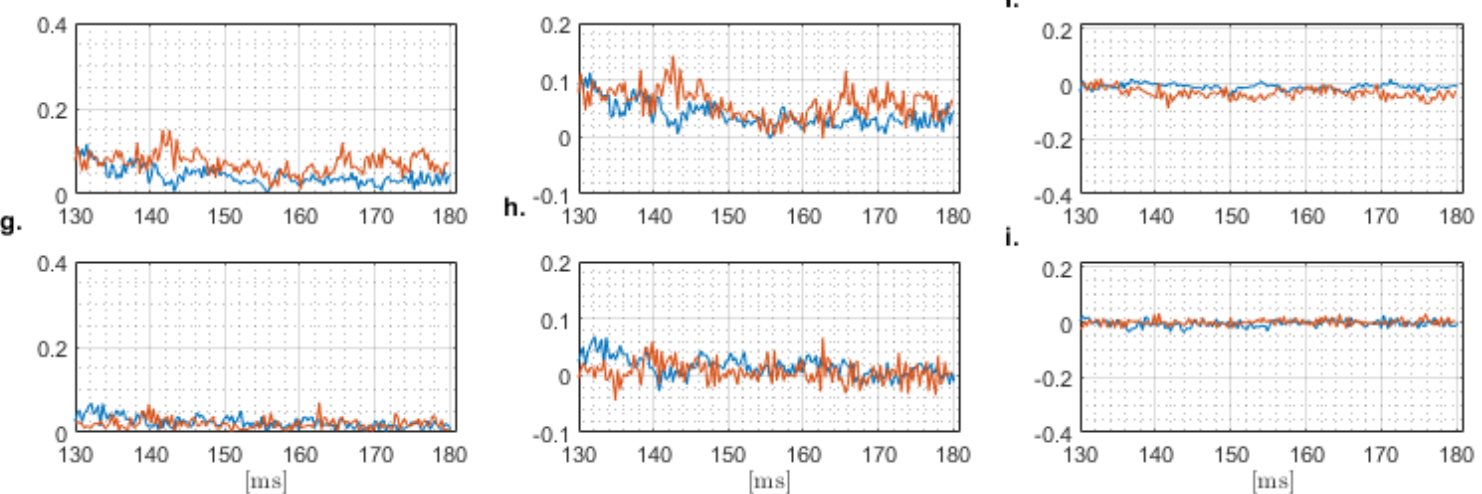

Azul - 0; vermelho - 30응 